

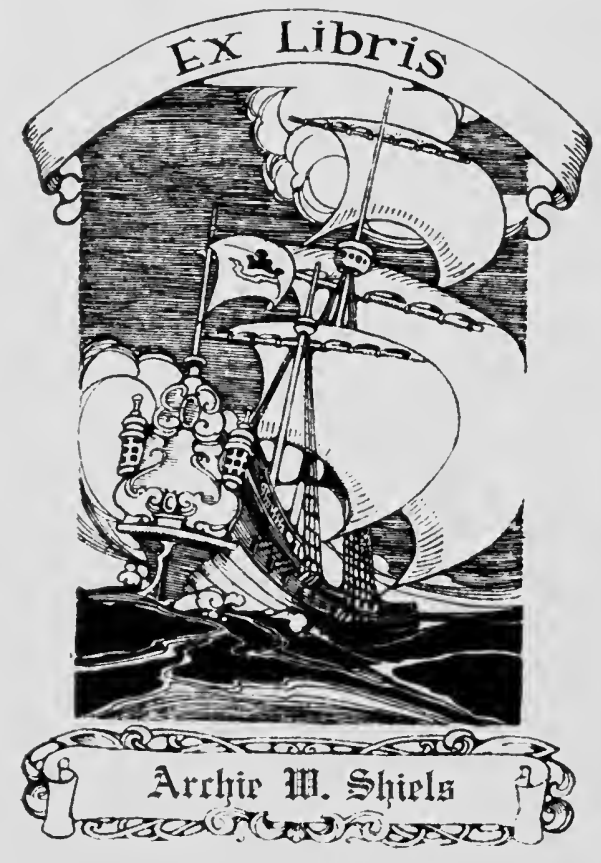


Digitized by the Internet Archive in 2007 with funding from Microsoft Corporation 

STEAMSHIP CONQUEST OF THE WORLD 




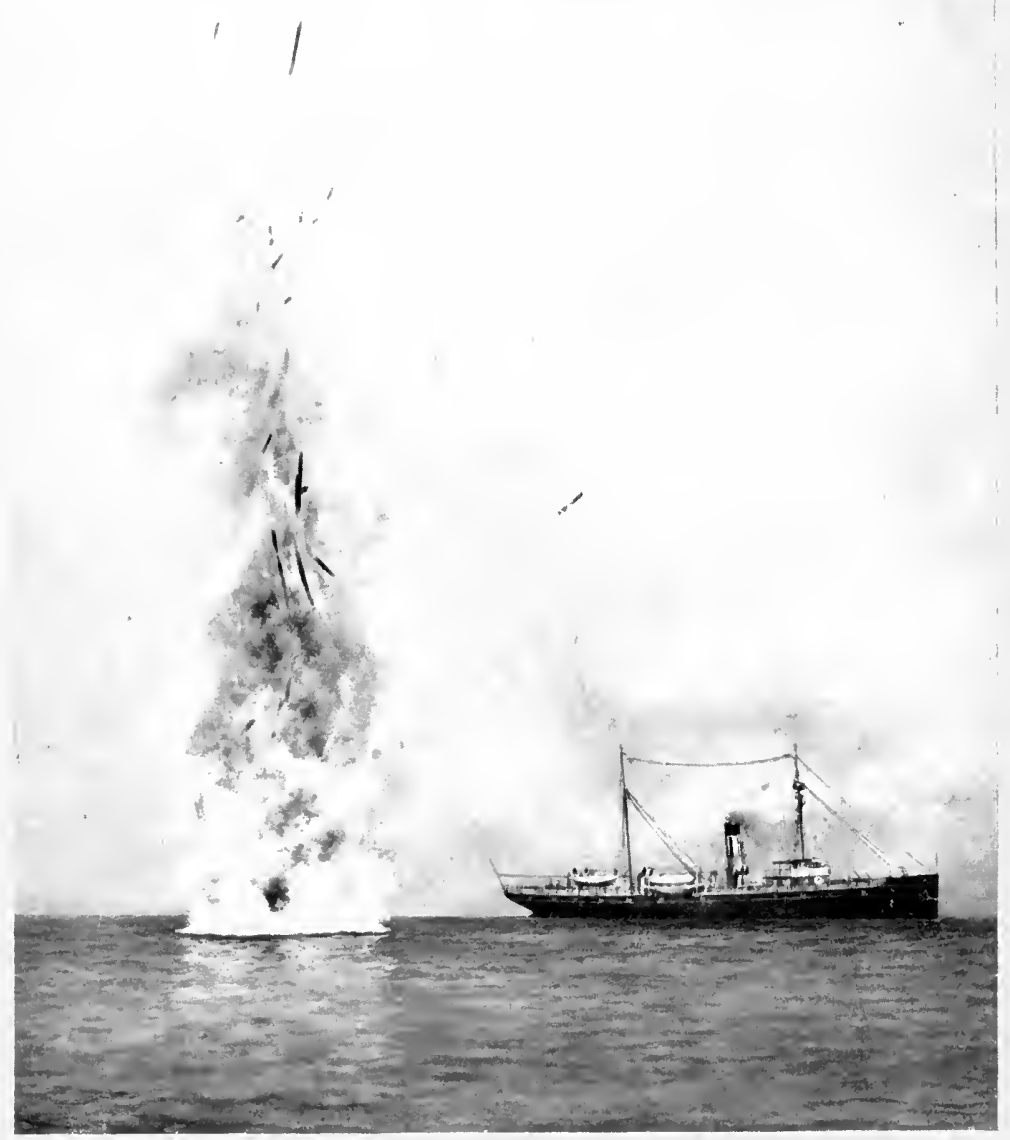

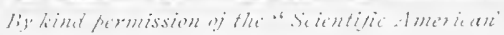

1\%, whtisplice

BLOWIAR IP A MIREIACT

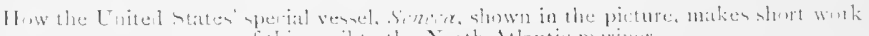
of this peril to the Nenth Mlantic: muine?. 


\section{STEAMSHIP CONQUEST OF THE WORLD}

BY

FREDERICK A. TALBOT

AUTHOR OF

"railway CONQuest of The WORLD," "Moving pictures," etC.

\section{ILLUSTRATED}

PHILADELPHIA

J. B. LIPPINCOTT COMPANY LONDON: WILLIAM HEINEMANN 
Printed in Enstand. 


\section{PREFACE}

THIs book is not a history of steam navigation. It has been written rather to show how water transportation has developed: the present position in the eternal struggle between science and disaster: the wonderful and rapid growth of the big, express Liner during the space of one hundred years.

I have not confined myself to the steamship itself purely and simply, as the welfare and safety of the ocean-travelling public are affected very materially by several other influences. Although the North Atlantic figures largely in the volume, this is due to the fact that it is the busiest of the seven seas: it is where new developments and revolutionary inventions invariably receive their ocean-going commercial baptism : where luxury and elegance have been carried to a supreme degree: where the ingenuity and skill of the engineer are revealed most strikingly: and finally, because it is the arena in which the struggle for supremacy between the various maritime nations is contested most keenly and enterprisingly.

In the preparation of this book I have received the heartiest assistance of various interests, both in connection with the letterpress and the illustrations. In the majority of cases this co-operation is acknowledged in the text and beneath the photographic reproductions. In addition I am indebted to the Hydrographers of the British and United States Admiralty Departments, the editor of the Scientific American, and also the commander of the United States derelict destroyer Seneca.

The volume is written essentially for the general reader, who is not familiar with the technics of the shipbuilding 


\section{PREFACE}

art; who entertains only hazy notions concerning the steamship, its design, construction, appointments, and the efforts that are being made to render water transportation absolutely safe; and who has no idea of the character of its influence upon the world's progress.

Frederick A. Talbot.

October 1912. 


\section{CONTENTS}

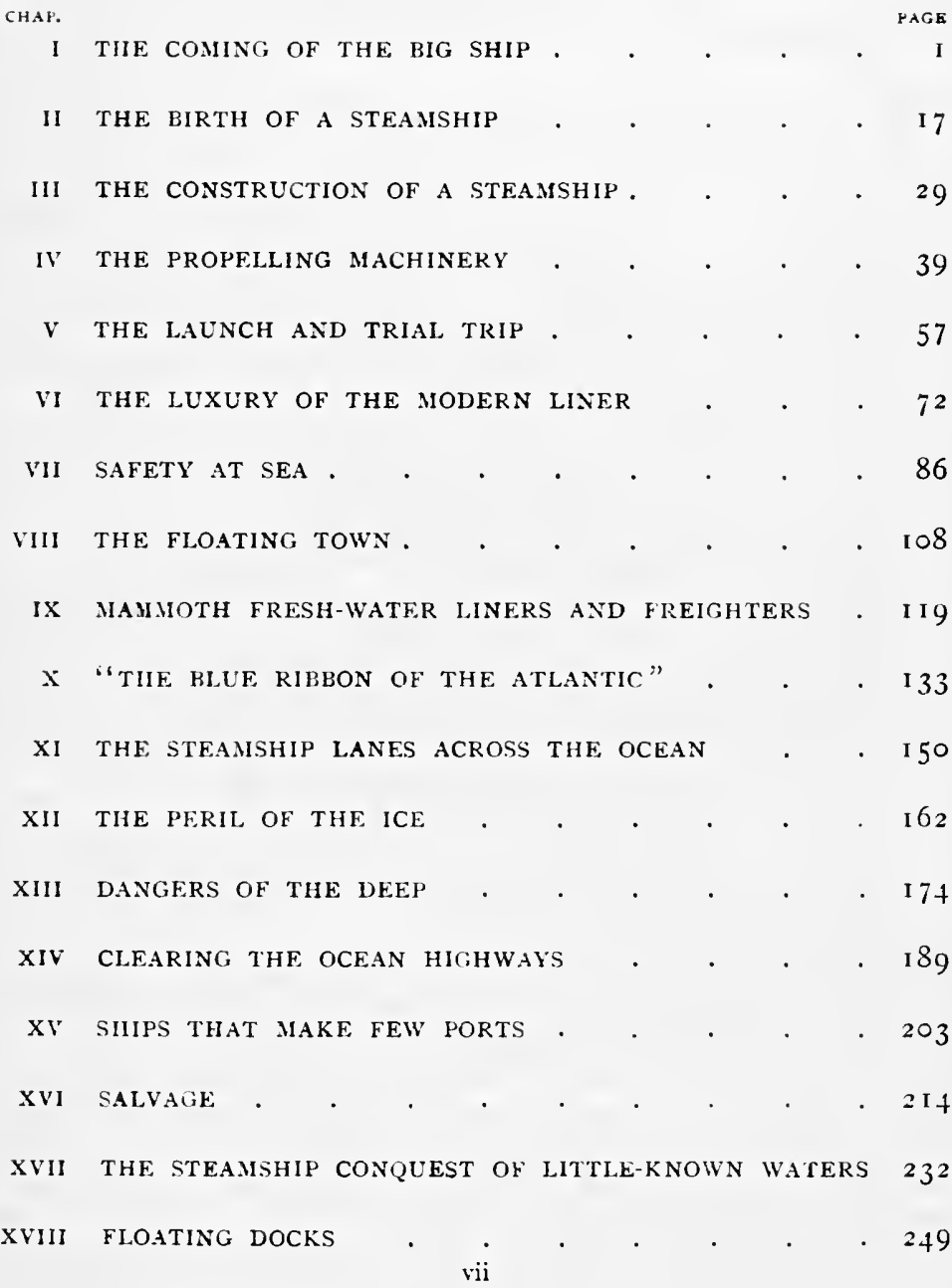


char.

XIX THE SURVEYOR OF THE SEA AND HIS ADVENTUROUS CALLING.

. $26 \mathrm{I}$

$\mathrm{XX}$ WIRELESS TELEGRAPHY

276

XXI GRAVEYARDS OF TIHE OCEAN

290

XXII STEAMSHIP SURGERY . . . . . . . 302

XXII STEAMLESS SHIPS . . . . . . . . 316

XXIV WHY GERMANY BUILDS HER OWN LINERS . . . 327 


\section{LIST OF ILLUSTRATIONS}

Blowing up a derelict

To face fage

The first steamship to eclipse the Great Eastern . . . . 2

The White Star "Nine-day boat" Baltic . . . . . 3

The manmoth German intermediate liner George Washington 3

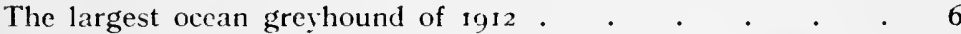

Mother and daughter-the tiny Turbinia lying beside the

Mauretania . . . . . . . . . . 7

Germany's marine giant-the Hamburg-American liner Imperator . . . . . . . . . . 7

Britain's reply to Germany's challenģ . . . . . . 12

. 1 cradle of British big ships . . . . . . . . . 13

The testing tank. . . . . . . . . . . . 24

The mammoth liner's backbone . . . . . . . 24

Why the Mauretania is the safest ship afloat . . . . ${ }^{25}$

A massive casting . . . . . . . . . . $\quad 3^{2}$

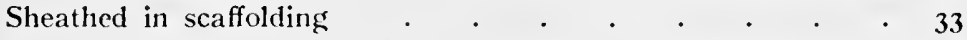

The stern ribs of the Olympic . . . . . . . . . 36

The Mauretania ready for launching . . . . . . 36

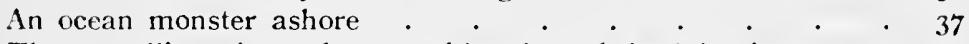

The propelling giant of a record-breaker of the 'nineties . . 40

The Turbinia, which revolutionised steamship travel, showing

her paces . . . . . . . . . . 4 I

The first Atlantic turbine liner . . . . . . . 44

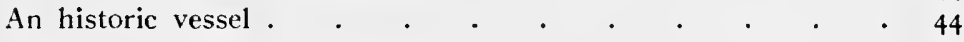

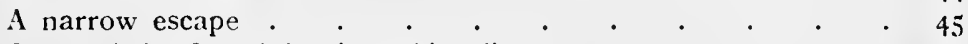

Stern of the first Atlantic turbine liner . . . . . $\quad 45$

A ship which carries railway trains . . . . . . 48

A palatial Pacific coastal liner . . . . . . . . 48

One of the cylinders of the Olympic . . . . . . . . 49

A complete ring of turbine blades for the Matretania. . $\quad 49$

The triumph of the Parsons Turbine . . . . . . $\quad 5^{2}$

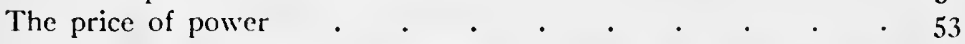

Floating 2oo-ton crane leaning over vessel and picking up engine bed-plate. . . . . . . . . . 53

A novel autonobile tunnel . . . . . . . . . . 54

An avenue of boilers . $\quad . \quad . \quad . \quad . \quad . \quad . \quad . \quad . \quad . \quad 54$

After cradle of the Mauretania . . . . . . . 55 
Titan crane lifting $\cdot \cdot \cdot 55$ The power behind the Cunard fliers . . . . . . $5^{8}$ A thrilling moment . $. \quad . \quad . \quad . \quad . \quad . \quad . \quad 59$

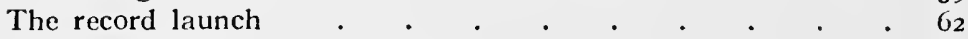
Ifloat! . . . . . . . . . . . . . . . 63 The fastest liner in the world at full speed . . . . . 66 A novel launch . . . . . . . . . . . . 67 A rejected ocean grcyhound . . . . . . . . . . 67 Luxury in the Canadian steamship service. . . . . $7^{2}$ The drawing-room of the Lusitania . . . . . . . 73 Modern domestic architecture on an Atlantic liner . . . 74 Architectural beauty on an Atlantic liner . . . . . . 75 A regal suite . . . . . . . . . . 76 The first-class dining-saloon of the Olympic . . . . . 76 The first-class lounge of the Olympic . . . . . . . . 77 The first-class smoke-room of the Olympic . . . . 77 The imposing entrance and door to the smoking-room of the Deutschland . . . . . . . . . . 82

A seat in the grand entrance on the boat deck . . . . $\quad 8_{3}$

$\Lambda$ beautiful French tapestry panel in the first-class lounge.$\quad 8_{3}$

$\Lambda$ first-class state-room on the upper deck of the Mauretania . So The first-class smoke-roon of the Mauretania . . . . 88

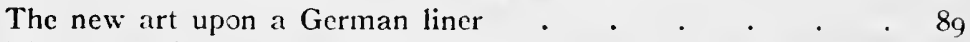

The water-tight door-the secret of a vessel's safety when in peril

A combined life-saving deck seat . . . . . . . $\quad . \quad 95$

The brain of the ship. . . . . . . . . $\quad .95$

The simplest and quickest boat-launching gear . . . . 102

The value of the quadrant boat davit . . . . . . . 102

The submarine bell in use . . . . . . . . 103

Two types of the submarine bell . . . . . . . . ${ }_{103}$

The electric lighting station of the floating city . . . . 110

A luxurious flat in the foating city . . . . . . 110

The verandah café . . . . . . . . . . . . III

A restaurant on the high seas . . . . . . . . 11 II

The kitchen of a floating hotel . . . . . . . . 114

The pantry of a floating hotel . . . . . . . 115

Checking the mail-bags . . . . . . . . 116

The floating post office . . . . . . . . . . 116

Stern half of the C.P.R. lake liner Keezealin being taken through the lock . . . . . . . . . 117

The two halves of the steamer being rejoined in dry dock . 117

An ore freighter in the "Soo" locks . . . . . . 122

The Hamonic, a luxurious fresh-water liner . . . . 123

The observation-room of the Hamonic . . . . . . 128

The dining-saloon of the Hamonic . . . . . . 128 
The Servia, the first Cunarder built of steel

Greyhounds of the 'eighties .

A gigantic yacht

The Atlantic record-breaker of the 'nineties . . . . I37

The Lucania, a famous British Atlantic greyhound . . . 137

Germany's first kid for speed . . . . . . . 142

Germany's fastest Atlantic liner . . . . . . . 143

The liner which regained the Atlantic speed record for Great

Britain . . . . . . . . . . I43

A victim of the iceberg. . . . . . . . . ${ }^{5} 5$

The terror of the ocean . . . . . . . . 159

Keeping open the steamship highways in the Baltic Sea . . I70

An ungainly deck load. . . . . . . . . I7I

What winter means on the North Atlantic . . . . . I7I

When greyhounds collide at sea . . . . . . . I80

Trapped in the fog . . . . . . . . $18 \mathrm{I}$

A derelict, almost awash . . . . . . . . . 192

The crew of the United States derelict destroyer Seneca

boarding the Frederick Roessner . . . . . . 192

The battered hulk of a derelict . . . . . . 193

Rust, barnacles, seaweed and chaos . . . . . . 218

The Constance, sunk in the Tyne . . . . . . 219

The Vauxhall at high tide . . . . . . . . 2 I9

A difficult task . . . . . . . . . . . . 222

A double disaster. . . . . . . . . . 222

Temporary erection of the Sybil on the Clyde . . . . 223

Re-erecting the ship at Port Florence . . . . . . 223

Approaching completion for launching . . . . . 236

Getting a boiler on board . . . . . . . 236

Shipbuilding above the clouds . . . . . . . $\quad$. 237

A motley squad . . . . . . . . . . . . 237

High and dry . . . . . . . . . . . 250

An unusual lift . . . . . . . . . 250

The self-docking floating dock . . . . . . $\quad 25 \mathrm{I}$

On the deck of the self-docking floating dock . . . . 251

A floating dock being towed across the North Sea . . . $25^{8}$

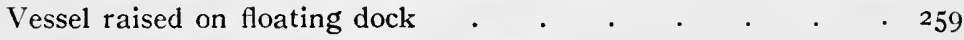

Vessel transferred from dock to gridiron . . . . . 259

Section of dock itself lifted for overhaul . . . . . 259

The Marconi wireless operator on guard . . . . . 282

The Marconi aerial of the Olympic . . . . . . $28_{j}$

Wireless set for cargo boats. . . . . . . . 283

A badly "broken nose" . . . . . . . . . . 288

The Mimi after being aground . . . . . . . 289

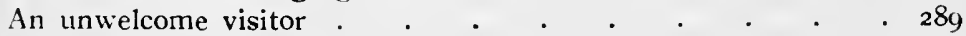

A big hole . . . . . . . . . . . 294 
To face page A complete smash . . . . . . . . . 295

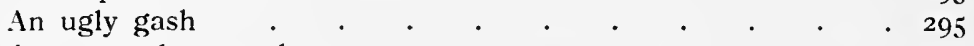
An unusual spectacle . . . . . . . . . 304 The salvaged half of the Milwaukee in dry dock . . . 305 Joining the old and new parts of the Milwaukee . . $\quad 308$

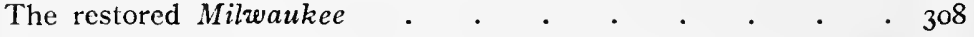

A delicate operation in steamship surgery . . . . . 309 Fitting the new bow to the Ermack . . . . . . 312 A disastrous collision . . . . . . . . . 3I2 The crushed bow of the Florida being removed bodily after severance . . . . . . . . . . . 3 13

The liner with her new bow . . . . . . . 3 I 3 Is this the future type of ocean greyhound? . . . . 318 The starting platform in the engine-room of the motor-ship Selandia

The dining-saloon of the Selandia . . . . . . 319

The engine-room of the motor-ship Selandia . . . . $3^{24}$ The Electric Arc. . . . . . . . . 325 Engine-room of the Electric Arc . . . . . . $\quad 325$ The Toiler, the first motor-driven ship to cross the Atlantic . 325 The growth of the German shipbuilding industry . . . 328 The pride of the German mercantile marine . . . . $\quad 329$ A glimpse of the children's room . . . . . . 332 1 corner of the library . . . . . . . . . 332 The utility of the floating dock . . . . . . 333 


\section{CHAPTER I}

THE COMING OF THE BIG SHIP

If it were possible to bring back to life those early dreamers of steamship conquest-Fitch, Bell, Fulton, Niller, Watt and Brunel-to give them a glimpse of the Lusitania tearing along at thirty miles an hour, or of the Olympic displacing some 60,000 tons, their expressed opinions would prove entertaining. In their wildest dreams they never anticipated such speedy and huge monsters as ride the waves to-day. While probably most of these hard-working pioneers would desire an immediate return to their resting-places, one-Isambard Bruneldoubtless would show no signs of perturbation or astonishment, as he, during his wonderful career, was accustomed to conceiving and doing big things in the varied fields of engineering.

From the days of 1784 , when poor Henry Fitch, the American engineer, discussed the possibility of vessels being propelled by steam, and was considered crazy for his pains, to the present time, is a far cry. Yet in that comparatively brief period of less than 150 years much has happened. The seven seas to-day are ridden by wonderful constructions in size, power and luxury, to fulfil every purpose of water transportation. And developments move so quickly in marine circles; the shipbuilder is a man of such infinite enterprise, skill and ability, that nowadays the public ceases to wonder. The marvellous of to-day becomes the commonplace of to-morrow.

The Comet, which created such widespread consternation and wonder as she ploughed up and down the Clyde in 1812 , could be stowed upon the deck of the marine 
monster of 1912, and escape observation. It would require nearly two and a half vessels of the size designed with such infinite labour by Henry Bell, to reach, laid end to end, from taffrail to taffrail amidships of the Olympic. A century of marine engineering has produced vessels goo feet in length by 90 feet wide, 175 feet in height from keel to rim of smokestack, carrying 3,500 passengers, and weighing upwards of 60,000 tons. The engines of the Comet developed four horse-power: the mistress of the ocean of a century later requires seventeen thousand times the power of the engines fitted to the pioneer craft to maintain her speed of 26 knots per hour.

There has been considerable diversity of opinion as to whether Bell or Fulton, the American (though of Scottish birth), was the inventor of the steamboat. The Americans claim the honour, seeing that Fulton's first steamer appeared upon the Hudson River in 1807. But Fulton's admirers ignore the fact that their hero got his ideas from Bell, and even followed the latter's advice. Bell submitted his scheme for steam propulsion to the British Government, and, as was to be expected, met with a rebuff from an administration soddened with conservatism, and resolutely opposed to the march of progress. Lord Nelson recognised the value of Bell's invention, and did not omit to convey his personal opinion to the Admiralty that "If you do not adopt Mr. Bell's scheme other nations will do so."

So it proved, because the inventor at once communicated with the United States Government, who directed Fulton to get into touch with Bell. Subsequently, when the former was dispatched to England in 1804 upon a comnercial mission, he called upon Bell, and the subject was discussed further, as Fulton was impressed with the possibilities of his fellow-countryman's ideas. That the interview was fruitful is supported by the fact that the American took Bell's advice, and acquired his steam engines from Boulton \& Watt. In these circumstances it is difficult to transfer the glory of invention from Bell to Fulton, as without 


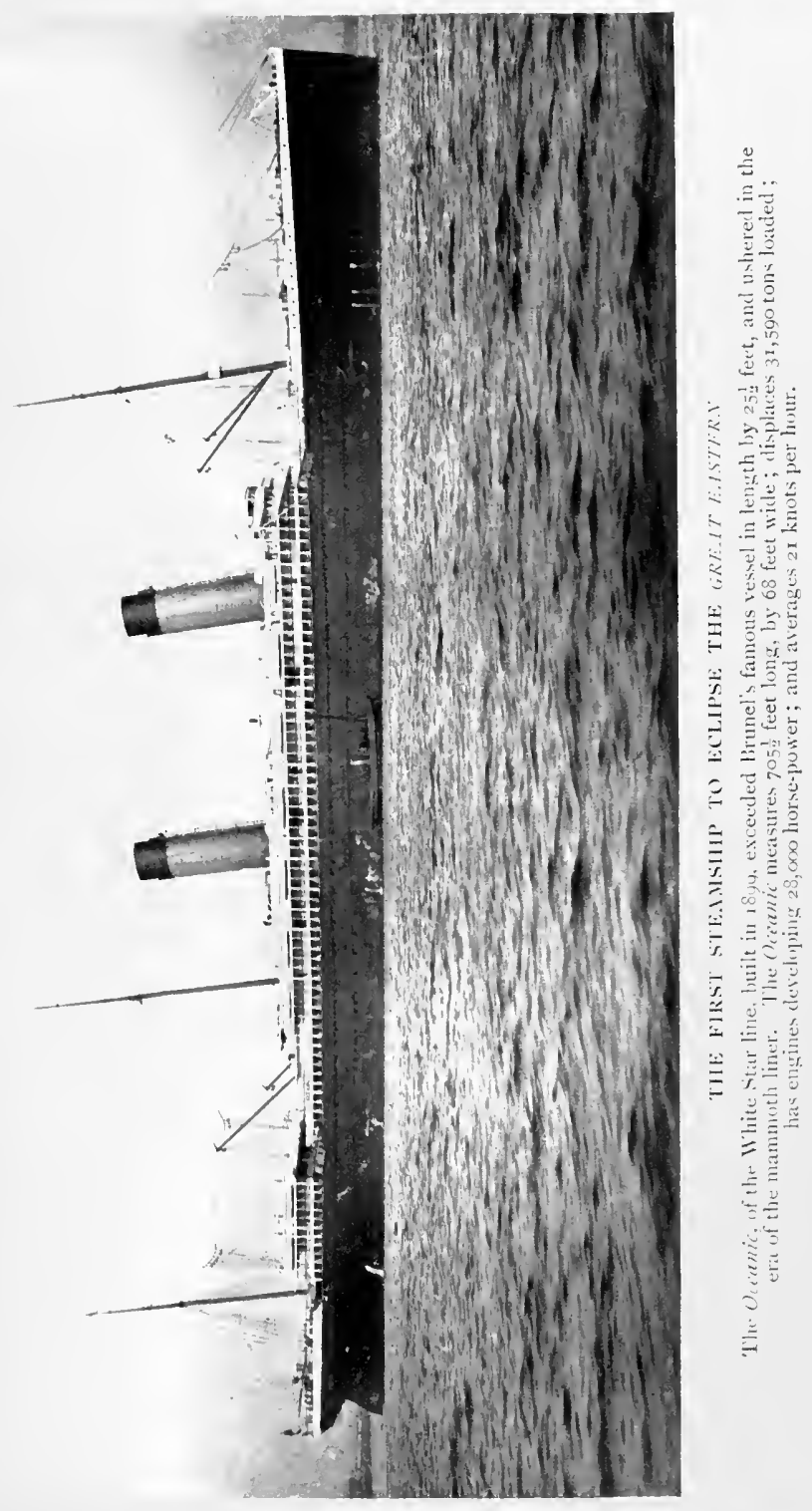




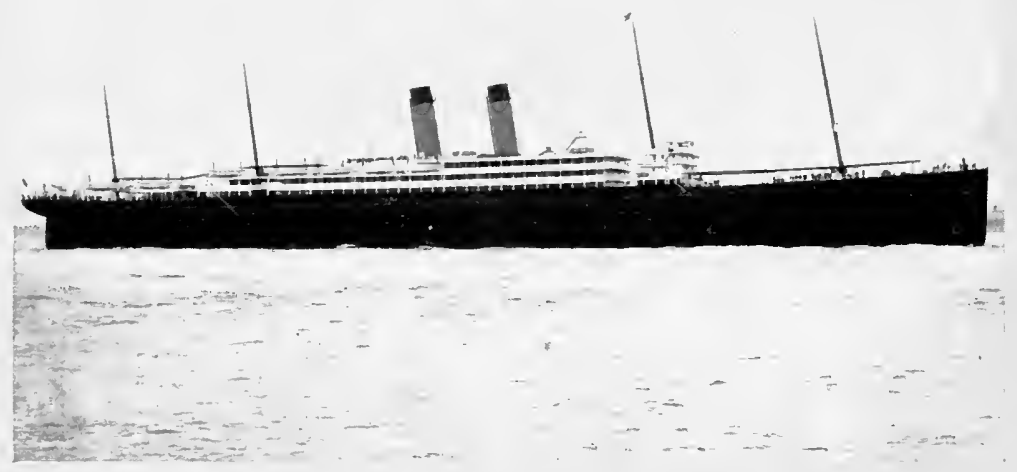

THE WHITE STAR "NINE-DAY BOAT" B.HTIC

The bis combined freight and passenger vesiel, although slower, but luxuriously equipped, has become highly popular.

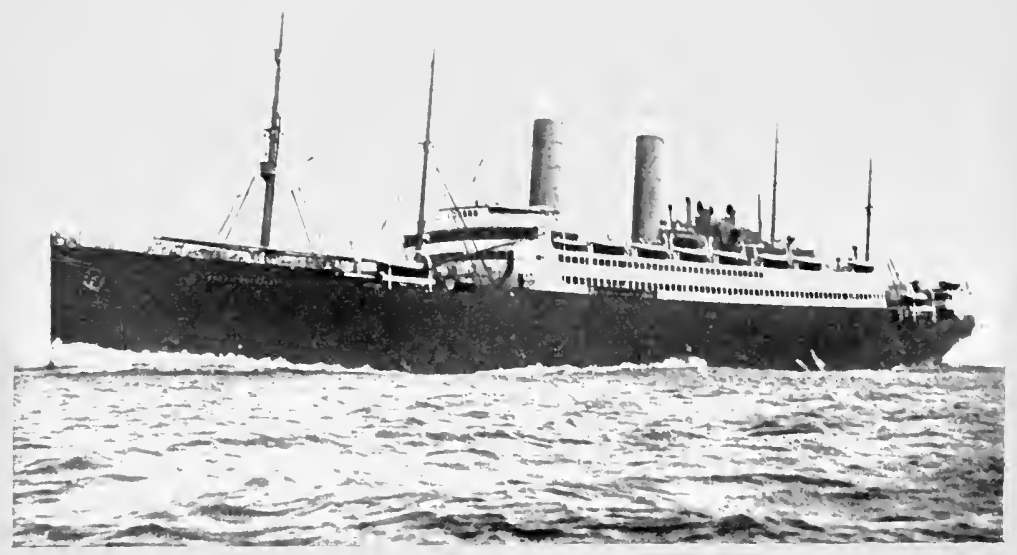

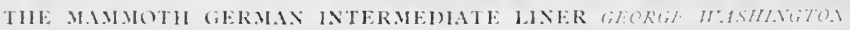

Jhe fiermans were not slow to realive the advantagen of the mammoth freighter, of which this Nurth German llind buat is the finest flying the leuten $f$ arg. 
Bell's assistance Fulton would never have steamed up the Hudson River in his boat 130 feet long.

Some six years after the Comet's momentous appearance the Atlantic was crossed for the first time by a vessel fitted with steam engines. This was the Savannah, although she could not be described as a steamship in the present meaning of the word. She was a hybrid. There was such little faith in the steam engine for ocean travelling that the captain of this ship hesitated to trust himself exclusively to the new system of propulsion. The paddlewheels with which she was fitted could be detached and lifted on board when desired. This vessel used her steam power for less than four out of the twenty-two days occupied in crossing from New York to Liverpool in I818.

The first steamship built for trans-Atlantic travel was the Great Western, designed by Brunel. It was Samuel Cunard, the merchant, however, who, while in Halifax, Nova Scotia, conceived the idea of meshing the seas with steamship routes in the same manner as the land was being criss-crossed by railways, and to run with a similar scheduled service and regularity. When the Government called for tenders to establish a system of carrying the mails between Britain and America by steamships, instead of the ten-ton "coffin brigs," Cunard came to England, to meet kindred spirits in Mr. George Burns and David MacIver. A company was formed, with a capital of $\mathscr{E} 270,000$, or $\$ 1,350,000$, the mail contract was secured, and the first regular trans-Atlantic steamship service was inaugurated under the flag of what is known now as the "Cunard Line." The first fleet was of humble pretensions, built of wood, the four ships each measuring 207 feet in length by 34 feet 4 inches wide, and 24 feet 4 inches deep, capable of carrying 115 cabin passengers with 225 tons of cargo at a speed of $8 \frac{1}{2}$ knots-9 $9 \frac{1}{2}$ miles-per hour, developed by engines of 740 indicated horse-power.

In the course of a few years wood was supplanted by iron for the hull, despite the mournful opposition of those who 


\section{STEAMSHIP CONQUEST OF THE WORLD}

stated confidently that iron could not be induced to float. At the same time the dimensions, displacement, and comfort of the passenger accommodation were improved, together with the power and speed of the engines. Each succeeding vessel embodied some important modifications as compared with its predecessor, as the shipbuilder and marine engineer took care to keep pace with scientific developments. When the first Cunarder appeared upon the Atlantic the shipowner was in advance of the shipbuilder, but in the course of a very few years the latter made up the leeway, outstripped the shipowner, and has maintained his advantage ever since.

But the big ship came in the late 'fifties, when Isambard $K$. Brunel conceived his great masterpiece and, as it was termed, his most colossal failure, the Great Eastern. As it proved, she was about thirty years ahead of her times. This vessel was a wonderful construction built on the Thames, with a length of $659 \frac{1}{2}$ feet, a beam of 78 feet 8 inches, and a total tonnage of 18,9 I5. Everything in connection with her eclipsed anything which had gone before; she was a novelty from stem to stern and from keel to funnel. Her creator was not the man to keep to hidebound traditions. Pioneering was more in accordance with his nature, knowledge and temperament. The building of this leviathan was watched with the greatest interest throughout the whole of these islands, Europe and America. It was fully recognised that if she were successful she would completely revolutionise ocean transportation.

The travelling public in particular anticipated her commission with ill-disguised pleasure. In those days a journey across the Atlantic was not to be undertaken lightly. For the maximum of expense one also endured the maximum of discomfort and misery, and there were very few voyaging Mark Tapleys to dispel the prevailing gloom. But with the Great Eastern everything was changed. The public saloons were large, lofty and spacious, as vell as being most comfortably appointed. 
The private cabins were designed upon the same liberal scale, while the broad, wide decks afforded excellent opportunities for indulgence in a constitutional. Then, again, would she not subjugate the terrors of mal-de-mer, owing to her great length and beam? Seas which made the average liner pitch, toss and roll in the most disconcerting manner would be unnoticed by this titan: in a gale she would ride the waves as firmly as a rock.

The vessel was fitted with both systems of propulsion. The paddle-wheel had proved its value and efficiency; but the screw was maintained to be the propelling force of the future. Inasmuch as there was a rooted antipathy to this form of propeller at the time, owing to its principles not being recognised, and because it had not been subjected to sufficient practical trial, the designers of the Great Eastern adopted both systems. On the trial trip the paddle engines developed a maximum horse-power of 2,800 , while the screw propeller engines gave out 4,700 horse-power. On this occasion, in running from Portland to Holyhead, she developed a speed of $14 \frac{2}{5}$ miles per hour. The dual driving system demanded the continuous stoking of II 2 furnaces, and the total fuel consumption ranged between 250 and 400 tons of coal per 24 hours. With her raking masts, on which could be spread some 50,000 square feet of canvas, and her five smokestacks, the Great Eastern certainly looked imposing, especially when passing the typical liner of those days.

This vessel, which, it was claimed popularly, would "flog the seas," and which tempted imaginative writers to indulge in fantastic comparisons with popular objects to emphasise her monster proportions, proved a lamentable failure as a liner. Her career was melancholy. Money was difficult to secure for defraying the cost of construction, and accordingly she was built in a hand-to-mouth manner, which was responsible for her long occupation of the building berth. By the time she was ready for her

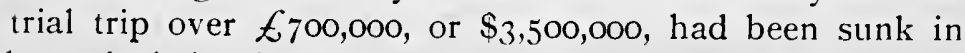
her. A chain of mishaps attended her appearance. During 


\section{STEAMSHIP CONQUEST OF THE WORIDD}

the launch she stuck on the ways, and defied removal for several weeks. While proceeding round the coast a boiler explosion occurred off Hastings, whereby seven men were killed and several were injured, and off the Eddystone she narrowly escaped collision with a brig which carried no lights, because the master of the latter considered them a luxury until he ran into danger.

In order to ascertain the possibilities of the vessel for her designed service between Great Britain and Australia, she was dispatched on a trial trip to the United States, and occupied eleven days on the journey. But she could not earn sufficient money on the Atlantic to defray her maintenance expenses and repairs, althougl she was engaged in troopship service, so that she never ventured to the Antipodes. From the passenger service she drifted into cable-laying operations, and her most historic journcy was that associated with the completion of the Atlantic cable. Then she degenerated into a coal hulk at Gibraltar. She was sold in London in 1884 for a mere $\notin 26,200$, or \$I,3I,000. For a time she served as a show-ship, and then ended her career as an advertising hoarding, after which she was broken up, and was sold under the hammer as junk for $\mathcal{E}_{5} 8,000$, or $\$ 290,000$. Such is the doleful history of the first monster steamship.

The Great Eastern practically sealed the fate of the paddle-wheel propelling system so far as oceanic travel was concerned. The Inman Line built screw-driven ships, and other companies followed their example. The Great Eastern served another purpose: she became the unit of comparison when describing succeeding shipbuilding marvels. Thus we read, in the praises sung of a new vessel, that "she is the largest vessel yet built, with the exception of the Great Eastern." This was a stock phrase among writers until I899, when the second Oceanic appeared. This was the first liner to eclipse the Great Eastern, and from that day to this it has been the practice to relate by how much a new monster exceeds Brunel's famous masterpiece. 


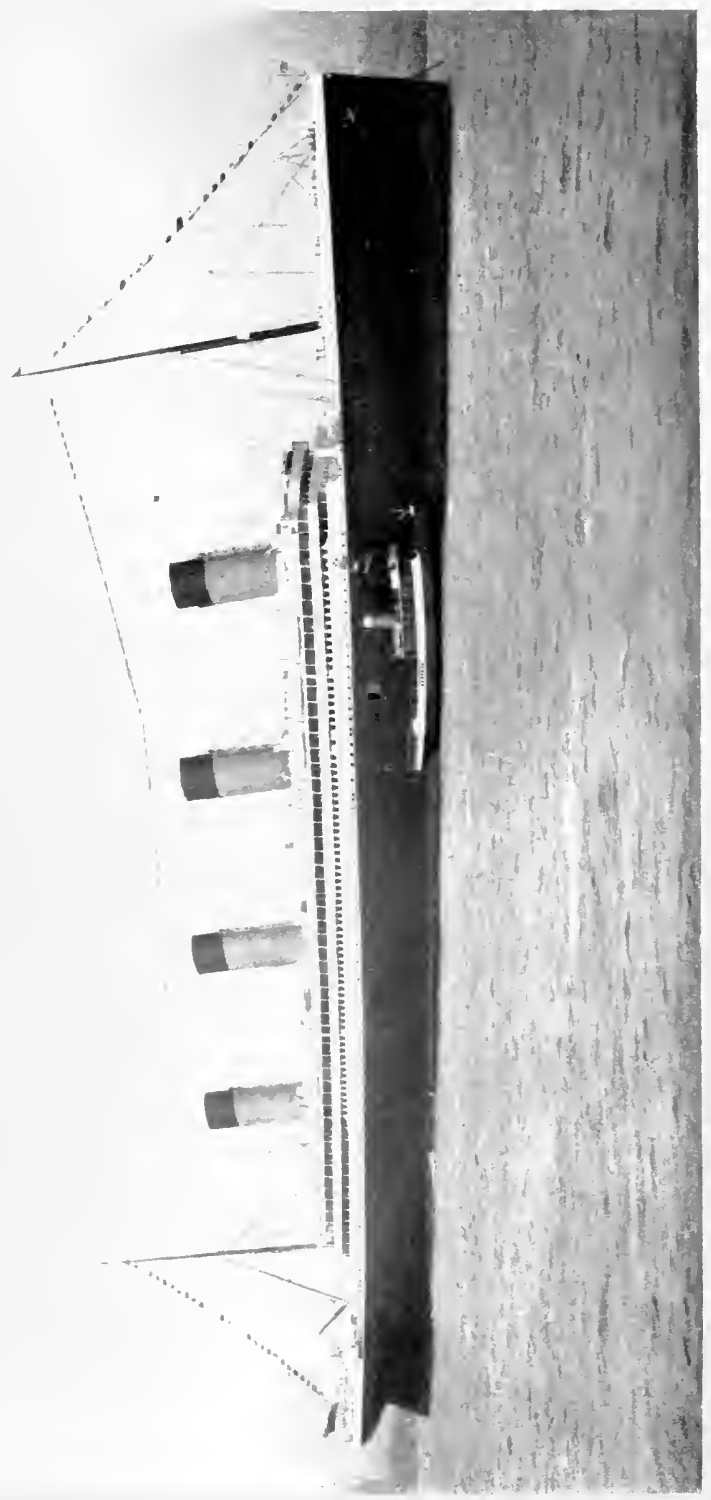

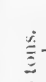



(5)

$=$

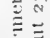

要

吾

政

$-$

$\dot{y}$

ก

5

政

$\div$

$\frac{1}{3}$

政

三

空

䓀

政

$\geq-$

三

s.

装

$=$

$\div-\frac{3}{3}$

年 

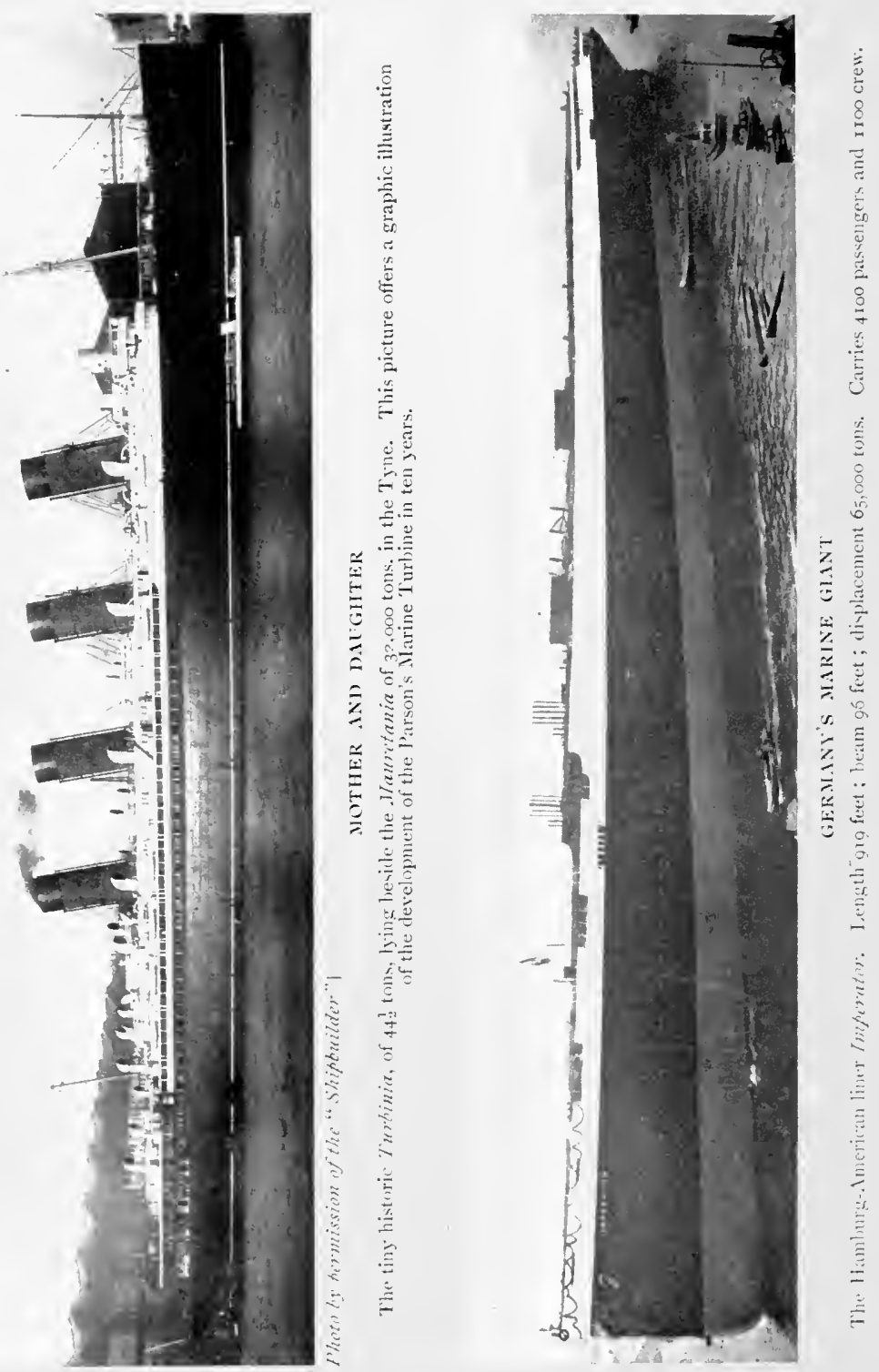
The appearance of the White Star Line vessels as competitors for the Atlantic traffic opened up a new era in the story of the Steamship Conquest of the World. This company was not a new one, but was in reality the development of a sailing line whose clippers had achieved a world-wide reputation in the Australian trade. During the seven years' gold fever in Australia the ships under this flag drove a thriving business, and carried about half a million adventurers to the diggings. In 1867 the fleet was acquired by Mr. Thomas Henry Ismay, who at once turned his attention to the developing traffic upon the Atlantic. Mr. Ismay knew something about this trade, as he had been a director of the National Line, whose vessels for some time held the blue ribbon of the Atlantic. He recognised a particular field which awaited development, and he seized it. He secured the co-operation of an old-time colleague in Mr. Imrie-the two had served their apprenticeships in the same firm simultaneously-and was also joined by $\mathrm{Mr}$. Fletcher, the firm becoming known as Ismay, Imrie \& Company.

They decided to refrain from participating in the speed mania, though now and again they gave their competitors, to whom this factor was the all-governing consideration, some awkward frights by building vessels which not only fulfilled the basic requirements of their owners, but were fleet as well. They set out to provide the traveller with every luxury, convenience and comfort. The arrival of the first boat of the new fleet, the Oceanic, created as much enthusiasm upon her arrival in New York in $187 \mathrm{I}$ as had the Cunard pioneer Britannia half a century previously. She was a magnificent craft, excelling anything that had been seen up to this time. Her graceful lines gave her the appearance of a millionaire's yacht rather than that of a vessel engaged in the prosaic freight and passenger carrying trade. She had a brilliant career, and sailed at one time or another over the seven seas. In one of these voyages she beat the Pacific record with $\mathrm{I}$ hour 56 minutes less than 14 days. She reduced the time occupied in the 
circumnavigation of the globe from the so days required by Jules Verne in his fascinating story, to 75 days. She ploughed to and fro over the Pacific until i895, when she returned home to undergo an extensive overhaul. But her life as a greyhound was over. She had been surpassed in every respect by later vessels, so she was sold for $£ 8000$, or $\$ 40,000$, and made her last trip from Belfast in 1896 to the shipbreaker's yard, to be reduced to scrap, after battling with the seas for a quarter of a century.

The appearance of the White Star Line created another precedent. Hitherto the Clyde and the Tyne had reigned supreme as the cradles for ocean ferries, but the new steamship company went to Ireland for its products. Messrs. Harland $\&$ Wolff, the largest shipbuilding firm in the world to-day, established their works in the Emerald Isle, having received the cold shoulder from Liverpool, and they formed an indissoluble compact with the White Star Line. Indeed, the two firms are so closely allied to-day that it is difficult to say where the one ends and the other begins. The builders have always been given a free hand to produce the "best possible," and have never been trammelled by contract prices. Under this policy there is no tendency to scamp the work in order to make ends meet; the builders, upon the completion of a ship, merely produce the account for the prime cost thereof to the owners, and then add a certain percentage upon the outlay to represent their profit. This system is becoming more widely adopted in Europe to-day, as it is conducive to obtaining the best and soundest materials and workmanship, as well as to securing the embodiment of the very latest developments, as they are perfected during the construction of the vessel, so far as it does not interfere with its fundamental calculations. This is the sole reason why the IVhite Star Line has been able to earn the distinction of having the most luxurious and comfortable vessels afloat. They may be slower as compared with the flyers of other lines, but there is a very large section of the travelling public which appreciates what may be 
described as an easy speed, provided that every luxury. is available.

The turning-point in the history of the White Star Line may be said to have commenced from the commissioning of those two magnificent passenger yachts the Majestic and Teutonic. They became the pride of the Atlantic, not only from the point of view of comfort, but also for their consistent running. From end to end they measure 582 feet in length, have a width of $57 \frac{1}{2}$ feet, with a moulded depth of 42 feet, displace 17,800 tons, with a draught of 29 feet $4 \frac{1}{2}$ inches, while the two sets of triple expansion engines, developing 17,000 indicated horse-power, give them a speed of $19 \frac{1}{2}$ knots. In these ships the masts, which hitherto had been carried so that sails might be spread to steady the boat in bad weather, were abandoned in favour of short masts forming flag-poles, while the two funnels were spaced apart so far as to enable the first-class dining saloon to be set between them, to form a long, open apartment extending the full width of the ship. These vessels were built in accordance with the Admiralty requirements for conversion into armed cruisers, for which provision a further subsidy was earned from the Government; and at the Spithead review (1889) the Teutonic appeared in this guise, being the first Atlantic liner to be seen converted and armed as a cruiser. The German Emperor was among the celebrated visitors to honour her with an inspection, and he was so fascinated with what he saw that he had to abandon his visit to five British war vessels, owing to the time spent upon the Teutonic. The applicability of an Atlantic liner to naval purposes did not fail to impress him, and as a result the German nation followed the same practice in connection with the vessels laid down shortly afterwards for the North German Lloyd and Hamburg-American Lines.

These two White Star boats succeeded in reducing the trans-Atlantic passage, as related elsewhere, and keen rivalry developed between these sister ships and the twin craft of the Inman Line, the City of New York and City 
of Paris. The practice of carrying twin screws, which had been introduced by the latter line, was followed in the case of the White Star vessels, upon the emphatic recommendation of Sir William White.

In 1897 the famous North German Lloyd steamer, Kaiser Wilhelm der Grosse, appeared, and created a flutter of excitement by her high speed. With her 649 feet of length, the Great Eastern was in danger of becoming eclipsed. This vessel revealed the ability of the German shipbuilders to turn out boats equal in every respect to the products of the British yards. The luxurious schemes of decoration inagurated by the IVhite Star and Cunard Lines were followed. The vessels are distinguishable by their four large funnels, although their rake and disposition does not render them so picturesque externally as the three-funnelled city vessels of the Inman Line. The success of this boat prompted her owners to lay down a sister ship, the Kronprinz Wilhelm, of 21,300 tons displacement.

Meantime the White Star Line had not been idle. It had secured a certain position upon the Atlantic, and resolved to maintain it. The Oceanic was its reply to the German move. Although this liner was not so fleet as the Kaiser Wilhelm der Grosse, it created just as great a sensation, as for the first time the Great Eastern was exceeded in length. The Oceanic is $705 \frac{1}{2}$ feet long by 68 feet beam, and $49 \frac{1}{2}$ feet moulded depth, displacing I8,300 tons when light. She is fitted with two sets of triple expansion engines giving an aggregate of 28,000 indicated horse-power, which is sufficient to secure a steady speed of $20 \frac{1}{2}$ knots per hour.

Some little disappointment was manifested in certain British circles because the White Star Line had not replied to the German speed challenge, but their new acquisition was regarded essentially as a revenue-earning craft, capable of carrying not only 1,500 passengers of all classes, but a large volume of cargo in addition. So far as the general lines are concerned she follows those of the Majestic and 
the Teutonic, though upon a more liberal scale. This boat achieved instant popularity on her maiden trip, owing to her steady running, comfort and behaviour in rough weather. Another point which did not escape the vigilance of the critical travelling public was her maintenance of speed under all and varying conditions. It is very seldom that the Oceanic is forced to ease up owing to heavy weather. In a way she was an experiment. Her cost was heavy in proportion to that of contemporary vessels, and she has never been duplicated, so that she ranks as a unique model of a trans-Atlantic liner.

The White Star inaugurated another type of vessel, which since has been copied by all the leading companies, with the exception of the Cunard Line. This is the heavy intermediate boat, represented by the Celtic, Cedric, Adriatic and Baltic. The first two named are sister ships. The length is $680^{3}$ feet, beam 75 feet, moulded depth 44 feet $\mathrm{I}$ inch, and each is of 20,904 tons. Their engines develop less than one-half the energy of those of the Oceanic, being only of 12,600 indicated horse-power, giving a speed of 17 knots per hour. They are practically nineday boats, and although in comparison they appear to represent a retrograde step, their success proves that intermediate speed is by no means a disadvantage. In fact, it was the success of these two boats which prompted the company to produce the Baltic in 1904 and the Adriatic in 1907. Both these vessels exceed the Oceanic in everything but horse-power and speed. The Baltic has a length of 708 feet 5 inches, with a beam of 75 feet 4 inches, and is of the same moulded depth as the Celtic. The Adriatic, built three years later (1907), is ro inches longer than the Baltic, 2 inches wider beam, 8 feet 7 inches greater moulded depth, and of 24,54I gross tons, as compared with the $2,3,876$ gross tons of the Baltic. While the latter is driven by engines developing 14,000 indicated horsepower, capable of yielding $16 \frac{1}{2}$ knots, the former is of I6,000 indicated horse-power, the excess being able to produce another $\frac{1}{2}$ knot per hour. 


\section{I2 STEAMSHIP CONQUEST OF THE WORLD}

Although travellers were deprived of speed in these four vessels, they were recompensed by enhanced luxury and comfort in regard to the internal appointments. Coinciding with this development in trans-Atlantic travel the White Star Line improved its Australian and other services, by providing these routes with vessels of the Atlantic type in point of luxury and cuisine, ranging from i 1,000 tons upwards, and with a speed of about 13 knots, all fitted with twin screws. This line has never neglected the Australasian traffic, which is highly remunerative, especially in point of freight.

The German companies did not rest on their laurels. They realised that the big ship is the greatest commercial success, a point which Brunel had advanced when designing his famous vessel. The North German Lloyd replied to the Oceanic with the Kaiser Wilhelm II, which surpassed the former by 2 I feet in length, while her displacement, when loaded fully, is 26 , ooo tons, or 2000 tons less than the White Star record-breaker. In this instance, however, speed was the primary consideration, in conjunction with passenger and cargo carrying capacity. Then came the Kronprinzessin Cecile in 1907, with her length of $706 \frac{1}{2}$ feet and displacement of 27,000 tons-still less than the Oceanic--but with speed as pronounced as ever. The German nation, however, now became outclassed hopelessly by British engineering skill-the British engineer can always come out on top when encouraged, both in the mercantile marine and in naval engineeringby the launching of the Lusitania and the Mauretania. Germany, in matters concerning shipbuilding for the mercantile marine, is sadly handicapped. Never has the Teuton displayed his talent as a first-class copyist or duplicator, rather than an initiator, so completely as in shipbuilding. The five speedy liners flying the flags of the North German Lloyd and the Hamburg-American Lines are to all intents and purposes sister ships. They are all of the same type in regard to their broad outlines, and confusion is very easy when the distinctive flags of the 


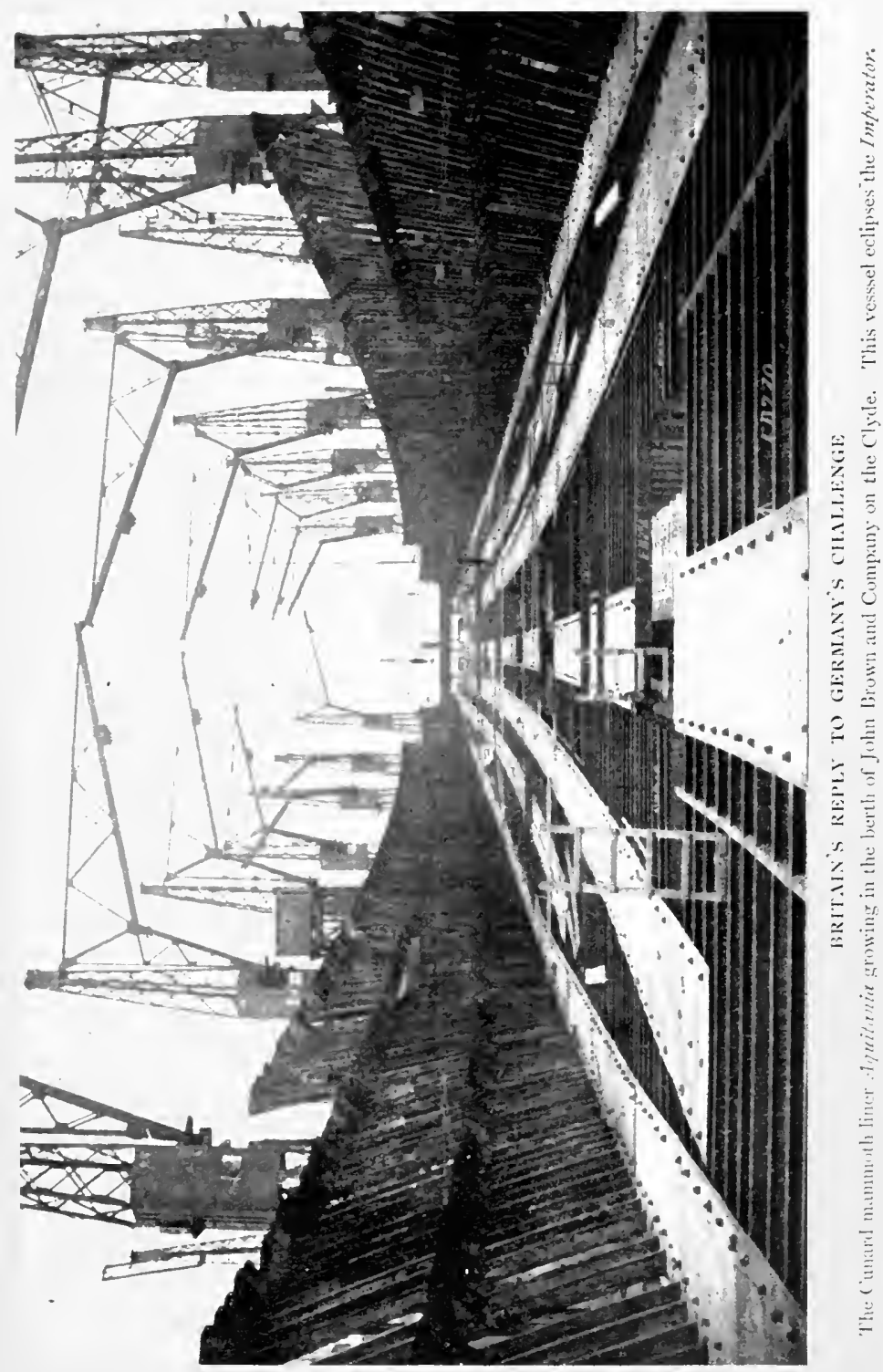



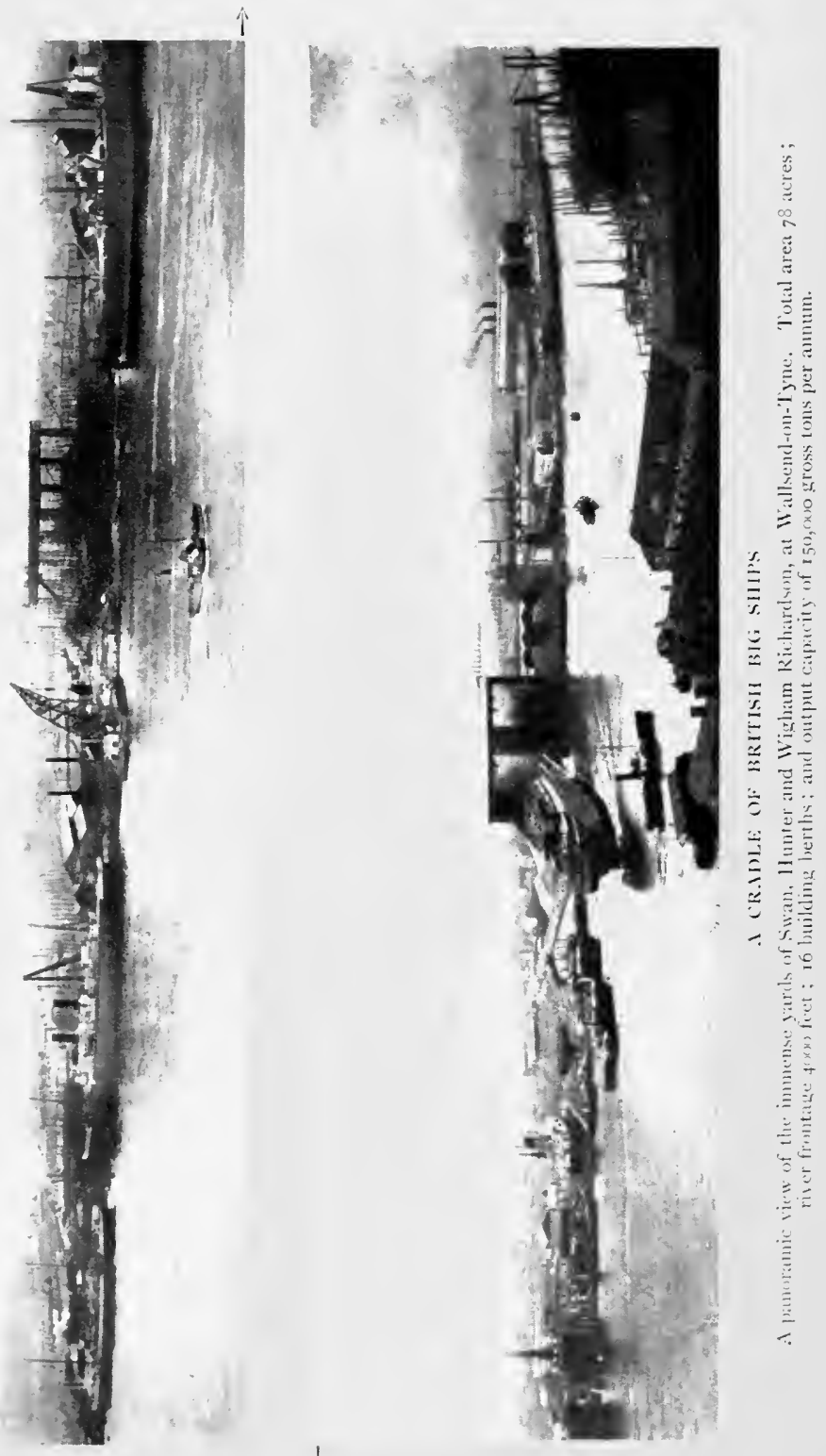
respective companies are not shown. The latest products of the German shipbuilder are the results of what they learned years ago in the British yards, when the native marine engineer considered that the height of his ambition was fulfilled by apprenticeship on the Tyne, Clyde or at Belfast. The British engineer, on the contrary, is always on the look-out for an opportunity to put forth another effort upon different lines. So long as initiative and enterprise are displayed by the British marine engineers, and so long as they can command the confidence of shipowners, they have nothing to fear from German, French or any other nation's competition in regard to this industry.

The attempt made by the United States to figure in the big-ship movement must not be overlooked. Through the enterprise of Mr. James J. Hill, the well-known Canadian railway-builder, two mammoth passenger-freighters, Minnesota and Dakota, were built. In length they did not eclipse the Great Eastern, being only 630 feet from end to end, with a beam of $73 \frac{1}{2}$ feet. A shipbuilding company was created specially for their construction, and though they represented magnificent specimens of naval architecture, they have been almost as huge a failure as was Brunel's unfortunate effort. The Dakota came to an untimely end off Japan. Had these two boats been commissioned for service on the Atlantic they might possibly have paid, but on the Pacific they were pitted against the Japanese, who are sweeping American shipping from those seas, as they are able to operate their craft at a much lower charge. This is an anomalous position of affairs, considering the prosperity of American shipbuilding upon the Great Lakes, and seems almost inexplicable. The raw material in the United States costs less, greater advantage is taken of time and labour saving machinery, yet the country, when ranged against European construction, and more particularly British yards, is completely outclassed. The item of wages rules United States competition out of court. When Canada sanctions the cutting of the Georgian Bay Canal, enabling larger ocean carriers to pass from the 


\section{I4 STEAMSHIP CONQUEST OF THE WORLD}

St. Lawrence to the Great Lakes, the knell of United States shipbuilding on those waters will be sounded. At the present moment they have a far better protection against invasion than the most formidable tariff walls could afford. British shipbuilders cannot compete in this market for the simple reason that they cannot build vessels exceeding a certain tonnage, as the connecting Canal will not permit them to pass. The American shipbuilder at present has lost the trade in the small craft, because the Clyde and the north-east coast are able to undercut him; and directly British shipbuilders secure an entry into the Great Lakes, such as the projected new waterway will offer, they will secure the lion's share of the trade in the building of the 10,000 and 15,000 ton freighters.

When the Cunard flyers appeared, this country set the big-ship movement upon a fresh footing. The displacement of the Adriatic was almost doubled, these two huge boats being of 45,000 tons on the load draught. They were eighty feet longer, measuring 790 feet from end to end, with a beam of 88 feet, and a depth to the boat deck of 80 feet. From the keel to the top of the funnel is a matter of 155 feet. Placed end to end, and moored beneath the Brooklyn Bridge, the thoroughfare of the East River would be completely closed. These vessels in their design reverted to the big yacht in appearance, with the four funnels spaced equidistantly, instead of in pairs, as in the case of the German vessels.

In point of size the Cunard liners have been rivalled by the White Star liner Olympic. This ship has brought the "ıooo-foot-liner," which has been heralded for years, within measurable distance of fulfilment. The Olympic has a total length of $882 \frac{1}{2}$ feet, with an over-all breadth of 94 feet upon the boat deck, and when fully loaded displaces 62,000 tons. The captain's bridge is 100 feet above the bottom of the keel, while the over-all height from the keel to the top of the funnels is 175 feet. The vessel is able to carry no less than 3,346 passengers and crew, and in her capacious holds can stow about 6000 tons of cargo. 
While the Olympic was being completed the Germans awoke, and forthwith prepared their plans to respond to the British challenge. The Hamburg-American Line completed arrangements with Harland \& Wolff for a huge boat, but the contract was cancelled after the necessary drawings were completed. When the shipping prosperity gave signs of returning the project was revived, but it was decided to build the boat, of British design, in a German instead of in the Irish yard-a somewhat curious circumstance. The Imperator measures 900 feet in length, has a beam of 96 feet, displaces 65,000 tons, carries 4, 100 passengers, and requires a crew of 1,100 , men and women to handle her. The British shipbuilding industry was somewhat chagrined at missing this contract, after having prepared the requisite plans, but since these were formulated shipbuilding science has made great strides in various directions. The Imperator will not hold the record for long, as she is being matched by the new White Star liner on the stocks, and which represents a very marked advance upon the German competitor, in length, displacement and every other respect. Even before this boat takes to the water the German rival will be out-paced, as the Cunard Line instantly retorted to the Teuton move with the Aquitania, which will create just as great a sensation as did the arrival of the two famous craft flying the flag of this line.

Where will it all end? The shipbuilder of to-day is far in advance of the shipowner. Lord Inverclyde, in a jesting speech, inquired if shipowners never were to have peace, as builders and marine engineers were always springing surprises upon them in the matter of improvements, and compelling owners to go in for larger, faster and more costly vessels. Seventy years ago the shipowner held the reins and drove the builder. To-day the position is reversed, and the builder is in the dictatorial position. The guiding hand of the Cunard Line has stated that the future of the Atlantic traffic rests with the 50,000-tonner. Lord Pirrie anticipates the arrival of the 1000 -foot boat of 


\section{I6 STEAMSHIP CONQUEST OF THE WORLD}

I00,000 tons. This latter ambition on the part of the builder is curbed only by one stumbling-block-lack of harbour accommodation. But the authorities of the ports are accepting the inevitable, and making adequate provision for the future. During the past thirteen years the growth of the big ship has been amazing. In this short span of time the liner has trebled in tonnage, the length has been increased about 40 per cent., the horse-power has risen from 28,000 to 70,000 , and speed has advanced from $23 \frac{1}{2}$ knots to 26 knots per hour. If the pace is maintained, the close of the first quarter of the twentieth century will see the realisation of Lord Pirrie's dream. 


\section{CHAPTER II}

\section{THE BIRTH OF A STEAMSHIP}

Altholgh the handiwork of the engineer always compels attention, the expression of his skill which probably arouses the deepest admiration is the steamship, especially when it is a huge and speedy liner. The sight of a structure of steel, measuring several hundred feet in length, weighing tens of thousands of tons, ploughing through the water 20,25 or 30 miles an hour never fails to stir the most indifferent soul.

Often have I heard wonder expressed as to how the builder of ships creates his handiwork. How does he decide the length, breadth, depth, tonnage and speed? How is it possible to fashion a fabric of steel able to maintain its equilibrium under all and varying conditions of weather : to devise the million and one component parts so that they may be united and adapted in such a manner as to be able to withstand the heavy blows inflicted by wind and wave?

These are easy questions to ask, but very difficult to answer clearly. The naval architect aspires to the highest range of mathematics, while his mind is steeped in figures and formulæ so abstruse as to defy resolution into the comprehensive simplicity of the alphabet for the benefit of the uninitiated.

When the shipowner decides to purchase a new vessel two courses are open to him. He can either appoint his own naval architect to prepare the plans and designs for a craft such as he desires, to be passed on to the shipbuilder for fulfilment, or he may go to the latter and say, "I want a steamship," accompanying the request with a rough idea 
of the contemplated carrying capacity of the boat, the part of the world in which it is to trade, the character of the traffic, together with one or two additional minor details, leaving the shipbuilder to work out the most satisfactory and economical design coinciding with these fundamental demands. This latter procedure, it may be pointed out, is the more successful and most generally practised, as the shipbuilder, having the whole enterprise from $A$ to $Z$ in his hands, and with his reputation at stake, may be trusted to give the utmost value for money, free from any novelties and fads which have not emerged from the searching school of commercial test. The shipbuilder is a hard-headed, practical man: he runs no risks, nurses no fantastic theories, but gives the product of approved design born of long and varied experience.

If the boat be of the tramp class, the chances are a thousand to one, if the shipbuilding organisation is of long standing, eminent reputation, and possessed of extensive facilities-such as, for instance, a firm like Swan, Hunter, \& Wigham Richardson, Limited, at Wallsend on Tyne-that a vessel possessing similar features, and which has proved highly satisfactory in operation, has been built previously for another shipowner. This former success forms the basis for the new boat; the pattern, as it were. The projected craft may vary in details of dimensions and speed, but the modifications to suit these conditions may be effected very easily. Neither the shipbuilder nor the shipowner will entertain any doubts about the result-the vessel will be built upon the fruit of experience. This, it may be mentioned, is the issue which governs the success of a shipbuilding yard more than anything else. The oldestablished concern which has turned out vessels of all descriptions year after year, and which consequently has accumulated comprehensive knowledge and skill in every branch of the industry, occupies a unique and unassailable position. Experience trained upon such lines must build up a powerful reputation of which the shipbuilder, naturally, is extremely jealous. 
With such firms shipbuilding is resolved into a state of affairs somewhat analogous to that of a tailor; that is, so far as the conventional class of vessel is concerned. As the worker in cloth keeps the measurements of a customer on record, so does the shipbuilder file the designs of every type of ship which he has built.

Of course, when the shipowner desires a vessel which represents a pioneer craft, something different from anything which has been launched before, elaborate preliminary researches and investigations are essential. This was particularly the case when the British Government came to the aid of the Cunard Line for the building of the Lusilania and Mauretania. Both vessels are the marvel of this age, no matter from what point of view they are regarded. The second vessel, in particular, is a wonderful creation. Not only has she astonished the travelling public and her owners, but the anticipations of her designers and builders have been adequately fulfilled. What is more to the point, fresh surprises are being sprung upon all concerned in her welfare at every turn. At the present moment she is not only the fastest liner in the world, but she stands as the most imposing monument to British marine engineering. She has been excelled in size, in accordance with the progressive spirit of the times, but in speed, luxurious comfort and consistent running she has not been eclipsed by the product of any other British or foreign shipyard. On her trial trips she notched the highest speed ever attained by a merchant vessel -27 knots, or 31 miles, per hour.

She ploughs to and fro the Atlantic, ignoring seas and weather, at a steady $25 \frac{1}{2}$ knots per hour, her best average speed from coast to coast, up to the time of writing, being 26.06 knots per hour. She has placed some other astonishing achievements on record also. Early in her first season one of her four propellers was damaged by striking some sunken wreckage, but the pressure of traffic was so heavy that the liner could not be withdrawn from the service to be dry-docked for an inspection. Accordingly it was c 2 
decided to run the vessel until the end of the season with the affected propeller and its turbine shut down. Yet, in spite of having only three screws working, she still was able to maintain the service adequately.

The most remarkable performance, however, was still to come. As is well known, the Lusitania and the Mauretania maintain the express mail service traffic of the Cunard Company between Liverpool and New York, the two ships being given a very brief rest in port on either side of the Atlantic, so that they are worked practically at full pressure the whole time. In one season the Mauretania completed 27 consecutive trips across the Atlantic-I $3 \frac{1}{2}$ round voyages -reeling off no less than 77,500 knots-89,242 miles-at an average speed throughout of $25 \frac{1}{2}$ knots, or $29^{\circ} 36$ miles, per hour. This is a record absolutely unprecedented in the whole history of the steamship.

Yet when one reads about these smart achievements of the Mauretania, or sees her driving along at full speed, one never gives a thought to the infinitely laborious experiments and calculations involved before even her keel was laid. A long list of men, famous for their association with marine engineering problems-such experts as Sir William White, Sir E. J. Reed, the Honourable Sir Charles A. Parsons, Dr. Brum, Messrs. George B. Hunter, W. Johns, McQuorn Rankine, IV. and R. E. Froude, together with the expert staff of the builders-contributed to her design.

In planning a special type of vessel many varied factors have to be taken into consideration. There are questions of stability-one of the vital problems of the ship-speed, economy and steadiness when travelling at full speed, not only in smooth, but also in rough, weather, which have to be threshed out thoroughly. When the Mauretania was taken in hand the mathematicians prepared ideas which, they concluded, would fall within the four corners of the essential requirements; but calculations were not sufficient. At the Admiralty experimental tank at Haslar small models were prepared from paraffin wax, 
in accordance with mathematical deductions as to shape and form of the hull, and which were in proportion to the vessel contemplated. For instance, one model corresponded to a full-sized ship, 760 feet in length by 80 feet wide, and displacing 34,000 tons of water; while another was the diminutive edition of a boat 725 feet long by 80 feet wide, and displacing 32,900 tons. Each successive model varied from its predecessor in some detail or other. One had a very much sharper bow, another had a finer run aft than its fellow, and so on. Time after time these models were towed through the experimental tank by an overhead travelling carriage, upon which were mounted delicate instruments to record the towing speed, and a mass of other technical data. From the accumulation of these repeated tests, at varying speeds, it was possible to see how closely mathematical deductions were allied to practice, and which was the most favourable and scientifically correct design.

In the experimental tank the wax models were what are known as "naked forms." That is to say, only the bare shape of the hull was taken, without any allowances being made for increased resistances and disturbances arising from the projections from the body, such as those carrying the propellers. Nor were the most advantageous positions for the third and fourth screws determined thereby. The upper works of the vessel were also omitted in these investigations, and seeing that, in the case of the Mauretania, three additional decks were to be provided above the level of the top of the model, which corresponded to the shelter deck, together with four funnels, navigating bridge, etc., it will be realised that a considerably increased area was to be offered to the wind in the ultimate liner, which was certain to exercise a marked influence upon the speed.

Realising the portentous risks attending the venture, the builders of the Mauretania embarked upon a series of searching experiments independently of the Investigation Committee appointed by the British Government. The 
experimental tank tests had settled the main dimensions of the ship-790 feet by 88 feet beam-together with the form of the hull, and therefore the carrying capacity. The additional investigations were made to decide profound questions left unsolved by the tank experiments, such as those pertaining to the driving machinery of the vessel, etc. Speed was such an imperative consideration that it was essential to settle the position, size and shape of the propellers, together with the collection of data respecting the effect of wind upon the superstructure. At the time practically nothing was known about the propulsion of vessels by four propellers, and very little about triple propellers. The twin screw was the standard practice; the three propellers had just come into vogue, but conclusive data concerning this subject, as a result of commercial application, was lacking.

The Tyneside builders designed a small launch, one-sixteenth of the size of the projected liner, for the purposes of their investigations. Whereas the wax models had been towed in the tank, this little craft was self-propelled, being fitted with electric motors for this purpose, sufficient accumulators being stowed aboard to permit it to be driven at full speed continuously for three hours. Each propeller shaft was fitted with an independent motor, so that its screw might be started and stopped independently as required.

The Northumberland Dock, having a width of roo feet and a depth of 24 feet of water, was selected for the tests. In this space the launch was given a clear run of about 440 yards to travel at its maximum speed, with margins at either end in which to secure a flying start and to pull up respectively. Although, of course, such adverse influences as currents and other underwater disturbances were not manifest, on the other hand the launch was subject to the effects of the wind. Time after time it was driven up and down this confined area at varying speeds and under divergent conditions, not only for the purpose of obtaining new light upon certain obscure issues, but also to check and counter-check the data gleaned with the 
wax models in the testing tank. Delicate recording instruments were placed on board the little craft to measure speed, wind resistance, engine-power, propeller revolutions and so forth. The information secured as a result of these investigations, spread over a period of two years, was of the most voluminous and exhaustive character.

Some of the results obtained certainly were startling. For instance, in order to give an idea of the wind forces and their influences upon speed, power, etc., it was calculated that to enable the Mauretania to maintain a speed of 25 knots per hour against a head wind blowing at equal velocity, 12 per cent. more power would be required than to uphold the same speed in calm weather. On the other hand, with a following wind of identical velocity the liner would be able to notch the 25 knots per hour with about 4 per cent. less power than in calm weather.

Over 500 speed trials were made with this launch to determine the most suitable propellers with regard to high number of revolutions and high efficiency. Twelve sets of propellers, of different proportions, each reproduced exactly to scale in every particular from those contemplated for the full-sized ship, were made. The position of the third and fourth, or wing, propellers, driven by the highspeed turbines, also occasioned elaborate and patient study. The importance of these trials may be gauged from the fact that there was a variation in power for the same speed of as much as 5000 indicated horse-power. Altogether some 400 diagrams, each containing about 12 tests-an aggregate of nearly 5000 records-were obtained from these two years' work; and from these prolific data the dimensions and other details concerning the horse-power, displacement and a thousand and one other indispensable facts were resolved.

It is doubtful whether the construction of any vessel in the history of the merchant marine ever has been attended hy such exhaustive preliminary work for the purpose of reducing the element of chance to its most infinitesimal proportions. Of course, the expenditure of $£ 2000$, or 


\section{STEAMSHIP CONQUEST OF THE WORLD}

$\$ 10,000$, by the builders of the Mauretania upon these researches has contributed a wealth of new information pertaining to shipbuilding science, over and above that required immediately for the Cunarder. It has enabled the organisation identified therewith to place itself in the foremost rank among the world's shipbuilders, since it has fathomed problems and has harvested knowledge which still remain to be sounded and reaped by rivals.

When the calculations for a vessel have been decided, and the naval architect has elaborated his scheme, what are known as the longitudinal section, or "profile," and the "'midship section" drawings are prepared. The latter is a cross-section of the vessel amidships. On this drawing all the dimensions of the steelwork constituting the skeleton of the vessel, together with the skin, the decks and other information, are indicated, for the guidance and approbation of the surveyors of Lloyd's, or of any other classification society, in accordance with the rules of which the vessel is being constructed. These societies have laid down the dimensions for the integral parts of vessels of varying tonnage, length and duties, and from the "'midship" section, together with the full 'details inscribed thereon, the surveyor is able to see just how and of what material the ship is to be built, inasmuch as every other part of the boat must bear its relationship to this section.

The designer now proceeds to "lay down the lines," or shape of the hull, upon paper. As is well known, a vessel is very sharply pointed at the bow, the stem being a kind of knife-edge to cut the water. Thence the hull swells out gradually to amidships, which is the widest part of the boat, whence it gradually decreases in width once more as the stern is approached. The deck of a ship, when looking from above, somewhat resembles a cigar, the point of the latter corresponcling to the bow, and the blunt end to the rounded stern.

Now the shipowner, after the designs for his boat have been prepared, naturally wishes to have some idea of its ultimate appearance. For this purpose, what is known as 


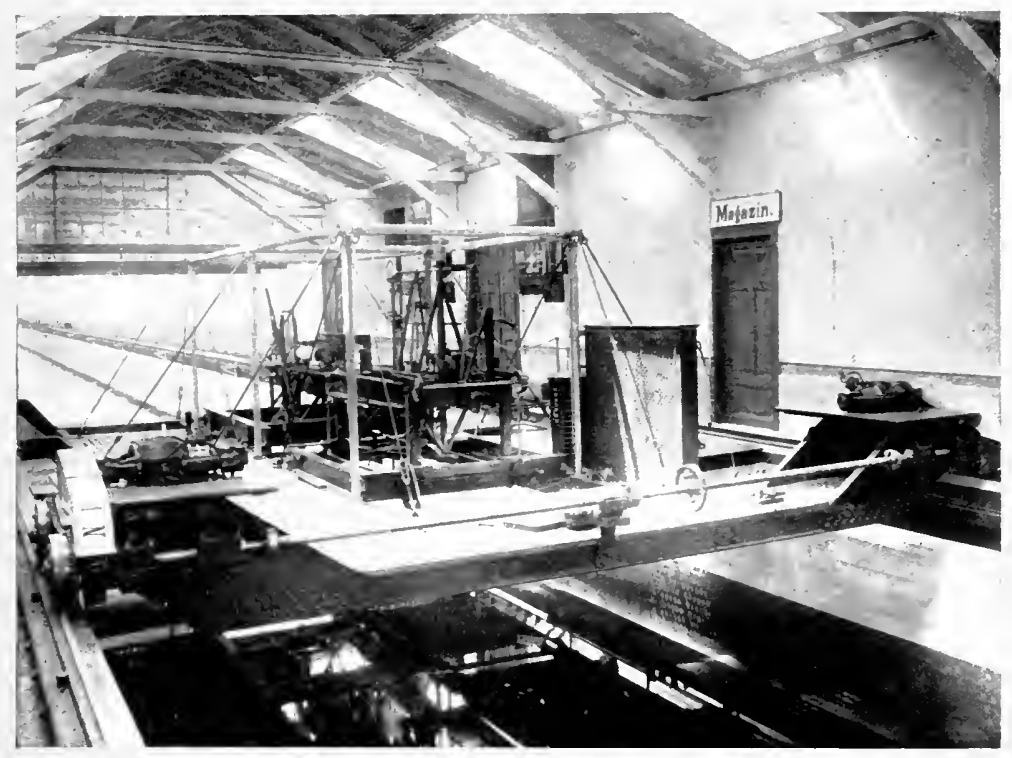

liy fermission of the Horth (reman Lloget]

\section{THE TESTING TANK}

Wax molels are prepared to sca'e to be towed by means of an overhead travelling carriage. carrying numerous delicate recurding instruments.

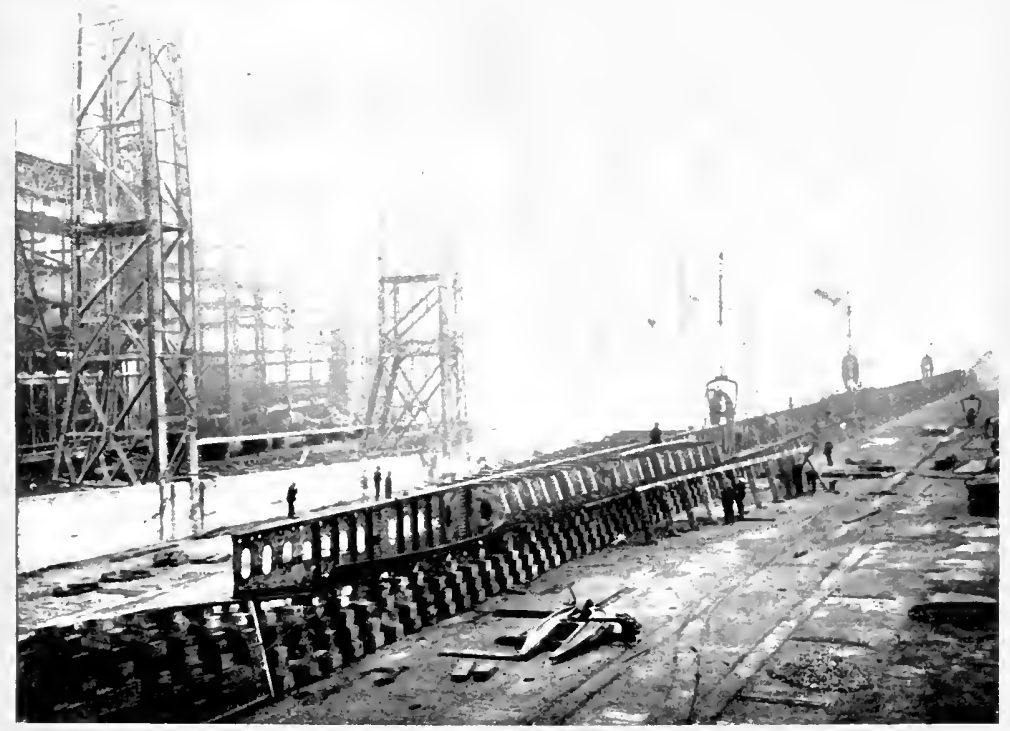

THE M.MMGTH LINER'S B.LCKBONE

The "Keelson" of the dympic. showing the huse powerful hy dritulic riveter" sispended from the overhead cranes. 


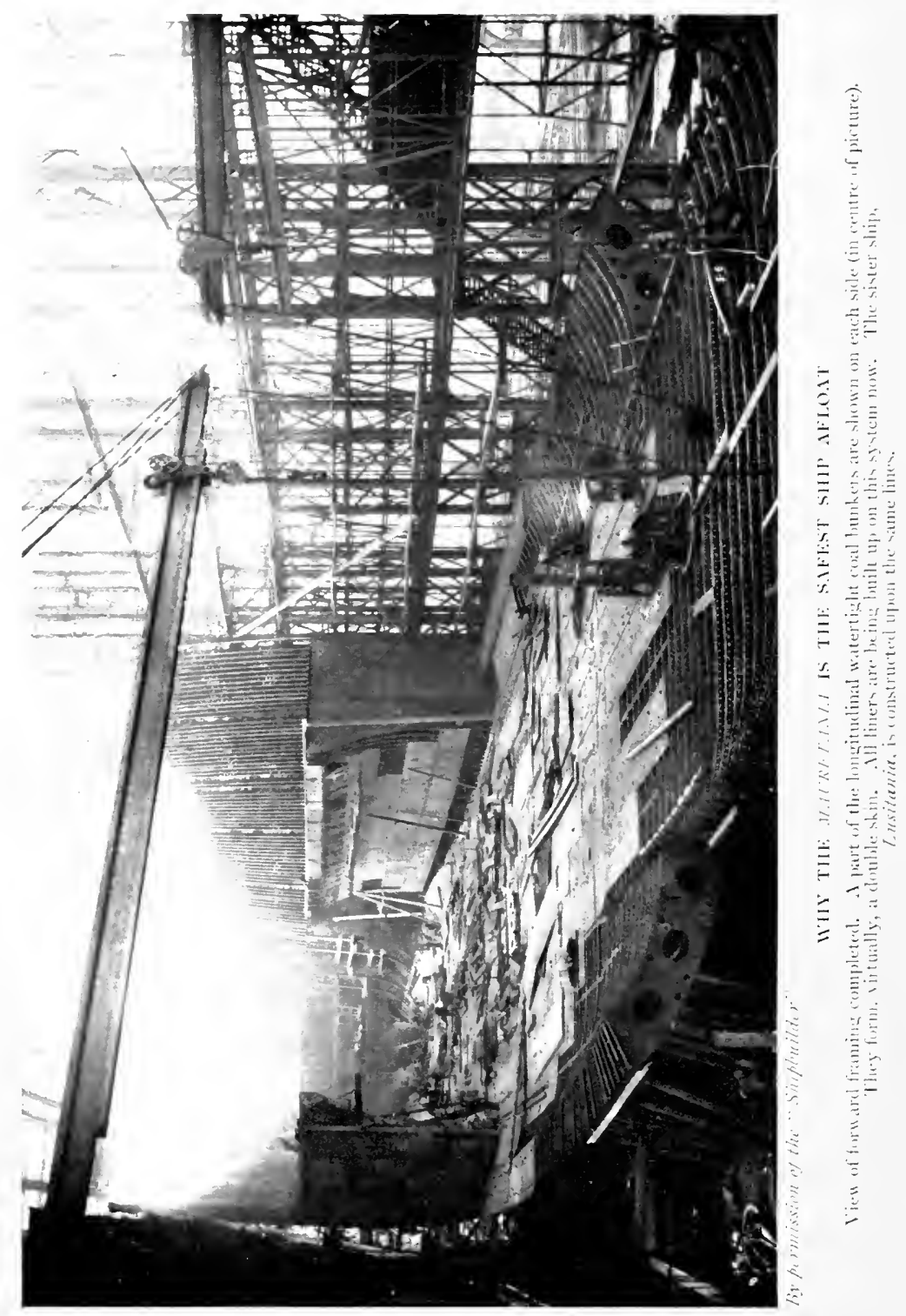


a "half-model" is made. This is fashioned from solid wood, generally to the scale of $\frac{1}{4}$ inch to the foot, but which represents only one-half of the ship, cut vertically in twain from stem to stern. A model of the whole vessel is not necessary, because the two halves must be alike. This half-model is mounted upon a board, and submitted to the shipowner for his approval. At this point some modifications in the shape of the hull may be deemed necessary. Looking at the model, the experienced eye of the builder, or even the owner himself, may suggest that it should be a little fuller here, finer there, a little rounder somewhere else, and so on, for the improvement of the ressel.

As it is usual for the lines of a ship to be put down approximately in the first instance--the half-model is prepared therefrom-when the shape of the model is adjusted, the lines themselves, as laid down by the draughtsman, are revised simultaneously. The half-model is of great assistance to the shipbuilder, inasmuch as thereon are marked the frames, the plates, and various other details, to facilitate the ordering of the constructional material.

"Drawing the lines," which is virtually the translation of the contour of the half-body from the model to a flat surface, is carried out at the Wallsend shipyards upon large marble-topped tables. This surface is far and away preferable to paper, which, being liable to shrinkage and expansion, is apt to render the drawings less accurate, while alterations may be made more cleanly, and when the work is finished the whole may be erased with soap. To the uninitiated the drawing at this stage represents a tangled network of lines, but the draughtsman knows exactly the meaning of each outline, and instantly can inform one what part of the hull it represents.

While this work has been progressing calculators have been busy resolving the paper ship into its equivalent of material, and have prepared estimates of just how much metal of all descriptions, forms, shapes and sizes will be required. Also, they have computed the number of rivets 
which will be necessary to hold the fabric together, the quantity of wood to complete the decks and internal fittings, the upholstery for the furniture-in short, every one of ten thousand parts, down to the uttermost cup-hook in the steward's pantry. These estimates are voluminous records, varying from a few pages for a small launch to a bulky volume or two in the case of a monster liner. Not an item is overlooked, no matter how small and insignificant it may appear. Individually minor details may represent only a trivial amount-a copper or two-but in the aggregate thev form an imposing total. Thus, one will see so many tons of plates for the hull, so many hundred thousand rivets, not in hastily judged round numbers, but to the utmost digit, with no allowances for waste. The timber is similarly itemised, the estimated quantity, perhaps of as many as thirty different qualities and varieties, being duly set forth. The system and procedure are just the same as those incidental to the erection of a house. As the surveyor takes off the quantities from the domestic architect's drawings, so does the shipbuilder ascertain exactly what his constructional requirements will be in connection with the vessel. The only difference is that the work of the latter is far more elaborate and intricate, owing to the more complicated character of the ship, and the larger number of component parts necessary for its completion.

Another calculator proceeds with the estimate concerning the cost of labour in the various trades involved, which may range over thirty or more. Thus there will be estimates of the cost of labour in regard to plating, riveting, joinery, painting, polishing the woodwork, upholstery, installing electric light, plumbing, machinery and so forth. These schedules are exceedingly comprehensive and thorough, but are imperative, because no single item must be overlooked or be a mere guess. Haphazard calculations mean all the difference between "profit and loss"; the omission of this or that detail endangers the shiphuilder's balance on the right side very seriously. For instance, in the steelwork waste has to be reduced to the very smallest 
possible limit, for the simple reason that "scrap," if you care to call as such that metal which is not used, when returned to the steelmakers only fetches about one-third of what it cost the shipbuilder originally. Under-estimating is just as serious as over-estimating. The shipbuilder bases the price of the boat upon the cost of material at the time of the tender. Should he, therefore, find himself short of material some six months later, when the vessel is assuming its shape on the stocks, and have to remedy this deficiency, he may be called upon to pay considerably more for his additional needs, if the prices of materials have risen in accordance with market fluctuations. It is not surprising, therefore, that the most scrupulous care is displayed in preparing the estimates, and that the work is carried out by the most experienced men, who, from many years' service in this one branch alone, are not likely to err on one side or the other. Similarly, one does not wonder that elaborate checking and counter-checking are followed, to make assurance doubly sure.

To the untrained eye the stage at which a ship commences to assume its definite and familiar form is in the mould-loft. This is a spacious, well-lighted building, paved with a substantial wooden floor, which is blackened. The shipbuilder, in technical parlance, calls this the "scrieve-board," but the school-boy would describe it as a huge blackboard laid on the ground, because it recalls this indispensable unit of the school-room's equipment. The "loftsman," armed with a substantial piece of chalk, wanders over this black field, transferring the drawings of the ship prepared by the draughtsman to its surface, only in this instance the drawings are to full size.

This is one of the most responsible stages in the whole evolution of the vessel, because, should an error have crept in and have been overlooked in the drawing office, it should be detected here. Under an expert eye this is not difficult, as a mistake which might not have been readily discernible when working upon paper at a scale of $\frac{1}{13}$ inch per foot now becomes glaring, inasmuch as it is greatly magnified, 
owing to the translation of the design to full scale. The frames are drawn, together with the precise points at which they are connected up to other parts of the skeleton or body of the hull, while the exact places at which the ribs, or frames, are to be fixed to the keel are indicated.

The lines committed to the floor, the curves are taken by means of long, flexible wooden battens, which are deftly and quickly bent to the chalk outline, to provide a wooden pattern, or template, for fashioning the steel frame to form one of the ribs, beams or some other part of the vessel. The other details of the structural parts are completed in a similar manner. The templates are not only made to shape, but are drilled wherever required, to indicate the position of the rivets, and so on. Thus it will be seen that the skeleton of the ship, in the first instance, is prepared in wood throughout, in sections, and to full dimensions. Each template receives an identification mark to signify its relative position in the hull, and then is turned over to be copied in metal.

The mould-loft is one of the most fascinating corners of the shipbuilding yard, because one is enabled to realise the untiring care and patience that are displayed in the initial stages pertaining to the creation of a vessel. The foundations, as represented by the mathematical calculations and drawings, arouse only a fleeting interest, but in the mould-loft one sees the ship maturing in wood from a bewildering array of figures and apparently unintelligible lines and curves. 


\section{CHAPTER III}

\section{THE CONSTRLCTION OF A STEAMSHIP}

ONCE the steamship has emerged from the chrysalis stage in the moulding loft its growth is rapid. Down by the waterside gangs of brawny workmen are engaged busily preparing the berth in which the creation of steel is to assume its permanent, familiar form. The berth, or building slip, is pitched on a gentle slope shelving into the water, for the purposes of launching, as described in a subsequent chapter, and the first step is to align and level the blocks of wood upon which the keel, or backbone of the ship, is laid.

The yards are a humming hive of noisy bustle. They contrast vividly with the placidity and unostentatious activity prevailing in the drawing offices. There the birth of the steamship is carried out amid a quietness which is impressive, because, as mentioned already, it is an operation effected among figures and drawings. Down in the yards the fruit of brains is translated into energetic muscular force; tranquillity gives way to an ear-splitting and nerve-shattering din, as metal meets metal, in the task of bending, trimming, shaping and riveting up.

The modern shipyard is a striking illustration of highly developed organisation, applied science and expert human skill in its most compelling phase of muscle and brain. Where an ounce of physical energy may be saved and a few seconds of time economised by mechanical devices, they are adopted with alacrity. The equipment of a yard varies considerably. I have been in some where the berths are open to the sky, but are flanked on either side by tall, spidery cranes, having long, slender arms of steel which 
pick up weighty pieces of metal, whisk them through the air, speedily lifting and swinging them round meanwhile, finally to be lowered exactly into the desired positions. At Wallsend, on the other hand, the larger berths are under lofty glass roofs, shielding the workmen from inclement weather, so that work may be continued uninterruptedly. A few feet below the roof heavy girders stretch from end to end and from side to side. By craning the neck one may see, high above, ugly, irregular blotches of drab silhouetted against the transparent glass. They are moving continually to and fro like restless spiders, which, indeed, they resemble, so high are they above the ground. These are the overhead electric travelling cranes, and from each depends a long, thin cable, terminating in a ponderous hook. The latter grabs a massive sheet of steel or a long, thin girder, and without a sound lifts it. While the weight vanishes upward the crane travels lengthwise and transversely simultaneously, so as to bring the load over the appointed spot. Then, lowering rapidly yet carefully, the charge is brought to rest just where it is required, to be held stationary for a moment or two until it has been secured to the accumulating fabric, when the hook is released, recedes quickly upwards, and the crane dashes off for another load.

As the wooden templates come from the mould-loft they are diverted to one of a hundred departments, to be reproduced in steel. Massive machines appear to be scattered about with apparent indiscrimination on all sides, and in their black, hump-like heads may be seen a small, glittering tooth of steel. A sheet of metal, maybe an inch in thickness, twenty-five feet in length by six feet in width, and tipping the beam at three or four tons, is seen clasped in the monster's jaws. The steel tooth moves up and down with monotonous regularity, and with each stroke a little disc of metal falls to the ground. The machine is punching rivet-holes through the ponderous steel plate with as much ease as a tasting scoop bores into cheese. Another machine, a planer, is cutting off shavings of steel as if it 
were working pitch-pine, imparting a smooth, even face to some great plate; while a bevelling machine, with terrible grunting and groaning, is forcing back the right-angle flange of a steel frame with no more effort than one bends a piece of cardboard.

Each shed appears to be engaged in a deadly struggle to rival its neiglibour in the creation of noise. If sound offers any criterion as to the volume of work that is being accomplished, then one and all of the departments must be working at tip-top pressure. One shop in particular emits a terrible clatter. This is where the slender ribs of the ship are being shaped. It differs from the average conception of a workshop, inasmuch as it is open on three sides, while overhead, in the low roof, is the ubiquitous electric-travelling crane, with its human guide perched upon what seems to be an extremely uncomfortable seat. The floor resembles a huge, perforated wooden mat, such as is to be seen in the scullery and kitchen of a hotel to protect the feet from damp. But in this instance the peculiar flooring serves a vastly different purpose. The mat is built up of great slabs of cast-iron, six inches or more in thickness, with the holes, about one and a half inches square, spaced about four inches apart in both directions.

Scarcely a dozen men are to be seen, and the place looks deserted. Stealthily the overhead crane creeps forward, bearing a long, light and pliable length of iron bent to an outline. It is one of the templates for a rib. The foreman of the gang clutches the template and dumps it upon the perforated floor. In the twinkling of an eye a chalk line has been drawn along the edge of the template upon the flooring, as if it were a ruler upon a piece of paper. The outline is tested to see that the contour is dead correct, and then the template is moved to one side. The workmen pick up short lengths of bent pieces of metal - dogs, they call them-and drop them into the holes at desired distances apart, on one side of the chalk mark.

In close proximity to the perforated floor a furnace is 
roaring hungrily. It is fired with suction gas, and the heat within is intense. This furnace is no small affair. From end to end it measures between 80 and 100 feet, and when the door is swung open heavy, long pieces of metalangle-bars or frames, they are termed-may be seen glowing within.

The foreman gives a signal wave with his hand. The workmen hurry forward, fling open the furnace door, and with a long hook grab the end of an angle-bar within. A rope is attached to this hook, and with a cheery "Heaveho!" the glowing bar is dragged out and thrown upon the floor. One end of the beam is made fast by means of "dogs" clamping it on either side. Some of the men, armed with the hook, seize the opposite, free end of whitehot metal, to pull on it with might and main, while others, with dexterous strokes of their heavy sledge-hammers, pound the dazzling, ductile length of metal at different points, so that it is bent speedily to the required curve inscribed on the floor. Before long the rib has lost its lurid tone, and has assumed a bluish tinge. The squad passes along its curved length to see that it lies evenly upon $\mathrm{its}$ bed. If there is a slight kink, a few powerful blows with the hammers eliminate the bulge. The practised eye of the foreman glances along the rib to see that it toes the chalk line from end to end. Having met with his critical approval, the electric crane fusses up, a hook is passed round either end of the rib, and the crane backs down the shop, bearing away the frame to cool and to await its call to the berth, to be erected in its allotted position upon the slip.

When the great Cunarder was in the making, the abnormal lengths and great size of some of the ribs teased the benders time after time. The heary sledgehammer did not quite meet the situation, so the engineers set to work to devise an improved mechanical means of driving the refractory parts of a rib up to the chalk line. This was a small hydraulic machine, recalling a lawnmower in its general appearance. When the benders were 


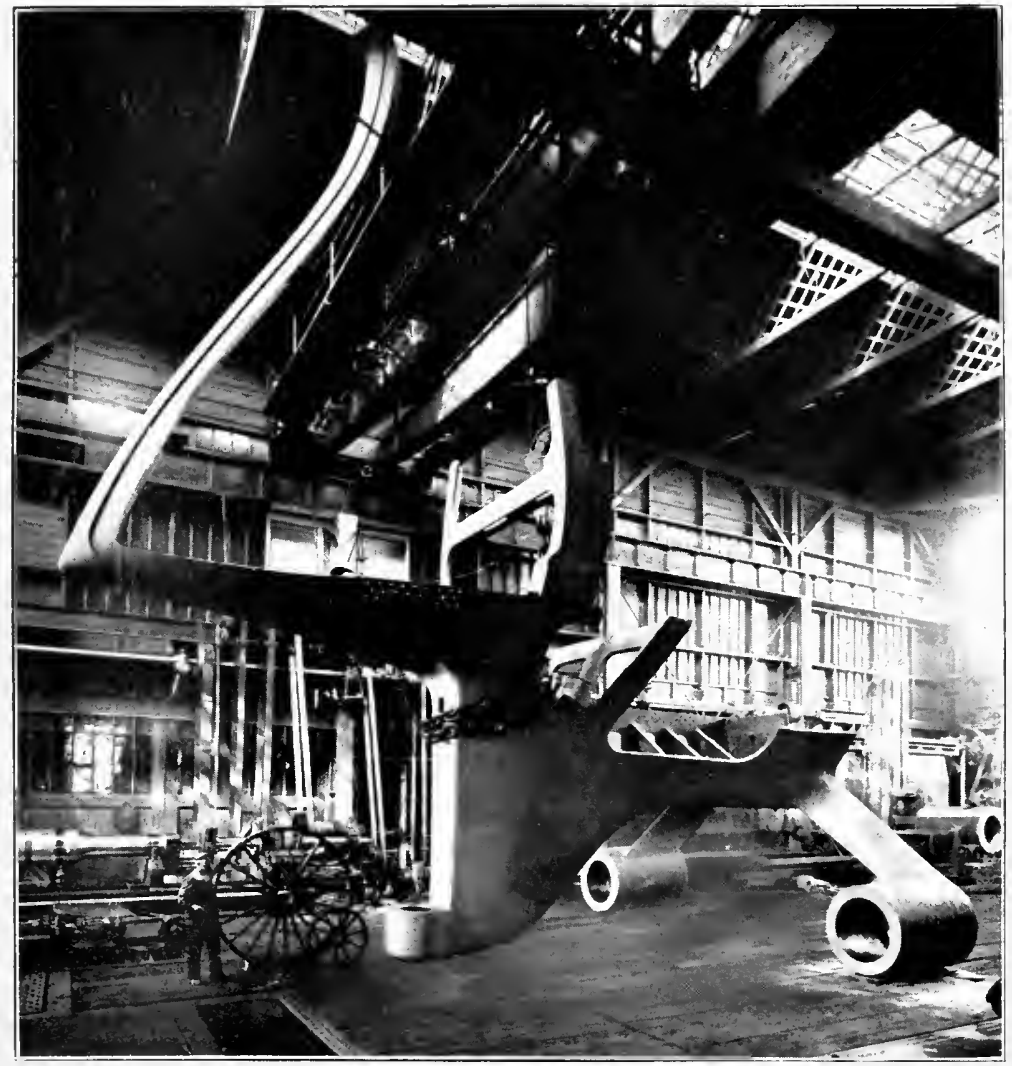

A M.ASTI\% (.ISTIR

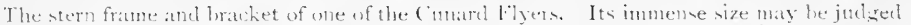

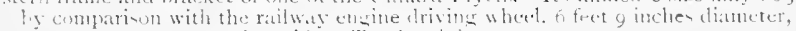
alongsicle. Total weight, ror lonr. 


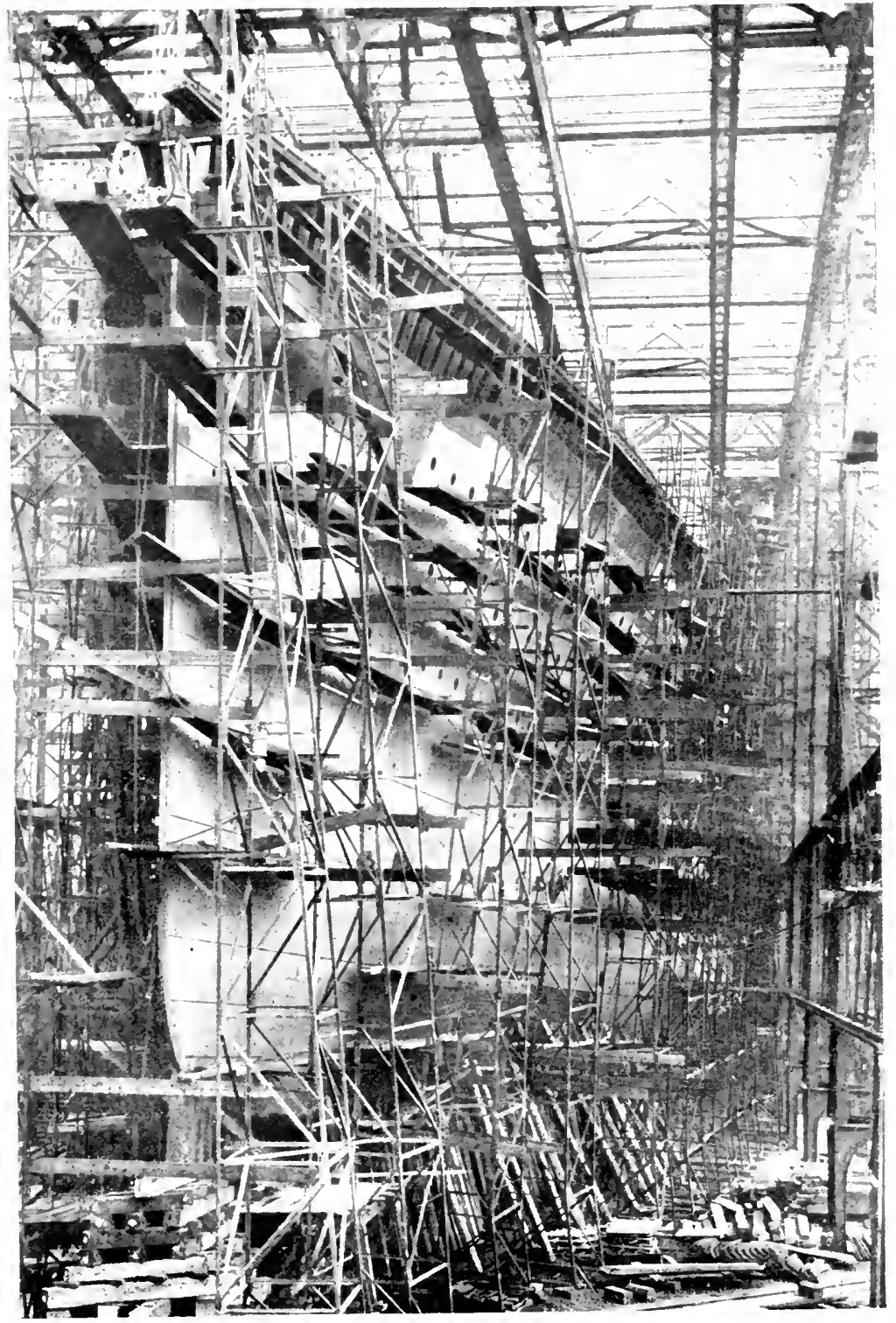

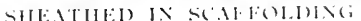


confronted with a ticklish piece of shaping, this little machine was wheeled up, its nose brought to bear against the frame, while its feet, dropping into the floor-holes, kept it rigidly in position. A flexible pipe coupled to a hydrant was turned on, and the water admitted into the cylinder. Instantly the tiny nose of the ram reached out, and, bearing against the hot, soft frame, it forced it forward, with a pressure of several tons, to the required curve. This was only one of many ingenious devices which the engineers of Swan, Hunter, \& Wigham Richardson contrived to meet awkward situations. It proved so successful and rapid, and so much more effective than the muscle-swung hammers, that it has been extensively adopted. Whenever a length of steel evinces a disposition to resist the pounding of the hammers, this ram is adjusted, and the metal is soon compelled to submit.

The first actual constructional operation in the shipbuilding berth is the laying of the keel. In the average modern ship this comprises a flat plate, instead of a projecting vertical bar, with which popular conception associates the term "keel." The latter was employed before the flat-bottomed ship came into vogue. While a single plate is sufficient for the keel-plate in a small vessel, more may be required in a large boat. The Mauretania's keel-plate, for instance, comprises three thicknesses of plating. This plate acts as a rubbing piece, while riveted above and to it, by means of angle-bars, is the "centre keelson," which extends from end to end of the ship, to form a massive continuous girder connecting the two skins forming the inner and outer bottoms. As this structure constitutes the backbone of the ship, it is built up of most substantial plates riveted together solidly from one end to the other. The backbone of the Mauretania is decisively heavy and massive, ranging between five and six feet in height, the latter increased depth being introduced at the points where the weight of the machinery and boilers is imposed. As this "centre keelson" is solid from end to end, the cellular bottom, or space between the two skins, 
is divided longitudinally. The flat bottom of the ship rises in a graceful curve to meet the sides, and the bilge keels are placed at the bends to reduce rolling.

When the keel-plate has been laid and the "centre keelson" has been erected, the floor-plates, or numerous divisions of the cellular double bottom, are placed in position. The frames are then taken in hand, and this task is generally commenced from amidships, to proceed in either direction towards the stem and the stern. Simultaneously the bottom plating is carried on, together with the formation of the skin of the inner bottom, or tank-top plating, as it is called. As soon as the frames are partially erected the bulkheads are pushed forward, while the deck beams are set in position. If the stem bar which completes the forward framing of the ship is ready, it is generally set in position at once, so as to get it out of the way.

So far as the erecting work in the front part of the ship is concerned, the task is fairly straightforward. On the other hand, the most difficult section is the stern, and as a rule the shipbuilder strives to get its heaviest and most ungainly component parts in position early. The weightiest part of the whole is what is known as the stern-post, the propeller brackets and the rudder. The first-named is the piece which forms the rearmost part of the hull's frame; the propeller brackets in ships having more than one screw, are, as the name implies, the two arms which support the extremities of the shafts carrying the propellers; while the rudder explains itself. Another reason why the shipbuilder endeavours to make headway with this part of the hull is to be able to proceed with the plating in good time, since many of the plates under the ship's counter and round about the stern-post have to be shaped specially. This is particularly the case with ships having more than one propeller, as in this instance the plates must be bent round the propeller brackets and those frames which are "bossed," or swelled out, to provide space for the propeller shafts.

In the case of a huge liner like the Mauretania the stern- 
post, propeller brackets and rudder are formidable pieces of the metal-worker's craft. In this Cunarder the stern post complete represents a weight of 54 tons, the forward and after brackets weigh 95 tons, while the rudder turns the scale at 64 tons. These were all special castings, and elaborate preparations had to be made, therefore, by the Darlington Forge Company, which has achieved some very noteworthy records in this particular field. Although these weights are huge, they have been since eclipsed by those pertaining to the Olympic, which are phenomenal. In this vessel the stern frame represents a massive casting weighing 190 tons, 70 tons being in the stern-post itself. The rudder, when placed upright, towers to a height of $78 \frac{3}{4}$ feet, is $15 \frac{1}{4}$ feet wide, and weighs a matter of $101 \frac{1}{4}$ tons !

Much of the riveting nowadays is accomplished by means of hydraulic tools. These are cumbersome appliances of tremendous power, and they have solved the difficulty of dealing with heavy riveting in a most complete manner. For such work as connecting up the plates forming the "centre keelson," there is a huge jaw, which drops over the girder, being suspended in position from an overhead trolley. The rivet in the red-hot state is popped into its appointed hole by means of a pair of tongs ; one jaw of the tool fits over the head, and the other clasps its point. The hydraulic energy is applied, and the jaws, closing with the force of fifty tons, crunch the rivet like a nut, spreading its bottom end so that it is burred over to nip the attached pieces of steel firmly together.

In other instances the compressed-air riveter is used. In this tool there is a small cylinder having a head which vibrates rapidly. When the rivet is slipped home in its hole, the end of the cylinder is held over the protruding point, and while the head of the rivet is held tightly up, the hammer of the tool pulsates at high speed, jamming the edge of the rivet over with a deafening and distinctive "Br-r-r-rp-br-r-r-rp-br-r-r-r-rp!"

Hand-riveting, however, has not been superseded altogether. There is much of the shell and many awkward 
corners on a ship where both the hydraulic and compressedair devices for this purpose are impracticable. Then the rivet is driven home by the dexterous strokes of the human riveter. Two expert workmen with a few deft swings pound the exposed glowing point of a rivet, causing it to grip tightly by spreading in its hole. A couple of blows upon the head of a chisel held against the protruding rivet cuts away the superfluous metal, when another hot rivet is inserted into the next hole, which is treated in a similar manner. The workmen now return to the previously driven rivet, and strike at its cooled end until it clinches the two pieces of superimposed metal on either side. Two attacks are made upon each rivet, with a brief interval between, to complete the work satisfactorily.

The steel plates forming the skin of the vessel are disposed in rows, or "strakes," as they are called in the shipbuilder's language. These sheets of metal vary in size, weight and thickness, high-water mark in this respect, so far as the Wallsend yard is concerned, having been reached with the Mauretania. These plates in some instances measured 48 feet in length, and weighed as much as 5 tons apiece, so that they were formidable sheets of metal to manipulate. They were secured together and to the skeleton by rivets $\mathrm{I} \frac{1}{8}$ inches in diameter. By the time the vessel was completed over $4,000,000$ rivets had been used, representing an aggregate weight of 700 tons.

After the frames, bulkheads and beams are placed in position the skin plating is completed, and the deck plates are laid down. The only space left is the gaping hole to admit the engine and boilers, which are bedded after the vessel has been launched and towed alongside the fittingout wharf. Previous to sending the ship into the water, it is usual also to place in position the propeller shafting and to affix the propellers themselves. By the time the Mauretania was ready for launching a total weight of 16,800 tons was standing in the berth, and this represented the heaviest weight that had ever been sent down the ways up to that time. 


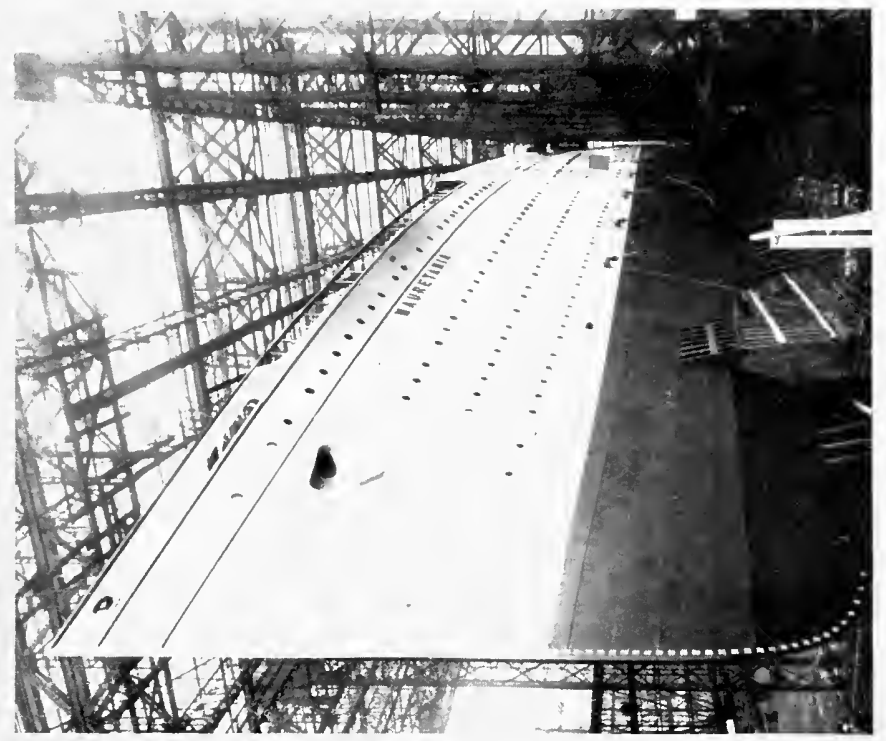

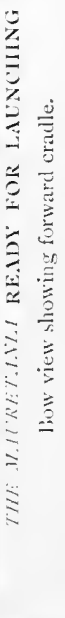

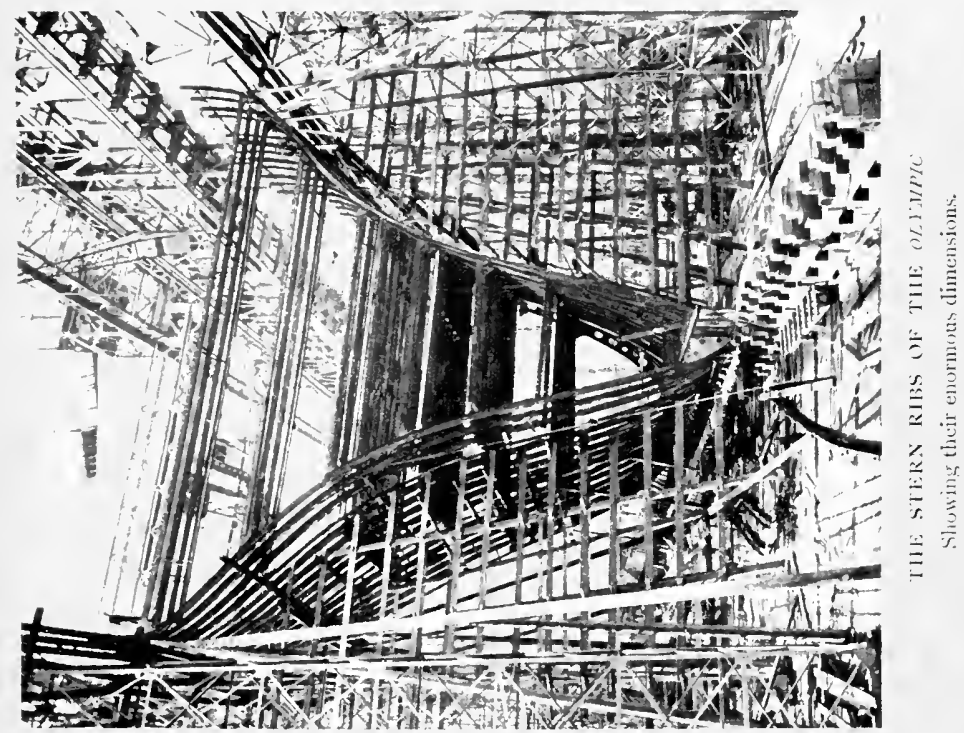




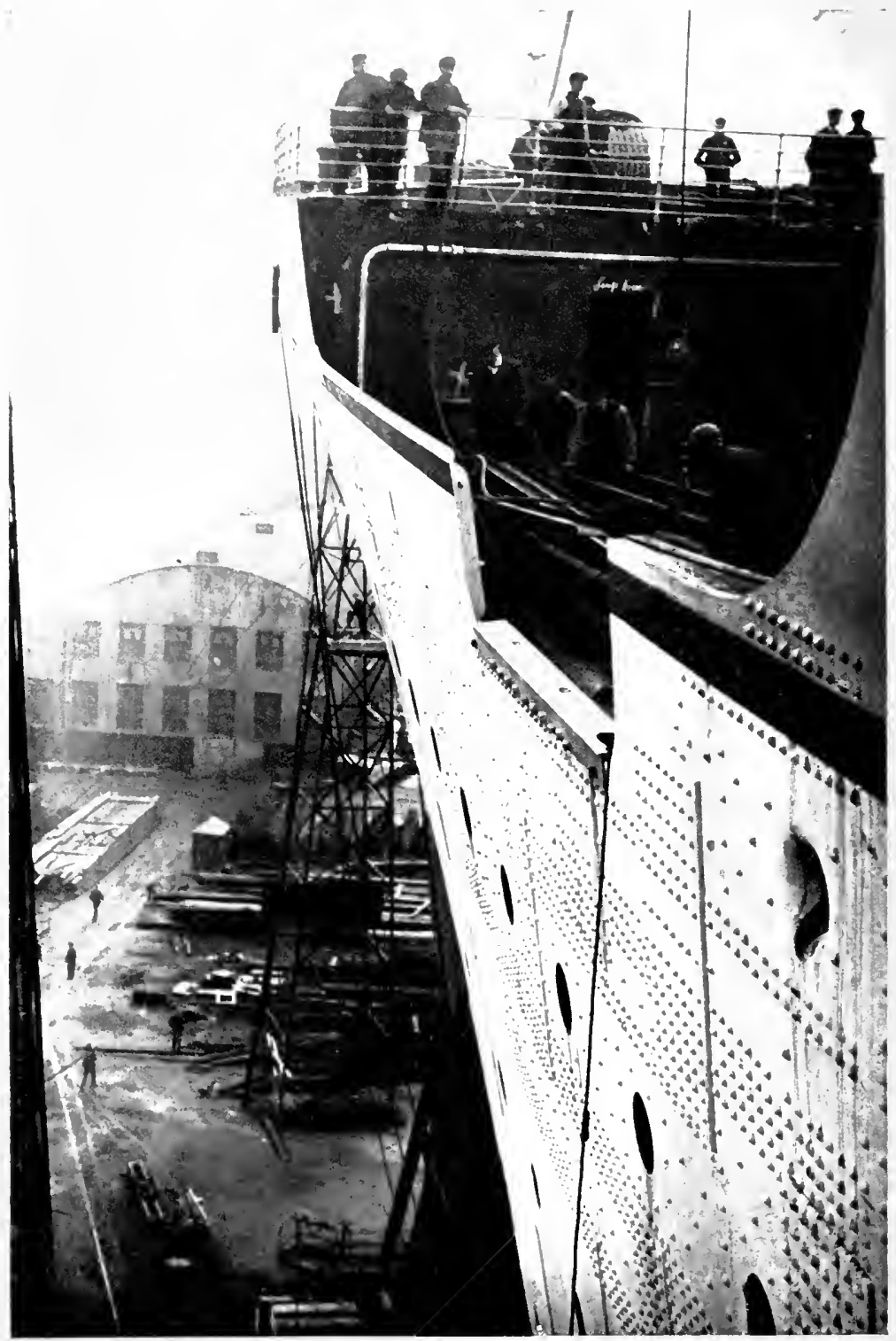

AN OCEAN MUNSTER ASHORE

This photo affords a striking idea of the immense height of the bow of the Olympic as she rested on the stocks. 
There are one or two terms employed in connection with a ship which deserve explanation, seeing that they so often lead to confusion. As a rule length measurements are expressed in two ways-"over-all" and "between perpendiculars" respectively. Thus, for instance, the Mauretania measures 790 feet over-all, and 760 feet between perpendiculars. The former explains itself: it is the extreme length of the ship from tip to tip, as it were. The second term is quite different. It signifies the distance between the perpendicular line of the stem and that at the stern from the extremity of the "centre keelson." As is well known, the deck of a ship overhangs the propellers, while a sharp curve is described upward from the end of the keelson to the point where the rudder-post enters the fabric of the ship proper, and in which the screws revolve.

Considerable misunderstanding also exists in the lay mind concerning the terms tonnage and displacement. Thus we read that a vessel has a certain gross tonnage, a net tonnage, and that it displaces so many thousand tons. Gross and net tonnages are merely measurements of capacity for what might be called legal and statistical purposes, as well as forming a basis for the levy of port dues. Such tonnage is an arbitrary measurement, ion cubic feet being taken to represent one "ton." In cargo ships the carrying capacity of the vessel is stated in "tons dead weight," that is, tons avoirdupois, although for special trades, such as the transportation of fruit, capacity in cubic feet may be given.

Displacement is often confused with tonnage. As a matter of fact, it has a distinctively different meaning. When we say that the Mauretania displaces 44,540 tons, or that the Olympic has a displacement of 62,000 tons, we mean that the ship, with everything on board and laden to her maximum load-line, or draught, displaces these respective weights in avoirdupois tons of water. In plain English, these figures represent the total weights of the respective vessels, including their loads. Displacement is an elastic term, because it varies from hour to hour. As 
. 8 STEAMSHIP CONQUEST OF THE WORLD

the furnaces eat up the coal and the passengers consume the provisions, the ship becomes lighter and lighter, so that in the case of an Atlantic greyhound the difference in the displacement when arriving at New York, as compared with that when leaving Europe, may vary between 5000 and 7000 tons. 


\section{CHAPTER IV}

\section{TIIE PROPELLING MACHINERY}

IT is a far cry from the year 1838 , when the steam conquest of the ocean was achieved definitely and commercially, to 19I2. Yet in these 74 years progress has been marked. The pioneer liner Sirius was driven by paddlewheels, and with the collective energy of 320 horses resolved into harnessed steam her engines were able to give her an average speed of $7 \frac{1}{2}$ knots- $8 \frac{3}{4}$ miles-per hour. At the time this was considered an amazing engineering achievement, but it pales into insignificance when ranged beside the pace of the crack liners of to-day, especially of those famous sister ships flying the Cunard flag. They travel $3 \frac{1}{2}$ times faster than did the Sirius, but their engines are more than 200 times as powerful in order to cross the North Atlantic in a quarter of the time occupied by the little vessel which led the way. This comparison offers a graphic idea of the enormous strides that have been made by the marine engineer in the space of threequarters of a century.

Yet evolution was comparatively slow. For years the paddle-wheel held undisputed sway, although that brilliant engineering genius, Brunel, attempted to force the pace with the screw in the Great Britain, designed for the North Atlantic mail and passenger service. When this vessel was designed originally, paddle-wheels were to be the means of propulsion, but during the long interval that ensued in her construction, the master-mind busied himself in experiments with the screw, and finally considered this to be the system of the future. At the time of this decision the paddle-wheel engines of the Great Britain 
were half completed, but Brunel, with his characteristic disregard of expense, scrapped this effort, and completed the screw propeller and machinery for the ship. His judgment was vindicated by results, although other shipowners of the time, in concert with the shipbuilders, regarded the innovation coldly, and refused to acknowledge its advantages.

The knell of the paddle-wheel liner was sounded by the Inman Line, which came into existence in I850, to share the harvest of the Atlantic passenger and mail trade with the Cunard Company. This rival line started operations with the City of Glasgow, built on the Clyde, and driven by a single screw. The Cunard Company had been in competition with the Collins Line, and was now beaten by a new rival. But the vanquished company clung tenaciously to the paddle-wheels until I862, when the China with a screw propeller appeared on the seas under its flag. This tardy action on the part of the Cunard Company appears somewhat inexplicable, inasmuch as single screw steamers had been running in its Mediterranean service with complete success for ten years previously.

A few years later came the twin screw liner, the shortcomings of a single propeller having been made plain by one or two alarming accidents. The twin screw held the field until the Hon. Sir Charles A. Parsons produced his epoch-making steam turbine. Then the Dumbarton firm of Denny Brothers, which has played an important part in the history of steam navigation, introduced a third propeller, for reasons explained later, and the vessel so equipped having created a sensation in engineering circles, the idea became widely adopted. This development received its crowning triumph in the Lusitania and Maurctania. After months of the most searching investigations by the foremost marine engineers of the day, it was decided to fit these liners, owing to the extreme size and power of the engines, with four propellers. If present indications afford any criterion, this will be the standard for fast, huge ocean liners of the future. 


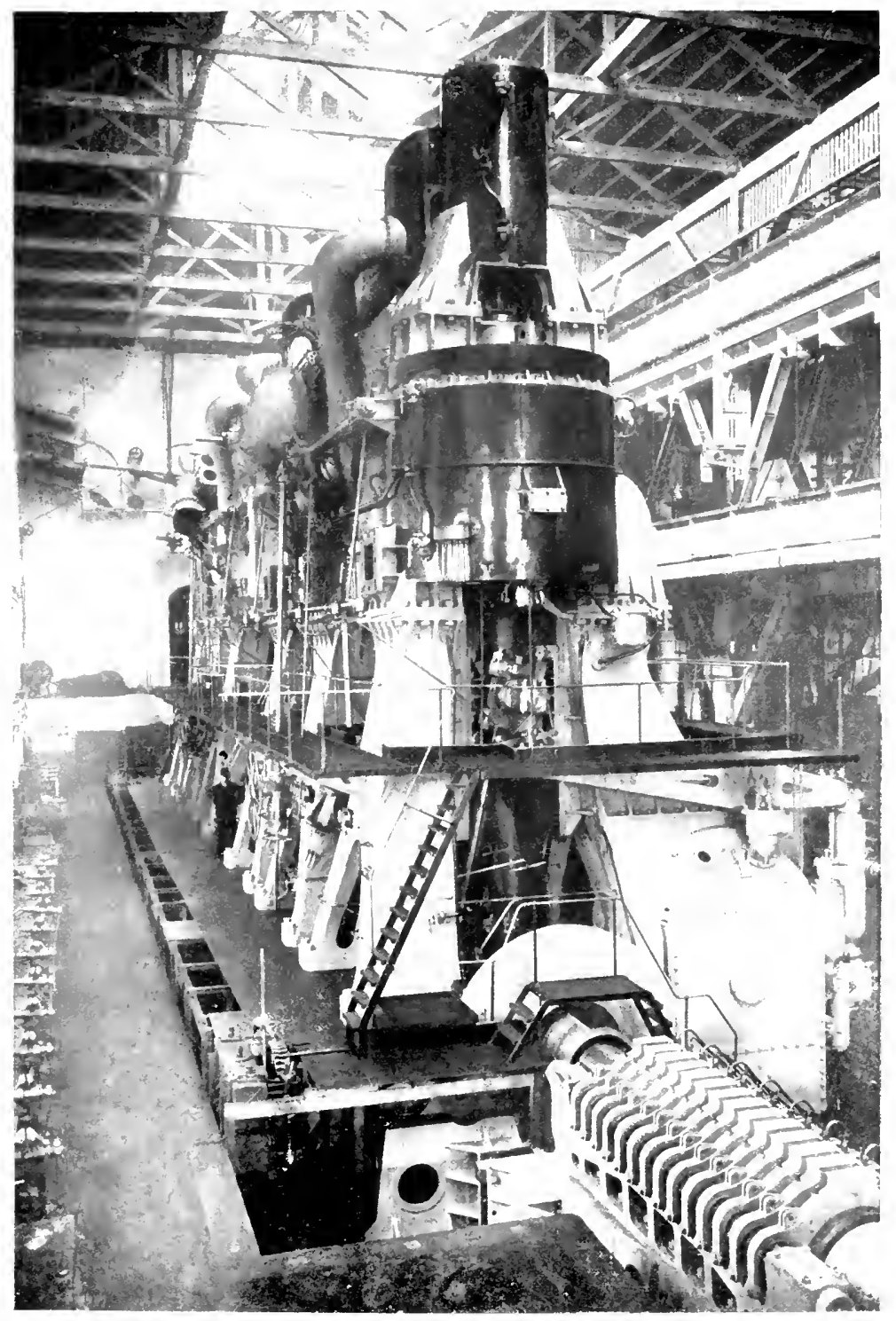

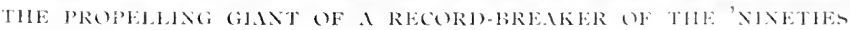

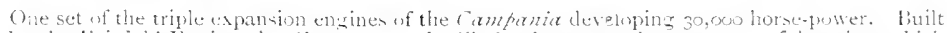

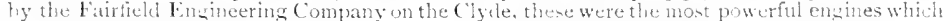
had been cometructed up to 1892 , and wive the Cunbeler a speed of 22 knotn iver hour. 


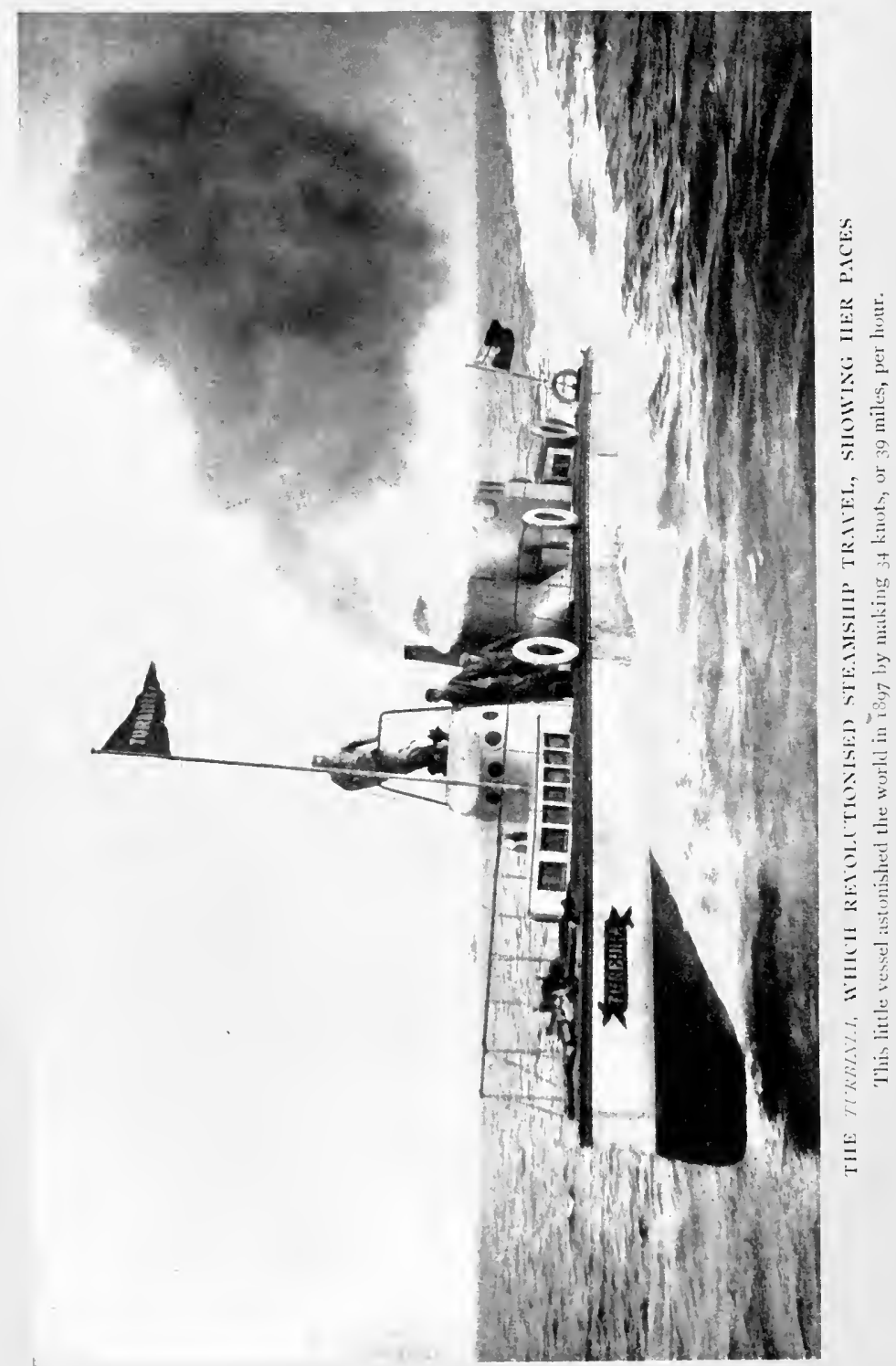


The engines supplying the requisite power to the propellers have undergone a similar change. The earliest engines were exceedingly primitive. They may be compared with the modern engine for driving a ship just as the Rocket may be compared with the latest railway locomotive. After the steam had completed its work in the cylinder by driving down the piston to impart a rotating movement to the crank, which in turn revolved the paddle-wheel or screw, it was permitted to escape into the outer atmosphere. As science advanced, the engineer came to the conclusion that a considerable quantity of power was lost in the exhausted steam-that it had not expended fully the energy it possessed. Accordingly, a second and larger cylinder with its piston was coupled to that into which the steam was admitted direct from the boiler. The first cylinder was of relatively small proportions as compared with its neighbour, and the gas, after completing its work in the former, passed into the latter, where it was deprived of a further proportion of its latent energy. This arrangement was known as the compound engine, and for many years it held the field.

The system was successful, but as time went on the engineer became dissatisfied. He was convinced that the steam which issued from the second cylinder could perform more useful work, and accordingly a third cylinder, larger still, was introduced. This gave the triple expansion engine, so called because the steam expends its force in three degrees-in the high, intermediate and low pressure cylinders respectively. This stage did not indicate finality. More power could be squeezed out of the steam after it emerged from the third cylinder; consequently, a fourth was added, to produce the quadruple expansion engine, which represents the high-water mark in marine engineering to-day, so far as the familiar reciprocating engine is concerned.

As the twin ships, Lucania and Campania, the Teutonic and Majestic, and the City of New York and City of Paris, were the crowning triumphs of half a century of steam- 
ship navigation, so their respective engines represented a magnificent achievement in engineering. So far as the first two vessels, which were built in the shipyards of the Fairfield Engineering Company on the Clyde, are concerned, the two sets of triple expansion engines fitted within their steel walls were the most powerful that had been built up to that time. The combined output of each installation is 30,000 horse-power, which enables the ship, measuring 620 feet in length by $65 \frac{1}{4}$ feet wide, and weighing 19,000 tons, to be driven at an average speed of 22 knots per hour. Each set of engines comprised five inverted cylinders - two high pressure, one intermediate and two low pressure respectively-and the top of the cylinder is 47 feet above the base of the engine. The pistons are arranged to work on three cranks, set at an angle of 120 degrees from each other, the pistons having a common stroke. Each set of engines is placed in a water-tight compartment, separated from its fellow by a longitudinal bulkhead extending the full length of the engine-room, and provided with water-tight doors for the purposes of inter-communication. The engines are fed with steam raised in twelve boilers, each measuring 17 feet in length by 18 feet in diameter.

Speed demands power, and when the German companies set out to sweep the Atlantic they had to concentrate their energies upon the engine-room and its machinery. The Deutschland weighs about 6000 more tons than the Cunarders she eclipsed, is 66 feet longer, and requires 5000 additional horse-power to eke out an additional $1 \frac{1}{2}$ knots per hour, her two sets of quadruple expansion engines developing 35,000 horse-power. Each engine has six inverted cylinders, the pistons being connected to a shaft having four cranks. This was the largest crankshaft which had been forged up to this time. To keep these two huge masses-one for each set of enginesrotating at full speed 16 large boilers fired by I 2 furnaces are required, devouring a ton of coal between them every three minutes. More impressive still are the engines of the 
Kronprinzessin Cecilie, also of the quadruple expansion type, and which develop 46,000 horse-power in the aggregate to drive 27,000 tons across the Atlantic at a steady speed of $23 \frac{1}{2}$ knots per hour. Here it will be noticed that the increase in engine power over her rival the Deutschland is no less than $\mathrm{I}, 000$ for a similar speed, while the vessel is 20 feet longer and weighs 2000 tons more. It was hoped in Germany that this enormous aggregation of energy would enable the vessel to rival the crack Cunarders pace at $25 \frac{1}{2}$ knots per hour, but these anticipations were not fulfilled. The crank shafts are mighty forgings in steel, while the four-bladed propellers weigh no less than 79,200 pounds. Steam is raised in 19 cylindrical boilers, each weighing about 100 tons when empty, and approximately 150 tons when filled with water, so that the steam-generating equipment alone represents a total weight of no less than 2,800 tons in working order.

As may be imagined, this remarkable growth in size, power and speed brought its own evils. The worst of these was vibration, which increased in magnitude until it became so acute as to render travelling in the very highspeed boats nauseating. The slower British boats were comparatively free from this disadvantage, and consequently retained their patronage, leaving the fastest boats to that hustling section of the public which would fain cross the Atlantic in a single night, if the facilities were available, and which is prepared to face any discomfort, so long as the cravings for the annihilation of time and distance are satisfied.

The British engineers realised that this problem of vibration must force itself to the front sooner or later, so, by infinite experiment and investigation, they strove to reduce it to the minimum. Messrs. A. F. Yarrow, John Tweedy and Robert Humphrys were particularly active in these researches, in collaboration with Dr. Otto Schlick. Their combined efforts were successful. By the adjustment of the cranks, and the relative positions and movements of the various moving parts of the engine, they secured prac- 
tically the complete elimination of the vibration bogey, and accordingly the majority of large and powerful marine engines of the reciprocating type-so called because of the up-and-down motion of the pistons-incorporate the discoveries of these workers in their design, and are described as being balanced upon the Yarrow-Schlick-Tweedy system.

With the advent of the Deutschland and her. $23 \frac{1}{2}-\mathrm{knot}$ contemporaries, it was generally believed that the economical limit in regard to this type of marine engine had been reached. Meantime, however, in Great Britain an inventor had been working steadily and quietly in a new field with a different system of power generator. This was the Honourable Sir Charles Algernon Parsons-son of the famous third Earl of Rosse, who, in the early part of the last century, erected a gigantic astronomical telescope at his seat near Parsonstown, in Ireland-and his invention was the modern steam turbine, which has changed completely the whole science of express steamship practice, where high speed is the paramount consideration. For years he prosecuted his experiments with dogged perseverance, and finally produced a small craft, the Turbinia, driven by nine propellers arranged in sets of three upon three shafts.

This famous little vessel measures 100 feet in length, has a beam of 9 feet, and weighs complete in running order $44 \frac{1}{2}$ tons, of which the driving installationmachinery, boilers, screws, etc.-represent 22 tons. The total horse-power developed is about 2000, and this suffices to drive the little craft at a speed of 34 knots-nearly $39 \frac{1}{2}$ miles-per hour, a speed which had never been attained upon the water before.

The possibilities of the turbine were impressed upon the world in a dramatic and, it must be admitted, in a startlingly conclusive manner. The Turbinia attended the Great Naval Review at Spithead in 1897 , on the occasion of Queen Victoria's Diamond Jubilee. The little boat, as she rode at anchor, did not arouse any attention, because outwardly she resembled one hundred or more other craft 


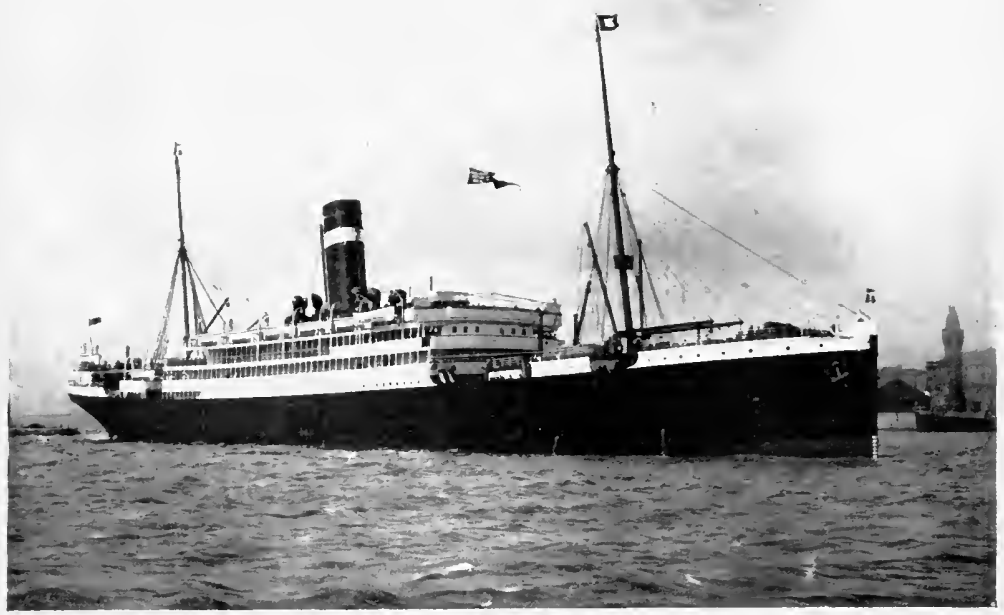

THE FIRST ITLANTIC TLRBINE LINER

The Allan Greyhound Iictorian driven by Parson's marine turbines and 3 propellors.

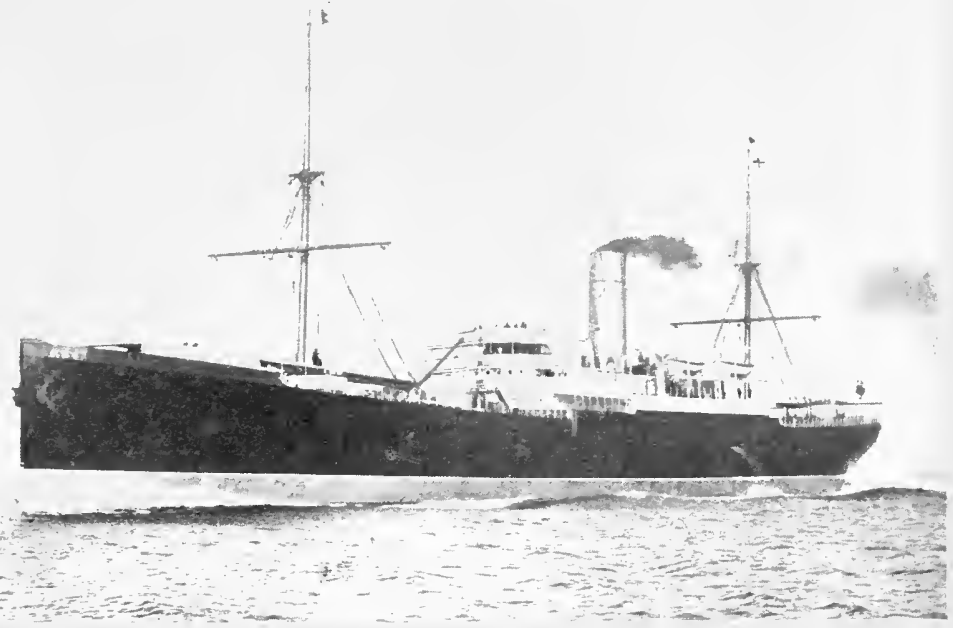

IX IISTORIC VESTEL

The Ctaki, built by Denny Brothers, of Dumbarton. wan the first ve-sul propelled by a combination of Paron is turloines and reciprocating engines with triple sorews. 

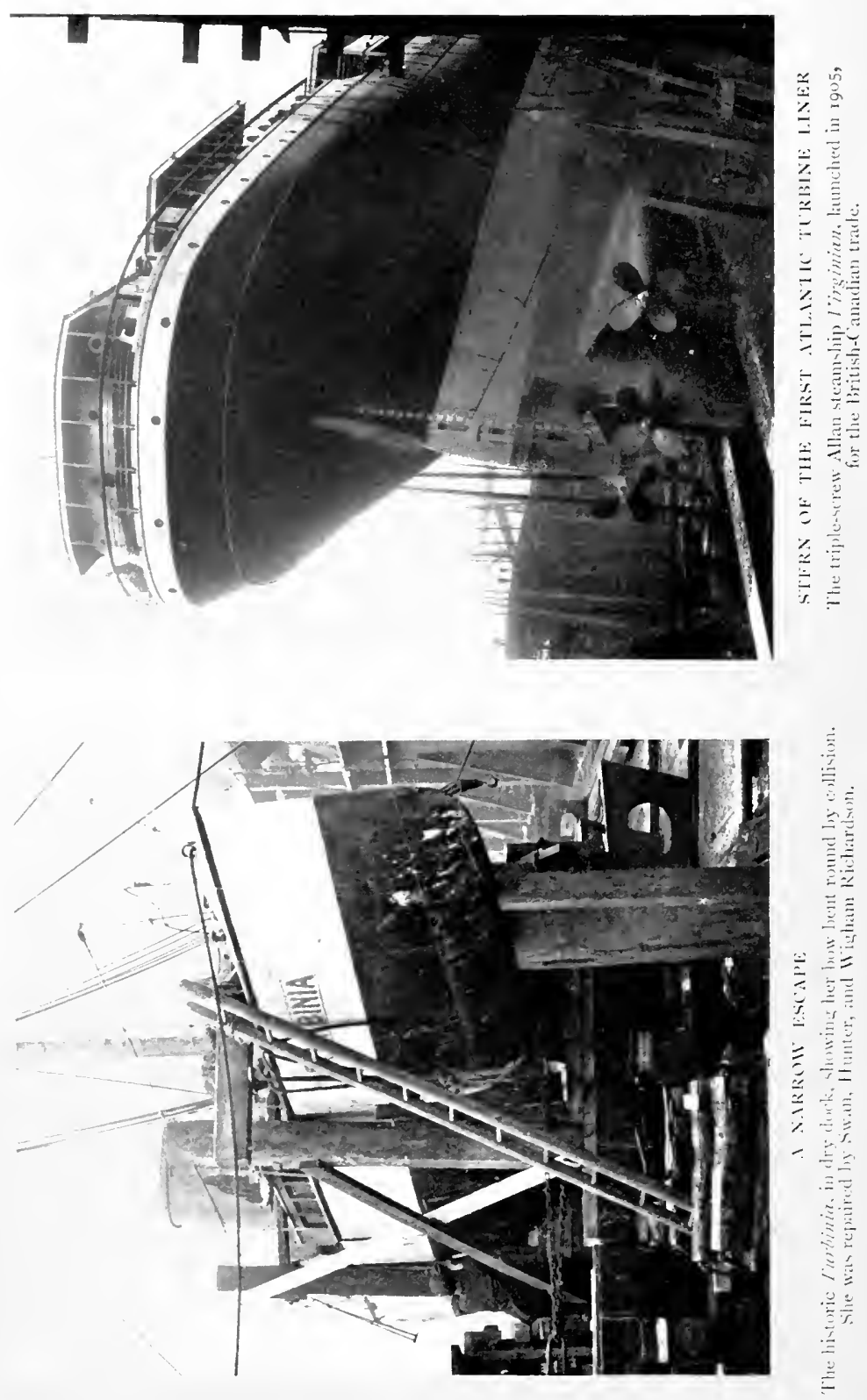
of a similar size. She certainly did not occasion a second thought among the vast concourse of naval engineers of all nationalities who were present. For some reason or other, the Turbinia got out of her position, and entered the long sea lane between the serried rows of naval vessels. Two of the fastest torpedo boats patrolling the lines were dispatched after her at full speed, to drive her back. But, to the astonishment of the crews of the pursuers and those on the battleships who watched the incident, the Turbinia proved more than a match for the speedy torpedo boats. She raced away, showing them a clean stern. The pursuers crowded on every ounce of steam, and although proud of the speed which their boats could attain, the interloper, instead of being overhauled, drew farther and farther away.

It was a sensational surprise, and complete in its effect. Every one wanted to know the name of the wonderful vessel which could romp away so easily from the fastest boats in the British Navy. When they heard that turbines were responsible for the speed, they asked what the turbine was. It was not mere idle curiosity, but was prompted by expert engineers who prided themselves that they knew as much about speed as was possible at the time. The Turbinia and her new engines leaped from obscurity to become the most prominent topic of conversation in technical circles between the two Poles.

Still, it was an uphill struggle for the inventor and his supporters to overcome the prejudice and extreme prudence characteristic of the shipowner and shipbuilder. A commercial trial had to be made. In this, as in other radical developments in marine matters, Great Britain led the way. An enterprising Scottish firm of shipowners gave a contract for a Clyde passenger steamer to the eminent Dumbarton firm of Denny Brothers. The record of this vessel, the King Edward, completely convinced the sceptics. She runs at her designed speed of 20 knots-mearly 25 milesper hour with ease, is remarkably steady, and the bogey of vibration, which was held in many quarters to be inevitably connected with speed, was effectively disposed of. 
The broad working principles of the Parsons turbine are exceedingly simple. There is a spindle on which rings of blades, or vanes, are mounted, these rings being spaced equidistantly apart. This section of the mechanism is known as the "rotor," from the fact that it is the rotating member. The shaft and rings of blades revolve in a circular chest, or drum, in such a way that there is only just sufficient clearance between the tips of the moving blades and the inner wall of the drum. In the latter, rows of similar vanes are disposed radially, and attached to the wall of the drum. These rings likewise are spaced equidistantly, so that the blades of the drum fit into the spaces between the rings of blades on the rotor. Consequently, when the whole is set up, and counting from one end, fixed rings of blades attaclied to the casing, or "stator," as it is called, because it is the stationary member, alternate with the moving rings of blades on the rotor. Lengthwise these blades are straight, and project at right angles from the surface of the rotor and stator, but sectionally they are curved, so that each blade represents a kind of scoop. Steam is admitted at one end of the drum, and as it is driven through the blades and expands it causes the rotor to revolve.

After the practical success of the King Edward, the installation of steam turbines upon vessels proceeded apace. This development was influenced materially by the success of the British Admiralty with the engine. Cross-channel steamers adopted the idea, and their experience definitely confirmed the statements advanced by the advocates of the system. Then, in order to obtain comparative technical data concerning the efficiency, economy, and so forth, respecting the two systems of propulsion, twin ships of the same dimensions, displacement and design-as like as two peas-were built, one being fitted with reciprocating engines and the other with turbines, to run side by side in the self-same services. The first experiment in this direction was made in connection with two vessels engaged in the Irish Sea traftic between Heysham and Belfast, while 
the most notable was in connection with the Cunard Atlantic liners, Caronia and Carmania. In this way incontrovertible comparative information was secured respecting the two systems, which proved of incalculable value to those engaged in the exploitation of the invention.

In the earliest types only one turbine-the high pressure -was used, but it was found that the steam, when it was expelled, had by no means completed the whole of its useful work. Another turbine was introduced (for purposes of distinction known as the low-pressure turbine), which is operated by the steam issuing from the first, or high-pressure, turbine. The former is of far greater dimensions than the latter, owing to the increased length of its blades. By the time the steam emerges from this chest it retains very little energy, the pressure being only about ten pounds per square inch, or nearly half as much again as that of the atmosphere.

The grreat advantage of the reciprocating engine is that it runs as easily backwards as it does forwards: in other words, it is reversible, which is a useful feature for moving astern. In the case of the steam turbine, however, reversibility is impossible with a single plant. Consequently, for reversing purposes another turbine has to be introduced, and reserved purely and simply for backing the ship.

After a little experience it was found that, although the steam turbine was unrivalled in economy when travelling at the highest speeds, it became somewhat more expensive than its older rival when the speed was reduced below a certain limit. Further research work was carried out to ascertain the practicability of combining the two systems, so as to secure the greatest advantages of both, and the defects of neither. After prolonged experiments in this direction success was achieved.

The steam turbine owes its introduction to the Atlantic steamship traffic to the enterprise of the Allan Line. This company has played a very important part in the development of the steamship. Brought into being for the express purpose of cultivating direct trading relationship between 
Great Britain and Canada, the Allan Line has always been foremost in the adoption of far-reaching improvements in trans-Atlantic travel. When it entered the Atlantic arena in 1819 , its first vessel was a little brigantine, Jean, of some 169 tons. In the late 'forties it abandoned wood in favour of iron, and in $188 \mathrm{I}$ it introduced steel to the same waters with the Buenos Ayrean. When the marine engineers announced that bilge keels would minimise the bugbear of rolling and thus conduce to the comfort of the passengers, the Allan Line did not hesitate; it brought out the Parisian, with bilge keels, in $188 \mathrm{r}$, and this was the first vessel to cross the Atlantic so fitted.

Accordingly, it is not surprising to learn that the Allan Line, after following the developments of the turbine with cross-channel and other similar boats, decided upon a huge step forward. In 1905 they brought out the Virginian and a sister ship, the Victorian. Each vessel is 540 feet in length, of 12,000 tons, and is propelled by three screws driven by turbines. These two ships rank among the finest engaged in the Canadian trade, and they have indulged in friendly rivalry in the matter of establishing records. So far the honours have rested with the Victorian, which has reduced the North Atlantic sea passage between Liverpool and Rimouski to a few hours over five and a half days. These turbine vessels have proved so popular with the travelling public that their owners decided upon two additional ships, each 600 feet in length and of 17,000 tons, driven by the latest type of quadruple screw turbine machinery with a speed of 19 knots per hour. Another conspicuous feature of these vessels which is somewhat new to the Atlantic trade is the cruiser stern, which hitherto has been peculiar to war vessels. This design not only secures additional protection to the main steering gear, but adds to the stability of the vessel at sea. When the Grand Trunk Pacific Railway ordered its twin ships, Prince Rupert and Prince George, for the Pacific service between Seattle and Prince Rupert from the yards of Swan, Hunter \& Wigham Richardson, this type of stern was designed 


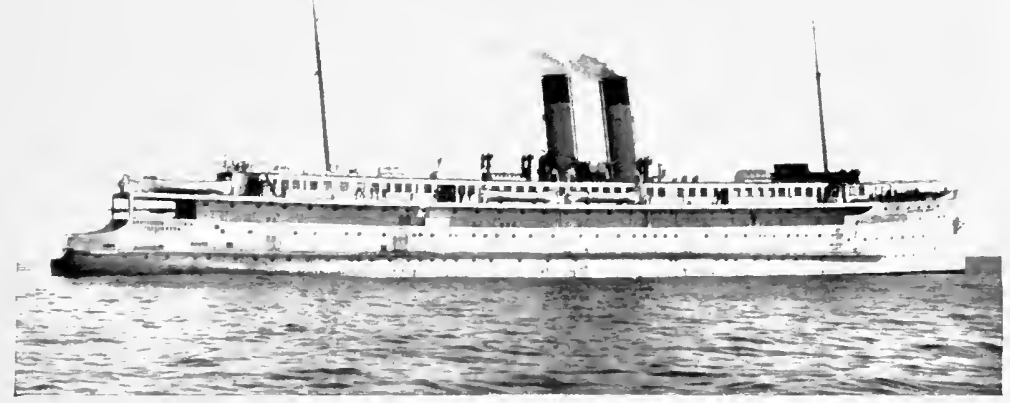

A SHIP WHICII CARRIES RAILWAY TRAIAS

The Drottning I Ioturia, which plies between the fierman and Swedish railway as a ferry. The main deck is fitted with railway tracks on which the trains are run and made fast for the sea journey.

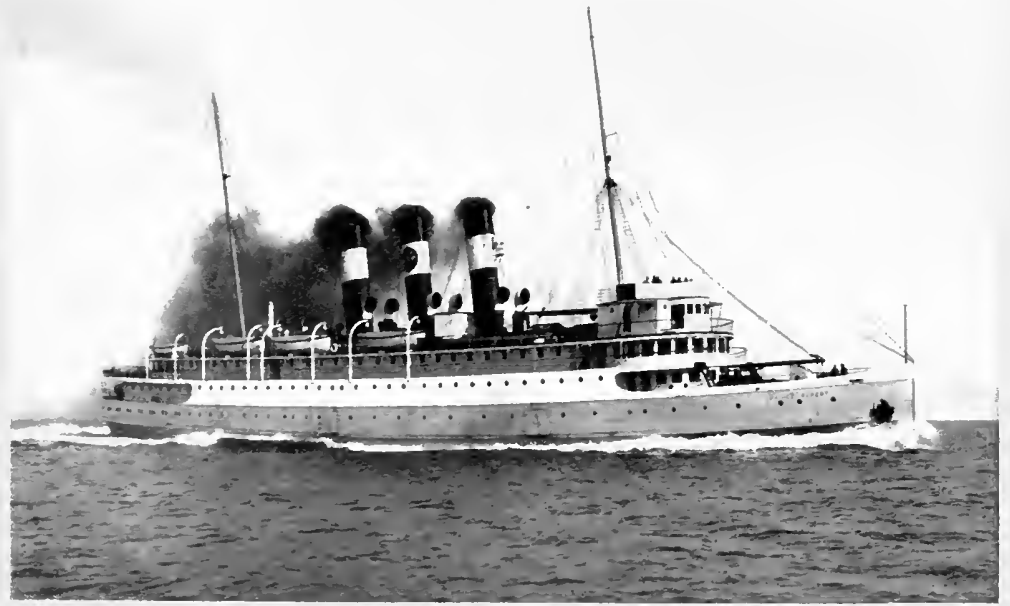

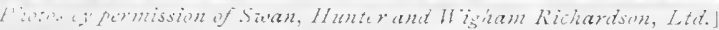

A P.ALATIAL PACIFIC COASTAL LIXER

The "rince Rupert, running between I'rince Rupert and seattle. This loat is fitted with a cruiner stern, which design is uw being intruduced upon the Atlantic. 

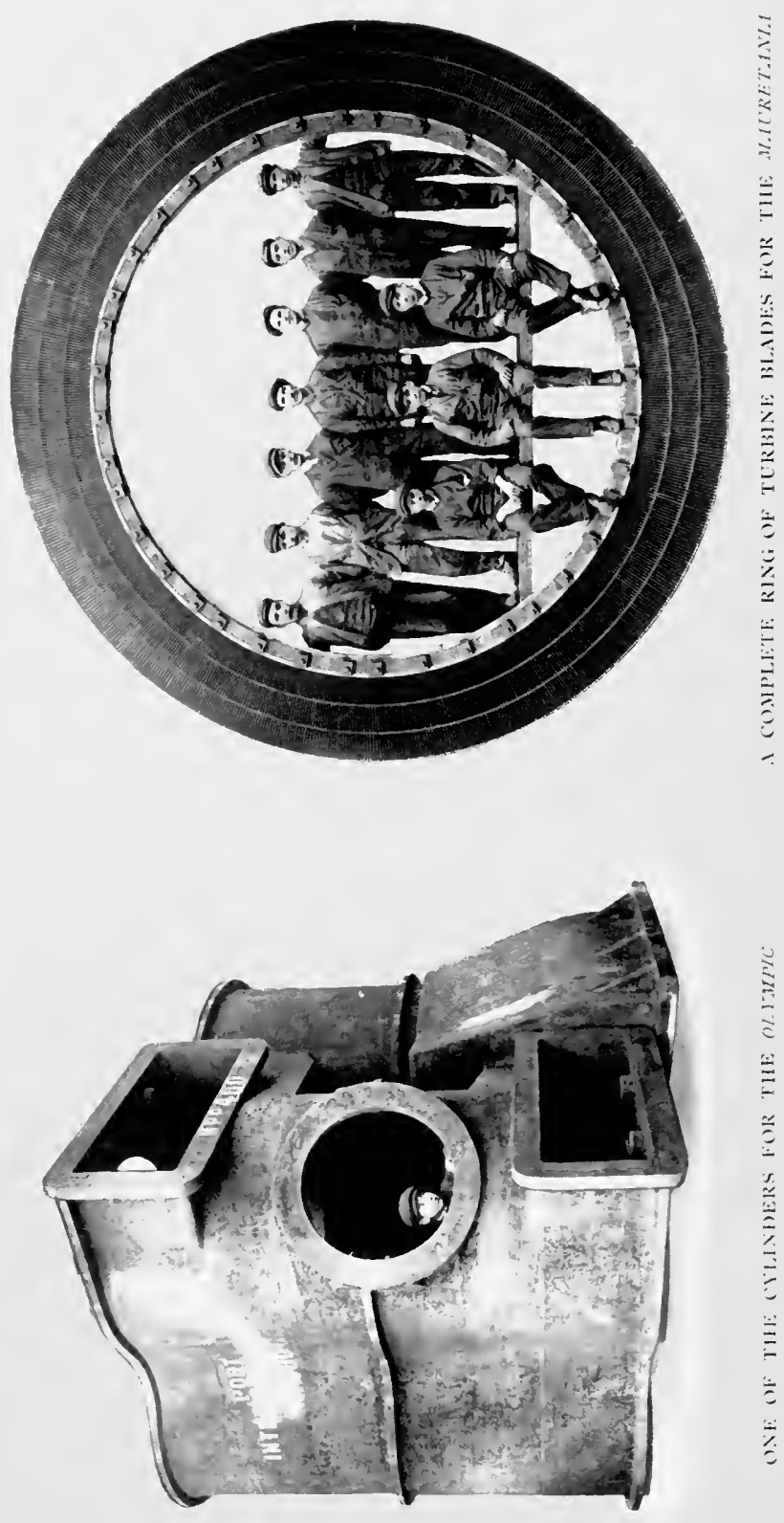

0
$\vdots$
$\vdots$
$\vdots$
$\vdots$
$\vdots$
$\vdots$
$\vdots$
$\vdots$
$\vdots$
$\vdots$
$\vdots$
$\vdots$
$\vdots$
$\vdots$
$\vdots$
$\vdots$
$\vdots$
$\vdots$ 
and incorporated by the builders, and it may be pointed out that, in addition to the foregoing advantages, an extra knot per hour was obtained.

After the triple screw, came what is known as the combined system of propulsion, wherein the reciprocating engines exhaust their steam from the low-pressure cylinders into a low-pressure turbine, in order to squeeze the uttermost fraction of useful energy from the gas. The advantages of this system were brought out very strikingly by the Otaki, built by Denny Brothers for trading between Great Britain and New Zealand, involving a round trip of 26,000 miles.

The crowning vindication of the steam turbine came with the construction of the two Cunard flyers, and more particularly, perhaps, with the Mauretania, which, by her remarkable records, has demonstrated most conclusively what turbines can do in regard to fast travelling for commercial purposes. The creators of the wonderful machinery with which this liner is equipped, the Wallsend Slipway and Engineering Company of Tyneside, were successful in securing as guiding spirit in their design the services of one engineer, Mr. Andrew Laing, who had been responsible in a great measure for the successes of four previous famous Atlantic record-breakers-the Umbria, Etruria, Campania and Lucania-during his association with the Fairfield Engineering Company on the Clyde.

One noteworthy feature in connection with the production of the engines of this giant may be noted. They were designed and built hard by the spot where the inventor, some twenty years previously, had displayed such tireless energy and patience in the evolution of the little Turbinia, which startled the whole world in 1897 . To-day the little craft responsible for this revolution in the mercantile marine is enjoying a well-earned rest and place of honour within the works of her creators, and close to the organisation which was responsible for the birth of her biggest daughter only ten years later. The historic Turbinia, however, had a narrow escape from making acquaintance with 
the bottom of the Tyne. She was moored alongside the yard wall of her owners, when a ship launched from the opposite side of the river blundered into her. The tiny Turbina was caught almost amidships, and her forward part was bent round about 45 degrees. She was put into one of the dry docks of Swan, Hunter, \& Wigham Richardson, where the ship surgeons cut the craft in twain and rebuilt the forward end. They then brought up their huge Hoating crane, the Titan, which picked up the little vessel and carefully deposited her on the quay of her owners to secure her from further harm.

The Cunard greyliounds are driven by turbines purely and simply. As speed was the governing consideration for their construction, no expense, labour, experiment or effort were spared to produce the best humanly possible. I have referred already to the elaborate experiments which were carried out with the small launch at Wallsend to secure the best possible results from the engines and propellers, before a line was committed to paper in connection with the design.

The power unit comprises six turbines, the ship being driven by four propellers. This installation is divided into three sections. There are two high-pressure turbines driving the wing, or outermost, propellers, one on either side, these screws being set back 80 feet from the stern propellers, which are driven by two low-pressure turbines, while the latter two propellers carry a second turbine each, for moving astern. The high-pressure turbines are each placed in a water-tight compartment, while the low-pressure and two astern turbines are accommodated in a common central water-tight space. The advantage is obvious. It is scarcely probable that an accident would affect both high-pressure turbines, as they are disposed on either side of the vessel. Should the liner's hull be pierced and let in the water, the vessel could always get home on the. remaining three screws. It is difficult to conceive any mishap, short of the total destruction of the underwater stern of the ship, whereby the ressel could be rendered 
as helpless as a log, owing to the ingenuity of the subdivision of the hull by the bulkheads at this vital spot.

As may be imagined, owing to the immense size and speed of the vessel, everything pertaining to the propelling machinery exceeded anything attempted before, so that the builders were compelled to carry out pioneer work in every direction. Some idea of the dimensions of the integral parts of the propelling installation may be gathered from sizes and weights. The high-pressure turbine measures 8 feet in diameter, while its rotor weighs no less than 72 tons. The low-pressure turbine has a diameter of i feet 8 inches, and its rotor, which turns the scale at 126 tons, is fitted with vanes ranging from 8 to 22 inches in length. The astern turbine measures 8 feet 8 inches in diameter, the length of the blades varying from 2 inches at one end to 8 inches at the other.

No expense was spared in the fashioning of the weightiest essential parts. Seeing that the rotors upon which the blades are mounted have to withstand such heavy work and high speed-the revolutions range up to i 80 per minute-a special method of fashioning them was followed, in order to secure a metal which was thoroughly homogeneous. The rotor was cast in a solid block, about 120 tons of steel being run into a mould some 6 feet in diameter. While the metal was still molten the mass was subjected to the enormous pressure of 12,000 tons per square inch; a power sufficient to compress molecules of steel tightly and closely together in a manner otherwise quite impracticable. Consequently, a fracture from faults in the metal itself is rendered virtually impossible. When the turbines are running at full speed the outer tip of the blades have a velocity of about 10,000 to 11,000 feet per minute. In other words, if this revolving speed were resolved into a straight line across country, the tip of a blade would travel about 2 miles in the space of a minute-I 20 miles an hour -and this speed has to be maintained for about 108 hours during the trans-Atlantic journev.

When the turbine first made its appearance, the practice 
was to fix each blade separately in its groove in the rotor and in the stator. With such a huge plant as that carried upon the Mauretania this would have been quite impossible, seeing that there are over 800,000 blades in the six turbines. A novel system of building them up in segments was evolved, ten of these segments forming a complete ring. For this blading work the builders devised special machinery, which ranks as one of the most complete and perfect installations of its class in the world.

The propeller shafts are each 30 feet 2 inches long by $22 \frac{1}{4}$ inches in diameter, they are hollow with a ro inchdiameter hole, and each carries one propeller with three manganese bronze blades. The propellers are built up, $i$. $e$. the blades are bolted to a steel boss by steel studs and manganese bronze nuts. This built-up system is preferable to the solid casting, although the latter is practised extensively in small passenger boats, tramps and freighters, since, should a blade become damaged, it can be replaced quickly and easily without detaching the whole propeller. One of the great advantages arising from the use of manganese bronze for the blades is that the metal does not corrode quickly in sea water. Steel and iron propellers within a short space of time become honeycombed by corrosion, and then break very readily. Manganese bronze, however, is somewhat expensive-averaging about $\notin$ ioo - $\$ 500$ - per ton, so that a propeller which weighs 20 tons or more represents a costly item in itself.

The steam for these mighty turbines is raised in 23 double-ended and 2 single-ended boilers, distributed in four rooms and placed athwart the ship in rows of three each. It would have been possible to have set them in rows of five each, had not the interests of safety demanded otherwise. Instead of the boiler-rooms proper stretching from wall to wall of the ship, either side of each boilerroom is flanked by a longitudinal bulkhead, and the interior of these spaces serve as coal bunkers. This wise arrangement virtually provides these vessels with a double skin for about two-thirds of their lengths. Consequently, 


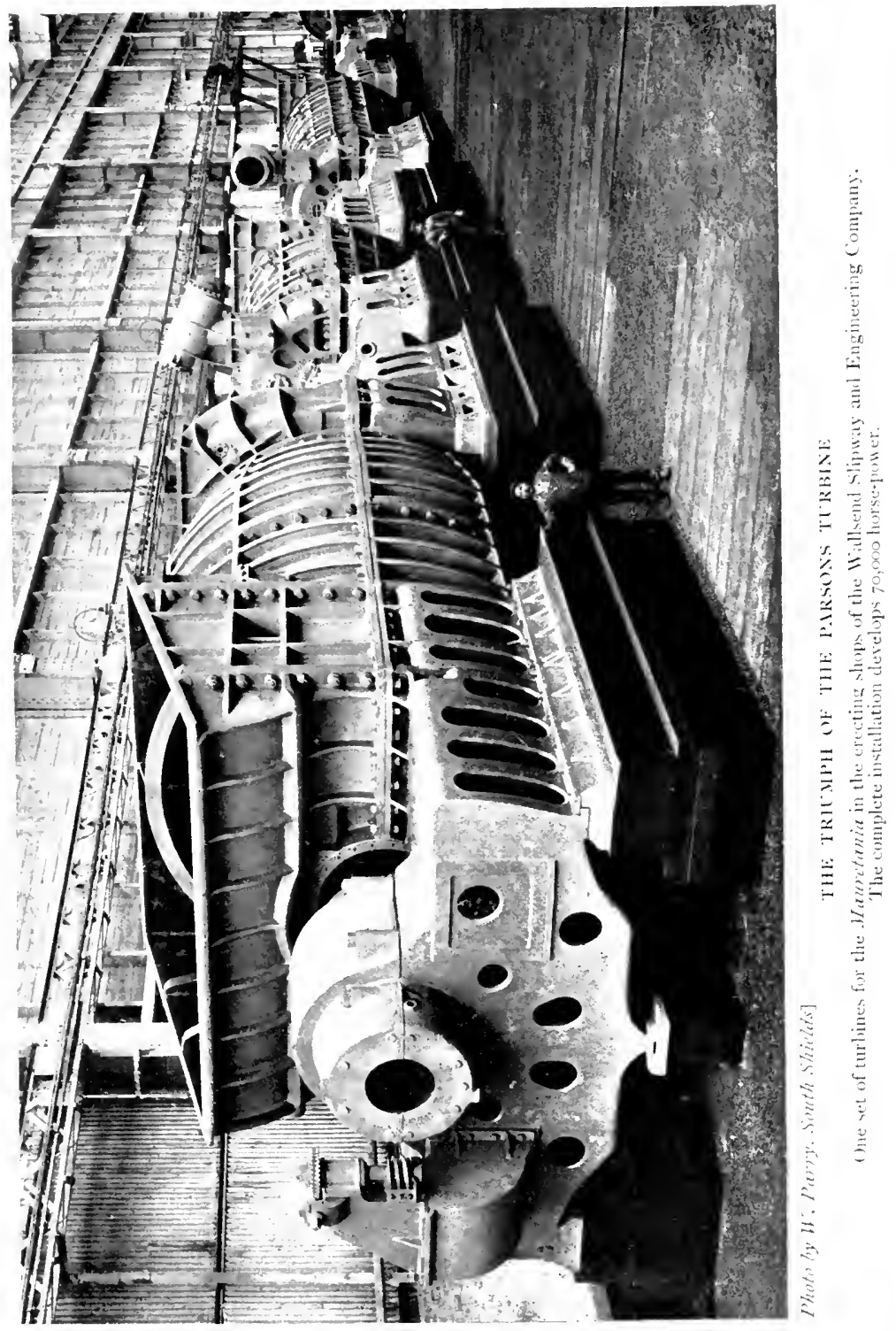



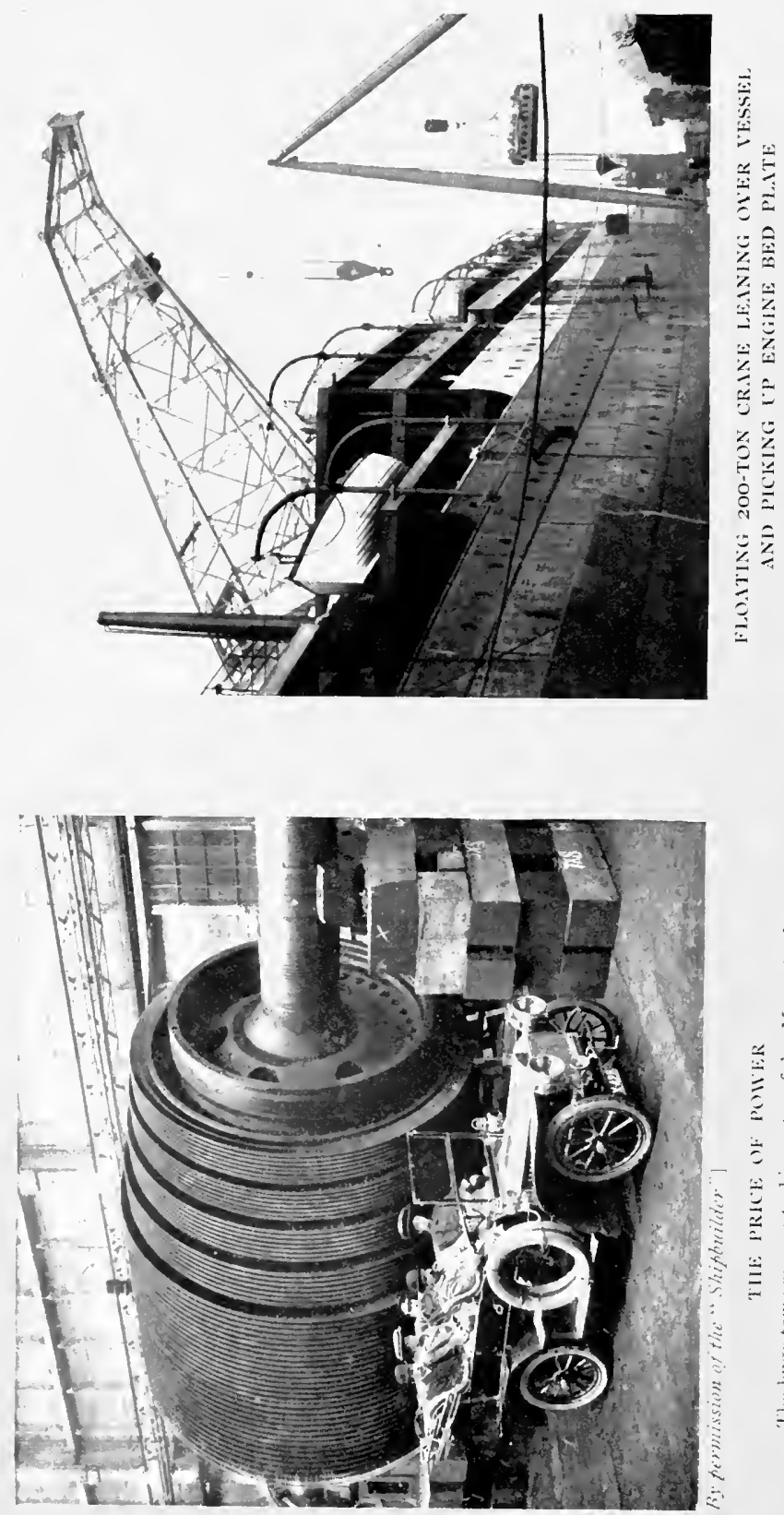

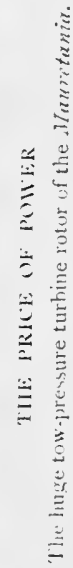


should the hull of the ship be pierced below the water-line in the vicinity of the boiler-rooms, the danger of the stokehold being flooded is removed, unless the invader drove its way so deeply into the liner as to break down the boiler-room bulkhead. This is such a remote contingency, however, that it need not be entertained.

The double-ended boilers each measure 22 feet in length by $77 \frac{1}{4}$ feet in diameter. Each has eight furnaces, four at either end. The single-ended boilers are of the same diameter, but only is feet long, and, as the description indicates, are provided with only four furnaces at one end. Each double-ended boiler in its empty condition weighs I Io tons, and when charged with water and fuel the weight all told is approximately 180 tons. When the liner is travelling at full speed and the whole battery of boilers is working at top pressure, the 192 furnaces eat up the coal at the rate of a ton about every $\mathrm{I}_{2}^{\frac{1}{2}}$ minutes, so that some idea of the price of speed may be obtained. The bunkers are able to carry 6000 tons. Just what this means may be realised from the fact that, in order to coal up the Lusitania and Mauretania every time they leave Liverpool or New York, 22 trains, each hauling 30 trucks, and each wagon carrying ro tons, have to draw into the port and dump their loads into the vessel's bunkers.

The steam is raised to a pressure of 195 pounds per square inch, and is led into the high-pressure turbines. After it has accomplished its useful work in these engines, it is led through a valve either into the low-pressure turbines or direct into the condensers. The valve through which the steam issues is a massive piece of work in itself. A man six feet high may stand in the pipe, and yet leave three inches clearance between the crown of his head and the inside of the valve. By the time the steam has emerged from the low-pressure turbine it is in a very exhausted condition, containing practically no energy for further work. But it is not permitted to escape into the outer air. It can be restored to water, passed back into the boilers, and re-vaporised. In addition to recovering the 
water from the steam after it has been exhausted from the turbines, the condensers perform another very important function. This is the maintenance of the vacuum, whereby a great increase in power is secured, as the pressure of the steam is raised by the reduction of the atmospheric pressure.

The condenser in reality is a gigantic still having a network of small pipes, through which circulates continually a stream of cold water. The exhausted steam led from the low-pressure or the high-pressure turbine, as the case may be, becomes condensed under the chilling effect of the water playing upon the pipes. The water employed for the cooling operation is drawn direct from the ocean, and driven steadily and constantly through the condensers by means of powerful pumps. I have often heard passengers, when looking over the taffrail of a vessel, express curiosity concerning the stream of water which pours out from the vessel amidships on either side. This is the water ejected from the condensers after it has completed its chilling work. Upon such a ship as the Lusitania, Mauretania or Olympic the condensers are of huge proportions, and the voiume of sea water drawn from the Atlantic to cool the spent steam from the engines is stupendous. It is stated that every minute of the day and night on the Cunarders over 65,000 gallons of water are driven through these stills-a colossal total of $93,600,000$ gallons every twenty-four hours. If this were fresh water, it would provide each of the 7,000 ,ooo persons comprising the population of London with nearly $13 \frac{1}{2}$ gallons a day.

To keep the Maurctania steadily developing between 68,000 and 70,000 horse-power to maintain the average hourly speed of $25 \frac{1}{2}$ knots, or nearly .30 miles, I0,000 tons of steam have to be raised and driven every day through the turbines at a speed varying between 200 and 250 feet per second. The consumption of air to bring about the combustion of the coal in the furnaces is equally astonishing. The voyager has probably observed the bewildering array of capacious cowl ventilators scattered over the topmost deck, 


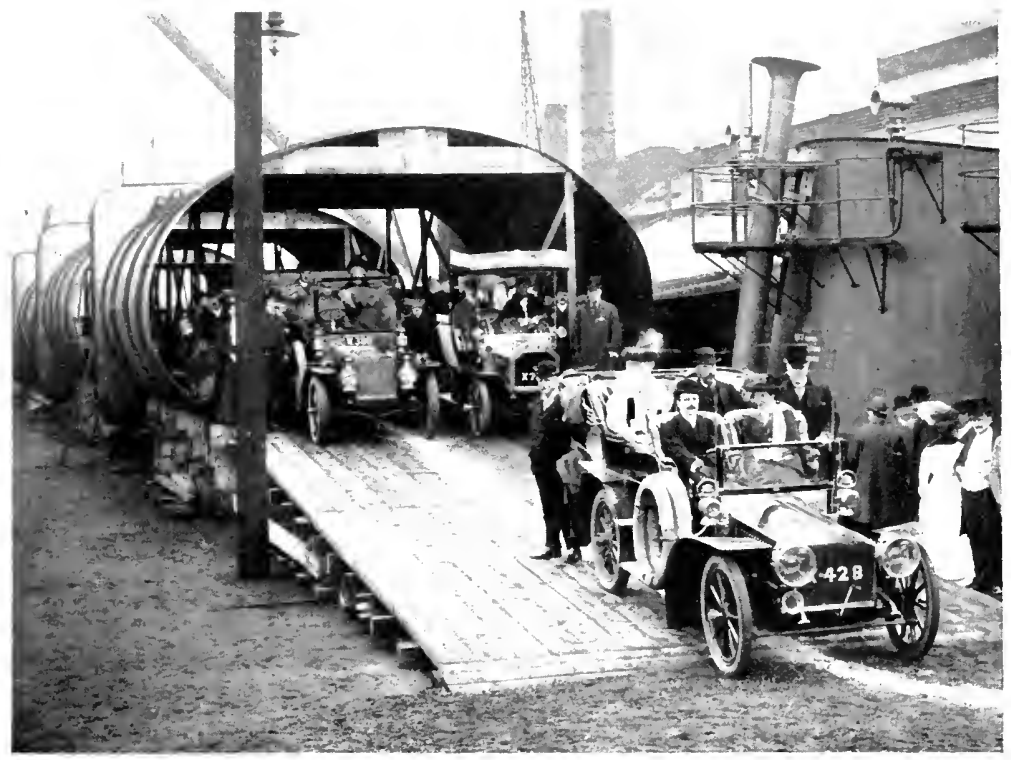

A NONEL ALTOMOBHE TLNNEL

This illustration conveys a striking impression of the immense size of the Mawnetania's funnels. Laid on their siles two streams of vehicles passed throush abreant with tase.

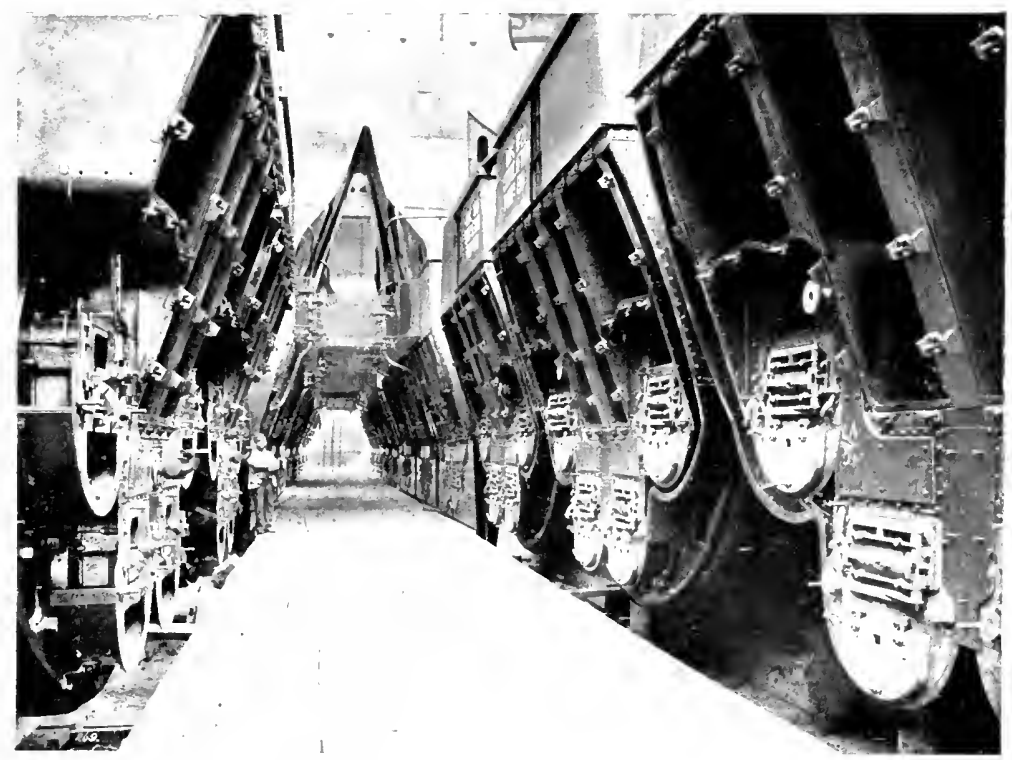

IN MFILE OF BULFRS 


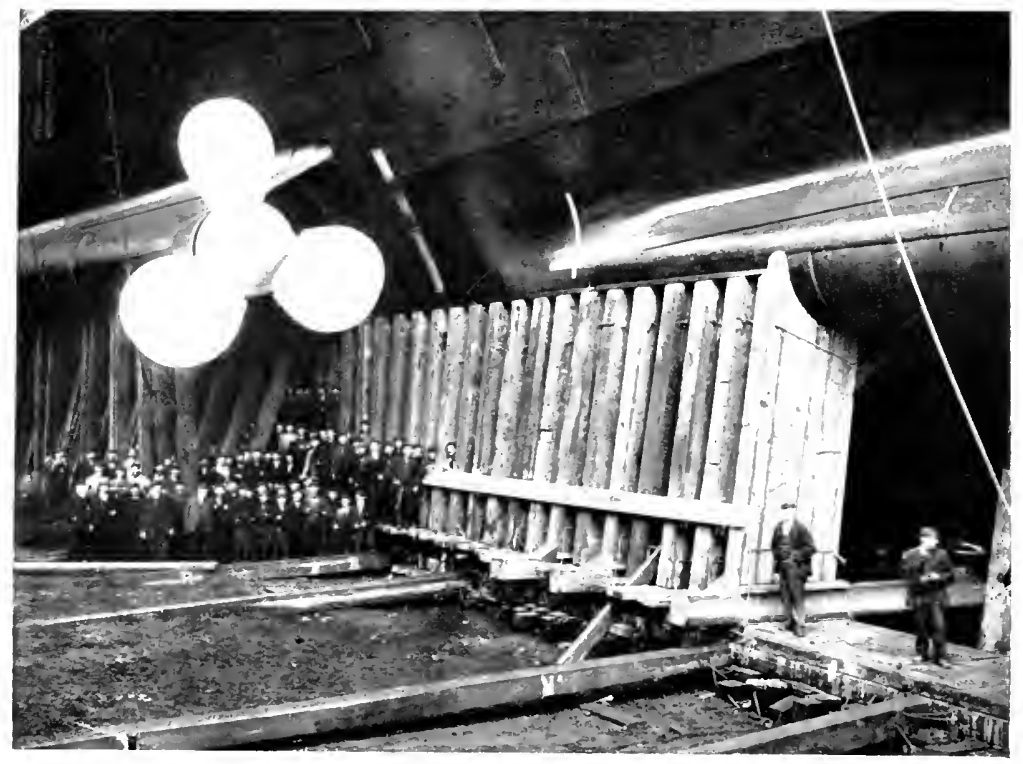

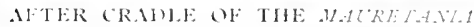

The finely-shaped -tern rest on a collapsille timber structurestanding on the sliding way.

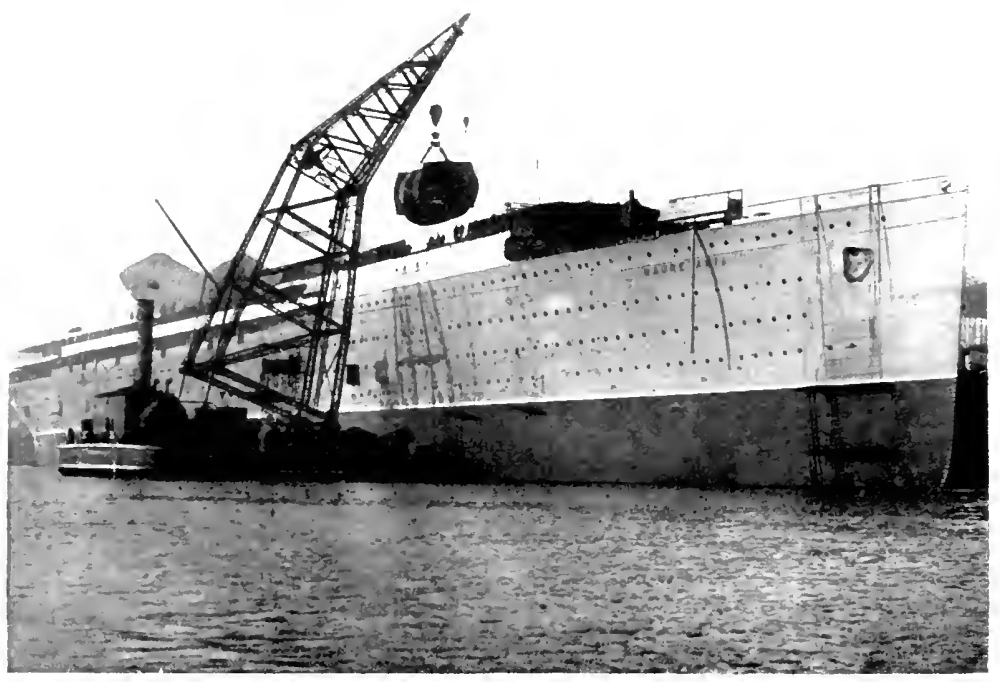

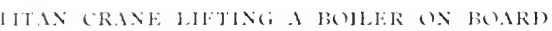

The weighty mas of I 
and perhaps has speculated as to their purposes. They convey air into the stokeholds of the vessels, 25 pounds of air being required to bring about the combustion of I pound of coal. Assuming 14 cubic feet to the pound, this represents a tax upon the atmosphere for oxygen to the extent of $784,000,000$ cubic feet, or $56,000,000$ pounds, in the course of the twenty-four hours. It is lucky for the marine engineer that on the broad Atlantic there is an ample supply of water and air to keep the machinery going.

Yet the propelling machinery is only one element, although the most important, for which steam has to be raised. In addition there are no less than 66 other engines demanding energy, the work of these auxiliaries being as varied as their number. There are air and water pumps for all sorts of purposes: oil-pumps to keep the turbines thoroughly lubricated; pumps for the supply of power to the water-tight doors to close the various compartments, should the liner be menaced with an accident; flushing, fire-extinguishing pumps, and so on.

In the Olympic the combination system is highly interesting. In this instance the turbine is of the lowpressure type, and is designed to work with the steam after it has done its utmost in the reciprocating engines. These engines, of the quadruple expansion type, receive the gas at a pressure of 2 I 5 pounds per square inch. By the time they have finished with the steam its pressure has been reduced to 9 pounds per square inch. The turbine picks it up at this juncture, and when the steam passes from this unit into the condensers it has been expanded down to I pound. In this instance the reciprocating engines develop 30,000 indicated horse-power, while the turbine in its turn yields no less than $\mathrm{I} 6,000$ horse-power. With this combined energy of 46,000 horse-power the three propellers can drive the ship at an average speed of about $22 \frac{1}{2}$ knots per hour.

As may be imagined, the Olympic being the largest ship in service in 1912 , some huge weights are to be found in the engine-room. The crank shaft of each of the two sets of quadruple expansion engines weighs no less than 


\section{STEAMSHIP CONQUEST OF THE WORLD}

I 8 tons, while the heaviest cylinder tips the beam at 50 tons. Each of the wing propellers weighs $3^{8}$ tons, while the central, or turbine, screw is of 22 tons. The total weight of the low-pressure turbine is 4 ro tons, of which the rotor represents 130 tons and the casing ${ }^{6} 63$ tons. These engines demand the combined services of I59 furnaces raising steam in 24 double and 5 single ended boilers. As may be supposed, an extensive staff is required to keep the engines going, no less tlian 322 men being employed in the stokehold, in shifts of four hours' duty with eight hours' rest. It may be mentioned that the numbers alone of those responsible for keeping the Olympic steaming represent one-eighth of the passengers carried, and about one-eleventh of the total population which the ship is able to accommodate. In fact, in this White Star liner nearly thrice the number of men are required to attend to the engines and furnaces as the total number of passengers which the Britannia was able to carry, while the black squad outnumbers the complete roll of passengers and the crew of the first Atlantic liner. 


\section{CHAPTER V}

\section{THE LAUNCH AND TRIAL TRIP}

WhEN the final rivet has been driven home, completing the steel shell, the shipbuilder is faced with his most critical, anxious and difficult task-the transference of the inert hull from dry land to the water. In Great Britain this operation is carried out so successfully and smoothly, and with such an immunity from accident, that the average spectator is apt to regard the operation as comparatively simple, though he agrees that it forms an impressive spectacle. As a matter of fact it is the most wonderful phase in the whole creation of the vessel, particularly in the case of a modern titan.

The preparations for a launch are of a most comprehensive character. Nothing is left to chance. Every detail is checked and counter-checked. While the ship is assuming its form in its cradle, a launching diagram is being prepared by men of long experience, and they prepare a complete schedule bristling with particulars. Every effort is made to see that the actual operation coincides with this programme to the uttermost limit.

The date of the launch is indicated, together with the hour, this factor being governed by climatic and other conditions over which mankind has no control. The condition of the water in the river, the state of the tides and currents are set out, these deductions being prepared from tables arailable for the purpose. Weather conditions exercise a far-reaching influence. The hull towers high out of the water, and offers enormous resistance to an unfavourable wind. It is quite unmanageable until the tugs can be attached to tow her, and it stands to reason that if a heary gale be bearing broadside upon the ship's 
massive length and height, the tugs would find it extremely difficult to get hold of her and thereby bring her under control. Often a launch has been postponed owing to the unpropitious character of the wind, or the direction from which it is blowing on the day which has been set aside for the committal of the ship from land to water.

Similarly, the temperature conditions are vital. If the thermometer drops below a critical level the launch becomes impossible, or at least uncertain, since the tallow required for greasing the ways becomes congealed, and instead of permitting the hull to slide downwards gracefully into the water, it acts as a check. On more than one occasion a launch has proved abortive from this reason. The hull has started on her journey, only to slow up and stop before she has proceeded many feet, and examination has revealed the cause to be the too solidified nature of the grease.

In addition, the exact weight of the hull at the launching, and the manner in which the various component weights forming the aggregate are distributed, are shown. A table is prepared also dealing with the exact acceleration of the huge mass, at various intervals, as it glides down the ways, together with the moment when it will come to rest, its distance from the ways and position in the waterway at that period. There is also the disposition of the drags which check the descent of the vessel, their weight, method of action, and the precise moments when they will commence to exercise their retarding influences, in order to bring the ship to a standstill within the distance allowed.

There are two calculations relative to a launch which are of extreme importance. These relate to what are known as "tipping" and "lifting" movements. At the launch the vessel is supported entirely upon two cradles and the ways, which are described later. Now suppose the vessel is being launched stern first. If, when the latter part enters the water, it is buoyed up insufficiently, there is a tendency for the pressure on the forward cradle to be relieved, because the stem of the boat tries to tip up. If this took place it might cause the cradle timbers to become loosened. so that 


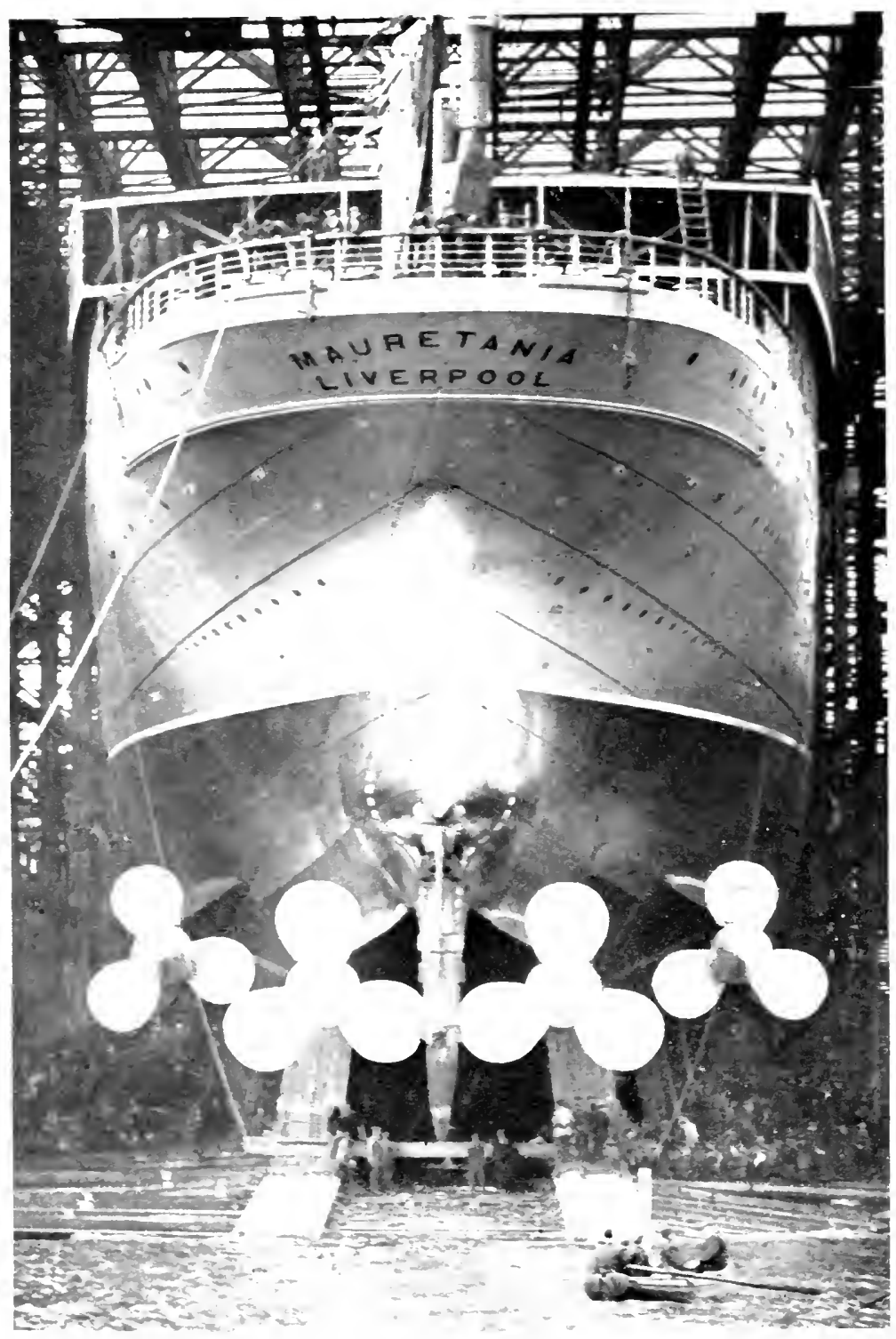

IHE PUWE BEHCD IHE CLCIRH FLIFR

The fun proutlh we which o 


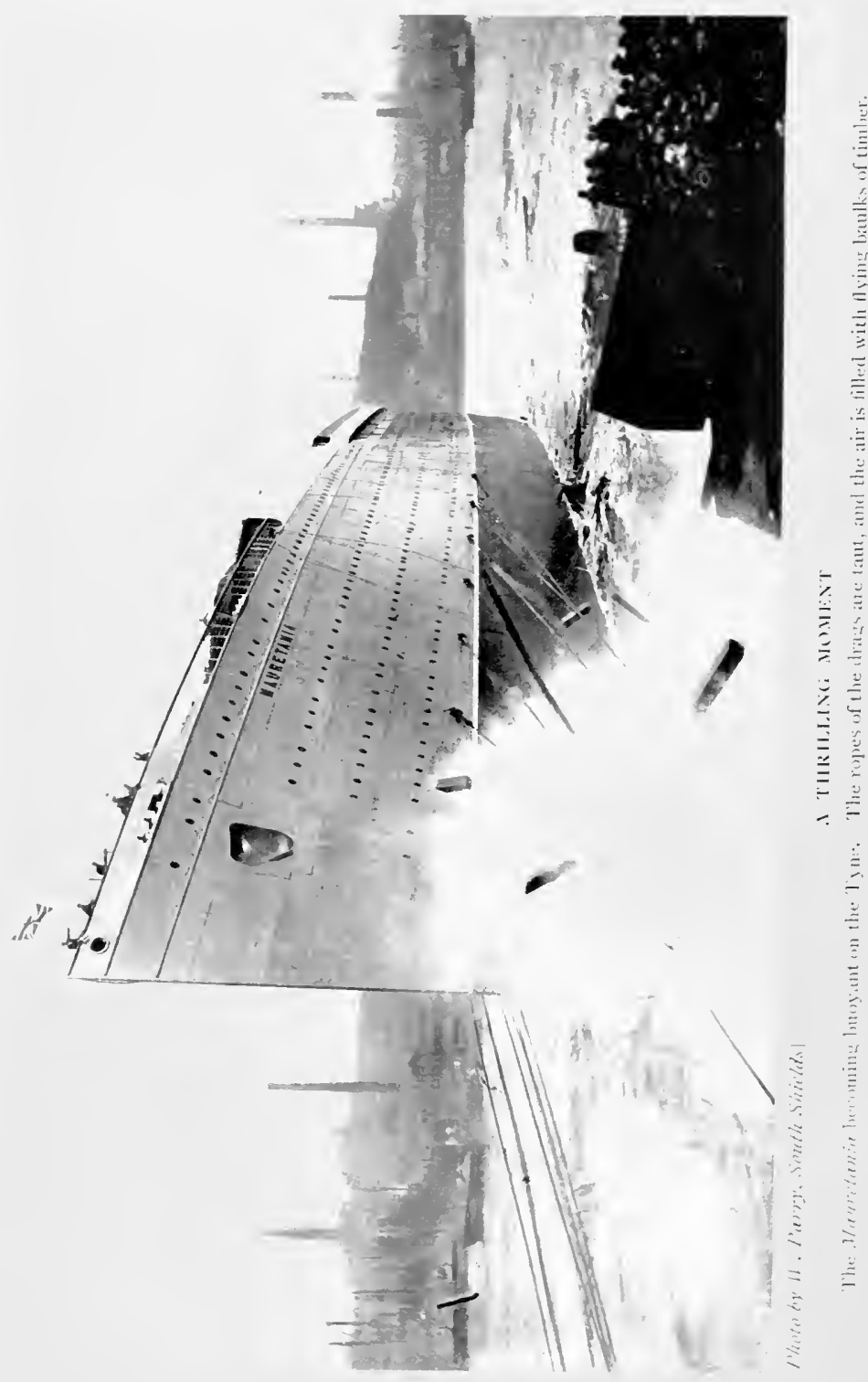


when, a few seconds later, the pressure was brought to bear upon the forward cradle by the stern lifting, the stem might come down so heavily as to cause its cradle to collapse. On the other hand, if the stern were too buoyant it might impose an enormous crushing strain upon the forward cradle, which would increase as the hull slipped farther and farther into the water, and possibly cause the cradle to break up before it had completed its ordained work. Those who witness a thrilling spectacle such as a big launch affords, and which seems such a straightforward operation, neither see nor hear anything of the calculating work previously made to ensure success, and which is far more remarkable.

As a rule a vessel is launched stern first, although some yards adopt the practice of sending the ship into the water bow first. In other instances, when the area of water available for the reception of the vessel is very limited, the ship will be sent broadside down the ways. Such a launch is somewhat more stirring from the mere sightseeing point of view, inasmuch as the vessel strikes the water at such an angle that the uninitiated wonder how the ship contrives to regain her even keel.

As the vessel grows within her berth she is supported on each side by timber props, and when the hull is completed it appears to be resting upon a decapitated forest. When the vessel is ready to be launched these supports are removed. to permit the ship to rest upon the launching ways. These comprise two component parts, known respectively as the ground ways and the sliding ways. The ground ways are laid upon the ground, and remain stationary. They resemble a massive wooden railway, extending from the forward end of the vessel right into the water. The upper face is rabbeted, and upon this surface rest the sliding ways, which similarly extend the full length of the vessel, and these engage with the rabbet, or flange, in the ground ways so as to be guided during their descent into the water. In some instances, instead of the launchways being flat and rabbeted, the ground way is 
made concave, while the sliding way is convex, so as to fit into the groove of the former.

The sliding ways are so called because they slide along the groundways, carrying the ship, which is supported thereon throughout its entire length, into the water. The engaging surfaces of the ways are liberally dressed with tallow, soft soap and oil, to facilitate the movement of the sliding ways by reducing the friction.

When a vessel has fine lines fore and aft, what are known as "cradles" are built on top of the sliding ways, to support the fine ends of the ship. These cradles are formidable structures fashioned from wooden baulks, the upper ends of which are shaped to the contour of the hull, but are not attached to it. In the case of bluff-ended, flatbottomed cargo boats the cradles are very insignificant structures.

The launch of the Mauretania on the Tyne was remarkable, because it coincided in every particular with the careful pre-determined calculations. In this instance the operation was delicate, owing to the narrow width of the river. Then, again, the weight of the hull was enormous; in fact, at that time it was the heaviest hull ever launched, the total weight of the mass sent into the water being I6,800 tons. Since then, this record has been eclipsed, as when the Olympic was transferred from her building berth to the water at Belfast she weighed no less than 27,300 tons, while the German liner Imperator weighed 27,000 tons.

The launching ways for the Mauretania at Wallsend were spaced 25 feet apart and were 635 feet in length. The falling grade of the ways averaged about $\frac{9}{16}$ of an inch per foot, and at the lower end they were submerged at high water to the depth of 7 feet 7 inches. They were dressed with 32,536 pounds of tallow, i 13 gallons of train oil, and 3,464 pounds of soft soap.

When everything is ready for the launch the vessel rests entirely upon the ways, but is prevented from taking to the water prematurely by triggers which hold hack the 
upper, or sliding, launchways. As a rule, when these triggers are released the vessel commences to slip down the gradient under her own weight. Still, the shipbuilder takes no chances of her proving stubborn. The lessons of the Great Eastern, which refused to float upon the bosom of the Thames until $£ 50,000$, or $\$ 300,000$, had been expended on the launching operation, has been learned only too well. To guard against the repetition of such a contingency, the shipbuilder has devised an ingenious arrangement whereby the vessel is given a welcome push, should she fail to start when the triggers are released. This is a hydraulic ram, the nose of which, when water is admitted into the cylinder, exerts a pressure of several hundred tons against the upper launching ways, thus sending them downwards. In the case of the Mauretania several of these rams were placed in position, ready to give the necessary starting movement if the emergency arose, but owing to the perfection and forethought bestowed upon the preparations their services were not required. Once started, there usually is very little likelihood of the huge mass coming to a stop until she is afloat.

But an ungainly mass must not be set in motion without the inclusion of some means of stopping her when she has become water-borne. If a vessel were dispatched down the ways without restraint, she would keep going until resistance and friction of the water pulled her up. If there is plenty of space available such a system may be adopted safely, but as a rule a shipyard is situated in a congested district. In Italy, however, it is usually the custom to launch a vessel direct into the sea, because the waters of the Mediterranean are non-tidal, and the builders need only wait for a smooth sea to achieve their object. In such a case the vessel is sent down the ways and allowed to travel through the water until she stops, or the tow-ropes of friendly tugs are able to pick her up. In the case of such narrow, busy waterways as the Clyde or the Tyne these methods are quite impracticable.

There are several means whereby a ship may be pulled 
up and brought under control when afloat. Sometimes anchors are buried in the ground at regular intervals and connected to the hull by hawsers. One after another the latter become taut, and thereby gradually break the advance of the ship. Another system, which is practised often at the Wallsend shipyards and elsewhere, is to attach the ship at one side only by means of a hawser to an anchor buried near by in the river's bank. When the ship is water-borne and is rushing onward the hawser becomes taut gradually, so that the ship not only finds her mad rush arrested, but she is slewed round in mid-stream as well. Occasionally a big shield of timber is built across the stern-post of the vessel. This offers considerable resistance to the water, and helps to bring the hull gently to a standstill. Yet another method of bringing the vessel when afloat to a state of rest is to attach hawsers, fixed to the hull at certain points by means of eye-bolts, and the other ends to huge timber wedges placed between heavy wooden grips. As the pull becomes successively imposed upon these hawsers they drag the wedges tighter and tighter between the grips, and thus pull the vessel up.

A highly effective system was adopted to check the Mauretania when she slid down the ways at Wallsend, and which is utilised when launching large vessels from these yards. On either side of the vessel in the berth are disposed coils of chains and other weights. Each drag weighs from 80 to 100 tons, and they are placed certain distances apart. The chains are piled in a special manner to form a large square, and around the upper side of each coil a heavy wire hawser is passed and attached to a cable fixed to the side of the hull by means of an eye-bolt. As the ship slides down the ways, the first cable in due course becomes tightened, and pulls on the coil to which it is anchored. It cannot drag the mass of chain along the ground immediately, because the connection is made to the upper side of the heap. The mass must first be turned over completely, which action in itself acts as a brake, while when the heap has been inverted the square becomes elongated 


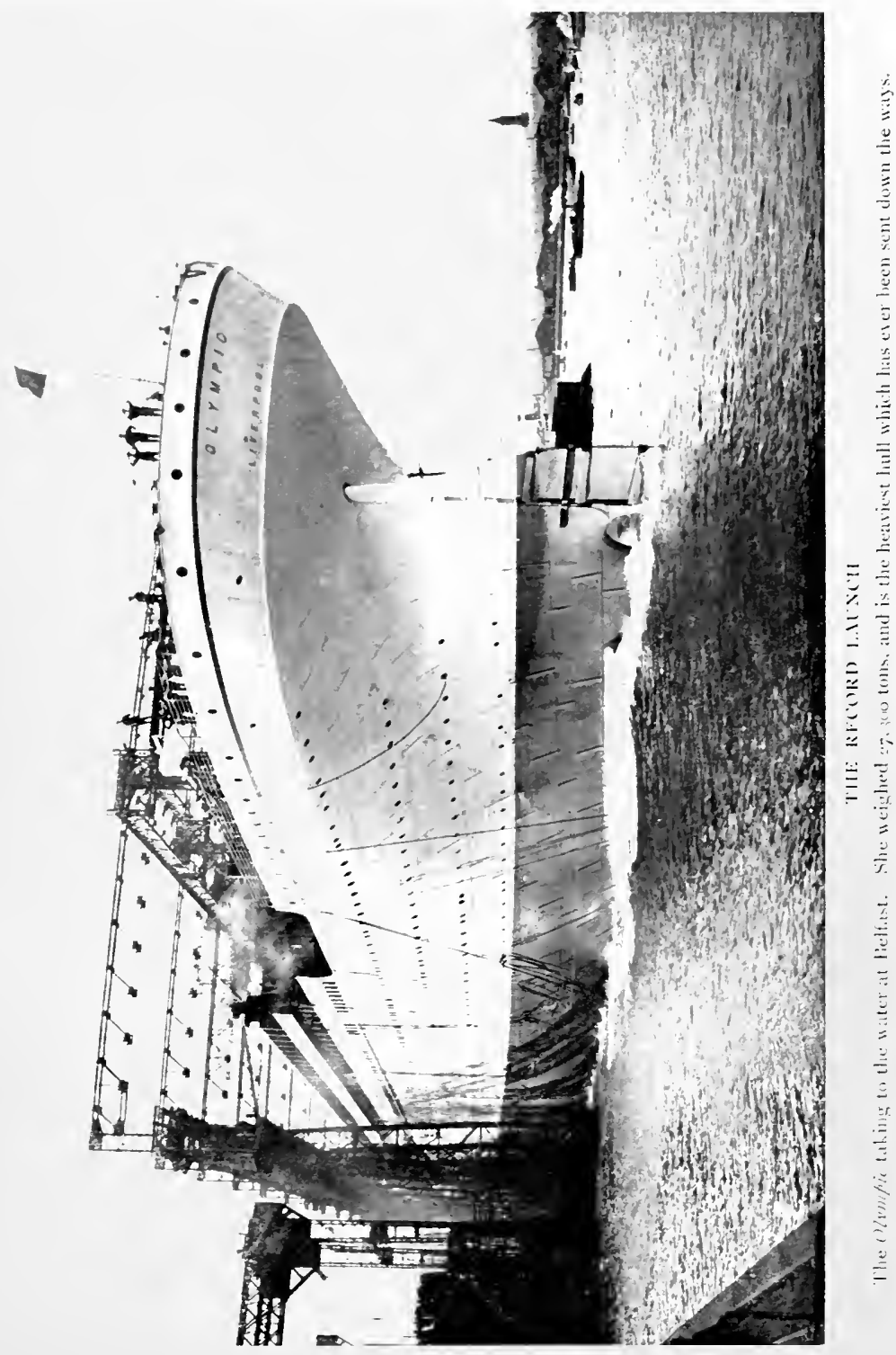




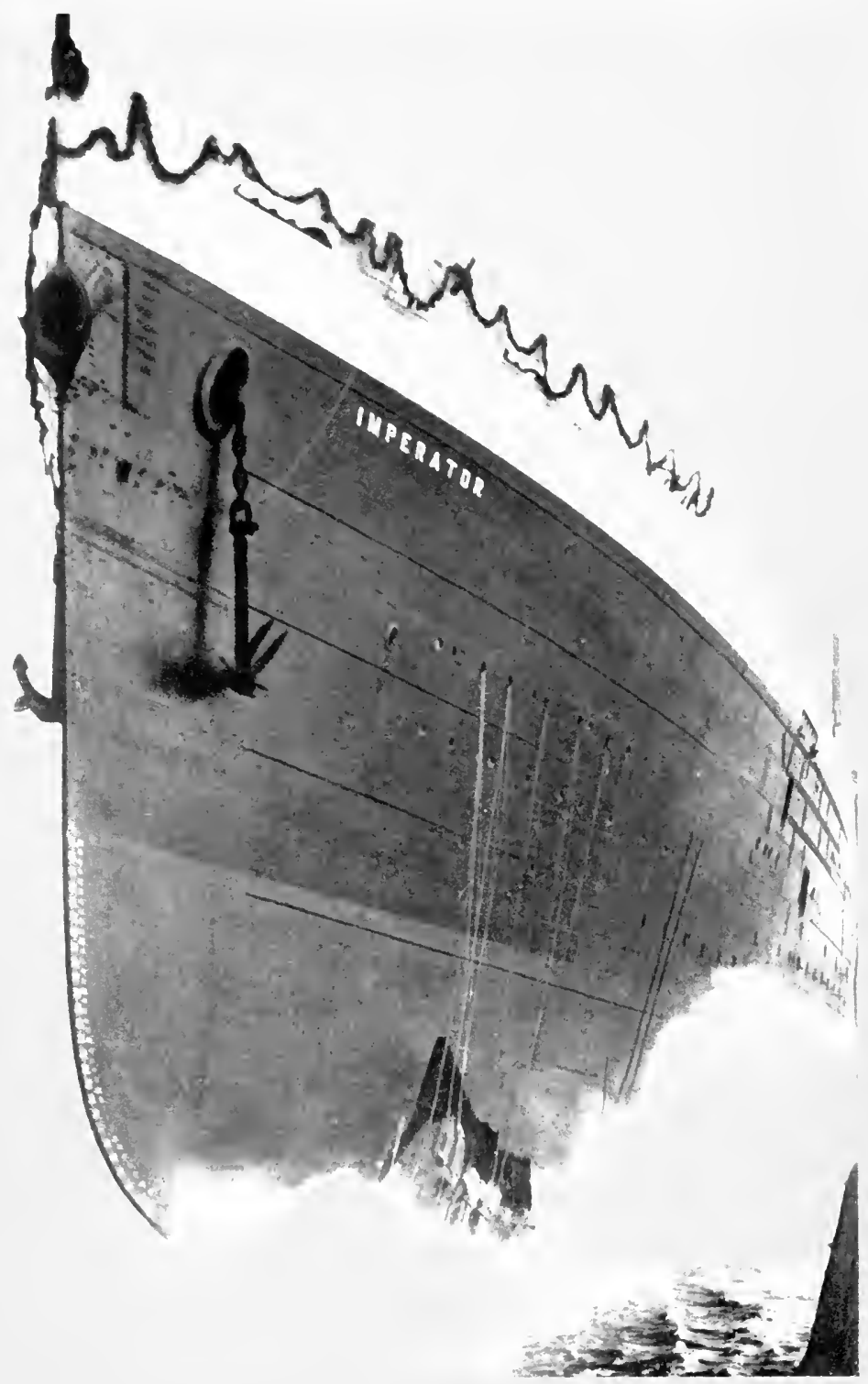

$11.01 \%:$

The tors of the Imperator just leaving the wiłs. The forward cradle is collapung, as the veset is almunt buyam. 
into a loop before it is dragged along the ground. Accordingly, the instant the hawser connected to a pile of chains becomes taut, a gradually increasing check is produced. When this retarding action is stepped, one pile after another being brought into action, the sum of the drag represents a powerful brake.

The actual launch usually does not take more than a minute or so. The naming ceremony is performed by a lady, who breaks a bottle of wine across the bows of the ship rearing up before her, names her, and wishes her success. Simultaneously the upper launchways are released by the triggers, and the vessel commences to glide down the greased ways with accumulating velocity. In Japan a very pretty ceremony accompanies a launch. A cage of birds is attached to the overhanging bow, and fair hands open the door to allow the songsters to escape, the action being symbolic of the freeing of the ship from dry land.

Should the release of the triggers fail to set the ship in motion, the hydraulic ram is permitted to expend its enormous pressure, and the boat begins to move, almost imperceptibly at first, but with rapidly increasing speed.

The stern (or bow) cuts gradually into the water, as the cradle, clinging still to the ways, becomes submerged. A white ruff curls round the rudder and extends along the sides, mounting higher and higher as the screws slip from sight. As the vessel thrusts herself farther into the water she becomes gradually more and more buoyant, until finally she is bearing, like a lever, upon the forward cradle. The after cradle and sliding ways, relieved of the weight, float away in pieces on either side. All the strain becomes imposed upon the front cradle, and this is the crucial moment. The pressure brought to bear upon the front cradle is tremendous-indeed, it is so great that were the ship to stop suddenly the timbers would crumple up under the strain. But the hull is moving rapidly; the enormous pressure is no sooner imposed than it is relieved. There is a terrible creaking and groaning. Baulks forming the 


\section{STEAMSHIP CONQUEST OF THE WORLD}

cradle fly out in all directions under the pressure, there is a cloud of spray, and the front cradle falls to pieces, to drift hither and thither-the liner is water-borne.

Scarcely has the retreating shell of steel become fairly afloat when it feels the check. One after another the drags come into action, so that before the vessel has gone very far through the water the force of the retarding influence is exerted to its maximum, and the ship is brought gently to a standstill.

In the case of the Mauretania it was necessary that the vessel should be swung round in the river the moment she was afloat. For this purpose a heavy anchor was buried in the river bank upstream on the same side as the shipbuilding yard, and the cable leading from this to the stern of the liner was designed to become taut the moment the ship had cleared the ways. As the bow dipped into the water this cable exerted its pull and swung the hull round, the anchor being dragged 120 feet in the process. As the vessel drew up another anchor was dropped to moor her, while simultaneously half-a-dozen tugs, waiting in readiness, hurried up and made fast to the bow and stern, to tow her to the fitting-out berth just below the shed from which she had just previously emerged.

The most noticeable feature of this launch, which was a brilliant success, was the complete fulfilment of the calculations predetermined by the naval architect. There was not the slightest hitch. From the moment the shapely mass commenced to move after being christened until she was at rest in the river only 77 seconds elapsed. The liner glided down from a height of 34 feet and travelled $95 \mathrm{I}$ feet, starting from a state of rest to attain a maximum velocity of $14 \frac{1}{2}$ linots per hour in the course of 480 feet, and being brought to rest again in this brief period.

Now and again, despite the elaborate precautions taken to ensure success, a mishap occurs to scatter the carefully laid plans to the four winds. On the Clyde, as a ship slipped down the ways, the lower parts of the latter subsided suddenly, bringing the ship to a standstill before 
she reached the water. Some days elapsed before the vessel was floated. In this instance the river had been dredged after the shipbuilding berth was laid down, and the foundations of the latter became undermined, with the result that the ways, when submitted to the weight of the moving ship, sank, and thus pulled up the travelling hull.

On another occasion, on the north-east coast, a heavy steamer was being launched, when, for some obscure reason, after the stern had slipped into the water the vessel eased up, and came to rest with her bow still resting on its cradle, a few feet short of the lower end of the ways. This was about as precarious a position as a vessel could assume during this operation, because the stern being buoyant, it rose and fell with the movement of the tides. The strain imposed not only upon the forward cradle, which remained intact, but on the vessel herself, with her bows pinched as it were in a vice, while her stern lifted and dropped continually, was terrific. The builders were faced with a teasing problem. There was the fear that the vessel might break her back, or that the front cradle would collapse. After many anxious days and the expenditure of considerable skill and marvellous ingenuity, the ship was extricated from her situation and got afloat. She was then hurried into dry dock, to see if she had bent or buckled in any way under the terrible ordeal. But, to every one's surprise, the vessel was as perfect as if she had slid into the water in a few seconds, instead of days, which testifies to the soundness of her construction.

Occasionally, however, a mishap in the launch precipitates a ghastly calamity. There was the case of the Daphne, a small steamship launched on the Clyde. She had just reached the end of the ways and was practically water-borne, when she heeled right over and sank. There were large gangs of workmen on board at the time, hastening forward the internal structural arrangements, and of this army 124 were drowned. It is surmised that the stacks of material on board got adrift, upset the stability of the craft, and thus caused her to capsize without a 
moment's warning. This vessel was salved and completed, only to develop into one of those "hoodoo," or unlucky, craft which at rare intervals disturb the shipowner's and seafarer's peace of mind. She was renamed the Rose, but her career was summarily interrupted at Londonderry where she renewed her acquaintance with the sea-bed by becoming filled with water. Once again she was got afloat, but a little later she fouled some rocks at Millport, and her bottom was mauled badly in the process. Her owners grew somewhat tired of this repeated "hard luck," and sold her. Once again her name was changed, to Ianthe, but there came no welcome change in her fortune. She was continually in trouble, and her new owners in disgust sold her to a Greek firm, to trade along the rocky coasts of the eastern Mediterranean. What has become of her since I have been unable to ascertain, but she was viewed with trepidation by all who knew her gruesome history.

The Italians appear to be somewhat unfortunate in launching vessels. One ship came down the ways as beautifully and as gracefully as the most accomplished shipbuilder could desire, but when she was water-borne she began to heel over. Those on board took alarm, and promptly jumped clear to save themselves. As she careened more and more the water entered her lower portholes, which incautiously had been left open, and the inrushing water so disturbed her balance that at last she rolled over on her side. In this instance no lives were lost, as the crew swam ashore in time. On another occasion, while an Italian ship was coming down she gave a list before she cleaved the water, and stopped dead in a most alarming position. The cradles collapsed, leaving her stranded on the ways as if she had been thrown ashore by a huge wave, where she presented a perplexing problem for her recovery.

At last, when the fitting out has been completed and the last hook has been affixed in the wardrobe, preparations for the trial trip are taken in hand. This may be a perfunctory function in the case of a tramp, or of an ex- 


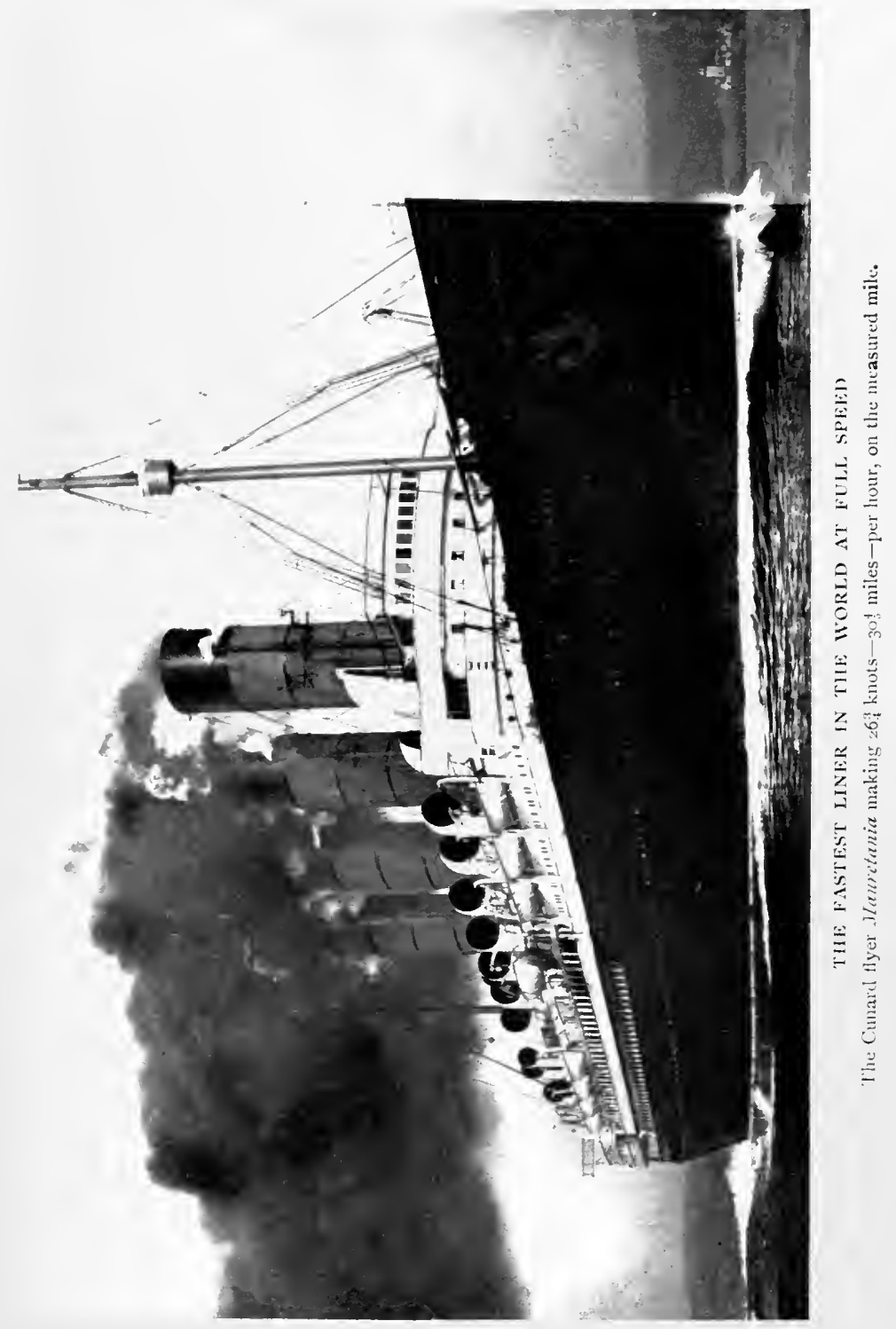




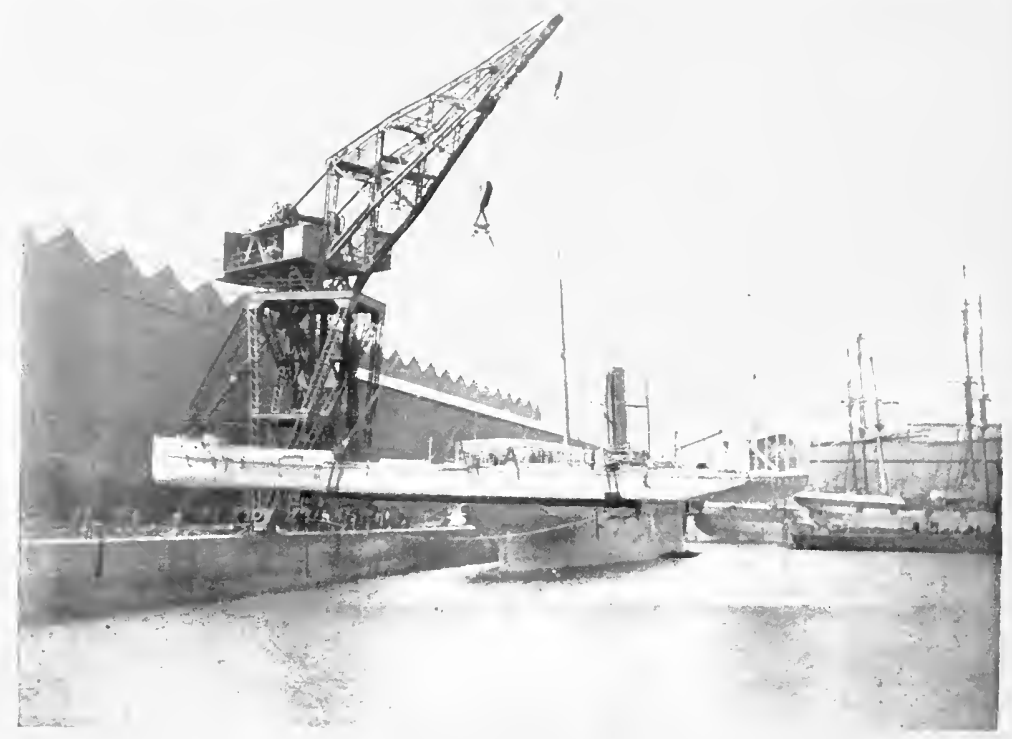

A NOVEL, L.IL XCH

The stern-wheel steamer Axholme, 140 feet lons and weighin r yo tons, was deposited in the water by the rjo-ton crane at the Birkenhead shipyard of Menr. Cammell, laird $\mathbb{N}$ Co., l.ti.

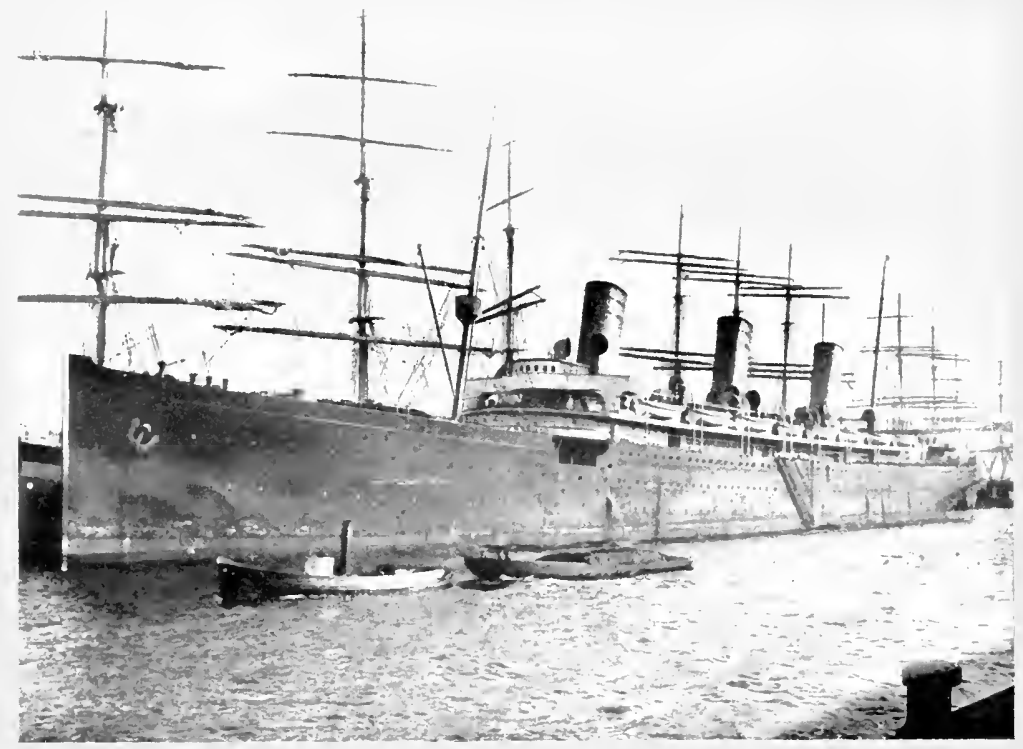

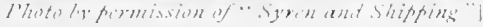

I RFJE(TED (WEAN GREYIIOT ND

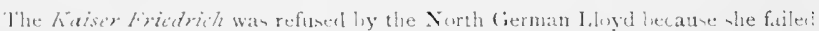
to show the contrat apeet. The lay at anchor in llanhurg harbuar fior 15 years befire she found a purchaser. 
haustive character with a huge liner which has been built for speed. The shipowner, when he placed the order, stipulated for a certain speed, and he now ascertains if this requirement has been fulfilled. If the vessel rises to the occasion, and the owner is completely satisfied, the captain and crew are sent to the shipyard, the vessel coals up, and away she goes on her maiden voyage. If the trials should be attended by a speed less than that mentioned in the contract, then the builder has the risk of the vessel being thrown upon his hands.

Fortunately, among British shipbuilders this is a contingency which is not feared, although at times no little difficulty is experienced in squeezing the last knot out of the ship. Then the engine-room staff have an exciting and, it may be added, exceedingly arduous time. The vessel has got to touch the limit by hook or by crook to satisfy the owner, and the black squad toil like Trojans to consummate this end. Of course, wind and weather exercise far-reaching influences upon this question. Many a craft has only just scraped through her trial trip because everything has been completely favourable at the time.

If the contract for the vessel has been handed, lock, stock and barrel, unfettered to the shipbuilder, from her preliminary calculations to the finished product, no doubt prevails that the vessel will meet the owner's requisitions in every particular, because every detail has been checked and counter-checked carefully at each successive stage. With an ordinary tramp, moreover, the risks of the builder are somewhat mitigated. If she fail to show her paces on the trial trip and is declined by the owner, the ship being a stock standard size for everyday work in her field, no difficulty is experienced in finding a purchaser.

When a vessel is designed for special traffic, such as the North Atlantic express mail and passenger service, the failure to show the demanded turn of speed has an alarming result. An ocean greyhound commands a limited market : she is suited only to the work and purpose for which she has been designed. Consequently, the shipbuilder takes 
every care to err on the right side. It is far better to give the ship half-a-knot per hour in excess of the contract than to fall a quarter of a knot below it. Probably the most colossal blunder in this direction on record was that of the Kaiser Friedrich. She was built in 1897 for the New York service of the North German Lloyd, and is a magnificent three-funnelled liner of 12,450 tons, fitted with engines developing 24,000 indicated horse-power, capable of giving a speed of about 20 knots per hour. She prob-

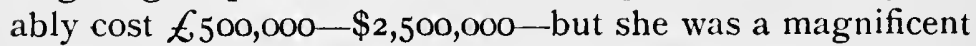
failure. She failed to come up to the guarantees, and her owners refused to accept her under any circumstances. Useless for the North Atlantic trade, she was quite unsuited to any of their other services, and accordingly she was laid up in the harbour at Hamburg. For fifteen years she rode quietly at the end of her mooring chains, a striking example of calculations and building gone astray. No one wanted her, and no one gave a thought to her. She was a white elephant to her builders, and her maintenance charges and expenses in the harbour must have aggregated a big sum by the time a French company came along early in 1912, looked her over, and finally acquired her for the River Plate trade. The circumstance of a splendid liner lying idle for fifteen years is probably unique in the annals of the mercantile marine and shipbuilding. In this instance, while the builder got rid of a bad bargain, from his point of view, after a weary wait, the buyers secured a crack ship-the fastest in the trade--no doubt at a knock-down price.

A similar result, though with a fortunate ending, befell a Clyde shipyard in 1873 , when the Inman Line was in the running for the blue ribbon of the Atlantic. This company contracted for a ressel, the City of Rome, 449 feet in length and of 4,790 tons. She made one or two trips, bringing the trans-Atlantic passage within eight days, and then was returned to her builders, because she failed to fulfil the guarantees. In this instance, as the Atlantic trade was in its infancy, the builders did not 
suffer. The rejected of the Inman Line became one of the finest vessels of the Anchor fleet, and for many years her three black funnels were conspicuous on the ocean, while she became a great favourite among the travelling public.

The trial trip is not always convincing. There was a Cunard flyer of two or three decades since of which much in point of speed was anticipated, but she failed to come up to expectations. The Cunard Company, however, decided to retain her, and, strange to say, she steadily improved after her acquisition, until, in the course of a few round trips, she developed a speed in excess of the contract, and maintained it steadily. A similar result attended the Cunard purchase of the Oregon, 501 feet long and of 7,375 tons, with engines of 13,500 horse-power. She was built for one of the Cunard's competitors, but was secured by the pioneer line. Her first trip was somewhat disappointing, but she soon made amends, and at last broke all records by crossing the Atlantic westward in 6 days 10 hours 9 minutes. Her consistent running so impressed her new owners, particularly when she lowered her westward record by 18 minutes, and maintained an average of 6 days 14 hours for the passage to and fro, that they ordered two larger and more powerful vessels from her builders. The Umbria and the Etruria were the resultant productions-two ships which occupy a prominent position in the history of steam navigation.

It is extremely doubtful whether any vessels intended for express passenger service ever have been subjected to such severe and searching trials as those which the Lusitania and Mauretania had to undergo in order to comply with the British Government's requisitions. The country was paying the bill for a novelty in marine practice -turbine propulsion--and it resolved to secure value for the outlay.

Both vessels had to pass through a 48 hours' full-speed trial under conditions as similar as possible to those prevailing on an Atlantic journey, and at loaded draught. 
The course was 350 miles in length, extending from Corsewall Point off Wigtownshire to the Longships off Cornwall. Each ship had to complete this round trip twice, and as the builders were keen to uphold their reputations, they did not fail to concentrate their efforts upon the establishment of startling records. These trials gave striking indications of what the liners would achieve when placed in regular service, for both succeeded in maintaining over $25 \frac{1}{2}$ knots per hour during the whole 48 hours' run. The Mauretania distinguished herself in particular by reeling off an average of $27 \cdot 36 \mathrm{knots,}$ or over 31 miles, an hour on the second run from north to south, while her average speed came out at $26^{\circ} 04$ knots, or nearly 30 miles an hour, for the whole period.

There were some exciting moments down in the stokehold during this test. The men came from the north-east coast, and there was a powerful manifestation of friendly rivalry between the Tynesiders and their comrades on the Clyde, who had been out with the Lusitania some weeks previously over the self-same course. I was in the stokehold while the Mauretania was running round the north of Scotland on her way to enter the measured distance and tests. The ship was running easy at the time, and a gang of eager giants of the black squad had gathered before one of the boilers which at the time was not working, and were holding forth strenuously upon the speed merits of the two ships. A stoker who hailed from South Wales, and accordingly had no interest in either riversides, started the argument by extolling the performance of the Lusitania over the I, 400 miles' trial trip. He worked his north country comrades to such a pitch that at last one of the brawniest wielders of the stokehold shovel bawled out, "Look you 'ere, mate, we'll lick the 'Lucy,' even if we bust the "Mary' to do it!" 'To which there was such a vociferous and enthusiastic "Aye! aye!" that I knew the Mauretania was destined to be put through her paces with a vengeance. Then they hinted raguely at what the ship had done out in the North Sea on the occasion of the 
builders' private investigations as to the speed of their creation. They talked darkly about the 30 knots they had notched on one occasion, and there was a shake of the head which told me that it would not be their fault if the liner did not do something striking. No brawn and muscle were spared on that 48 hours' run in tossing the huge shovelfuls of coal from bunker to boiler furnace; the engineer never had the least doubt about the pressure of the steam within the boilers; the black squad below were seeing to that, because the pride and glory of Tyneside were at stake.

The trial trips ended and proving satisfactory, the ship passes out of the hands of the builders into those of the owners. The vessel takes up her position in the scheduled service, and settles down to her round of toil. 


\section{CHAPTER VI}

\section{THE LUXURY OF THE MODERN LINER}

READERS of Charles Dickens have sympathised with, and have been amused no doubt by, the efforts of Martin Chuzzlewit and Mark Tapley to make themselves comfortable while crossing the Atlantic in the very early days of steam navigation. Their experiences, virtually, were those of the novelist who taught us how to laugh and to cry himself, on the occasion of his visit to North America. $\mathrm{He}$ received his baptism of the Atlantic upon the first Cunarder, the historic Britannia, whereon it defied the wit of man to make himself snug, because comfort was the very last thing which the vessel offered. The passenger paid his money to be transported across the ocean; not to be entertained like an Oriental potentate amid barbaric luxury and splendour.

What a change has been wrought in steamship travel during a short three-quarters of a century! Then, the firstclass cabins were cell-like apartments, scantily and dismally furnished, replete only with the barest necessaries, badly lighted, and indifferently ventilated. An oil-lamp safely moored in one corner threw a fitful glimmer over the cupboard, and blackened the ceiling. A rude bunk, which to-day an emigrant would spurn, served as a bed which caused every bone in the body to ache instead of resting the human frame; the walls were plain wood of a dingy tone, and the essential hangings and embellishments, reduced to the very barest requirements, were musty and nauseating. The passages were like caverns, so that one had to steal along warily to preserve the limbs intact; the public rooms were cramped, bare and oppressive, while the "constitutional" had to be taken in a space upon the 


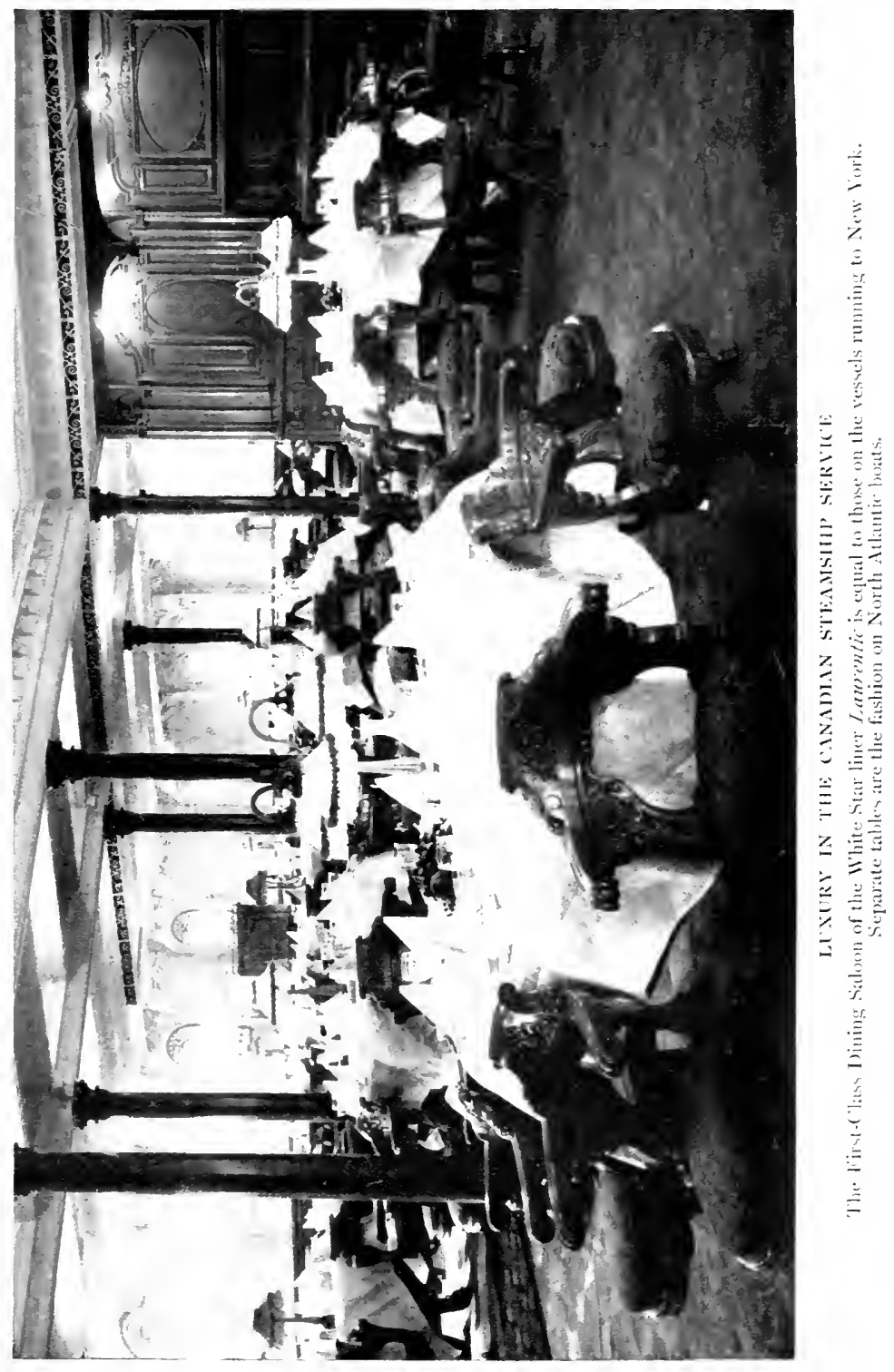




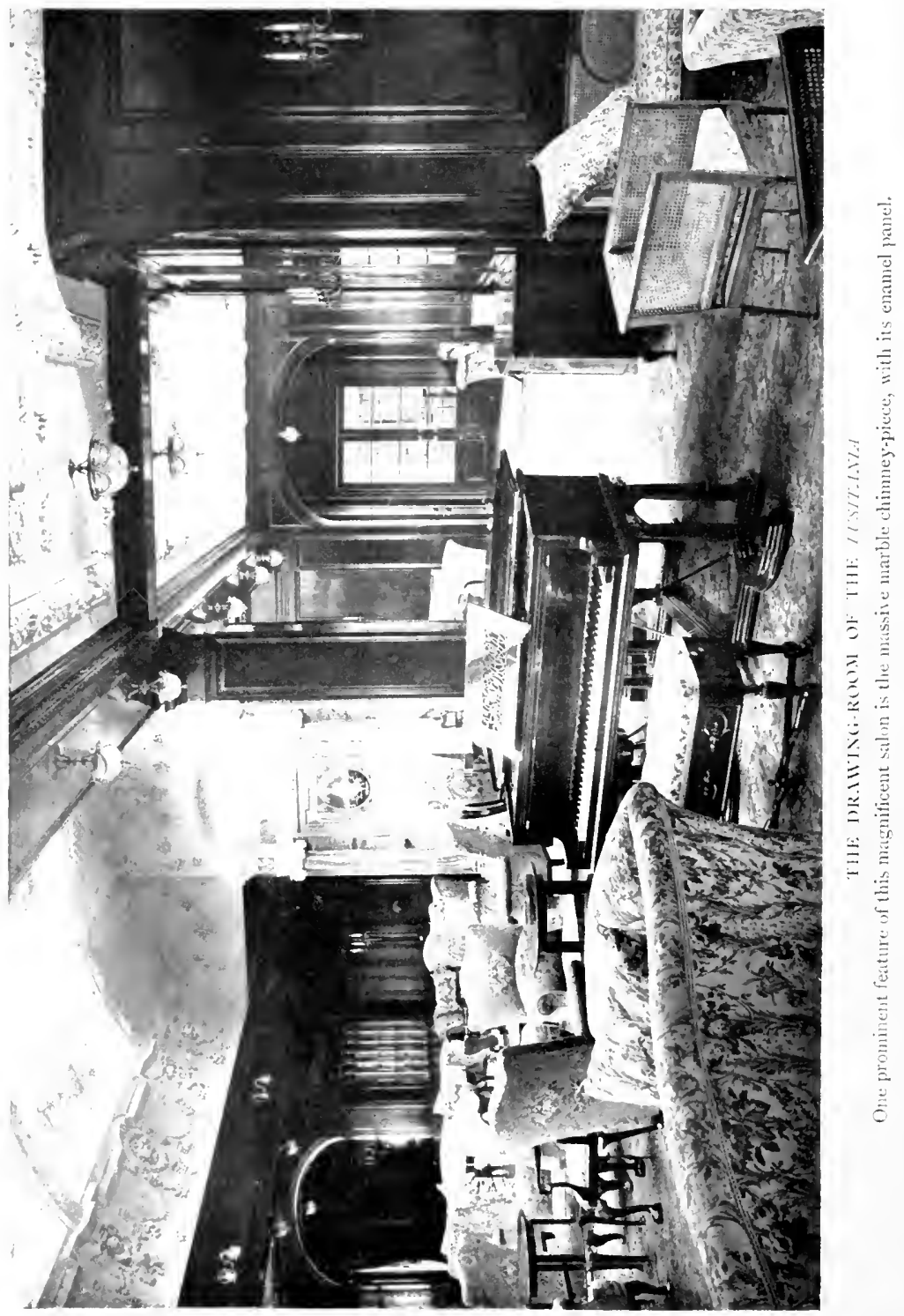


deck recalling a prison yard, where it was quite impossible for the healthy, active person to stretch his limbs. The boat being small, narrow and light, was practically the sport of the waves, rolling and pitching like a cockleshell, so that the plight of the travellers was pitiable in the extreme, mal-de-mer claiming all but the hardiest sailors as victims. I have been unable to obtain any particulars of the victualling arrangements of those days, but, judging from the character and dimensions of the vessel, the doctor, if such a minister to humanity were carried, must have been a busier man than the chef.

As the mercantile marine grew and prospered, the convenience and comfort of the passengers received more and more attention, but it was not until the 'seventies of the past century that the shipowners realised the significance of the traveller in their revenue accounts. In the first instance, trans-Atlantic and other liners came into existence fundamentally to carry mails; passengers were on a footing with cargo. But as time passed, and the subsidies awarded for mail contracts diminished, the owners awoke to the fact that the human element was destined to play an important part in the financial success of vessels.

Yet the keynote of modern shipbuilding luxury may be said to have been struck on the appearance of the White Star liners, the Majestic and Teutonic, and the Cunarders Lucania and Campania. In the first two vessels comfort was the vital consideration; in the second comfort and speed were combined for the first time, because here a new era in shipbuilding was inaugurated. The naval architect had reigned supreme hitherto. Now the domestic architect was called into service. The former was held responsible for the staunchness, safety, seaworthiness and speed of the boat; the latter was entrusted with the task of planning and decorating the accommodation for the travelling population; to dispel the idea that one was really on board ship, in favour of illusion that one was living in a luxurious hotel.

In this work the domestic architect has been given a 
very free hand, and, so far as those vessels which are constructed essentially for mail and passenger service are concerned, no financial obstacles are placed in his way. The idea appears to be rather to introduce the voyagereven the wealthiest-to an atmosphere of luxury which he has never seen in his life on shore, and as the competition for this type of traveller has become keener and keener, owing to the number of lines engaged in the traffic, each succeeding vessel represents a marked advance upon its predecessor.

This unceasing struggle for more extravagant luxury has been responsible for another development, which to-day has attained a position of importance. When the decorative period, as it may be termed, came into vogue, the average domestic architect was adequate for the purpose. He handled his new foundations in the same manner as he would a villa or a mansion on dry land. But as time progressed it became more and more apparent that there was a very wide gulf between these two branches of the art. The ship demanded special treatment. The naval architect, by the evolution of improved and stronger metals, was enabled to suppress the nakedness of his essential metalwork more and more up to a certain limit, and there he has been compelled to stop. The naval architect argued for safety and staunchness of his product; the decorative artist insisted upon the requirements of his tastes and fancies being fulfilled. The latter failed to recognise the imperative work of the former, and the designer of the ship ref used to budge to gratify artistic idiosyncrasies. The latter proved victorious in the struggle because the regulations of the classification societies such as Lloyd's, the British Corporation, the Bureau Veritas, and similar bodies of other countries, supported him in his contentions.

An amusing instance of this breach between utility and decoration was related to me. A domestic architect, occupying one of the pinnacles in his profession, was called in to embellish the public rooms of the liner, and was given a free hand. He prepared his designs, which were exe- 


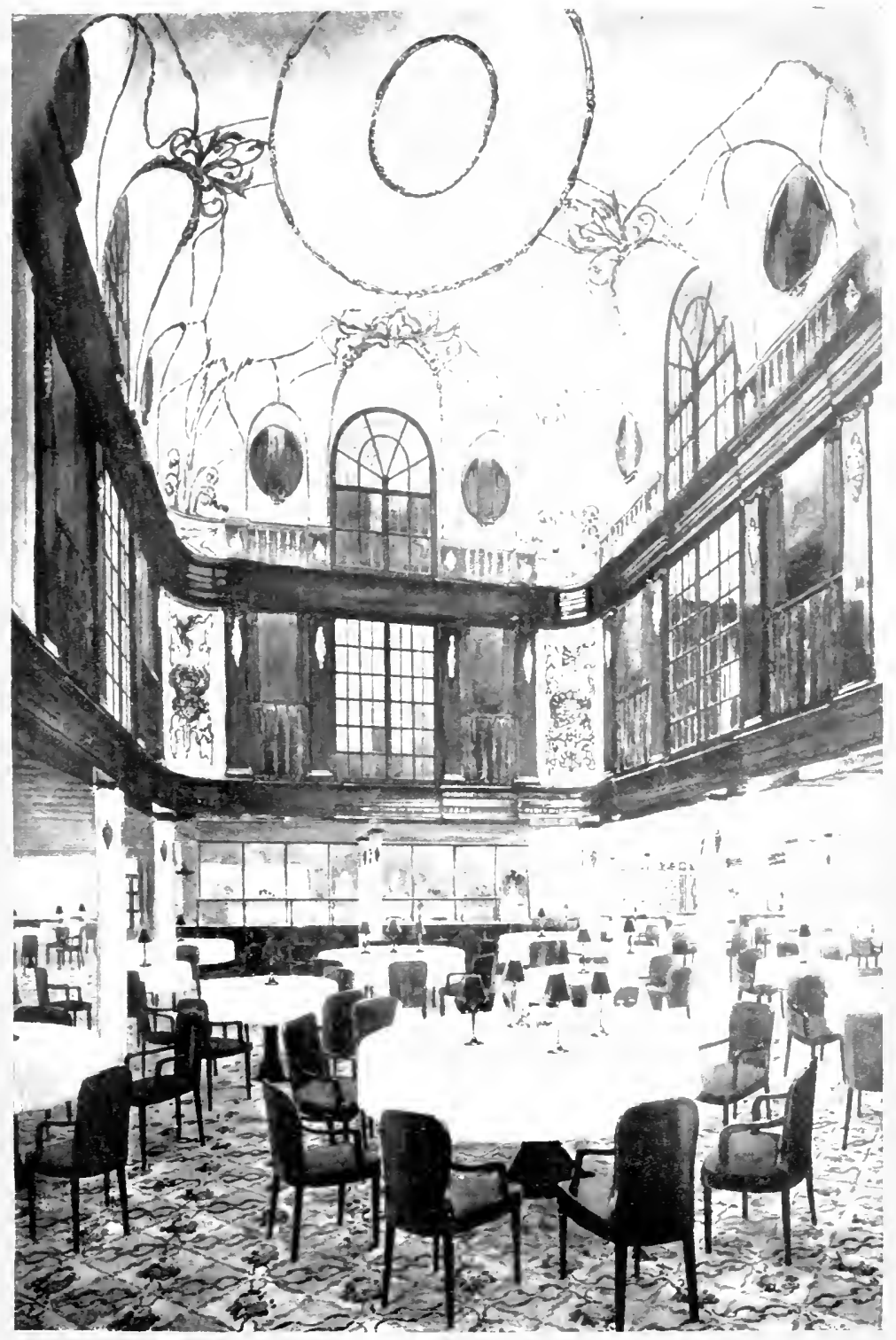

IUDERN DOMESTIC ARCHITECTLRE W IX ATLANTIC LINER

The Firt Claw Dining Saloon of the North German Lloyd intermediute steamer

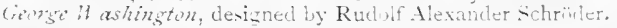




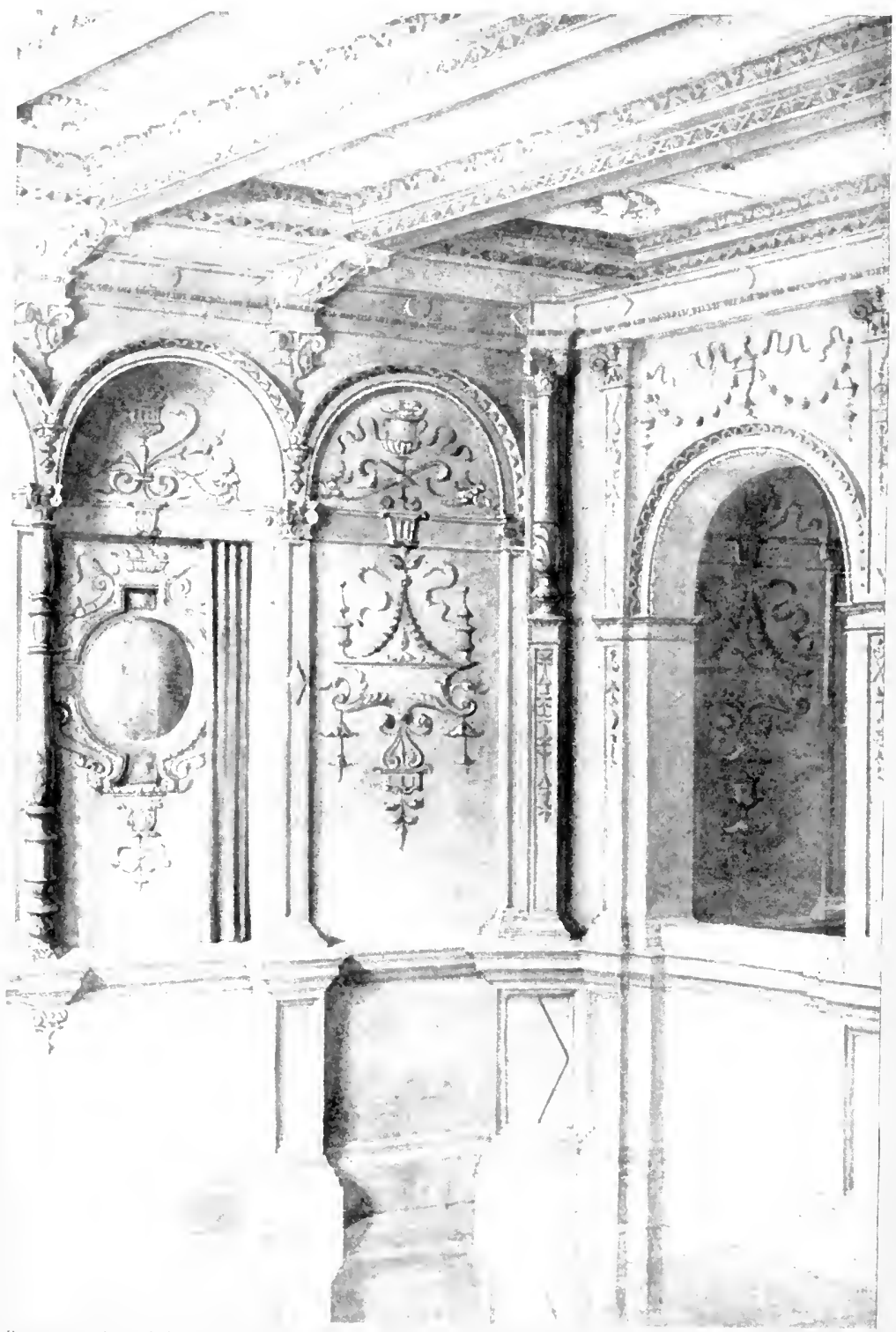

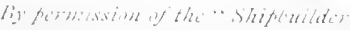

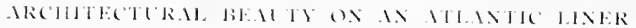

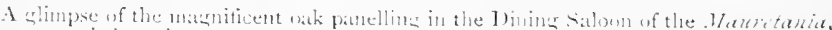

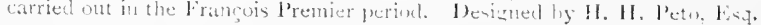


cuted, and then visited the shipyard in order to inspect the progress of his handiwork. When he gained the diningsaloon he gave a cry of horror. The naval architect, who was accompanying him, inquired what was the matter.

"It will ruin the whole scheme," wailed the decorative artist. "Look at those pillars, and"-pointing to the ceiling-" those beams." Then, with a lordly wave of his hand, he cried, "Take them away."

Certainly the pillars dotting the space and rising up in their ugly nakedness, and the beams cutting across the width of the ship in their grim, drab grey, were enough to wound æsthetic susceptibilities, but the naval architect shook his head quietly.

"Why not?" inquired the artist.

"Oh! only because if you do you'll have the two decks above and the captain's bridge come clattering down," replied the practical man. "You see they keep the superstructure up, and also help to hold the ship together, while I am afraid that if you took them out, Lloyd's and the underwriters would be after you. It is necessary to keep the fabric together somehow!"

The artist said no more, but he cherished deep-rooted opinions concerning the lack of artistic taste possessed by the practical man. Still, he learned that in shipbuilding there are certain structural details which will thrust themselves forward willy-nilly, and that it is imperative to combine decoration with utility. This feature has resulted in the development of domestic architects, who specialise in the craft, realising that their naval colleagues only can meet æsthetic requirements up to a certain limit, and that the artist must make these indispensable invaders into his field as attractive as possible to harmonise with his scheme.

In the early days decorative ideas followed somewhat conventional grooves. They were either massive and solid, or bright and gaudy. White and gold figured very extensively, giving the interiors somewhat the appearance of a glorified tea-shop, or German bierhaller. The architect 
suffered from inexperience and nervousness. He hesitated to launch out into daring designs lest they might fall short of their purpose, and feared to play upon the strings of variety for different rooms, in case they became bewildering. This conservatism and monotony prevailed until one or two artists, bolder than their colleagues, wandered farther afield to introduce ideas and embellishments which never were contemplated in connection with ship decoration. The older members of the craft stood aghast. The new movement was dismissed as "arrant anachronism"; but to their chagrin the new departure pleased the public. The result is that upon a modern liner as many as thirty different decorative styles, belonging to as many different schools, distributed among as many rooms, are to be seen, and the variety is pleasing rather than otherwise.

Some of our British shipbuilding architects and the German architects have achieved eminent distinction in this field. It is a difficult fold for the artistic aspirant to enter, no matter how great his fame in his craft, owing to the peculiar difficulties attending the work. A certain knowledge of shipbuilding practice is essential to realise what the naval architect is compelled to carry out. As one eminent ship-architect described the situation to me, "It is essential to recognise the necessary eyesores and evils of the builder, and then to disguise them as much as possible or turn them to useful account in the decorative scheme."

The majority of the geniuses associated with this work have grown up with the development. Many can relate an association of a quarter of a century or so. Johann Poppe, for instance, has been responsible for the embellishment of the Nord-Deutscher Lloyd steamships for a matter of twenty-five years, and has been a very aggressive pioneer in many branches of his handicraft. These men have caught the prevailing spirit and fashion of the age, and have a keen knowledge of public requirements, while at the same time they strive incessantly for individuality. To be a success, the decorative artist working in this arena must be ever on the alert for something new, must be a 


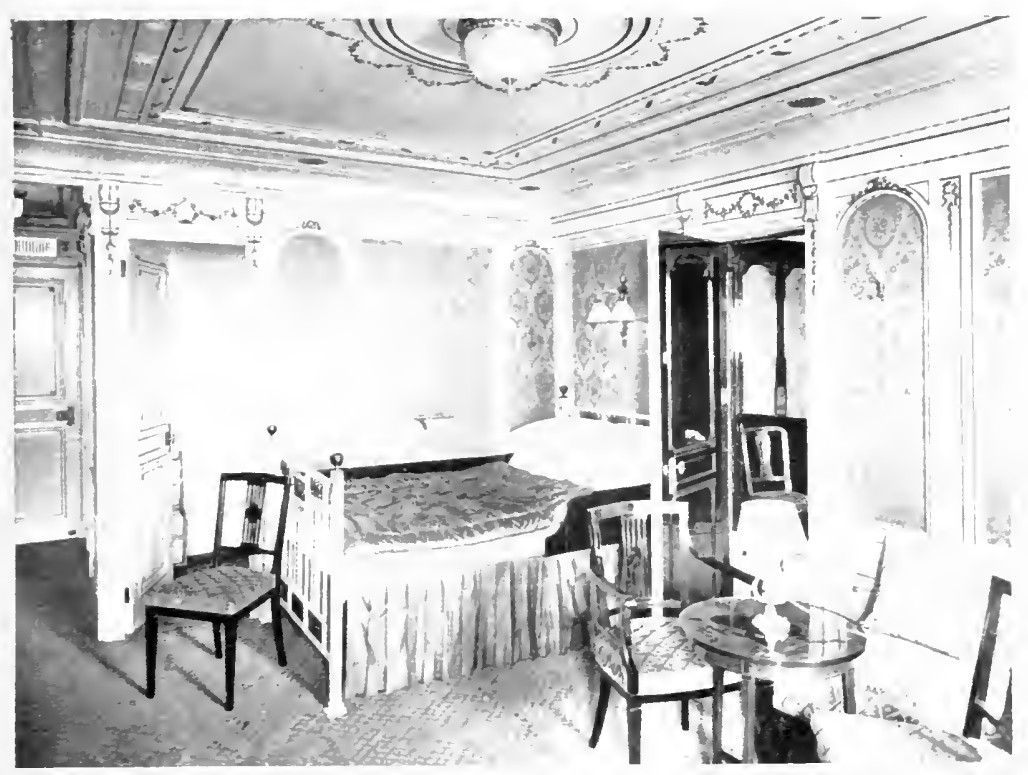

I RFGiJL S[TT]:

This form of luxury has becone a feature in modern ocean travel.
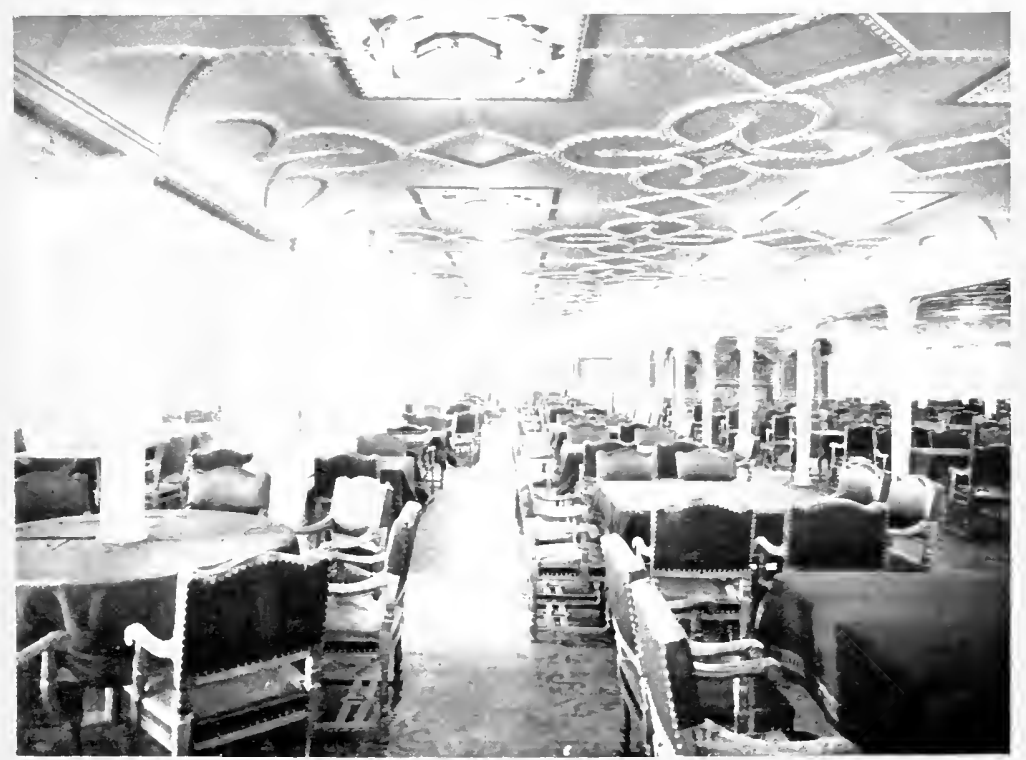

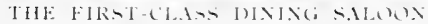

ART ANID LEXLRS ON THI OLYHIIC 


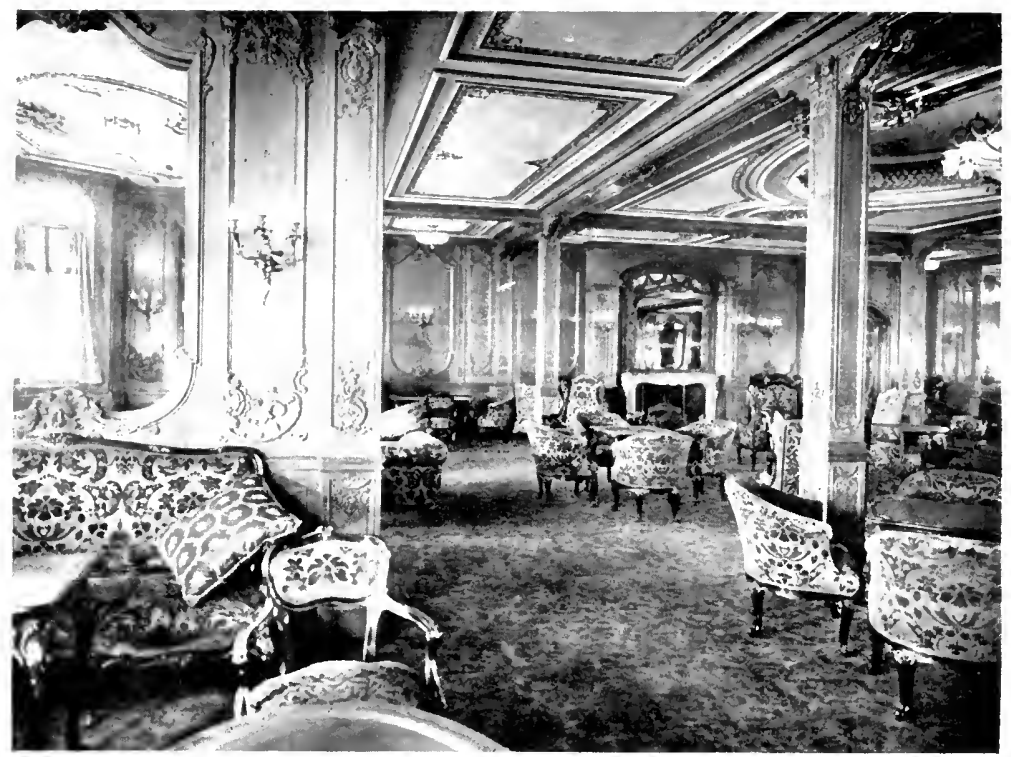

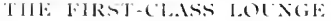

This in the style of Lunis $\mathrm{XV}$, with detail copied from the lalace at Versible.

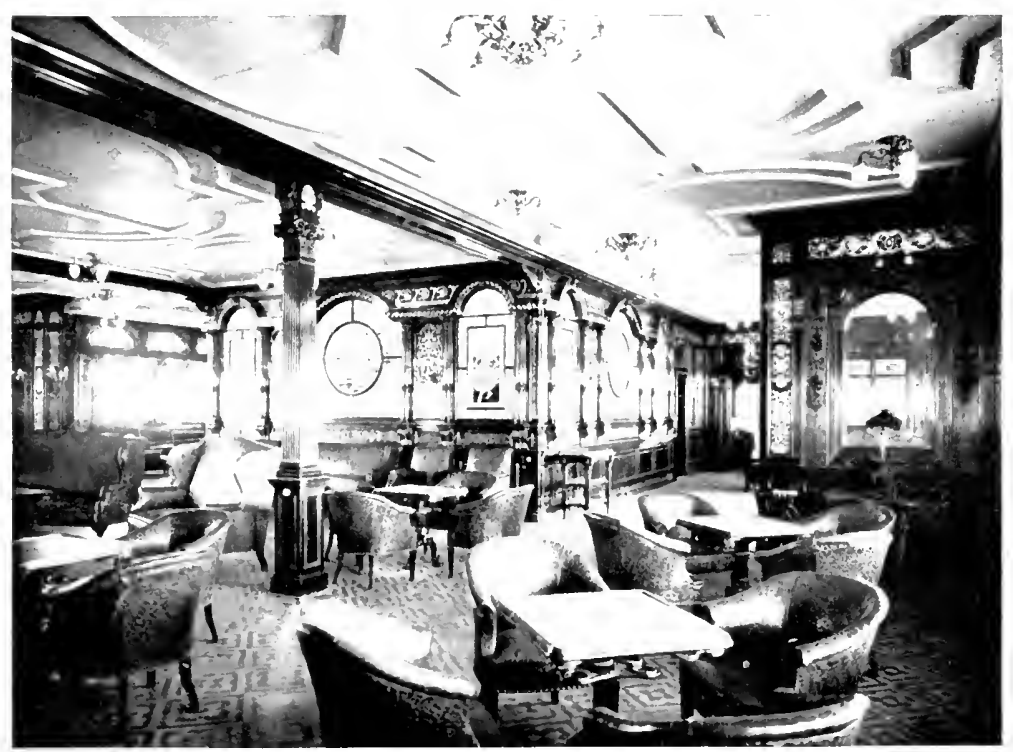

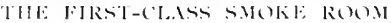

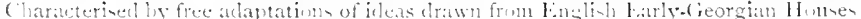

(ahout 1720 ), with muther-of-pearl inhly insteat of woul carring.

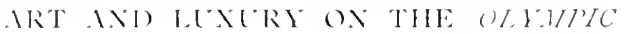


creator, and be possessed of fertile imagination, no matter whether he is handling massive oak and carving, or delicate tones and colour effects upon flat surfaces.

Variety and purity of styles are the characteristics of present-day ship decoration, assimilated with pleasant glimpses of modern art to give relief. Thus, for instance, on the Olympic Louis Seize, Empire, Adams, Italian Renaissance, Louis Quinze, Louis Quatorze, Georgian, Queen Anne, Modern Dutch and Old Dutch, are to be found side by side among the regal suites. These, indeed, are very favourite styles for these self-contained luxurious flats, and are followed very extensively in the majority of the latest liners, more particularly the British vessels.

It is in the public rooms such as the dining, drawing, writing and smoking saloons where the decorator has the greatest scope, because ample space and height are available to permit his artistic bent to be displayed to the utmost. The schemes may favour either the heavy, bold and impressive, or the dainty and delicate, according to the avowed purpose of the apartment. A few years ago the artist was somewhat restricted, inasmuch as the twin screw reciprocating engines, when driven at full speed, set up an extreme vibration, which, being transmitted throughout the length and breadth of the vessel, was liable to shake the dainty and delicate decorative work to pieces. The artist therefore had to confine himself rather to treatments which could withstand these strains. But with the advent of the turbine, and especially of the combined turbine and reciprocating engines, together with the more scientific balancing of the heary, moving masses, whereby vibration is reduced to insignificance, the artist now has greater opportunities than ever to display his skill and talent.

Some of these public apartments have been brought to a high artistic standard of luxury, and the expense disbursed upon the decorative work in many instances runs into enormous figures, because the artist is under no restraint. There is the mural work in the dining-saloon of the Mauretania, for instance. The style is the François 
Premier; the straw-coloured oak panelling is richly carved, and the true characteristics of the period are retained, no piece of carving being an exact facsimile of its fellow. In every instance the carving is by hand, cut back from the face of the solid wood. Perhaps no sister ships offer such divergent styles as the two famous Cunarders. In striking contrast to the above dining-saloon, that upon the Lusitania follows the Louis Seize, with an old rose as the general colour for the curtains, hangings and carpet. On the Olympic the artists ransacked the seventeenth century for their ideas, and have displayed the prevailing tendency in ship decoration by copying details from several Jacobean houses of the period, so as to secure purity of style. The reproduction of the decorative details of famous residences and mansions of distinctive periods upon board ship is becoming quite fashionable. Instead of the original suggesting an idea, as has been the vogue hitherto, it is being reproduced in facsimile, even to the smallest detail. If this development is carried to the extreme, we shall see the public saloons of the future liner presenting replicas of famous British castles and historic seats-a dining-room from Penshurst Place, a drawing-room from Chatsworth, a baronial hall from Holyrood, and so on. The tourist then will be spared the round of visits through these islands - he will become familiarised with our historic architectural treasures while crossing the ocean by rambling through his temporary floating home.

The freedom which has been extended to the architect, and the diversity of his schemes, have imposed supreme tasks upon the joiners and upholsterers, who are responsible for the conversion of the artist's handiwork into wood, textiles and metal-work. The increasing demand for accuracy is placing a more emphasised premium upon skill and workmanship, and at times the craftsman is hard pushed to fulfil the designer's ideas. In completing one room upon the Mauretania several countries had to be scoured for thirty different woods, some of which have become very rare. Valuable and historic designs have to 
be unearthed to provide correct patterns and colourings as well as material. The Cunarders have become famed the whole world over for their beautiful embellishment. The distinction is not misplaced. The peculiar conditions under which they were built gave the artists unique opportunities which were not lost, with the result that these two vessels represent the pinnacle of ship decoration.

Although it is the tout ensemble which compels attention, examination of the various details will demonstrate the keen competition to excel. There is not a single jarring note; everything is in harmony. The main consideration is to convey the idea that one is not at sea, but on terra firma. Half a century ago the round portholes were the sole means of admitting daylight into the various apartments, and they were left in all their naked ugliness; to-day fancy windows, wrought according to the decorative scheme of the apartment to which they belong, are the fashion, finished off with curtains and hangings. The dome to the dining-saloon, which throws a flood of subdued light over the apartment below, secures infinitely careful and expensive treatment, the ceiling round the light-well being relieved with mural paintings, exquisitely executed, more often than not by a master hand, or beautiful carvings. Such incidentals as the ceiling roses for electric lights, fasteners to the windows, grills enclosing the electric radiators-all are designed and fashioned in accordance with the style. Here and there are what appear to be, at first sight, anachronisms, such as an aluminium grille for a period when wrought-iron was used. But it will be found in every instance that the "modernisation" has been carried out for specific reasons, such as to save weight, which in a high-speed liner is an important consideration, and no injury is done to the artistic spirit.

The Mauretania has been described as the most costly decorated vessel afloat. But it is British in style, treatment and workmanship, solid and durable, so that it fulfils national traditions. On the other hand, it is stated that the British firms do not offer very material encouragement 
to our artists. In other words, the mural paintings, while being works of art, are not specimens of famous living painters. This is undoubtedly true, because an atmosphere of anonymity pervades the whole decorative scheme; but it is a moot point whether the traveller does not benefit. $\mathrm{He}$ is spared "artistic atrocities" which are usually the fruits of fame.

Contrast this practice with that prevailing in Germany. In the early days of the present ocean greyhound era, the ornate rococo was favoured very extensively, but as the pace for steamship decoration was set by the British builders, the German owners were forced to introduce a new element. They sought their foremost artists and offered them the mural decorations, mosaic, sculpture and plastic embellishment. The result is that every modern liner flying the German eagle constitutes a picture-gallery of famous native painters and craftsmen, and the work of the artist is acknowledged, so that all may admire-or deprecate. For instance, on the wall of the staircase of the Prince Friedrich Wilhelm are two beautiful mosaic panels designed by Professor F. A. O. Krüger of Munich; the staircase of the George Washington is the handiwork of Professor Bruno Paul; Heinrich Pellenberg was responsible for the children's play-room on the same vessel, and it is one of the prettiest apartments on the boat. 'The deep frieze round this saloon depicts scenes from the fairy tales so dear to the young imagination, and it is not surprising that travellers of tender age upon this vessel find infinite enjoyment in their special apartment. This artist was responsible, also, for the embellishment of the drawing and music-room on the Berlin. Evidences of his tasteful handiwork are scattered throughout the Norddeutscher Lloyd fleet.

This country might very well follow the Teuton example to encourage ship decorative art, as craftsmen fitted naturally and by inclination to this class of work are so very rare. The Norddeutscher Lloyd possesses a master in Johann Poppe, but the time will come when this hand 
will be overtaken by inexorable, rapidly-striding Fate. The late Dr. Wiegand, while controlling spirit of the destinies of this organisation, fully cognisant of this circumstance, decided to make provision for the future. While the Kronprinzessin Cecilie was on the stocks, he conceived the idea of inviting some of the foremost German artists to submit competitive designs for many of the private rooms. Thereby he extended a hand of encouragement to representatives of the modern school, and also anticipated the discovery of one or two geniuses who might be able to follow his right-hand designer Johann Poppe when the moment came. In addition to a number of avowed domestic architects, the three accepted leaders of the modern German art movement-Professors Josef Olbrich, Bruno Paul, and Richard Riemerschmidt--were chosen for the contest. The work of these three painters aroused widespread attention. They not only displayed their innate aptitude for this special class of work, but introduced three distinctly new styles, each of which possessed many characteristics. The contest was highly successful. All three were regarded as promising successors to Poppe. Riemerschmidt's work secured innumerable admirers owing to its refreshing originality; Paul's because there was a pleasing combination of the artistic with the practical; while that of the Viennese artist Olbrich instantly claimed the farour of the fair sex from its daintiness, delicacy and versatility. His work betrayed an intimate acquaintance with the caprices of fashion, and he had instinctive knowledge as to how to capture "my lady's" eye and approval. Some of his ideas were daring, but they were typical of the painter. His premature death was deeply deplored, as he did not have the opportunity to display his artistic temperament upon a scale which would have revealed his mastery of the subject for steamship purposes.

On the other hand, Professor Paul, by his ideas, promised a complete revolution in marine decorative art; some of his work is of a beautiful character. Upon his appoint- 
ment to the post of Director of the School of Applied Art in Berlin, where his influence became manifested very rapidly with highly satisfactory results, Dr. Wiegand made another master stroke of policy. He promptly established a branch of the United Workshops for Arts and Crafts at Bremen, and secured the collaboration of Professor Paul in its management. This is virtually a training-school for marine decorative architects, so that the Norddeutscher Lloyd is not only securing provision for the future, but is making doubly sure of obtaining first-class craftsmen for the embellishment of forthcoming vessels.

The French ship decorative school has acquitted itself successfully in connection with the latest greyhound France. In this vessel the national artistic qualities have been given full reproduction regardless of expense, as the vessel has been built to attract the wealthiest class of passenger. The main feature is the improvement upon the cabin de luxe, or regal flat, which is such a feature of the latter-day liners. This is a princely suite of rooms known as de grand luxe, which probably represents the most expensive development in this phase of steamship luxury yet attempted. It is designed for the accommodation of six persons, so that a family, or party, is able to travel in complete isolation. The sleeping accommodation contains one double and one single brass bedstead, and three canopy beds. There is a dining-saloon, a drawing-room, the latter being executed after the salons of one of the Touraine châteaux, in the period of Louis XVI, with a dining-room of the purest Empire style, together with bath-room and other domestic conveniences. The appointment of one of these apartments alone represents an outlay of nearly $£ 2000$, or $\$ 10,000$.

The sleeping accommodation has been re-modelled, so far as first-class passengers are concerned. On the France the sleeping-berth, or bunk, forming a fixture against the wall of the cabin, is abandoned in favour of a single brass bedstead. This is an improvement which will be appreciated very highly by travellers, as in a double cabin the 


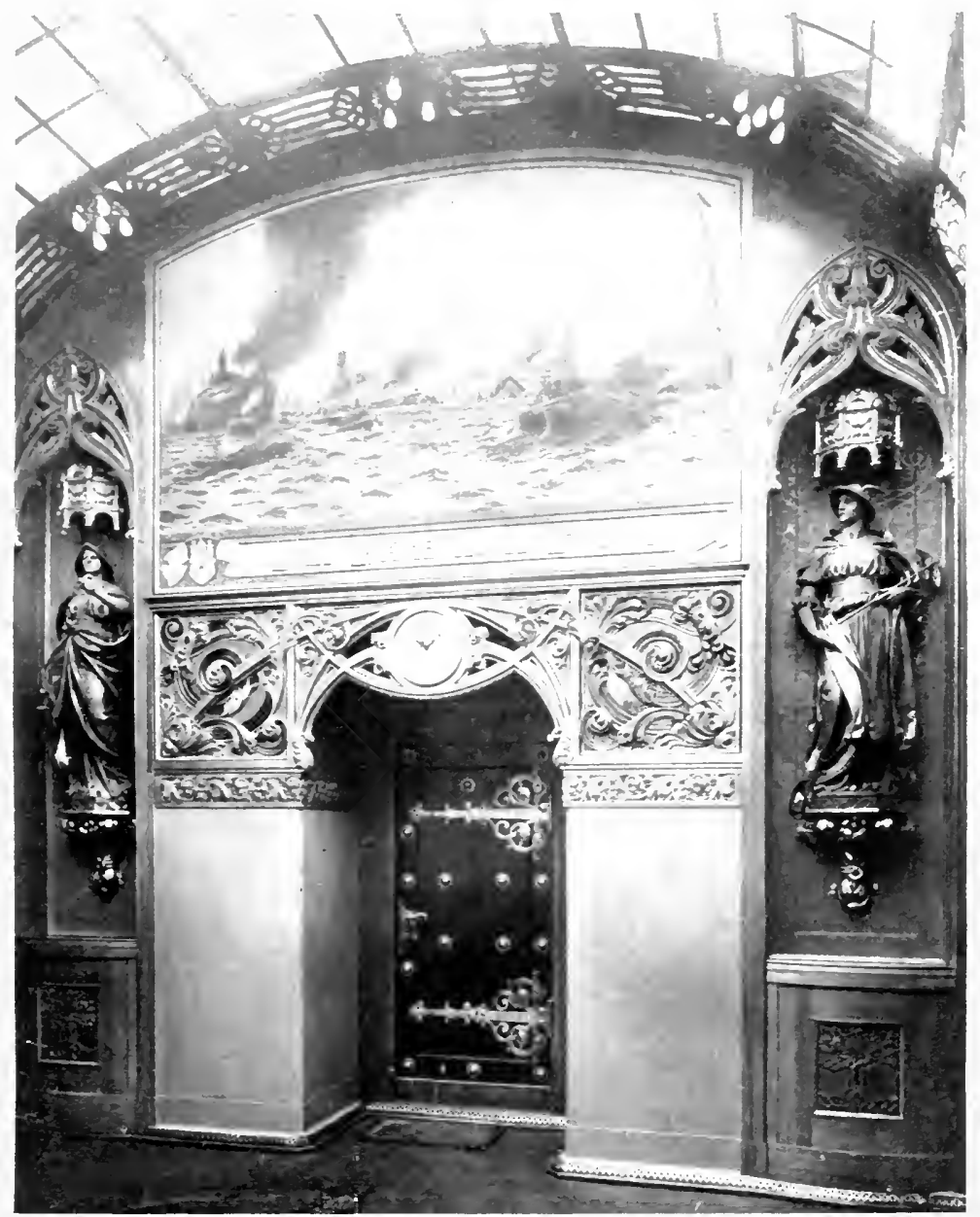

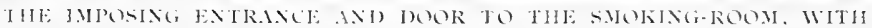

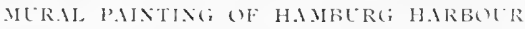

ART INI) LEX(R) ON THE IELTSLHI.AWI) 


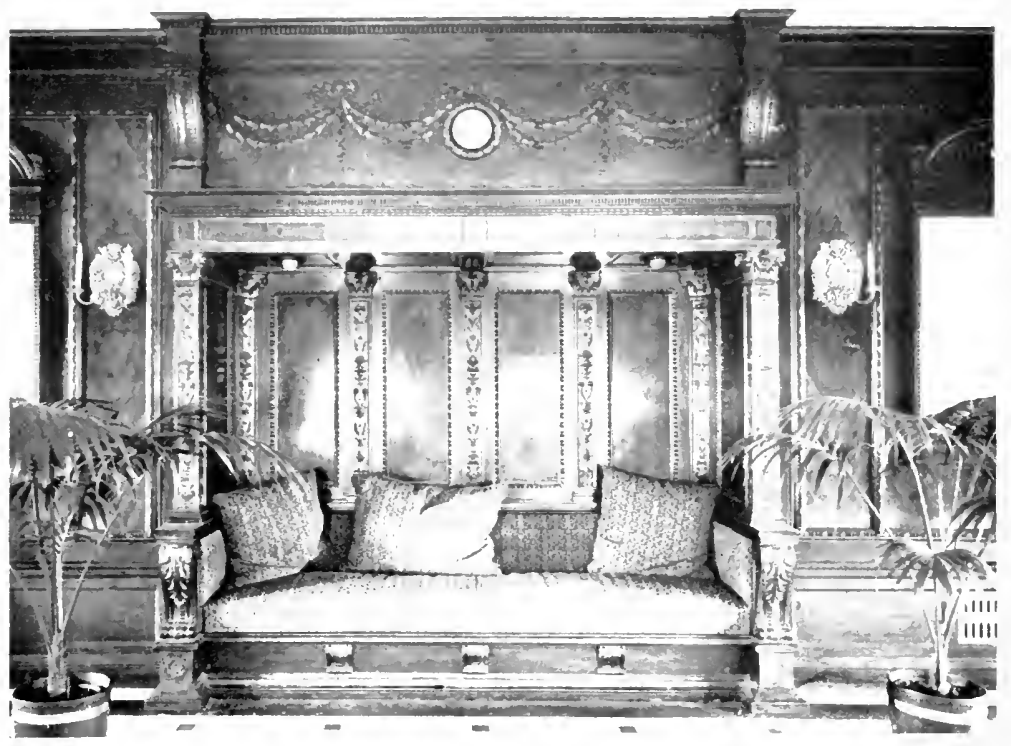

A SEAT IX THE GRANH EXTRANGE ON THE BWT HECK

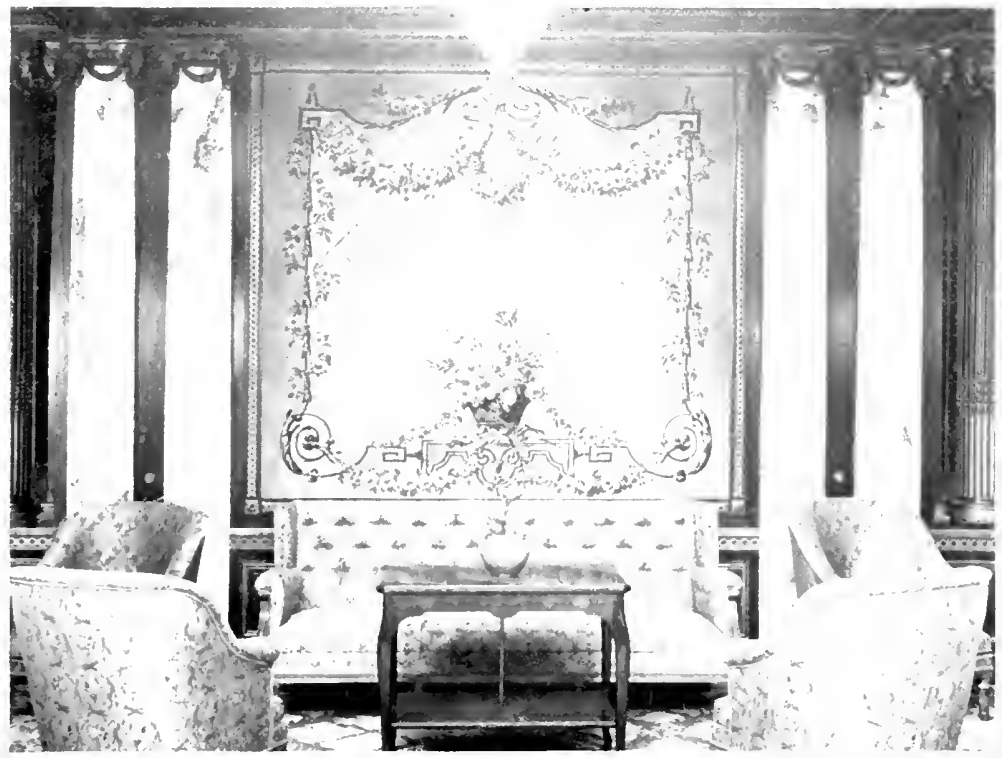

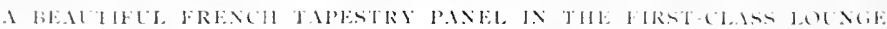

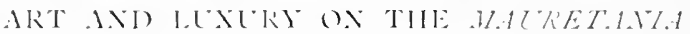


struggle into the upper berth at times is far from pleasant to the occupant of the lower couch.

The dining-saloon is a masterpiece of artistic taste. It extends through three decks, and from the floor level to the top of the dome is about 30 feet in height. The salon is divided into two floors, the upper dining-saloon being disposed around the well and overlooking the lower floor, with communication provided by a graceful and beautiful staircase reminiscent of a palace, with a massive and exquisite painting on the panel facing the saloon. The decoration of the dining-saloon, which will seat 350 people simultaneously at small tables in the general style favoured by modern liners, has been borrowed from the ancient mansion of the Comte of Toulouse, carried out by Robert Décotte, pupil of the celebrated Mansard. The wood-carving is noteworthy, together with the painting on the staircase depicting "La Grace Française," which is the signed work of the French artist La Touche. This painter was responsible also for the mural embellishments to the dome, which are of exquisite charm and grace. In the lounge is another fine painting, a full length portrait of Louis XIV by Hyacinthe Rigaud, after the well-known painting preserved in the Louvre, flanked by portraits of Princesse de la Tour du Pin, Madame de Maintenon, Henriette d'Angleterre, and la Duchesse de Bourgogne. At the opposite end of the apartment, facing Rigaud's portrait of Louis XIV, is another picture after $V$ an de Meulen in the museum at Versailles, representing this monarch upon his return from the hunt in the Park of Versailles. The other artistic acquisitions comprise a statue wrought in bronze of "France," the work of the sculptor Nelson, set in a prominent niche in the entrance-hall; and in the drawing-room, executed in the Regency period, are two exquisite works by the Italian painter Laroix. These are original canvases, bearing the date 1774 . Another imposing public apartment is the Moorish salon, with its fountain and a frescoe Algeriea by the Oriental artist Poisson. Some idea of the money that has been lavishly expended upon the appoint- 
ment of this pride of the French mercantile marine may be gathered from the fact that $£ 40,000$, or $\$ 200$, 000, were spent upon the furniture and painting for the dining and drawing-rooms alone, of which total a single painting in the drawing-room cost $£ 2000$, or $\$ 10,000$. In view of these lavish outlays upon details, merely to please the public for a matter of six days, one is not surprised to learn that the liner cost a round $\ell_{1}, 000,000$, or $\$ 5,000,000$, to build and equip. Huge though this sum appears, it is eclipsed by the cost of the Mauretania and the Olympic, which undoubtedly represent the costliest expressions of ocean travel luxury.

Nowadays the traveller, when he steps aboard, enters Utopia. He becomes the pampered child of indulgence. The modern leviathan is provided with seven or more decks, but one is spared the tedious climb and descent of the staircase from one level to another. The citizen of the floating town presses a button, a grille rolls back to reveal an elevator, and he is whisked to the desired floor. There are seductive lounges and saddlebag easy-chairs in the smoking-room, and a winter garden where a cup of tea or a modest glass of beer appear instantly in reply to demand. Maybe the day is hot, but welcome relief may be had in the cooling, refreshing waters of the swimming-bath. The advocate of physical culture will find in the well-equipped gymnasium every facility to keep in the pink of condition. When time hangs heavily on one's hands, and when shuffleboard, quoits and other orthodox games have expended their fascination in the open air upon deck, there is the racquet court, where prowess may be matched against a fellow-traveller, or a welcome companion in a favourite author may be found in the well-stocked library. Even the luxury of a Turkish bath is not denied to its votaries.

When the traveller finally retires to his couch he makes himself snug and comfortable upon a spring mattress beneath a mass of snowy-white linen. A scarcely perceptible movement of the hand clicks a switch to extinguish the electric light, or, if one be an inveterate reader in bed, 
there is a friendly shaded light at the elbow. Perhaps some refreshment is desired. The push of a button within arm's reach brings a steward to the bedside. In the morning, upon waking, a few steps brings one to the bathroom to revel in the invigoration of a needle or spraybath. Before the bugle announcing breakfast rings out, a constitutional may be taken on the promenade deck, and a mile can be covered within two or three laps of the vessel.

My lady possesses equal, if not greater, conveniences. On the dressing-table is a natty device, which, with the turn of a button, enables her to heat the intricate implements for completing the coiffure. Or she may prefer to leave this delicate, though essential, operation to other and more highly skilled hands. Forthwith she seeks the services of the master in hairdressing, manicure and massage.

Then the morning paper is out. The latest doings on terra firma have trickled into the ship viâ the wireless telegraph during the night. The news is set up in terse, cold type in the printing department, and is duly printed upon an unpretentious sheet. While enjoying breakfast one may become acquainted with the world's happenings as easily as on shore.

This atmosphere of luxury and convenience is by no means confined to the magnificent liners flying to and fro between the United States and Europe. A steamship girdle has been woven round the earth, and the travellers to and from the most distant countries have become just as capricious as their colleagues journeying between the Old and New Worlds. This upward movement has attended the general desire for a pronounced speeding up in all directions so as to shrink the world.

Where will it all end? No one can say. Apparently there is no finality to luxury on board ship, and the capricious nature of the travelling public compels the shipowner to maintain his determination to excel. 


\section{CHAPTER VII}

\section{SAFETY AT SEA}

HAND-IN-HAND with the development of the design, the utilisation of stronger materials, and resort to more powerful machinery, unremitting attention has been devoted to the question of safety. The enormous value of the modern liner, the number of souls she carries on board, the regularity of the service, irrespective of weather conditions, high speed, and the many perils lurking along the great steamship highways render the safety question of paramount importance. A catastrophe in mid-ocean was too terrible to be contemplated, but it was believed to be so impossible that no one gave two thoughts to the subject, the timid being reassured, time after time, that such a contingency was impossible, because the modern liner was claimed to be unsinkable. On one occasion when the late Captain Smith was discussing the subject, he replied, "I can conceive no accident which would send a modern liner to the bottom; at least, not before all her passengers had been got off."

Such was the blind faith in the belief that science had triumphed completely over disaster. Unfortunately the navigator who gave expression to the above statement had the misfortune to meet with an accident which ruthlessly destroyed his optimism, because the ship he was then commanding, the largest afloat, on her maiden voyage, fouled one of the obstacles to be found littering the ocean lanes, and went to the bottom within four or five hours. It was not the intrinsic worth of the ship which staggered humanity, although it was huge in all conscience, representing as it did some $f_{2}, 000,000$, or ten million dollars, but the heavy death-roll, over half of the floating town meeting with a watery grave. 
No shipbuilder will admit that a ressel is unsinkable; and in fact never has made such a statement. But it was believed, until the terrible disaster of 1912 , that a liner would keep afloat for several hours, or even days, after she received a mortal wound. On the other hand, the naval architect will not maintain that unsinkability is impossible. He assumes an agnostic attitude, born of the hope that ultimately science will emerge victorious. Probably if the designer were permitted to have his own way, and was not influenced by commercial considerations, he could produce a vessel which would be virtually unsinkable, but it would be of no utility to the shipowner, and would be shunned by the sea-traveller, who, after all, is the deciding factor. The naval architect strives to secure absolute safety within the compass of his limitations, and the very fact that heartrending marine disasters are so few and far between is the best testimony to his ability and to the high degree of safety that has been gained.

The safety of the twentieth century liner has been brought to its present pitch through successive disasters, and the shipbuilder has not been slow to profit from the lessons to be gained from a wreck. When the Collins Line made a bold bid for the supremacy of the Atlantic, those responsible for the venture announced far and wide that the vessels, specially built for the service, were the safest afloat, proof against every peril of the sea, except fire and collision. It was a vain boast, because it was one of the two exceptions which led to the undoing: one of their ships encountered collision, and sank within four hours.

This accident revealed one important fact--that if a vessel were completely open from stem to stern she was doomed in the event of being torn open and the hole being too big to cover with an emergency device. The water was certain to flow from end to end and to rise higher and higher, until at last the buoyancy of the fabric was destroyed. The calamity which befell the Arctic gave the shipbuilder an idea. Why not split the interior of the vessel into com- 
partments by the introduction of walls, or bulkheads, extending from side to side of the vessel? The first move in this direction was made by introducing such a partition in the bow. As head-on collision, either with another vessel, derelict, or iceberg, was to be feared the most, this wall became known as a collision bulkhead, and there is no doubt that many of the ships of that day, which were fitted with this protection, and had the misfortune to plunge into an obstacle, owed their survival to its existence. At any rate, it saved the Guion liner Arizona, the fastest and largest vessel of the late 'seventies of the past century, when she struck the iceberg while feeling her way across the Grand Bank. Her stem was carried right away, leaving a gaping hole from keel to taffrail, through which the water rushed. The nose of the liner dipped under the weight, but the bulkhead held, and the liner was able to gain St. John's, Newfoundland. Similarly when the Florida rammed the Republique in 1908, although the bow of the former vessel was crumpled up like a concertina, the forward bulkhead fulfilled its designed purpose and enabled the liner to regain New York.

After the collision bulkhead had proved its value, it was not long before further subdivision was carried out. Gradually the whole of the hull became split up into a number of sections, in the same way as a building is divided into rooms by party walls and partitions. The Great Eastern, though a dismal failure from every other point of view, was a masterpiece of safety, since Brunel was somewhat lavish in his adoption of bulkhead subdivision, and, moreover, the hull was provided with practically a double skin. She was the safest vessel afloat in her day, and, in fact, it is doubtful whether she has ever been surpassed. Shipbuilders might profitably pocket their pride and render their vessels safer if they would deign to extend tardy recognition to a master of half-a-century ago by copying his ideas.

Yet as events have proved, the very means which were devised to render a ship less apt to sink when violently 


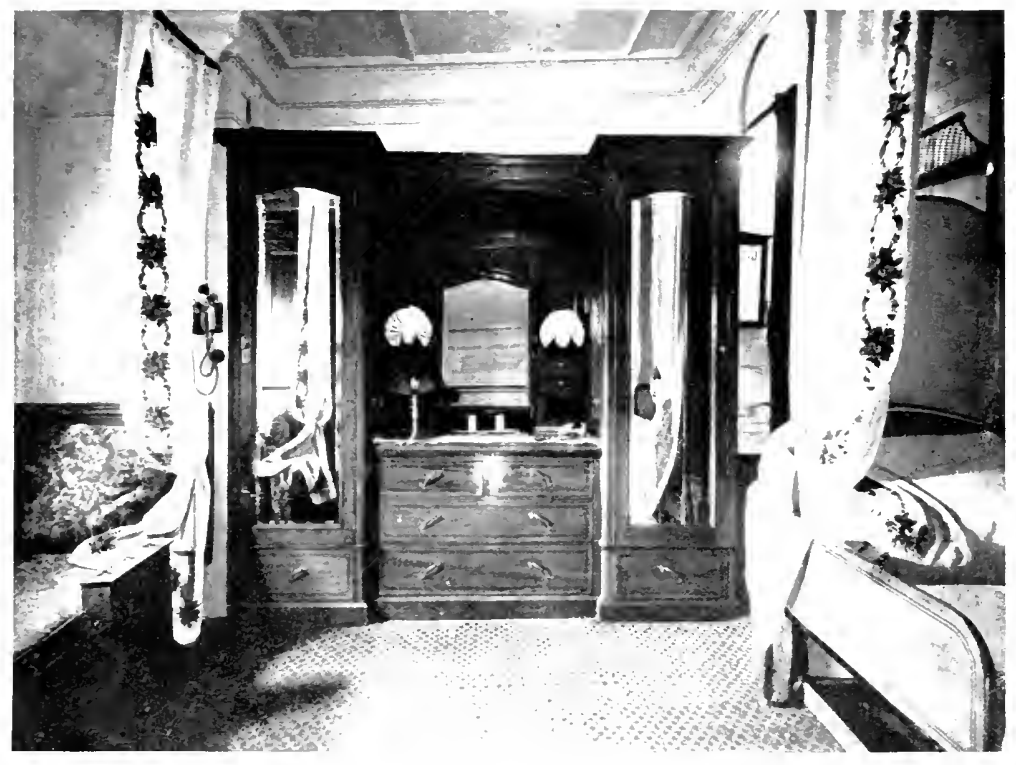

I FIRST CLAST STATE-ROM ON THE IPPER DECK

The telephone, electric ratiator, and electric curling irom are among the

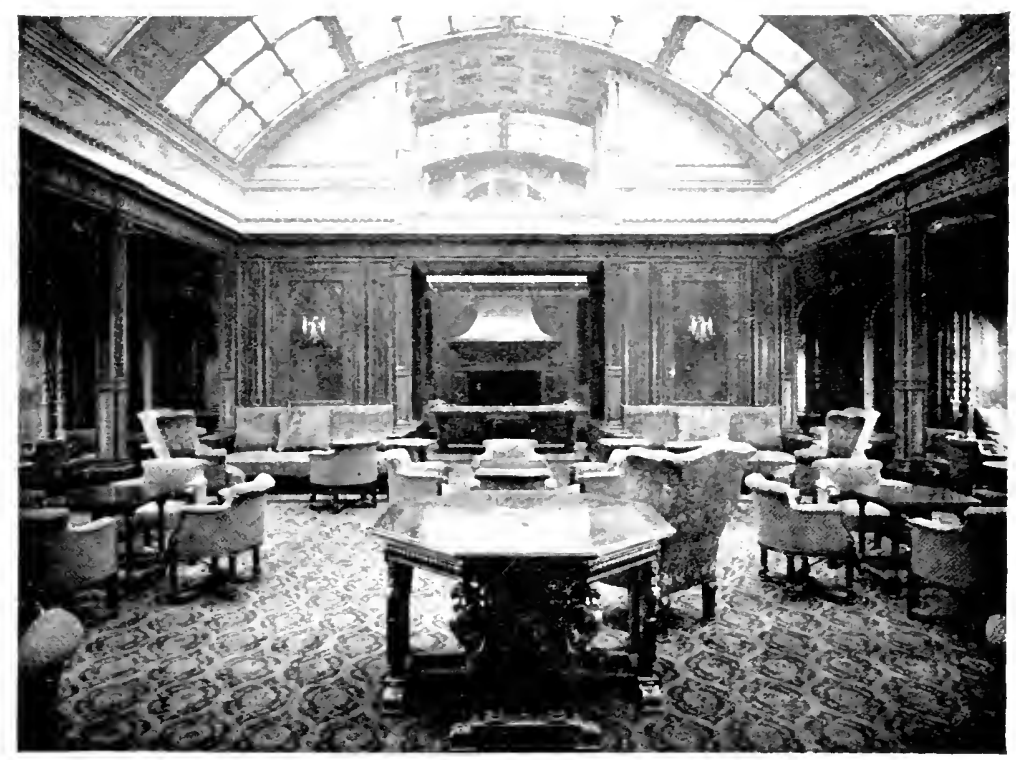

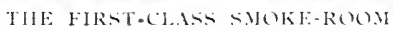

The artistic fentures in:lude ualnut pillars and patnelling. with a mazniticent word hood to

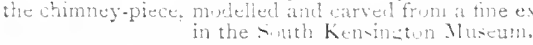

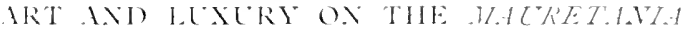




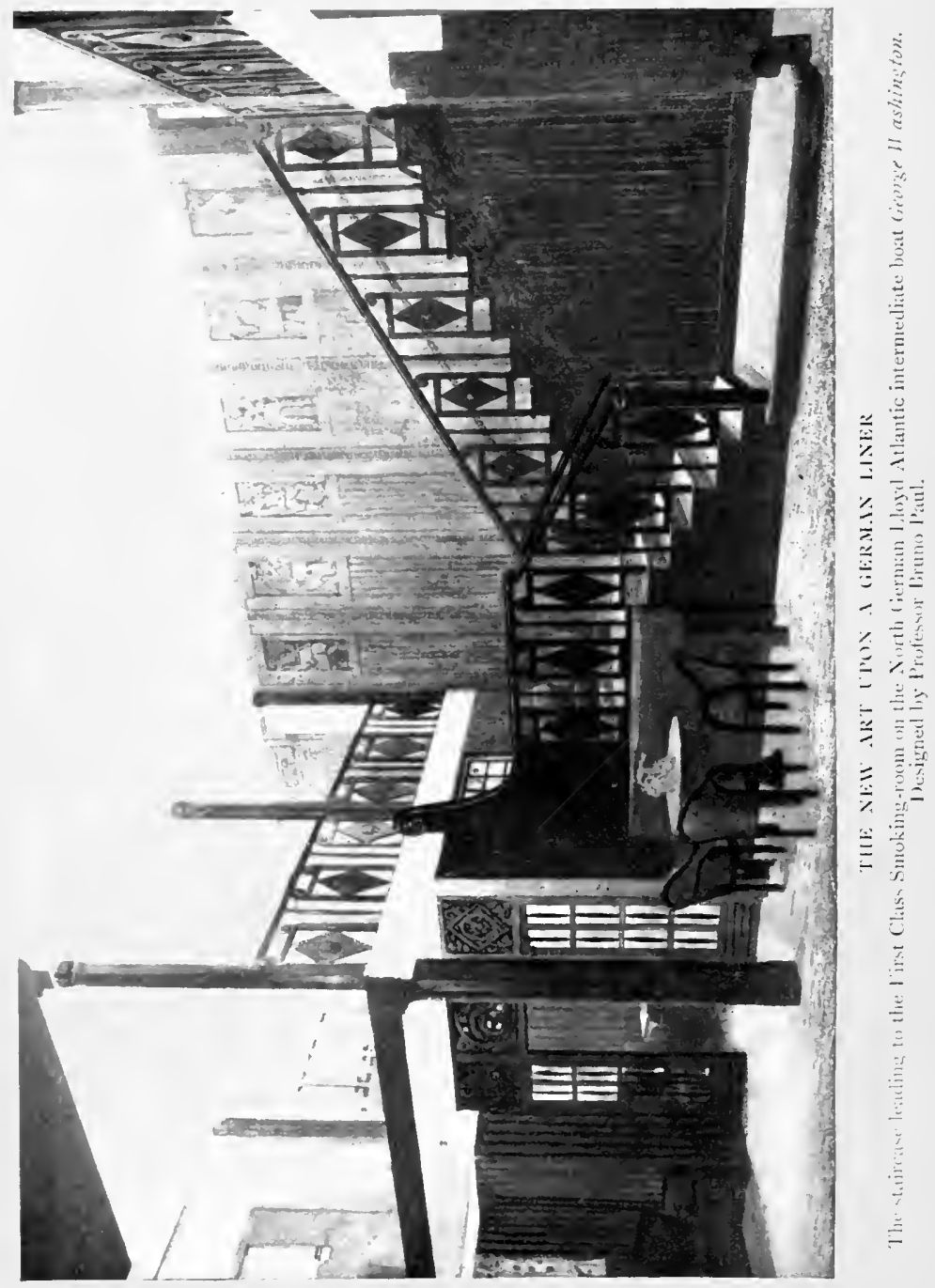


struck became a source of danger. It was all very well to divide the hull into compartments by the aid of bulkheads, but these protective walls had to be pierced with openings to permit intercommunication. True, these openings were provided with doors which, when closed, converted the bulkhead into a solid whole, but the doors had to be shut by hand. This was the vulnerable feature in the idea. The human factor is never dependable, especially in time of dire emergency, no matter how thoroughly and persistently it may be drilled. The sinking of the Bourgogne emphasised this point. When the Cromartyshire drove into her, ripping open her hull as if it were paper, the black squad made a mad rush for the decks. In their stampede the stokers forgot all about the water-tight compartment doors; they left one and all open, allowing the incoming water to complete its fell purpose. Had the crew below not lost their heads, it is probable that the wounded liner would have kept afloat, at any rate for a sufficient length of time to have enabled every one to have made good an escape.

This terrible disaster illustrated the fallacy of depending upon the men to close a bulkhead door. Accordingly efforts were made to perfect a system of accomplishing the desired end by mechanical effort controlled from a central point. The Norddeutscher Lloyd Company, in collaboration with the Deptford engineering firm of Stone \& Company, embarked upon a number of experiments, whose scope was the perfection of a system which would answer the danger call instantly and thoroughly, and be proof against tampering. Investigations were crowned with success, and the Stone-Lloyd automatically closing watertight doors have become indispensable in every liner worthy of the name and where safety is considered. Numerous other devices to the same end have been evolved, but they have failed to withstand the tests of experience, and to-day the Anglo-German system stands supreme and is in universal application.

When the system was first introduced upon the Kaiser 
Wilhelm der Grosse in I897, the innovation was regarded with mixed feelings by the crew working in the depths of the ship. They did not feel secure with a system of shutting the doors from the bridge. The less enlightened feared that the doors would close and shut them in to drown like rats in a trap. It took some time to convince them that such a result was quite impossible. It was pointed out that even if the door did descend, those within had only to turn a handle to raise it and effect their escape, and the door would close upon them directly under its own power. One or two antagonistic spirits refused to be satisfied upon this point even by demonstration. In their own wisdom they sought security by propping up the open doors. But they were defeated in this ingenious scheme, as when the power was applied from the bridge, and the propped doors naturally failed to close, the captain was able to locate the latter from the indicator on the bridge. When the captain and engineer appeared before the refractory doors and the reason for their inaction was apparent, those responsible for disabling them received a few straiglit words with threats of penalties that would be meted out if they practised the subterfuge in future. The more enlightened men in the stokeholds realised the meaning of the safety appliance, as well as the fact that they were quite secure from imprisonment. So by a little hammering were able to infuse feelings of security into their denser colleagues. In a short time all antagonism to the new notion was overcome.

The water-tight door ranks as one of the greatest contributions to the unsinkability of a vessel that ever has been made, especially as it is quite free from complicated or delicate mechanism. Its principles may be grasped by an engineer in a few seconds; there is practically nothing to get out of order. The crew also may become familiarised with its main features and working without effort.

Although no mechanical device can be made infallible, the advantage of this invention is that should anything go wrong with the operating mechanism, the doors imme- 
diately close and remain in that condition until the apparatus has been repaired, although the members of the crew are able to pass to and fro without hindrance, merely by turning a wheel to open the door.

The evolution of the device entailed prolonged and laborious research to ensure reliability, instantaneous action, simplicity, and automatic operation. Various systems of power, such as compressed air, electricity, steam and hydraulics, were tested searchingly, but it was ascertained that, from the all-round point of view, the lastnamed method was the most satisfactory. Since the original system was introduced continued investigation has resulted in greater perfection being obtained, and the device as it stands to-day is conceded to be perfect in its design, purpose and working.

Extending throughout the ship is a hydraulic main communicating with every door. The pressure in this main is maintained by means of two pumps, placed in a convenient position among the auxiliary machinery. These two pumps are always working, so that the doors respond to the action of the control lever instantly. The pumps are in duplicate, so that should one fail or be thrown out of service, the other is quite capable of fulfilling all requirements. These pumps charge a large tank, or accumulator, as it is called, from which the pressure of water is maintained in the operating main. The control itself is placed on the bridge, and all that is required is the depression of a lever on a pedestal dial. From fifteen to twenty seconds after the movement of this handle, every door throughout the ship is closed, and the vessel is made watertight from end to end. As the doors descend, an electric gong, attached to each opening, emits a sonorous blare, warning all those who may be in the vicinity to stand clear. Thus, while the ship is travelling, should the officer on watch observe an unavoidable danger ahead, he can at once protect the ship by closing the whole of the doors, so that at the moment of the impact the ship is watertight throughout. 
Suppose the menace, be it another vessel, a derelict, rocks, or iceberg smash through the hull, the doors are kept closed to confine the incoming water to the damaged compartments. The ship draws clear, and search is made then for the extent of the injury. I'hen this has been determined the flooded compartments may be sealed, and kept in that condition until port is reached. All that is necessary is to screw up a valve outside each door of the damaged compartments, and then the bulkhead is made as solid as if there were no doorway. This not only renders it impossible to reopen the door leading thereto, but also disconnects it from the remainder of the system. The commander then lifts the lever on the bridge, when all the doors, except those detached, open simultaneously.

The doors are solid masses of steel, driven down through heavy spur gearing with a force of two tons. This enables the descending mass to crunch through coal and other obstructions with as much ease as a knife will cut through butter in summer. A special type of door has been devised for working in connection with the coal bunkers. This has an angular motion, and is fitted with a knife-like edge, so that it is able to cleave its way through the lumps of coal as if they were putty. In other cases, owing to lack of space to fit the vertical type of door to the bulkhead, it is made to slide horizontally, but in every instance the power exerted and the resultant effect are the same.

On the bridge, over the control handle, is a small indicator, resembling that employed in connection with electric bells. On the dial is a plan of the ship, with the exact position of every door, and each of the latter is represented by a small circular orifice, behind which is a telltale inscribed with the number of the door to which it refers. As the door closes the number comes into view, but should any door fail to respond to the movement of the lever, the number is obscured, and the captain is able to ascertain at once why such and such a door is not closed.

The control is effected from one point, and one point only -the bridge: and no one, except the commander or officer 
on watch, can either close or open the doors, except temporarily to pass to and fro. Even the independent opening of any door for this latter purpose is intimated on the bridge indicator, so that the captain has the exact condition of the doors throughout his ship before him constantly. It may happen, however, that certain doors, for reasons of general convenience, either shall remain closed or only partially open, when the others are fully extended, and the control lever is raised on the bridge. This requirement is often necessary in the case of the doors to the refrigerator rooms and the coal-bunkers when the fuel is piled up against the door. The necessary adjustments can be made at each of the doors in question to meet the end in view, and so arranged that they can be opened locally, as and when required. But the moment the captain applies the pressure from the bridge, the doors throughout the ship must close. Under no circumstances whatever is it possible for any door to remain open or partially open all the while this pressure is maintained, unless wilfully propped open, and this fact, as already mentioned, is communicated instantly to the navigator by the indicator.

The men working within the compartments are fully secured. When the door has closed they can pass out leisurely, despite the pressure being maintained. All that they have to do is to operate a small control-one is placed on either side of the door to enable passage in either direction. The door rises easily, and the man passes through. He does not have to close the door behind him ; the moment he releases the control the constant closing pressure applied from the bridge asserts itself immediately, and the door runs down automatically with a force of two tons. The value of this local operation of the door has not been lost upon the crew. They realise that under no circumstances whatever can they be caught like rats in a trap. Consequently there is no inducement to tamper with the mechanism, and in fact such action, if it were attempted, would be resented by the majority of the men themselves. 
This is the outstanding feature of the Stone-Lloyd system. It has the confidence of the men working far below the waterline, and accordingly they respect it; but they would entertain very different ideas if no such local temporary automatic control were placed within their hands.

There is another point which should inspire the public travelling on a boat fitted with this system. In times of danger the commander can proceed on his way with his ship water-tight from end to end by closing every door. When enveloped in a fog, when navigating dangerous channels, or when threading a tortuous way through water crowded with traffic, and where the dangers are extreme, the captain can shut down every door, and then all his bulkheads are as if they were built solid. The doors might be left closed for days and nights at a time, merely by keeping the control lever depressed, the hydraulic pressure being maintained fully meanwhile. No inconvenience is caused to the army working the vessel: intercommunication is not interrupted. The advantage of this facility is obvious : it imparts a greater degree of safety to the ship and its hundreds of inhabitants.

The simplicity of the system lends itself to frequent testing. The captain is able to ascertain the efficiency of the doors at any moment. The operation of closing and opening may be completed within sixty seconds. This is a factor which ensures the system being kept in the pink of condition, with certainty of action when the crisis arrives.

The only danger attending the employment of an hydraulic system is from frost. To mitigate this evil to its smallest dimensions a special non-freezing compound is used, which not only accomplishes the avowed purpose, but which also tends to keep the integral parts of the mechanism in first-class condition. One great advantage of the hydraulic system is that should any leakage occur it can be detected easily and quickly by the escape of the fluid, which is not so simple a task either with electricity or compressed air.

The system also can be rendered automatic if desired. 


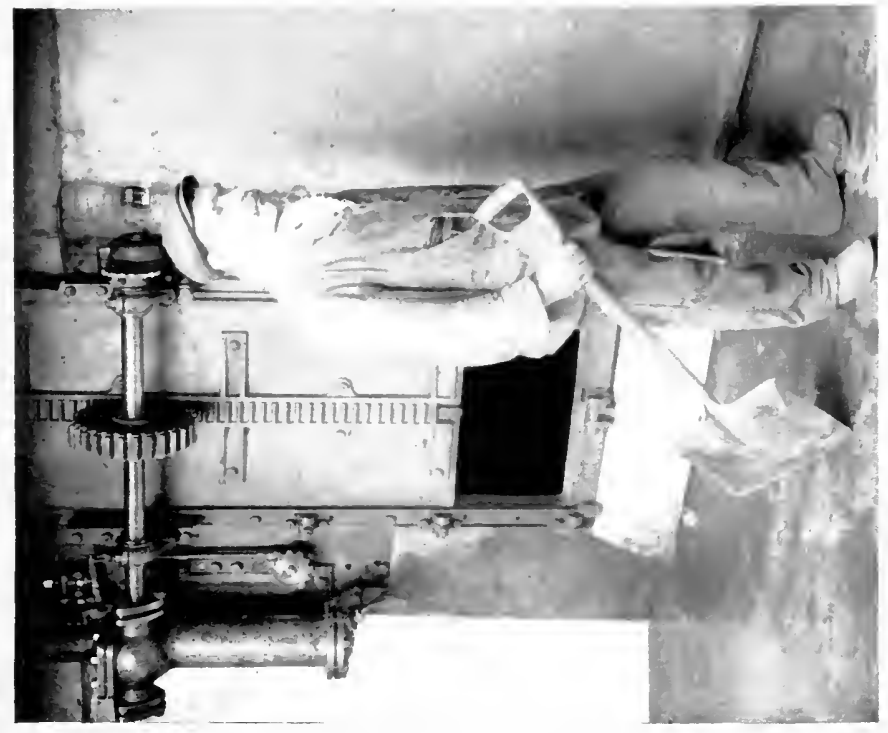

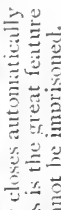

家芯

至言

跤

言先

政

8

$=$

管=

产要

政

严莽

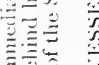

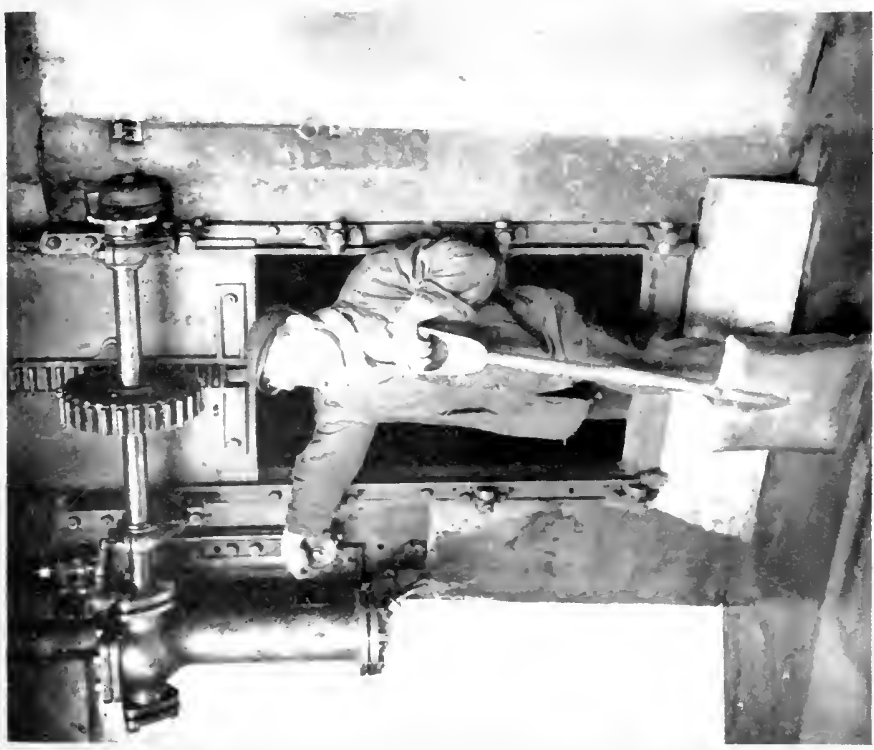

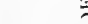

$\rightarrow \quad$

$\stackrel{n}{\Xi}$

政

至

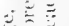

言美

恶

三

$5 \div \equiv$

要

政

政

次

三

= 


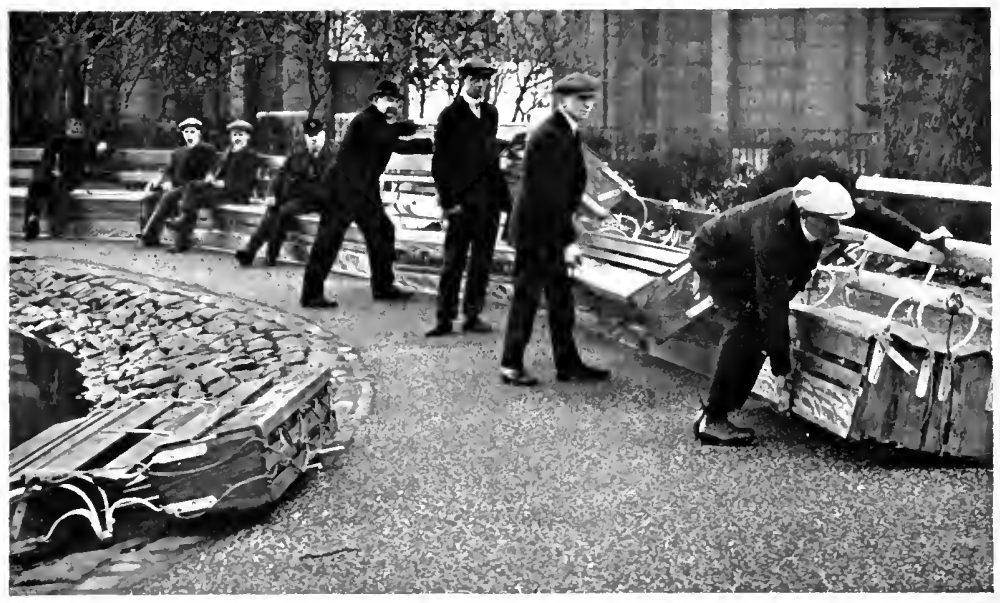

I COMBINED I.LFE-SIVIXG DEK SEAT

The ingentows Linkleter seat, which can be intantaneondy loumened, and which fiatteris unt to matie an excellent ratt.

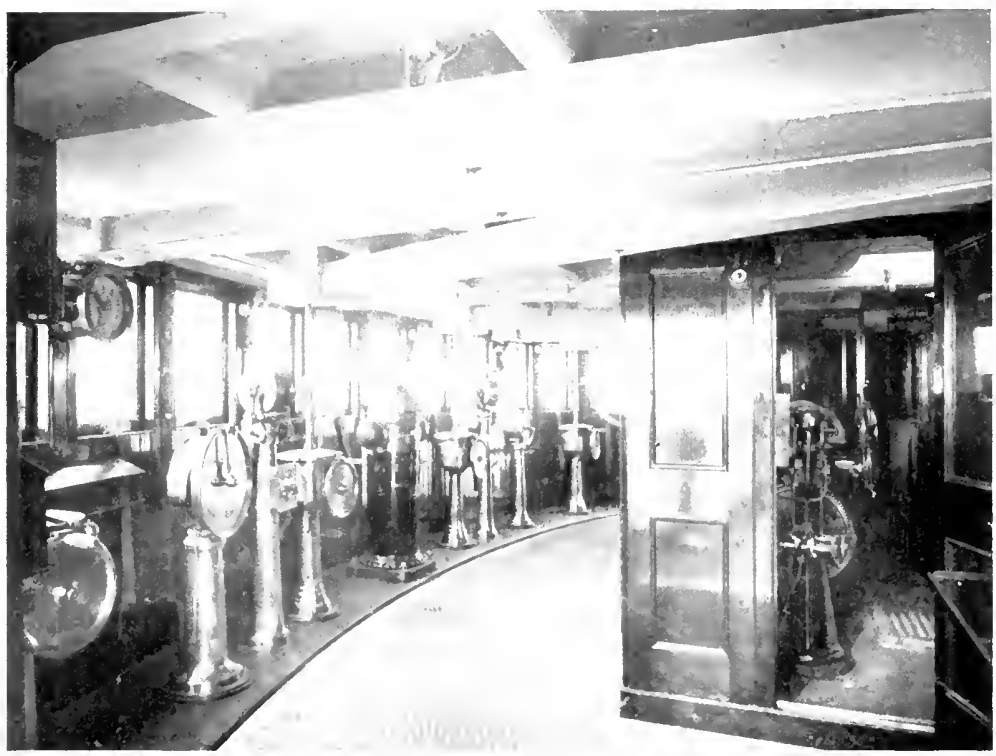

THE IRRAX QF THE SHIP

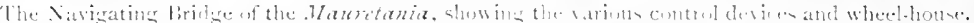

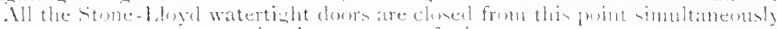
by the presure of at leser. 
For this purpose a bilge float is employed. Should any water penetrate the vessel unknown to the crew, this, when it has attained a certain level, naturally lifts the float. The latter has previously been set at a point, and when disturbed automatically closes the door of the compartment and simultaneously the officer on the bridge receives intimation of the circumstance by the tell-tale number referring to the affected compartment coming into view upon his indicator. Seeing that such a contingency in a modern liner is very remote, the float gear is seldom incorporated, as the devolution of responsibility upon automatic appliances, which have an unhappy tendency to go wrong at a critical moment, is not to be recommended. Moreover, the introduction of such auxiliary measures tends to complicate an otherwise simple apparatus.

Once the idea was perfected the German steamship company, realising its advantages, forthwith incorporated the system in their new boats, and the additional security thereby afforded was not lost upon the travelling public. For a time British and American shipping companies held aloof, but the success of the German applications induced them to follow suit. The Teuton shipowners have not only applied the system to their new vessels, but are converting their existing craft as well. Practically the whole fleet of 700,000 tons flying the North German Lloyd flag is protected in this manner. The Kronprinzessin Cecilie has 52 water-tight bulkhead doors, 24 of which are fitted with this apparatus; while the Lusitania and Mauretania are fitted with 36 doors acting upon this principle.

At the moment it is doubtful whether any vessels afloat so closely coincide with the term "unsinkable," or are so safe as the two crack Cunarders. In these liners subdivision and compartmenting have been carried to the superlative degree on the most approved scientific lines. The question of subdivision was investigated very searchingly independently by the builders, by the owners, and also by the special committee that was selected by the Government in the evolution of the design. All the transverse bulk- 


\section{STEAMSHIP CONQUEST OF THE WORLD}

heads are carried up from the bottom to the level of the upper deck. Where it was found impossible to take the protection in a continuous vertical line the bulkhead is carried to the lower deck, and thence in steps to the upper deck, achieving exactly the same end as if the bulkhead were a perpendicular wall. The protection of the engineroom and the longitudinal bulkheads are particularly noticeable. The boilers, as described in another chapter, are set across the width of the ship, and divided into four groups by intervening bulkheads. On either side there is a longitudinal bunker, reaching practically the full length of the boiler space, and for some 280 feet of the total length of the ship in the centre. The high pressure turbines are located in separate water-tight compartments, on either side of the vessel, with the low pressure turbines occupying a third compartment between the two.

Altogether there are no less than 175 water-tight compartments, and it is safe to assert that subdivision has never been carried to such limits in a merchant vessel, either before or since. The disposition of the coal bunkers and their bulkheads running longitudinally have been appreciated, as in the latest French liner subdivision is carried out upon closely analogous lines.

Grounding is one of the greatest dangers to be feared with such large ships, and a misadventure where considerable damage may be wrought. Consequently the vessel is fitted with a double bottom, the two skins being spaced five feet or so apart in the boiler-rooms and holds, with an increased depth under the engine space, and continued up on either side to the bilge keels. Consequently it would be a bad accident which penetrated both bottoms; while if the outer wall were strained and broken, the water would be kept back by the inner skin.

It would be difficult to conceive an accident which would incapacitate or even sink the Cunarders. Had one of these twin ships met with the iceberg, instead of the Titanic, the chances are a thousand to one that she would have kept afloat, if not long enough to make port, at any rate for 
several hours, to permit her passengers to be saved. In the case of the Titanic, once the hull was penetrated below the waterline, there was nothing to prevent the ship being flooded throughout her complete width, especially if, as is surmised, a rent were torn along her side for a considerable distance, thereby inundating several compartments. In the case of the Cunarders, had the iceberg struck the ship anywhere below the water-line a long, ugly gash undoubtedly would have been inflicted, but the longitudinal bulkhead would have proved a difficult barrier for the water to overcome, while the coal lying between the bulkhead and the skin would have offered additional and appreciable resistance. The ship would have assumed a nasty list, without doubt, but, by the manipulation of her water ballast tanks this could have been minimised so that, except perhaps for settling somewhat lower than usual into the water, nothing abnormal would have been apparent externally.

Probably the bulk or tank oil steamer is the safest type of vessel afloat. These craft are subdivided extensively, both longitudinally and transversely, in order to split the cargo into small units. The nature of the freight handled demands that these bulkheads shall be exceptionally strong and tight, so that the contents of one space may not leak into another compartment, possibly containing a different grade of spirit. In addition to this "compartmenting" the ressel is divided into three sections by what are known as coffer dams, placed forward and aft of the oil carrying space. The coffer dam is really a massive, solid transverse bulkhead, or rather two bulkheads, placed from four to five feet apart, with the intervening space filled with water.

Extensive subdivision notwithstanding, ample provision must or should be made for emergencies. In other words, in the event of a vessel receiving such a fearful blow as to seal her fate, the passengers should have a sporting chance, at least, to save themselves. Unfortunately development has not lept pace with progress in this field. Is the 
foundering of the Arctic demonstrated the need for bulkhead subdivision, so the sinking of the Titanic illustrated the essential need of adequate lifeboat facilities.

The outcry following the disaster of I $19 \mathrm{I} 2$ is by no means new. It followed the wreck of the Elbe in the North Sea, was re-echoed after the disaster to the Bourgogne, and indeed has formed a popular theme for theoretical discussion after every stirring catastrophe. The regulations demand that every cargo vessel shall carry sufficient boats on either side to accommodate the whole crew of the vessel. On passenger liners, with possibly three thousand lives at stake, while such provision was more imperative, yet it was deemed absolutely impracticable. The provision of boats is not an easy problem to solve. The capriciousness of the ocean-going traveller is a severe stumbling-block. If boats sufficient to carry off every soul aboard were carried he would wail long and loud about deprivation of space in which to stretch his legs, or the forfeiture of some other convenience. When a calamity overtakes a liner he is just as vigorous in his criticisms, because a sufficiency of boats are not carried, assails the owner for lack of foresight, and condemns him on sight of criminal negligence.

Boats may be stowed aboard in sufficient numbers to meet every contingency, but that is not to say that every one can be launched when the emergency arises. It seems a simple operation to swing a boat over the side and to lower it into the water, but the panic of shipwreck upsets the best-laid schemes and calculations. Under these circumstances it is essential that the launching gear shall be of the very simplest and fool-proof design to cope with a stampede. Fortunately this end has been met by the ingenuity of a persevering investigator, Mr. Axel Welin, M.I.N.A. The davit and launching gear of this inventor have attained a deservedly world-wide reputation, since they are the acme of simplicity and the essence of reliability.

Launching a boat is not an easy task. Unfortunately a ship when she meets with an accident as a rule immediately cants to one side or the other. The result is that when the 
boats are swung over one side there is a short, straight drop into the water, while on the other side the bulging hull of the vessel thrusts itself into the way, and renders a clean fall quite impossible. Many ingenious minds have devoted their energies towards the simplification and perfection of this task, but with indifferent success. To-day the Welin davit ranks as the survival of the fittest, from whatever point of view it is considered.

It is known as the quadrant davit, for the simple reason that it works upon the quadrant principle. The davit comprises a metal arm which is pivoted on a travelling nut working in a frame fixed to the vessel's deck. The upper end of this swinging arm curved over the boat carries the blocks suspending it. The lower end of the davit is built in the form of a quadrant which has teeth engaging with a rack at the bottom of the supporting frame. The davit is operated by a crank handle and an endless screw, threaded through the travelling nut, with the result that when the handle is turned in one direction or the other, the quadrant rolls backwards or forwards along the rack, swinging the boat either out or in. When the boat is stalled, it is resting on the chocks on the vessel's deck, but directly the handle is turned, the chocks are knocked out of the way and the boat is swung clear. Once the boat is over the vessel's side it is a simple matter to pay out the two ropes, one on each davit, to allow the boat to fall until it reaches the water. Having received its load, the movement of a simple attachment cuts it adrift, so that the passengers may row clear of the ship.

The advantage of this system is its elasticity. It may so happen that the boat must be swung a considerable distance over the side, or perhaps it may be necessary to stow two boats side by side on the vessel's deck. In the latter event the davit is given a longer travel so that it can roll further inboard. The first boat can be picked up and lowered, and the quadrant then swung over to pick up the inner boat and to deposit it also in the water. 
The invention is not confined to one form, but it can be modified to meet all and practically every requirement. The boat which when slung inboard and permitted to rest upon the deck, owing to its width and bulk obviously occupies considerable deck space, which may be devoted profitably to better purposes. The inventor, Mr. Axel Welin, sought to remedy this drawback, and accordingly devised a conspicuous improvement, in which the upper half of the davit is of different design, being curved in such a way that the boat may be held suspended in a rigid position within the bend by suitable devices and chocks. In this instance the boat is carried in the air clear of the deck, yet just as ready for instant use as in the former and more generally practised method. There is no greater demand upon the manual effort to swing out and lower the boat, because the design is thought out so carefully that perfect balancing and simple powerful leverage are obtained to facilitate the various operations. Quite half the space required in deck stowage is saved, and in connection with a comparatively small vessel this is an important consideration.

When this simple and ingenious invention appeared on the market, naturally it was assailed with a whole sheaf of objections. Shipowners had become well wedded to the system, which, as one architect remarked, "had probably been in operation since the days of the Ark," and were tardy to depart from the orthodox. One objection took a very pointed turn. What would happen if the gear got frozen up? Upon this point the inventor could offer no conclusive reply, inasmuch as opportunities never had presented themselves to him to test its capabilities under such conditions. Besides, any boat gear would be rendered well-nigh inoperative with ice and snow clogging everything, and it is doubtful whether it could be got clear very quickly, if at all. However, one of the German companies decided to make an experiment. Two boats were fitted on this principle, and the captain received strict injunctions to get the gear frozen up if he could, and then to ascertain 
its workability or otherwise. The captain obeyed the injunctions to the letter, but it took him nearly two years to do it. Then he replied that before the gear could be brought into operation, he had to smash the ice on the frame base before it would work.

Scarcely had the report come home when it was announced that the inventor had met the new situation. The quadrant was fitted with teeth which, as the operating handle was revolved, were sufficient to crush all the ice collected upon the rack. This objection, so soon as it was proved, was overcome.

Other critics maintained that the system would impose heavy strains upon the deck. This fear was dispelled very conclusively. A 5,500 ton vessel was shipping coals on the Clyde, when for some reason or other she assumed an ominous list. The captain could only conceive one rapid means of restoring her to the normal position. The boats slung on the Welin davits, on the opposite side, were filled with water and run out. In this way a counterweight of sixty tons was obtained, and the boats were kept in the out-swung position with their loads, until the vessel's list had been corrected. The vessel's deck revealed no evidences of having suffered from the unusual treatment. This result effectively disposed of the apprehensions as to deck straining.

By means of the IVelin davit the boats in time of danger may be slung out in far less time than is possible with the ordinary davits, as comparative tests have demonstrated in no uncertain manner; while, when a vessel has taken a list, the boats may be run out and lowered with less risk of being smashed against the hull. In one instance where the liner had heeled over I I degrees, the boat was lowered into the water from the high side by this type of davit in 45 seconds. When the ship is rolling to a fair degree, it has been found possible to achieve the same end by the aid of four men in less than 60 seconds, without the boat suffering in any way. It must also be remembered that the possibility of the davit being swung farther inboard to pick 
up a second boat is another outstanding feature, as it doubles the capacity of the davit without the introduction of further complications, such as pushing the second boat towards the taffrail before picking it up.

Recently, the question has been discussed energetically as to whether the boats are not really carried upon the wrong deck. Liners have grown so enormously in height, that the practice of placing them upon the highest deck has introduced further difficulties, as well as the necessity for the passengers, in the moment of danger, to have to fight their way up four or five staircases. The Titanic disaster revealed the shortcomings of this practice, and accordingly on one of the latest gigantic liners the whole method is changed completely. The boats are carried by what is known as the overframe "Welin Lower Deck Davit" upon one of the lower decks. The advantages are obvious. The boats will be stationed at a more convenient centre, where the crush of passengers is certain to be greatest in time of panic, and at the same time will be placed nearer the water. Mr. Axel WVelin, furthermore, has introduced another distinct improvement in the form of a "Boat control." It comprises a system in which the winch governing the lowering and hoisting operations is actuated by a power-driven shaft. Each davit has a local control, and al! complications in the form of clutches, reversing gear, and so forth, are eliminated. At the same time the control is so simple that it can be operated literally by the little finger when lowering. Wire ropes are used in this latest modification, carried either in covered channels or across or underneath the deck. In the latter instance the control itself is placed beneath the deck. By this means increased efficiency is obtained, with a simplification of the apparatus, as well as certainty of action. Obviously, so far as the power-drive is concerned, this is only requisite for lifting the boat, as its own weight accomplishes the lowering action.

The ordinary type of lifeboat, being bulky, occupies considerable space, and obviously, if sufficient boats were 


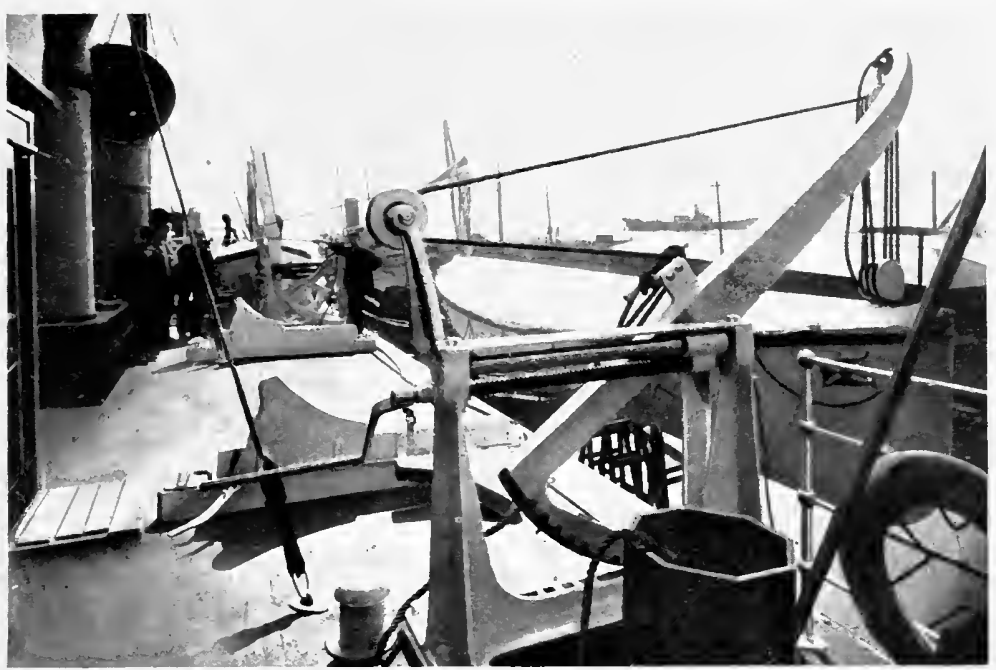

THE SIMPIEST ANI OUICEST BO.AT-LAEXCIING GE.R

The Welin Davit, showing boat swung out ; also toothed quadrant and rack.

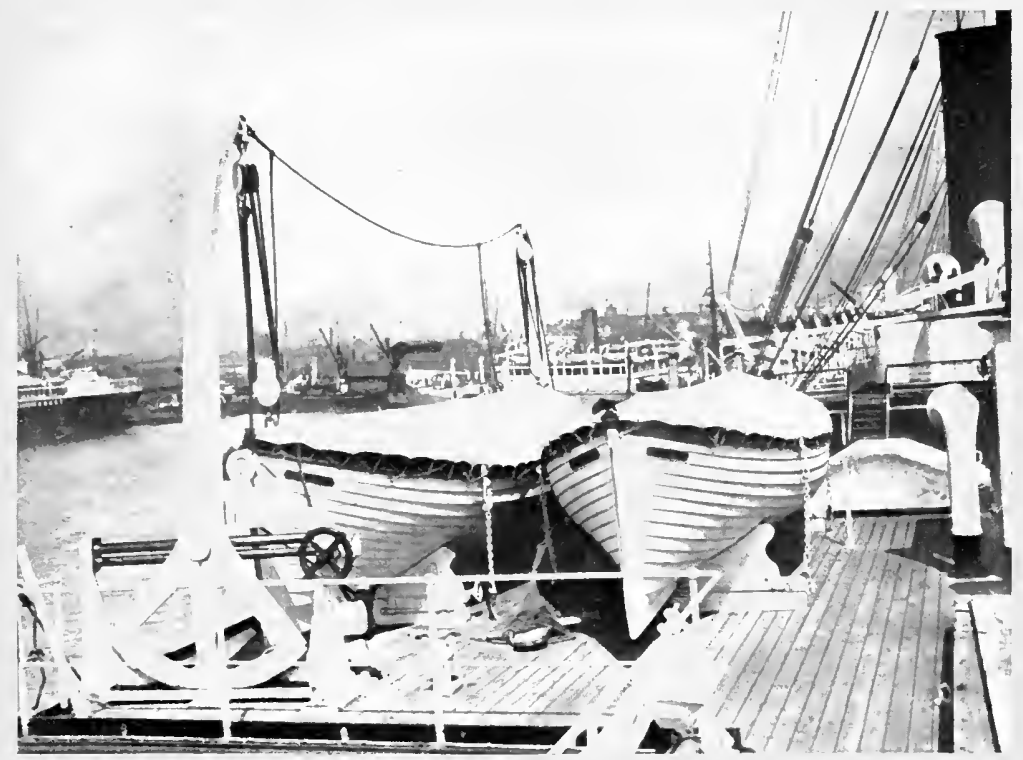

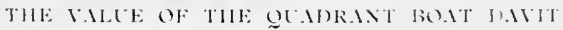

In outstanding fuature of the 11 elin invention in that two hata may he served ly one davit, thereby doubling it efficiency. 

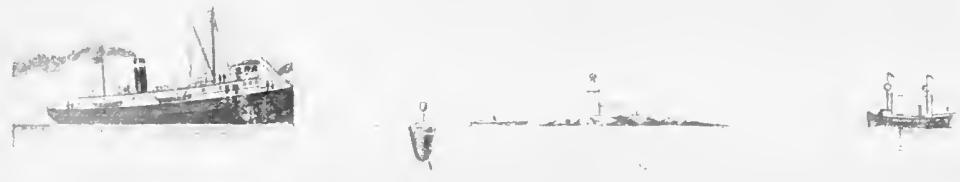

THE SLBMARINE BELL IN ISSE

Rung by electricity on lighthouse; by compressed air or other mechanical means on lightship;

by the motion of the waves on buoy. The receivers are placed port and starboard on board ship with communication to the navigating bridge.
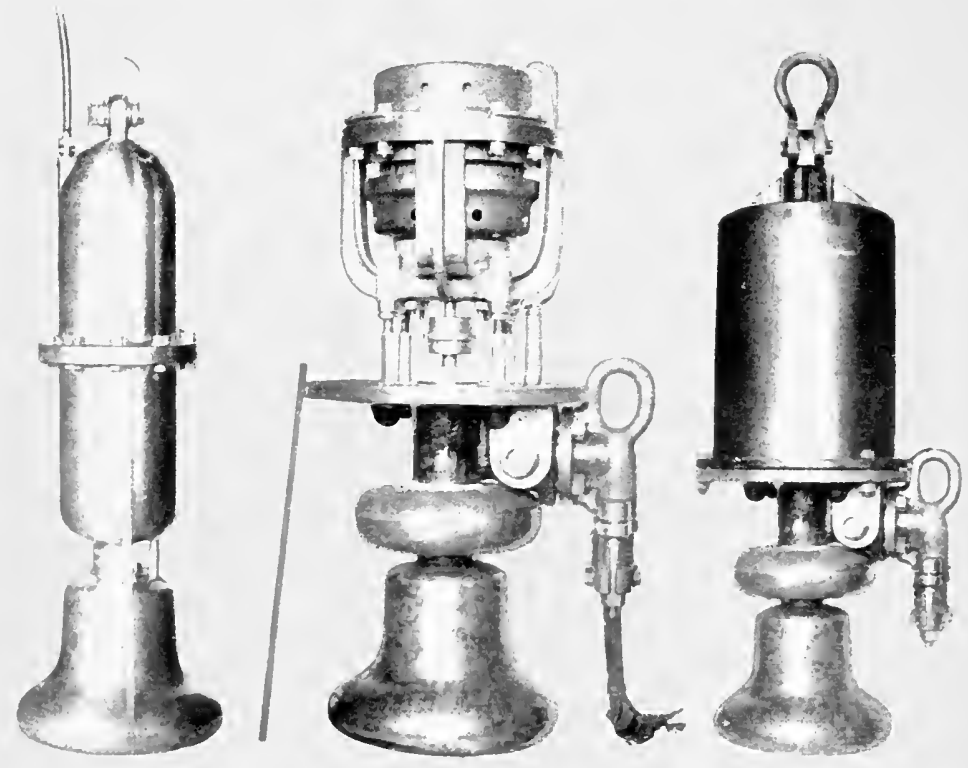

THO TYIRS UF THF SIBMIRIDE HEIL.

Compressed air hell at left used generally on lighthips. Interior of electric bell, showing operating mechanism, in centre; same lell complete at right. 
to be carried to cope with, say, 3000 people, the passengers would have to forfeit a very considerable proportion of the space on the deck, otherwise used for promenade purposes. This situation has been met by resort to collapsible and semi-collapsible boats, which, being light and capable of stowage within a small space, especially when nestedpacked one on top of the other-enable sufficient boats to be carried to take off every passenger and member of the crew. Rafts have been devised also, but the generally conceived device of this character is practically useless, especially in a sea, as it is liable to be broken up by the waves. Then it is essential that as little space as possible on board ship should be occupied by articles which cannot be turned to account when not in use and without impairing their designed purposes. The Linkleter life-raft deckseat is an excellent means of placing the practical to profitable advantage. On board they resemble the conventional deck-seats, with their backs. They measure about nine feet in length, and each is fitted with four metal air cases to secure buoyancy. As a seat it is secured to the deck by a lashing over a hooked hinge-pin at either end. When the front half of the seat is lifted upwards the hooks are upset and the seat is released, at the same time flattening itself out. Another point is that should the deck upon which the seat is placed become submerged, owing to its buoyancy, the front part of the seat immediately floats upwards, turning round the attaching hook so that the seat comes adrift and floats to the surface in the form of a raft. The novelty of the device is the elimination of the necessity to release the seat and to flatten it out by hand.

Another Linkleter life-raft, which has been adopted upon the Canadian Pacific liners, is that adaptable to either sailing or rowing. The little deck is supported on either side by a cigar-shaped cylinder. Each raft has twelve distinct air-cases, and this is adequate to carry forty persons and to support as many others as can cling to it. In this instance either side of the raft serves equally well as the supporting deck. No care is necessary in throwing it 


\section{STEAMSHIP CONQUEST OF THE IVORLD}

overboard, because either one side or the other must be exposed, since it cannot float edgewise.

The lessons of the marine disaster of 1912 have not been allowed to pass unheeded. All the great passenger lines are carrying a sufficiency of life-saving appliances to meet every demand. The French liner France, for instance, though comprising a floating community of 2,500 souls, is fitted with 22 large and 2 small life-boats, together with 32 life-rafts, sufficient to carry in the aggregate 2,788 persons.

Yet all the devices to prevent loss of life are not to be compared with means of avoiding danger. The two greatest achievements in this direction are the submarine bell and wireless telegraphy. Both have rendered ocean travelling incalculably safer than it was ten years ago.

Sounds transmitted through the air are subject to extraordinary aberrations, and this factor renders dependence upon syrens, gun-cotton detonations and whistles from lighthouses and lightships, or other vessels, during a thick fog, utterly unreliable. The sounds may reach the ears of the commander of a liner groping through the fog, and be so faint as to lead him to conclude that he is well clear of danger when in reality he is right upon it. On the other hand, the reports may be so loud that he is induced to sheer off, when as a matter of fact there is no necessity for him to alter his course. Yet a sound produced under water can be heard clearly and distinctly a considerable distance away, and is not subject to any interference or aberration during its transmission.

This idea of warning the mariner occurred to a young American scientist, Mr. A. J. Mundy of Boston, who subsequently secured the collaboration of a famous American physicist, Professor Elisha Gray. In the first experiments they were content to use the bells which serve various purposes on land, but these were found to be useless. As a result of four years' ceaseless investigations, they discovered that a somewhat high musical note which, useless in the air, when submerged produced the best tone-carrying 
characteristics. A bell weighing a thousand pounds was fashioned and submerged off a cruel stretch of the Atlantic coast in sixty feet of water $I, 500$ feet from shore. It was connected to the latter by an electric cable, and was in service for a whole year. It was eminently successful, although as a result of further tests it was found possible to secure equally efficient results with a smaller and much lighter bell, the tolling of which could be heard sixteen miles away.

Another difficulty experienced was in connection with the detector. On board ship so many and varied local sounds are produced-“"ship's noises," they are calledthat it was found difficult to sort out the tone of the bell. This really proved to be the most difficult part of the invention to solve satisfactorily. Mr. Mundy, however, by means of a simple experiment succeeded in establishing a point which proved to be the crux of the problem. He took an empty kettle and within it placed a tumbler, filled with a chemical solution he had made, and also a very sensitive microphone. The tumbler was so placed that it was in contact with the wall of the kettle. The kettle was floated at one end of a tank, and a bell was rung under water at the opposite extremity. The tones of the bell were heard distinctly. The experimenter then removed the microphone from the tumbler, and fixed the microphone to the kettle's side. On this occasion the sounds of the bell, although heard, were very faint. Obviously, as this simple experiment showed, the peculiar solution within the tumbler and its position played an important part in collecting and intensifying the sound.

In determining the correct position for the detector on board ship it was therefore necessary to select a point where the "ship's noises" offered the minimum of interference. Then it was discovered if the solution contained in the microphone receptacle were of greater density than the surrounding sea water, and the microphone were tuned to tones of high pitch and not low vibrations, that the tone of the bell could be heard quite distinctly and free from the 
local sounds. The latter apparently pass along the hull of the boat, and do not enter the microphone apparatus at all.

Two detectors or receivers are used. They are placed in the bow, one on either side of the ship, and are attached directly to the plating of the hull. A wire leads from each detector to the bridge, and this is connected to a receiver, similar to that of the ordinary telephone. The navigator either may apply the receivers to his ear and thereby locate from which side the sounds are received, or he may consult an indicator, which fulfils a similar purpose. If the officer in the former case faces the bow, and by listening at the receiver ascertains whether the warning is audible, say, to the right side, but cannot be detected from the receiver attached to the left-hand side of the ship, he learns that the danger spot is on his starboard, and vice versa if the left and not the right-hand detector emits the warning. If the sounds are to be heard from both detectors, then it is evident that the ship is driving headlong into danger. In the most approved forms the sounds can be picked up quite easily from a distance varying between sixteen and twenty miles, so that the navigator receives ample warning of his peril.

Directly the invention demonstrated its reliability and positive indications, it was adopted widely. To-day the submarine bell signalling apparatus forms an important part of the equipment on every large liner, and never yet has led the mariner astray. The bells have been improved vastly, and may be operated either by electricity or compressed air, or mechanically. It has come to be regarded as an indispensable adjunct to lightships and lighthouses, and also in connection with buoys, the tolling of the bell in this instance being carried out by the motion of the waves. While the signal cannot convey any intimation as to how distant the ship is from the danger, yet a captain is able to determine whether he is approaching or clearing the peril by the varying intensity of the sounds. Naturally as he draws closer and closer the warning becomes more and more distinct; while on the other hand, when moving 
away it grows fainter and fainter, until at last it is lost altogether, through the ship having passed beyond the audible range of the tolling.

After all is said and done, despite the elaborate precautions which the ship designer, builder and owner take to secure complete safety at sea, the public has the final word. Speed and comfort are now the ruling considerations, and the traveller is prone to grumble if a vessel is a few hours late, or there is any interference with his convenience. A disaster horrifies the world, and a panic ensues in which the most extreme and impracticable measures are demanded. Fortunately, the public memory is short. There is a check, and a popular outburst for a few days. Then the world settles down to things as they were before the calamity, content to depend upon the sharp eye and steady hand of those entrusted with the vessel's safety. Meanwhile those responsible for the creation and management of these speedy ocean monsters are quietly seeking to eliminate dependence upon the human factor more and more, because they are fully alive to its fallibility. On the other hand, the public must be prepared to bear its full proportion of the risk, and must not complain when occasionally the penalty for speed and luxury is exacted. 


\section{CHAPTER VIII}

THE FLOATING TOWN

ReFerence is made so often to the modern liner as a "floating town" that the average person has come to regard the description in the light of a synonym or colloquialism. As a matter of fact the term is as correct in the actual as in the figurative sense. Many a rising township would be proud to boast a population which one of the foremost liners often carries. If a census were taken of the ships speeding simultaneously between North America and Europe, for instance, it would be found that the aggregate of floating inhabitants would not be far short of 40,000 in the height of the season. A similar count among the ships plying between Europe, the Antipodes and other parts, and afloat at one time, would show a total approaching roo,000. These figures appear to be huge, but that they are under, rather than over, the mark may be realised from a little reflection concerning the carrying capacity of the largest of these craft. The passengers of all classes alone represent a total ranging up to 4000 , while the army required for the handling of the floating island may be anything between 700 and $\mathrm{I}, 200$ in number. It is no uncommon circumstance for eight of the crack Atlantic liners when afloat at one and the same time to have nearly 20,000 people distributed among them.

But the vessel bears a still stronger resemblance to a modern town than mere population conveys. Here in one corner of the steel hull is an electric lighting station, capable of supplying sufficient energy to meet the demands of a town of IOO, 000 people; in another corner is a complete refrigeration plant keeping cold storage houses going; in another part are the waterworks supplying fresh soft water 
for a thousand and one purposes. In a fourth quarter is the fire station, while on a lonely stretch on one of the decks is the isolation hospital for infectious diseases. One saunters along deck, and, desiring a cup of coffee or a whisky-and-soda, drops into the marine counterpart of the luxurious café of the city. Or perhaps one fancies a chop. There is the grill-room, excelling in comfort and luxury the finest restaurant to be found on dry land. In fact, every convenience, with the exception, perhaps, of a trolley tram-car, motor-omnibus, and golf-links, is found upon board ship.

Each of these public facilities possesses its individual interest, and more than half of them are concealed from the traveller's eye, being buried in obscure parts of the vessel's gloomy depths. It seems impossible to be able to accommodate in a small space on the Mauretania an electric station which would do justice to a town of 100,000 people, but such is the case. If one remembers that electric energy has to be supplied to no less than 6000 electric incandescent lamps, each of i6-candle power, all of which may be burning at one moment, then doubt gives way to wonder. In the case of this particular liner the electric lighting station is not in a suburb, but in the auxiliary machinery-room. Here there are four Parsons turbo-generators disposed in two water-tight compartments, so that should one room be flooded the other may be kept going. Each of these small machines makes 1,200 revolutions per minute to develop 4000 amperes at i Io volts. The large switchboard is divided also, so that, should any accident befall one half, the other still may be kept in operation, the ship thereby being spared a sudden transition from dazzling brilliancy to inky darkness. The switch-board is of the most modern description, and could not be rivalled in any land station. From these panels no fewer than 250 miles of cables of all sizes and character, varying according to the work to be performed by the energy conveyed, radiate to all parts of the ship. In these Cunarders, besides the lighting of the lamps in the private and 
public rooms, as well as the engine-rooms and stokeholds, facilities are provided for working a 24 -inch searchlight, since it must not be forgotten that these two vessels are intended for use as auxiliary armed cruisers in time of war.

But electric lighting is only one convenience operated by this handy source of energy. Distributed throughout the ship are a thousand and one electric motors of all powers and sizes, from a $\frac{1}{4}$-horse-power motor driving a bootcleaning machine, to a 50-horse-power motor actuating the fans which supply the forced draught to the furnaces. The hoists which lower and raise the passengers' luggage from the deep holds, the elevators, ventilating fans-in short, everything possible of movement by power is operated by this means. Electricity is the maid-of-all-work on board the modern ocean greyhound.

In the olden days the water intended for domestic purposes had to be carried aboard in barrels or stored in tanks, somewhat after the practice with railway trains. Such a method, however, would be quite impracticable nowadays, when some 3000 passengers and crew demand attention, because, on the basis of only 30 gallons per day per passenger, some joo,ooo gallons of fresh water, representing a dead weight of over 2000 tons for a six days' voyage, would need to be stowed somewhere or other on board the ship. Moreover, fresh, or distilled, water is required for the boilers for the purposes of steam, and obviously it is quite impossible to carry a reserve on board for all these purposes. The engineer has devised ways and means of drawing all requirements in these directions from the ocean itself by evaporating and distilling machines, so that the modern liner carries a complete waterworks. This installation upon the Mauretania is able to supply no fewer than 18 ,ooo gallons of drinking water and I5,000 gallons of water for washing and bath purposes during the 24 hours, so that so long as the pumps and plant can be kept going, there is no danger of the ship running short of this essential commodity. 


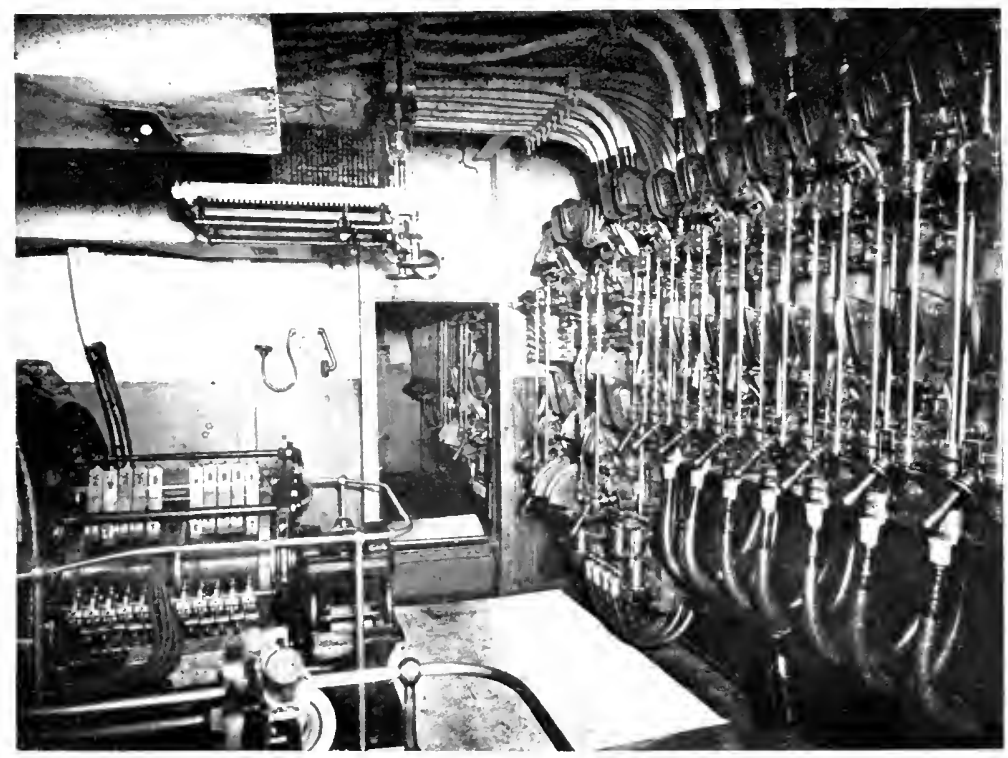

THE ELECTRIC LIGHTIXG STATION OF TIE FIOATIXG CITY The power-room and switchboard of the Lusitania.

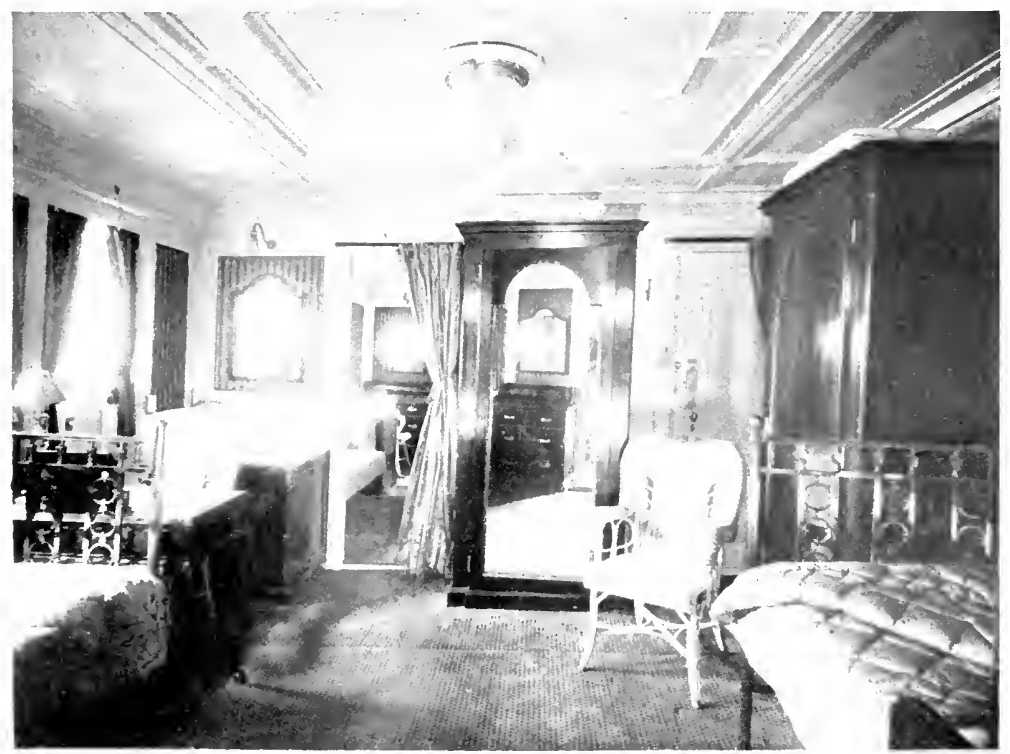

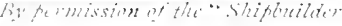

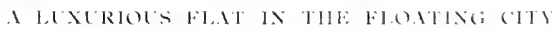

A regal suite on the Mantetania. 


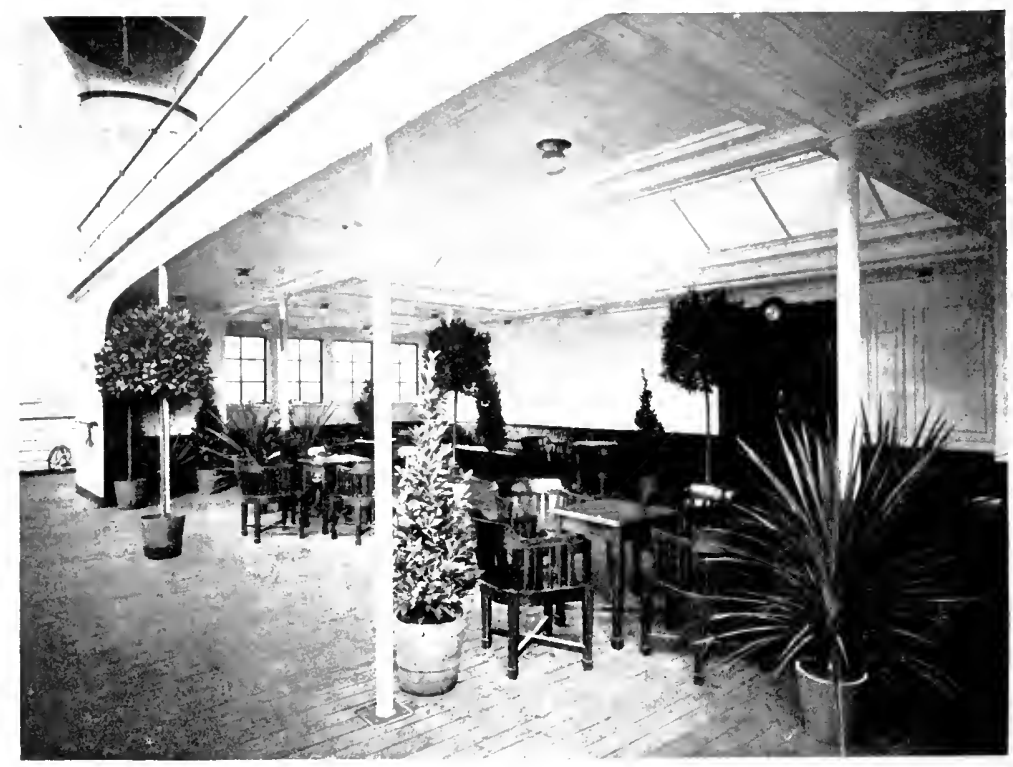

THE VER INJMH C.ME

The most popular coner on the Mauntanias decks. The evergreens

convey the impression of shore comforts.
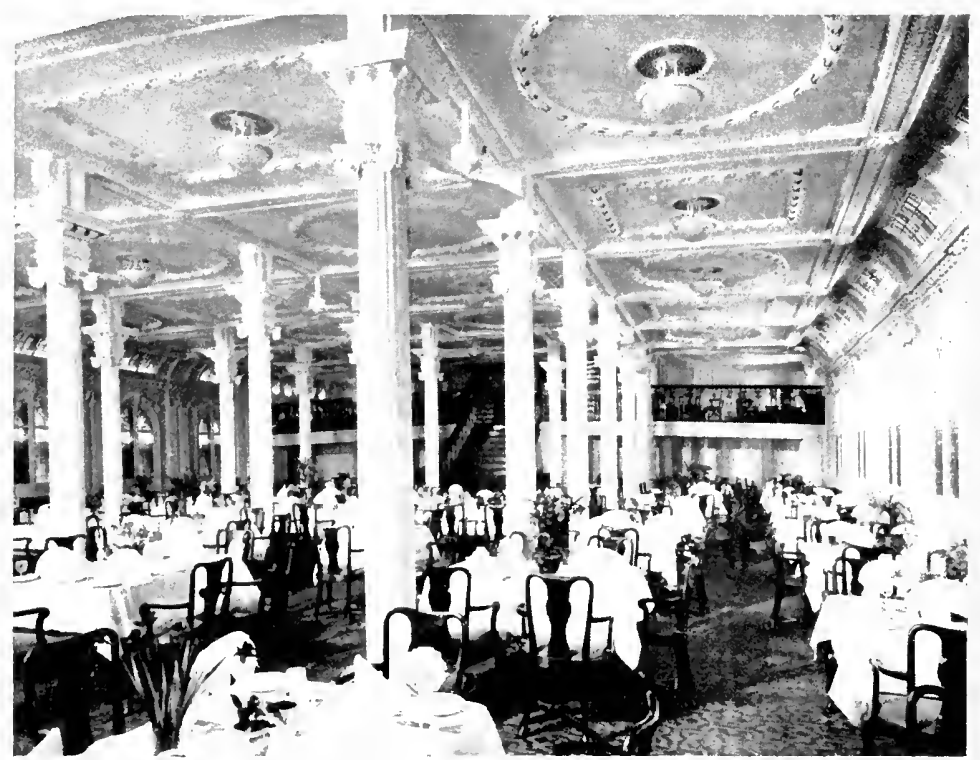

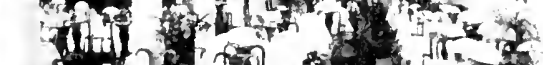

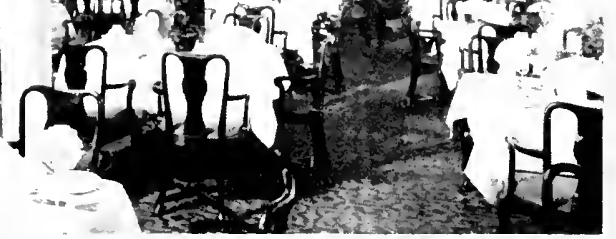

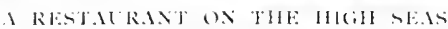

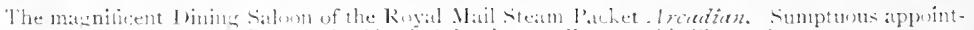
ment in not confined to the Nurth. Itlantic trabeller as this illustrattion proses. 
Gone are the days when fresh meat, vegetables, milk and other comestibles were impracticable, even on the shortest voyages. The liner of to-day carries a complete cold-storage equipment, where every description of perishable comestible may be kept in the pink of condition. The cold chambers are insulated with granulated cork, or some other suitable medium, and here carcasses of beef, mutton, poultry, game, bacon, also milk, fruits, vegetables, as well as malt liquors and drinking water, may be kept preserved at any desired temperature. The ingenious mind that first conceived the means of keeping these chambers at a low temperature for preservation bestowed an incalculable boon upon the travelling public. It is possible now to enjoy a varied menu in a tropical sea, hundreds of miles out, composed of dishes as fresh as are to be found upon dry land anywhere. I have been in the cold storage rooms when the thermometer has registered $100^{\circ}$ or more on the open decks above, and collected snow from the pipes around the chamber. The vegetables are as crisp and cold as are to be found in any market garden in the middle of winter, the leaves breaking like glass; while the meats appear as fresh and brightly coloured as if they had just emerged from the slaughter-house, although, possibly, they have been on board for a round week or two. The gourmet wanders through the ten or twelve dishes on the menu, comprising every type of edible, and marvels at the juiciness and flavour of the viands, but it is doubtful whether he ever gives a thought as to how his epicurean tastes are met in mid-ocean, and in a broiling climate. He calls for a bottle of nutty, full-bodied wine, and enjoys its refreshing coolness with eminent satisfaction, but regards its condition as a mere matter of course. If he is asked how they contrive to keep the liquid so cool, he merely replies nonchalantly, "Oh, on the ice!" never giving a thought as to how the ice is obtained, or retained, on board a ship. Verily he owes a debt of gratitude to the inventor of the refrigerating machinery which is humming away merrily in the engine-room below, pumping the temperature- 
reducing and preserving brine through the coils of pipes distributed round the cold-storage chambers.

When a passenger on the top deck wishes to make an inquiry of the steward, purser, or some other official, or wishes to converse with a travelling companion residing two or three decks below, or at the other end of the ship, he does not embark upon a doubtful hunt afoot for his quarry; he merely picks up a telephone receiver in his room and calls up the exchange, buried somewhere in the depths of the vessel. He communicates his wishes to the "hellogirl," and in less than a couple of seconds is switched through to the individual with whom he desires to talk. The telephone is one of the latest conveniences placed on board ship, and now that decks are lengthy and numerous, and the search for officials or other cabins is no easy matter, it undoubtedly constitutes a far-reaching convenience. When the ship reaches port, the liner's telephone system is joined to the network on land by means of a flexible connecting link, and passengers on board are brought into direct touch with any subscriber ashore, either locally or upon the trunk systems. Thus the financial magnate sailing from Liverpool can keep in conversation with his office in London, or while at New York may hold discourse with any town in connection with that city, right up to the moment of the vessel's departure. The telephonic system on board the twentieth-century ocean greyhound in its completeness and flexibility might be envied by a large town. Indeed, the floating town has a great advantage, because there are many communities ashore, with twice the number of inhabitants, who are denied this convenience.

On the captain's bridge, or in the navigating-room among the host of other indicators for all purposes concerned with the handling and welfare of the liner, is a small indicator. It does not occupy very much space, but nevertheless its mission is of far-reaching importance. It is the fire alarm! Distributed at frequent points along the vessel's passages are break-glass fire alarms, similar in their purpose to those found stationed at intervals in the 
thoroughfares of a city. Should a conflagration break out in a cabin, the occupant does not run hither and thither crying "Fire!" and throwing the whole community into a state of terror; he merely sounds the alarm, when the officials are brought to attention. The breaking of the glass releases one tell-tale in the chart-room, and another upon an indicator in the engine-room simultaneously, to warn the navigator and the engineer respectively that the fire-fiend is loose, at the same time intimating the section of the ship in which the outbreak has occurred. Hand extinguishers are distributed freely about the vessel to quell a small conflagration, and these generally suffice for the purpose in the case of a cabin outbreak, or a similar accident in any of the public rooms. But the communication of the fact to the chart-room and the engine-room warns the respective officials of the accident and enables them to complete their arrangements for a "district call" should the flames exceed the capacity of the extinguishers. There is little danger to be feared from this calamity in the residential district of the ship. The greatest dangers arise from the holds, packed with cargo, where a human being does not penetrate during the voyage. But special precautions have been provided for this contingency, as well as means of combating the flames with steam jets, water and noxious gases.

Ventilation is another important feature in the modern vessel. Formerly this was accomplished by the aid of cowl ventilators raised above the deck, in the form of huge trunks and each fitted with a revolving hood turned towards the wind, so that the breeze blew directly into the open mouths to circulate through the apartments or other offices below. This unsatisfactory method, however, has been superseded by a more scientific and reliable system, known as the thermo-tank. These apparatus, mounted in obscure positions so as not to impede movement on the decks, are fitted with electrically driven fans, which suck the outer air, or exhaust the vitiated atmosphere from below. The great advantage of this method is that the temperature of 
the air may be regulated to a nicety. If the outer air is cold it is first warmed by being passed over a steam-heated coil, raised to any desired degree, and is then discharged into the passages and public rooms in such a way that no draught is created. The result is that no vitiated or oppressive air is able to collect in any part of the ship, while, at the same time, the incoming atmosphere is of extreme purity, free from dust and other contamination. In fact, the atmosphere within a cabin, dining-saloon, drawing-room, on a lower deck or in an interior passageway, is as bracing as upon the open deck above, and one is able to secure as much needful ozone as in the exposed position overhead.

Probably the most important feature of the whole of the vessel's equipment is in connection with the commissariat. It is an undoubted fact that upon the crack liners of to-day one is able to live much more regally than in the finest hotels ashore. Certainly the menu is far more varied, and more appetising and dainty, as the digestive organs of some, driven into rebellion by mal-de-mer, have to becoaxed to perform their natural functions, while the bracing air develops a keen appetite among others. While the cuisine is largely dependent upon the artifices and cunning of the chef and his extensive staff, yet, at the same time, as bricks cannot be made without straw, attractive dishes can only be prepared with a sufficiency of raw materials both in quantity and variety.

The stock for the liner's larder reaches mammoth proportions. Its regular supply might tax the resources of a large provision merchant, and would stagger a frugal housewife. Every time the Cunard flyers set out upon their journey, the chief steward stocks his cold-storage rooms with the carcasses of 40 oxen, 60 lambs, so sheep, I 30 pigs, and Io calves, to vanish in the forms of cuts from the joint, steaks, chops, cutlets, and what not. Game is represented by 2000 fowls, 400 pigeons, 250 partridges, a similar number of grouse, 800 quail, 200 snipe, 100 brace of pheasants, 350 ducks, 150 turkeys, and go geese. Three 


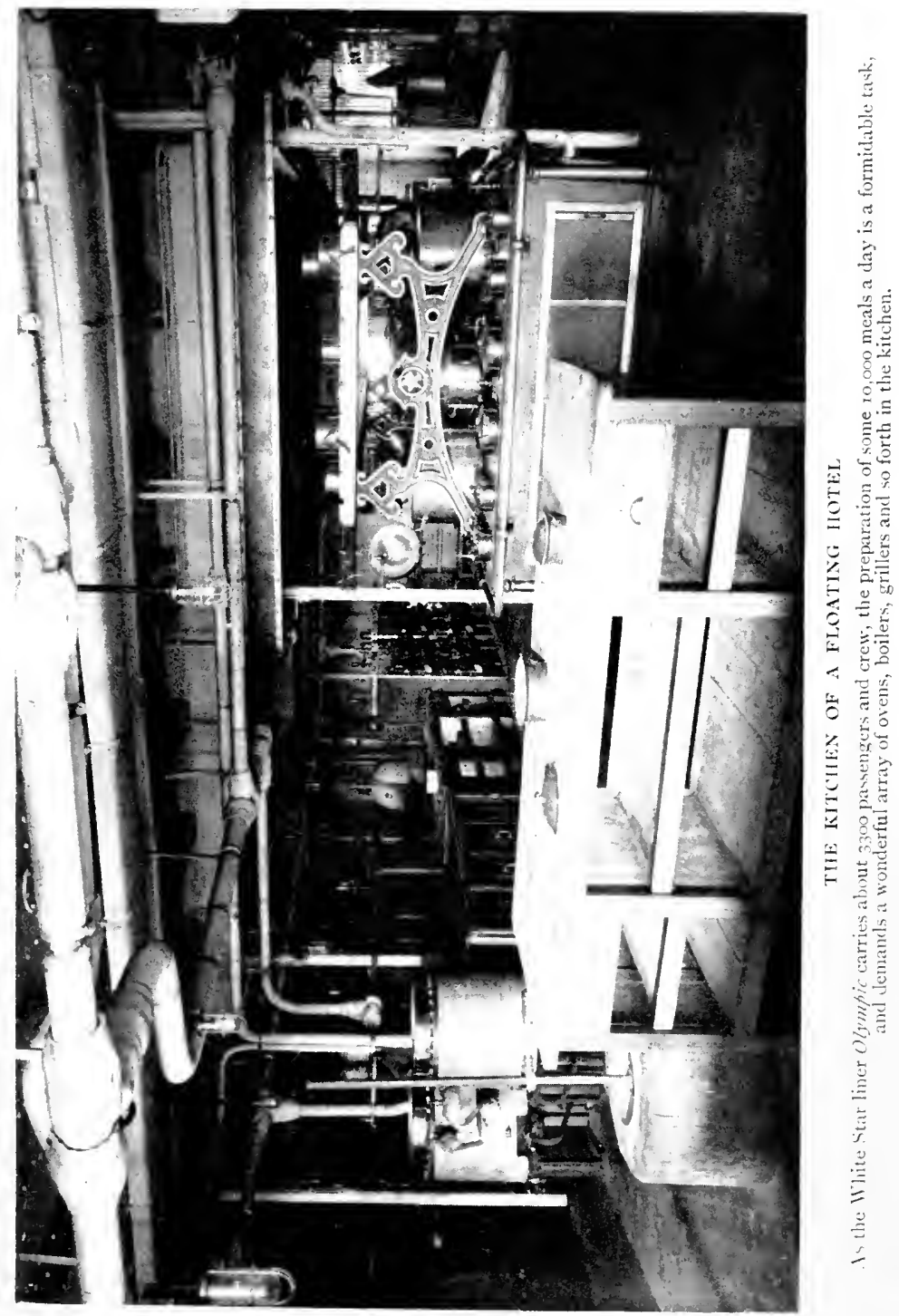




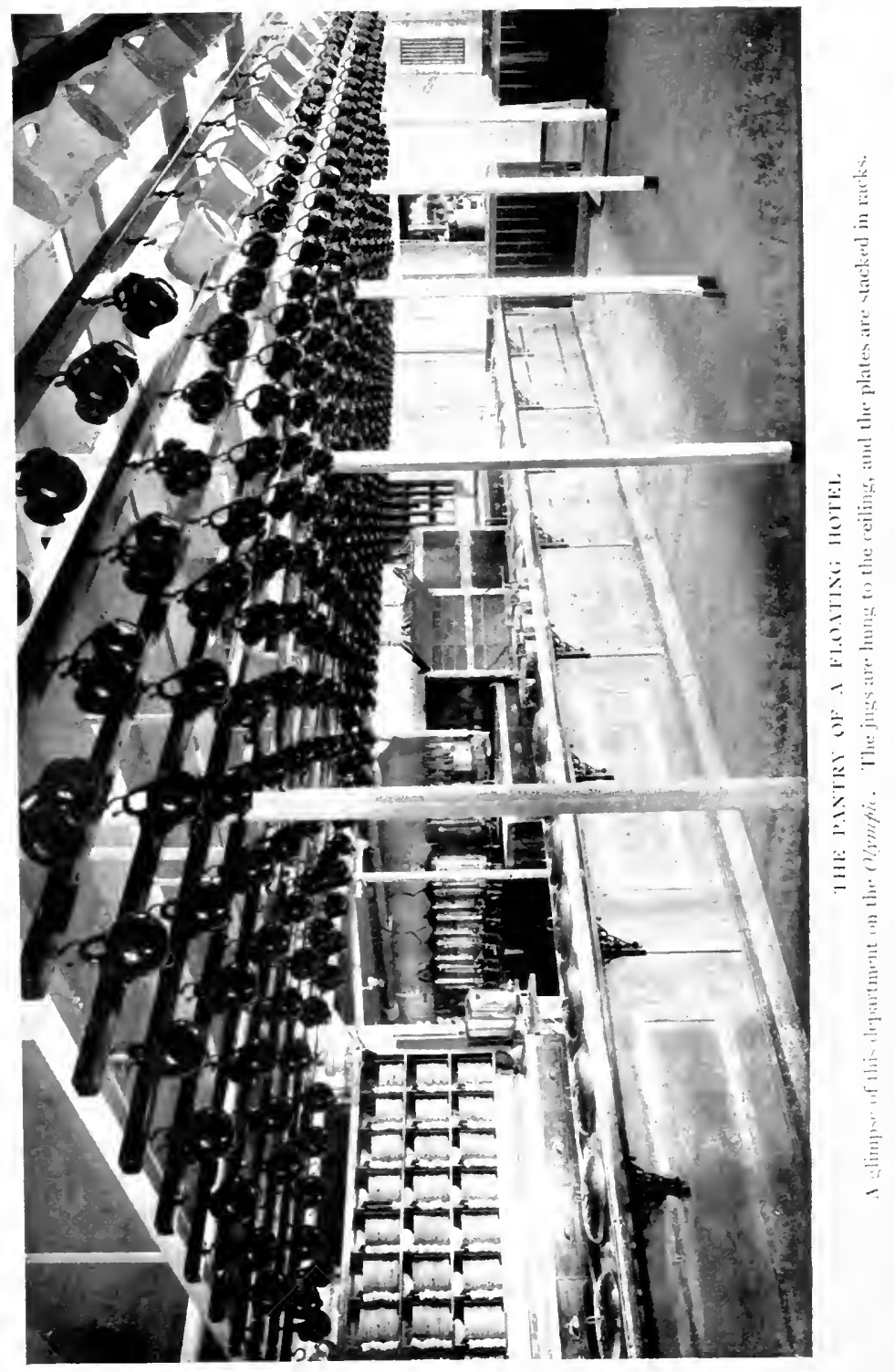


turtles, each weighing 325 pounds, assist in the concoction of soup; while 3,500 pounds of ling, 12 boxes of herrings, 60 boxes of kippers, i 2 barrels of red herrings, 36 boxes of bloaters, Io boxes of fresh herrings, I,500 pounds of salmon, 84 boxes of haddocks, and 45 boxes of fresh fish, such as turbot, sole, plaice, halibut, etc., are stowed away to meet the enormous appetites of the passengers.

The Deutschland takes on board just as heavy and mixed a larder. To feed her I,300 passengers for a week this liner requires, among other things, I,700 dozen eggs, I,300 pounds of butter, 2,500 quarts of milk and cream. Some 60,000 pounds of potatoes are consumed in a single trip, together with 3000 pounds of ham and bacon, nearly IOO crates of assorted vegetables, 2,500 lettuces, 20 crates of celery and tomatoes, as well as nearly 9000 pounds of fresh fruits of all descriptions. The baker requires no fewer than 17,000 pounds of flour and 350 pounds of yeast to convert into bread, biscuits, cakes and pastry. As to the beverages, these are supplied by some 2000 pounds of coffee, 300 pounds of tea, I 2,000 quarts of wine and other liquors, nearly 4000 gallons of beer carried in casks, and 3000 in bottles, in addition to 6000 bottles of various mineral waters.

Nothing is left to chance. The steamer may break down and be forced to continue her voyage only at very low speed; or gales may rage, delaying her progress. Accordingly, the victualling department must have a good margin in regard to supplies to meet such possible contingencies. Then, again, the liner may meet a starving, disabled windjammer or tramp in sore straits, and this unfortunate is succoured from the liner's stores with a sufficiency to carry the lame duck to the nearest port. By such acts of hospitality the needs of the greyhound's hundreds of passengers must not be imperilled.

Variety is the key-note of the modern liner's success. If its cuisine should bear an indifferent reputation either as regards quality, quantity or variety, it is shunned by the travelling public as if smitten with the plague. There are 
three classes of passengers for whom the chief steward has to cater, and it is quite possible that as many as thirty different dishes have to be prepared for breakfast, and twice as many for dinner.

In one single year the fleet of the Norddeutscher Lloyd consumed $13,000,000$ pounds of meat of all kinds, fresh, dried and tinned; $1,250,000$ pounds of fresh and dried fish, in addition to some 750 ,000 clams, oysters and crawfish ; over I,300,000 pounds of ducks, fowls, turkeys and geese, and more than 70,000 partridges, snipes, hares, etc.; some I, 200,000 tins of meats, fish, fruits, vegetables and other preserves; $67,500,000$ pounds of assorted provisions, together with 6,500,000 eggs, and 4,500,000 oranges and lemons. The heaviest individual item during the year was ice, of which nearly 25,000,000 pounds were consumed, followed by $20,779,000$ pounds of potatoes. "My lady Nicotine" was satisfied with $2,327,000$ cigars and cigarettes, as well as tobacco; while beverages were represented by over 500,000 gallons of lager beer, 520,000 bottles of mineral waters, and 940,000 bottles of different wines. The total expenditure of the victualling department in the twelve months exceeded $\mathcal{E} 200,000$, or $\$ 1,000,000$.

When the famous French greyhound France started out on her maiden voyage, early in 1912, the chief steward concluded that the requirements of the passengers on the voyage would be satisfied with 9,000 pounds of fresh meats, I 8 barrels of paté-de-fois-gras, 800 chickens, 700 pigeons, 250 grouse, I, IOO quails, 400 ducks, and $55^{\circ}$ partridges. Some 10,000 pounds of various fish were taken on board, together with 600 dozen oysters. Other commodities were represented by 37, ooo pounds of potatoes; 2,250 pounds of carrots; I,800 pounds of onions; 2,200 pounds of artichokes; I,700 pounds of radishes; 5,900 salads; 15,000 pounds of dried vegetables such as herbs, peas, etc. ; 40,000 pounds of flour; 35,000 eggs; 3000 pounds of butter; $5 .-400$ boxes of preserved fruits; 3,750 pounds of cheese; yooo oranges, 6000 pears, 6000 apples, 389 pots of jam, and so forth. Beverages were to be prepared from $75^{\circ}$ 


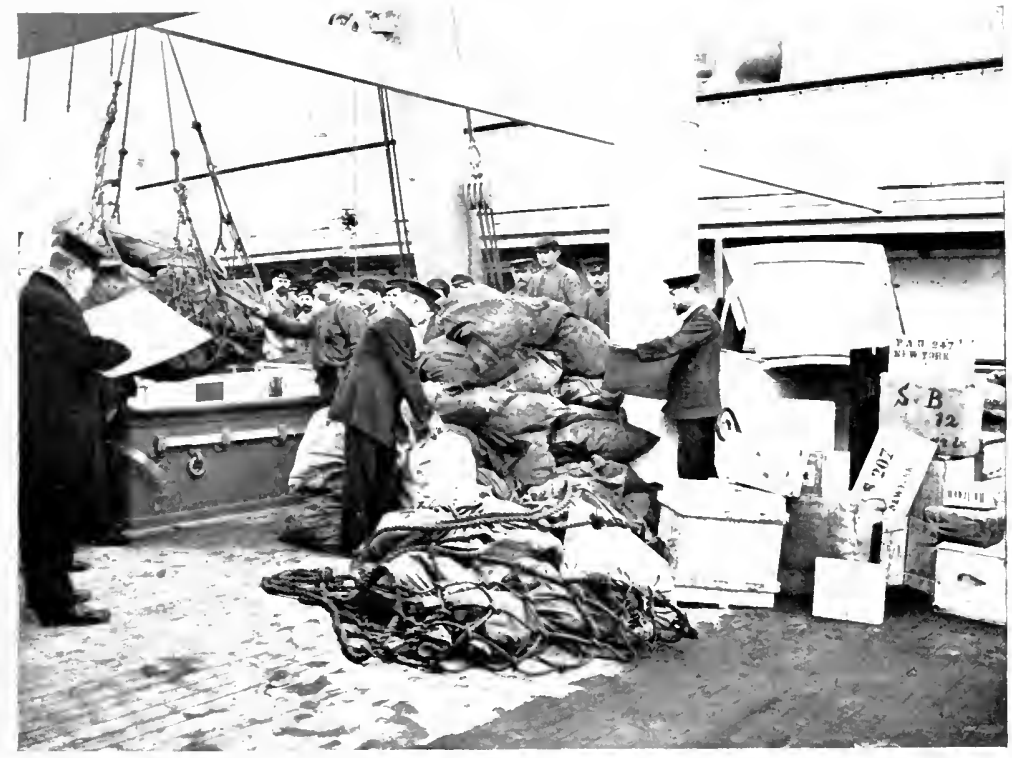

CHECKIXG THE MAIL-B.HGS

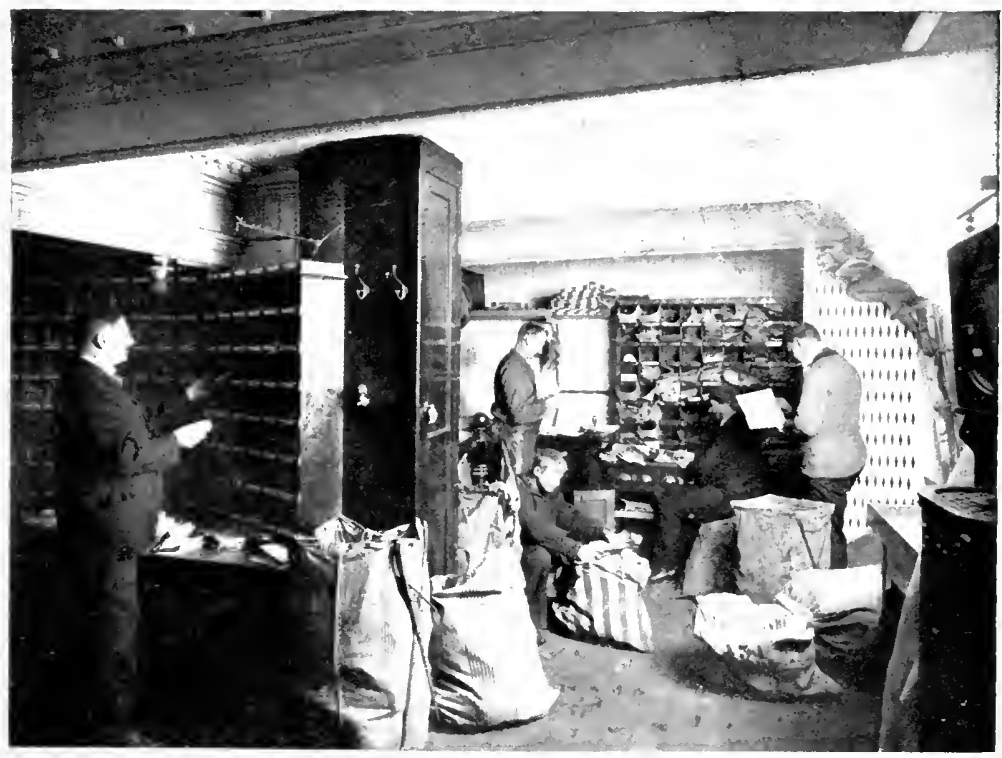

THE FLONTIA POST OFFILF

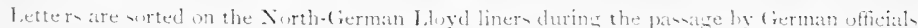
when tratbelling eastward, and by a L'nited states ntaff on the wenti ard run. 


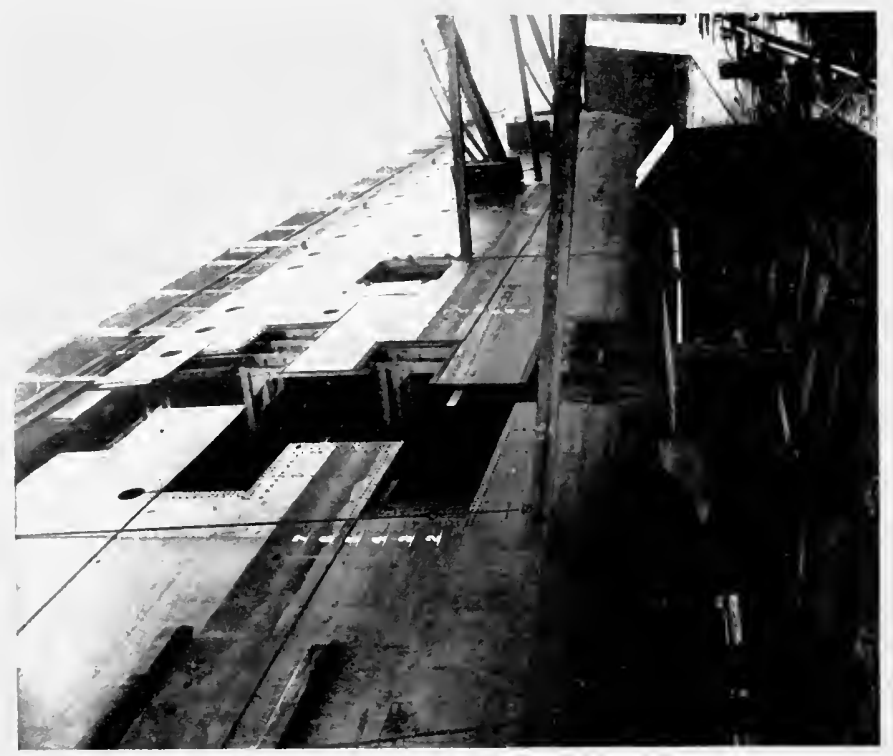

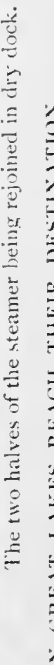

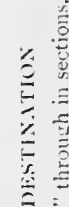

$\stackrel{\overrightarrow{0}}{\circ}$

$\Xi$

$\stackrel{0}{\Xi}=\stackrel{3}{=}$

$=5$

范

蛋占

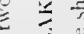

$\stackrel{\Xi}{=}$

等

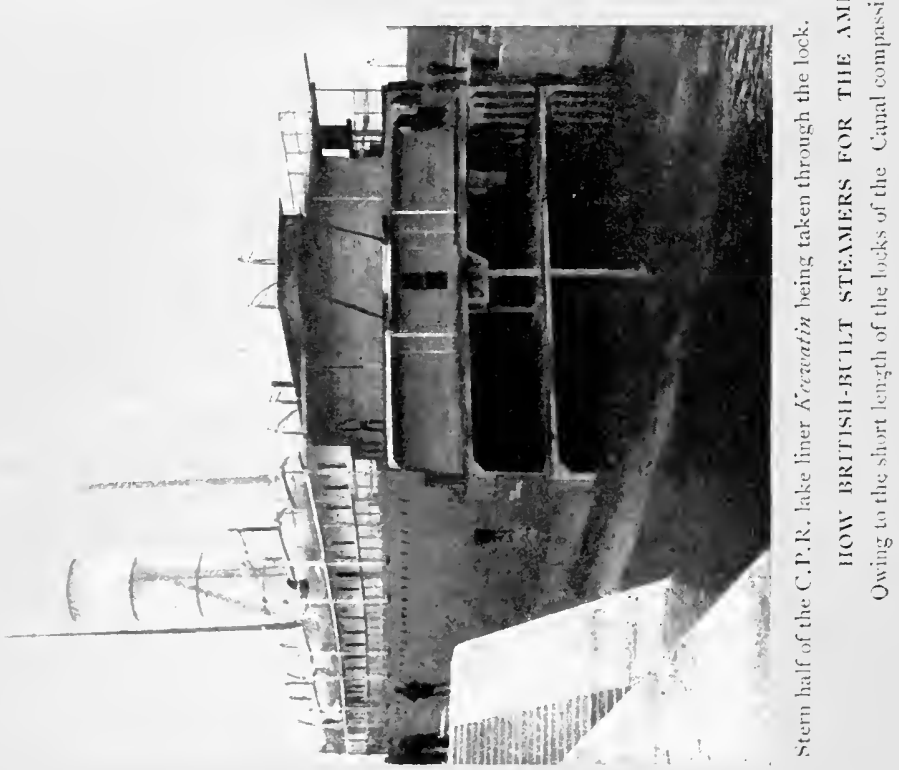


pounds of tea, 1,250 pounds of chocolate, 375 pounds of coffee, 6,340 quarts of milk, and 15,000 pounds of sugar. In the wine vaults were stored 60,000 flagons, comprising 2,300 bottles and 2000 half-bottles of champagne, 1,800 bottles of wines, 2,500 bottles of beer, 1,250 bottles of various liqueurs, 5,300 bottles of mineral waters, 1,500 bottles of lemonade, 25,000 bottles of ordinary wines, and 31,700 quarts of wine in bulk for the crew.

Such a commissariat, for less than a six days' journey, o: a double trip across the Atlantic, affords some insight into the cost of maintaining the victualling department of an Atlantic liner. The average floating town of about 2000 passengers consumes more in a week than a town of twice the population on dry land would eat in a month.

The handling of the garbage and refuse, as well as the sanitation, is simpler on board a vessel than in a town of half the size ashore. No refuse destructors or sewage destroying facilities are demanded here. The open ocean is the general dumping-ground, without affording inconvenience to any one. The only difficulty, if such it can be called, is in reference to the ash and clinker arising from the consumption of from 500 to Iooo tons of coal per twenty-four hours, which is certain to be enormous. In the olden days this waste had to be hauled on the main deck in sacks, or other suitable receptacles, and shot overboard, generally to the discomfiture of the passengers and the littering of the decks. Here, again, the engineer has come to the passengers' assistance with his perfect ingenuity. The refuse from the furnaces falls into a hopper, where it mixes with a jet of water, and the whole is then driven upwards through a conduit by compressed air, to be discharged into the sea about twenty feet away from the vessel's side, so that the travellers aboard do not suffer the slightest inconvenience. Owing to the friendly services of the water-jet, the possibility of clouds of dust being whirled aboard is rendered impossible.

The ship has also a deck flushing system which a modern town might envy. Hoses are connected up to the standing 


\section{STEAMSHIP CONQUEST OF THE WORLD}

hydrants, and the pumps below in the engine-room send a powerful jet of water from the nozzle, cleansing the decks thoroughly, while the services of a squeegee at once rids the promenade of all the surplus water.

Truly the imaginative writer, seeking for picturesque descriptions, who has likened the modern liner to a floating town, has come nearer to the truth than he ever dreamed. 


\section{CHAPTER IX}

MAMMOTH FRESH-WATER LINERS AND FREIGHTERS

At intervals the columns of the daily newspapers are illuminated by graphic descriptions of apparently smart performances in the handling and loading or unloading of large liners, driven to record-breaking round trips between Liverpool and New York. The descriptive writer paints stirring pictures of elaborate arrangements made to achieve this end, and the reader lays down his paper to marvel.

Yet there is little occasion for such amazement. What is done once in a while with a liner in a big salt-water port is accomplished every hour of the day at the leading centres scattered around the shores of the Great Lakes of America, where even the smartest of smart performances-records, if you like-do not attract more than four lines of attention in the local Press, and even then the items are tucked away in an obscure corner as if to fill up space! The truth is that the Press and the people in the countries abutting these inland seas have become so accustomed to quick handling that they regard it with indifference. The abnormal and wonder-provoking feats among the maritime ports are the commonplace about these inland seas.

It is difficult to convey an adequate impression of the tremendous water-borne traffic of the Great Lakes. Figures are abortive-they are so huge as to be meaningless--one cannot grasp their significance. It is equally difficult to draw comparisons, for the simple reason that similar conditions are not to be found in any other part of the world. Every one has heard of the Suez Canal, and knows that a very heavy volume of traffic flowing between Europe and the East, as well as Australia, is diverted through this short cut. Bearing in mind the size of the liners and their 
great carrying capacity, the average person might be pardoned for concluding that the largest individual aggregate of freight makes its way through de Lesseps' great masterpiece of construction, and that this canal is the busiest place in the world. This assumption is strengthened by the knowledge that widening and deepening operations are in constant progress, to meet the exigencies of increasing traffic.

But is the Suez Canal the busiest waterway in the world? If figures offer any criterion, it is hopelessly outclassed by the few miles of waterway forming an artificial channel, or rather reclaimed river, known as the Sault Ste--Marie -Soo-See-Naree-which connects Lakes Superior and Huron. Seven times as much freight passes through this waterway between American and Canadian ports as the whole world sends through the Suez Canal in the course of the twelve months. When it is remembered that traffic on the lakes is confined to a short season of twenty-six weeks in the summer, the teeming trade upon this slender neck of water may be appreciated. If it were open the whole year round the volume of traffic would be twice as great, because it is there to be handled; it is only the ice which interrupts the continuity of the traffic stream, and man has not yet succeeded in devising ways and means of keeping the navigable channels across the lakes open during the winter. When this end is achiered the boats, instead of lying-up in long rows in the various docks, at once will accept the facilities offered to keep running.

Before one is able to grasp the extent of this unique ocean traffic it is necessary to grasp some idea of the dimensions of these great seas of fresh water. Their indications on the atlases convey nothing. Iake Superior is the largest sheet of fresh water in the world. It covers an area of $3 \mathrm{I}, 200$ square miles, almost large enough to contain the whole of Ireland. From end to end it measures 412 miles, and it is 167 miles across at its broadest part. It shelves away from the Canadian and American shores on either hand, until at its deepest part the sounding lead 
must sink $\mathrm{I}, 008$ feet before it touches the bottom. Lake Huron comes next in size, with a superficies of 23,800 square miles, while its extreme length is 263 miles, and its breadth, ignoring Georgian Bay, is 105 miles. Lake Michigan, which is a somewhat more elongated, oval-shaped lake, is 335 miles from end to end, with a width varying from 50 to 88 miles, and covering 22,450 square miles. Lake Erie, which is in the chain of connected seas, is much smaller, covering only 9,960 square miles, with a length of 240 miles by some 60 miles from shore to shore. These are the principal lakes associated with navigation, Lake Ontario being somewhat isolated from the great volume of traffic, owing to the Niagara Falls preventing through communication between the lakes. This breach, however, is circumvented by a useful Canal, through which pass the steamers sailing from Europe, to penetrate to the head of Lake Superior or to call at Chicago. Upon these connected great sheets of water it is possible to participate in a round voyage of over 2000 miles, so that it is not surprising to hear such a tour described as the "longest and finest fresh water sea voyage in the world!"

Scattered around the shores of these four lakes are a number of busy ports, the collecting and clearing houses for a vast assortment of products gathered from the contiguous western country - the great ore lands of Minnesota and the extensive grain-growing provinces of Western Canada and the Middle United States. The volume of products handled on the shores of these waterways alone is tremendous, reaching staggering figures scarcely to be realised. At Port Arthur the Canadian Northern Railway has an elevator which stores 7,000,000 bushels of grain; at Fort IVilliam, four miles to the west, the Grand Trunk Pacific Railway has completed the first part-containing 8,000,000 bushels-of a stupendous elevator which, when completed, will hold no less than 20,000,000 bushels of grain. At Duluth the ore docks stretch for miles, one battery of bins being able to hold over 600,000 tons, while the grain elevators between them can store no less than 
40,000,000 bushels. Superior has twelve grain elevators which can cope with $17,500,000$ bushels, while the coal docks have a capacity of $3,000,000$ tons.

In view of such figures as these, is it surprising that the traffic over the Great Lakes renders them easily the busiest scene of marine activity in the world? Is it surprising that special vessels of tremendous size have been built merely for handling these products, and that millions sterling have been expended in the equipment of the ports with the very latest labour and time saving devices, to expedite the respective tasks of loading and discharging? At Escanaba thirty vessels may draw up in lines alongside the quays and be loaded with ore simultaneously. Over 400,000 feet of timber were consumed to build the docks projecting a quarter of a mile into the lake at Marquette, representing an outlay of $\$ 4,000,000$, or $£ 800,000$. The handling devices are among the most wonderful to be seen in any place on the globe. At the granaries the grain is weighed in huge hoppers, as big as a suburban drawingroom, and shot pell-mell in a continuous stream into the holds of the steamers. The ore is loaded in much the same manner, only in this instance the boat is provided with perhaps a score of hatchways. The vessel is so moored alongside that a hatchway comes opposite the discharge chute of an ore-bin, the latter is lowered, and with a deafening din twenty or more red streams pour incessantly into the boat, until either the bins are emptied or the boat has received its full load. The former contingency is scarcely possible, as upon the land side trains are continually drawing up to discharge trucks laden to bursting-point with ore, so that the hoppers are charged as rapidly as they are emptied.

The lake freighter is a race of ships apart. You will not meet its like the whole world over. It is a mere shell of steel from 400 to 600 feet in length. Right forward, raised above the bow and recalling a battlemented castle, is the navigating bridge. At the opposite extremity, and apparently crowded into the stern space, are the engines 


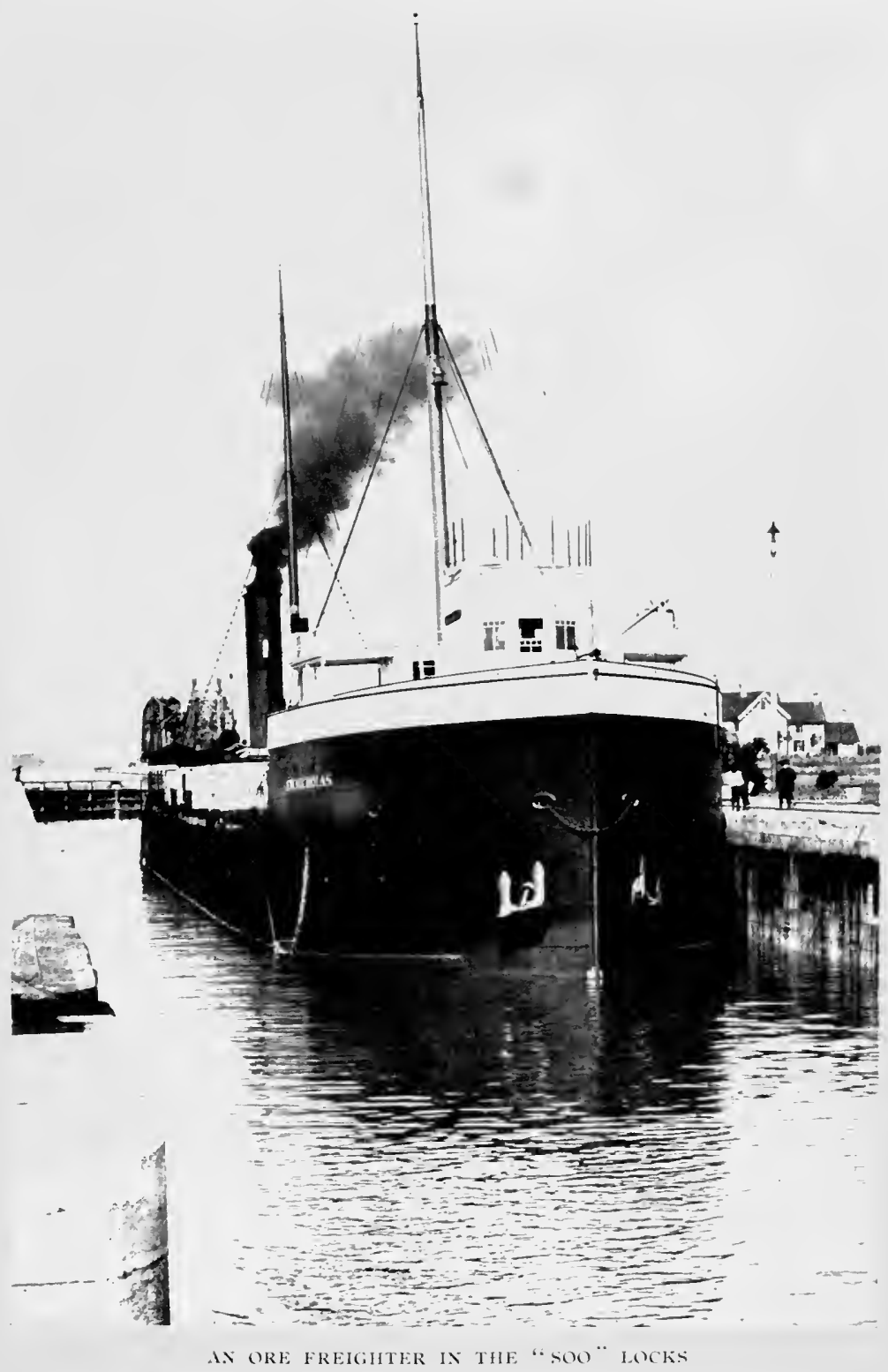

These bluff-endect boats are able to carry from 10.000 to 15.000 tom of ore. The Navigating Bridze in in the bow. 


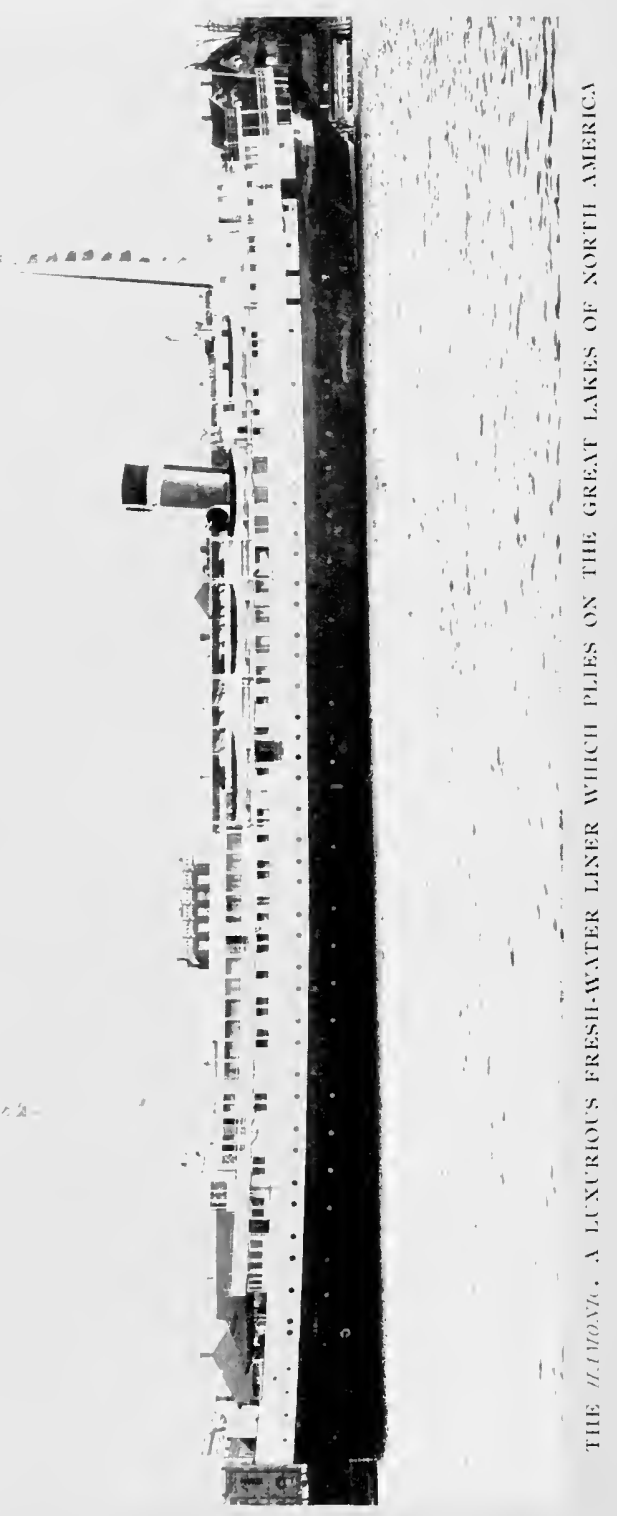


and boilers. It looks as if the builder somewhat regretted having to waste valuable carrying space upon a navigating bridge and engine-room. At all events he crowds them into the minimum of space at either end, so that in reality the vessel recalls a cyclopean barge. Indeed, it might be termed a steam-driven craft of this class. The whole of the space between the bridge and the engine-room is one capacious hold, like a long skating rink, in which the ore, grain or coal is dumped.

The boats are as impressive from their size as their unusual design. When the lake traffic was in its infancy, mere barges, such as we see upon our rivers, were satisfactory and quite able to meet all demands. Then the United States, realising the significance of the future of steel, and being possessed of illimitable deposits of ore and coal, developed this industry, so that the traffic grew, and small ore-carriers driven by steam were introduced as an experiment. They only carried a few thousand tons apiece, being somewhat similar in design and carrying capacity to the familiar small coasting tramps common to British waters. As the steel industry thrived and became organised upon a more comprehensive basis, the dimensions of these craft became augmented automatically and proportionately. This movement culminated in 1905 with the formation of the United States Steel Trust, which acquired the extensive ore fields of Minnesota, to keep its numerous huge works well supplied with raw material. In this year appeared four vessels which in carrying capacity were equivalent to the whole fleet engaged in this service in 1870 , each boat being able to carry 15,000 tons. These enormous vessels are rather abnormal. The 10,000-tonner is the most popular type, as it can be taken into practically any port along the shores of the lakes. The 15,000-ton freighter became necessary, however, for the reason that when the United States Steel Corporation took over the Superior ore fields, it undertook to increase the annual volume of ore mined from $1,500,000$ tons in 1907 to $8,250,000$ tons in 1917 . Consequently, in order to meet this increase year by year 


\section{STEAMSHIP CONQUEST OF THE WORLD}

until the maximum was attained, larger boats had to be built, in order that the cost of transportation might be reduced to its very lowest level. It was calculated that by 1917 a fleet of vessels would be necessary on the Great Lakes capable of handling 50,000,000 tons of ore during the six months' season. At the present time it is estimated that the aggregate of freight traffic borne over these waters is no fewer than $80,000,000$ tons per annum, and the I00,000,000 tons mark is within sight, from the immediate developments which are maturing.

One is able to obtain a tangible idea of the enormous dimensions of this freight traffic by making a voyage across the Great Lakes, say from Detroit to Duluth or Fort William. The laden boats from the north pass in an endless stream, following one another so closely that sometimes they are scarcely half-a-mile apart. About half-amile distant is the up-going stream of empty craft, similarly spaced apart, returning north for fresh supplies. It is a tremendous endless conveyor laid on its sides, the vessels representing the buckets. The loading-point is at any of the ports at the heads of the upper lakes, while the discharging end, where the buckets round the ladder, as it were, is at the ports around the edges of the lower lake. At night, when the weather is clear, the paths across these seas recall a brilliantly lighted thoroughfare, with the lamps of the freighters gleaming brightly. This is the "Great White Waterway" of the lakes, through which the passenger boat is able to proceed with the ease of an automobile speeding along a city avenue.

The whole traffic appears to run with the precision of a clock. There is no fuss or flurry. The ships, upon reaching their destination, are moored alongside the dock in the course of a few seconds, and in a manner that would make the master of an Atlantic liner gasp. Ere the screws have ceased their revolutions and the hum of the engine has died down, monster and wonderful transporting devices have awoke from their sleep, the hatchways have been thrown open in the twinkling of an eye, and the ore is 
being discharged. This is, perhaps, where the finest expression of mechanical handling is displayed. It is a comparatively easy matter to load the ship, as the ore flows into the holds by gravity; but unloading is a different problem, since the material has to be lifted. The unloaders are a bewildering array of overhead steel towers and platforms, along which the carrying devices are whisked at high speed, dipped into the holds, lifted, and run backwards, to be emptied on the unsightly mountains of ore behind. It costs some $\$ 300$, or $£ 60$, per day in wages, insurance, fuel and other items to run one of these freighters. Consequently it is imperative that the period of enforced idleness alongside the loading and discharging wharves should be reduced to the minimum, especially when it is remembered that the ore is carried at a very low rate-between 60 and 70 cents, or from $2 s$. $6 d$. to $3 s$., per ton. Yet so perfect and expeditious are the unloading methods that the most up-to-date ore-carrier, fitted with the very latest devices, can be relieved of its 10,000 tons of ore in about four hours, and at a cost of $\$ 70$, or $£_{14}$, equal to about one-third of a penny per ton. This sum may be reduced even lower, the cost in some cases being barely a farthing, or half a cent, per ton.

Some of the performances achieved by these monster freighters are extraordinary, both in carrying and discharging. One freighter came down with 14,000 tons of ore, another brought down 421,000 bushels, or 12,661 tons, of grain in single loads. It is by no means uncommon for an empty freighter to enter one of the northern ports, take on 10,000 tons of ore, and be off again in less than a couple of hours, the loading operation itself being achieved in about eighty minutes from the moment the hatchways are opened and the ponderous shoots lowered. In discharging, the same celerity is manifest; the same steamer will rid itself of its load in about four hours, to steam away merrily for another cargo. On the Great Lakes losses from delay have been reduced to the minimum, expedition being the sole object. There is a friendly rivalry among the various 
freighters and their crews in the endeavour to set up records, and this spirit being fostered, has led to many marvellous achievements.

Possibly the two spots where the must intimate impressions of this peculiar freight trade may be gained are at the huge docks at Sault Ste--Marie and on the Detroit River. The "Soo locks," as they are called colloquially, are among the most famous, and certainly are the busiest, in the world. When the traffic upon these lakes commenced, the difference of eighteen feet between the level of Lakes Superior and Huron was considered an insurmountable obstacle. The water pours out of the former into the latter lake in a mad downhill race known as the "Soo Rapids," which are half-a-mile in length. Before the white man came, the Iroquois, Huron and other Red Indians shot the water declivity in their delicately balanced dug-outs with no more fear than the average oarsman pulls along the upper reaches of the Thames, while on the upward run they hugged the banks, taking advantage of the eddies and overhanging branches to crawl gingerly upwards, or else made the portage.

When the freighters arrived such methods were impracticable, while the transference of cargo from one ship to another at this point was just as impossible. So the engineers built the locks. As the levy of tolls would have placed an undue handicap upon the shipping industry of these fresh-water seas, the American and Canadian Governments, combined, made the locks international, and now permit ressels to pass without any charge whatever, the cost of operation being shared by the respective countries. The "Soo" is the focus of the whole trade upon the Great Lakes, and it is by no means unusual for I 20 vessels to be passed through these locks in the course of a single day. As the vessels come up from the south or down from the north they line up in a long queue on either side of the fairways leading to the huge waterlift. The ponderous dock gates are swung open and the vessels enter, as many being admitted as the lock will hold. The various craft 
almost touch one another, being packed as dexterously as sardines in a tin, so that no valuable water space within may be lost. In this manner three or four boats will be handled at one time. Directly the lock is filled the lower gate is closed, and, the water being admitted in huge streams through underground pipes, the ships are lifted bodily for a height of about twenty feet. Now the spectators on the lock wall are peering down on the deck of the freighter within the box space; three minutes later the hull, a cliff of steel, is towering above them. As the upper gates are opened the lifted vessels pass out, and the foremost in the waiting string crawl in, to be lowered into the St. Mary River. During the season the scene is one of extraordinary activity both day and night, as the operation continues incessantly, the scene after dark being brilliantly illuminated by flaming electric lights.

Over 50,000,000 tons are now passed through these locks in the course of a season. In 1884 the total was less than $3,000,000$ tons. These figures speak for themselves; but show the amazing development that has taken place in the freight trade of the Great Lakes. The Detroit River traffic is somewhat heavier, as it is swelled by that coming from and going to ports on Lake Michigan which need not pass through the Soo Locks. The result is that over $70,000,000$ tons of freight go through this narrow waterway, representing a value exceeding $\$ 700,000,000$, or E1 $140,000,000$, in the course of six months.

The construction of these freighters has become a prosperous trade in itself, and the shores of the lakes are dotted with bustling shipyards, where rivalry is keen, and where the building facilities are of the very latest description. One can order a boat measuring 500 feet in length by 50 feet beam and 30 feet deep, and within 90 days after the keel blocks are laid the ro,ooo-tonner will be afloat, complete and ready for service. In an effort to determine just how quickly one of these craft could be built, there was a race against time, and the boat was built and placed in commission in a little over 40 days. 
The freight traffic, however, is only one branch of the maritime commerce upon these seas. The passenger trade is one of great dimensions, and the boats engaged in this service, like the ore-carriers, are remarkable. They are essentially constructed for the most part for pleasure purposes, freight is not carried, and in appearance they differ materially from similar boats in British waters. The vessel looks ungainly and top-heavy, with its three tiers of open decks extending from stem to stern, with the wheel-house and navigating bridge perched high above the water. Their finely pointed lines are indicative of speed, and to a certain degree appear dangerous, but accidents among these craft are very few and far between. Around the shores of the lakes are many attractive and picturesque beauty spots and resorts, so that it is no unusual sight to see one of these craft, with all its decks packed tightly with some 3000 gaily diressed passengers, threading its way through the streams of freighters. These are the excursion boats, and the trips are run at very cheap rates indeed. Here and there, however, may be seen more imposing vessels which do not differ in any respect in their general appearances from the majestic liners which draw alongside the landing-stages of Southampton, Liverpool, Bremen, or any other great ports of the world.

The liners of the lakes vie in accommodation and speed with any to be found upon the Atlantic or Pacific Oceans, though obviously their general design and internal appointments vary, to meet the requirements of the peculiar traffic. Every artifice of the shipbuilders' skill which enters into the fashioning of the stately salt-water liner is found reproduced, with essential modifications. Take the Hamonic, of the Northern Navigation and Grand Trunk Railway Companies, which is one of the finest and swiftest of her class. From end to end she measures $36_{5}$ feet, with a beam of 50 feet, moulded depth of 27 feet, of 5000 tons, and with a speed of $21 \frac{1}{2}$ miles per hour. She has accommodation for 400 first and 75 second class, together with a crew of ro. The hull is divided into water-tight com- 


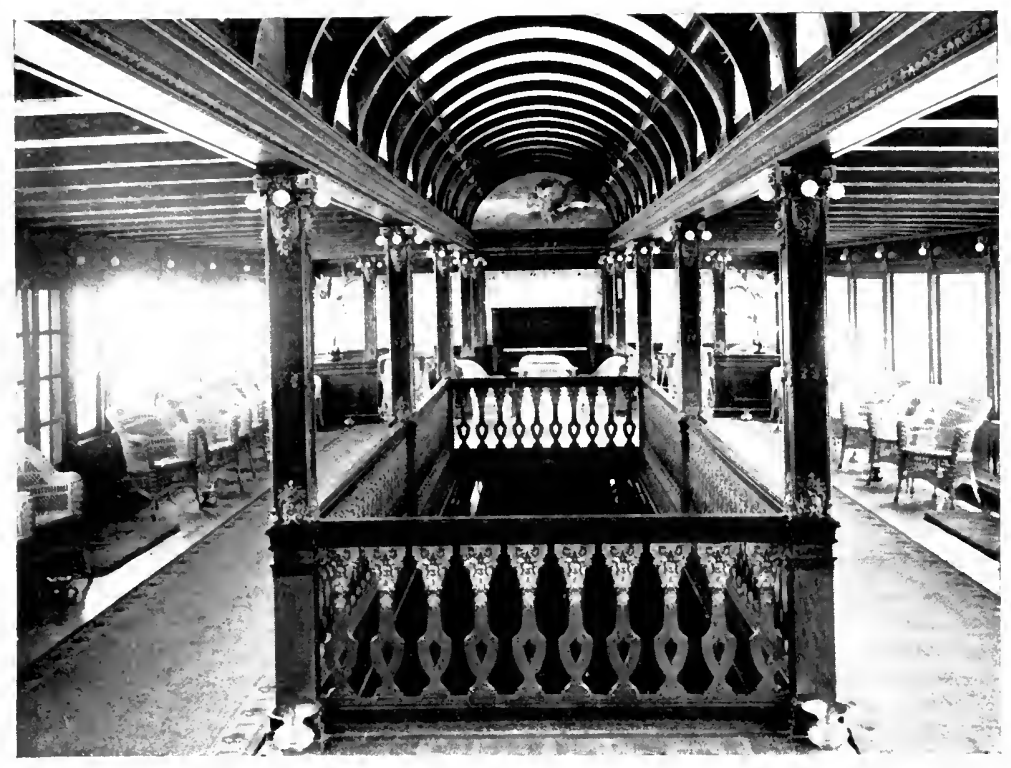

THE OBSERVATION-ROOM OF THE H.1.WOW

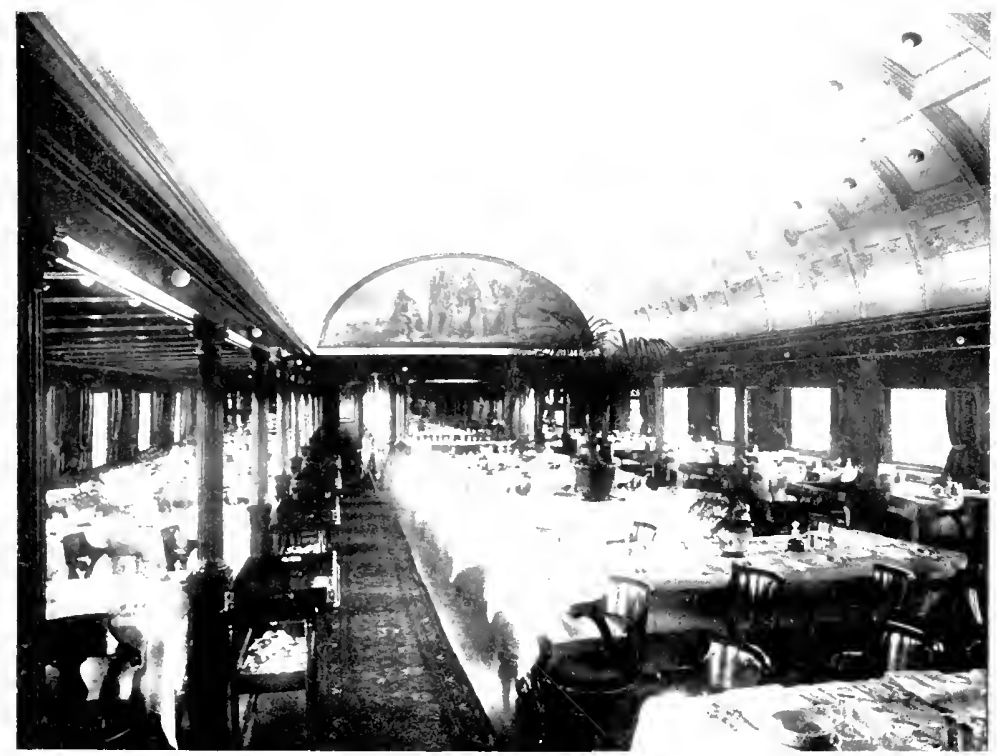

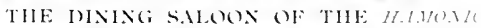

STEAMSHIP TRAIEL ON THE GREAT LAKIES OF NORTI AMERICA 


$$
\| 1
$$


partments, she is fitted with bilge keels to minimise rolling, and makes a regular run from Sarnia in the St. Clair River to Port Arthur at the head of Lake Superior, calling at Fort William and Duluth, the round trip approximating 1,500 miles. The vessel has five decks, seven laps around the longest constituting a mile, is lighted throughout by electricity, has a complete refrigerating plant, and also a wireless telegraph installation.

Internally the vessel is fitted up in the most luxurious manner, with a long dining saloon the full width of the ship, a drawing-room amidships which resembles a lofty domed hall, and a smoking lounge and library at the stern. She is a floating palace in the fullest sense of the word, and in the summer season the demand for berths is so heavy that they must be booked several days in advance. A cruise around these Great Lakes has developed into as popular a holiday among the Americans and Canadians as a trip to the fjords of Norway or the Mediterranean is among Europeans, while many trans-continental travellers welcome two days on these waters as a pleasant interlude to the 4000 miles of railway ride from the Atlantic to the Pacific seaboard.

Some of these vessels, however, are closely similar in their design and appointments to those found in British waters. Many have been built upon the Clyde or Tyne, have steamed across the Atlantic, and then have been floated through the small locks of the canal in sections, in order to get round Niagara into Lake Erie, as described in another chapter. The British boats are extremely popular, the closer alliance with the ocean greyhound in design and equipment appealing to local tastes. Many of the Canadian Pacific Lake liners have been built and sent to the inland seas in this manner, and these are among the fleetest and best patronised craft on the lakes.

Now and again the monotony of the regular round is relieved by an exciting incident or thrilling adventure. One amazing accident, fortunately unattended with loss of life, occurred while one of the Canadian Pacific steamers 


\section{I30

was proceeding through the Soo Locks. The vessel was coming south, and, through some miscalculation or error, a large freighter which was to be lowered simultaneously smashed into the lower gate, carrying it away. Immediately the water, boxed up to a height of twenty feet, rushed out with tremendous force. The liner was helpless. She was picked up like a cork, to be flung out broadside into the St. Mary River, crashing into one or two vessels waiting below to be lifted into Lake Superior, and in turn sending them adrift. It was a terrible mêlée, and those on board the liner thought their end had come. Yet, although the vessel was the sport of the seething water, the captain stuck to the wheel, trusting to luck, and desperately endeavoured to regain control of his ship. When she got into the centre of the river she almost heeled over broadside, but changed her mind under the manipulation of the engines and the rudder, came round in a broad circle, floating on a level keel, and as unhurt as if nothing had happened. It was a miraculous escape, and a terrible disaster was only avoided by the cool-headedness and smart seamanship of the captain.

Although these large sheets of water are completely land-locked, it must not be thought that a journey is always akin to a trip across Windermere or Loch Lomond. At times the scenes of torment, when wind and wave are in deadly battle, are as wild as those encountered in midocean. These lakes have achieved an evil notoriety for the character and severity of their storms. Many a vessel has put into port as badly battered and bruised as if it had been engulfed in a hurricane in the Pacific, while wrecks are of frequent occurrence. In fact, the vagaries of the weather at times are extraordinary. On one occasion when I made the lake journey from Sarnia to Port Arthur the four seasons were experienced in twice as many hours. The negotiation of the Soo Locks at midday found the vessel and all the passengers sweltering in a heat-wave, with the temperature hovering around 100 degrees in the shade. The meteorological conditions were somewhat unusual, 
although the longest day was barely a week distant. At five o'clock in the afternoon the vessel, evidently having passed beyond the limits of the heat belt, encountered a driving rain, reminiscent of spring, which an hour later gave way to a raw fog such as one expects in the autumn. The thermometer descended so low that top-coats became necessary, and by eight o'clock all the steam radiators were going, in the effort to impart some warmth throughout the public and private rooms of the vessel.

As the winter closes down upon the lake the freighters and floating palaces make for their home ports, to hibernate for six months in the docks. As they arrive they are berthed in long rows, stretching for miles after mile, safe from the fury of winter. The crews scatter to find other employment, and the great seas present a desolate and deserted appearance, to be encased by the end of November in a thick armour of snow-covered ice. With the first warnings of spring the crews return to the docks, and soon are engaged busily overhauling the engines, polishing the fittings, and making doubly sure that the vessel will be right and sound in every detail for the frantic rush that sets in directly the waterways are released from the grip of the ice.

The United States have struggled hard to restore their bygone mercantile supremacy upon the Atlantic, but their efforts have proved futile. Other competitors have entered the lists, competent to cater for the travelling public in a better, cheaper and more satisfactory manner than the American-built craft. It is somewhat strange that a system of subsidising ocean-going vessels is advocated as the only means whereby a footing may be obtained upon the Atlantic and Pacific. The opponents of such a bounty system point to the astonishingly flourishing condition and prosperity of the United States' shipping upon the Great Lakes, where not a coin is expended in subsidies. About two-thirds of the total annual shipbuilding output of the whole of the United States, and nearly eighty per cent. of the total lakes' tonnage, is built on the shores of K 2 


\section{I32 STEAMSHIP CONQUEST OF THE WORLD}

and for service upon these inland seas. In the face of these circumstances the antagonists to subsidy methods may be pardoned for asking why, if the United States can hold its own upon the fresh-water seas, should it fail to make headway on the salt seas? 


\section{CHAPTER $X$}

\section{"THE BLUE RIBBON OF THE ATLANTIC"}

Competition is the life-stream of commerce. Thus it was inevitable, when the two first, but differently owned, steamships emerged from British yards, that the anomalous principle-friendly rivalry-should become manifest immediately. The navigator, provided with a propelling effort which relieved him from the caprices of the winds, could not resist falling a victim to the intoxication of speed, and the possibilities of a spirited race stirred the inllabitants of both the Old and New Worlds very deeply.

The first round between rival liners, if such they might be called, was fought in 1838 . Brunel, seeking new victories for his craft, resolved upon the steamship conquest of the Atlantic. The Royal William, in its passage from Quebec to London in 1833 , demonstrated the possibilities of the steamship in a most emphatic manner, and, accordingly, this engineering genius decided to establish a regular steamship service between Bristol and New York. About this time another enterprising spirit had conceived the formation of a rival organisation, which was registered as "The British Queen Navigation Company," after the name of the first vessel constructed for it. Brunel, not to be outdone, retorted with the Great IVestern, a paddlewheel vessel 2.36 feet long, with a beam of $35 \frac{1}{2}$ feet, and of I,300 tons. The British Queen claimed to have given the idea to Brunel by the publication of its prospectus, and was in danger of being robbed of its honour of having established the first steamship service across the Atlantic, as the firm entrusted with the construction of the British Queen upon the Thames was overwhelmed by financial disaster. It appeared as if Brunel's Great Western were 


\section{STEAMSHIP CONQUEST OF THE WORLD}

certain to get away first, but fortunately the promoters of the original enterprise learned that another steamship, the Sirius, was approaching completion, and forthwith she was chartered for the occasion, in order that the British Queen Navigation Company might not be deprived of its glory. The Sirius, built at Perth and engined on the Clyde, was 178 feet in length, with a beam of 25 feet, a depth of 18 feet, had a gross register of 703 tons, and was fitted with engines which developed 320 horse-power, capable of developing $7 \frac{1}{2}$ knots per hour.

As both these vessels were ready for the voyage about the same time, a spirited race across the Atlantic was promised. The Sirius left Liverpool on April 4, I838, and called at Cork on her way out. Captain Roberts was in command. The royage proved historic. Both steamships were on the ocean at the same time, and both masters strained every nerve to reach New York first. The news of the race provoked the greatest excitement in New York, people coming long distances in order to greet the winner.

There was considerable speculation concerning the time of arrival, and the enthusiastic spectators waited day after day, crowding the lower end of Manhattan Island to gaze anxiously and longingly seawards for the first sign of a trail of steam in the sky. At last the cry burst out, "There she is," and in the distance were descried the outlines and wreaths of smoke curling from the funnel of the leader, though it was not known which had won. She proved to be the Sirius, which had steamed across the Atlantic in I 7 days. On the following day the Great Western arrived. She put out from Bristol three days after her rival, and had made a fine passage in 15 days. The Americans went wild with excitement; they realised the significance of the new force which had come to bring the two countries nearer together. The ships were dressed with bunting, and vast crowds bore down upon the waterside to explore the latest nautical novelty.

The journey of the Sirius, however, had not been without its measure of excitement. The night before she entered 
New York the captain fouled the shoals off Sandy Hook. As the weather was quite calm, and the tide low, the master was able to back off without suffering any damage when the water rose. But for this untoward incident the vessel would have steamed into the port several hours earlier.

Both the Great Western and the Sirius made several transAtlantic passages, the former being a pronounced financial success. The latter ship was then withdrawn to revert to her designed purpose-trading between ports around these islands. She came to grief finally in 1847 while running from Glasgow to Cork by crashing ashore, during a dense $\mathrm{fog}$, in Ballycotton Bay, and became a total wreck. True to the spirit of the times, the villagers raided her, considering the wreck their lawful prey. The boat had a consignment of Guinness's stout on board, and the salvors (?) made so merry over this unexpected streak of fortune that two of their number succumbed to their excesses. The main shaft of the vessel was recovered and was set up in a neighbouring mill, where it is still working, while the ship's bell was secured and hung in the chapel at Ballinrostig, where it still summons the faithful to prayer. The wreck lay in the bay uncared for and practically forgotten for about half a century, when she was recovered by a salvage firm. The latter received a competent reward for their trouble, inasmuch as the whole of the metal was purchased by a Birmingham firm, to be fashioned into souvenirs, while the stout timbers, converted almost into jet by their long immersion in the salt water, were also found highly useful.

The success of this initial experiment for the accelerated transportation of passengers and mails led to the foundation of the great Atlantic mercantile marine, as narrated elsewhere, and the inauguration of the Cunard Line. The latter fleet, however, was never in competition from point of speed until 1848, when the United States, impressed with the success with which Messrs. Cunard, Burns, and MacIver were meeting in their new undertaking, decided to compete for the Atlantic trade. Accordingly, an American 
line was established, and a stately ship, the Washington, was launched to uphold American dignity. Southampton was selected as the British terminal, a choice which has remained unchanged to this day, while of course the rival line had its headquarters at Liverpool, which likewise never has been forsaken by the Cunard Company.

What might be termed the first trans-Atlantic race-the contest between the Sirius and the Great Western was unequal, seeing that the ships left the home port on different dates-was that between the Cunard "flyer" Britannia, some eight years old, and the spick-and-span new rival Washington, both of which sailed from New York on the same day. The latter proved no match for the Cunarder, which won in a canter, being berthed in the Liverpool docks two days before her competitor reached Southampton.

The blood of the Americans was now roused thoroughly. They smarted under defeat, and determined to spare no effort to trounce the English company completely. To this end the Collins Line was founded, and the Government came to its assistance in a most liberal manner with a subsidy of $\mathcal{E}_{1} 87,75^{\circ}$, or $\$ 938,750$, per annum. 'This company placed four large boats, named respectively $A$ rctic, Atlantic, Baltic, and Pacific, in commission in 1850 . The Cunard Line was deposed severely by these ships; in speed their boats were outclassed completely, but their owners were in no way perturbed. They knew that the Americans were putting forth every nerve to maintain their position, and were suffering very heavily financially in the effort to hold the Blue Ribbon. Mr. Maclver likened the tactics to "smashing windows with sovereigns," and the simile was not inappropriate, as subsequent events proved. The Collins Line was somewhat surprised to find that it could not sweep the Cunarders off the Atlantic as it had anticipated, a fact due to the firm hold which the English company had secured among the travelling public. The latter was not scared, but at the same time it made its move to meet the situation by vessels built in consonance with the march of progress, rather than run untold risks to life, 


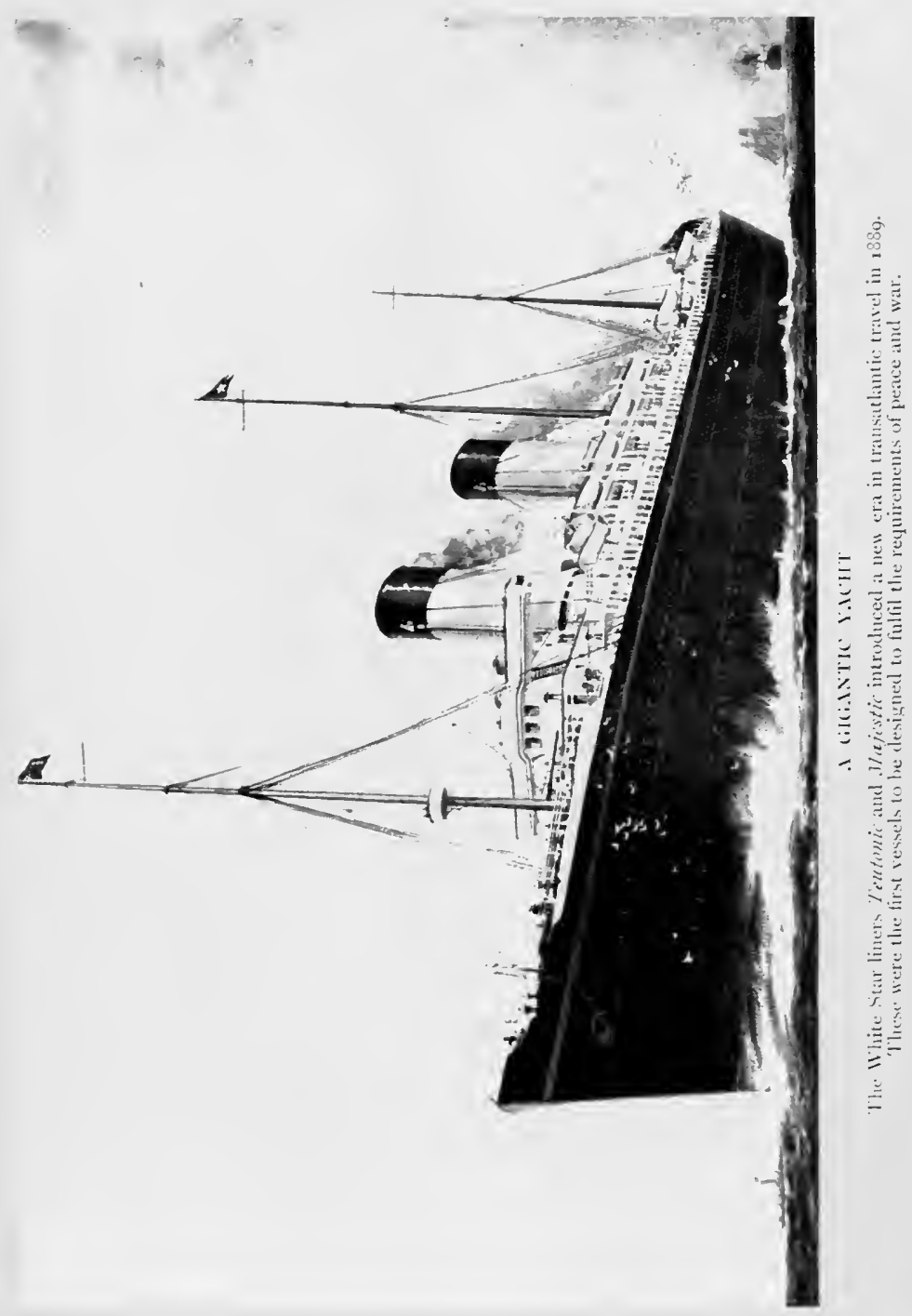



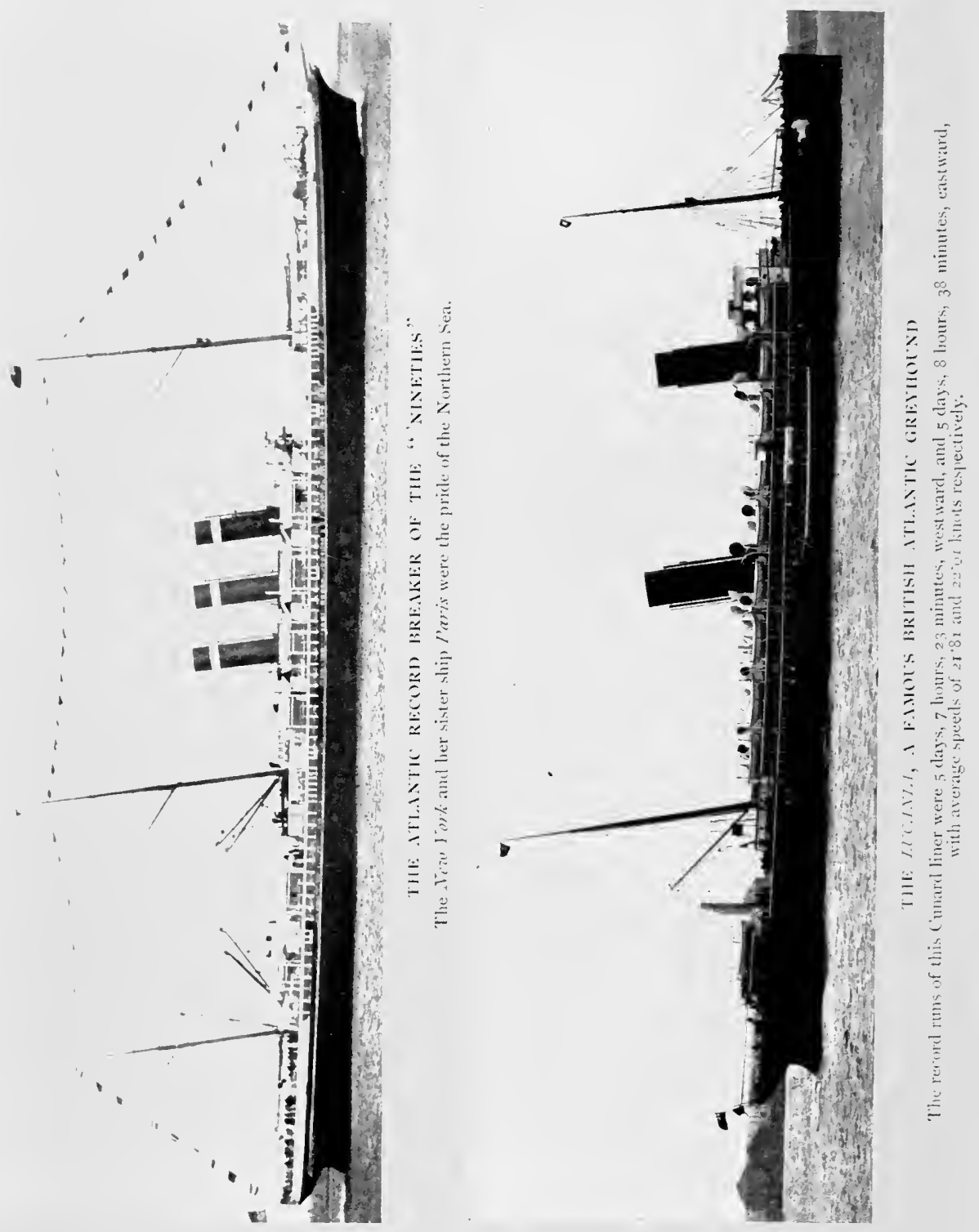
limb and boat in the determination to regain speed supremacy.

For four years the American competition was extremely fierce, and their boats ruled the Atlantic. Then they paid the penalty for their mistaken zeal and incompetence in navigation. A whole string of disasters overwhelmed them. The Arctic was run down by the Vesta and sankonly 15 of her 233 passengers, and 31 of the crew of 135 , were saved. This calamity produced a scare, and the Collins Line lost favour. But worse was to follow. Less than six months later the Pacific sailed from Liverpool and was never seen nor heard of again, while the underwriters were left poorer by $\$ 2,000,000$, or $£ 400$,ooo. Money was provided hastily to provide two new ships to replace the lost liners, but it was too late! The new Cunarders were afloat, and they in turn outpaced the Collins vessels hopelessly in point of speed, seaworthiness and comfort. The public, too, had learned the bitter cost of wild speed, and extended its patronage to the steady and safe Cunard Line. The American line fought desperately against overwhelming odds and ill-fortune for four years, incurring such colossal losses that at last the United States Government felt obliged to intervene. The subsidy was withdrawn; the Line, deprived of its sheet-anchor, collapsed in 1858, and the Cunard was left in undisputed command of the Atlantic, while no further vessels sailed under American auspices until I 892, when the Inman Line transferred its allegiance from the British to the American flag.

The harvest which the Cunard Line was reaping was too rich not to tempt further enterprising spirits to participate in it, notwithstanding the fate that had overwhelmed the former competitor. The Inman, or International, Line appeared on the Atlantic with screw propellers, and was instrumental in overcoming the prejudice to the new method of propulsion. This new aspirant was the first steamship line to carry emigrants, which hitherto had been regarded somewhat as a superfluity in steamship traffic, but which to-day are recognised as one of the mainstays 
of trans-Atlantic commerce. By slow and well-considered evolution the Inman Line crept up to the pace of the Cunarders, and at last eclipsed them, so that for some years it held the blue ribbon of the Atlantic, by bringing New York within eight days' steaming of England.

It is interesting to observe how the length of the passage has been cut down persistently and steadily. The Britannia, with her displacement of 2000 tons, and engines developing 740 indicated horse-power, giving an average speed of $8 \frac{1}{2}$ knots, occupied between 14 and 15 days on the journey, as compared with the 17 days taken by the Sirius. The Collins Line brought the passage down to about ten days, and then the Cunard Company replied with boats which in turn cut the voyage to $8 \frac{1}{2}$ days, the fastest trip being made by the Russia, of 2,960 tons and 3,100 horsepower, with $\delta$ days 28 minutes. This vessel, it may be mentioned, covered 630,000 miles on the Atlantic under Captain Cook, without an accident of any description, and carried between the two worlds over 26,000 passengers. The Inman Line reduced the journey to less than 8 days by means of the City of Brussels, which ran from Queenstown to New York in 7 days $23 \frac{1}{2}$ minutes in 1869 , and the City of Berlin, which covered the journey in the opposite direction in 7 days 14 hours 12 minutes.

In 1852 the Allan Line appeared with a steamship service between Great Britain and Canada direct, where, although startling speeds were not aimed at, a new development was inaugurated by the carriage of mails between these islands and Quebec, avoiding the delays that ensued by landing them at Ialifax. In 1856 the Hamburg American Line came into existence, followed by the North German Lloyd Company two years later, and the French rival, La Compagnie Générale Transatlantique in 1862. Although all these lines were destined to play an important part in the struggle for speed supremacy later, their introduction did not affect the fortunes of the Cunarders to any marked degree, since the pioneer company was entrenched too firmly. A little later three other competitors entered the 
lists, namely, the Guion, National, and the White Star Lines, so that by 1879 the Atlantic became somewhat crowded, and the fight for mastery commenced in grim earnest.

The gauntlet was thrown down by the Guion line, who beat the Cunarder Sidonia with their vessel Adelaide. The White Star boats, however, drew first blood. They clipped hours off the journey, and the Cunard Line, which had been eclipsed by the Inman vessels, were relegated to a still lower position. The Inman Line resented the new arrival most keenly, as their fine runs became eclipsed. However, they buckled up their girths, and contracted with the Clyde for two new steamers, the City of Rome and the City of Berlin. The former, 440 feet in length and of 4,780 tons, became the "Pride of the Atlantic," and in 1873 cut down the journey to 7 days 18 hours 50 minutes. For some reason or other the liner was not considered satisfactory by the owners, and accordingly was returned to the builders. The second ship did better, reducing the previous vessel's run by 4 hours 38 minutes in 1874 . The City of Berlin was the largest ship which had appeared up to this time, being 488 feet in length and of 5,526 tons.

The White Star Line replied inmediately with two vessels 455 feet in length and 5000 tons, named respectively the Germanic and Britannic. In 1877 the Inman record was eclipsed with a passage of 7 days Io hours 50 minutes, by the latter vessel going westward, while her sister ship put many doughty records to her credit before she finished her career in the passenger service. In I89I, when seventeen years old, and when faster vessels were speeding to and fro, she came home on one occasion in 7 days 7 hours 37 minutes.

There is one point which must be explained in connection with these contests for the Blue Ribbon of the Atlantic. The course is not laid from port to port. So far as Liverpool is concerned, it reaches from Daunt's Rock off Queenstown, or the Fastnet, to Sandy Hook, while in the case 
of the boats travelling viâ the English Channel the distance is between Bishop's Rock off the Scilly Islands, or the Needles, and Sandy Hook. Then, again, the distance varies according to the season of the year, when either the northern or southern route is being taken, and whether the vessel is travelling eastwards or westwards. Whereas by the north track eastwards the distance from the Fastnet to Fire Island lighthouse is 2,699 miles, by the south track in the same direction it is 2,779 miles. Westwards the journey by the north track between the same two points is 2,726 , and 2,813 miles by the southern lane, which is followed in summer.

The Guion Company made a powerful bid for public support with the Arisona, which brought the record down to 7 days 3 hours. Travellers now began to talk confidently of the time when the Broad Atlantic would be spanned in less than a week, and this anticipation was supported by the Cunarder Servia of 7,392 tons, 515 feet in length, and 9,900 horse-power, the fastest journey of which was 7 days I hour 38 minutes from New York harbour to Queenstown. The Cunard achievement was shortlived, however, as the Inman Line brought out the second City of Rome in 1881, shortly after the Servia was placed in commission. This was a fine vessel, 542 feet in length and of 8,144 tons, which notched 20 knots an hour on her trials. When she settled down to her stride she sent the Cunarder's achievement by the board with a run of 6 days 21 hours. The Atlantic was spanned within the week. The Guion Line resented this speeding-up, and as a challenge produced the Alaska, of 6,932 tons and fitted with engines of 10,000 indicated horse-power. This vessel, from her turn of speed, was the first to receive the title of "Greyhound of the Itlantic," because she outran all her competitors by covering the journey in $6 \frac{3}{4}$ days. In turn the Alaska was eclipsed by the American of the National Line, a smaller ship, which made the passage still shorter by clipping off a further $t_{4}^{\frac{1}{4}}$ hours. The Cunard retorted with the Oregon, which, before she was run into and sank, 
though happily without the loss of a single life, pulled the time down to 6 days io hours.

Why was this rapid development in speed maintained, and in a way encouraged by the various competing lines? This is an obvious question. Then, as now, the passenger was the deciding influence. The fastest boats received the traffic; and also there were the mails and the subsidy attached to their carriage. The respective Governments were compelled by the iron fist of business exigencies to send letters by the quickest route, and the companies were always striving for the unattainable-the fastest boat. This tendency kept the shipbuilders strung to a high pitch of development, because the firm which could offer the "latest development in ship design" was that which would secure the orders.

Still there was no rest for the various lines. The Cunard Company had been vanquished so completely that it became roused thoroughly and determined to make a spirited bid far and away in front of anything which had been achieved up to this time. The Umbria and Etruria were the two ships which they laid upon the Atlantic for the other lines to play to. Both were handsome vessels, and both represented striking advances upon anything which had been seen up to this period. They were sister ships, with a length of 500 feet, a gross tonnage of 8,127 tons, with accommodation for $55^{\circ}$ first-class passengers and 800 emigrants. They were equipped luxuriously, and, indeed, may be said to have ushered in a new epoch in trans-Atlantic travel so far as the passengers' convenience and welfare were concerned, while their engines, developing 14,500 horse-power, were able to produce a speed of $19 \frac{1}{2}$ knots per hour.

As may be supposed, they retrieved the long-lost laurels for the Cunard Company, as the passage was reduced to within two hours of the six days. Launched in I884, these twin craft ranked as the Cunard Company's crack boats for some eight years. Even then their life was not exhausted, nor were their speed qualities impaired, as 


\section{STEAMSHIP CONQUEST OF THE WORLD}

in September and August, 1892, the Etruria covered the 2,787 miles between Queenstown and Sandy Hook in 6 days 22 minutes, and 6 days 20 minutes respectively! while in July of the same year the Umbria, on her eightysecond trip, made the 2,780 knots in daily runs of 461,502 , 427,592 , and 388 knots, bridging the ocean in 5 days 22 hours 7 minutes, at an average speed of $19^{\circ} 57$ knots per hour. In fact, the performances of these two boats, in what might be termed the evening of their lives, were most astonishing, and were a striking tribute to the workmanship and skill of their builders.

Rivals did not spurn the gauntlet thrown down by the Cunard Company. The White Star Line were soon in the field, matching the Cunard flyers with the Teutonic and Majestic. Both these boats vindicated the confidence of their owners and builders. The Majestic romped over the 2,777 knots at $20^{\circ} \mathrm{II}$ knots in July $\mathrm{I} 89 \mathrm{I}$, covering the journey in 5 days i 8 hours 8 minutes, while her sister ship, Teutonic, did even better at $20^{\circ} 35$ knots per hour in August of the same year, over 2,778 knots in 5 days 16 hours 31 minutes. The Inman Line also accepted the challenge. They rivalled the Cunarders and White Star boats with the City of New York and City of Paris built on the Clyde. These liners exceed the Cunarders in every point, being 560 feet in length over all, with a beam of $63_{4}^{\frac{1}{4}}$ feet, and a moulded depth 42 feet, while they are of 19,498 gross tons. It was stipulated that they should have engines capable of driving them through the water at a minimum speed of 20 knots per hour.

These two vessels created a considerable stir. At the time they were the prettiest boats on the Atlantic. They resembled gigantic luxurious yachts, rather than Atlantic greyhounds, with their schooner bows, short bowsprit and long, overhanging stern. They also marked a new era in trans-Atlantic travel, as they were driven by twin screws.

These magnificent sister ships played havoc with existing records, and retrieved the Blue Ribbon easily. For the 


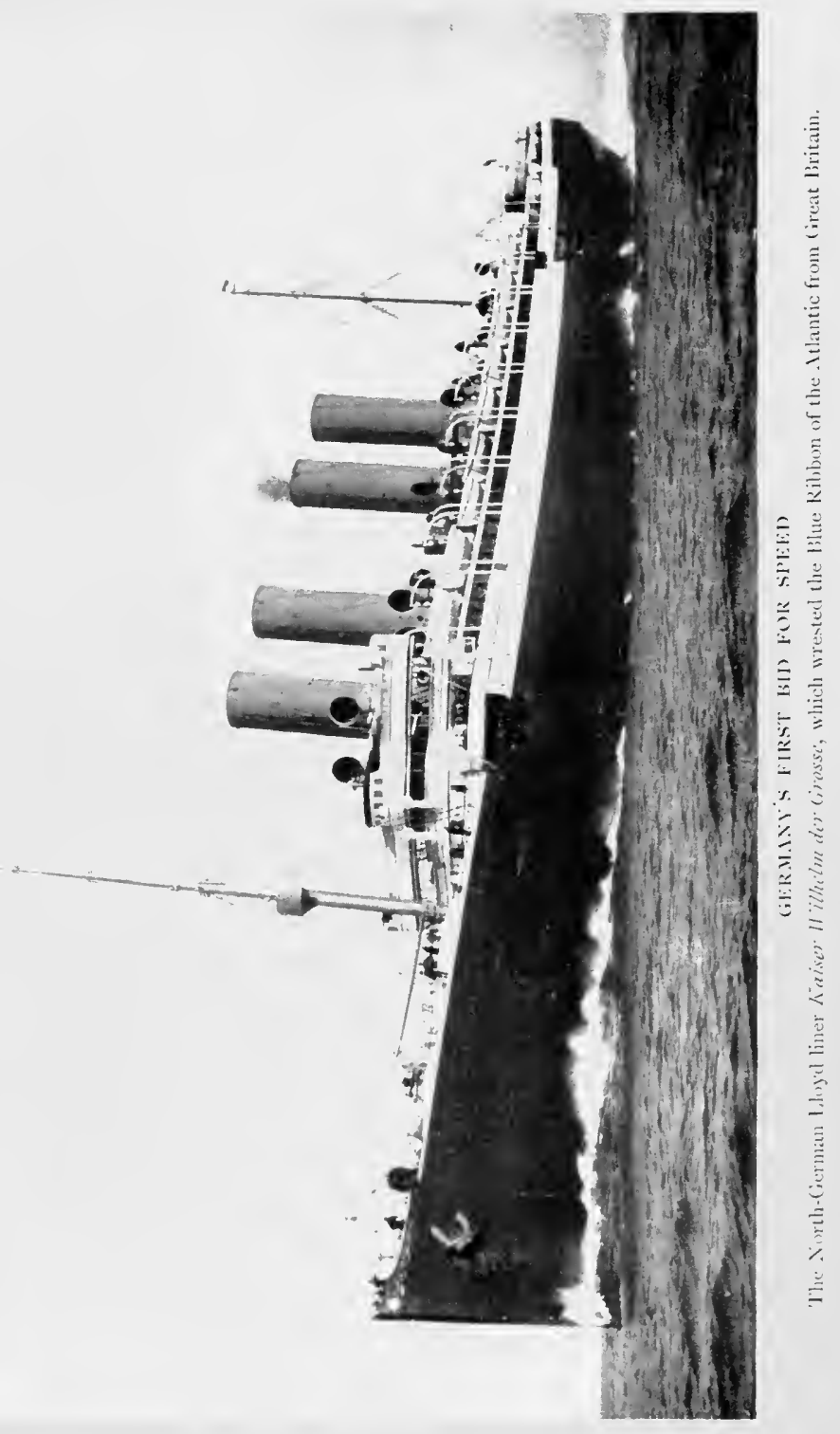



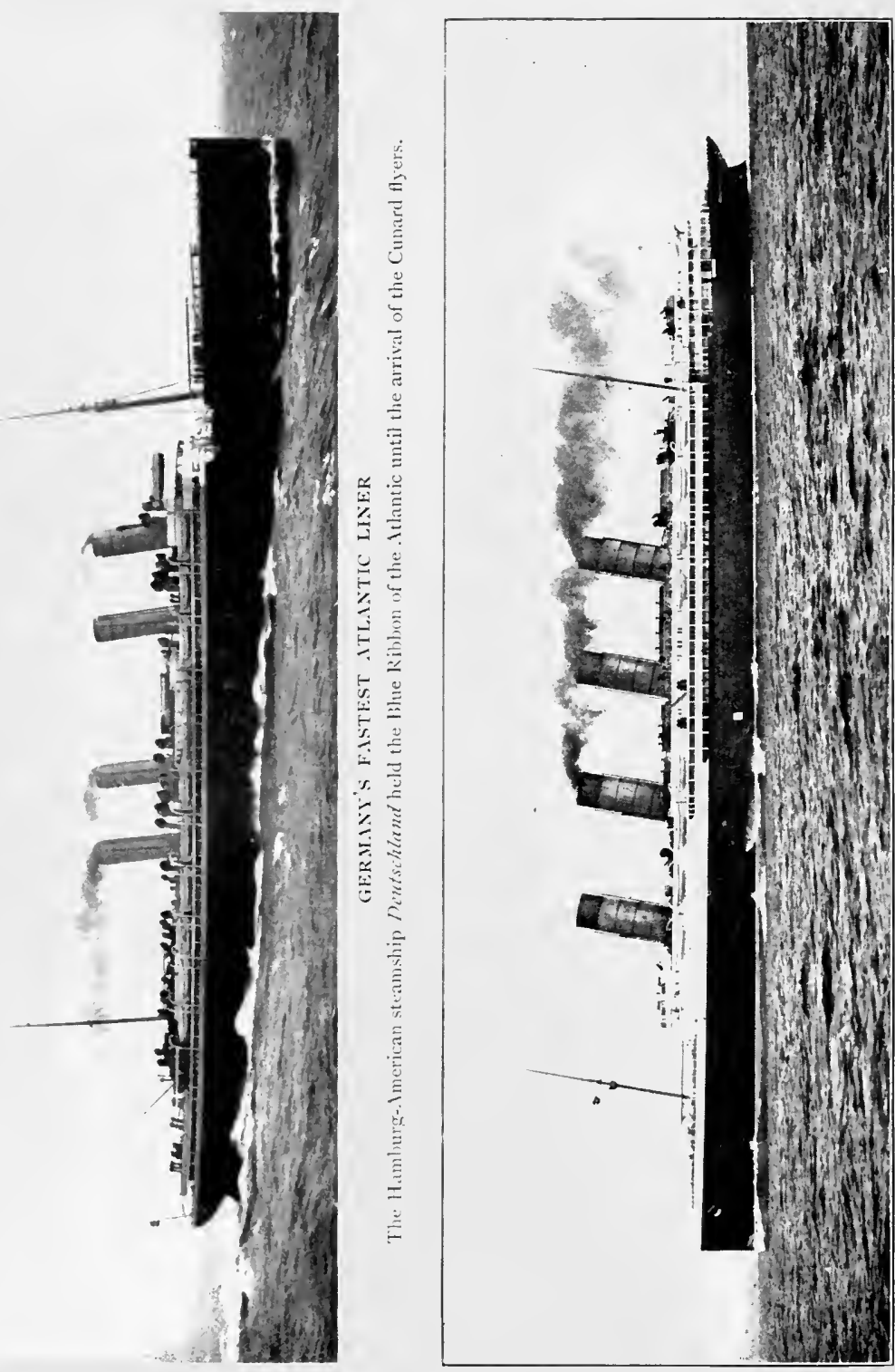

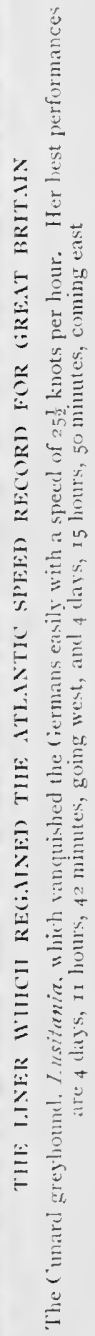


first time the two worlds were brought well within six days' travelling of one another. The City of Paris did the journey in 5 days 14 hours 24 minutes, and her sister covered the distance in 5 days 20 hours 39 minutes. The Inman Line regained its lost trophy, and, as events have proved, this was the last attempt made by this company to compete in the race for speed. Shortly afterwards the two boats were transferred from the British to the United States flag, and were supplemented by the American-built liners St. Louis and St. Paul. These four boats are still in regular service, have scurried regularly across the Atlantic for twenty years, and are practically as good to-day as when first launched. The prefix "city of " was abandoned, and, after her adventure on the Manacles, the Paris was overhauled, repaired, re-decorated and re-christened Philadelphia, so that the craft of the Inman Line now bear the names of four prominent United States cities.

The pace grew hot in the early 'nineties. Scarcely had the Inman Line ordered their fast boats, when the Cunard followed suit, going one better with the Lucania and the Campania. These two vessels not only recorded a marked advance in speed, but also in naval architecture generally. The twin screws having emphasised their superiority from all points of view, were a feature of the new Cunarders. Each vessel measured 620 feet in length, by $65_{4}^{\frac{1}{4}}$ feet beam, with a depth from upper deck of 43 feet, and was of I 2,950 gross tons. The two sets of triple expansion engines were the most powerful ever set in the hull of a mercantile steamer up to this date, being of 30,000 indicated horsepower.

These two vessels swept the Atlantic. On her first trip the Campania, which was the first afloat, could not be let out to her full speed owing to bad weather and heavy seas, so that the run from coast to coast, a distance of 2,865 miles, occupied 6 days 8 hours 34 minutes. This, however, was the quickest maiden trip ever placed on record, and at times the speeds touched $20 \frac{1}{2}$ knots per hour. One day when the elements were kind the captain and engineer gave the vessel 
the rein, and she notched 22 knots per hour, as well as putting up a day's run of 545 knots. This exceeded the previous best daily run established by the White Star liner Teutonic. A little disappointment was evinced by the section of the travelling public which places speed before every other consideration, that the Campania did not bring the trans-Atlantic passage within 6 days, but the vessel dissipated their doubts on her homeward run by covering the 2,899 miles between Sandy Hook lightship and Queenstown in 5 days 17 hours 27 minutes. For the first time passengers were landed in Liverpool on the sixth day after leaving New York.

The Campania is still running as the third boat in the service supplied by the Lusitania and Mauretania, and is doing better than ever, her steadiness, regular running and seaworthiness, as well as comfort, rendering her a great favourite among the patrons of the Cunard Line. The Lucania came to an untimely end after some seventeen years' work by being burnt out while lying in port. The damage inflicted, aggregating about $£ 100,000(\$ 500,000)$, was considered too great to render the vessel worthy of repair, especially as the whole chess-board of the Atlantic had changed under further competition, so she was broken up.

Why all this incessant struggle for speed? This is a point which may strike the average reader, who does not understand its commercial value. In the first place the passenger benefited very materially, because the spirited competition kept the various lines on tenter-hooks and compelled them to keep abreast of developments. In the earliest days rapid evolution was only to be expected as marine engineering advanced by leaps and bounds. The Government fostered the activity of the Cunard Line by giving them the contract for the mails. When $\mathrm{Mr}$. Cunard and his collaborators secured the first mail contract which brought about the construction of the Britannia, the Government undertook to pay a sum of $£ 60,000$, or $\$ 300,000$, per annum for seven years, for a service of three 
ships, but this was altered subsequently to $f 81,000$, or $\$ 405,000$, per annum, as a fourth boat was insisted upon, together with adherence to a fixed schedule of sailing dates. Four vessels met the situation perfectly. This subsidy was regarded with favour by other competitors, who entered the lists in the hope of wresting the contract from the pioneer line, more especially when, in 1847 , the

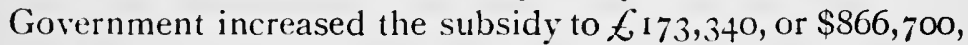
per annum, in return for a double service to meet the increasing traffic. This figure remained unaltered until I868, when, owing to greater competition, the Post Office was able to dictate its own terms. Accordingly, advantage was taken of the situation to save the country a considerable sum by reducing the subsidy to $£ 80,000$, or $\$ 400,000$, per year. In 1869 this price was lowered to $1 ; 0,000$, or $\$ 350,000$, which remained in vogue until 1876 , when the annual lump-sum payment was discontinued in favour of a poundage basis, varying with the amount of correspondence carried per voyage. This enabled other lines to contribute to an improved mail service. There was no necessity to hold over letters until the sailing dates of the Cunarders, as they could be forwarded by the first boat sailing after posting.

The contest for the Blue Ribbon was one of the most satisfactory circumstances for the British shipbuilding industry. Although various nations were competing for the honour, the boats in nearly every instance were built in British yards. The North German Lloyd, the HamburgImerica, and the Inman lines obtained their flyers from the Clyde or Tyne, as did also the Compagnie Générale Transatlantique, so that our marine engineers profited handsomely from the strenuous and continued struggle for supremacy.

But the closing years of the last decade of the nineteenth century brought a complete change. The German companies, having learned as much as they could from the British builders and owners, ordered their boats from native yards, and the French company followed suit. This 
brought new aspirants for the coveted honour upon the Atlantic. In 1897 the North German Lloyd brought out a magnificent vessel, Kaiser Wilhelm der Grosse, of 28,000 horse-power, 649 feet in length, by 66 feet beam, and displacing 20,000 tons. It was calculated that the engines were of sufficient power to develop between 22 and 23 knots. Her first few trips completely fulfilled anticipations, and the Blue Ribbon passed from Britain to Germany. The British lines made no effort to regain the distinction, as the Atlantic traffic was in a condition of transition. It had been realised by the travelling public that comfort was preferable to speed. The German rival captured the honour easily, as on her maiden trip she took 5 days 22 hours 3o minutes to cover 3,050 nautical miles between the Needles and Sandy Hook, with an average speed of $2 \mathrm{I}^{\prime} 30$ knots. Coming back she completed the 2,0,62 miles between Sandy Hook and the Eddystone in 5 days 15 hours 25 minutes. Her fastest passage was made at 23 knots in November i899. Her speed was wonderfully consistent, a year's working giving an average of $2 r^{\circ} 94$ knots per hour under all weathers and conditions.

The North German Lloyd remained in undisputed possession of the record until 1900 , when the native rival, the Hamburg-American liner Deutschland appeared on the scene. For years this ressel has floated as the finest expression of the marine engineer's skill in point of speed. From end to end she measures 686 feet, has a width of 67 feet, and is 44 feet deep, while her two sets of quadruple expansion engines are capable of exerting 35,00o horsepower. On her first trip the record of the Kuiser II'ilhelm ier Grosse went by the board, for the new aspirant steamed over the 3,073 nautical miles of the Atlantic in 5 days 16 hours 15 minutes, at an average speed of $22^{\circ} 42$ miles per hour. Coming home she did better, for she ran from New York to Plymouth in less than a quarter of an hour within the $5_{2}^{\frac{1}{2}}$ days. Even this latter record was eclipsed a little later with 5 days 7 hours 39 minutes from New York to Plymouth. 
The contest was now left for decision between the two German rivals, and the North German Lloyd replied to the Deutschland with the Kronprinz Wilhelm. Virtually this is a sister ship to the Kaiser Wilhelm der Grosse, being of 2 I,300 tons, 663 feet in length, and fitted with engines of 33,000 horse-power. This vessel, however, was no match for the Deutschland in point of speed, although she accomplished some very fast trips.

The Hamburg-American boat remained undisputed mistress of the Atlantic for seven years, when her records were ruthlessly shattered, and the Blue Ribbon wrested from Germany with a vengeance by the performances of the Cunard flyers Lusitania and Maturetania. 'These are the fastest vessels that have yet appeared upon any of the seven seas. With their length of 780 feet, beam $8 \delta$ feet, depth $60 \frac{1}{2}$ feet, and a displacement of 43,000 tons, they outstripped the German or any other boats built up to this date in every particular. But the greatest interest was centred in their enormous engines, which develop 70,000 indicated horse-power, and more particularly because the Parsons turbine was employed in its direct form. The whole world awaited the appearance of these two mammoth liners, as it was anticipated that some wonderful achievements in point of speed would be established, especially when it was related that on her trials the Slauretania had attained a speed of $27 \frac{3}{4}$ knots per hour. Nor were there any disappointments. By means of these two vessels the Atlantic was shrunk still further, and the five-days' passage, which had been dreamed of for so long, became an accomplished fact. The Germans did not respond to the challenge thrown down by the oldest Atlantic steamship company, and so these two vessels have had to be content with record-smashing between themselves. Up to the time of writing the laurels rest with the Maturetania, the two records of the sister ships being as fullows- 


\begin{tabular}{|c|c|c|c|c|c|}
\hline \multirow{2}{*}{ Fastest passage west } & \multicolumn{2}{|c|}{ Lusitunia. } & \multicolumn{3}{|c|}{ Mantritan:ax. } \\
\hline & Nays. Ho:trs & $\operatorname{lin} 6$ & Days. & $\begin{array}{c}13 \text { nots } \\
10\end{array}$ & Mins. \\
\hline Fastest passage east & 15 & 50 & 4 & 13 & 41 \\
\hline Best average speed west . & $25.88 \mathrm{knots}$ & & $26^{\circ}$ & $6 \mathrm{knots}$ & per hr. \\
\hline Best average speed east & $25.57 \mathrm{knots}$ & & $25^{\circ}$ & knots & per hr. \\
\hline Fastest day's run west. & 666 knots & & 676 & knots & \\
\hline Fastest day's run east & 608 knots & & 614 & knots & \\
\hline Best average speed for & & & & & \\
\hline Best average speed for & $26 \cdot 69$ & & $27^{\circ}$ & & \\
\hline day cast. & $27 \cdot 10$ & & $26^{\circ}$ & & \\
\hline
\end{tabular}

What is the price paid for this high speed? From the company's point of view it is very heavy. The Deutschland's engines were designed to give a speed of $23 \frac{1}{2}$ knots with 35,000 horse-power. In order to get an extra $I_{2}^{\frac{1}{2}}$ to 2 knots out of the Cunarders the engini-power virtually had to be doubled, although, of course, several other factors decide this question. But the price of speed is reflected more convincingly in the coal bills. In order to get the $8 \frac{1}{2}$ knots per hour out of the 740 indicated horsepower engines with which the Britannia and her sister ships were fitted, 38 tons of coal per day were required. The latest Cunarders burn rooo tons per day. The City of Paris and New York average 320 tons per day for a speed of 20 knots per hour. The Deutschland, with her 112 furnaces, heating sixteen boilers, gets through 500 tons in the course of twenty-four hours. The Kronsprincessin Cecilic, which is the latest, finest and fastest liner flying the flag of the North German Lloyd, demands 124 fires to eke out a speed of $23 \frac{1}{2}$ knots, and 81 men at a time are kept going night and day feeding the hungry 124 fires with 30 tons of fuel per hour. Such is the price of speed, and the cost of the "Blue Ribbon of the Atlantic."

Does it pay? The success of this crack Cunarder offers the most conclusive reply to this interrogation. During the year I9I the Lusitania alone completed sixteen round trips between England and New York, covered over 100,000 nautical miles, and carried more than 41,000 passengers during this period. This represents an average 
'THE BLUE RIBBON OF THE ATLANTIC' 149

of 2,500 passengers per round journey. One day the Lusitania and a 20-knot liner left New York within a few hours of one another. The Cunard boat, in round numbers, had 1000 passengers aboard; her slower rival had less than 200! Comment is needless. 


\section{CHAPTER XI}

THE STEAMSHIP LANES ACROSS THE OCEAN

THE imaginative writer, in his effort to emphasise the vastness of the salt-water expanses dotting this globe, seeks to give effectiveness to his point by reference to "the trackless sea." It is picturesquely descriptive, and to a certain degree is impressive, but nevertheless it is quite erronenus. The watery waste is no more trackless than the British Islands or any other developed countries are void of highways. True, there are no milestones or sign-posts to guide the navigator on his way. Nevertheless the paths of the ocean are defined just as clearly, and are hugged by vessels, as they move to and fro, just as tightly as wheeled traffic clings to the macadamised roadway.

Some years ago a brilliant French mind sought to apply dry-land methods to the restless ocean. A city street was illuminated by lamps on either side, so why should not the same principle be adapted to the sea to indicate the rightof-way to the speedy liners? He suggested that two rows of buoys should be strung on either side of a wide swathe from coast to coast. These buoys were to be moored by chains, and connected to the Atlantic telegraph cables. Each buoy was to be equipped with a light, with a sufficiency of fuel stowed in its body to keep the beacon glowing for two months continuously without attention. An illuminated sea street some 3,500 miles in length sounded very fascinating. while the suggestion that each buoy should be attached to the submarine cable was highly diverting. This scheme was advocated in the interests of safety. In the event of an accident befalling a ship a boat was to put off to the nearest buoy aind to call up London, New York, or Paris, whichever city happened to be nearest 
to the disabled craft, for assistance. In this manner the perils of the sea were to be mitigated very appreciably. Needless to say, the scheme never went beyond the paper stage: the maritime nations appeared to be unutterably slow to recognise its merits. Since that time, however, the latter part of the inventor's dream has been fulfilled in a different manner-wireless telegraphy.

Yet some means of securing greater safety to those passing between the Old and the New Worlds became imperative. The ports on the United States sea-board, which attracted the bulk of shipping from Europe, then as now, were New York, Boston, Portland and Philadelphia. This traffic was not confined to the transit of mails and passengers by any means, since the fast boats jostled with slow-going, heavily-laden tramps making to and from the same centres. The two classes of shipping-fast and slow -were mixed up in a maze in a limited zone, as all the routes converged rapidly near the American coast, which being very rugged and dangerous compelled adherence to certain channels. Navigators, therefore, ran the risk of collision every hour of the day and night once they had passed longitude fifty degrees going west, and were not clear of danger until this line had been crossed on the eastward passage.

At that time there was tremendous rivalry between the various steamship companies. Steam had commenced to emphasise its possibilities on the Atlantic, and naturally the owners in the effort to capture trade and patronage spared no effort to make quick runs. In cutting down the duration of the sea journey to the minimum, the ressels obviously favoured the shortest route between Europe and America, and this, as reference to the map will show, lies close to the Newfoundland shore with its dense fogs, icebergs and other perils.

Two other factors aggravated the situation. The steam engine certainly was in the ascendant as a propelling agent for ships, but sailing vessels were more common in these seas, and as they tacked to and fro, wandering practically 


\section{STEAMSHIP CONQUEST OF THE WORLD}

to all points of the compass to take advantage of favourable winds, thereby fouling the routes generally followed by the steamships, they menaced the safety of the latter very seriously. The second obstacle, and this created quite as serious a danger, was the fact that the liners cut across the great fishing ground lying to the south of Newfoundland. Fishing fleets put out from Massachusetts, Nova Scotia and Newfoundland to reap the harvest of the sea in this great field, and when the fisheries were in full swing it was by no means uncommon for two or three hundred of these craft to drift with their nets over a comparatively small area. To these hardy folk the normal perils of their calling were enhanced by the danger of a big liner crashing into them at full speed, unseen and unheard in the blanket of mist lying upon the water. No record has been kept of the number of fishing vessels which have been run down by the big liners in their mad haste, but it runs into scores.

Under such conditions, as may be supposed, disasters were frequent. Collision, icebergs, derelicts and grounding all claimed their victims, and gathered them promiscuously from the ranks of mail carriers, tramps and windjammers. Many a vessel tight and trim put out from the American and British ports never to be seen or heard of again. The North Atlantic holds its secrets tightly, and although the fate of these craft is merely conjectural, it has been surmised that collision either with another boat or a floating obstruction was responsible for the greater number of these mysterious disappearances. The accident to the Collins liner Arctic appears to support such a contention. This boat left Liverpool for New York with about .37o souls on board on September 21, 1854. Six days later the liner was blundering through the fog hanging over the Grand Banks, about fifty miles south-east of Cape Race, when suddenly there loomed through the mist the shadowy outlines of another vessel. The two boats scarcely had descried one another when there was a terrific crash. WWhen they released their deadly embrace and backed away, the stranger, the French steamer l'esta, gave signs of 
foundering, and at once turned to make for the harbour of St. John's, Newfoundland. At first it was thought that the Arctic had escaped serious damage, except to her upper works, but in a few minutes the awful intelligence came up from the depths of the ship that water was coming in rapidly, and that the fires would soon be extinguished. The captain turned his prow towards Cape Race, the nearest point of land, with the intention of running ashore at full speed, but he was prevented. A heavy gale was raging. After four hours' labouring with wind and sea, the furnaces were extinguished by the rising water, and the Arctic shortly afterwards made her fatal plunge within a few miles of shore. Only forty-six souls were saved. Most of the boats were smashed in attempts to launch them, and a large hastily improvised raft, which the seamen had fashioned when they learned the vessel was doomed, and on which seventy-six people sought refuge, was broken up by the waves, leaving a solitary survivor. The French vessel was more fortunate, since she succeeded in making St. John's, although in a sinking condition.

Four months later another fearful disaster was recorded, probably in the same part of the North Atlantic. This rictim was the Pacific, sister-ship to the ill-fated Arctic. She left Liverpool on January 23,1856 , with 45 passengers, 141 in the crew, and cargo valued at $£_{400,000}(\$ 2,000,000)$. She was never seen nor heard of again; not even a stick belonging to her was found. Probably she got caught in the fog off the Grand Banks, and either blundered into a tramp or sailing ship, or was run down by an iceberg. These disasters, in combination with innumerable other catastrophes of a minor character, brought home with compelling force the perils of navigating the North Atlantic. The travelling public grew somewhat alarmed, and as is usual at such times, demanded some means of rendering travelling by sea safer than apparently was the case, although it could not suggest any practical way of accomplishing this end.

In the meantime a brilliant young officer in the United 


\section{STEAMSHIP CONQUEST OF THE WORLD}

States Navy, Matthew Fontaine Maury, had been thinking and working long and hard. He had been placed in charge of the department of charts and instruments of the Hydrographic Office at Washington. Naturally in his duties a mass of material of every conceivable description relating to the North Atlantic Ocean, and bearing vitally upon navigation, came under his notice. Suddenly an idea occurred to him. The public was perturbed by the frequency of marine disasters off the American sea-board, owing to the chaotic condition of the routes followed. Could not this tangled skein be straightened out, and specified routes elaborated to ensure safer sea travelling? By studying the charts and data in his departments he observed several outstanding characteristics. The winds and currents followed well-defined lines at varying times of the year, and were tolerably regular in their occurrence. Derelicts were tossed about from point to point by these moving forces; icebergs were released from the northern seas to follow approximately the same paths year after year, and penetrated to a certain southern limit, where they disappeared under the melting action of the Gulf Stream; while the greatest enemy, fog, which caused the Great Banks to be so fearful a danger spot, only spread its pall for a certain distance to the south. Moreover, he was able to ascertain when these last-named perils assumed their most formidable aspect.

He went farther. He foresaw that the number of ships engaged in the mail and passenger services must increase, while larger dimensions and high speed were inevitable with progress. Thereupon he elaborated certain lanes which these vessels should follow when passing to and fro, and suggested that these tracks should be reserved exclusively to this class of traffic. He maintained that if such a procedure were followed the slower-moving crafttramps, sailing-ships and fishing boats-knowing the thoroughfares frequented by the high-speed liners would, in their own interests, give them a wide berth.

This was a rational attempt to regulate the traffic of 
the ocean, somewhat after the lines adopted in the control of vehicles in crowded city streets. When the scheme was first submitted to the varied mercantile interests in 1855 , it was not greeted with very marked enthusiasm. Some lines, recognising its advantages, at once embraced the idea; others regarded it with unveiled hostility. At the time there was considerable rivalry between the various lines engaged in the ocean-carrying traffic, especially in connection with the mails. Maury's projected lanes lay somewhat to the south, and involved a longer course than that which was generally followed, in order to reduce the sea-passage. One line could not adopt the suggestion, otherwise it would place itself at a heavy disadvantage in relation to its spirited competitors, who by following the short sea-route, and thereby reducing the length of the sea-passage, would not be slow to publish the fact to attract custom. In those days, as now, there was a gencral tendency to reduce the sea journey to the minimum, and the fastest line following the shortest route obtained the heaviest traffic.

The terrible catastrophes to the Arctic and the Pacific within the short space of six months, and the loss of some 400 lives, followed by the public outcry, caused Maury's scheme to be regarded with greater interest by the mercantile community. It was observed that the young officer, in preparing his route-map, had assisted the speedy flyer as much as possible consistent with safety. For instance, there was set out what are known now as the "northern" and the "southern" routes respectively. The former is followed in the winter and the latter during the summer months. The indication of seasonal tracks revealed the extreme care and study which the officer had bestowed upon his project. From the data at his disposal he had found that during the winter a shorter path might be followed safely. The icehergs were bound up tightly bv the northern winter, and the fog zone off the Grand Banks shrank to smaller area. In view of these conditions it was safe to lay out a path more to the north, thereby saving 
several miles. On the other hand, on the southern route it was necessary to swing more towards the equator, in order to compass the known southern limit to which icebergs drifted, and to escape the fog area which in summer becomes extended.

He also emphasised another useful point, and that was the strict observance of the rules of the road. To attain this end he arranged two tracks, one to be followed by steamships eastward bound, and the other for those going west. The rule of the sea is that ressels shall "keep to the right" and pass one another on the port side, and accordingly the inner track was for west-bound vessels. This arrangement was indicated in such a way that the possibility of vessels colliding with each other in the region where the danger from ice and fog is greatest is eliminated practically, as at this point the inner and outer tracks on both the northern and southern routes are about fifty miles apart. This radius was provided to permit a captain on the inner track to make deviations to the south in order to compass a danger, if the exigencies arose, and yet be safe from venturing upon the right-of-way of the steamers moving in the oppositc direction.

Although the suggestion was looked at askance by the various lines when first suggested, the merchants and underwriters of New York instantly realised its many advantages, and displayed their appreciation in a practical way. Shortly after the project was launched, Lieutenant Maury was presented with a handsome service of silver and a purse of five thousand dollars in gold as a recognition of his services in designing the steamer lanes and in shortening the sailing route, compatible with safety, between Europe and the northern ports of the United States.

It was not until i $89 \mathrm{I}$, however, that the utility of these lanes for liners became formally recognised by the mercantile community. The occan greyhounds had grown in size and speed, and represented far larger sums of money, than in the fifties, so that the risk attached to the practice of following indiscriminate routes, determined by the 


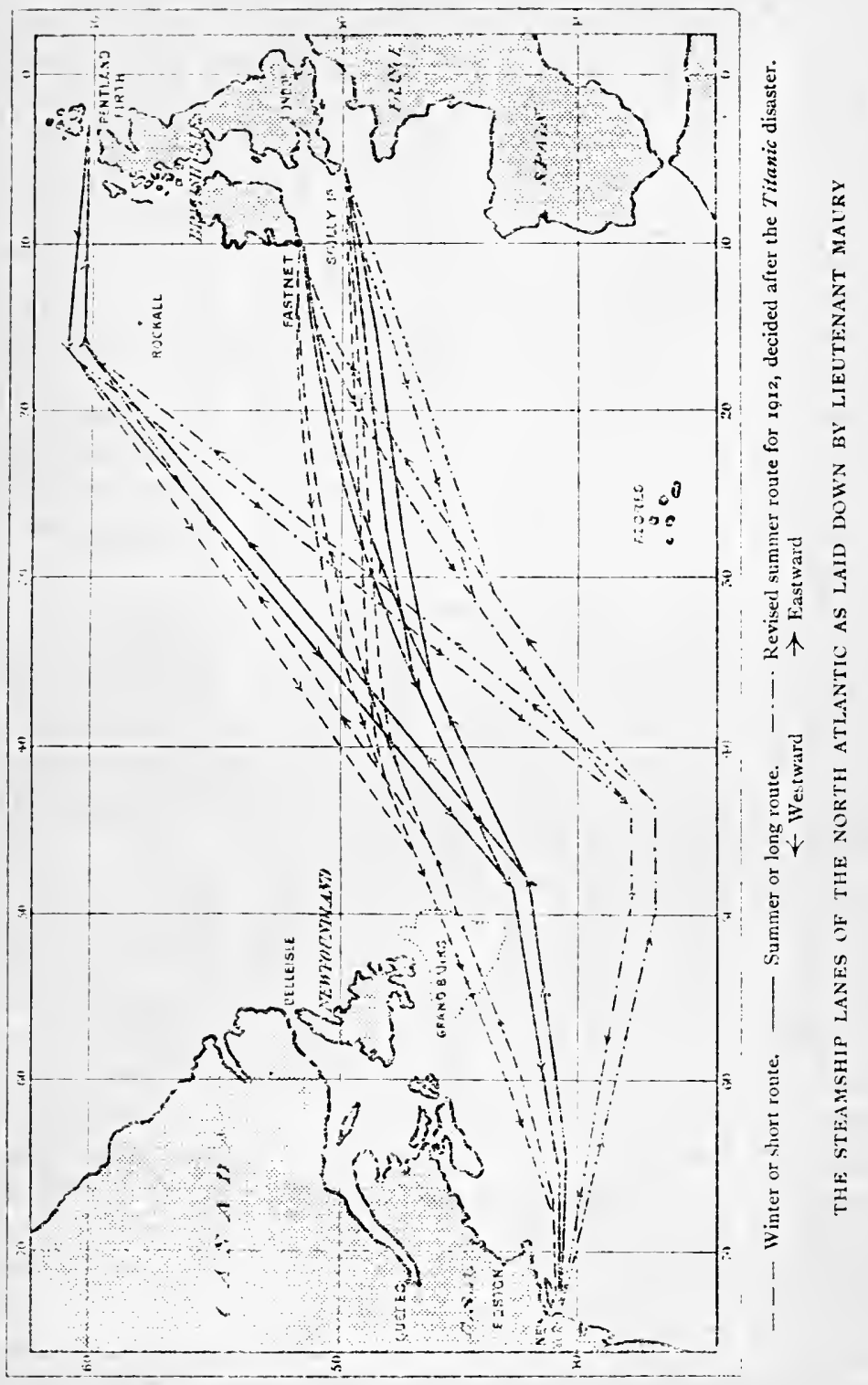




\section{STEAMSHIP CONQUEST OF THE WORLD}

captain, whose responsibilities thereby were appreciated very sensibly, was too great to be incurred. Therefore in that year the Cunard, Guion, Inman, National and White Star Lines mutually agreed to accept the definite lanes first laid down thirty-six years before by Maury. This decision practically inaugurated the opening of the Atlantic thoroughfares, as some such combination of powerful interests was necessary to prevent one line gaining a doubtful advantage over another in point of distance and quick passages.

Once the ocean highways became recognised in this manner the United States Hydrographic Department spared no effort to keep them open and free from obstruction, so that the movement of vessels might be facilitated. The captains following these lanes are requested to keep the department posted with full information respecting dangers to navigation, such as icebergs, derelicts, etc. The position of these menaces are communicated far and wide by the department, both on its monthly charts, and also in other publications issued at intervals for the benefit of all those whose livelihood is on the broad Atlantic.

In 1898 there was another conference, and on this occasion the whole of the trans-Atlantic steamship companies consented in a written agreement to follow the tracks at first laid down by Lieutenant Maury, and these are the lanes along which the huge speedy greyhounds travel to and fro to-day. The companies practically accepted Maury's schedule as it was prepared by him nearly half a century previously. The only radical modification was in regard to the time of the year when the northern should be superseded by the southern lane, and when the reversion to the former should be made. After some discussion it was decided that the changes from the northern to the southern tracks should be made in January, and from the latter to the former thoroughfare again in August. It will be seen that the shorter route between the opposite shores of the Atlantic is open only for five montlis in the yearduring the winter-but this is a secondary consideration, 


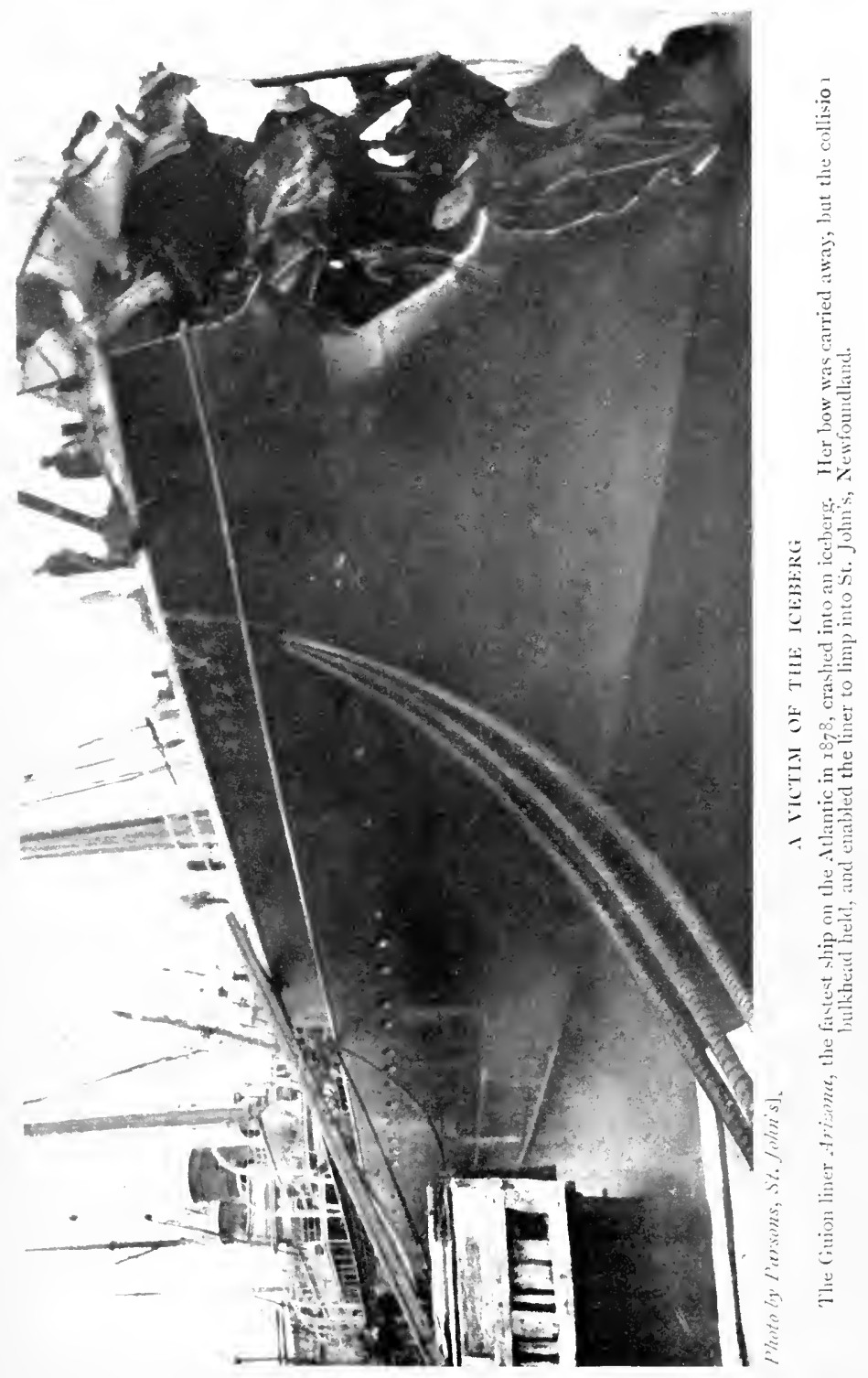




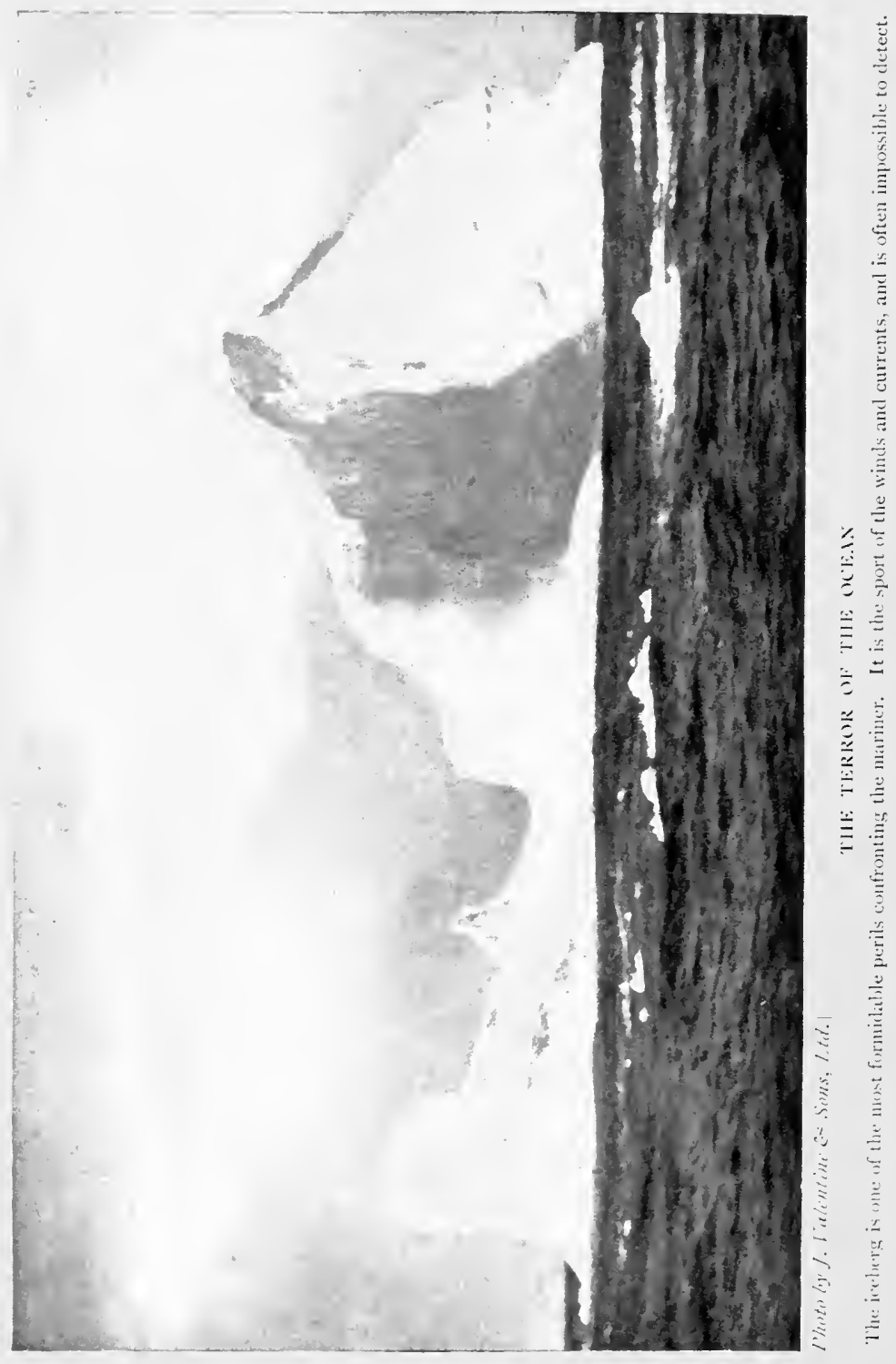


seeing that safety to life and property was the principal incentive for mapping these lanes-not speed. If the latter were all-important, and if it were possible to expect a greater immunity from fog and ice, a more northern route still could be taken, but in the North Atlantic fog and ice are two capricious obstacles. Consequently the lanes were laid far to the south of the worst danger spot. Thus in the month of April fog may be expected to hang over the Grand Banks south of the indicated northern tracks for about one-half of the month. On the other hand on the inner track of the summer route at longitude forty-seven degrees west, where the captain sets his course northwestwards to gain New York or Boston, the probability of fog is reduced to about six days in the same month. The danger from ice increases toward the northward, and decreases toward the southward in about the same ratio as the fog. Thus, in running around the dangerous tail of the Grand Banks of Newfoundland during the months from mid-January to mid-August, the steamship companies undoubtedly pursue a course consistent with the wisdom of definitely recorded experience. When the steamship companies investigated Maury's projected water highways dispassionately, they were impressed with the patience and researches that he must have made to have laid down such excellent paths. It was recognised that had the highways been followed earlier, the great majority of the accidents which had befallen vessels in the North Atlantic might have been avoided.

The value of Maury's work is proved by the fact that accidents upon the lanes he laid down have been very few and far between. The most terrible was that which befell the Titanic on April 14, 1912. The vessel was moving along its designed track on the southern route-i. $c$. the inner track on the summer route which lies about fifty miles north of the eastward right-of-way-and was rounding the danger area in exact accordance with the understanding between the various steamship companies. Every catastrophe brings its lessons, and in this instance the 
question arose as to whether Maury's paths might not be revised in connection with the summer route, and be set still farther southward, especially during a period of considerable Arctic ice movement, such as prevailed in the spring of 1912. In fact, this procedure was taken immediately after the catastrophe when the extent of the field of icebergs became known, the southern route being moved about four degrees farther to the south, almost in a line with the Azores. It is quite possible that henceforth this will stand as the southern route, seeing that the leading steamship companies mutually agreed to adhere to this diverted highway in order to ensure greater safety.

Which part of the Atlantic Ocean is the most densely crowded with shipping? Probably no one could answer correctly. Of course I do not mean to take into account the coasting steamers hugging the shore lines, more or less, but the broad expanse of the ocean. At the present moment the most crowded area of this busy sea is that lying between $45^{\circ}$ and $50^{\circ}$ of longitude west of Greenwich and between latitudes $38^{\circ}$ and $37^{\circ} 40^{\prime}$ north. At this point all the great routes meet. The Scandinavian navigator after he has traversed the troublous waters of the Pentland Firth, and has got the forbidding hump of Rockhall well to his south, by reaching latitude $58^{\circ} 40^{\prime}$ north, sets his course to a point $27^{\circ}$ farther south on the $45^{\text {th }}$ meridian; the German, Dutch and Thames liners bound to points north of the Gulf of Mexico, when they have dropped the Bishop's Rock, make for the same point; the vessels sailing from Havre and Liverpool follow the self-same practice, the Liverpool liners setting the course from the Fastnet: the ships from Italian and other Mediterranean ports, when they have emerged on to the Atlantic, pass the Azores on the port side to reach $38^{\circ} \mathrm{N}$. by $45^{\circ} \mathrm{M}$. All these craft then follow one behind the other along this parallel until the 5oth meridian is gained. Then the captain bound for New York, Boston or Portland, after having rounded the corner off the Grand Banks, steers a course to the north-west, while the skipper en route for 
the Gulf of Mexico swings off to the south. Thus the summer lane has a busy junction at either end of its midAtlantic section, where the point farthest south is gained. This diversion of the trans-Atlantic flyers has influenced the low-powered steamers-tramps-plying between the Mediterranean or Eastern ports reached viâ the Suez Canal and New York, since now they hug parallel $36^{\circ}$ after rounding Gibraltar across the breadth of the Atlantic to meridian $65^{\circ}$, when they swerve rapidly north-westwards to enter the Hudson River estuary. From this it will be realised that since the revision of the sea lanes the busiest open ocean spot is where all these routes converge at the southern extremity of the danger zone.

It is the same with the steamship routes to other parts of the world. In the southern seas navigation is menaced by the icebergs drifting northwards from the Antarctic, although in this instance there are no Grand Banks with their impenetrable shrouds of fog to hamper movement.

However, it is on the North Atlantic, where fifty or sixty mighty liners may be afloat simultaneously, where the necessity for the defined ocean thoroughfares is experienced keenly, and where to-day Lieutenant Maury's work and ingenuity are most appreciated. As the man with a horse and trap does not venture upon a railway track where mile-a-minute expresses fly to and fro, neither does the tramp enter the lanes set aside for the fast mail-boats, running between Europe and North America. The windjammer likewise keeps well away from them, while the fishing fleets do not invite disaster by trespassing on the fast through roads. One often hears trans-Atlantic passengers express disappointment at not having seen a single vessel during their journey. I have explained the reason. Lieutenant Maury outlined where speed might be maintained with perfect safety-indicated the galloping stretches of the Atlantic. The captains of the flyers take full advantage of these facilities, and all slower moving boats allow the ocean Juggernauts to have the whole of the salt-water speedway to themselves. 


\section{CHAPTER XII}

THE PERIL OF THE ICE

THE year I9I2 will stand as a milestone in the annals of the mercantile marine, as it witnessed not only the greatest shipwreck on record, but because it drove home to the public more forcibly than ever the serious menace that the iceberg offers to navigation, and the helplessness of man when he is pitted against such a formidable antagonist of the deep. The wisdom after the event displayed upon this occasion was extraordinary, and the average person might have been pardoned for concluding that the loss of this liner was the first accident of its character on record. This was very far from being the case. The ice claims several victims every year, while the number of ships that have been crippled so severely as to threaten a disaster of almost equal, if not greater, magnitude are by no means few and far between.

It is surmised that the greater proportion of the myssterious disappearances associated with the Atlantic have been due to collisions with icebergs. On March I, I854, the City of Glasgow left Liverpool with 500 souls. She was never seen or heard of again. A similar fate befell the Pacific. Another liner, the City of Boston, disappeared without leaving a trace, although a boat supposed to liave belonged to her was picked up off the coast of Cornwall, with the brief intimation that this ship, whose name was cut upon the relic, was sinking. Considerable doubt has been expressed, however, as to whether this boat ever belonged to the vessel in question. On February 11, 1893, the White Star vessel Naronic put out from Liverpool with 70 souls on board, to disappear from all mortal knowledge. Several months later a Norwegian ressel sighted and 
hauled in a drifting boat off the Azores. It was stove in, but examination revealed that it had belonged to the missing freighter, as well as the fact that it had been launched evidently in a desperate hurry, as the lashings had been hacked free by a knife or other weapon, instead of being released in the usual manner from the davits.

How these boats vanished so completely-swallowed up by the ocean-remains a mystery to this day, but there appears to be a general consensus of opinion that they were sent to the bottom by the ice. So much for total disappearances from which nothing definite may be learned. From the survivors of a deadly embrace with this foe, however, much information has been gleaned. The Arizona, the fastest and largest liner of her day, was ploughing Liverpoolwards when she crashed headlong into a berg. Her bow was torn away as if it had been made of paper. The captain turned her round and ran full speed for St. John's, which port he contrived to reach, to land his passengers. Comment has been raised as to the indifferent look-out maintained by the Titanic, while the action of her captain has been criticised severely because he drove at full speed through a dangerous zone after warning had been received. In I899 a disaster which may have eclipsed even that of the year 1912 was within an ace of being recorded. One day the citizens of New York were astonished to see a stately liner come limping into the harbour with her bows almost awash. She had come to grief in the deadly ice zone, and the 1,600 passengers aboard had received a terrible fright. The captain was of an exceptionally cautious character, and when he reached the danger area he reduced speed to about ten knots per hour, and doubled his watch with men of wide experience and keen perception. The weather was clear, and yet, despite the precautions observed, the liner blundered into a growler which had escaped detection by the look-outs and navigating officers. Fortunately, in this instance the vessel struck the menace a safe blow-her side was not ripped open-and the collision bulkhead held against the 
enormous pressure of water, though the fore part dipped alarmingly low into the sea. The captain in this instance turned his head towards New York, proceeding slowly, so as to ease his crippled craft, and in this manner crept into port. This narrow shave brought home to the travelling communities in no uncertain manner the extreme difficulty that mariners experience in discovering an iceberg under peculiar conditions; this year the Corsican had an equally lucky escape.

The ice movements in the Atlantic are one of the wonders of Nature, and occasionally passengers are treated to glimpses of what takes place in the ice-bound country beyond the northern snow-line, and are able to admire the fantastic sculpture of Nature, because these masses of glittering white and green often assume the most beautiful forms. One I saw off the Strait of Belleisle resembled a lofty arch, through which the ressel could have passed easily; another had two pinnacles like the twin steeples of a church; while in a third instance the mass assumed the form of a huge hump, with a cavernous opening in one side where the ice had been eaten and broken away.

Most of these bergs are fragments of the great ice cap, formed of compressed snow, which rests upon the inland plateau of Greenland. In that cold country the rivers are masses of ice, which are continually pushing their way towards the sea, and end abruptly at the water's edge in a precipitous cliff. From time to time fragments break off under natural disintegration, and this production of bergs is known as calving. The pieces vary in size. Some are small lumps weighing only a matter of a few hundred tons; others are immense chunks half-a-mile or so in length, and jutting a hundred feet or more above the water, with the Hatness of the top side relieved by pinnacles and spires.

There is one popular fallacy in connection with icebergs. It is frequently stated that only one-eighth or one-ninth part of the total height of the berg stands out of the water. In other words, if roo feet are seen above the waves, this 
means that from 800 to 900 feet are submerged. This is an error; it is about one-eighth or one-ninth of the total mass or weight of the berg which is visible-a totally different thing. This statement was proved conclusively by the authentically recorded instance from the Strait of Belleisle, where a berg having an attenuated spire topping 100 feet grounded hard and fast in 96 feet of water!

There is no hard and fast season for the calving of bergs. The production takes place the whole year round, but the majority are liberated during the summer. Some idea of their number may be gathered from the fact that as many as 7,500 have been sighted and recorded in the course of a single year at the signal station at Belleisle, irrespective of growlers. Under these circumstances it is only too evident that they are "calved" at the rate of several thousands per year.

When the Arctic winter commences to break under the approach of spring, the bergs commence their stately march to the sea and more southern climes, being driven in an endless procession by the wind, tide and current through Davis Strait into the main Labrador stream. Here their pace is quickened, as this current swings along at velocities varying from ten to thirty-six miles per day, and when the wind is favourable the masses of ice make long journeys during the twenty-four hours. Fortunately for the mariner only a very small proportion ever reaches the Grand Banks. The Labrador coast is fringed with ridges of sharp rocks, against which the bergs are thrown by the sea, to be grounded and pounded to impotent fragments. Many of those which escape this premature fate collide with one another, and thus bring about their mutual destruction, splitting into curiously shaped fangs and teeth, as the ice has a tendency to divide perpendicularly. Consequently, by the time the berg has reached the limits of the steamship traffic it has depreciated in size very considerably, although it is still formidable. The bergs are borne down the east coast of Newfoundland, and become scattered over the Grand Banks, riding ever southwards, until at last they 
enter the Gulf Stream, where the warm water brings about their annihilation very speedily. Occasionally, however, when the berg is of abnormal dimensions (the western edge of the Gulf Stream flowing round the tail of the Grand Banks is streaked with bands of cold water, and in this region the cold under-runs the warm water at depths varying from 300 to 600 feet) it will weather the width of the Gulf Stream, and wander much farther southward. In some instances the floating sculpture has penetrated as far as the main steamship route between the Azores and the English Channel, which proves that they must have been pushed along by a very powerful submarine current flowing in the opposite direction, or transversely, to the Gulf Stream. Bergs have been sighted as far south as Bermuda, off Cape Hatteras, and even the Florida coast. It is a fortunate circumstance for the mariner that the berg seeks self-destruction very rapidly, even if it clears the rock-bound Labrador coast or avoids collision with a fellow-wanderer. As warmer climes are approached the submerged portions become melted, causing the berg to break up. Alternate melting and freezing, and the unequal strains set up between the very cold contracted interior and the warm and comparatively expanded exterior, bring about a similar result. The sun, pouring down upon the exposed mass during the day, melts the snow and ice, and the water penetrates crevices and cracks. At night this water freezes, and splits the crevices open wider and wider with the force of a wedge, thereby rending the berg in twain or a thousand pieces.

The ice of which the berg is composed is exceedingly brittle. It can be split in two by the blow of an axe, while even the concussion arising from the discharge of a gun has been known to produce fractures. Traversing a field thickly infested with bergs is an uncanny experience, especially at night. One might think that a naval battle was in progress, or that the bergs were being bombarded, from the deafening noise, resembling explosions, heard on every hand. It is neither the one nor the other; the bergs 
are breaking up under natural disintegration, the reports being due to the rending and cracking of the masses of ice and the plunge of large detached pieces into the water.

From the point of view of navigation, the greatest danger incidental to the berg is the submerged spur which often extends for some distance from the under-part of the obstacle, and which is as dangerous as a granite or coral reef. The captain of a vessel has often considered himself clear of the menace, only to find his hull ripped open from the projecting fang of ice which was invisible. The British steamship Nessmore was passing through the southern fringe of the great ice-field and hit a berg head-on, stoving in her bows. The ship made port safely and docked. Then it was found that she had scraped along a spur for some distance just above the keel, for there was the corroborative mark on her hull, while four frames were found broken, and many plates had been cut almost through.

The ice peril is not confined to the berg. The field-ice is another form of this menace. This is formed along the shores of the Arctic Ocean and Newfoundland every year, and every spring sees it set adrift. This ice is the accumulation of years, and may range from twelve to fifteen feet or more in thickness. As a rule it enters the open sea in small patches, but these gradually come together under the action of contrary winds and currents, to form a vast mass several miles in length, absolutely impassable, and broken up in the most rugged manner, with hummocks and undulations, while here and there may be seen the wicked pinnacles of bergs embraced by the gathering clumps. This floating débris is swelled every year by the masses let loose by the breaking up of the iceseal upon the St. Lawrence River, which emerges into the open Atlantic through Cabot Strait. For about a month every year, from mid-April to mid-May, this strait is impassable. The ice, in its endearour to hurry out of the gulf into the Atlantic, becomes jammed in the narrow neck of water, to form a solid barrier between St. Paul Island 
and Cape Ray. This block, which is known as "the bridge," lasts at times from three to four weeks, and it is recorded that on one occasion it held up no fewer than 300 vessels. The break-up of the field-ice precipitates the greatest danger to navigation, as then the bergs which have been imprisoned, perhaps for many months, are liberated. These are the evil growlers, which lie low in the water, and, being dark in colour, cannot be distinguished very readily or easily by the sharpest pair of eyes.

While the mariner has no infallible means of detecting the immediate presence of ice, there are certain signs which may assist him to discover his enemy, though not one is dependable, as varying conditions enter so much into the question. As a rule, before the ice is seen from the deck of a vessel its proximity is indicated by the "blink." This is caused by the reflection of the rays of light from the sun or the moon. On a clear day, over the ice on the horizon the sky is much paler and readily distinguishable from that overhead, so that a sharp look-out becomes urgent. Under good weather conditions a berg may be seen from a considerable distance, owing to its glittering brightness. Similarly, on a clear night it may be discerned by the effulgence, or light, radiated from the mass, while in foggy weather it may be picked up by its apparent blackness, if such a term may be used, as the outline is revealed in a deep shadow through the whiteness of the mist. If the fog-horn or syren is sounded a berg may be discovered, and its distance calculated approximately. The time elapsing between the blast of the whistle and the echo, multiplied by 5.50 , will give the distance of the peril. Thus, if two seconds elapse between the blast and the echo, and $55^{\circ}$ is multiplied by 2 , the result--1, IOO-represents the distance in feet between the berg and the ship. Icebergs often reveal themselves by the sounds produced as they break up, while the absence of swell, or wave motion, in a fresh breeze is an indication of land or ice upon the weather side. The appearance of herds of seals or flocks of birds far from land betrays the proximity of ice, while a fall in the 
temperature of the atmosphere, and also of the water under certain conditions, are useful guides.

None of these indications, however, are infallible. The growler, for instance, cannot be discovered by any of the foregoing indications. There is a glorious opportunity for inventive ingenuity in the perfection of a simple apparatus which will detect accurately the presence of ice in any form. A step towards the realisation of this objective has been made by Dr. H. T. Barnes, a distinguished professor of physics at McGill University, Montreal. He has evolved what he terms an electro-microthermometer, which works upon the same principle as the electrical resistance thermometer. The professor himself carried out repeated experiments with the apparatus in the St. Lawrence River, and during the summer of I9Io it was used on board the Canadian Government steamer Stanley during her visit to Hudson Bay. These experiments and practical tests were highly encouraging, and there is every hope that, when perfected, the device not only will detect the proximity of ice, but also give warning of the approach to land and shoai water.

The iceberg has certain uses, though these do not affect the luxurious modern and speedy liner. Occasionally tramps, when traversing the field, seize the opportunity to obtain a stock of ice for their refrigerators, for which purpose it is admirably fitted, if the berg has not been honeycombed by prolonged sea erosion, as it consists of the purest fresh water. If a gale is raging, an ice-field will form an excellent lee in which to ride safely, as the field will break up the force of the sea like a breakwater. But the navigator must not dare to approach too closely even to this shelter, because the edge, if it should strike the ship, invariably will crush in its sides like an egg-shell, no matter how strongly the boat may be built. The bergs are propelled in their southward journey almost entirely by the current, and often they will force their way through immense fields of heavy ice. Vessels may take advantage of this factor. A captain often will attach his 
boat to the drifting berg with a substantial ice anchor and a strong tow-line. In this way he may be towed through the obstruction in safety, whereas otherwise he would be doomed possibly to a long spell of inactivity, if not helplessness. As the berg advances through the field open water is left to leeward, while the loose ice floats by on either hand, so the boat being towed is perfectly safe. The sealing and whaling vessels often land on the largest monsters to quarry the ice, in the same manner as stone, to obtain fresh water.

The berg, though such a fearful menace to navigation, fulfils its sphere of utility. It is responsible for the prolific fisheries on the Grand Banks. When the ice breaks away from the Arctic glacier, the underwater parts are charged heavily with detritus-rock, sand, gravel and other rubbish -which has been collected as the frozen river moved slowly seawards from the interior of Greenland. As the majority of these masses of ice disappear off the great submerged plateau known as the Grand Banks, the greater proportion of this inorganic material is deposited at this spot, to build up the breeding grounds for the cod, herring and other edible fish. Thus, while the bergs, as it were, seek to destroy in one direction, they build up in another, and have been responsible for the foundation of one of the richest industries in the northern hemisphere, as well as providing a livelihood for thousands of "Captains Courageous" who brave perils untold to reap the rich harvest of these waters.

While the ice on the open sea is a serious menace, it may be compassed by taking a circuitous route, as the ocean is broad. On inland seas and in harbours, however, a different state of things exists. Take the Baltic Sea, for instance. The water freezes up, and a thick glassy armour is produced. This becomes broken up, to drift hither and thither to form hummocks and packs which render the seaway impassable. The eminent Russian naval engineer, Admiral Makarolf, determined to reduce this evil as far as practicable, and he commissioned the construction of a 


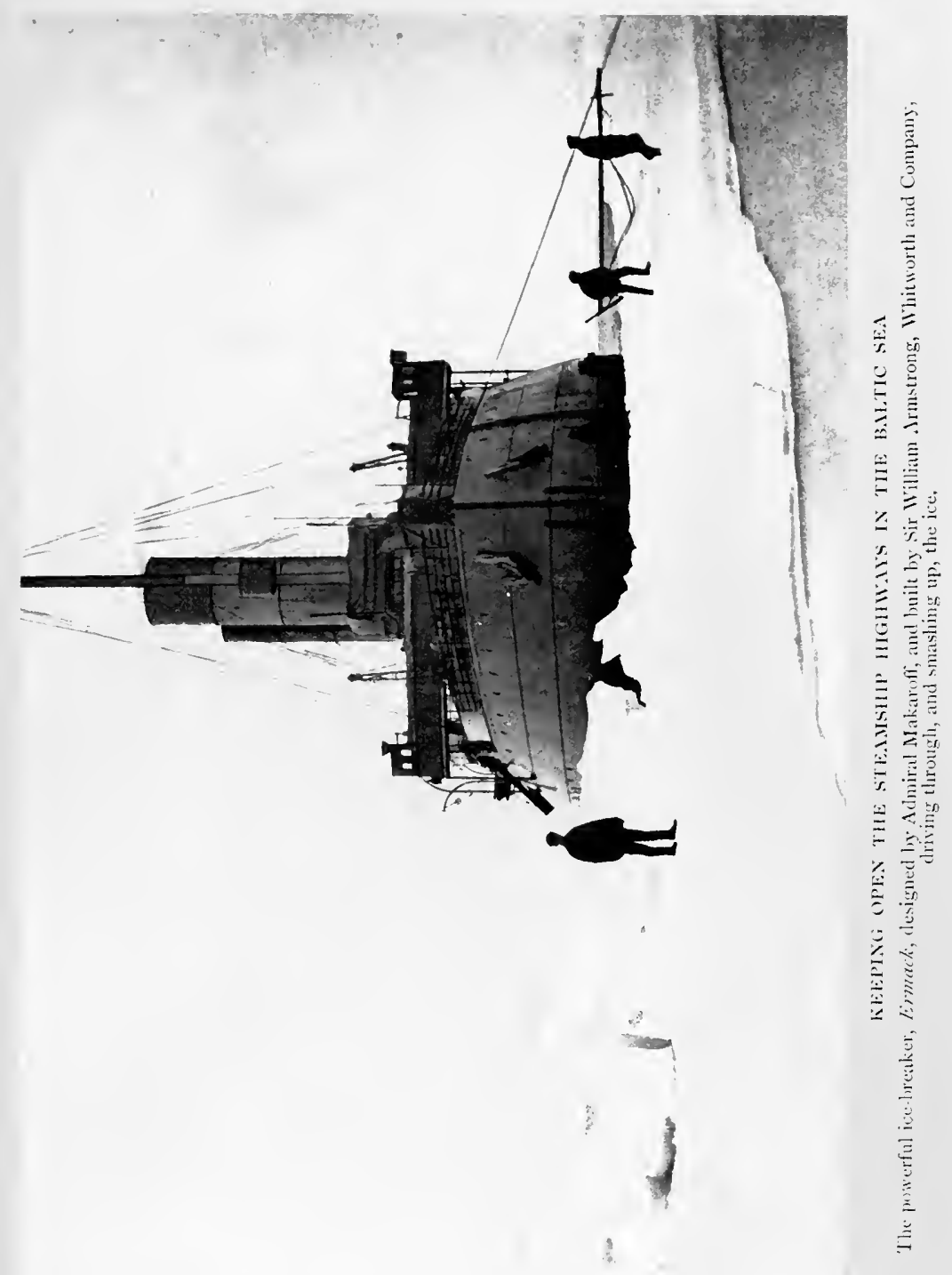




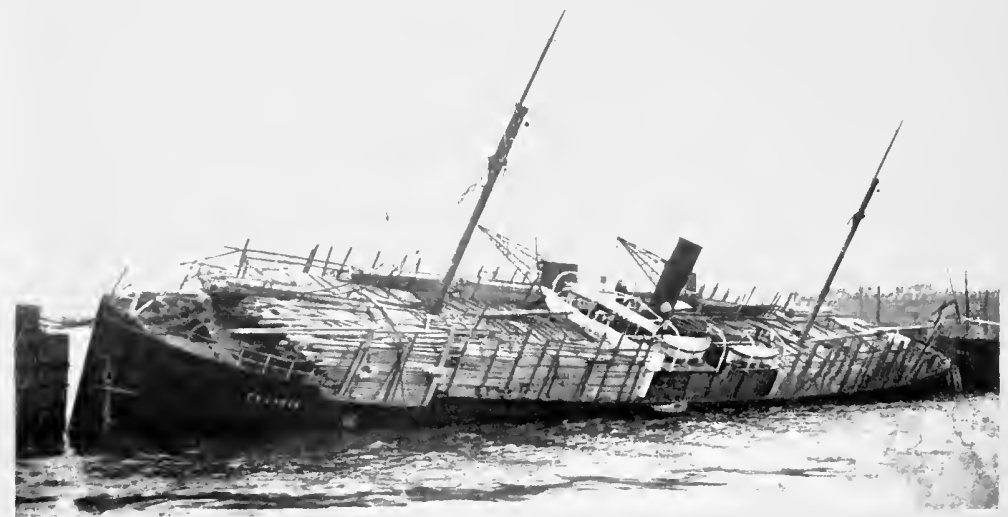

Thoto by firmission of "Sy'th and Shitping" "]

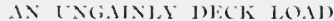

The fielicio, in Mans harbour, with a list of 27 degrees, Heavy deck-thading in timber-carry ing vessels is a frequent canse of dinater.

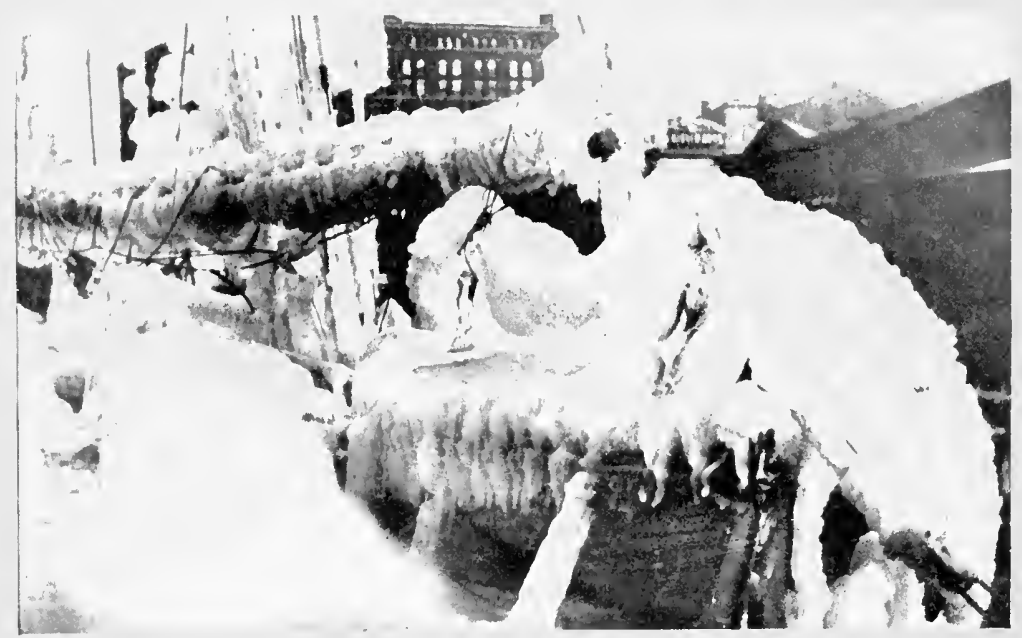

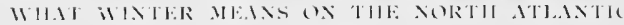

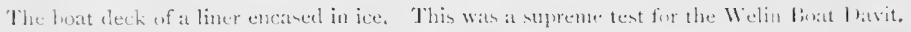


powerful vessel for smashing up the ice. This strange craft was built on the Tyne, and was fitted with both stern and bow screws, of massive design, so that she is able to plough her way through twenty feet or more of the packed mass, to enable steamers to follow an open channel to the sea. Subsequently this vessel was altered, as her bow design was not entirely satisfactory, and since then she has performed marvellous work. When the ice becomes too thick and dense for her to cut through it directly, the heavy bow is formed to ride upwards on to the ice surface, and the layer becomes broken up through the sheer superimposed weight of the vessel and the propelling effort exerted. Since the Ermack was designed and proved her utility, several other vessels for similar work have been built for service in the various ice-bound bays and harbours of the world. On Lake Baikal, where a steam ferry service is maintained between the interrupted arms of the transSiberian Railway and a short cut is offered across the breadth of the lake, the powerful vessels have an icecrushing bow and screw, whereby they are able to cleave a way. In Canada a combined survey ship, yacht and icebreaker was constructed in this country for similar work, while the ice-bound waters of the Scandinavian Peninsula have several of these craft in operation.

During the winter season navigation upon the American Great Lakes is suspended entirely, these inland sheets of water being frozen over. In fact, the shores of Lake Superior have been described as the coldest spot upon the North American continent. When the weather breaks in the spring a remarkable sight is presented. The glassy armour covering the lake is broken up into all manner of shapes and sizes, and the fragments are caught up by the currents and borne away, to be piled up in tangled heaps upon the shores or carried away southwards by the rivers. Clear water instead of ice in the narrow neck of water known as the River St.Clair, joining Lakes St. Clair and Superior, is regarded generally as announcing the resumption of navigation. Then the mariners associated with the bustle 
of water-traffic maintained upon these inland seas see to their boats, since the instant the ice breaks up, the vessels rush for the ports with joyful impetuosity, after the forced lay-up extending over five or six months.

A few years ago the first vessels out had an exciting experience. The steamer Pentland made her way northward through the St. Clair River, and emerged upon the broad waters of Lake Huron. Then she struck a solid pack of ice, estimated at fifteen miles in width, and reaching to the bed of the waterway-a depth of about thirtyfive feet. A number of other vessels which had been lured out of dock by the early thaw ventured southwards too, and were caught likewise, so the unusual sight of fifteen ressels being held in the ice was presented. It was a precarious position for the ships, however. The ice was just as likely to close around them as it does in the Polar seas, and there was the danger, as they were not built to withstand such rough treatment, that their hulls would be cracked like walnuts. For several days the unhappy situation prevailed; the masters and crews had to maintain unceasing vigilance to watch the slightest movements of the ice, so as to secure an escape if anything happened. At the end of about a fortnight the ice cleared a trifle, permitting the ships to get through, after an imprisonment of fifteen days. Then the wedges of ice came together once more, and the jam remained as solid as a masonry wall for another week.

The barrier was caused by the winds and currents. As retiring King Winter released his grip upon the northern lakes under the approach of the spring sun, the ice split up, and the blocks were driven down-stream. The St. Clair River is like the neck of a bottle, and when the masses of ice were driven into this narrow fairway they jostled and rode over one another, unable to edge through, until a solid wall was presented from the river-bed to several feet above the normal level of the waterway. It was a picturesque spectacle; the river resembled an Arctic sea, with the hummocks, of fantastic shapes and unwieldy sizes, piled up in a heterogeneous mass, while the noise, as the pieces ground 
together and became crushed to smaller fragments, was deafening at times. The whole of the navigation in these waters was brought to a standstill. Boats had put out from the northern ports, and had hurried southwards with their heavy cargoes of ore from Duluth, wheat from Port Arthur and Fort William, and mixed freight from the ports along the shores of Lake Michigan, to be arrested, while the extensive docks of Detroit and other southern ports had been emptied of vessels anxious to get northward. Both ends of the St. Clair River were filled with queues of crafts of all descriptions waiting to proceed northwards and southwards respectively. One boat, more venturesome than the rest, drove its way forward through the softer ice, and then, exhausted, came to a dead stop. She had driven her nose into the place where the ice was jammed into a solid block. She could not even back out of her untenable position, as the ice had closed behind her. Fortunately, a ferry-boat which is built for ice-breaking purposes came up and obligingly smashed up the ice sufficiently to enable the imprisoned freighter to retreat slowly.

For twenty-two days the extraordinary situation prevailed. When finally the jam gave way, a remarkable sight was afforded at the lower end of the river. The water and ice poured out of the bottle mouth at the rate of ten miles an hour, the ice being piled up to a height of seven feet or more above the level of the lake in the mad rush. Immediately one intrepid master who had been held up for three weeks attempted to drive his way forward. Crowding on every ounce of steam, and with the engines working at "full speed ahead," he crept into the narrow strait. But although his engines were powerful, the current and escaping ice were stronger still, and the ship was pushed back into the lake below. Time after time the ship was bucked into the ice without success. Then the navigator reluctantly concluded that he was wasting great effort to no purpose, so drew back to permit the ice to disperse, and until the waterway reverted to its normal character. Ice-jams on these inland seas are of rare occurrence, but they hring about a complete disorganisation of traffic. 


\section{CHAPTER XIII}

\section{DANGERS OF THE DEFP}

Although ice undoubtedly constitutes a formidable menace to navigation, the seas bristle with many other dangers of a peculiar character. The majority of these perils may be avoided by skilful seamanship - the balance is well-nigh, if not quite, beyond the wit of man to circumvent. The situation on the ocean is unique. If the captain betrays human frailty by committing an error which precipitates a disaster, the whole world sits in judgment upon him, and more often than not in prejudice. A holocaust on shore is merely a nine days' wonder, no matter how terrible it may be; a wreck on the high seas is kept before the public eye for weeks and months, from a succession of protracted investigations and inquiries, official and otherwise, although the death-roll arising from the marine catastrophe may be only one-tenth of that associated with the dry-land disaster.

The navigator's greatest enemy is fog. It disorganises movement upon the water more completely than it interferes with traffic on terra-firma. The ship and sea are enveloped in a cloak of dense, impenetrable mist, which smothers sound and vision. It conceals unknown obstacles, to reveal them when it is too late. The captain has to grope his way forward cautiously and slowly, like a blind man feeling his path across the street, with eyes wide open to catch the slightest shadow in the pall, and with ears alert to distinguish the faintest sound differing from the noise produced by the ship herself. The guiding force on the modern liner is placed at a heavy disadvantage as compared with the mail-steamer of half a century ago. The navigating bridge is perched so high-from 35 to 80 feet, according to the size of the ship - that it is impossible 
to see the water below. Any dangers lurking there unseen, and which escape detection by the look-out, are able to wreak their devastating effects without let or hindrance.

Probably fog is responsible for ninety per cent. of the calamities at sea. The ponderous ship must be kept moving at a speed which, in the case of a smaller craft, might be considered high under such conditions, in order to maintain control, so that she may answer her helm readily, as well as to off-set the drift of the ocean currents. If the engines be stopped the bulky mass is a more serious menace to herself and passing craft than if she were moving, since some 40,000 tons, drifting along idly at even four or five miles an hour on the bosom of a current, strikes an object with considerable force. On the other hand, if she be moving forward, say at ten miles an hour, then, by keeping her course, she stands a greater chance of swinging clear of a sudden danger, as she will be able to respond instantly to her helm.

Unfortunately, when a collision does occur under these conditions, it is not always the smaller vessel which suffers the most severely. A little craft of a few hundred tons is quite capable of stabbing the larger boat a fatal blow. This was borne out by the wreck of La Bourgogne. This French liner, of 7,395 tons, was driving through a dense fog off Nova Scotia at high speed, when she fouled the Cromartyshire, a small wind-jammer of $\mathrm{I}, 460$ tons. The impact was terrific; both vessels staggered. The sailingvessel had her bows cut off as if with a knife, the plates being twisted and doubled in the most fantastic manner, testifying to the force of the blow. Her foremast and main-topgallant mast were carried away, and came crashing to the deck in a hopeless tangle. She lay crippled on the water, and the crew instantly made preparations to take to the boats, as the master confidently expected his craft to sink. But the collision bulkheads had been strongly fashioned by her builders on the Clyde; they kept the water back, and the rest of the hull was as tight as a drum. Satisfied, the skipper immediately put about, 
with the intention of making a run for Halifax, the nearest port.

In the meantime the liner, which up to this moment had escaped identification, had sheered off into the fog and had eased up. Four sharp blasts rang out from her syren. The wind-jammer's captain thought that help was going to be offered to him, but, to his intense surprise, the next minute he found the sea alive with people. The liner had gone down suddenly, dragging some 500 souls with her. The captain of the Cromartyshire scarcely could believe that his little craft had inflicted such a severe wound in the liner's hull as to send her to the bottom, but afterwards it was discovered that the wind-jammer had rammed her blow home only too well. She caught the liner just abaft the bridge, tearing a gaping hole, through which the water rushed fiendishly, breaking down bulkheads and sweeping everything away in its mad rush. The engine-rooms and stokeholds were flooded in a few seconds; before those on board realised what had happened, La Bourgogne had settled down, preparatory to her final plunge. The Cromartyshire picked up 200 survivors, which a few hours later were transferred to the Allan liner Grecian, she herself was taken in tow, and the two vessels made their way slowly to Halifax, which was reached safely.

This wreck, it may be mentioned, ranks as one of the most melancholy associated with the North Atlantic, owing to the fearful and desperate fights for life which ensued upon the French liner in the rush for the boats. All discipline and self-control were lost, with the result that only 6 I passengers out of a total of 597 were saved, including one solitary woman, while rof out of 223 constituting the crew were rescued. In this instance the liner was to blame entirely. Not only was she travelling at excessive speed, but she was no less than 160 miles off her course. This was the penalty for departing from the scheduled lanes of the sea, as described in the preceding chapter. Had she been on the right road she would not have encountered any sailing-vessels. 
The perils of fog assume their worst manifestation when approaching shore. Perhaps the navigator has been unable to catch a glimpse of the sun for days, in order to pick up his bearings, but has been compelled to rely upon "dead reckoning." In making this calculation the mileage indicated upon the patent log-the liner's speedometer-for the previous twelve or twenty-four hours, is compared with the number of revolutions which have been made by the screws during the selfsame period. The engineer knows how far forward his vessel moves with each revolution of the propellers, and then, by making certain allowances for drift by currents, and so on, the position of the ship may be determined fairly accurately. It is merely a calculation, however, and is not implicitly reliable, so that great risks are incurred when approaching a dangerous coast. The huge American-built liner Dakota, the largest ship built in the United States, of 28,000 tons, piled-up on the rocks off the Japanese coast ; an Atlantic Transport freighter fouled the wicked rocks lying off the Scillies; and the St. Paul missed the entrance to New York harbour and became stranded on the sandy coast, merely because the respective captains lost their way in the fog.

Fortunately, in these days of wireless telegraphy a ship is spared this menace to a very noticeable degree. It is no unusual circumstance for a liner to enter the British Channel without sighting the Bishop's Rock lighthouse, to meet the tender at Plymouth, and to put off again without having seen land at all. The general procedure is for the liner's wireless operator to communicate with the Lizard station, asking them if they can hear the liner's distinctive syren blasts, and the character of the signal, such as two long and one short, three long, or some other variation. The Lizard man listens for the special signals, and will hear them in all probability. To make assurance doubly sure he asks the ship to repeat them. The Lizard man will detect their droning through the fog, possibly faintly, or maybe somewhat loudly, because the aberration 
of sound on the water is extraordinary. He then communicates to the vessel the direction from which the signals have come to him, the captain sets his course accordingly, and maintains constant communication, with variations of his blast signals; the wireless operator at the Lizard guiding him at frequent intervals by relating the varying directions from which the blasts come to him on shore; neither sees the other, they speak through the white blanket.

$W$ ind and wave exact their respective tolls, but the staunchly-built liner of to-day is a match for the heaviest seas, so that any damage inflicted is confined rather to the superstructure. Even on the largest boats, however, the seas, when thoroughly roused, are given the respect they demand. The captain, when the odds are against him, slows his vessel down, and permits the elements to exhaust themselves harmlessly. At times the upper decks get knocked about very badly-boats are stove in, port lights are smashed, ventilators and deck-houses scattered, and the taffrail twisted and bent by the fury of the elements. Still, it is very seldom that the seas are able to claim a victim: but when they do it is a complete conquest, bringing about either the sinking of the craft, or its conversion into a derelict, and thereby strewing the ocean lanes with another deadly peril, which is described in another chapter. The British Prince was as solidly built a vessel as ever left a British yard, but she was caught by one of the wicked gales in rgot while off Sable Island. The first big sea that got home gave her a staggering, knock-out blow. Before she could recover, another sea smashed into her and completed her helplessness. Exposed to the full fury of the storm, the trip-hammer blows got home one after the other, and the hull could not withstand the pummelling. The plates opened up, the water rushed in, and within a very short time the boat formed another contribution to Davy Jones's locker, taking with her the greater part of her crew.

When the Adelaide Steamship Company's ressel Bulwarra entered the IVest Australian port of Fremantle, early 
in 1912, she aroused considerable curiosity. Rising from her deck was a strange-looking structure, which, as she drew alongside the quay, resolved itself into a tower of corrugated iron. When the boat had made fast, another of those occasional sensational stories of the sea was narrated. The Bulwarra had been engaged in a deadly grapple with the elements, and although she had emerged triumphant, she had received plenty of scars. She had put out from Port Hedland on the northern coast with a cargo of cattle. Scarcely had she got out to sea when she ran into a cyclone. The wind, whistling along at a speed varying between 70 and 100 miles an hour, caught hold of the funnel, unseated it, and brought it to deck with a terrific crash, where it smashed up everything until finally it came to rest. The ship was stricken helpless, since to attempt to steam, was to smother the decks with dense clouds of smoke, while there was every chance that a hungry comber might curl aboard and empty itself down the yawning hole where the funnel had stood, to precipitate consternation and injury in the stokeholds. Indeed, one such sea did get up to expend its rage upon the bridge, 34 feet above the water, spreading destruction on all sides. The anchor was let go and the ship steadied, while oil was poured out by the bucket to keep the waves down. IVhen the Bulwarra emerged from the storm she presented a sorry sight, but the crew got to work without delay. The dismembered funnel was tumbled overboard, together with the carcasses of the cattle which had succumbed from terror and injury. Several sheets of corrugated iron were brought up from the holds, together with some heavy pieces of timber, and with these a jury-funnel was built at the expense of two days' incessant labour. The extemporised structure enabled the engines to be set going once more, and the ship crawled into Fremantle little the worse for her hard gruelling, as on examination the hull proved to be as tight as a drum.

In view of experiences of this nature, the question naturally arises, That speeds do winds attain, and what 
are the heights of ocean waves? So far as the wind is concerned, its velocity appears to be illimitable. When blowing at a mile an hour, the breath is scarcely perceptible, but when multiplied twenty-five-fold it produces a brisk gale. Double this velocity and a storm is obtained, while at speeds of 80 to roo miles an hour the wind creates a hurricane. In regard to the waves, there is considerable discrepancy, with a tendency to exaggeration. When a vessel is in the trough of the sea, the advancing wall of water does assume a tremendous height, but the description "mountainous seas" as commonly employed, is illusory. From the collected estimates and scientific measurements that have been made, the average height of the waves during a gale in mid-ocean is about 20 feet. But associated with these regularly running ridges of water are larger and higher walls or waves, which occur at fairly frequent intervals, and these will run to a height of 40 feet in the North Atlantic. When, therefore, a mariner mentions 40 -feet or 50 -feet waves he does not intend to convey the impression that all the waves were of this height, but refers to the intermittent ridges of water which bore down upon his ship. In latitudes where typhoons are experienced, the maximum waves certainly exceed this limit, while the tidal wave, produced by abnormal conditions-as, for instance, an earthquake-may reach a height of 75 feet.

In the days of the single-screw the worst injury that could be inflicted upon the vessel was the loss of its propeller. Often this seals its fate, because the ship, deprived of its driving effort, becomes the sport of the elements. Out of control, drifting aimlessly, the plight of a craft so stricken in a heavy gale is pitiable, as she is continually swept from end to end by the merciless seas. Probably the most sensational journey under these extreme conditions was that of the Cunard steamship Pavonia, of 5,587 tons and 4000 indicated horse-power, running in the Boston service. A heavy gale sprung up and the liner dropped her propeller. She was picked up 


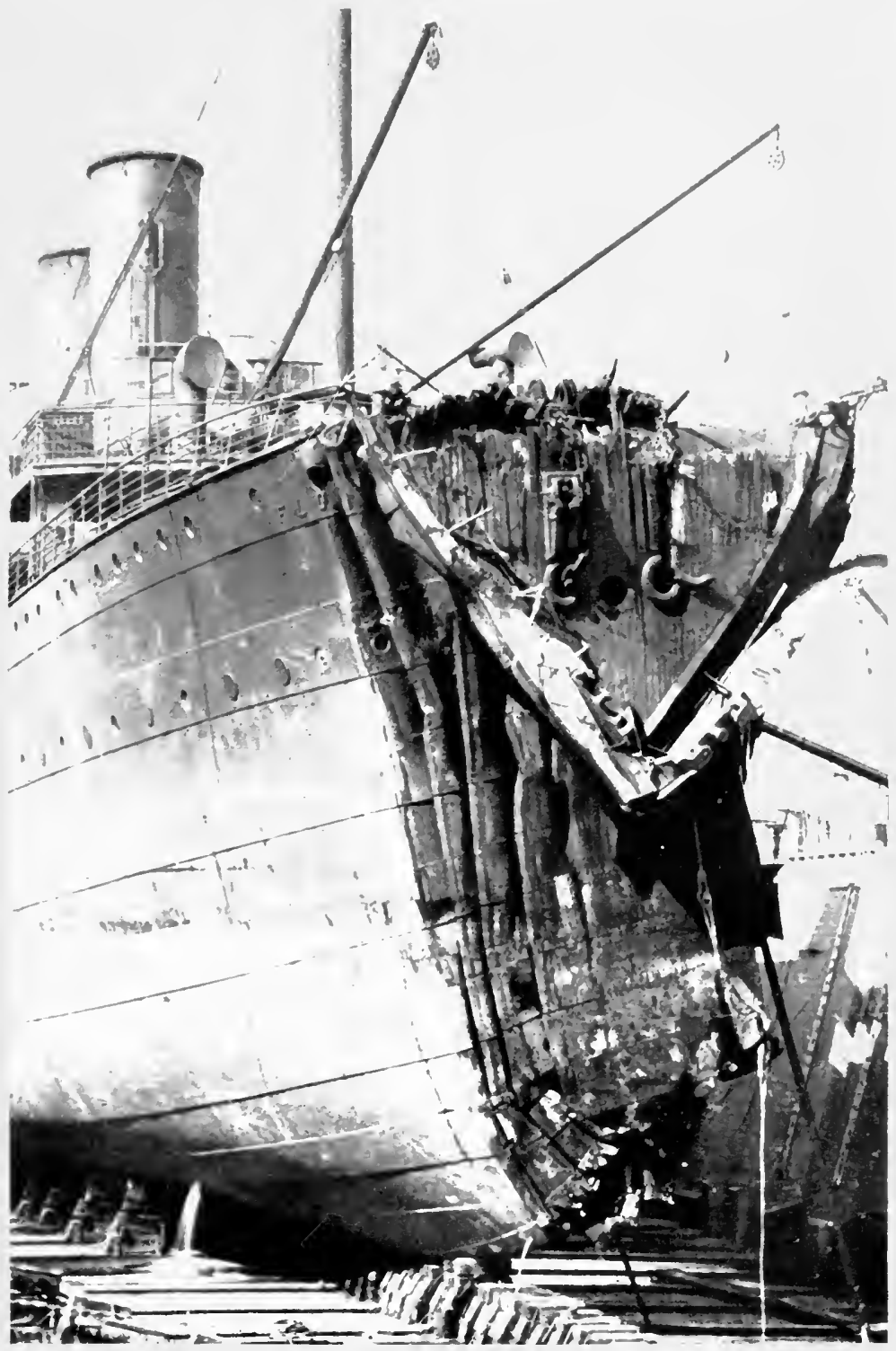

WHEX GREYHUTNOS (ULLHDE DT SEI

The Floria, after she had rammed and sunk the Repulinue in the Nimth delantic: The force of the impact was so steat that 30 feet of the liner's bow were crumpled into a riguce of 5 feet. 


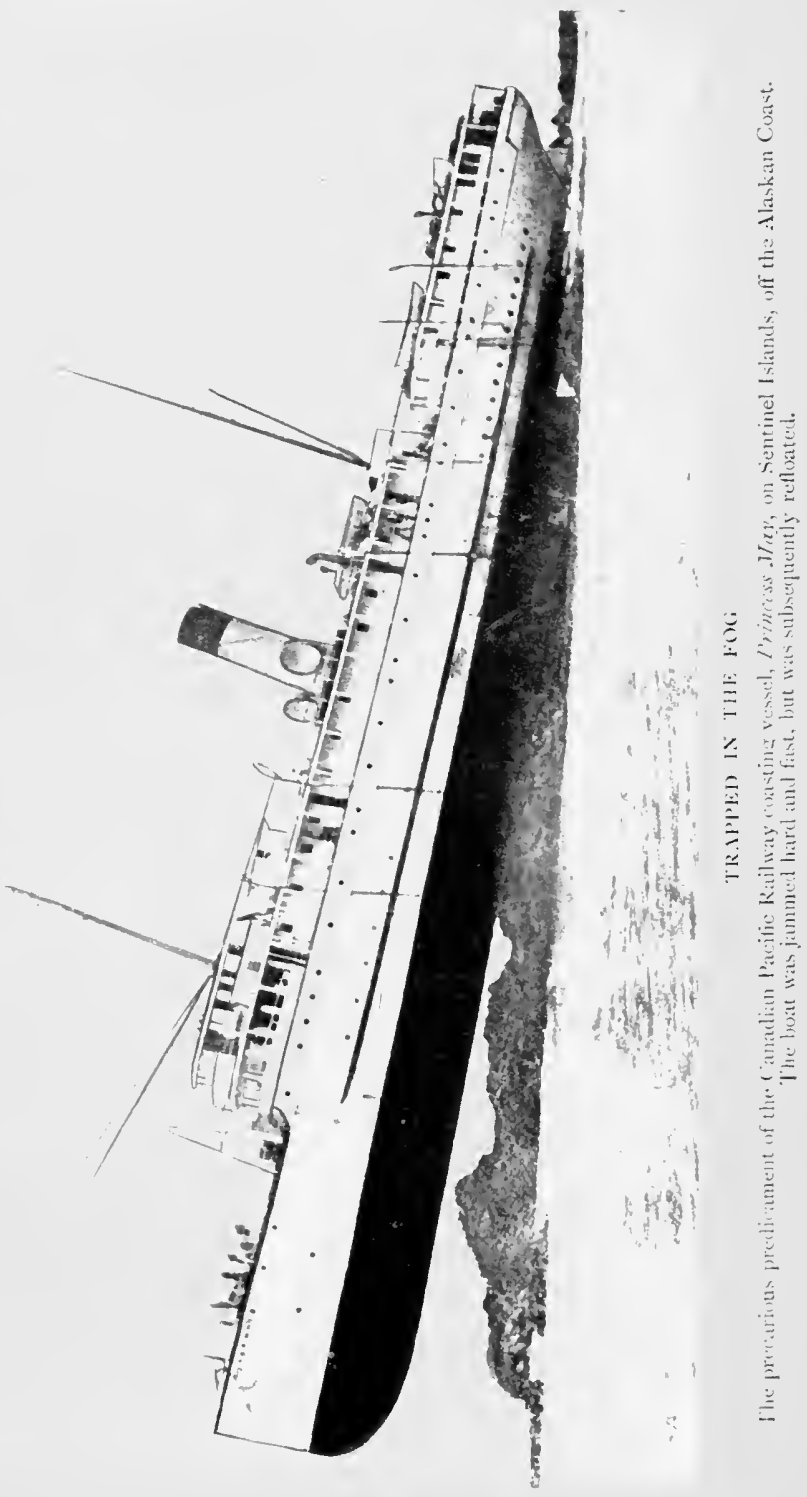


by the contrary currents and winds to be tossed from side to side like a $\log$, and in a short time was carried beyond the great steamship lanes extending from the Old to the New World. Day after day passed and no tidings whatever were received from passing vessels, although one and all were warned to keep a sharp look-out for the missing boat.

Had the Pavonia contributed another mystery to the broad Atlantic? Had she fouled a derelict, smashed into an iceberg, or foundered through collision with another craft? In herself she was as seaworthy as any liner frequenting these seas, so it was generally believed that she had met with an untoward accident and had gone to her last account with every soul on board. Just when the last flickering rays of hope were being extinguished, the tidings were flashed home that she had been discovered, tumbling among the waves off the Azores. She was completely unmanageable, and bore sad evidences of her frightful experiences. Her journey had been most thrilling. The instant the propeller was dropped she floundered like a lame duck, climbing this ridge, and rolling over that wall, of water. This unusual treatment had the expected result. The massive boilers, swayed violently to and fro, moved on their seatings, and gave every indication of breaking loose. This was a calamity too fearful to be contemplated. Six unwieldy, heavy cylindrical boilers, rolling from side to side in the stokehold, would have finished the career of the Pavonia in a few minutes, as they would have battered through her sides. In frantic haste the weight of the masses was reduced so as to minimise the strain upon their seatings. The steam was suffered to escape, the fires were drawn, and the water was run off, the firemen displaying heroic fortitude in the scalding steam and water. But they saved the ship. Emptied of their contents, there was not so much fear of the ungainly boilers becoming detached.

The rescue of this unfortunate liner was as thrilling as her accident and drift. The Wolviston, a small steamer of 2,565 tons register, sighted her about noon one day early 
in February, and answered her signals of distress. A heavy sea was running, but the Wolviston crept within hailing distance, and saw the unhappy passengers crowding the liner's decks imploring help. Captain Snowden, of the tramp, at once decided to take the disabled craft in tow, but this proved no easy matter, as she was rolling dangerously in the trough of the sea. An officer managed to put off from the helpless liner, and he was asked if her captain would abandon his ship, after the passengers and crew had been transferred. The master of the liner refused point-blank, until the Pavonia was doomed. Accordingly, a heavy towing-rope was passed from one boat to the other, and the tedious journey homewards was commenced. They had scarcely got under way when the rope snapped like a thread, and, the gale increasing, it was found impossible to pass another line. Captain Snowden, for his own safety, had to resort to extremely skilful navigation to prevent the seas sweeping his craft from end to end. Oil had to be distributed freely on the water whenever he wanted to turn his ship, as when the first towing attempt failed, he decided to stand by the helpless craft until another favourable opportunity occurred to resume the operation. With the advance of night, however, the gale increased in fury, and it was imperative to keep the Wolviston's head to the sea. The result was that the Paronia drifted away, and when morning broke she was nowhere to be seen. The master of the Holviston rode the gale, and then shaped a course which he concluded would bring him up with the helpless liner once more. For five hours he ran in this direction, covering 45 miles, and then sighted a bright light directly ahead. Captain Snowden immediately sent up all kinds of signal-rockets, blue lights -in fact, everything that could be thought of. The vessel in distress responded, and to the delight of the 11 olviston it proved to be the Pavonia. The two kept company that night, and in the morning another towing-rope was passed from ship to ship in another effort to reach safety. No further untoward incident happened, and after five 
days' steaming, at an average daily speed of 135 miles, St. Michael's was sighted, and the Pavonia was berthed safely, the passengers thankful for their deliverance from the deep, but otherwise little the worse for their remarkable adventure.

With the introduction of the twin-screw vessel the possibility of such an accident was rendered more remote, but in October 1907 the German greyhound Kaiser Wilhelm der Grosse had an unlucky experience. She was homeward bound, and driving her way through a typical October gale, into which she ran when a few hundred miles out of New York. Suddenly she gave a shiver, slewed, and then shot forward. The movement of the wheel betrayed that something had gone: it was the rudder. The nearest port was Halifax, about a day's steaming distant, and the captain's first thought was to make for that harbour. A little reflection convinced him, however, that he could reach Europe safely by steering with his propellers, varying the speed of one in relation to the other to keep the ship's nose in the desired direction. Two or three passing ships who spoke him offered assistance, but it was declined, as the liner was making good progress, and four-and-a-half days later the Bishop's Rock lighthouse was picked up. The captain stuck to the bridge day and night during the whole journey, never leaving the wheel for an instant, and when at last the Channel was entered, and he could take a short rest, his feet were found to have swollen so badly that his boots had to be cut off.

The captain who has the misfortune to lose his rudder or to have his screw incapacitated, and is thus condemned to helplessness, does not give up the fight without a stiff struggle. One single-screw boat was ploughing across the Atlantic and lost two blades of her propeller. In the morning an effort was made to repair the accident. The fore-peak of the ship was gradually filled with water, and in this way she was caused to tip so that her stern and screw were lifted out of the water. A plank was lowered over the stern, and on this swinging foothold two or three 
of the engineers, with life-lines tied round their waists, set to work clearing out the holes in which the bolts were set in the boss, in order to attach new blades which happened to be on board. It was an awkward perch upon which to ply tools, while the tossing of the ship rendered their task more difficult. At times they heard a shout from the lookout above, grabbed their life-lines tightly, and held on for grim death as a wave swept over them. It was painfully slow work, and the cramped quarters did not give the men much elbow-room, but the new blades were fitted at last. The fore-peak was then emptied, the stern settled into the water, the ship regained her trim, the furnaces were fired, and the steamer resumed her journey as if nothing had happened.

The engineer, when he finds himself in a tight corner, is a man of infinite resource, patience and perseverance. The single-screw steamer Milton was on her way from Cape Town to Australia, and was about r,500 miles out, when, in the height of a gale, the vessel got out of control. At first it was thought that she had dropped her propeller, but examination revealed the welcome fact that the screw was intact. Something had gone wrong with the shaft, and the accident was somewhere within the ship.. In the morning the shaft was examined, and it was found to have been fractured in about as awkward a place as could be conceived-right at the extreme end of the ship, where only about three inches of space separated the tube from the sides of the boat. The fore-peak was filled with water, and the after-peak was emptied, in order to lift the stern into the air, and thus to bring the propeller out of the water. A plank was lowered over the stern, and on this narrow, lurching gangway two or three men, with life-lines, dared the extremely heavy seas which were running, lowering a hawser round the blades in order to lift them up, and bring the two ends of the broken shaft together. It was found that a piece of the propeller-shaft had broken clean away, and this had to be removed. Then the two ends were brought as close together as possible 
and held while longitudinal slots in line with one another were cut into the ends of the two shafts. Six of these slots had to be cut with infinite labour, for the space was so small that only one man could work at a time, and then only intermittently. Cutting slots a foot long, by some three inches wide and two inches deep, in the steel of which a propeller-shaft is made, and with hand tools, is almost a hopeless task, but the men did it.

The engineer was equally ingenious in discovering metal and fashioning it into keys to be sunk into these slots to bind the two pieces of the shaft together. He tore stanchions out of the deck, heated them in the boiler furnaces, and forged them; whatever machining that was required being completed with a small lathe carried on board. The keys thus fashioned were driven into the slots and held there by bolts sunk into the shaft. Three clamps were then improvised from suitable fittings taken from other parts of the ship, and which could be spared. These were tightened round the ends of the shafts to hold the rough joint tight. All this time the vessel pitched and rolled in a fearful manner as the gale raged with unabated fury, as if maddened by the engineer's ingenuity and perseverance. At the end of twenty-five days and nights of continuous labour, the engineer had the satisfaction of seeing the repair completed, and the I, I 84 miles to Port St. Louis, Mauritius, were covered safely at a speed of $4 \frac{1}{2}$ miles an hour. For this remarkable piece of work, which saved the ship, the engineer and his comrades were rewarded handsomely by the underwriters, who thereby escaped insurance upon a total loss.

Many of the dangers incidental to ocean travelling arise from within the ship herself. Fire is probably the greatest peril to be feared. A conflagration on shore is terrifying, but it is a thousand times more so at sea. The calamity that befell the steamship Sardinia off Malta has not been forgotten, but, fortunately, such a disaster is of rare occurrence in passenger-vessels on the high seas, although it is by no means uncommon in port. The cargoes often 
precipitate a calamity of this character. The coal stored in the bunkers to feed the boilers, which may easily represent 5000 or 6000 tons in a modern monster, is liable to spontaneous combustion, and small outbreaks from this cause are by no means uncommon. Cotton, wool and hay are apt to burst into flame from the same cause. The most terrible holocaust on record arising, it is thought, spontaneously, was in connection with the Great Queensland in August $18 ; 6$. This vessel put out from England for Melbourne, with 560 people aboard, and with a cargo which, among other things, included a large quantity of gunpowder! The ressel never was seen again, although some shattered wreckage was picked up off Cape Finisterre. It is believed that she caught fire, the explosive cargo became ignited and blew the ship to pieces, together with her passengers and crew.

The most dangerous cargoes, however, are handled by special vessels, such as, for instance, those engaged in the transportation of oils. The Blengfell, of 1,2 IO tons, was being towed through the Downs on Monday, October 17 , 1898. She had a cargo of naphtha, stowed in barrels in the after hold. Suddenly there was a terrific explosion, accompanied by a sheet of flame. The after part of the ship, together with the captain, his wife and child, the officers, and the pilot, who had stepped aboard only the previous evening to take her into the Thames, were blown to atoms. The ressel drifted on to the Tongue bank and there burned herself out, I 3 of the crew being saved in the nick of time. Vessels laden with cotton appear to be unlucky in respect of fire, since cases of spontaneous combustion in connection with this cargo are quite frequent. When an arowedly inflammable rargo is being carried, extreme precautions are taken to ensure as much safety as possible, but now and again ingenious man receives a severe shock. There was the steamer Snorre, for instance. She put out from Odda in Norway with a cargo of calcium cynamide, but never reached her destination. On the voyage a search was being made for mouse- 
holes in the crew's quarters, and a lighted match was brought near a hole. Instantly a tongue of flame shot out, followed by an explosion which shattered the ship, and launched eight out of the thirteen hands forming the crew into eternity. The gas had been given off by the carbide, had collected in the hold, and ignited upon the first approach of a naked light. The shipping community had looked at the transport of this chemical product askance for some time past, but, assured by the chemists that they had secured a perfect means of rendering it innocuous, accepted it as a perfectly safe cargo. This accident shattered the claims of the inventor in a ruthless manner, and made underwriters more suspicious than ever.

One would not think that wood pulp is a dangerous cargo for a ship to handle, but the mariner will tell you it is about the last thing he would care to have aboard a ship while she is being knocked about by rough seas. A sailing-ship with a load of this material put out from Nova Scotia cn route for England. When about 300 miles out she was overwhelmed by a gale. The masts and rigging were splintered, and the water poured on board continuousiy. The crew stuck to the pumps like heroes for several days, in the endeavour to prevent the water reaching the cargo, but they became exhausted by the severity of the task. The wood pulp sucked up the water like a sponge, and in expanding exerted such enormous pressure upon the hull as to split it open in all directions. Eight of the crew were picked up in a small boat; the remainder of their mates went to the bottom with the ship.

Breakdowns of the machinery often precipitate some anxious moments in the engine-room, and it is only the tireless vigilance of the engineering staff which has saved many a fine ressel from an untimely end. The Lucania was bowling along at full speed for home when, in the middle of the night, the music of the engine-room was disturbed by a terrific crash. The engines were stopped promptly, and then it was found that the piston-rod of the port engine was smashed, and ponderous pieces of metal 
were flying about in all directions. The engine was crippled completely, but investigation proved that no harm had been inflicted upon the vessel's structure. The starboard engine was re-started, and the liner got home under reduced speed on one propeller.

The greyhound City of Paris, which afterwards ran upon the Manacles, did not escape so lightly under a similar accident. She was travelling home at full speed with wellfilled cabins when, off the coast of Ireland on March 25 , I 890 , something went wrong with the starboard engine. In a short time the engine-room was flooded, and the port engine became disabled. The liner was now as helpless as a derelict, and at the mercy of winds and currents. There was only one possible way to obtain assistance-to put off for it. Accordingly, a lifeboat was launched, with some of the crew to row to Queenstown, where they told their story. The plight of the liner was precarious in the extreme, so no time was lost in dispatching a steamer to her assistance. Fortunately the liner was picked up unharmed, although the passengers had been exposed to a fearful peril, rolling helplessly in the trough of the waves for nearly four days. The friendly towing-rope was passed from ship to ship, made fast, and the Paris was towed into the Irish port to drop her passengers and mails, about three days late, little the worse for her misadventure. This accident brought home the fact very conclusively that even a twin-screw. vessel may become totally disabled by a breakdown with her engines, though only under abnormal circumstances. To-day, an accident like this would be trifling, as, thanks to wireless telegraphy, assistance could be summoned, and the crowded state of the steamship lanes would ensure help being rendered within a few hours of the mishap. 


\section{CHAPTER XIV}

\section{CLEARING THE OCEAN HIGHWAYS}

“April 25, Lat. $38^{\circ} 42^{\prime}$, Long. $57^{\circ} 54^{\prime}$, passed a whitepainted spar standing upright and projecting about 7 feet out of water, apparently attached to a submerged wreck. -Mauretania (Br. SS.)."

This terse statement in the Daily Report of the United States Hydrographic Office means more than appears at first sight. It conveys the intimation that the great steamship lanes of the North Atlantic are obstructed by wreckage, offering a danger to navigation. Perhaps the announcement will appear a dozen times in the same report, having been sighted by as many various vessels in as many different places. But it warns all and sundry -the tramp as well as the ocean flyer-that vigilance must be maintained by the look-out to avoid a collision with an almost invisible peril, the extent of which is not fully apparent from the surface.

The obstacle, such as a spar or deck-house, may be detached and floating aimlessly to and fro. On the other hand, it may be attached to a vessel, in which event the hull of the latter is floating several feet below the surface, and able to inflict serious damage to the hull of the craft which ventures to scrape a passing acquaintance.

The derelict is one of the greatest menaces to navigation. The battered, shapeless hulk, barely protruding above the waves, lies in wait for the passing vessel and right in her path. She may escape the eagle eye and alert ears of the unsuspecting approaching ship, particularly if the weather be thick. There is a sharp blow or a wild quiver. The vessel lurches forward; a few plates are dented or ripped, according to the force of the blow, or a propeller is dropped. 
These are the methods in which the derelict completes its deadly work.

Whence come these drifting obstructions to other craft? For the most part they are sailing-vessels, although now and again a steamer will be included in their ranks. Ninety-nine times out of a hundred they will be laden with lumber, constituting one of the most fearful masses against which a ship could rush. They are victims of wind, wave, fire and icebergs. A vessel puts out from port with a full cargo and as tight as a drum. A storm sweeps down upon her, and she is soon reduced to a helpless, tangled mass. Masts are snapped off by the combined elements, to come crashing down with yards and rigging. Totally disabled, the trip-hammer seas do the rest. They pound and batter the craft mercilessly, starting leaks in all directions, so that the boat settles down into the water. The crew, unable to effect any repairs, either put off from the foundering craft in their boats, leaving her to her fate, or are taken off by a passing ship, which answers their signals of distress. Then the long, long, drifting cruise of the derelict commences. It does not end until she is ground to pieces among the ice, destroyed by explosives, shot and shell, or perhaps splits open in a hundred different places under the tremendous pressure exerted by the swelling cargo within, which effects its escape, to become scattered broadcast, while the hulk itself goes to its last account. Occasionally the derelict escapes this fate for one better. She is picked up by a passing boat and towed into port, possibly bringing the salvor a rich reward for his perseverance.

These waifs of the ocean are more nomadic than the most perfect tramp on shore. They are tossed to and fro, being first swept southwards, then northwards, are scurried towards the American coast to be beaten back by adverse winds and currents towards Europe. In some instances highly remarkable journeys have been made by these masterless craft. There was the Crown, which left Nova Scotia for a South American port, with a valuable cargo of 
lumber. The crew of this Norwegian barque had an unenviable Christmas Day fighting desperately for their lives and their ship against a hurricane which they experienced off the Sargasso Sea. The elements won. The ship was reduced to a chaotic mass of mastless and rudderless wreckage. It was impossible to make port, so the crew put off in their boats and were never seen again. Had they stuck to their ship they might have been saved, as the Crown, after disappearing from sight for three months, suddenly reappeared on the western edge of the Sargasso Sea, the fabled resting-place of derelicts. She had drifted no less than 700 miles in these 93 days. She slipped from sight once more to be espied still farther west, a fortnight later, and finally was seen drifting off the Bermudas. Then she vanished from all mortal knowledge, although mariners are keeping a sharp look-out, as it is quite within the bounds of possibility that she will crop up again, perhaps off the coast of Ireland, unless her swelling cargo has wrenched her to fragments.

The Netta Champion was another wanderer of the first class. She fouled the same hurricane that devastated the Crown and was similarly abandoned. Without a guiding human hand she started off on a long trip towards Europe, and wandered into the great steamship lanes. Liner after liner dodged her, until on May 16,1912 , she was espied near the 3 oth meridian and latitude $50^{\circ}$, making apparently for the west coasts of the Shetland Islands.

But the most extraordinary instances of the long journeys sometimes covered by these hulks, are afforded by the schooners Alma Cummings, the Fannie E. Wolston, and the W'yer G. Sargent. All three put up remarkable records as much for the irregularity of their wanderings, as for the distances covered. The $\mathrm{H}^{\prime}$ yer G. Sargent was caught in a storm while threading the troublous waters around Cape Hatteras on March 31,1891 , and was abandoned as a total wreck, her crew thinking that within an hour or so she would enter that ocean graveyard. But to the surprise of the crew she was sighted thirty-five days 


\section{I92 STEAMSHIP CONQUEST OF THE WORLD}

later, well on an uncontrolled voyage to Europe, having covered several hundred miles. Then, caught by adverse winds and currents, she was driven 300 miles back, and on June Io was apparently making for the spot where she had been left to her fate. Navigators thought they had seen this danger for the last time; they surmised that once she got tangled among the Diamond shoals she would never emerge upon the ocean again. They were doomed to disappointment, because on July 2 she was sighted right on the main track between New York and Europe, northeastward bound, and going strongly. By the $15^{\text {th }}$ of the same month she had put another 800 miles to her credit, and then she became most capricious in her movements, as she incessantly doubled and redoubled upon her tracks. On October 20 she was seen making for Madeira, barely Soo miles away, but suddenly changed her course, as on November 23 she was spoken farther south and more to the west. She was seen for the last time on December 6 . Her end no one has been able to guess, but from that day to this she never has troubled navigation further.

The Fannie E. Wolston was abandoned in October of the same year as witnessed the apparent foundering of the Wyer G. Sargent, and curiously enough also off Cape Hatteras. From this point she drove straight across the Atlantic to longitude $40^{\circ}$, hugging the outskirts of the steamship lanes. Then she struck south, blundered back in a north-westerly direction, and kept zigzagging to and fro around one spot, until she ventured on a long trip southward. Then came a long reach towards the American coast, the helpless craft being sighted south of the Bermudas en route to Cape Hatteras. The vessel, however, changed her mind, wore southwards, and then worked up the Florida coast, where she slipped from sight after wandering about the North Atlantic for some four years, imperilling steamship traffic in all directions. She was sighted on no less than forty-six occasions, was boarded time after time, but she was not worth the expenditure of a tow-rope. The last party who boarded her sought to 

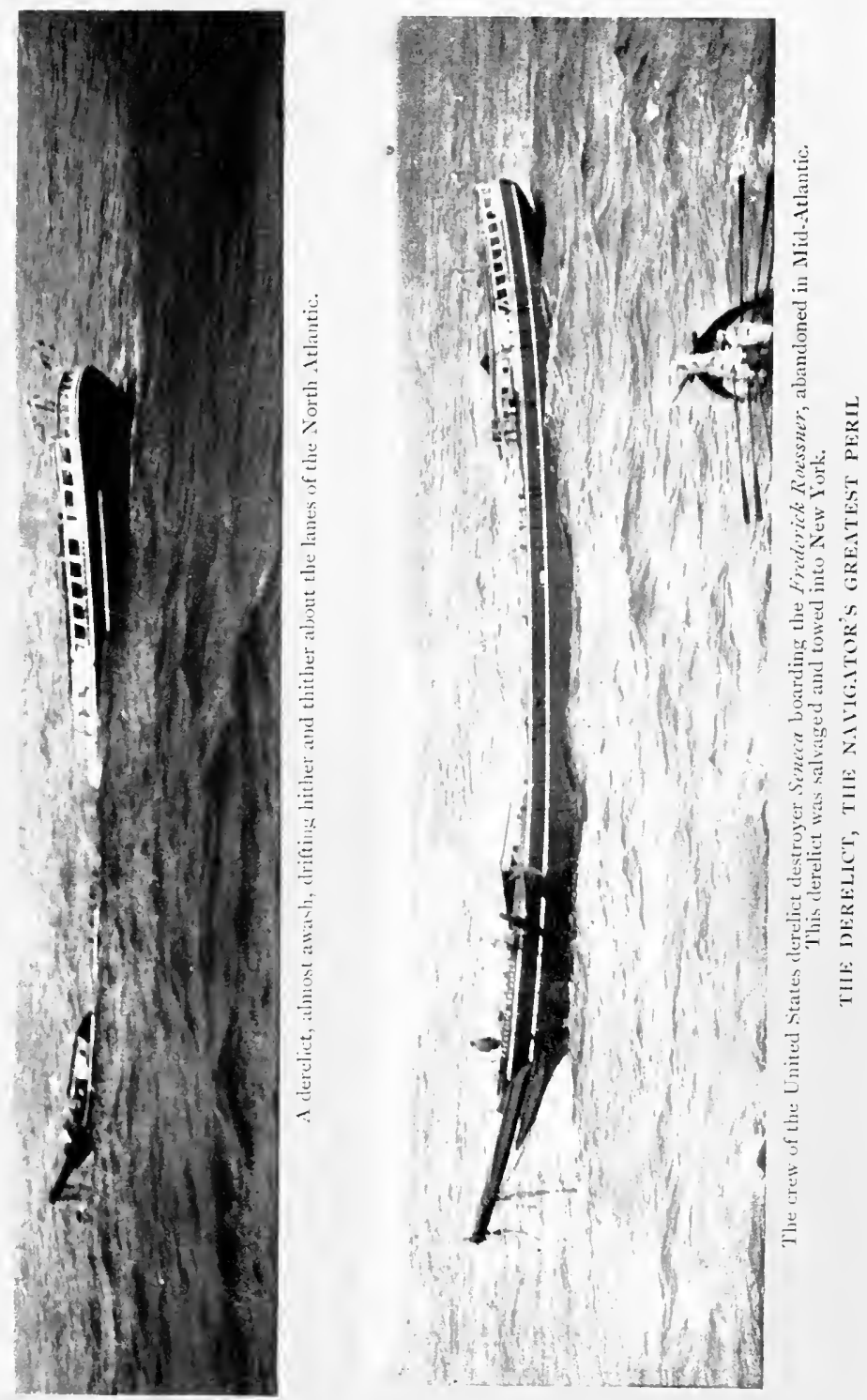


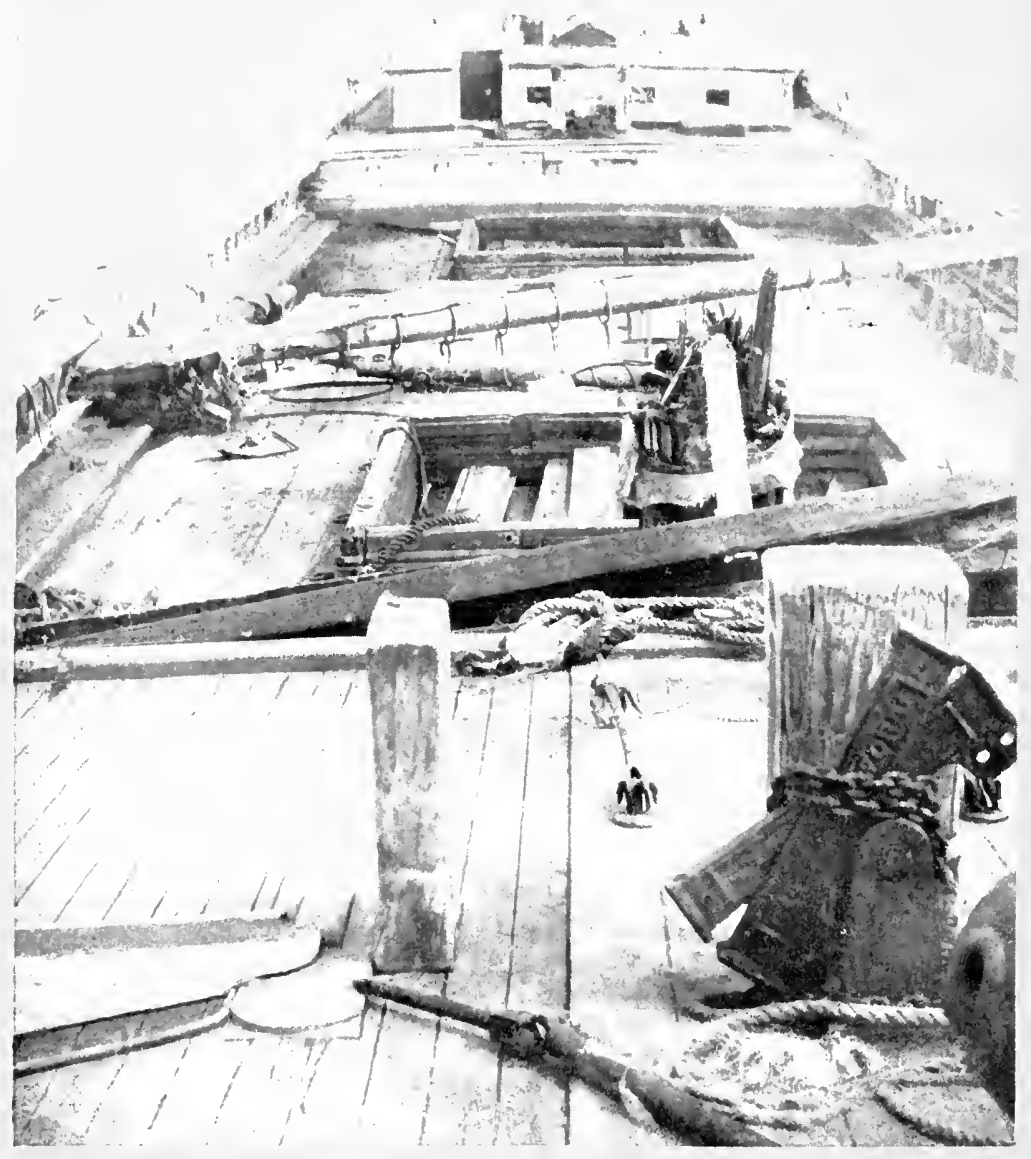

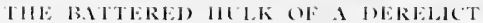

Showing the complete nature of the dectruction wrught ly wind and wave. When the above abandoned ventel wat raught by the crew of the United stated derelict destroyer Seneca, and boarkd, she was deemed worthy of silvage, wo was towed into New York. 
bring about her destruction with fire, leaving her to drift a flaming beacon until she was burned to the water's edge. Whether this hurried her final disappearance or not, no one knows, but before she was seen for the last time, a charred, battered wreck, she had covered over 9000 miles without a hand to guide her.

The story of the Alma Cummings is somewhat more sensational. She fouled a blizzard off Cape May during February 1896 and suffered sorely. Her masts and rigging were carried away, together with every stick of superstructure on the deck. Labouring in the trough of the sea the waves bore down on her time after time, flooding her cabins and reducing the crew to a pitiable condition. All the provisions were spoiled, and even the friendly fire was denied them, since all the matches were soaked. After careful deliberation the captain decided to abandon her, but realising that she might stray into the ocean highways, he decided to send her to the bottom once and for all. The problem was, how to bring about this destruction. Scuttling was useless, as she would simply settle lower into the water to become a more difficult obstacle for detection. At last a can of paraffin was brought into the cabin, and the vessel was set alight by discharging a rifle into the oil. When the crew finally bid the Alma Cummings adieu to be taken on board a friendly vessel attracted by the smoke, she was burning furiously. One and all thought that her end was merely a matter of a few hours.

But the expected did not happen. A few weeks later a hulk was espied off the English coast and boarded. It proved to be the Alma Cummings, whom every mariner thought was safely imprisoned in Davy Jones's locker. Her deck had been devoured by the flames, but the cargo being soddened had refused to burn, and the fire had wrought no vital damage. It was hoped that she would smash herself to pieces on the iron-bound coasts, but when this fate appeared certain the vessel made a dive southwards along the coast of France, cleared the deadly Ushant, and was next seen off the Azores. Then she made another 


\section{STEAMSHIP CONQUEST OF THE WORLD}

weary drag across the Atlantic, covering some 6000 miles before she threw herself on the shores of Panama, never to ride the waves again.

It is very seldom indeed that a steel steamship will keep afloat when she has been badly smashed by the elements, but there was one notorious boat of this type which defied destruction. This was the single screw tramp Dunmore. This steamer of 3,500 tons left Cardiff on December 20, 1905, for Newport News with 3000 tons of Welsh steam coal. The whole vessel as she floated was worth some $E_{14}, 000$, or $\$ 70,000$. The close of that year was unlucky, owing to the numerous and terrific blizzards which swept the Atlantic, wreaking widespread damage to shipping. The Dunmore had well-nigh completed her journey when she lost her propeller. The captain held on to his ship for some time, in the hope that he would be picked up, but was disappointed. Then the vessel, as a result of the pounding received from the heavy seas, commenced to leak and gradually settled down. Fearing that she might take the final plunge at any minute, the crew put off in their boats, and contrived to reach Baltimore, the vessel having been left to her fate about 600 miles off Cape Cod.

The trans-Atlantic liner St. Louis came into New York during the following March with one of the strangest stories of the sea that has ever been related. At midnight, on the $14^{\text {th, }}$ the look-out suddenly drew attention to a steamer behaving curiously right in the track of the greyhound. She was riding the waves, and it was seen in a moment that she was out of control. The liner swung to the south to clear the strange craft and hailed her. There was no response, but as they drew near they heard the rats scuttling to and fro, startled by the blast of the syren. The boat had a heavy list to one side, was a mass of red rust and the funnel had been snapped off like a carrot. It was fortunate for the St. Louis that the night was clear and bright, for she was off the Grand Banks at the time, and had the usual fog prevailed and the liner 
had crashed into the hulk head on, another terrible calamity probably would have been placed on record.

The weird derelict proved to be the Dunmore, long posted as having foundered, but from all appearances fit to ride the seas for many a day. The shipping community became anxious, for the 3,500 tons of helplessness was floundering to and fro across the steamship lanes. In their alarm a sealer was chartered at St. John's to go out to search for her, and either to sink or tow her to port. But the sealer scoured the Atlantic in vain: she never caught a glimpse of the derelict. Time after time the vessel was spoken by the various mail-carriers, as she persistently clung to the ocean highways. Once or twice a vessel paused, passed a tow-rope to the derelict and dragged her several miles to one side out of the way, but she always got back again. The companies urged the British Government to dispatch a warship on her tracks and to settle her once and for all with a mine or bombardment. In response to this appeal five cruisers set out from Bermuda, and although they ransacked the North Atlantic the Dunmore eluded them completely. Merchantmen still continued to sight her repeatedly, and one or two even attempted to get her to port, as the salvage award would have been heavy, but the rope always broke, and the Dunmore got away. What her ultimate end was no one knows-probably she was cast ashore to be smashed to smithereens, or in turn was rammed and sent to the bottom. The fact, however, remains that she kept the companies engaged in the greyhound service on tenterhooks for weeks. She might have been put out of harm's way when abandoned had the crew only thought of opening her sea-cocks. Then she would have gone to the bottom like a stone.

The derelict, if it can be recovered, is invariably worth every effort put forth for this purpose. She is generally laden with lumber, which always fetches a high price, more particularly if it is well-soaked from long immersion in salt water. There was the single screw steamer Loch 


\section{STEAMSHIP CONQUEST OF THE WORLD}

Maree, which left the American seaboard with a cargo of cotton. While rounding the north coast of Ireland she was assailed by tempests, ran out of coal, and in distress signalled a passing steamer. The tow-rope was passed, and the Maryland endeavoured to bring the helpless cargo boat into safety, but was so damaged in the process that, after taking off the crew, she let the Loch Maree go. The freighter drifted, an unmanageable hulk, towards the Hebrides, but a tug in Liverpool, hearing of her wealthy cargo, put out, firmly resolved to get hold of her. The derelict was secured 180 miles north of Inishtrahull, and within a few hours was made fast to the quay at Belfast, little the worse for her adventure, but the rescuing tug richer by $\mathcal{E}_{7,960}(\$ 39,800)$ as salvage award. The Cubana was another rich prize. She put out from Newfoundland with a cargo of copper ore for South Wales. She weathered the Atlantic safely, but off the Irish coast came to grief in a gale, which carried away her rudder. As the winter was advancing, and the ship was drifting away from the usual tracks of passing vessels, the crew left her to the mercy of the elements. The Cubana drove to and fro over the seas for the whole of that winter and the succeeding spring, keeping well to the northward.

One morning the fisher folk on the west coast of the Shetland Islands were astonished to see a sailing-vessel standing in to shore. Her sails were torn and dishevelled, and her masts were somewhat knocked out, but otherwise she appeared to be all right. They hailed her, but received no response. Then they put out in a boat and boarded her. Utter silence prevailed. The deck was littered with débris, but the ship herself was as sound as the day she first slipped into the yater down the launching-ways. She had been abandoned-that was all too evident. Satisfied upon her seaworthiness a scratch crew was made up, and the little party got her safely berthed in the nearest port,

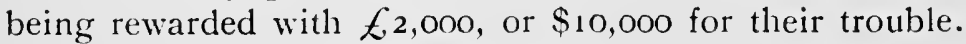

Seeing that many of these derelicts are so valuable, why is not a sound commercial effort made to hunt them down 
and to bring them into port? It is computed that nearly 200 derelicts are drifting to and fro in the Atlantic every year, and ten per cent. alone of these prizes would well

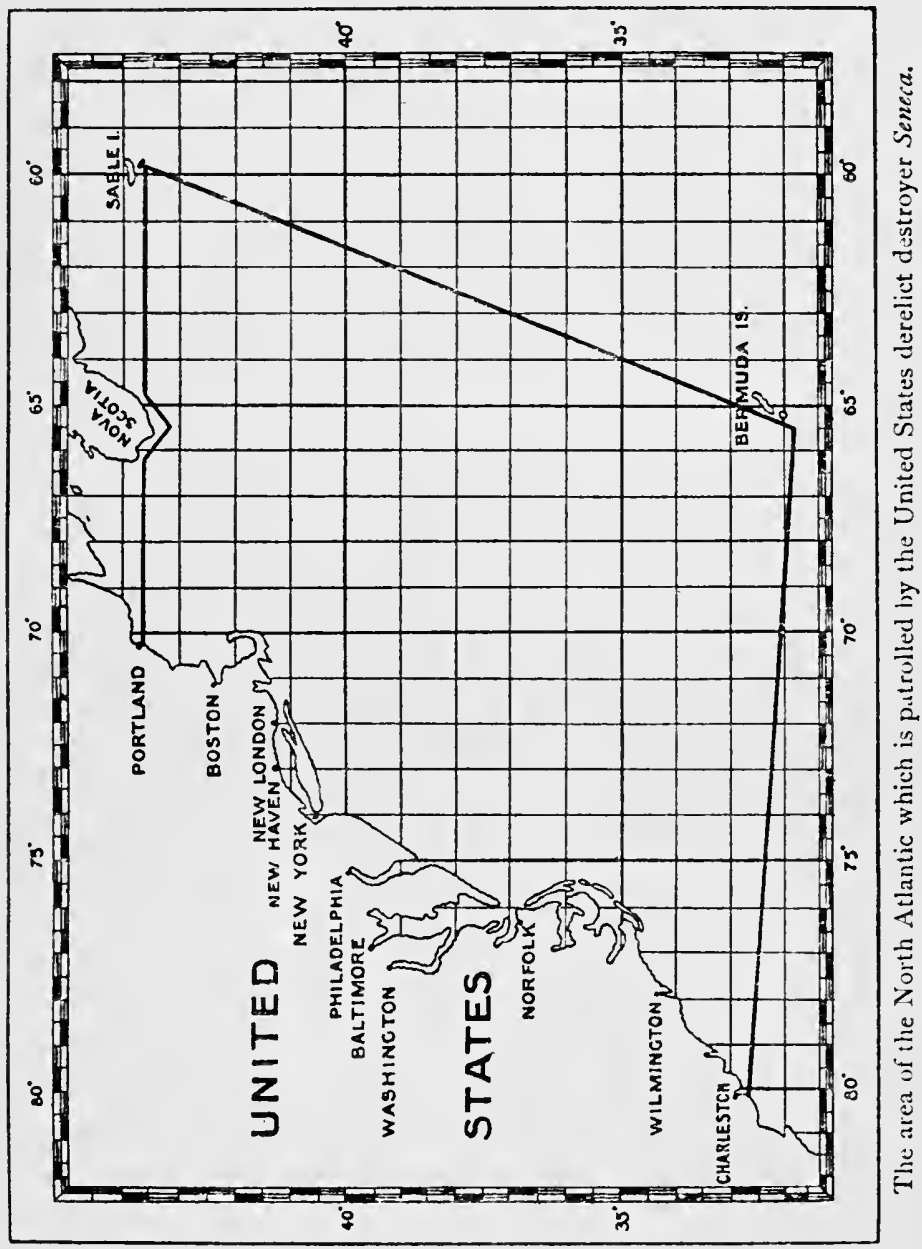

repay derelict hunters. That the enterprise is full of possibilities the experience of the United States derelict destroyer Seneca proves very convincingly. This ressel was built specially for this work by the United States Government, which, realising the crowded nature of the 
ocean lanes, decided that they should be kept as free from obstructions as a busy thoroughfare in a large city.

The Sereca is known officially as a Revenue Cutter, being attached to this service, but her calling is varied. She performs whatever duties may be required in the revenue service, is a derelict hunter, and also a life-saving ship. She has a wide area of sea to patrol, stretching from Portland, Maine, to Sable Island, Nova Scotia, thence southwards as far as Bermuda, and from that point westwards to Charleston, South Carolina, this cruising radius being about 4000 miles. She is not severely limited to this tract, however. If the exigencies arise she will scour farther afield, and indeed on several occasions has gone many hundred miles beyond the boundary of her operations.

She was placed in commission in October 1908. Her over-all length is 294 feet, beam 34 feet, schooner rigged, with two pole masts without gaffs. She may be identified readily from the signal yard carried on the foremast, from each end of which is displayed a black spherical shape, about three feet in diameter. She is equipped with wireless telegraphy, and carries two occulting truck lights, red on the foremast and white on the main-mast, with simultaneous fifteen-second flashes and intervals for nightsignalling. Her home station is Tompkinsville, Staten Island, New York, and she is kept ready for service at a moment's notice, either to save life, for which she is completely equipped, or to trace an obstacle and then to destroy it. An incoming vessel, which has sighted a derelict, is requested to communicate the intelligence to a land station, giving its exact location when sighted, the force and direction of the wind and sea, together with an estimate of the drifting speed of the obstruction. Upon receipt of this intimation the Seneca sails, and with the details provided as a guide, carries out her search. If the wreck when found is worth recovering, she is brought back into port : if not she is blown to atoms, and her days of threatening danger are ended abruptly. If the Seneca happens 
to be at sea, the vessel is invited to communicate the intimation direct by wireless, by calling the letters "R.C.E." If the destroyer is within wireless call, she answers promptly, and is able to hurry towards the derelict wherever it may be, without any delay.

But this hunt for a derelict is not nearly so simple as it seems. The ocean waif is a most elusive quarry. Upon arrival at the location indicated by the wireless or other message, the captain of the Seneca computes how many miles the wreck may have drifted since it was sighted. He then follows an expanding spiral course around this central spot, sweeping the sea on either side for a glimpse of the quarry. Once it has been rounded up there is no escape. An inspection is made from the small boats to determine its character-whether the flotsam is detached, or is merely a projection from a hull beneath. In any event the obstruction is shattered by the aid of explosives, if not worth recovery. The Seneca carries complete facilities for coping with any description of wreckage, although its principal destructive servant is gun-cotton, twenty-five sixty-pound charges of which are carried with primers, detonators, battery, wires, etc., to operate them.

The gun-cotton comprises little blocks measuring 3 inches square by 2 inches in thickness. These are packed into copper canisters measuring $9 \frac{1}{2}$ inches square by 12 inches high, around a central case slipped into the mine. The latter is filled with dry gun-cotton to form the firingcharge, the latter being ignited by the aid of a fulminate of mercury primer, which is electrically detonated, the wires for this purpose being led through a special watertight rubber cap. The requisite current is furnished from a small battery.

The method of blowing up the wreckage varies according to its character and circumstances. If it is a mast, a chain is lowered over the top of the obstacle and the mine attached to it is sunk until it reaches the bottom of the spar. The crew then row away to a safe distance, paying out the firing cable as they proceed, and when at last 
beyond the zone of the explosion, the button is pressed, and the spar is shivered to pieces in a column of water. If the wreckage is a deck-house or some other bulky fitting which has broken away from its ship, a cable is passed around it in such a way that the mine connected with it is brought approximately beneath the centre of the obstruction. In this instance the derelict is split into fragments, which either sink, or being of harmless dimensions, are permitted to drift.

A complete vessel is a much more difficult obstruction to handle. In some cases, if the craft can be boarded safely, the charge is distributed in suitable quantities within the hull, and then detonated. In this case the ship is split open in all directions, to permit the water to enter, and thus to bring about her complete disappearance. This method, however, is practicable as a rule only with iron and steel hulks. With wooden ships nothing short of complete annihilation is satisfactory, and in this instance a considerable quantity of gun-cotton has to be expended. Sometimes the wreck has settled to the bottom, but lies in the shallow fairway of passing vessels, and thereby obstructs their safe movement. This was the case with the Belle Halliday, which foundered with a cargo of pavingstones. Two boats, each bearing the end of a cable to which the mines were attached, rowed alongside the wreck and lowered the mines carefully, so that they were swept by the tide to a position under the bilges of the sunken schooner. When this charge was fired, the wreck was sent sky-high with her cargo, the whole being blown literally to atoms, and leaving the channel quite clear.

But the Sencca is not a destroying force purely and simply. If a wreck can possibly be retrieved she will spare no effort to bring it into port. The latest feat of this description up to the time of writing was in connection with the Frederick Roessner, which was abandoned on June 9,1012 , in latitude $35^{\circ} 48^{\prime} \mathrm{N}^{\prime}$, by longitude $74^{\circ} \mathrm{05} \mathrm{J}^{\prime} \mathrm{IV}$. She was reported to the Seneca, who immediately gave chase, and four days later she was run down in latitude 
$37^{\circ} 4 \mathrm{o}^{\prime} \mathrm{N}$., by longitude $68^{\circ} 5 \mathrm{o}^{\prime} \mathrm{W}$., having drifted no less than 285 miles in 96 hours. When picked up she was a helpless hulk. Not a stick of her rigging was standing, and her decks were awash. A reconnaissance revealed the fact that, despite her desperate plight, the derelict might be saved, so a towing-rope was hitched on, and the wreck was towed into New York. Since she was placed in commission, the Seneca has cleared 40 obstructions from the ocean highway, including the Frederick Roessner, of which total 6 abandoned vessels were salvaged and brought into port; 8 pieces of floating wreckage had been removed; 9 parts of dangerous vessels had been shattered into harmlessness; while I7 spars attached to submerged rigging had been dealt with.

From the experience of the Seneca in the western North Atlantic waters, it would seem that a similar vessel might very advantageously be kept in commission by the British steamship companies or Admiralty. Not only would it protect their costly liners, but at the same time the outfit would be almost self-supporting, judging from the Seneca's harvest, inasmuch as the recovered vessels would bring in handsome salvage awards. Seeing that the volume of British shipping completely eclipses that of any other nation, it is somewhat surprising that no thought is given to its insurance against one of the greatest perils to which it is exposed.

Some misconception has arisen in connection with derelicts. Often one may pick up the newspaper to read that such-and-such a ship reports having struck a submerged derelict in mid-ocean. It is difficult to realise how this can be the case, since, unless some part of the ship is protruding above the water, it must sink to the bottom. It could not remain in suspension, as it were, at a depth of 30,100 or 1000 feet, if completely covered. It is quite possible that the buoyancy of the obstruction might be reduced to such a point that its weight exactly equalled that of the water displaced, in which event it would float at the surface without revealing any of its form above the 


\section{STEAMSHIP CONQUEST OF THE WORLD}

water, but this is very problematic. Directly the weight of the hulk exceeds that of the water displaced, it must founder. The only manner in which a derelict may be described as submerged, is where the deck itself is covered for ten or more feet, and a mast attached to it projects above the water. In this instance the latter only continues visible, since the weight of the submerged hulk is less than the weight of the water displaced. Directly the mast is removed the wreck sinks to the ocean bed. 


\section{CHAPTER XV}

\section{SHIPS THAT MAKE FEW PORTS}

While the great ocean ferries ply regularly along the well-defined lanes connecting specified ports with the precision of railway trains, other vessels innumerable, of all sizes and speeds, sailing as well as steam, wander aimlessly about the seven seas, picking up sustenance, in the form of freights, wherever and whenever they can, ready to go anywhere, with or for anything. These are the gipsies of the ocean, forming that great tramp fleet which, although it is somewhat unfamiliar to the public, nevertheless is of overwhelming importance, as it constitutes the backbone of the mercantile marine, and is responsible for the supremacy of Great Britain as a maritime nation. These vessels transport goods which the spick and span haughty mail and passenger flyer regard with disdain, and the character of which is as varied as the tramps themselves.

In order to grasp the significance of this class of vessel one has only to wander around the docks of any big port, to find, jammed between the bigger and better-known boats, or tucked away in obscure corners, craft which touch ports of which the average person knows nothing. More often than not the appearance of the craft substantiates its generic name. It recalls the nomad of our highways, being ill-kempt and even at times repulsive in its appearance. Possibly the paint has been battered from its hull by wind and wave, until one is unable to imagine its appearance at the time it left the builder's yard. Its original garb has been superseded by a red rust applied with Father Neptune's brush-salt spray. The deck looks woe-begone, while the engines rattle like shot in a tin can. Yet the ressel is as tight as the glistening lordly liner 
moored near by, and the chances are that when at sea, with the elements raging in torment, the insignificant, disreputable-iooking tramp is the better sea-boat of the two.

All tramps, however, do not coincide with this description. Many rank as large as a liner, and are just as trim and prim, the paint still retaining its sheen, the brasswork reflecting like a mirror, and the engines moving as noiselessly and as rhythmically as in the finest leviathan afloat. But the tramp cannot help being knocked about. It has to weather seas which the titan seldom or never meets, and at times has to carry cargoes which are nauseous or awkward. It is an all-round type of craft, capable of riding a hurricane, penetrating the Arctic or Antarctic circles, ready to handle grain or iron, and to maintain a steady eight or nine knots under varying conditions as the flyer is able to cross the Atlantic in six days or less.

These vessels penetrate to the uttermost parts of the earth, and when the captain puts out from his home port he never knows when he will see it again. The skipper is a unique type of navigator, full of resource, dauntless, and ready for any emergency, with an affection for his forlorn, despised craft that is difficult to understand. He knows her every whim, coaxes her when she is disposed to be sulky, and handles her gently when she is thrown head first against the trials and tribulations of the deep. Probably one cannot mention a stretch of water with which he is not familiar, and he has very expressive opinions concerning the various ports of the world. Even if he is dispatched to a sea which he has never penetrated before he does not hesitate.

How many people have ever heard of Ivitgut or know anything about "kyrolith"? Yet every year from eight to twelve ships put into this port and receive a full cargo of this material, which is of great commercial value. It is about one of the most difficult and hazardous shipping points to reach, for it is within a few miles of the Arctic circle, on the south-west coast of Greenland, and is approachable for only a few weeks in the year. The 
deposits of this product are worked by a Danish company which has established a small colony at this port, and this handful of hardy toilers receive supplies and necessaries from Denmark once a year. The whole of the output is purchased by a firm in the United States, and what is known as the "chemical fleet," from the peculiar names of the vessels engaged in the trade, take it to Philadelphia.

In order to gain Ivitgut the vessels have to thread most treacherous seas. During the winter the port is as marooned from the outside world as the Poles, being imprisoned behind a barrier of ice. The vessels put out from Philadelphia in the spring, and the journey is never free from exciting adventure and sensational tussles with Nature in one of her most compelling forms. The Labrador current, coming down from the Arctic, swings along this coast, laden with masses of ice broken off the Greenland ice-cap. The kyrolith-carriers are exposed to the full brunt of this peril as they come sailing down Davis Strait in a never-ending line, while the pack-ice threatens to engulf any vessel which has the temerity to venture within its grip. The wind-jammers engaged in this service are of especially strong construction, the bows being reinforced to enable the ships to drive through heavy ice obstructions. They do not resemble craft engaged in the transport of necessities of commerce; rather they look like vessels bound upon voyages of discovery to the North Pole.

After leaving Philadelphia the vessels make for a cape bearing the mournful name of Point Desolation. As the northern seas are entered the fight for progress becomes more and more grim. They have to smash through the drifting ice, dodging the larger bergs, which is no easy matter, bearing in mind their prolific numbers, and more than one has retired from the fray badly battered and bruised, with timbers strained and leaking ominouslymute evidence of the heaviness of the seas, the severity of the gales, and the grinding action of the ice. If the varied forces of Nature should happen to combine, then the odds pitted against the vessel are overwhelming. In one season 
the fleet suffered badly. One vessel was lost-dismantled, probably, by the gales, crushed by the ice and pounded by the seas, so that her stout timbers opened up, to let the water in. At all events she never was heard of again. Two sister ships a little later battled against adversity, but could make no headway-they retired from the unequal conflict and arrived home empty, with the crews thoroughly worn out. Another had a stiff fight struggling with an icepack, and reached Ivitgut a month late. It is a precarious journey, but the traffic has been in progress for about half a century, and, taken on the whole, the losses have been small. The vessels are built so stoutly that a complete disaster is well-nigh impossible.

Clipperton Island is not familiar to many ears, yet it is visited once or twice a year by a schooner to bring away a valuable cargo. It is private property, having been purchased for the exploitation of its phosphate deposits. It is about as dreary a spot as could be imagined, seeing that there is not a tree or any kind of vegetation upon its arid hump, rising above the Pacific many hundred miles off the Northern Pacific coastline. Three men drag out a weary existence in this Robinson Crusoe-land, with the gannet birds and sand crabs as companions. They expect a schooner to arrive about mid-spring for a cargo, but if it misses the trip they pocket their chagrin and settle down to a weary wait until September. Down off the South American coast, far removed from the tracks of the coasting vessels in the Southern Pacific and around the loneliest islands lying off the Australasian mainland, small vessels may be seen steering to unknown places, to load up with guano. These journeys are made through terribly lonely seas, where, should disaster supervene, the chances are overwhelmingly against any of the crew or ship ever being seen again. Other craft proceed warily for hundreds of miles up the inhospitable Orinoco or Amazon, braving the dangers of malaria and other scourges, to take on board unusual cargoes, such as one of the rare earths necessary to the manufacture of a certain commercial product, a 
consignment of dead flies of a peculiar species possessing great nutritive value for chicken-food, grasses, and so on.

About thirty miles off the coast of New Zealand there is a wicked group of rocks. The average vessel gives them a wide berth-a simple matter, because they are very conspicuous, both to the eye and nostril. They form a desolate mass rising some 900 feet from the sea, and the stranger might be excused if he took it for a belching volcano in full blast, judging from the dense white clouds which continually rise heavenwards to a height of 1000 feet or so, and from which the spot takes the name of White Island. If the wind be blowing towards the passing vessel, every one on board is afflicted with violent coughing, gasping and sneezing, as the vapour is charged heavily with sulphuric and hydrochloric acid fumes, so powerful that in a strong wind they may be detected sixty miles distant.

On the island is a large lake of what, at first sight, appears to be unsavoury boiling water, from whose surface the white vapour rolls off like a thick fog, with blowholes belching forth along the shore on all sides. The lake is a mass of sulphuric and hydrochloric acids hissing and bubbling at a temperature of i io degrees Fahrenheit, and a journey across its breadth is a most exciting experience. A friend of mine visited the island by one of the small tramp steamers that call there occasionally for sulphur, with a view to the exploitation of the various mineral deposits. After infinite labour a boat was dragged across the beach and launched on the lake, with a view to a closer inspection of the blow-holes and the abundance of sulphur lying on every side. They escaped suffocation from the fumes, but only missed a worse fate very narrowly. As they came ashore the boat nearly dropped to pieces, and had to be abandoned after the vessel was regained-the rivets had been corroded by the acids.

At rare intervals a small tramp steamer crawls into the semicircle forming Crater Bay and casts anchor. Boats put out to gain a flimsy little landing-stage, formed of a 
single plank propped up to support a tiny tramway, down which the sulphur is rumbled, to be transported to the tramp outside. The shipping of the acids has not been taken in hand yet, a job which probably would be refused by the most needy tramp, as somewhat too dangerous an undertaking.

The varied freights a tramp will take on board during a single cruise at sea are astonishing. Here is a typical case. A 2000-tonner put out from a Welsh port, bound for Canada, with a cargo of steam coal. When this was discharged, a consignment of steel rails was taken on board at Sydney, Nova Scotia, bound for Prince Rupert. This was a journey in itself, as the vessel had to steam down one side of the whole American continent, round Cape Horn, and then pull up the opposite coast-line for an almost equal distance. Railway metals are one of the worst cargoes that a ship can be called upon to negotiate. They make the ship exceedingly stiff and rigid, and if bad weather should be encountered she gets knocked about and strained very badly. Rid of this freight, the captain was ordered to run south to San Francisco, where he took on board a cargo for Shanghai. There was another short run to Hong Kong for a cargo of cement, which was hurried to an Australian port. A cargo of coals entailed another short journey round the coast of the Southern continent, and then, taking on board a shipment of apples, he set his head for home.

At times the tramp sets out upon a mission of mystery, or at any rate upon a journey of dubious intent. Some of the more unscrupulous tramps a few years ago were in the habit of gradually edging towards the South Sea Islands, for the purpose of indulging in the profitable game of "black-birding." This was the forcible acquisition of Kanaka labour, which was secured by methods reminiscent of slavery in the Southern States, the unhappy and unwilling captives being stowed on board these vessels, to be smuggled into Queensland to meet the deficiency in white labour among the sugar planters. It was a highly re- 
munerative, although somewhat risky, game while it lasted, but the Government took the question sternly in hand and suppressed it. Now and again, however, a few of these luckless natives will be got aboard a passing tramp, the captain of which is willing to incur the risks incidental to the calling, and for a high consideration will take them to the mainland. Taken on the whole, however, the tramp steamer prosecutes a clean above-board traffic, as she very seldom experiences any difficulty in getting a legitimate cargo of some kind, sort or description.

What of the men forming the crew of these wandering craft? Undoubtedly they are amongst the best types of sea-dogs to be found, hardened by rough usage to the many, varied and heavy knocks inflicted by the sea; infused with a striking spirit of dare-devilry and selfreliance; hard workers, and of dauntless spirit, ready to face any emergency that may be sprung upon them. The life is one continual round of adventure and hardship, with very few short interludes of pleasure. As a rule they are engaged in a hand-to-hand struggle for their preservation, since, running promiscuously from sea to sea, they never anticipate a very long spell of fine weather. The "Plain Tales of the Sea" are all narrated by the men of the tramps, and if one questions a weather-beaten oldtimer, more often than not he will express his inability to recollect how many times he has been wrecked. The average person is apt to regard the immaculately uniformed officer on an ocean liner as a typical illustration of the merchant sailor of to-day; but compared with the rugged, blusterous boy of the tramp, the former is a fresh-water navigator, who does not know what trouble is, and who never has been thrown up "against it" probably once in his life. Among the crew, and especially among the "black squad," you will meet many a one who has done his gruelling on the tramp, and who, if he is in the humour, can relate many an exciting story.

Take the case of the Port Darwin. She left Cardiff for Algiers, and then backed to Rotterdam with a cargo of 
iron ore. But the latter freight was never delivered. Off the Spanish coast she fell in with a gale, and the angry Atlantic rollers swept her from stem to stern. She weathered this ordeal with very little signs of the punches she had received, only to smash against a sunken reef off La Guardia. The hull was punctured like a pneumatic tyre, and the water rushed in so furiously that the engineer hazarded the guess that i 50 tons entered during the first minute. The men down in the stokehold felt the bumps of the hull against the rocks, and knew only too well that the vessel was doomed; but they stuck to the furnaces until the water was up to their knees, when they concluded that it was time to go up on deck to see what was being done. They tripped up as if going off duty, and found the remainder of the crew assembled on the bridge discussing the situation with the captain with as much coolness as if they were conversing at a street corner. The ship was in a perilous position, and salvation seemed quite impossible under the circumstances. The skipper thought that the best thing was to try to run the ship another five miles inslore, so as to beach her. He turned to the begrimed firemen and asked them if they were willing to descend into the stokehold, to enable the attempt to be made. One and all signified assent, and once more the black squad disappeared into the depths of the vessel. The pumps were set going to their utmost, although the water got in faster than it was pumped out, while the firemen worked like Trojans, crowding on steam for the last run. Fortunately one bulkhead held out, and that kept the vessel afloat; but to make that five miles the ship took a solid four and a half hours, during which time the lifeboat and the dinghy were smashed to atoms by the waves. IVith a crash the vessel was thrown on the rocks, the firemen rushed up the ladders hand over hand, and as they got to the deck the ship broke in two at the bunkers. The boat was lowered, and the whole of the crew made a jump for it. Some missed, and as the boat was swung to and fro by the waves she jammed the unfortunate men against 
the side of the ship. The survivors contrived to get ashore, made their way to Vigo, and thence were shipped home. The narrator of the story considered the episode quite an everyday affair, and once he touched the home port he bustled round to find another berth.

The crew of the Kinkora had an adventure such as is seldom heard, but which eclipses the most brilliant imagination of the novelist. She loaded up at Vancouver with a heavy consignment of lumber for London, and a large deck load was carried into the bargain. When well out in the Pacific she sprung a leak, and although the pumps were manned and the crew stuck bravely to the superhuman task for several days, they could not keep the water down. It gained upon them steadily as they weakened under the effects of fatigue and exhaustion, and at last they went to the captain and declined to pump any longer, as they were played out. The captain suggested that the deck load should be thrown overboard to ease the position somewhat, but the proposal was of no avail. At the time Clipperton Island was the nearest land, and the skipper promised to head there if the crew would resume their tasks at the pumps. They agreed, but to their dismay, when the steam pump was brought into action once more, the crown of the boiler burst, and it was rendered useless.

Clipperton Island was gained, and with infinite difficulty a landing was effected. Then it was found that they had exchanged one peril for another. They were faced with starvation, and could not be assisted very tangibly by the three men dwelling on the island engaged in mining the phosphate. As a vessel was not expected for several months, the captain with his twenty-three men decided to make a desperate effort to reach Acapulco in Mexico in the two lifeboats. It was a fearful journey, entailing a pull of 700 miles across a wicked piece of sea. However, they started off, only to meet a fresh adversity at the outset. One boat was smashed while being launched. This meant that some of the men would have to be left behind, and volunteers were called for the second boat. 


\section{STEAMSHIP CONQUEST OF THE WORLD}

The party put off, expecting to take twelve days on the long pull. Water was their greatest anxiety, but they were somewhat relieved under this heading, as for the first six nights out it rained in torrents, to the full fury of which they were exposed. During the day the sun was intensely hot, and they suffered fearfully, while dangers of being swamped and capsized had to be avoided every minute. For sixteen days they drove ahead without seeing a vessel, except on the day before they reached Acapulco, when a stream of smoke was descried in the far distance. It proved to be H.M.S. Amphion, which left Acapulco the day before they arrived. When they landed the men could not stand, being doubled up with cramp from their tight positions in the boat. A wire was sent to England urging assistance to be sent to Clipperton Island to succour the other survivors. H.M.S. Comus was dispatched post-haste from Victoria, B.C., to the island, and picked up the rest of the crew, after they had been marooned for forty days.

Similar stories of the sea associated with the tramp, some of which make the blood run cold, may be related without end. Yet, curiously enough, despite the hazardous character of the work and the hard, grinding life without a shred of comfort, one and all associated with the tramp have a supreme contempt for the mighty, comfortable liner. They prefer the roving life to one of flying to and fro over a certain stretch of sea like a shuttle. This characteristic is typical of the average British mariner, being the product of centuries. The master of the tramp maintains that the captain of the liner is no navigator: he simply keeps to a track as if it were marked off with a fence on either side !

Now and again fortune smiles kindly upon the master and crew of the tramp by placing a fine piece of salvage in their way. The liner Waikato was on her way between the Cape and New Zealand, when, crash! her propeller sliaft gave way. Being only a single-screw steamship, she was at once stricken helpless, and, to make matters more serious, the accident happened in a lonely stretch of sea. Day after day she drifted, without seeing the sign of a 
sail, or a curl of smoke from the funnels of a steamer. The mercaníile community grew anxious, and when 100 days passed without tidings of the Waikato she was given up as practically lost. On the hundred and second day after the accident, however, the tramp Asloun, which was coming up from one of the little-known ports down south, and which likewise had been driven out of her course by heavy weather, spoke the Waikato. By that time the liner had drifted 4000 miles. The Asloun caught hold of the lame liner, and a course was shaped for Fremantle, which was entered safely three weeks later. As nothing had been heard of the Waikato for over four months, her safe arrival caused the underwriters to breathe freely, since they were saved a heavy disbursement on insurances, while the feelings of relatives of the passengers and crew may be imagined. The liner proved a rich prize for the humble tramp, as she was laden with a cargo valued at $£$ I 30,000 , or $\$ 650,000$, and for the services rendered the court awarded the Asloun the sum of $£, 16,500 \quad(\$ 82,500)$, for division among the owners, master and crew. From this it will be seen that occasionally the tramp steamer makes a rich haul, which comes as a welcome interlude in the usual daily round of harassing and unremitting toil. 


\section{CHAPTER XVI}

SALVAGE

Probably there is no phase of marine engineering which is so full of romance as that of salvaging. As a calling it is also remunerative. So much so that in various parts of the world, organisations have been established which do nothing else but reclaim wrecks. They are equipped with special and powerful mechanical appliances to facilitate the peculiar work, and retain the services of highly skilled men who are at home in a diver's ungainly suit, and who experience no more difficulty in working thirty feet below the surface of the sea than does a bricklayer on a scaffold a similar distance above the ground.

The salvor is as confirmed a gambler as the underwriter. He is prepared to complete his work for a lump sum, will undertake the task upon a certain percentage of the value reclaimed, or even will be prepared to face the uncertainties on the basis of "no cure, no pay." The latter is the biggest gamble of all. Tens of thousands may be expended by the salvors upon a task, but unless they achieve what they have set out to accomplish they receive no remuneration. It is certainly a speculative proceeding, and at first sight appears highly attractive, but it is conducive to the infliction of more damage to the vessel in the efforts to get her afloat than she is worth. In this case the salvors do not care one whit what they do so long as they fulfil their part of the contract-retrieve the vessel. It is like tempting a body of firemen with a rich reward for the extinction of a blazing building crammed with goods worth a million sterling, instead of a percentage upon the value of the goods saved undamaged. The fire can be put out provided sufficient water is brought to bear upon it, but the extinguishing process not only achieves 
its designed end, but probably reduces the unburnt proportion to valueless pulp.

So far as Great Britain is concerned, no encouragement was extended to native salvaging ingenuity until a few years ago. These islands, despite the overwhelming preponderance of their maritime interests, were at the mercy of foreign organisations for the salvaging of vessels, to the detriment of native engineers. Take the case of the liner Paris. She got jammed inextricably upon the Manacles. The underwriters were faced with a prodigious loss. Immediately after the wreck, a British engineer, Mr. Henry Parker, offered to get her afloat. His proposal was accepted on the condition that, if he had any doubt as to achieving success, he should return to London at once. The engineer accepted the terms, and was forthwith instructed to procure the appliances he required, together with the services of necessary divers. He was then asked when he could proceed to the wreck, and he replied as soon as he could get a Root's Blower with a fourteen-inch outlet, or delivery.

The engineer reached the wreck on Friday, June 2. The Paris had got into an awkward position, as the granite fangs had driven clean through her bottom and were holding her fast. When he stepped on deck he found that little damage was observable around her top sides, that the after part was clear, but that the fore-peak and hold were full of water. Without delay he sought out the liner's chief engineer, and found that there were air-pumps aboard for working the refrigerating plant. These pumps were connected up to the fore-peak, which was entered by a diver, and were set to work. The compressed air drove out the water very speedily, exposing the rent in the hull, the dimensions of which were taken by the diver. Then a plate was prepared to be dropped over the hole, secured in position and made water-tight. When this was ready the diver re-entered the fore-peak with the patch, the water was driven out, the cover was placed over the wound, made fast, while another plate was added in a bed of cement. 
The air pressure was kept applied until the cement had hardened, and then was released. The patch held, and no water re-entered the space. When the tide rose to its full height the repair was examined, and was found to be holding tightly and solidly.

Meantime the engineer had instructed the foreman shipwright to close up the hatches at the ceiling level of the lower hold, which was just free of water at low tide. He also devised an air trunk, fashioned from planks bolted together, with a retaining valve on the under side of the hatchway, while a manhole was provided to permit ingress and egress from the hold. All the seams were rendered air- and water-tight by caulking. The Root's Blower was then erected and attached to the air trunk leading into the hold, power being applied through a belt from a winch, to which the salvor attached a wooden pulley of sufficient diameter to drive the blower at the speed required.

On the day that Mr. Parker arrived on the Paris, the representatives of a German firm of salvors appeared. The fore-hold of the ship had been pierced by the jagged teeth of the Manacles, and as the latter were anxious to remove these projections by blasting, the British engineer sanctioned the proceeding.

By the fourth day the rock had been removed, the Root's Blower was started up, and the air, driven into the confined space, forced out the water. On the next low tide the hold was found to be quite free-the compressed air kept the water back. The critical moment had arrived, and Mr. Parker completed his arrangements to get the liner free. On the rising tide the blower was kept going at full speed, and as the water could not re-enter the ship, owing to the greater air pressure maintained within the space, the vessel lifted with the tide. When the water had risen to its highest level the Paris was afloat, free of the rocks which had held her so firmly a prisoner. Regaining her buoyancy, the ship slipped aft several fathoms and changed her position. This fact was proved very conclusively by the morement of her compass. 
The salvor, elated with his success, which had coincided with his carefully laid plans, was about to send for a number of tugs to tow the Paris into Falmouth on the next tide, which would be eighteen inches higher than that which lifted the liner free. But, to his intense disgust, he was requested by the special agent of the underwriters on the spot to return to London immediately-the contract had been awarded to the rival foreign firm on the "no cure, no pay" system. It was a galling position for the British engineer. He had accomplished the hardest part of the task, and his rivals were to reap the rewards. However, he accepted the inevitable, and left the wreck, to receive recompense for the work he had carried out.

The foreign salvors sought to improve upon the British engineer, but failed signally. Instead of taking the Paris into port on the next tide, between four and five weeks elapsed before the task was consummated. By the time the Paris was brought into port she had suffered extreme damage. Hearty congratulations were extended by the British Press upon the so-called triumph of foreign salvage engineers, notwithstanding the fact that Mr. Henry Parker, after five days and nights of incessant labour, had the Paris ready for moving with the tide on the evening of June 7 ! This offered a brilliant illustration of the truth of the axiom about changing horses in the middle of a stream, for which the underwriters paid very dearly. In those days British salvage engineering was at a discount in comparison with so-called German skill. Happily, an opposite state of affairs prevails to-day-British engineers lead, and the Germans are outclassed hopelessly.

Another very smart salvage achievement was completed by a Scottish engineer, Mr. Thomas Napier Armit, of Leith, in the Bay of Gibraltar. The night of March 17 , I 89I, was as black as pitch, and a heavy gale was raging. The Anchor liner Utopia was making her way across the bay with about 1000 people on board, of whom a large proportion were Italian emigrants. By some means or other she was carried on to the bows of H.M.S. Anson, 
whose heavy ram smashed through the hull of the steamship, tearing a terrible rent, and sending her to the bottom with some 600 souls.

The collision caught the unlucky liner near the stern, so that the bows were lifted into the air by the incoming water. The unfortunate passengers rushed to this elevated position, and jumped or were thrown into the water as the liner lurched. Fortunately, the death-roll was minimised somewhat by the smartness of the crews of the Mediterranean squadron riding at anchor in the bay, although their task was difficult, owing to the intense blackness of the night and the storm.

When morning dawned the top of the funnel and the mast projected mournfully above the water, showing where the liner had settled down. Divers descended, recovered a large number of bodies, which were buried ashore, and found also that the Utopia lay in 56 feet of water at the stern, 43 feet at the bows, and had a heavy list. The ram of the warship had torn a gaping, irregular hole 26 feet long by 15 feet in width, and had crashed through the shell, bulkheads and engines as if they were paper, without suffering the slightest injury herself.

The position of the sunken liner constituted a serious menace to navigation, and the problem of her removal was discussed at once. Seeing her comparatively shallow position, the problem of raising her naturally occupied attention. A famous continental firm of salvage engineers expressed their willingness to lift her, but demanded from nine to twelve months for the job. Mr. Armit, who had previously accomplished some smart performances in this field, telegraphed from Leith that he would take the work in hand, and get her to the surface within a few weeks. His offer was accepted, and he set to work.

This engineer proposed to adopt the coffer-dam process, which he had used so brilliantly in salvaging the Austral, which foundered in Sydney harbour. This constitutes the erection of a massive timber wall, or falsework, upon and extending from the deck of the submerged steamer to the 


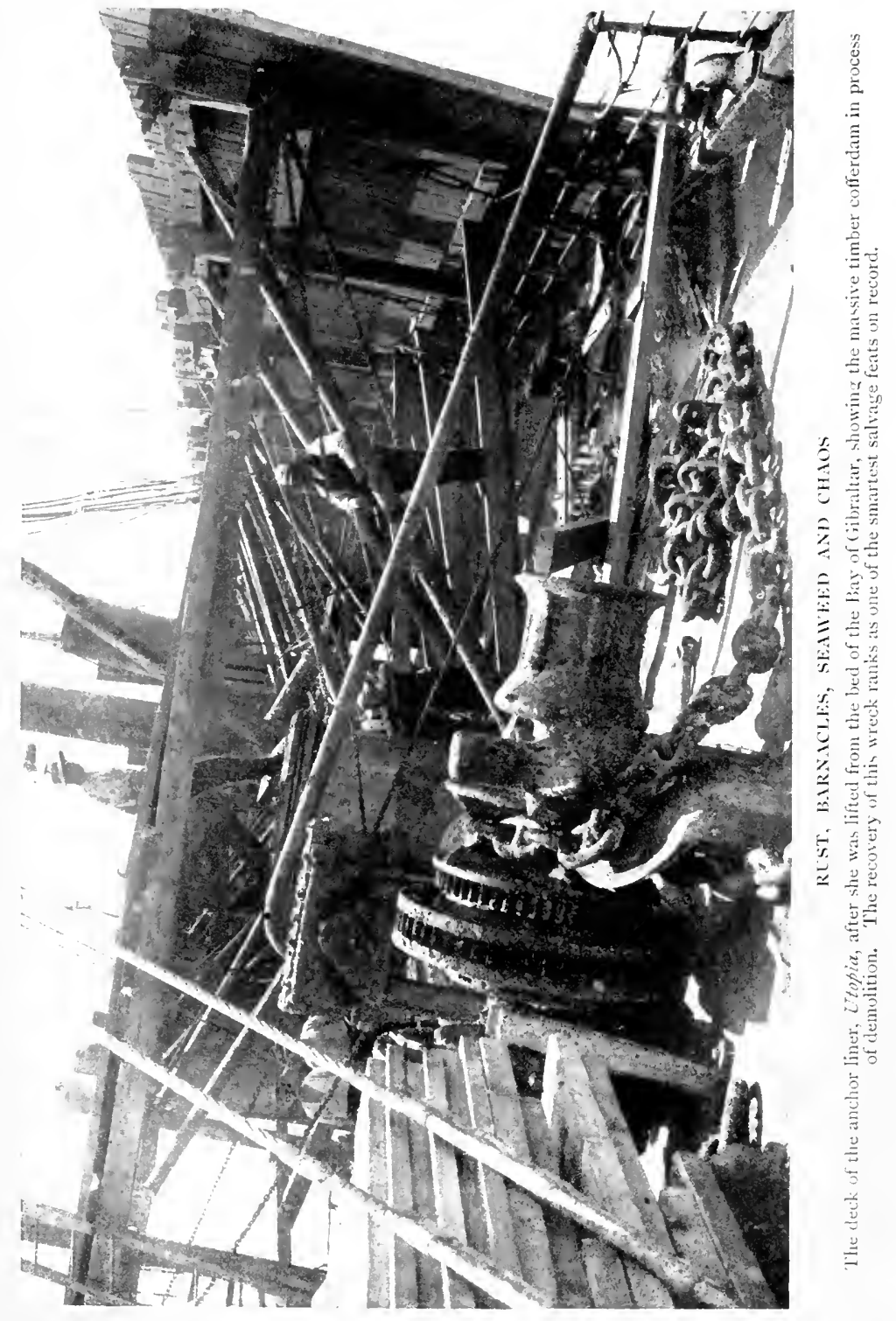




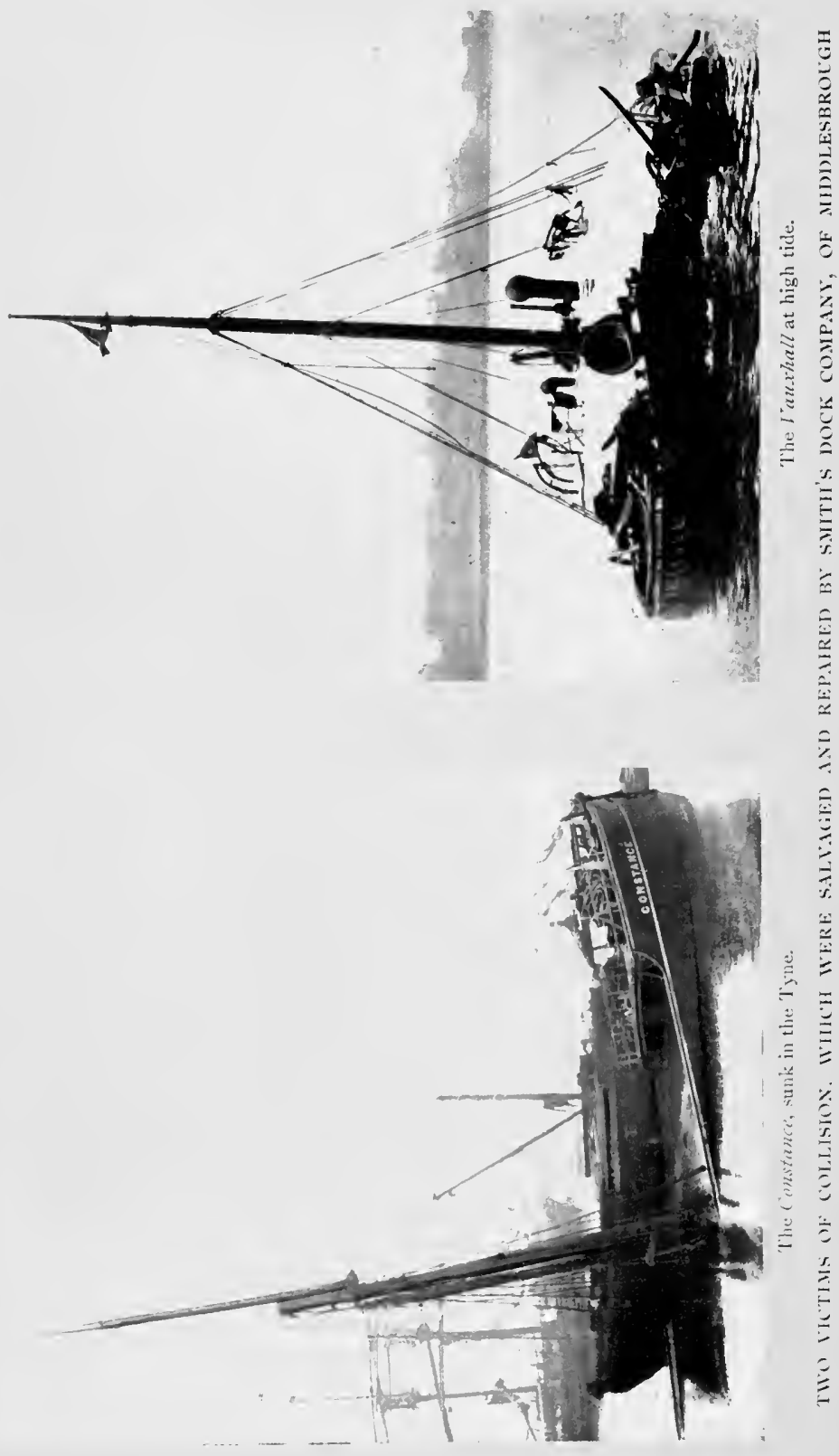


water-level, and then removing the water from within the enclosed space, after the rent is closed, by the aid of pumps. As time was of primary importance, the engineer decided upon a novel method of clamping the timber superstructure to the bulwarks of the wreck, instead of drilling holes and bolting the fabric to the hull with bolts -a very tedious and exacting task under water. Without visiting the wreck, but acting purely upon telegraphic information, the coffer-dam was prepared in Glasgow and dispatched to the wreck within ten days-a smart achievement in itself.

The coffer-dam was a formidable and substantial piece of work. The wooden baulks were set up vertically, and then braced and supported by diagonal, transverse and side beams to secure rigidity. Some idea of their bulk, size and weight may be gathered from the fact that each piece of oak measured 6 inches thick, except at the stern, where they were of 7 inches. This timber wall was carried for a length of 3 io feet along either bulwark of the vessel, across the deck at the bow, and around and to the curve of the stern. The latter was the most massive and strongly built part of the whole fabric. This superstructure had to be erected under water by divers, and the task, owing to the strong currents and exposure to south-west winds, was by no means easy, especially as the longest oak baulks ran to about 26 feet in length. Work was carried out continuously night and day, until at last the vessel was provided with a stout wooden casing 13 feet high at the bows and 24 feet in height at the stern.

A temporary deck was laid upon the upper surface of this coffer-dam, to afford foundation for the powerful Gwynne centrifugal pumps-these appliances are indispensable to the salvage engineer, and therewith many remarkable achievements have been put on record in connection with wreck-raising-for emptying the enclosed space. The breach made by the warship's ram was covered with a massive patch, wrought of oak baulks bolted together and rendered water-tight with canvas and other material. 
When all was ready the battery of pumps was set going. The water was ejected at the rate of 70 tons-i 5,680 gallons - per minute. In the course of an hour the vessel slowly returned to her upright position. The bay was dotted with boat-loads of spectators, while the shore was thickly packed with dense masses of people following a novel spectacle, and the first fruits of success were hailed with much cheering. The pumps were kept going with monotonous regularity, and by the time that some 750,000 gallons of water had been removed from within the hull the wreck, with its superstructure, began to rise. When the top deck emerged above the water the superstructure was demolished, while at the same time tugs caught hold of the wreck and hauled her into shallower water, this process being repeated as the hull rose higher and higher, until the refloated Utopia was beached upon a shoal. Here the vessel was pumped out completely, and presented a weird appearance. The decks, cabins and saloons were draped with seaweed and encrusted with other marine growths, which had assumed fantastic forms. The decomposition of the cargo and the bodies of luckless passengers and crew still imprisoned on board rendered the task ghastly and nauseating to the salvors, and order was given to flush the ship out from stem to stern. Then the corpses were recovered, in advanced stages of decay, and, being transported to the middle of the Straits of Gibraltar, were re-committed to the deep with every ceremonial.

The salvage was a complete success in every respect, but the most outstanding feature was the celerity with which it was accomplished. From the day Mr. Armit received instructions to go ahead until the Utopia was beached high and dry only two months had elapsed. Bearing in mind the size of the vessel, and the difficulties of the work, this ranked as an unparalleled achievement at the time, and certainly constituted one of the cheapest instances of salvage work on record.

The remarkable recovery of one-half of the Suevic--the after part, with all machinery-is still fresh in the public 
mind. This liner got astride the dreaded rocks off Cornwall, with a cargo of rabbits and other frozen meat valued at $\mathcal{E}_{\mathrm{i} 40,000}(\$ 700,000)$. Her bows were entangled hopelessly with the rocky teeth, so she was cut in twain with dynamite, the after part was brought to Southampton, a new bow was built and fitted, and to-day the Suevic is running as well as ever between Great Britain and the Antipodes. It was a smart piece of work, but was deprived of its novelty, as the salvors, the Liverpool Salvage Association, had previously accomplished a similar and more brilliant feat.

The Milwaukee, of 7,317 tons, built by Swan, Hunter, \& Wigham Richardson on the Tyne, was making her way round the north of Scotland, en route to New Orleans, in ballast. She was one of the crack trans-Atlantic freighters of her owners, being 470 feet long by 56 feet beam and $3 \mathrm{I} \frac{3}{4}$ feet deep. She got out of her course, and finally came to grief on the cruel rocks at Port Errol, near Peterhead. It was about as luckless a place in which to become stranded as could be conceived, as the wreck was exposed to the full force of the gales coming from the north-east, east and south-east. The weather was rough, and her nose was being pinched as if in a vice; she bumped heavily. The engineers of the Liverpool Salvage Association arrived promptly on the scene, and saw at once that she was impossible of complete recovery. Haste was everything, as the dreaded equinox was approaching. The after-part, containing the machinery, was perfect, so without more ado the salvors decided to cut her in twain. A string of dynamite cartridge, enclosed in rubber tubes, was passed round the ship just forward of the bridge. The method adopted was to protect the bulkhead at this point from the effects of the explosions, although allowing them to accomplish their designed function. The task, owing to its novelty and delicacy, occupied many anxious days, but at last the stern, with the machinery, fell back from the iso feet length of the fore part into deep water, after 520 pounds of explosives had been used. 
The salvors were somewhat pprehensive about the stability and strength of the bulkhead, upon which success depended. They feared that directly this protective wall was exposed to the full pressure of open water it would collapse. There was also the danger that the disturbance of the vessel's equilibrium by being cut in half might cause her to heel over. The builders were confident of their handiwork, and expressed the opinion that the bullihead would withstand the pressure imposed. The salvors had occasion to appreciate the fact that the Milwaukee was built very stoutly, as they had to use 140 pounds of dynamite to bisect the keelson. Calculations showed how the vessel might retain her stability after being severed, and arrangements to this end were made.

The peculiar operation was completely successful. The results were exactly as anticipated. The stern, upon recovery, was picked up by tugs and towed stern first back to her builders' yards in the 'Tyne, the dismembered vessel actually assisting in the task by her own power, the screw, as the stern now became the bow, revolving in the reverse direction. Upon reaching the Tyne the fore part was restored, as explained in the chapter dealing with Steamship Surgery. This was the most marvellous instance of salvage up to this time, and accordingly, when the Liverpool Salvage Association found the Suevic in a similar plight, they repeated the process. In both instances the severed bow was abandoned upon the rocks, to be pounded into fragments by the angry seas.

The recovery of the steamship Netherton was a smart undertaking of another description. This boat was laden with a cargo of benzine in her fore-hold. Every one is acquainted with the highly explosive character of petrol, and its transport in bulk demands elaborate precautions in the interests of safety. The Netherton was traversing the China seas when she blew up. The effects of the explosion were extraordinary. A stately steamship was turned into a tangled mass of scrap-steel as if by magic. The steel sides of the ship were not wrenched open, as might be 


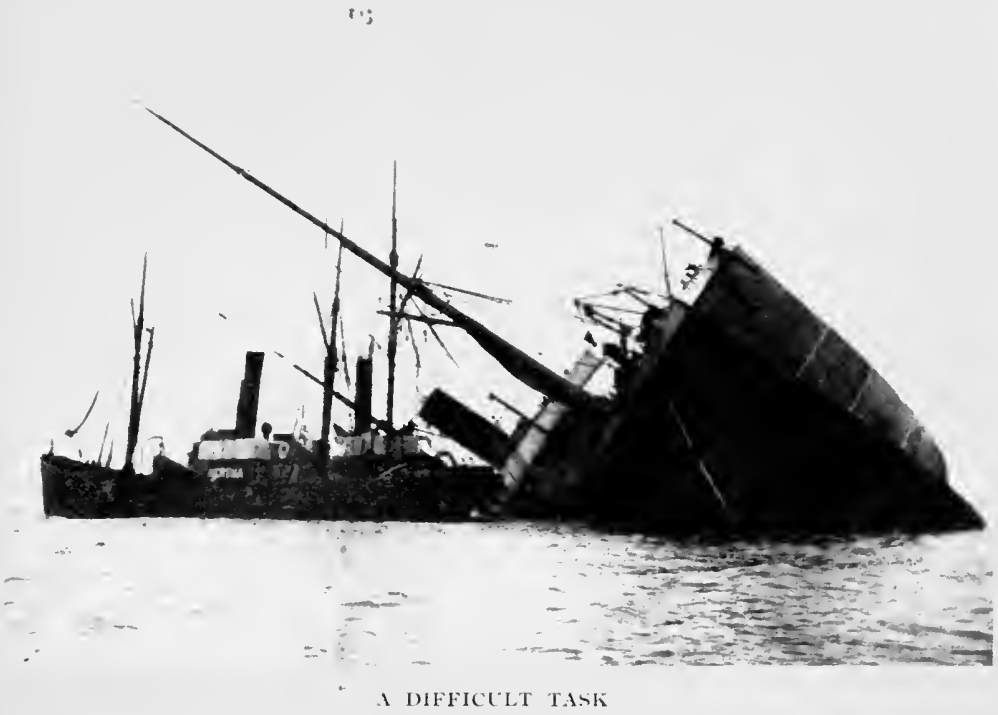

The Ilyatia heeled over and sank. The salvors, with their powerful appliances, lifted her up. this picture show her coming to an even keel.

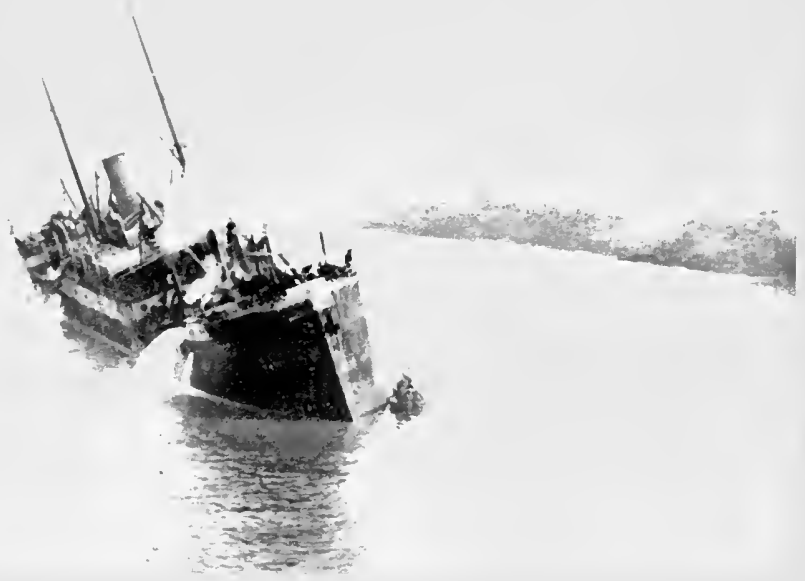

I DOCBLE DISASTER

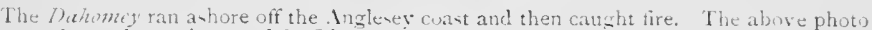
shows the enzineers of the I.iverpoul salvage A-sciation recovering the ship, and the pumpe dissharging the water from within the hull. 


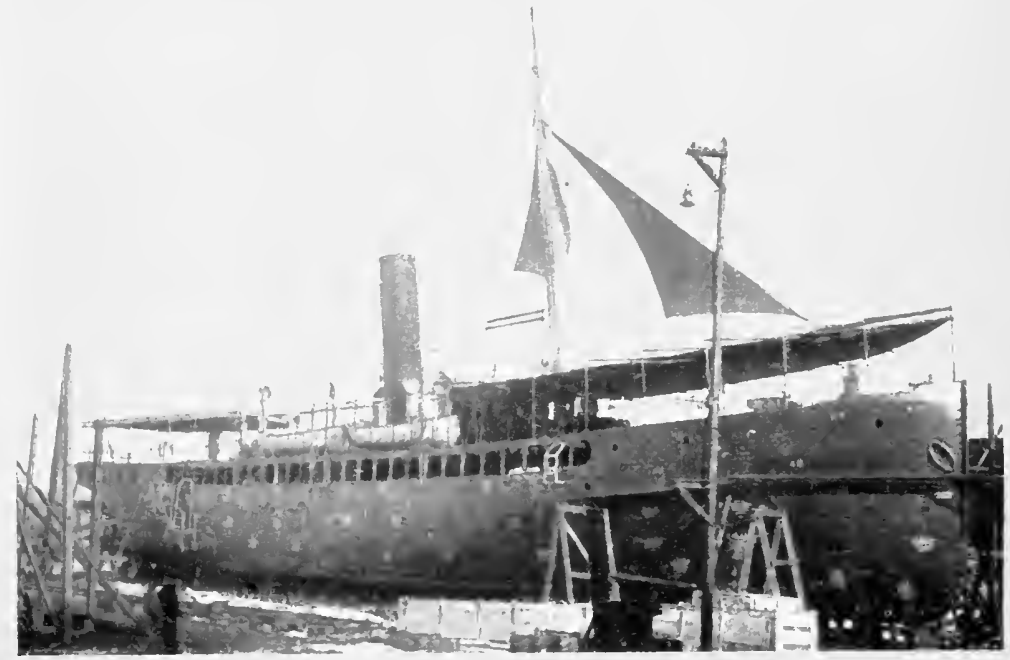

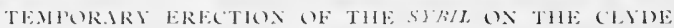

When put together, all parts were given an illentification mark. The ship wan distnanted. and tramsported in piecte to l'inumdit.

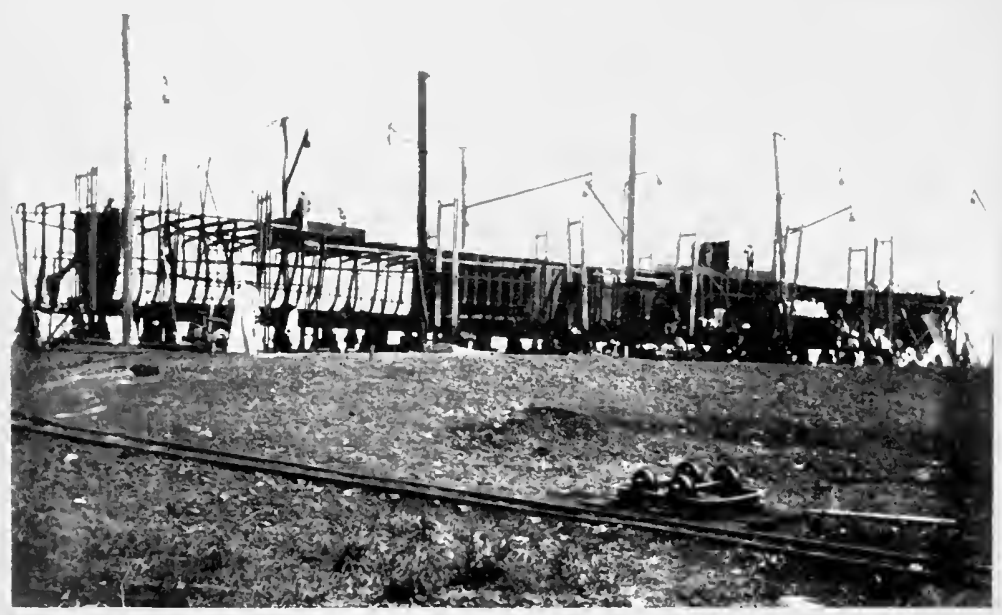

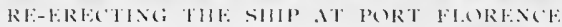

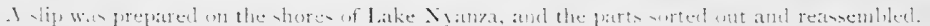

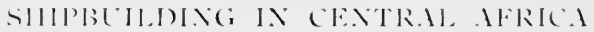


supposed, but were buckled inwards; the decks were transformed into utter chaos. She was brought into Singapore a hopeless wreck, and there abandoned, as she was not considered to be worth repair.

However, a north of England firm, Messrs. W. H. Loveridge \& Company, of West Hartlepool, thought there was every prospect of restoring the Netherton to her original serviceability, and accordingly bought her up practically at a scrap-heap price. They sent out an experienced marine surveyor, Mr. Russell, to bring her home if he could. The engineer proceeded to Singapore, and found the wreck everything that had been pictured. Parts of her hull had caved in to such an extent that a man could stand upon it. Forward, from amidships she was a heterogeneous mass of twisted steel, and she was filled to a depth of some five feet with rain-water. This was pumped out, and then Mr. Russell devised an inexpensive though substantial scheme of temporary repair. In order to strengthen the shattered hull, a girder was run forward from amidships on either side and secured to the fabric by heavy struts. The decks, demolished by the force of the explosion, were replaced by heavy wooden planking, covered with a layer of canvas, so as to render it as watertight as possible. As the ship might meet adverse weather on her homeward journey, a powerful pump was rigged up, to cope with any water that might find an entrance when an unfriendly wave crept aboard.

The boilers were tested and found serviceable, while the engines proved to be in good condition. But all the copper piping in the machine-room was gone. The natives had improved the shining hour by creeping aboard the shattered hulk as she lay neglected in the roads, and had stolen every inch of bright metal upon which they could lay their hands. Copper being an expensive commodity in Singapore, the engineer made shift with iron piping so far as practicable, only resorting to the more expensive metal whenever compelled.

Within about a month after his arrival upon the scene 
the Netherton was in a fit state to proceed to sea. The boilers were fired, and on a trial trip the vessel notched a speed of seven and a half knots per hour. As the underwater part of the ship was thickly encrusted with marine growth, the salvage engineer had her bottom cleaned, but he did not incur the prohibitive costs of a dry-dock for the purpose. He sought the services of a gang of Malay divers, and they accomplished the task to his satisfaction. As the trial trip had demonstrated the serviceability of the engines, the surveyor decided to come home under his own steam, notwithstanding that he was faced with some forbidding stretches of sea. A crew was engaged forthwith, and as the register of the ship had been cancelled, the salvor had to secure a temporary pass from the Government of the Straits Settlements in order to bring her home, which, after an inspection to decide her seaworthiness, was granted.

The salvage engineer is possessed of dogged perseverance, and his ingenuity is illimitable. A sunken vessel is an awkward mass to lift to the water-level, especially when currents run strongly, or when the position is exposed, and the sea-bed uninviting, with slippery rock or soft, shifting sand. The diver is his right-hand man, whose work is laborious, thrilling, adventurous and of ten very dangerous. It may be that operations down below can only be squeezed into the brief interval when the water is running slack at lowest tide. Then the diver has to toil with feverish speed to make the utmost of the handful of minutes at his disposal.

The Liverpool Salvage Association was confronted with a pretty problem in connection with the French steamer Canton, of 3,72I tons. She was dispatched to the East, and with several hundred soldiers on board she struck a rock. The captain, to avoid a holocaust, made a gigantic effort to beach her, as the water poured into her bows. He succeeded in his purpose, but the ship got into an uncomfortable position, where she laid until she was sunk by the north-west monsoon. Time after time the French battle- 
ships in the China seas sought to refloat her, but without avail, and at last abandoned their attempts. The underwriters in Paris, however, did not feel disposed to write the ship off as a total loss, so enlisted the services of the Liverpool salvage engineers. Captain Batchelor had previously pleased the French underwriters by bringing home the wrecked transport Rhine, and they felt that he would be able to do something with the Canton. He hurried out to Singapore with a diver and assistant, two engineers and two firemen, together with a couple of Io-inch pumps. A coasting steamer was chartered for the work, and steamed to the wreck, I, Ioo miles away. They got hold of the wreck, to find that she had rolled over on to her damaged side, and had a wound measuring 30 feet by 6 feet, torn and jagged in the most remarkable manner, with the fearful edges pointing outwards. The ugly masses of projecting steel were trimmed back with dynamite, and a massive patch of timber was fashioned and laid over the rent, witl a canvas bolster filled with oakum forming the joint, to secure water-tightness. When the pumps were set to work the vessel soon came to the surface, was towed into Singapore, and there repaired.

The Clan Grant offered the engineers of this organisation some anxious moments. She was 360 feet long and of 3,950 tons, and came to grief in an embrace with another vessel off Holyhead. The engineers got hold of her, and the ragged edges of the wound, which projected for some 6 feet around an irregular hole measuring i 7 feet deep by ro feet wide, were cut back with charges of blasting gelatine, placed in canisters, and surrounded by indiarubber cases bedded in china clay against the steel. In this case extreme care had to be taken to localise the effects of the explosion, as only i4 feet away was the engine-room bulkhead, which had already suffered from the collision, and the engineers did not desire to weaken it further. A wooden patch was placed over the hole, and the ship, in the vicinity of the rent, had her hull strengthened by the introduction of heavy girders 26 feet long. 
All this work had to be carried out by divers, and progress was slow, owing to the peculiar difficulties. When all was made fast the pumps were set to work, the ship was pumped dry, and was headed towards Liverpool.

At times the engineer sets to work to lift the wreck bodily. This was the case with the Sarah Brough, which went to the bottom also off Holyhead. Four massive cables were dragged beneath the wreck, and spaced at regular intervals. When the tide had receded two pontoons were brought up and moored alongside the wreck on either hand. The pontoon is a rectangular receptacle of strong construction, which, being filled with air, is naturally buoyant, and, moreover, possesses great lifting power, according to its dimensions. The ends of the four cables were fixed to these pontoons. As the tide flowed, the pontoons naturally rose with it, lifting the vessel off the bottom. As the wreck was swung clear of the sea-bed, tugs caught hold of her, and very slowly hauled her shorewards, until she grounded. Then a pause was made, and the process repeated with the next low tide. Rising water again lifted the wreck, and enabled her to be worked into still shallower water. This cycle of operations was continued until, after five lifts had been made, she was dropped in a position which left her high and dry when the tide had ebbed.

In some instances, if the vessel is irretrievable, it is possible to reduce the underwriting losses by salving the cargo, particularly if it is of an imperishable and valuable character. This was the case with the Oceana, which was sent to the bottom off Beachy Head after smashing into the wind-jammer Pisagua. The liner carried bullion to the value of $t_{750,000}$ or $\$ 3,750,000$, in bars of silver and gold, as well as a consignment of ivory. The wreck was in a badly exposed position, so much so that often for days the divers were unable to venture below, while under the best conditions they could not remain long on the wreck, with a pressure of 45 pounds-three times that of the air above-bearing upon every square inch of the body. 
At times the currents were so swift that the divers were in danger of being swept off their feet, while the ghostly form of the ressel was wrapped almost in utter darkness.

Diver Lambert was entrusted with the task of wresting this wealth from the deep by the Liverpool Salvage Association. He was so persistent and successful in his work that he recovered practically the whole of the bullion. It was no easy task groping through the bowels of the liner, 90 feet below the surface, swinging about the bars of goid and silver, since they ranged from 80 pounds upwards in weight apiece. The bullion was hoisted aboard the speciai salvage steamer Ranger, which served as the depôt for operations. In the course of ro weeks the men working on the sea-bed were able to put in only about 60 hours' work all told, but they went at the job with such a will that when the conditions were favourable they retrieved the ireasure-trove at the rate of $\ell_{12,500}(\$ 62,500)$ per hour. The task was completed without the slightest mishap, and it is computed that the salvors reaped about $6,60,000$ $\$ 300,000-0 u t$ of the transaction, while the feat ranks as the most imposing of its class in salvage records.

The recovery of the Catterthurn gold was even more sensational and exciting, although it did not represent such a huge sum in the aggregate as that of the Oceana. This steamer left Sydney on August 7, I895, for China. She had scarcely got clear of the harbour when she was overwhelmed by a storm, was driven on to the Seal Rocks, and lost. She had $\mathcal{E}_{\mathrm{I}} \mathrm{0,000}$, or $\$ 50,000$, in gold, stowed away in a tank beneath the floor of the chart-room. The underwriters resolved to see whether their losses might not be mitigated by the recovery of this specie. Accordingly, two vessels were sent out to find the wreck, with two divers - William May and Arthur Briggs-aboard. After consicierable groping the wreck was picked up in a depth of about 1 So feet. Diver Briggs made tiree descents to I44 feet, the first wo efforts being abortive, but on the third attempt he descried the wreck standing out like a grisly phantom in a dense fog. He could not rearh her, as his 
diving gear was not made for the greater depth, so the salvors returned to Sydney to await the arrival of improved diving gear from London.

The depth of the water was against the divers, as it involved withstanding a pressure of some 90 pounds per square inch when on the deck of the wreck. The underwriters were resolved to run no risks, so the divers were sent down to a corresponding depth outside Sydney Harbour, to demonstrate that they could withstand the pressure without suffering any ill-effects.

The salvage vessels then sailed for the wreck, which they had marked with a buoy. Briggs went down first, followed by his colleague. A cursory inspection convinced them that they would have to work quickly, as the vessel was tumbling to pieces rapidly. The rigging was rotting, the funnel was lying lengthwise on the crumbling deck, the topmasts were gone, and the ressel was flattening out like a pancake, under disintegration and the pressure. The divers found it difficult to keep their feet, as the tide and currents ran at about five miles an hour. They reached the chart-room, found the door torn from its hinges, and the floor under which the specie was concealed breaking up. Marine growths infested the hull thickly on every hand, imparting a most forlorn and dismal aspect to the wreck.

It was some time before salvage could commence, as stress of weather repeatedly drove the salvors to port. In one gale the locating buoy got adrift, and many weary hours were spent groping anew for the wreck. A supply of dynamite was brought up, the obstacles to the specieroom were blown away, and just as the divers were about to probe for the gold, the urgent signal to come up was sounded. The clerk of the weather was intervening once more, and he delayed operations for a solid month.

It was an eerie sensation working at a depth of 160 feet in the ocean. The loneliness was one that could be felt. The divers had one or two companions down below with them, one of which was by no means welcomed. This was 
a shark, who had entered into occupation of a space on the deck near the chart-room. Time after time the monster brushed his tail against the divers, but did not display any tendency to investigate closely the men in the strange helmets. He left them alone. This was more than could be said for others of the submarine population, as some of these deep-sea inhabitants enjoyed nibbling pieces out of the men's hands while they worked.

Lively times were encountered in hoisting the treasure to the surface when it was recovered. The bullion was not in bars, but in coin, and the wooden boxes containing the hoards threatened to collapse, owing to advanced decay. One consignment of $£ 5000(\$ 25,000)$ came up in a single box after breaking away from the hoisting rope five times. The divers suffered severely from the strain and pressure, May towards the end showed signs of collapse. They retrieved in all $\mathcal{E}_{7,944}$, or $\$ 39,720$. The underwriters expressed themselves so satisfied with this success that they declined to permit the divers to incur further risks in searching for the balance. One of the Chinese passengers who was drowned was said to have taken a nest-egg of f.2000 (\$10,000) on board with him, but this treasuretrove was disregarded. The divers received the sum of f, 1,191 i $2 s$., or $\$ 5.958$, representing 15 per cent. of the value recovered, between them as a reward for their labours, while the total salvage expenses represented about 45 per cent. of this value.

Another smart feat was in connection with the steamship Cyril. She sank into the bed of the Amazon with rubber

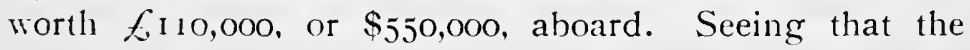
wreck was in 120 feet of water, the chances of salving the cargo were considered very slender, but the salvage steamer Ranger went out to South America with her divers and other plant, picked up the vessel, and the divers descended into her holds. Once the cargo was reached it was hauled to the surface with astonishing rapidity, and the salvors did not leave the wreck until they had brought more than $f 100,000(\$ 500,000)$ worth of the rubber to the surface. 


\section{STEAMSHIP CONQUEST OF THE WORLD}

At times the salvage of a wreck defies the most perfect of appliances, ingenuity and determination. The Wick Bay was a case in point. She was sucked down by the treacherous sands of the Wash off Lynn early in the 'nineties of the last century. Time after time efforts were made to recover her, but it was like pulling a vessel from a bed of liquid glue to attempt to extricate her from those greedy sands; Every time the effort was abandoned she relapsed more deeply into her couch, finally breaking her back, and thereby becoming useless for salvage. The money expended upon this wreck represents a formidable item. The Town Council of Lynn became entangled in the fiasco. About 1894 they secured official powers, by the passing of a private Act of Parliament, to raise a loan of $\mathcal{E}$ i 8,000 , or $\$ 90,000$, to remove her. The money was practically thrown away, and nearly the whole of this sum still remains unliquidated. The Wick Bay remained a serious menace to navigation, until Thomas Armit of Utopia fame came along, and he threw the hulk high and dry on the beach.

Even the destruction of a wreck which is impossible to refloat is not a simple task. If she has been sturdily built, even rynamite and blasting gelatine will not split her to shreds very readily. The citizens of Philadelphia had good occasion to be impressed with the high standard of British shipbuilding on one occasion. The steamship Bermuda was built at Sunderland in 1874 for the passenger service between New York and the Windward Islands. Prior to the Spanish-American War she was bought by the Cuban Junta, and was engaged in gun-rumning and other filibustering operations, to be resold in due course for service in the Tlest India fruit trade. She was lying off a pier in the Delaware River one day, when there was an explosion on board. It was thought to be caused by a cartridge which had worked its way into the bilges, and was there detonated. Whatever the cause, a big hole was blown in her bottom, and she sank into the mud.

She laid in the river-bed for some three years. Attempts 
were made to refloat her, but she refused to be drawn from her unsavoury soft couch. Thereupon it was decided to remove her piecemeal. The enterprise was handed to a contractor, and he set to work. But he found that dynamite, which will bring down tons of rock readily, could not destroy this solidly built steamer so easily. The work was slow and tedious. Time after time a charge would be fired, without, or only partially, doing its expected work. One big blast at last loosened her deck sufficiently to enable a powerful derrick to wrench away a solid piece weighing some twenty tons, which was lifted bodily and deposited upon barges, to be broken up on shore for sale as scrap-iron. It was some months before the remaining fragments of this old and historic filibuster were removed, and the fairway of the river was deprived of one of its most serious menaces. 


\section{CHAPTER XVII}

THE STEAMSHIP CONQUEST OF LITTLE-KNOWN WATERS

THE exacting demands of commerce, following in the footsteps of civilisation, have called the marine engineer and shipbuilder to many strange places. Even then one cannot suppress a start of surprise to find fully fledged steamships upon such inland seas as the Victoria Nyanza in the heart of Africa, Lake Titicaca among the clouds of Peru, or Lake Baikal in the centre of Siberia! How did they get there? The puzzle is not solved even when a decaying building-slip is discovered on the bank. It seems incredible that a ressel 200 feet or so in length, propelled by steam, and bearing every resemblance to a big yacht, could have been fashioned in such desolate situations.

At the same time when one recalls the weight and bulk of many of the component parts of a steamship, one finds it difficult to believe that the steamship could have been transported overland. A marine boiler is an unwieldy and cumbersome article to handle. Yet it is quite evident that the boiler could not have been put together on the banks of the inland sea, as its construction demands the use of hydraulic machinery, and other ponderous tools, in order to weld the joints so tightly as to resemble one continuous piece of metal; otherwise, directly steam is raised, disaster is certain.

The disinterested individual is apt to take things which he cannot comprehend for granted, and so possibly he does not give a second thought as to how the steaniship got into such outlandish places.

Yet the provision of these facilities upon an inland sca, cut off completely from the friendly ocean, has entailed prodigious efforts upon the part of the engineer. He has 
had to negotiate teasing problems innumerable, such as never arise in the shipyards of civilisation, completing his work with unskilled labour, with imperfect facilities, and often with improvised tools, puzzled every succeeding hour by some awkward development, and with plenty of adventure and excitement thrown in to leaven up the arduousness of the task.

In Great Britain there are one or two prominent shipbuilding firms who may be said to make a speciality of building vessels for such remote insulated seas: such as Messrs. Bow, McLachlan and Company, Limited, and Messrs. Denny Brothers, both of the Clyde. The firstnamed is always prepared to build a ship and to send it anywhere. The general practice is to erect the craft first in the native shipyard on the Clyde, completing it to the smallest detail. It is constructed only temporarily, being put together in the same manner as a costumier in the first place tacks the parts of a dress for fitting. When it is ready for launching the whole is then dismantled, every individual part is numbered and indexed, to indicate its precise position in the hull. As the ship stands upon the building slip, it looks as if it had been surrounded by a group of mischievous schoolboys, armed with chalk, for it is covered with a bewildering array of figures and hieroglyphics, which to the casual visitor would rival an Egyptian tomb.

Every mark and number conveys a mine of information to the engineer who must float that ship upon its destined waters. By means of the sheaf of drawings and models he is able to determine the exact position of any plate, door-handle, or guy-stay in a moment. As the fabric is dismantled the parts are packed in boxes and crates, each of which in turn is given a distinguishing number and sign, so that the engineer may be able to determine by reference to his detailed specification or catalogue the precise contents of each package, without being compelled to open them indiscriminately. The whole consignment is then packed into the hold of a steamer and sent away 
with the engineer in charge, assisted possibly by one or two skilled hands.

When the steamship, with her dismembered consort within, has slipped out of the home port, the real troubles commence. It is up to the engineer in charge of the enterprise to fulfil the contract. He has no knowledge of what confronts him on the banks of the waters upon which the craft is to float. He must land his precious freight as best he can; marshal all the crates and boxes upon the landing-stage of the quay; is dependent entirely upon his own ingenuity and resources to get them across country; while he has no more idea than the man in the moon as to how he is going to cope with the local labour problem.

Fortunately, the average engineer never troubles trouble until trouble troubles him. The voyage passes with scarcely a thought of what is looming ahead, and the engineer, realising that he is destined for a hard tussle lasting some months, takes the opportunity to secure a little relaxation. He may have a time-limit staring him in the face, but his cheery optimism prevents this factor from worrying him. It is useless to speculate upon this or that, because this class of engineer has found from bitter experience that the best-laid schemes have an inhappy knack of going sadly agley.

Take the case of Mr. Richard Grant, who was responsible for floating the first steamer, the Ililliam Mackinnon, upon the Victoria Nyanza. This sheet of water is as large as Ireland, aggregating about 20,000 square miles. The ship was ordered before the Uganda railway was built, and so in this instance the erecting engineer was faced with a pretty stiff problem, seeing that Port Florence is nearly 500 miles distant from Mombasa on the coast. When the parts of the steamer were landed they had to be transported across country on the heads of colies, and by whatever other means of transport were available. Despite the handicaps imposed the ressel was put together and launched.

Since that day four other vessels have been floated upon 
this lake, the traffic of which is increasing so rapidly that two other boats are in course of construction, and will shortly bring the fleet up to six twin-screw craft. One of the latest additions is a single-screw tug, 100 feet in length by 20 feet beam and $10 \frac{1}{2}$ feet moulded depth, drawing 7 feet of water, and with a speed of 8 knots.

The second and third units of this inland fleet, the Winifred and the Sybil, were dispatched to this inland sea shortly after the railway was opened for traffic in Igoz. They are sister ships, I75 feet in length, by 29 feet beam, and $9 \frac{1}{2}$ feet moulded depth, with a draught of 6 feet 2 inches. They are driven by triple-expansion engines, the high-pressure cylinder having a diameter of $9 \frac{3}{4}$ inches, while the intermediate is of $5^{\frac{1}{2}}$ inches, and the low-pressure of 25 inches diameter, the stroke being 16 inches. The marine return-tube boiler works at 160 pounds pressure, and the vessel can notch io knots per hour when fully loaded.

The transport of this consignment of parts, owing to the railway, was simplified appreciably because the line stretches from water's edge to water's edge. But the railway presented a sorry sight by the time the train of parts reached Port Florence. It looked as if the $5^{8}+$ miles of line had been swept by a hurricane, owing to the havoc wrought to the platforms and station buildings. There was not sufficient clearance between the tracks and the permanent structures to permit the ungainly freight to pass, since some of the parts were of unavoidably large dimensions, overhanging the trucks, and when these struck the buildings, or the latter had to be trimmed back to allow the train to continue on its way, considerable damage was done.

Upon arrival at the inland terminus a slipway was prepared by the engineer, launching-ways were laid down, and the re-erection of the steamers pushed forward without delay. Fortunately the abundance of timber enabled the engineer to run up stout derriclis for handling some of the bulky material and lowering it into position. The massive 
boilers, weighing some fifteen tons, and the condensers, were the most awkward sections to handle. The side of the hull had to be left open in the boiler space, so as to permit the steam generator to be transferred to its designed seating within the ship. The setting of the boiler, in fact, constituted the most difficult part of the undertaking. On the Clyde it had not occasioned a second's thought, as it was picked up by a heavy crane, whisked round and lowered into position with as much ease as if it had weighed as many ounces as it represented in tons. But on the shores of Lake Nyanza there were no such serviceable handmaids. The engineer surmounted the difficulty by erecting a massive timber runway, built up of heavy baulks, upon a foundation of heavy lumber. The cumbrous cylindrical part was warped and rolled into position at the foot of this wooden incline, and then coils of thick cable were passed round its girth and strained to a point on the opposite side. While the gangs of natives hauled on to the hawsers passed round the boiler, thus dragging it up the runway, another gang followed the ascent with huge wedges, which they knocked home on the under-side, securing the rotund fifteen-ton mass when the hauliers paused for a breather. In this manner the boiler was lifted inch by inch, until at last it reached the top of the incline and was then lowered into the hull, to be made fast upon its designed seatings.

Since then the builders of these twin-ships have sent two other steamships in pieces to the lake, erected them on the bank, and transferred then to the water. The third contribution to the fleet was considerably larger than its consorts, being $22+$ feet in length, by $32 \frac{1}{2}$ feet beam and Io feet moulded depth, with a draught of $6 \frac{1}{4}$ feet. The engines were larger, the diameter of the three cylinders being respectively 10,16 and 26 inches, with a stroke of 20 inches, griving a speed of 10 knots per hour. The fourth raft, the Nyanza, was larger still, the length being 220 feet, with a beam of 34 feet and a moulded depth of 11 feet, but of similar draught. In this instance the 


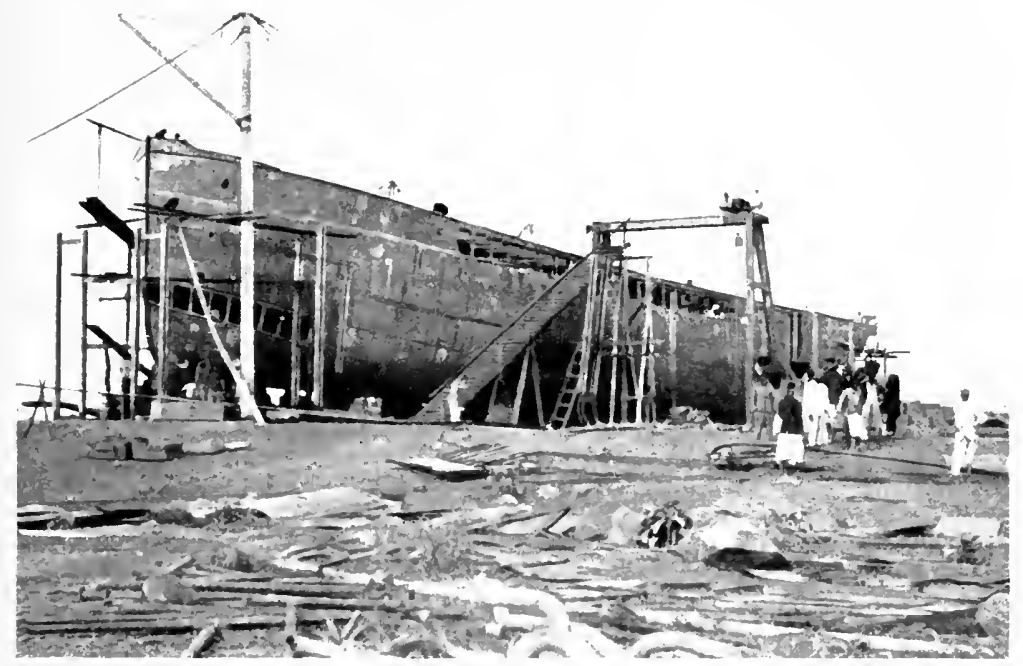

APPROACHIXG COMPLETION FOR LAL NCIISG

Vative labour wat enpluged under white supersision, but, when drilled, proved efficient.

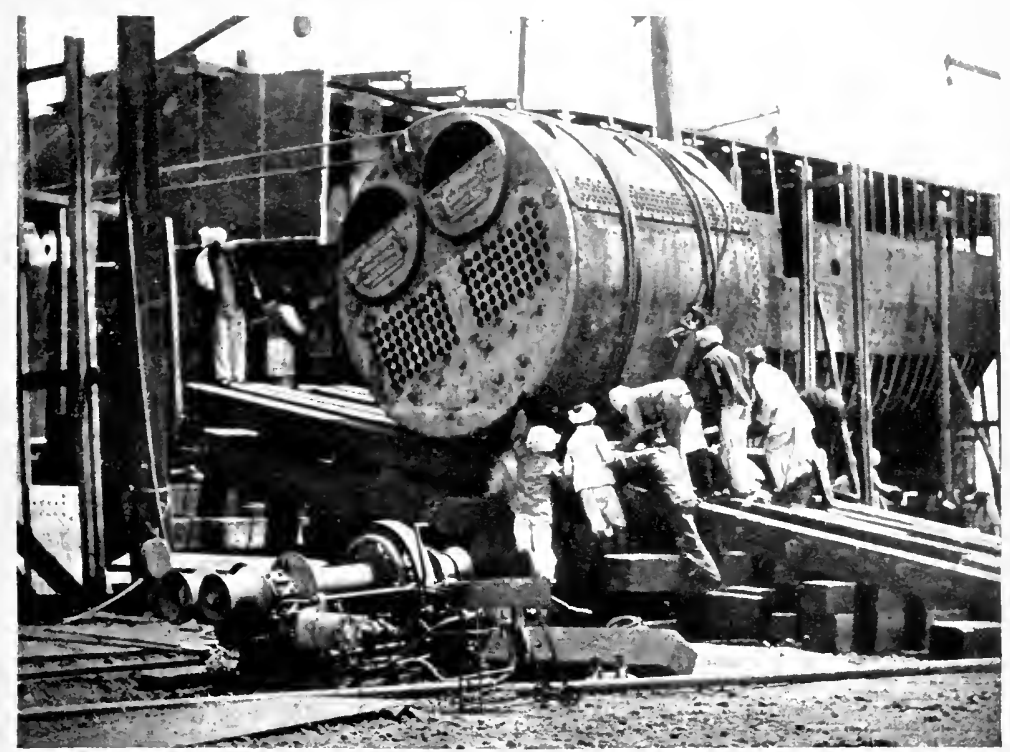

(IFTTIST, I BOHLER (N BU.SRI)

The hatuling of the steam (ienterators wats a pretty problem. This show how a boilet

wan mashed, prolled, and wediged into it plate in the hull.

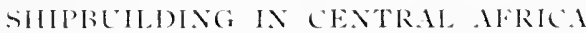




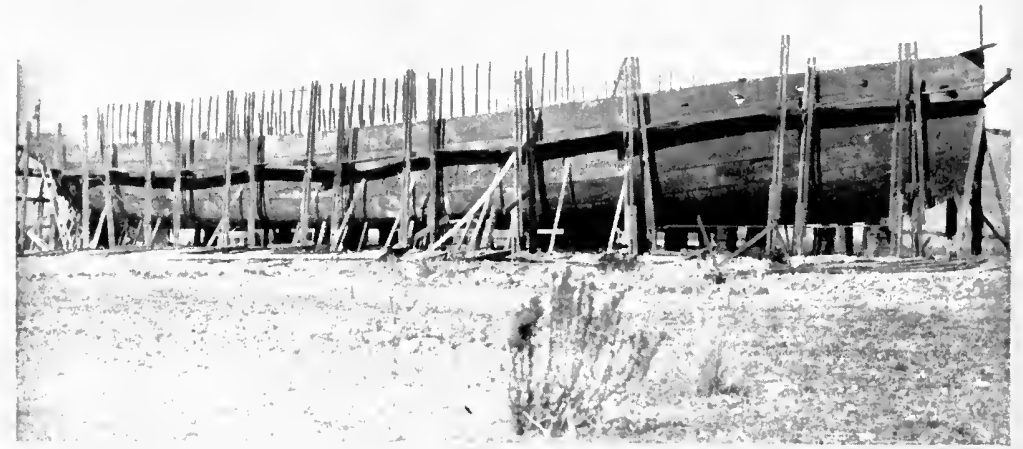

SIIPBIILANG ABOVE THE CIOLA

The steamship Coya was sent in pieces from the Clyole, and rebult on the shores

of 1 ake Tilicaca, 12,545 feet albose the ocean.

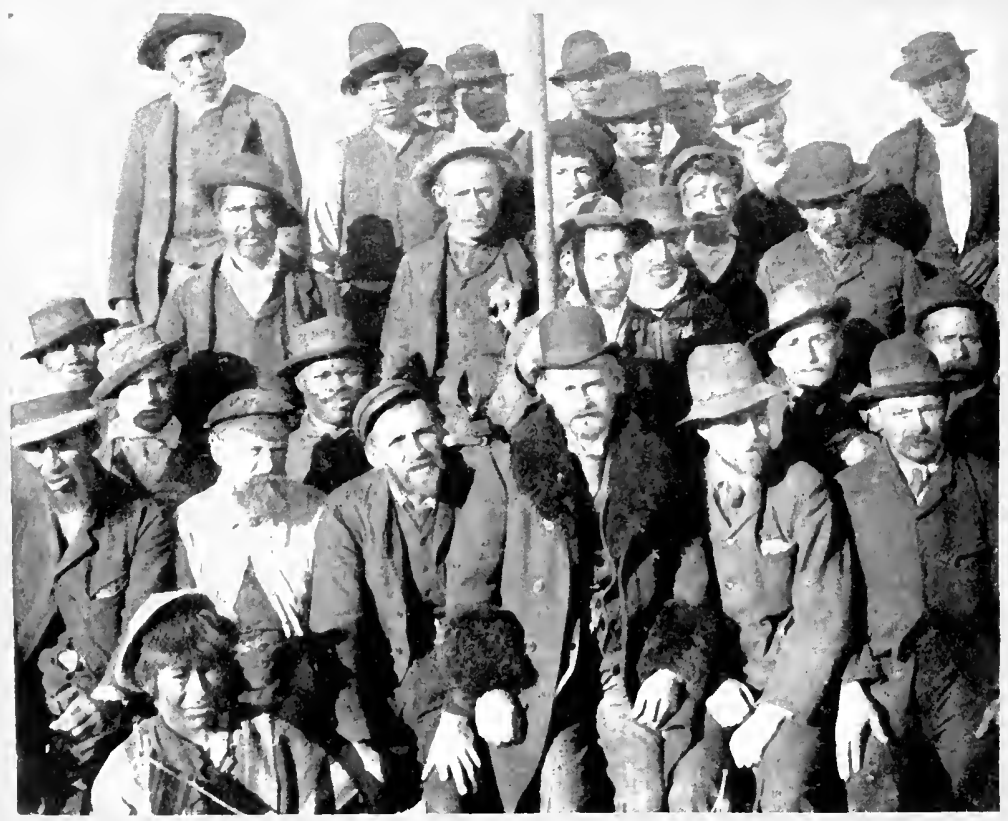

A MOTLEY S(O) ( MI)

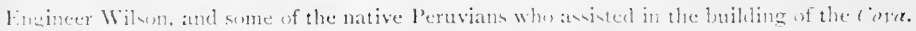


engines coincided with the first two vessels, having the same dimensions in bore and stroke and of identical speed.

When making the cruise around Lake Nyanza, one secures a strikingly picturesque combination of the primitive with the civilised. These steamers with their fine lines recall the steam yachts so familiar in civilised waters. They contrast vividly with the sailing dhows and the canoes, 40 and 50 feet long, built of bark, secured together with strips of fibre-no nails are used-and propelled by I 8 or 20 swarthy Masai. These were the vessels by which Europeans who ventured into this country before the construction of the railway had to make their way across the lake, tolerating many discomforts, especially in rough weather. To-day the water journey is no different from a trip up a broad river at home.

More exciting and trying was the task confronting Mr. John Wilson when he undertook to re-erect and launch a small steamer upon that sheet of water, measuring I 20 miles in length by 35 to 40 miles in width, nestling among the Peruvian Andes at an altitude of I 2,545 feet above the Pacific sea-board, known as Lake Titicaca. This was a case of building a steamship above the clouds, under the most adverse conditions, in grim earnest. Although this sea is at such an extreme altitude, and in the heart of such desolate country, yet it is a busy highway, practically forming a continuation of the Mollendo Railway, which creeps up the steep Andine slopes from Mollendo on the coast to Puno, a distance of some 300 miles. Then comes the water stretch to Cuzco, the capital. The first small steamer was placed upon this lake before the railway was laid, the integral parts being carried across country on mules. Before the advent of steam propulsion upon this sea, the native balsa was the sole means of water transport. It is a crazy and primitive craft in very truth, being fashioned from bundles of long stalks of the reeds which grow so thickly along the banks, and propelled either by a mat-sail made from the same material, or urged forward by quaint oars, in the manipulation of which the natives 


\section{STEAMSHIP CONQUEST OF THE IVORLD}

display great dexterity. These craft, however, were only suited to the calmest weather, and when the severe storms, to which this lake is subject, swept down, lashing the water to fury, traffic was interrupted.

The trade having outgrown the capacity of the little pioneer steamer, a second and larger vessel was ordered from the yards of Messrs. Denny Brothers on the Clyde, by the Peruvian Corporation, who had taken over the transport system of the country after the devastating wars. The Coya, as she is named, is a shallow draft steamer I 70 feet in length by 26 feet beam, with accommodation for 45 first-class and 30 second-class passengers, as well as ample space for freight. In this instance careful attention had to be devoted to the size and bulk of the individual packages containing the component parts, to secure passage through the tunnels and under the bridges of the railway leading up from the coast. Still, there were certain sections, the dimensions and weight of which could not be reduced very advantageously, namely, the boilers, which weighed fifteen tons apiece, and the condensers, which turned the scale at five tons.

The engineer started off on his long journey from the Clyde to Mollendo with his dismembered charge in the holds of the boat sailing for this Pacific port. Directly he reached the end of the ocean journey his troubles commenced. The landing of the cases occasioned many an anxious moment, as the port is quite exposed, and is subject to a heavy swell, with a nasty surf breaking on the shore. The greater number of the cases of the Coya were discharged in to lighters and brought ashore in that manner, but the exposed position, and the unpropitious nature of the weather, caused the wary Scottish engineer to investigate the coast-line, in order to discover, if possible, a more sheltered spot where the boilers might be transferred from the steamship to the lighters, thence to be towed into Mollendo and lánded. He found an excellent anchorage at Islay to the north, and here the trans-shipment was carried out. The engineer, however, took the precaution 
to plug the boilers before they were shipped; so that in the unlucky event of a lighter capsizing, the steam-generator would float, and be recoverable with little injury. The loss, or damage of, a boiler would have been disastrous. The engineer was faced with a time-limit of twelve months to complete the undertaking, and the schedule was cut so finely that the slightest delay would have proved serious. However, the boilers were landed on the wharf without a mishap, and the movement towards the lake was commenced.

The packages, crates and boilers as they were landed were transferred to railway trucks, twenty-two of which were required to carry the whole of the dismembered Coya to her final destination. The boilers were lashed and stayed to prevent oscillation and collision with the low tunnels and bridges, the clearance being a mere matter of inches only.

When the train reached Arequipa, Wilson broke the journey, partly to get accustomed to the rarefied and colder air. This point, at an altitude of 7,500 feet, is know as "The Half-way House." The locomotive slops of the railway are situated here, and as Wilson had been notified that by the time he reached Arequipa all tools and tackle required for his work would be ready, he pressed the halt into service to have these put aboard the train. His feelings may be imagined when he found that the sum of the arrangements provided was merely a collection of disused railway cross-ties or sleepers! There was not the sign of a tool: not even a hammer. This was an unexpected state of affairs. The builders at home had relied upon the railway authorities in this respect, and had not even sent out a hammer, convinced that IVilson would be able to get more than he wanted at Arequipa. What was worse, he could not purchase such a toul for love or money. This was a dilemma. To send back to England for a supply meant a delay of months, and here he was working against a time-limit. While Wilson learned the fallacy of trusting to South American railways, he 
realised that he was compelled to make the best of a bad bargain. Thereupon he scoured the railway scrap-heap, unearthed a few pieces of discarded steel, from which he fashioned the hammers and other tools he required. Fortunately, the carpenter had brought his tool-bag with him, so the railway sleepers, which had been thoughtfully placed on one side, were seized and sawn up into keel blocks.

Upon arrival at the lake further troubles awaited him. The sea, being tideless, the selection of a suitable point for his temporary shipyard and the launching ways was by no means simple, owing to the generally unfavourable character of the banks. The only spot which could be made to suit his purposes was a small potato patch, beionging to a Quichua Indian, which dipped into the lake. The potato patch was unkempt and almost forgotten when Wilson arrived, but when he suggested renting it for a few months, the value it assumed in its owner's estimation was astonishing. At first the Indian point-blank refused to let it under any conditions, and days were spent by the Scotsman and the cunning Indian in haggling and bargaining. At last, after careful prolonged discussion, and for a heavy consideration, the Quichua relented. The engineer was given permission to set up his shipyard and shops on the potato patch, on condition that he leased the Indian's residence for the same time! It is to be feared that the wily Quichua in this instance got the better of the canny Scot, for had he not got his own terms, and was he not a white man's landlord for a whole year!

The ways were improvised from timbers used by the railway in the erection of its bridges, and the berth was placed as near the water's edge as possible. The engineer, being robbed of tidal movement, resulved to press the scasonal fluctuations in the lake level to his aid. The water was low at this time, but he calculated that everything would be ready for launching by the time the water had risen in the wet season. Building, once a start was made, went forward with great rapidity under the circum- 
stances, though at first difficulty and delays were experienced in teaching the raw unskilled natives the art of riveting. After a little patience and practice, however, the Indians became quite expert at this work.

Progress was hampered sadly by the thieving tactics of some of the workmen. The Gringoes were the worst offenders in this respect, and stopped at nothing to gain their ends. They are the scum of the population, with the blood of a host of nationalities coursing through their veins. Directly they heard of the enterprise they flocked to the scene and promptly purloined any metallic articles within reach. They hung about the yard, interfering with the workmen who were peaceful and industrious, according to their lights, and at times menaced the engineer so threateningly that Wilson was compelled to demonstrate to them the possibilities of a revolver which he kept to hand, though fortunately he was not called upon to use it. A glimpse of the weapon was sufficient to scare the Peruvian loafer.

Holidays, in commemoration of some saint or another, were of almost daily occurrence. The engineer remarked to me that he concluded they have got almost enough saints in South America to carry every day in the year. Then he had a somewhat tiresome difficulty in controlling his men. He counted up the nationalities of his employees one day, and found that no less than fourteen different tongues were represented. The babble when they were talking in their work was bewildering, but, fortunately for him, one and all were more or less conversant with Spanish, so that he was able to communicate his instructions comprehensively.

When it came to lifting the heavier and bulkier parts of the machinery another dead-stop appeared imminent. The boilers measured $16 \frac{1}{2}$ feet long by 8 feet in diameter. Together with the condensers they had to be tugged and hauled by sheer physical effort from the railway yard to the berth, and there installed in the hull before launching. The railway did not possess a portable crane for hoisting the boilers into position, and he was puzzled how to 
contrive a set of sheer-legs, as the country, owing to its altitude, does not yield an inch of timber. He happened to hear that down at Mollendo an old wind-jammer was laid up, and that he might be able to get hold of the masts and spars to help him over the difficulty. He hurried down to the port, but news of his coming and mission sped ahead. When he unearthed the owner of the discarded sailing-vessel, this individual had not the slightest disposition to sell. He had cultivated an extraordinary affection for his old boat, though a week before he would have been glad to have sold it for firewood. Nore haggling and bargaining ensued, and it was some time before the wily owner relented. When he stated his price for the spars, the engineer nearly collapsed. He could have bought the whole ship as it stood for less. However, argument was useless. The engineer was cornered, so he smothered his feelings and made the best of a bad deal. He hastened back with the spars, rigged up a derrick, and after much labour the bulky weighty parts were set truly in position.

The launching ceremony was a red-letter day in Peru, and the population turned it into a national festival. The natives flocked to the shipyard from miles around, and the shore was lined with over 5000 Indians. The Bishop of Puno, supported by the Mayor and numerous other civic dignitaries, pronounced the religious ceremony in Spanish, the Mayor smashed the proverbial bottle of wine across the bow, as the impatient engineer let go the trigger holding the vessel on the stocks. Released, the Coya slid down the ways as if glad to leave dry land, her stern dipped into the water, and a second later she was buoyant. The yells and frantic halloos of delight from the Indians were deafening, but Wilson was the most satisfied member of the crowd. His six months' work was crowned with success-he had got the Coy'a afloat.

The vessel was towed alongside the primitive landingstage at Puno, and the upper works were completed rapidly. Unfortunately the engineer was stricken down 
by a severe attack of fever, brought on by the mountain sickness and malarial conditions, but while he tossed in delirium, his assistant, the ship's carpenter, who had come from Scotland with him, kept the Indians to their work, so no time was lost. The contract time was drawing to its close, and every effort was crowded on. The steam trials were made the occasion of further rejoicing, but at first things did not go smoothly, owing to the rarefied air not providing sufficient oxygen to maintain combustion, added to the fact that timber was used as fuel. This difficulty was adjusted in due course, and then the engines settled down to their running as if they had been working for years. The engineer made several trips across the lake, and then turned the vessel over to the local captain-one day before the expiration of the time-limit! The job, from the day he left Scotland with the dismembered Coya until she was taken over by her owners, occupied 364 days.

Two or three years ago, the traffic on the lake having grown, another steamer was ordered. This boat, the Inca, was built by Earle's Shipbuilding and Engineering Company, Limited, at their Hull yards, and also sent out in pieces to Mollendo, transported overland by railway, and re-erected on the bank of the lake. The whole ship was temporarily built or tacked together at Hull, and then dismembered and packed in the manner already explained. The saloons, state-rooms, pantries, etc., were built in the joiner's shop, a portion of the building being prepared to represent the deck of the vessel. This part of the work was completed practically in every respect, including upholstery, curtains, rods, dining-tables and so forth, as well as the steam-heating installation. The leads of the wires for the electric light, position of the switches, and all other details were indicated plainly on the cabin walls. The auxiliary machinery, fans for forced draught, with pipes and connections, were all fitted up on the ship.

In addition to what may be termed the structural fabric, a vast assortment of incidental fittings, such as bolts, nuts, 


\section{STEAMSHIP CONQUEST OF THE WORLD}

rivets, screws, pitch, paint, jointing material, as well as tallow, soap and oil for greasing the launching-ways, had to be made up. By the time the Inca in her dismembered condition was ready for shipment slie was distributed among 3000 packages, each of which carried a separate identification mark for the guidance of the re-erecting engineer, together with individual marks for shipment.

The difficulties experienced with the landing of the Coya at Mollendo were repeated, and at times the unloading, especially of the heavier and larger pieces, was attended with considerable risk. Still, the task was achieved with a commendable immunity from accident, owing to the care and vigilance displayed. Only in one or two instances were parcels damaged in the course of transit from ship to shore.

The Inca is the largest steamship engaged upon Lake Titicaca at present. She measures 220 feet in length by 30 feet beam, and it feet moulded depth. She is driven by twin-screws, the engines developing about rooo indicated horse-power. With a dead-weight of 550 tons on board, she steams at a speed of 12 knots per liour.

A different method was practised when Lieutenant Simon succeeded in placing two small gunboats upon the upper reaches of the Mekong River, 1,500 miles from the sea, in the heart of Lower China. He was dispatched to the East by the French Government to survey the whole length of this waterway, and one of the boats was sent out in five sections. The craft were small, somewhat recalling the excursion steamers one encounters upon the higher reaches of the Thames, or the backwoods waterways of the American continent. The dismembered boat was cut into five slices transversely, as if it were a brick-shaped loaf, each section being fitted completely, so that when the dismembered craft reached its destination it was only necessary to bring the sections side by side in a line in their proper positions, and then to bolt the whole together. Even this was no light undertaking, as some of the sections weighed over ten tons apiece. 
They were dispatched to the East in the hold of a steamer, landed, and put into the water. They then steamed up-country, along the waterway, as far as possible. When the Lieutenant encountered an obstruction, he subdivided the larger boat, drove a path through the virgin forest around the obstacle, laid a pair of rails, and lifted the boat, section by section, upon a low-wheeled truck, where it was wedged into position. It was then hauled by gangs of natives through the jungle. Regaining the river, the parts were put together again and the craft once more launched into the water from the wheeled carriage, the latter being tilted forward especially for the purpose. It was a highly adventurous undertaking beset with perils innumerable, and rendered further exciting because of the animosity of the Siamese to the hydrographer's advance.

When the Klondyke gold rush set in, from all corners of the globe, a steamship service was one of the first propositions entertained. Accordingly, the shores of Lake Bennett resounded with the clanging of hammers, a continuous rapping as rivets were driven home and the clatter of steel and iron. In these latitudes plenty of timber is available, so the erection of the slipways and stocks did not present many difficulties. The main problem was the haulage of the weightier and bulkier material from the coast at Skaguay, over the sinister Chilkoot Pass. Heavy sleds were built on which the boilers and engines were loaded, wedged and lashed tightly, to prevent an accident when rumbling over the rough ground, and these cumbrous loads were hauled in with infinite labour and privations by horses and mules. The vessels were launched, and then a link of communication was established over the great highway of the Klondyke-the Yukon River-between Whitehorse, Lake Bennett and Dawson City. To-day, although the boats still maintain the communication during the summer months, the shipyards of Bennett are only a terrible nightmare. The stocks and buildings have fallen into decay, except those required for repairing the existing boats and a scene of departed prosperity hangs over all. 
These frontier boats belong to what is known as the "Alligator" type. They draw only a few inches of water, seem unwarrantably top-heavy, but nevertheless are exceedingly convenient and safe. At the stern are big paddles resembling water-wheels, which propel the boat. The broad blades are of wood, and onc of the most common incidents upon these troublesome, rapidly rushing waterways of the frontier countries, is a grind, crash and scrape over submerged rocks, the toll being the splitting and loss of half-a-dozen blades or so. On several occasions I have encountered one of these curious vessels drawn into the shelter of the bank, with the crew swarming over the stern fixing new hlades with desperate haste. Delays of five days or more irom such a smash are by no means infrequent, but it is only the passengers who suffer. The companies operating these boats know the caprices of the waterways, and accordingly do not follow European practice by charging inclusive fares, but levy a daily tariff for the berth and meals in the proportion of a dollar or four shillings for the former, and fifty cents or two shillings for each of the latter per head, the passage money merely entitling a person to step on board. Thus a journey may be covered safely in two days, or it may take twelve days, according to the captain's fortune.

When these boats have fulfilled their mission on one waterway, and navigation is abandoned, the machinery is taken out, together with the other marketable equipment, and the hull is scrapped. The removed parts are sent across country to another waterway that is to be exploited, where a new hull is fashioned and launched to receive the machinery. When the upper Fraser River was exploited, the boilers and other fittings were shipped to Ashcroft on the Canadian Pacific Railway, thence transported overland on wagons to Soda Creek, I65 miles distant, where they were placed in newly-built hulls. This was no light undertaking, as the boilers weighed ten tons apiece, and although the road surface was fairly good for travelling, many teams of horses were required. The 
transport charges were unavoidably heavy, averaging 5 cents, or $2 \frac{1}{2} d$., per pound, so that the conveyance of a ro-ton boiler over the 165 miles represented an outlay of about $\mathcal{E}$ roo, or $\$ 500$-more than the article was worth in some instances, as it had already put in many years of useful service.

When the trans-Siberian Railway was driven across Siberia, the continuity of the metals was interrupted by tise long stretch of water forming Lake Baikal. To establish a through service before the rail was carried round the southern shore of the lake, a massive ice-breaking ferry, capable of transporting the trains intact across the forty miles of water, was acquired. The contract for this vessel was placed with Sir IV. Armstrong, Whitworth \& Company, and it was built in their yards at Elswick, while the machinery was built by Swan, Hunter, \& Wigham Richardson, Limited, at Wallsend-on-Tyne.

The vessel measures 290 feet in length by 57 feet beam, is fitted with 15 cylindrical boilers, and 3 sets of tripleexpansion engines developing 3,750 indicated horse-power. Its displacement, otherwise total weight, is 4,200 tons. The ice-breaker was erected complete upon the 'Tyne, every part being numbered for identification. Then it was dismounted, packed in pieces, and dispatched by steamer to St. Petersburg. Thence it was sent across Russia and Siberia to the village of Listvenitchnoie upon the shores of Lake Baikal, by whatever system of transport was available. Team wagons had to be used extensively owing to the railway being incomplete. At its destination a shipyard was improvised, the pieces were sorted out and put together. Despite the long overland journey, and the extreme difficulties attending the transportation of the thousand-and-one pieces, the ressel was rebuilt in its distant home without the slightest hitch. Shortly after its installation upon the lake another ressel of the same class, but about a quarter of the size, was built and transported in pieces to the same lake for the railway service. 
248 STEAMSHIP CONQUEST OF THE WORLD

The marine engineer, like his contemporary associated with the construction of railways, is prepared to go anywhere in the interests of his profession. So long as there are a few inches of water he will build and launch his vessel. 


\section{CHAPTER XVIII}

FLOATING DOCKS

THE amazingly rapid growth in the length and weight of ocean liners, combined with the fact that finality is not in sight by any means, has disturbed the serenity of those responsible for the provision of mooring and docking facilities in the various ports of the world. A dry dock which has to be excavated from the solid earth or rock is an expensive luxury so far as construction is concerned. Yet it is absolutely necessary. The gigantic liner must be removed from her native element at intervals for the purpose of cleaning the submerged portions of her hull, which become clogged with marine growths and retard her speed very appreciably. An express liner, to be in the pink of condition and to maintain her paces, must be groomed as carefully as a race-horse, whose counterpart, indeed, she represents upon the ocean. By keeping the under-water part of the hull as brilliantly polished as a mirror she will slip through the water with complete ease; if it is permitted to become encrusted and dirty the water clings to it and acts as a drag. Nor must the contingencies of repair and overhaul be overlooked. From time to time the propellers demand renewal, as their surfaces become pitted and worn, and they lose their efficiency. Accidents will happen, and to effect repairs below the Plimsoll mark the vessel's body must be exposed.

The two oldest methods of achieving this end are by means of the graving dock and the slipway. In the firstnamed instance the ship is admitted into an excavated space, and when berthed the entrance is closed with watertight gates or huge caissons. Then the water within the enclosed area is pumped out, leaving it empty and dry to 
pernit the workmen to reach the lowest parts of the craft, just as if she were resting upright upon the beach. The second method is to lay down an inclined plane, rising out of the water at a gentle angle, similar to the launchingways, on which travels an elaborate truck. This truck is run down the plane, which is continued well into the water, so that the carriage may be brought beneath the vessel. The ship then becomes deposited in a kind of cradle, built upon the truck, and then is hauled up the slips on the wheeled-carriage until she is high and dry.

While this latter system is suited to a small vessel, it is quite impracticable with a liner such as the Mauretania or the Olympic. In the first place, the inclined plane would have to be 3000 feet or more in length, the foundations would have to be excessively deep and solid to support a weight of some 45,000 tons and the hauling machinery would require to be of huge power, while the cradle would need to be a gigantic affair. Consequently, the slipway is ruled out of court entirely when vessels exceeding a few hundred tons are concerned.

So far as the graving dock is concerned, this is quite practicable-so long as the harbour is supported by a rich treasury, and can obtain any demanded sum of money to gratify requirements. Unfortunately, however, dockbuilding is somewhat costly, and, in order to keep pace with shipbuilding activity, extensions must be made continually, unless time is taken by the forelock, and the dock is made of sufficient dimensions in the first instance to meet future requirements for several years. If the harbour authorities concerned are in a position to keep spending money in order to keep abreast of the times, no apprehensions need be entertained, but the average harbour-trust is not in the happy position to ignore capital expenditure. As a matter of fact, the number of ports which are able to drydock a vessel of the proportions of the Olympic may be numbered upon the fingers of one hand. Suppose, for instance, the Titanic had survived the blow inflicted by the iceberg and had crawled into New York. What would 

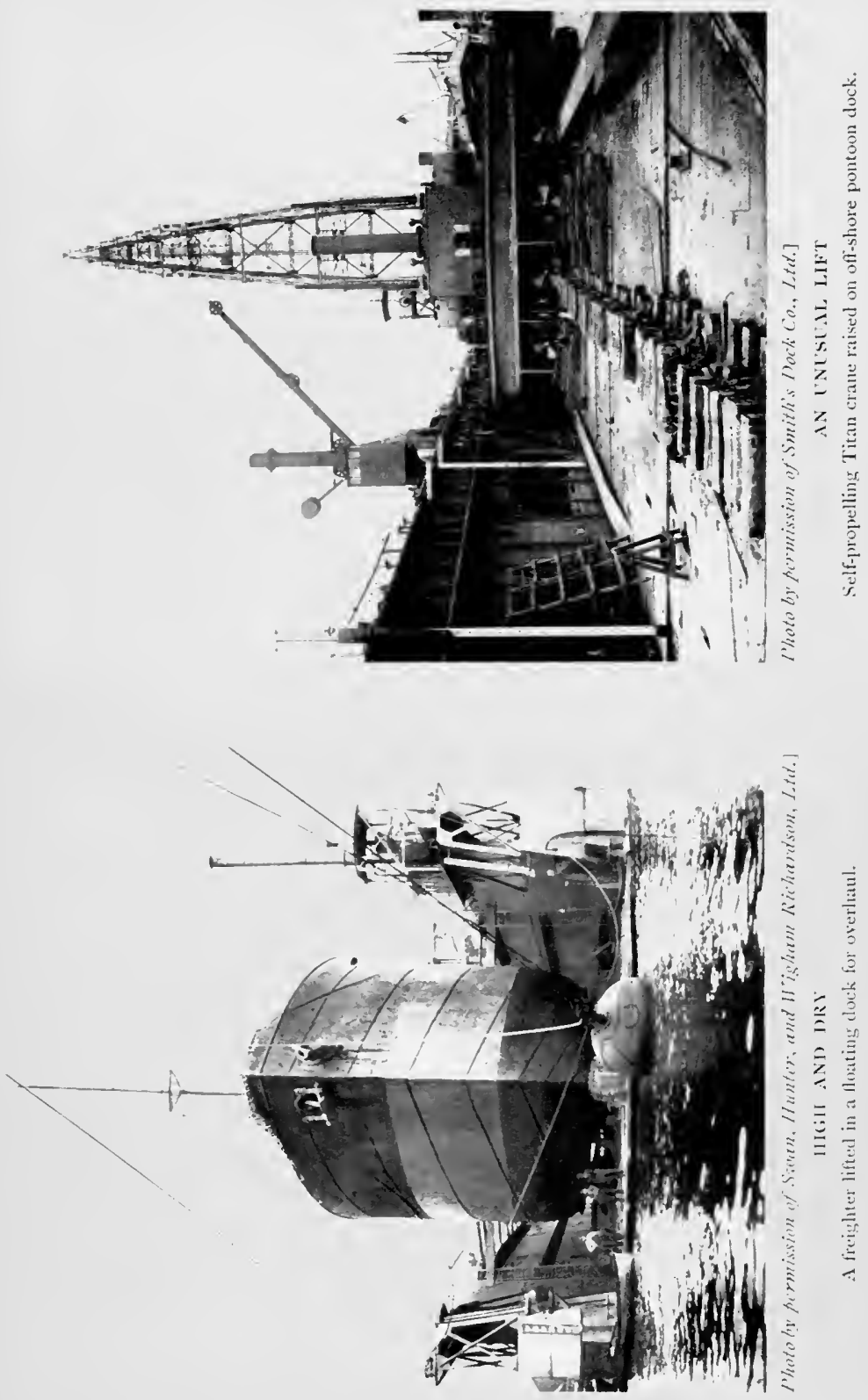


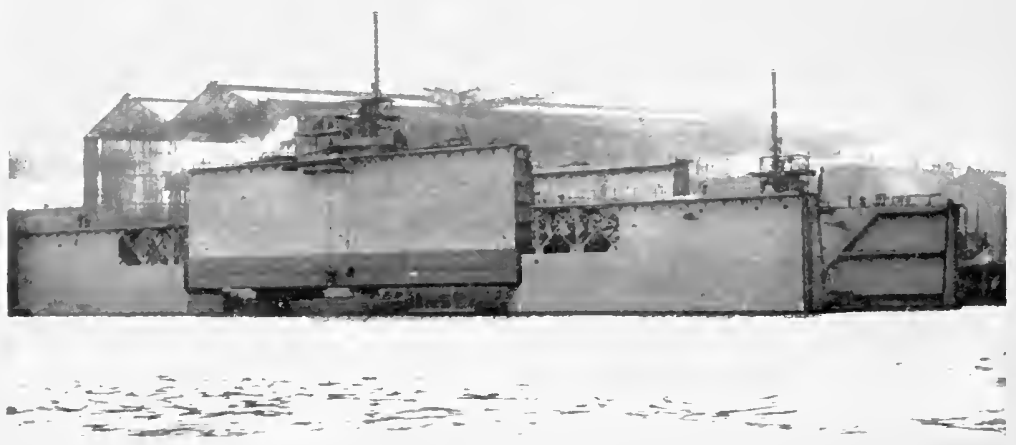

THE SELF-DOCKING FLATING H)(

The centrat we tion is released, and lifted by the two end, which are turned romul for the purpose.

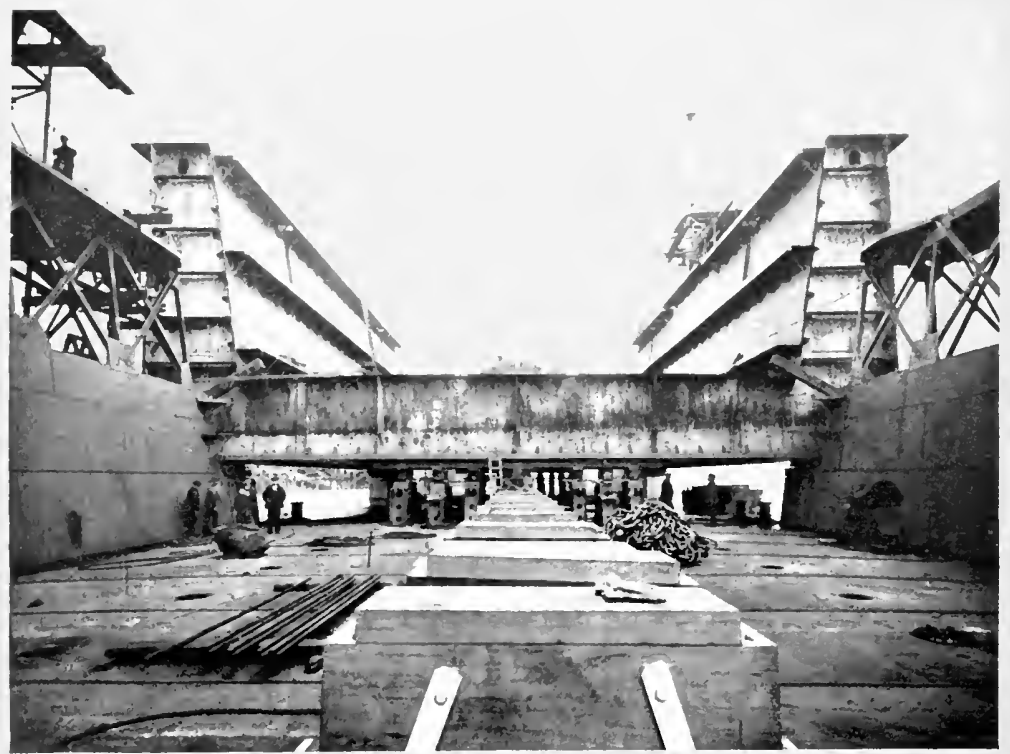

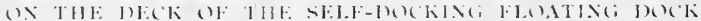

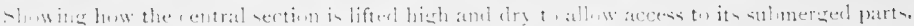


have happened? That port does not possess a single graving dock large enough in which repairs, even of a temporary character, could have been made. Divers would have been compelled to descend and patch up the wound as best they could to enable the boat to have limped across the Atlantic to a British port where she could have been revealed from keel to water-line.

Fortunately, engineering science has devised a highly successful alternative. The costly dock carved out of a spit of land, and lined heavily with masonry, is no longer necessary. Inventive skill has perfected a means of creating an artificial structure, wrought of steel, shaped roughly like a long box without the short ends or top, and with hollow walls and bottom, which may be sunk deeply by admitting water into the hollow spaces to permit the liner to be towed or to steam over the floor. Then by ejecting the water from these hollow spaces by means of pumps the structure may be rendered buoyant, to rise to the surface, lifting the vessel within, and laying every inch of her hull as bare and as readily accessible as if she were stowed high and dry in a graving dock.

This is the "floating dock," the perfection of which has changed the whole conditions of modern shipbuildingespecially liners-- to a very pronounced degree, although its influences are not appreciated so widely in Great Britain as in Germany. The origin of this simple method is buried in the depths of time. The idea is said to have been suggested by the device of an ingenious sea-captain who sailed the Baltic Sea. The copper hull of his craft demanded overhaul and repair, but he was sorely perplexed as to how he could get at the under-water portions for the purpose. Then a brilliant thought crossed his mind, which he resolved to put to the test. He procured a vessel called the Camel and removed the whole of its interior, leaving merely the hull or shell. He then cut away the whole of the stern, substituting a swinging water-tight gate in its place. This shell was submerged with its gate open, and the captain warped his vessel until she was well inside. The 
gate was closed, and the water within the disembowelled Camel was pumped out, causing it to rise and lift the ship within until her hull was exposed to enable the requisite overhaul to be effected. When the water was re-admitted the Camel sank until the berthed ship was buoyant once more, the gate was opened, and the repaired ship was free to emerge. Such is supposed to be the origin of the floating dock. How much of the story is fact, and how much is fiction, cannot be said, but it is more or less upon this principle that the floating dock of to-day operates.

There are about $35^{\circ}$ of these appliances scattered throughout the various ports of the world at the present time, and their number is increasing steadily. This development has been stimulated, for the most part, by the rapid increase in the size of warships, the docking of a Super-Dreadnought being a somewhat difficult matter, owing to the scarcity of masonry-lined graving docks. Curiously enough, although the floating dock is becoming so universally utilised, its design is virtually a British monopoly, the designs for the greater number of these appliances emanating from the offices of one firm, Messrs. Clark \& Stanfield, of IVestminster, London. These engineers have been responsible for over ninety per cent. of the floating docks which have been built within the past half-century, for countries as wide apart as Brazil and Germany.

Whether it is due to conservatism or ignorance, the fact remains that these islands have displayed the least enterprise in the adoption of such facilities for lifting a vessel clear of the water within the minimum of time. On the other hand, Germany and the United States have taken them up liberally, realising that they are superior, from the all-round point of view, to the average graving dock. So far as first cost is concerned, they are overwhelmingly cheaper than the permanent rival, are more convenient and handy, and, what is far more important, they are not condemned to one spot. They may be towed from point to 
point to meet changing conditions and exigencies, and when the vessels have outgrown the capacity of the dock, it may be sold and replaced by one of larger dimensions.

The dock is built in several forms, the factor fluctuating according to the conditions prevailing at the harbour to which it is to be attached, and the class of traffic with which it is intended to deal. In its most common form it is shaped like a flat-bottomed $\omega$, and open at both ends. The walls as well as the floor are hollow for submergence to permit the vessel to be floated in, and lifted merely by cmptying the water from the walls through the medium of pumps.

In the most approved type, however, the whole structure is built in sections, which are bolted together to form a continuous whole. Each section is complete and isolated from its neighbour, so that the structure is divided, as it were, into a series of compartments. The advantage of this system is that when repairs to the dock itself become necessary, they may be carried out expeditiously and easily. All that is required is to release the section demanding overhaul, which can then be lifted clear of the water by the other two sections, and even be docked high and dry like a vessel to afford perfect access to all its parts.

There is practically no limit to the dimensions and lifting capacity of these docks so long as there is space and depth of water for their satisfactory operation. Indeed, this latter point virtually determines whether a floating dock or a permanent structure shall be selected. Obviously, if a heavy sum has to be expended in dredging to a sufficient depth to permit the floating dock to work, the cost of so doing might approximate the outlay upon a permanent structure to achieve the same end, in which event probably the masonry structure would be preferable. But if the sea-bed is of such a character that sub-aqueous preparations are certain to be expensive, then the advantages are overwhelningly in favour of the floating dock. For instance, when dry-docking facilities for the navy were considered to be imperative at Bermuda, and the respective 


\section{STEAMSHIP CONQUEST OF THE WORLD}

costs of the two systems were compared, it was seen that the masonry structure would be abnormally costly, owing to the sea-bed being formed of hard coral. As it was, the sum of $\notin 60,000(\$ 300,000)$ had to be devoted to prepare the site for the reception of the floating dock. Whenever there is a good depth of water available, then the chances become overwhelmingly in favour of the floating dock. When the subject of dry-docking facilities for the Pacific port of Prince Rupert were discussed, it was found that the floating dock would meet the situation more economically owing to the vast area of the harbour, added to the fact that, if a permanent structure were attempted, the excavations would have to be carried to a great depth through hard, solid rock. In this instance the conditions are such that the dock can be moved from point to point within the harbour, a feature which appealed very strongly to the advocates of this system.

Several large docks of this class have been constructed and are in operation in various parts of the world, lifting vessels up to 46,000 tons in weight. Another feature which adds to the advantage of the floating type is the rapidity with which vessels may be raised. A tramp of 3000 tons can be lifted clear of the water in thirty minutes; a 5000tonner in three-quarters of an hour; a 10,000 -ton vessel in ninety minutes; while the Olympic could be lifted clear of the water in about six hours. A permanent graving dock cannot be operated at anything approaching this rate of speed. Before a vessel is able to enter the latter the dock must be emptied to permit the keel-blocks to be laid in position for her reception. Then the dock is filled, the ship floated in, and the water once more pumped out. On the other hand, as the normal position of the floating dock is "dry"-otherwise with her floor above water-the blocks may be prepared the moment intimation arrives that a certain vessel desires docking, so that by the time the ship comes up everything is ready for the dock to be lowered. There is another favourable feature. The vessel requiring docking may be beyond the lifting capacity of the dock to 
raise her clear of the water, and yet she may be elevated sufficiently for the submerged part of the hull to be given the requisite attention; while it may so happen that the vessel is longer than the dock, but nevertheless the dock may be used, in spite of the overhang-in other words, the dock may be induced to fulfil work which is really beyond it, to meet an emergency.

The $\cup$-shape, however, is but one form adapted to working in tidal waters, and for the largest classes of vessels. For smaller craft, and in non-tidal waters such as the Great Lakes and inland seas generally, the L-shaped dock possesses great conveniences. This dock has one side wall removed, but on the opposite side outriggers are attached to the wall so that the dock may not cant over when the weight of a vessel is imposed. Even this type may be varied. The outriggers may be of the floating type, so that there is no interference with the mobility of the dock. Again, in conjunction with what is known as a gridiron, the effectiveness of the dock may be increased extensively, as the vessel, after being lifted clear of the water, may be transferred to one of the gridirons.

The largest and most successful dock of this type is in operation at Barcelona, where the conditions for its use are ideal, and where the serviceability of the system is revealed very convincingly. The base of the dock, or pontoon, is not made up in the form of one continuous piece or sections bolted together, but comprises a series of pontoons projecting from the single wall like fingers from the hand. Each finger is separated from its neighbour by a space equal to the former's width. The staging forming the gridiron, which is erected along the foreshore, is built up similarly, with spaces between each horizontal bar as wide as the dock pontoon, while the grids correspond in width to the spaces between the dock's fingers. The docking process is the same as with the other types. The dock is submerged by the admittance of water into the pontoons, the vessel is warped over the deck, made fast, and lifted by enstying the pontoons. When the ressel has been 


\section{STEAMSHIP CONQUEST OF THE WORLD}

raised high and dry, the dock, with its load, is warped into line with the gridiron, so that the grids come opposite the spaces in the dock, while the fingers of the latter,in their turn, face the openings in the staging. The dock is then pushed or hauled home sideways, so that the opposing fingers slide into their respective openings in the same manner as one may lock one's two outstretched hands. When the fingers are brought right home, the deck of the gridiron appears to be continuous, and the vessel is transferred from supporting-blocks on the dock to those on the bars of the gridiron. This completed, the water is readmitted into the dock, once more causing it to sink, and the vessel is left perched on the staging. When the dockfingers have dropped clear of the underside of the gridiron bars, the dock is pulled away, and is now available for the repair of another vessel, either on itself, or after transference to another stretch of gridiron. In a large harbour - say, for instance, those on the Great Lakes of Americathere are no limits to the application of this system, as miles of gridiron may be laid along the foreshore to carry several vessels simultaneously, while the dock itself can be employed exclusively for docking and transferring the vessels to the permanent staging. In transferring the ship back to the water the foregoing operations are reversed. It may seem a roundabout process, but in reality the whole operation of docking and transference can be completed within a very short time. The gridirons are comparatively inexpensive, and may be extended as the traffic of the port develops.

A variation of this system is the off-shore dock, where, although the L-shape is preserved, instead of the structure being mobile, and fitted with floating outriggers, it is made a fixed structure, stability being secured by attaching the dock wall, by hinged boons, to rigid columns sunk into the foreshore. Here the dock is able to follow the varying level of the water due to the rise and fall of the tides, and yet retain its position. Several examples of this class of floating dock have been erected in various 
parts of the world, capable of handling steamers up to 7000 tons, but this by no means signifies the limit of its application, as the I I,ooo-ton dock at Hamburg, built upon this principle, convincingly demonstrates. In every instance, however, the practice is to make the appliance comply with the features of the self-docking type, so that any one of the sections of which it is composed may be detached and be lifted clear of the water, by the other part, for cleaning and repair.

The floating dock is the only means whereby docking facilities may leep pace with shipbuilding progress, unless a port is resolved to get well ahead of the times, and provide a permanent graving dock of sufficient size to meet requirements for many years to come. The majority of ports, however, are not as a rule animated by such a spirit of initiative, as it necessitates an excavation with a clear length of $\mathrm{I}, 200$ feet by about 120 feet wide and between 40 and 50 feet deep.

The port of Hamburg is particularly alive to the advantages of the floating dock. At the present time it has some twenty docks in operation, the largest of which is able to handle vessels up to 46,000 tons. The Germans certainly have not hesitated when necessity has compelled a display of initiative. When the Deutschland was launched there were no facilities in the port for handling her in this way, in the event of an accident. Fearing that, owing to this deficiency, she might be sent to Great Britain for repairs, one firm contracted for a dock large enough to lift her, in order to be ready for any emergency. Curiously enough, the opportunity arose, as this liner met with a mishap which demanded dry-docking. Seeing that the HamburgAmerican Line is engaged in the construction of three liners which are to exceed 50,000 tons, there is not the slightest doubt that the port will be provided with a floating dock sufficient to cope with this development. Both Southampion and Liverpool are anticipating the coming of these and other large liners which are now on the stocks or under contemplation by the construction of masonry 
graving docks, but other ports are at present marking time. When the Lusitania and Mauretania appeared, and it was thought that they might make their home port on the South of England coast, designs for a floating dock capable of lifting these 32 ,ooo-tonners were prepared, the cost of which was placed at about $\mathcal{E} 260,000(\$ 1,300,000)$.

As the designing of these docks is a peculiar British engineering speciality, so is their construction. The majority of those now in service have come from the Tyne yards of Swan, Hunter, \& Wigham Richardson, Limited, and this firm has placed on record some very smart constructional performances, which incidentally have emphasised another advantage in favour of this means of docking a ship. The largest type of dock may be completed within a year. The Io,ooo-ton dock required for Havana was built in these Tyneside yards and handed over to the authorities at its destination within eleven months of the placing of the contract. The 11 ,ooo-ton dock which the port of Stettin required post-haste was built in $7 \frac{1}{2}$ months, was towed across the sea, and lifted the first ship within eight months. This was a notable achievement, as the builders beat their contracted time by one month, nine months having been allotted for fulfilment of the undertaking.

As Great Britain acts somewhat in the capacity of universal provider in respect of these invaluable adjuncts to the mercantile marine, some remarkable towing feats have been placed on record in connection with their delivery to various ports of the world. A dock apable of lifting $12,000,16,500$ or 25,000 tons is an unwieldy craft to drag across wild stretches of ocean, and the special vessels which are selected for this service appear to be far 100 puny to keep such a structure under control in case of rough weather. But in this instance size is by no means any criterion of power, inasmuch as these ocean-going tug:; can battle against the wildest seas and yet keep lold of their ungainly charges. They think no more of hauling a monster floating dock across the greatest breadth of the 


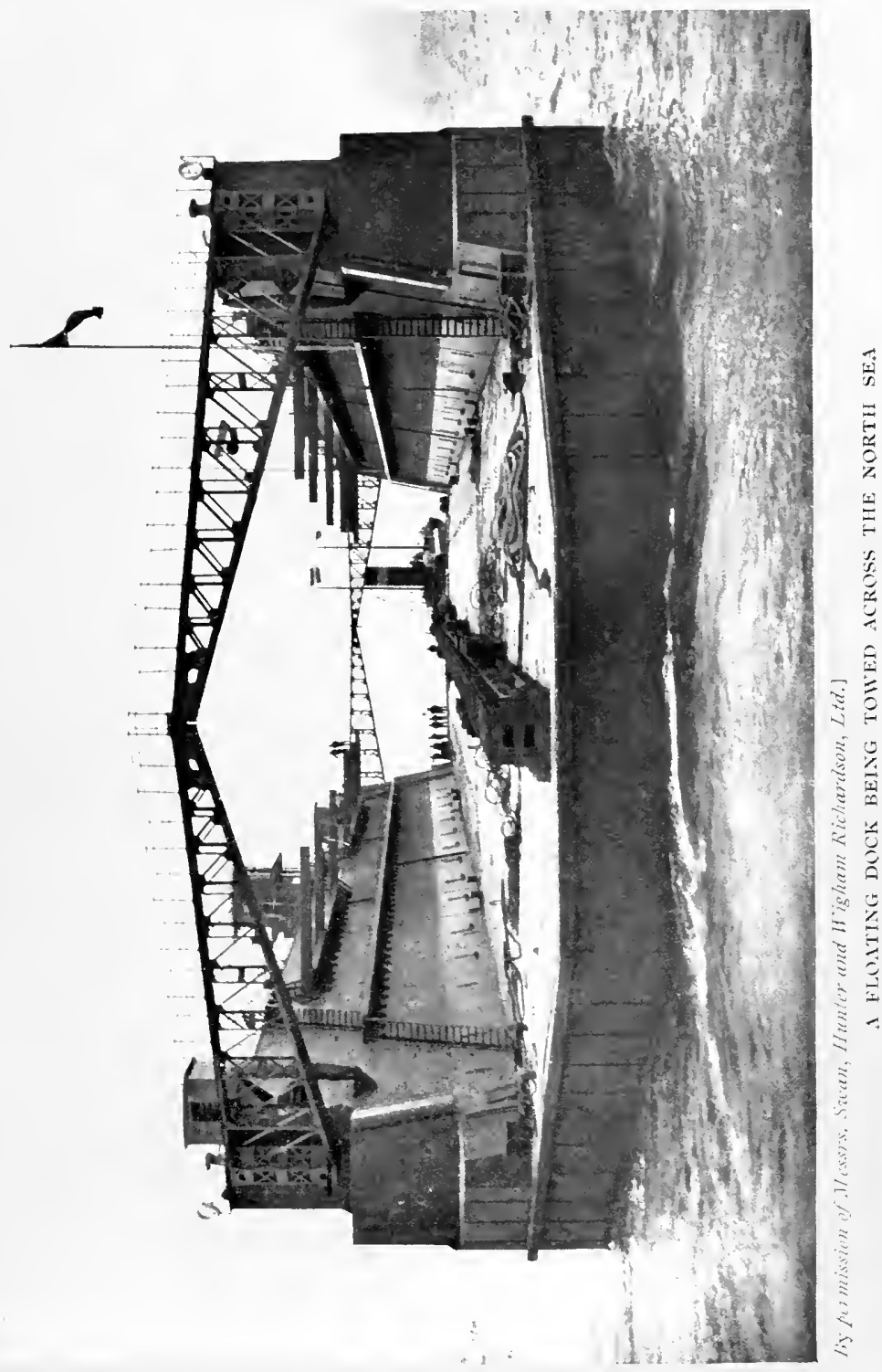



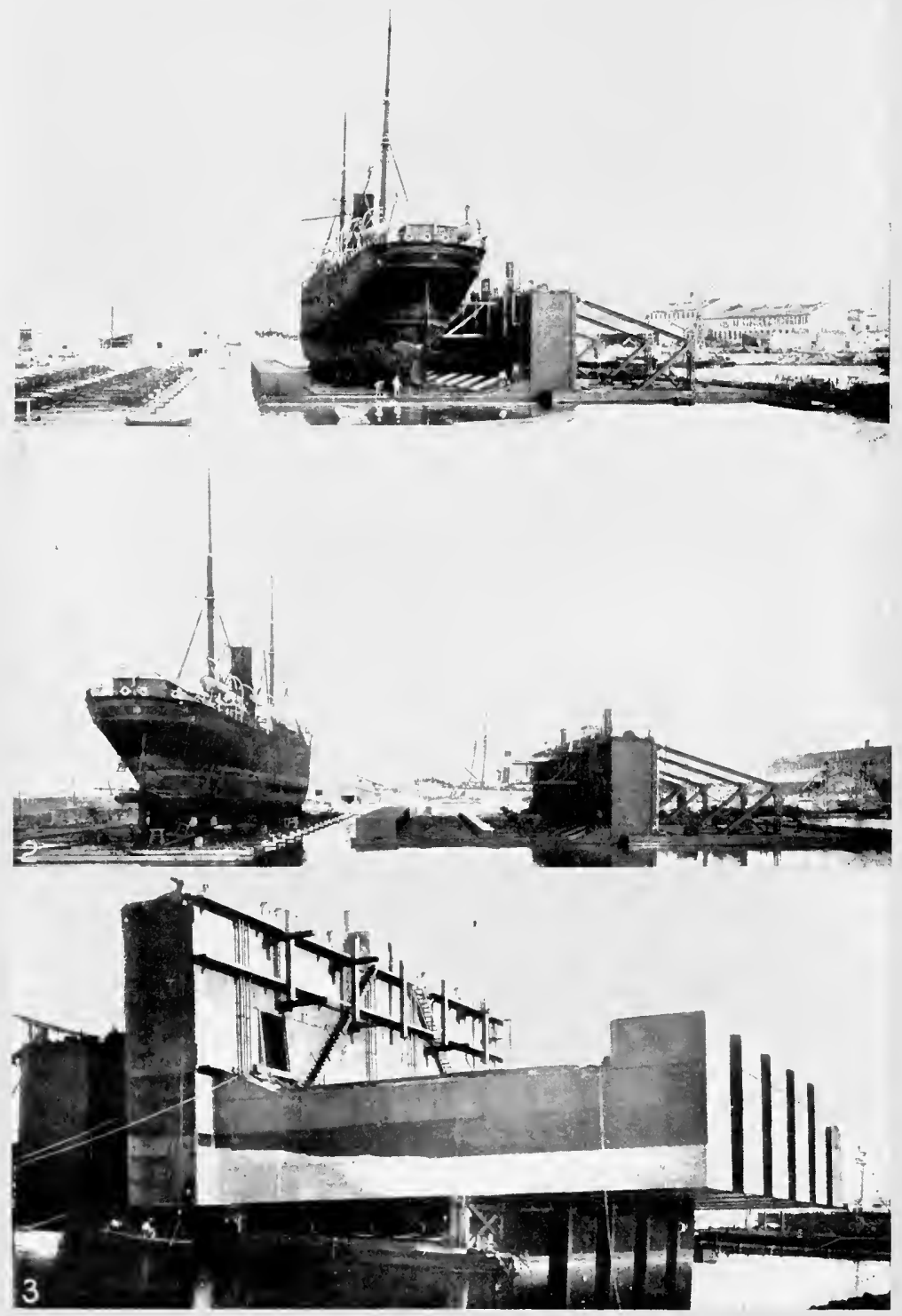

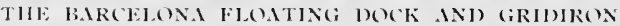

(1) Vessel raised on floating dock. (2) Versel transferred from dock to gridiron. (3) section of clect it elf lifted for owerhanl. showing finger-like pontinns. 
Atlantic and rounding the sinister waters washing Cape Horn, than of running a matter of 291 miles across the North Sea from the Tyne to Rotterdam. It is very seldom that any mishap befalls such an enterprise, or that the helpless craft breaks from its leashes. One such accident did occur while a dock was on its way from Britain to South Africa. A heavy storm rose, and the tow-ropes parted. The tugs struggled hard to regain their load, but without avail, and the dock came to grief. One of the greatest feats of this character was the towage of the Dewey dock from the American yards to the Philippines. Another was the haulage of the 7ooo-ton dock from the Tyne to Callao, a distance of 10,260 nautical miles, involving the negotiation of Cape Horn. The $16,500-$ ton dock constituted a heavy risk to underwriters during its conveyance over 4,065 nautical miles from the Tyne to Bermuda; while the handling of the 25,000 -ton floating dock on its voyage of 5,200 miles across the Atlantic to Rio de Janeiro was a very smart achievement.

The maintenance and repair charges are very low, as experience has proved, as are also the expenses of operation. An off-shore dock 360 feet long, capable of handling vessels up to 3,600 tons, and fitted with electrically driven pumping-plant, can lift a ship high and dry for less than a sovereign, or say five dollars, with electric current costing three-halfpence, or three cents, per unit. Maintenance charges are about 166 per cent. of the initial cost per annum. Thus a dock capable of lifting the giant Cunarders would absorb about $£ 4,316$, or $\$ 21,580$ per annum under this heading. This charge varies with the situation of the dock and the character of the water in which it is used, as obviously some waters exercise greater destructive properties upon the steel than others. For instance, severe rust is set up by the landlocked, tideless waters of Havana, while at Hamburg no signs of serious rusting are observable after $1+$ years. The Callao dock, which was of early design, and which has seen over to years' service, absorbed 0.73 per cent. of its initial cost per annum, this sum being 
inclusive of two complete overhauls which were effected during this period.

It is apparent that the floating dock affords the only economical solution, generally speaking, of meeting the increasing sizes of vessels with docking facilities. So long as the shipbuilder is supported in his developments, and the money is forthcoming, larger and larger vessels will be built, and it is the country which keeps pace with this progress which eventually will receive the cream of the trade. If one port will decline to meet the needs of the shipbuilder and shipowner, another, more enterprising and which does not attempt to arrest the wheels of progress, will benefit. Keen competition prevails among the big ports of the world for the ocean liner's patronage. This was revealed by the action of the New York Harbour authorities when the Olympic made her appearance. They did not feel disposed to incur the expense of lengthening the piers to receive this liner, hoping thereby that they might check shipbuilding ambitions. Instantly Boston offered to provide what facilities were required, and an effort was made to create a new port at Montauk Point, Long Island. What applies to piers also applies to docks, and the inability of any dock in North American waters to receive a modern mammoth liner reveals the fact only too well that every port worthy of the name must be provided with facilities to enable the largest ship afloat to be laid bare whenever the necessity arises. Taken on the whole, the floating dock is the clieapest means by which this end may be consummated. 


\section{CHAPTER XIX}

THE SURVEYOR OF TIIE SEA AND HIS ADVENTUROUS CALLING

WE admire the calculations of the ship-designer, the ingenuity of the inventor, the skill and workmanship of the shipbuilder, and the prowess of the navigator. Yet the efforts of one and all would count for nought, but for the labour of the hydrographical surveyor. Ocean greyhounds with their high speeds would be useless without charts for their guidance; sea travelling would be the most dangerous system of transportation extant if the coasts and seas were unmapped.

The average person knows nothing about the sea-surveyor and his work. Probably he is quite unaware of the existence of such a labourer in the interests of the world's progress. This worker does not come into the blinding glare of publicity. He prosecutes his task silently and diligently in the background, braving dangers untold, surmounting abnormal obstacles, and incurring risks which are encountered in few other walks of life. He is exposed daily to the ravages of climate, to the crippling effects of many of the worst diseases known to medical science, the battering of wind and wave, the hostility of mankind, and to death in some of its most awful forms.

The life has a peculiar and bewitching fascination for restless spirits of scientific attainments and with a love for adventurous exploration. The toll exacted by Nature in the probing of her secrets is heavy, but this penalty offers no cleterrent. The versatility of the work also tends to make an irresistible appeal; one engaged therein is taken into the most out-of-the-way corners of the world. Today the hydrographical surveyor may be busily sounding the entrance to a bustling port : next year he is imprisoned in the lonely frigidity of the Arctic or Antarctic circles: 
a little later with his theodolite and sounding appliances he is creeping up an African or South American dismal waterway, through swamps and malarial lagoons; thence he is sent to the dreary wastes of the Northern Pacific, or to seek for channels among the coral reefs and forbidding islets guarding the Australian continent.

One might be inclined to think that the whole of the navigated seas and coasts of to-day had been explored and charted, but this is far from being the case. Thousands of square miles of salt water between the outermost boundaries of the frigid zones remain to be explored, and hundreds of miles of tortuous coastline fringing the five continents still await triangulation. This is not all. The world is changing its contour constantly through the agency of its internal forces. The water conceals from sight exactly what is happening below. Valleys are being carved here, and submarine mountains are being formed somewhere else. Currents and tides collect sand at this point to deposit it in the form of a shoal at that place. Even the coasts do not remain constant. The hungry sea gnaws away miles of foreshore at one spot to throw it up again elsewhere. The greatest difficulty confronting the hydrographical departments of the Powers having mercantile interests at stake, is that of lieeping the guiding charts and maps for their navigators up-to-date.

This charting of the seas and coasts is a service attached to the Admiralty, and the men engaged in it are drawn from the officers on active service, in many instances at the request of those who cherish a fancy for this scientific labour. Every nation possessing a coastline retains special vessels for this peculiar work, equipped with all requisite appliances and a small select staff. Great Britain, whose shipping overbalances that of any commercial rival, has the greatest interests at stake. Accorclingly she is particularly active in mapping out the oceans, her forces engaged therein being scattered in all parts of the world. At the end of 1911 no fewer than 11 surreying ships, ranging from 4 ro to 1,300 tons, and from 
350 to 2,100 horse-power, were actively at work. Of this total, 5 were retained for service in home waters, while the other 6 were distributed all over the globe, from the shores of Newfoundland to the Strait Settlements and Australian waters. The work gave employment to 83 officers, of whom 61 were surveyors, and engaged an aggregate crew of 796 men. In the course of the year 19 II these vessels and surveyors reported no fewer than 442 rocks and shoals as dangerous to navigation, while 36 places which had been reported previously as dangerous, and had been charted, were expunged as being nonexistent. In the course of this 12 months 906 miles of coastline were charted, soundings were made over an area of 5,495 square miles, and the results committed to paper. The foregoing work is exclusive of that carried out by the Marine Survey of India, which is independent, 2 vessels being retained for this service, with 10 officers under a commander, and a total crew of 178 men. This organisation charted 212 miles of coastline as well as sounding 2,819 square miles of ocean in the above period, so that some idea of the activity of the British Hydrographical Service may be obtained. The United States also retains a complete, although smaller service, as its duties are more limited, while Germany, France and Russia also possess their trained corps of sea-surveyors.

The British Hydrographical Department perhaps is the oldest of its kind among the nations of the world, and its collection of maps and charts is far and away the most comprehensive, complete and varied. Many illustrious explorers and builders of empire, familiar to history, were at one time or another connected with the British sea-surveying work. Among these may be mentioned Captain Cook, Captain Vancouver, Sir John Ross, Sir John Franklin, Sir Wrilliam Parry, whose voyages of discovery and exploration are so well known. All these men followed the sea-surveyor's calling, and accomplished excellent work, as well as accumulating raluable experience hefore embarking upon their historic expeditions. 
The story of exploring the depths of the sea constitutes one of the most fascinating romances it is possible to conceive; its narration would fill volumes. For the most part these stirring tales are buried in official reports, or in the archives of learned and scientific institutions, but here and there glimpses of the thrills and sensations incidental to the task are set out in volumes which the surveyors wrote upon return from unusual expeditions or exciting journeys.

One hundred years ago the task was full of excitement. Fighting and charting went on side by side. The calling was extremely hazardous, as it carried the men into dangerous zones, where often they were compelled to cease abruptly, and to make good their escape in a running fight. At other times the men were surprised while following their occupation of sounding, and captured. The ordinary prisoner of war was wont to chafe at his incarceration, but others, who were familiar with the surveying work, turined their enforced idleness to profitable account. There was Commander Tuckey. After an exciting early life at sea, during the troublous times of the ciosing years of the eightcenth century, he was on the Calculta homeward bound, under Captain Moodriff with a convoy. They were surprised by the French fleet, and to save the convoy Woodriff showed fight. He engaged the whole of the opposing squadron, and although the Calcutla was compelled by sheer force of numbers to strike her colours, the ruse proved successful, since the merchantmen under her charge got clear. Tuckey, then a lieutenant, found himself a prisoner of war. Naturally he resented his inprisonment, but he set to work and compiled four large volumes on Maritime Geography and Statistics to pass away his enforced idleness. Upon his return to England these volumes were published, and were found to be an excellent work of reference and full of useful hydrographical information.

Subsequently Tuckey was entrusted with the survey of the River Congo. For this purpost a special ressel of 100 tons and drawing 4 feet of water was built. Bell 
had demonstrated the utility of steam propulsion for ships upon the Clyde two years before, and it was decided to equip this craft, christened the Congo, with a steam engine and paddles to enable her to make way more easily against rapids and currents in the river. This was to be of 24 horse-power and was to give the boat a speed of 5 knots per hour. The engine was built by Boulton and Watt, but was never used. Either through the machinery exceeding the contracted weight, or because the vessel drew more than the designed depth of water, the engines were taken out, and the Congo proceeded under sail. Tuckey forced his way 150 miles up the African waterway in his vessel, making careful observations meanwhile, but being unable to make headway against the vicious currents left his ship and pushed on in boats to the cataract "Yellala's Wife." Here the small boats had to be abandoned, the party continuing afoot along the banks of the waterway until they gained a point 280 miles from the mouth. Then disaster overwhelmed them: the men fell victims to the terrible climate. Fever broke out and there was a mournful retreat. The Congo was regained, but the disease had not completed its deadly work. 'Tuckey, two officers, ten of the crew, the botanist, geologist, zoologist, as well as a scientiic gentleman who had rolunteered to accompany the expedition, succumbed. It was a disastrous venture, but valuable work was accomplished.

One of the most prodigious surveyors the service has ever had was Vice-Admiral W. F. Owen. In the course of five years he traced 30,000 miles of coastline around the African continent, the results of which he communicated in $\delta_{3}$ charts. He joined the navy in 1788 , saw active service under Lord Howe on the Glorious First of June, played a prominent part in the famous Spithead Mutiny, for which he was promoted, and when not fighting the French off the Indian coast, was exploring the channels around the Maldive Islands. Finally he was captured, spent two years in captivity on the Mauritius, and came home convoying a fleet of merchantmen from China. 
Peace supervening, Owen was deputed to the work he loved so much. He was sent to Canada and commenced the survey of the Great Lakes, continuing until i 816 , when he entered the Hydrographical Office in Lonclon. Five years later saw him on active survey once more, with a staff of accomplished nautical assistants off the African coast. Lively times were experienced. He was crawling up the Mahong River sounding and taking triangles when the Zulus, not understanding the import of the curious duties, gave him a warm reception with assegais. The attitude of the natives became so furious that at the end of forty-six miles he returned to the coast. One of his right-hand men died under the terrible climate, followed shortly afterwards by two others.

The expedition now ran a flying survey of the coast, only to lose two more capable members of the party from disease. Mozambique was visited together with a few other islands, and then the party returned to English River to discover that its tender Cockburn, which had been left here with twenty officers and men, had a roll of only seven left, disease having swept off the others. The party then made for Simon's Bay, where the Cockburn fouled a reef and became a total wreck.

Later, Owen decided to examine the coast of the continent lying between Zanzibar and Cape Guardafui. On this expedition he was bowled over with rheumatic fever, contracted from the pernicious land wind, which produces a stroke of what is known as "the blat." Having recovered, he next concentrated his energy upon the survey of Madagascar, lost his principal hydrographer from dysentery, had to land another of his staff who was stricken down with a dangerous attack of yellow fever, while two offirers on the boat which had been purchased to take the place of the wreclied Cockburn were murdered by natives while engaged in their work. More men were lost before Owen decided to make the dangerous survey of the coast between the Cape of Good Hope and the Congo estuary. From its pestilential climate Africa has long 
been known as the "White Man's Grave," but the description was never more true than in those days. If it were not scurvy contracted on board from subsistence upon salt foods which claimed victims, it was malaria and fevers of all descriptions which developed while making triangulations upon shore. Owen suffered severely from these ravages. While coming up the west coast making surveys of its indentations, river estuaries, anchorages and islands, he lost man after man. The mortality was so frightful that the survivors were not sorry when at last the party headed for home. But Owen had not finished his work by any means. He made another visit to North America, after a journey to Fernando Po, where all but three of the gunroom officers and forty-six of the crew were claimed by disease. On the opposite side of the North Atlantic he accomplished excellent work, preparing charts of the St. Lawrence River, Lake Ontario, Toronto Harbour, and the Bay of Fundy.

Curiously enough, in the early days the work of these hardy and daring plotters of coast and sea was not issued by the Admiralty. The publication of the maps and charts was left to private enterprise. Subsequently many of the copper plates, from which the navigation guides were prepared, were purchased by the Admiralty when the Hydrographical Department was set upon a firm footing. The men in London also were paid weekly, like the clerks in a merchant's office, and there certainly was no permanency in their respective positions. A curious example of this official parsimony in regard to maps and charts was manifested on the occasion of the death of Alexander Dalrymple. As chief hydrographer he had prepared a magnificent collection of copper engraved plates for map printing and general information in regard to hydrography. In his will he offered his life's work for sale, first to the East India Company, in whose service he started life, and then to the Admiralty. Both declined, owing to the price demanded, and finally the plates were sold by auction, the copper realising a scrap price to be melted 
down. Through the exertions of a gentleman these valuable plates were spared this undignified end, and were obtained privately for the Government.

The sea-surveyor is a man of infinite resource, grim determination, and entertains a very light regard for his health or his safety, so long as he achieves his object. One expedition was dispatched to the Persian Gulf to prepare records of the danger spots in its treacherous waters and along its forbidding coastline. The surveyor was unable to carry out his work in one of the ship's boats, so was compelled to make use of a native craft. In this he moved to and fro, day after day, exposed to the elements. The argo was by no means water-tight, having passed long ago its span of usefulness, so the unlucky surveyor was forced to squat down with the water over his ankles, as he committed his observations to paper. It is not surprising that some two years' labours under these conditions played sad havoc with his health. Another surveyor had a more exciting time. He had to land upon this coast to accomplish his work. He was surrounded by the natives as they suspected that he was upon mischief bent. When they saw that he was a Britisher, and was by no means hostile, they did him no harm, but hung around him like wolves, watching his every movement. Fortunately hydrography was a science beyond their intelligence, and they did not interfere with his movements, except when he drew out his pencil and note-book to make records of his observations. Native suspicion assumed a formidable form: the surveyor's notes were seized. Is no one could fathom his peculiar hieroglyphics, it was deened adrisable by the crafty natives to secure safety in their destruction, and the hydrographical surveyor was warned that he would meet with different treatment if caught writing again. The natives were convinced that he was not there for their benefit. Yet the surveyor accomplished his object. With a stub of pencil, less than two inches long, he recorded the results of his observations upon his shirt cuffs and sleeves, the lieen-eyed natives never dreaming for a 
moment, when they saw the officer apparently rubbing his linen, that he was helping his memory with conclusive written notes. When he departed his shirt was as spotted with figures and rough geometrical shorthand notes as a Dalmatian hound.

The sea-surveyor is a man of many parts. He not only records the position of submerged rocks and other menaces of the deep, as well as the form of the coastline; he is a botanist, zoologist, geologist and handy man of science combined. He will investigate the movements of currents and tides, probe the innermost recesses of the sea to discover its life and characteristics, and haul up samples of the sea bed from a depth of two miles or more to determine its composition. Now and again he will land at a lonely spot to make experiments for additional information upon the figure of the earth. Or he will carry out astronomical surveys to throw further light upon certain phenomena. Elaborate precautions will be taken and arrangements made to decide the longitude of a certain point, or investigations will be effected to define whether a certain rock does or does not affect the magnetic properties of the compass, a belief often entertained by a captain to explain his deviation from a certain charted course.

For instance, during is8o, in the height of the summer, the survey ship Knight Errant carried out a series of soundings between Rona, north of the Hebrides, the Faeröe Islands and the Nun Rock, north of Cape Wrath, off the coast of Ireland, as the charts of this region were interspersed with blanks, slowing where further soundings were required. This work threw some interesting light upon the subjects of ocean circulation and the distribution of marine life at great depths. Between Rona and the Faeröe Islands the bed of the Atlantic rises to a large hump less than 600 feet below the surface. The leads and the thermometers were dropped first on the Arctic side of the ridge, and the temperatures of $39^{\circ}$ and $.40^{\circ}$ Falurenheit were recorded at a depth of 1,200 feet. When the instruments 
were dropped on the south or Atlantic side under the same conditions, the temperature did not fall below $42^{\circ}$ Fahrenheit.

On another occasion, owing to captains having reported strange variations of the compass needle off the Australian coast, the survey ship Penguin, stationed in these waters, set off to investigate this phenomenon. The point where extreme interference had been noted was found, but to the intense disappointment of the officers nothing unusual was noted. Suddenly, as they were passing Bezout Island, the north point of the compass moved two points to the left, and examination revealed a centre of magnetic attraction. The ship moved to and fro over the disturbance to find the needle swinging violently first $23^{\circ}$ to the left and then $55^{\circ}$ to the right, while what is known as a dipping needle was affected just as intensely. Soundings were taken, and the depth of water was found to be $\sigma_{3}$ feet, the sea-bed being composed of quartz and shells. When the magnetic instruments were set up on Bezout Island, two miles west of the focus of disturbance, nothing untoward was noted, but directly they returned to the spot the agitation was repeated. The disturbances were certainly remarkable, and this centre constitutes one of the strongest local magnetic attractions known in the world, while it was found to be purely local. Inless a ship happens to pass very closely to the spot its compass escapes affection.

Defining the longitude of a certain spot is another claborate operation which falls within the province of the hydrographer. The Penguin was requisitioned for this purpose during the year 1890 to decide the differtnce of longitude between Roebuck Bay and Adelaide. The telegraph connecting the two points, extending for a distance of $3.56 ;$ miles, was reserved solely and exclusively for the operation for an hour and a half on October 31 . The probabilities of the test being successful were regarded as slender, but thirty-eight perfect signals were sent from end to end, each signal occupying about one-third of a second in its transmission. The longitude obtained in this 
manner agreed with the previous measurements so far as Baudin Island was concerned, but the location of Roebuck Bay was corrected by about half-a-mile. This error was remarkably small, considering the roundabout means that had to be followed in the previous determination, and testified to the care with which the calculations had been made. When the British Astronomer Royal, Sir George Airy, determined the absolute longitude of Valentia, the little island off the coast of Kerry, where the Atlantic cables come ashore, thirty chronometers were carried to and fro twenty-two times before the mathematician was satisfied. Nowadays, by the aid of wireless telegraphy, this delicate and hitherto difficult task may be accomplished very easily and quickly. The most ambitious operation in this connection was between Paris and Tunis. Wireless signals were dispatched between clocks at each place, the comparison of which determined the longitude. The signals travelled from Paris to Tunis in the rov part of a second, which is equal to a velocity of nearly 200,000 miles per second.

The days of exciting adventure in sea-surveying are by no means over. From time to time thrilling experiences are related. There was the little party under Captain Tyson of the United States Hydrographical Department, which sailed north in the Polaris to investigate the ice phenomena. The commander, together with nineteen of his crew, became separated from the ship near the 77 th parallel, just south of Littleton Island.

Unable to regain their vessel, they stuck to the floe, which to their dismay commenced to drift. It was an uncanny position; the little party expected every succeeding minute on their unenviable journey southwards to be their last, from danger of grounding, collision with another berg, disintegration, or from one of a hundred other forces which bring about the destruction of these visitors in the northern regions. They subsisted as best they could, and were kept dangling upon the thread of suspense for six months, when they were picked up by the Tigress on April ,30, 1872, near 
the Strait of Belleisle. They had accomplished one of the most remarkable and sensational journeys on record, having covered 1,500 miles on this floe. Had they not been sighted by the crew of the Newfoundland sealer the chances are that they would never have been heard of again, as they were hastening to the southern latitudes where the floes break up and disappear very rapidly under the summer sun and the warm waters of the Gulf Stream. They were picked up in latitude $53^{\circ} 35^{\prime}$, near the great steamship lanes, and were safely taken into port, little the worse for their extraordinary adventure.

A more diabolical fate awaited Lieutenant James St. John Bower during his investigations with the British survey ship Sandfly among the Solomon Islands. He was a lighly skilled and daring surveyor of the sea, who had only just before been appointed to the charge of this vessel as a reward for his scientific labours. He put off with a boat and crew to land upon one of the islets for the purpose of taking the necessary angles. The natives espied the approaching boat, and drew back into the bush. Then while the little party were busy with their transit they crept between the men, who had scattered, and who had also thrown down their arms to facilitate movement among the undergrowth. Every man, with the exception of one, was treacherously laid low. The survivor succeeded in regaining the ship, and communicated the sad tidings of disaster. Immediately the young officer now in command rallied his crew, and put off fully armed. It was a risky dash, as he was supported by a mere handful of men, while the numbers of the natives were unknown. They got ashore and warily scoured the bush, ready to let fly with their rifles directly an enemy was detected. The natives hung about, but apparently were afraid to venture too closely to the grim, determined little band, with the result that the bodies of the hydrographer and his four unfortunate comrades were recovered.

The southern seas have achieved an unsavoury reputation among sea-surveyors, as the natives on many of the 
islands forming that vast archipelago look with no friendly eye on the charting of their cruel coasts and sinister seas. Time after time little bands have been surprised and slaughtered, the murderers being secure in the safety of their untrodden forests. It is difficult for the white man to range himself against native cunning in these parts, so it behoves him to keep a sharp look-out, with one hand on his cocked revolver ready for any emergency while he makes his angles. The British Admiralty probably has lost more promising young hydrographers in these seas from native treachery than in any other part of the world, while this hostility sometimes has assumed the most diabolical forms of barbarity.

The sea-surveyor must be prepared to face peculiar perils and hardships. They are inseparable from his calling. Shipwreck is an ever present danger, and it requires no little seamanship at times to get out of a tight corner, owing to wind, tides and currents. One vessel, while engaged in sounding an exposed bay off the Australian shore, had an unfortunate accident to her machinery. Repairs were taken in hand at once, but before they were completed a heavy gale sprang up. The commander made himself as secure as he could by throwing out several anchors. The vessel lurched, rolled and tossed terribly, while the cables groaned ominously under the strains imposed. If the anchors dragged or the hawsers broke disaster was certain, as nothing could save the ship and crew once they were cast upon the cruel rocks ahead. While the gale was raging the crew redoubled its efforts to repair the machinery, and at last this being completed satisfactorily steam was raised, and the vessel headed out to sea. The whole time she was riding in that open bay the crew were on tenterhooks, but once out on the broad ocean the gale aroused few misgivings in their minds.

IVhile the Research was busy sounding off the Devon coast in 1900, the vessel and crew had a narrow escape from annihilation. The survey ship steamed a little way, and then stopped to make her investigations. The captain of 
a Greek steamer, who was passing, observing these tactics repeated at short intervals, and not grasping their import, bore down to examine the reason more closely. Unfortunately for the surveyors the stranger overshot the mark, and collided with the Research. She reeled under the impact, but recovered, and although she was badly damaged she contrived to regain Devonport for repairs.

While this vessel was re-sounding the entrance to the English channel in I889-1890, over an irregular space of 2,990 square miles, the little band aboard had many uncomfortable experiences. At night she anchored in from 300 to 450 feet of water, in what was practically the open Atlantic, 150 miles off the Scilly Islands. When bad signs of weather arose, extra anchors were thrown out to make the vessel secure, and everything was made snug and tight, to face the fury of the storm. 'The vessel suffered little strain from the heavy poundings she received, although time after time she was swept from stem to stern by the big rollers. The plight of the surveyors, as may be imagined, was extremely miserable. For day after day they had to tolerate the inevitable disconfort with the best grace they could command. The ship could not run for the protection of a harbour with the approach of every gale, as serious interference with the work would have been the result.

Navigators, both of British and foreign vessels, continually report the presence of uncharted rocks or shoals on the shipping routes in all parts of the world. Directly they appear they are investigated. The majority, after elaborate research, prove to be non-existent, while other dangers which never have been charted are often discovered in the meantime. In one instance a big granite tooth, lurking about eight feet below the water, the cxistence of which never had been known, was found within a stone's throw of a crowded shipping lane, and passing ships hat been within an ace of disaster every time they rounded that point. When the menace at last was charted vessels wisely took a wider course. 
In another case the hydrographers were sorely puzzled for some time by reports of an uncharted reef on the ocean highway through the southern archipelago. Captains were confident that they were incurring serious danger by following the Admiralty charts, since everything pointedi to the fact that shallow water existed, where the guide said it was safe. The Alacrity scoured the region, but with no success. Navigators refused to be satisfied. Then the Alert appeared upon the scene, and dragged the sea-bed repeatedly, but no sign of a shoal was revealed by the soundings. The surveyors then offered an explanation of the signs which embarrassed navigators. It was observed by the officers that whenever the surface of the sea at this point became smooth, seaweed appeared thickly on the surface, forming a discoloration of the water closely similar to that produced by a coral reef about eight feet below. Again, as currents of different temperatures met at this point, shoals of fish often were seen, and the larger finny members splashing and throwing the water high into the air conveyed the impression of breakers on a shoal.

The public is impressed by the investigations which are carried out by expeditions to the North and South Poles, and marvel at the temerity of those essaying to penetrate those inhospitable regions. Tramps, liners and other vessels do not venture into the Polar seas, and their charting counts for little, so far as general navigation is concerned. On the other hand, the labour, zeal, energy and courage displayed in the face of extreme and varied dangers among the frequented seas go unsung, although it is precisely this toil which is vital to the mercantile world, and which tends to render ocean travelling as safe as movement along a highroad upon a fast motor-car. 


\section{CHAPTER XX}

\section{WIRELESS TFLEGRAPHY}

Probably no invention of modern times has so changed the conditions of ocean travelling as wireless telegraphy. A quarter of a century ago, after a ressel set out from port, nothing more was heard of her until she reached her destination, unless she happened to be spoken by a passing ship. To-day, at any rate so far as the Atlantic is concerned, the greyhound is never out of touch with land on either side. Every passenger-vessel carries her wireless installation, with which, from morning to night, a ceaseless conversation is maintained upon all sides.

In the closing days of the nineteenth century, Commendatore Guglielmo Marconi was striving hard to talk through the air, by the dots and dashes of the Morse code, over the thirty or so miles of water separating South Foreland from Wimerenx, near Bonlogne. The invention was resarded then in the light of a scientific toy, and although conversing through space was considered marvellous, no one ever thought seriously that it would become just as easy to talk across 3,500 as 20 miles.

Yet before the South foreland-W Wimereux experiments were completed the shipowner recognised the far-reaching advantages of the invention from his own point of view. If the range of conversation extended only over 50 miles, it would enable the owner to keep in touch with his navigators speeding across the Atantic. The "herring-pond," as it is colloquially called, was becoming dotted more thickly than ever with vessels passing to and fro, so that although the owner might not be able to speak direet with his vessel I,500 miles out to sea, yet he would be able to transmit a message in a series of jumps, or by relaying, as it is called, from ship to ship, to its destintion. 
Through commendable enterprise Great Britain was able to secure a powerful monopoly in wireless conversation, so far as the mercantile marine is concerned. Stations were established around the coast with the Marconi apparatus, and accordingly ships which desired to hold converse with these islands through the air were compelled to install this system. The result was that within a short time every Atlantic liner of importance carried this equipment. The Germans resented this tendency. Teuton inventors, following in Marconi's footsteps, developed a system which has become known since as the "Telefunken," whose advance, by the way, has been due to the personal endeavours and influence of His Majesty the German Emperor. Efforts were made by the leading liners to displace the Marconi in favour of the Telefunken system. But it was of no avail. The owners of the greyhounds sailing from Hamburg and Bremen argued that they were dependent to a very great degree upon British support, and accordingly adopted the Marconi method, as thereby they were able to maintain communication with British stations and ships, which would be impossible with the Telefunken apparatus. In fact, at that time Marconi stations refused to accept messages from the latter. This situation was alleviated by the astute German move at the Radio-telegraphic Conference of 1906, when it was agreed among the Powers that there should be free trade in wireless telegraphy, and that all stations should accept messages irrespective of the system adopted by the sender or receiver. In this way an attempt was made to boost the German system, but even that proved unavailing. Severe competition sprang up, but German enterprise was no match for British endeavour in this field, and at the present time more than eighty per cent. of the wireless apparatus employed by the world's mercantile marine is on the Marconi system.

Curiously enough, it was a Germain boat which inaugurated wireless telegraphic conversation on the restless ocean. The first liner fitted with this beneficial apparatus was the 


\section{STEAMSHIP CONQUEST OF THE WORLD}

famous Kaiser Wilhelm der Grosse in Igoo. The installation was effected more in the nature of an additional "safety device" to aid the commander in the navigation of his vessel. There was no idea at the time that passengers would express desires to use the facilities. It was thought that the traveller, after he had boarded the liner, would settle down composedly to a six or seven days' immunity from the cares, worries and anxieties of events on shore. But the restless spirit of the age dispelled this illusion very quickly. Directly the traveller discovered that there were means available on board whereby he could keep in touch with the world at large, he embraced them. It is rather amusing nowadays to learn that a decade ago a private wireless message was transmitted practically through the commander's courtesy. This apparatus was for service purposes only; a factor merely in the handling of the ship as is the compass. If the captain did not feel disposed to permit a private message to be dispatched he was quite within his province to decline. Now the position of affairs is reversed. Although the wireless is still, at the undisputed will of the captain, private messages constitute the bulk of the traffic, and represent an appreciable revenue.

After the Kaiser Il'illelin der Grosse had demonstrated, in a very convincing manner, the serviceability of the invention on board in connection with oceanic navigation, other vessels in the running for trans-Atlantic patronage were compelled to follow suit. The German flyer was securing a distinct advantage. Passengers were attracted to her cabins by the fact that she carried a means of communicating through the air while at sea, and that therein she possessed a powerful factor wherewith to summon assistance if nceded. Accordingly, in the year roor the Cunard, the Imman or American Lines, and the Compannic Générale Transatlantique acquired installations. Other lines did not hesitate to follow the example, and to-day a liner would no more dream of proceeding to sea without her wircless apparalus than she would entertain the idea of leaving her rudder behind. 
As the mercantile development proceeded by leaps and bounds, it became imperative to resolve the question into a harmonious whole. Ships were not to be permitted to wield the new power as caprice dictated. Accordingly, a scheme was prepared to obtain uniformity and cohesion in working, and to this the various shipping companies subscribed their support. This agreement remains in force to this day. Service messages naturally were given priority, but passengers were permitted to use the facilities when they felt so disposed. At the same time a code was prepared for the benefit of the respective navigators, and certain symbols were accepted to designate distinctive calls. Among these were incorporated the famous urgency call for use in distress, and the general call for all stations "ithin the range of the calling ship. The latter was the "C Q." Every station that received this symbol at once cleared the lines, or air, and disregarded all other messages. It was the signal to stand by in expectation of receiving some message of pressing importance, in much the same way as the telegraphic operator on land receives a clearing call over his wires.

The "C Q" thus became an urgency signal. It brought the operators at all the receiring stations within radius to attention, and they naturally strained every nerve to receive the following message. Those ressels which carry only one operator throw out the "C Q" call, when not in continuous communication, every two hours. By this means the ressel is able to ascertain whether or no it is within the range of other vessels which could proceed to its assistance if the occasion arose.

While the "C Q" was effective it did not meet every contingency. It was merely a stand-by signal, and the receiving ship continued on its course without delay. It was felt that a special emergency or distress call should be formulated, and accordingly the letter " $\mathrm{D}$ " was added to the stand-by signal. The distress signal thus became "C Q D." which has been resolved by the general public to signify "Come Quickly Danger." The third letter was added because, if the receiving station only received the 
" $C$ " and the "Q" the operator naturally would be on the alert, and when the call was repeated would receive the full signal.

It was agreed that this emergency call should not be given except by order of the captain of the ship in distress, or by other vessels sending the message forward. All stations within range are required to recognise its significance, and to disregard everything else in their efforts to establish communication promptly with the point from which the call is sent. The distress signal stands first and foremost. Even if an operator is in the midst of receiving or sending a communication of far-reaching importance between Governments, it has to be dropped in the interests of humanity. The " $\mathrm{C} \mathrm{Q} \mathrm{D"} \mathrm{call} \mathrm{towers} \mathrm{above} \mathrm{everything}$ else, since it is not given unless a ressel is in dire straits, when every minute is of importance.

At the 1906 International Radio-telegraphic Conference the distress signal was altered to "S O S," which colloquialism has resolved into "Save Our Souls." These letters were selected because they form a simpler signal to transmit than the one formerly in vogue, and it is not liable to confusion. The Morse translation of $\mathrm{SOS}$ is three dots, three dashes, three dots, thus . . . - _ . . . ; whereas that of the "C $\mathrm{OD}$ " is dash-dot-dash-dot, dashdash-dot-dash, dash-dot-dot, or -. - .

Even if the operator on a sinking ship became flurried and sent a heterogeneous signal of dots and dashes, the receiving stations, from the recurrence of the respective symbois and their apparent lack of meaning, would surmise that something serious was amiss, and intuitively would accept it as the "S O S" call.

When a ship is in danger this signal is pumped out continuously until the operator receives an answer. Then he immediately gives the position of the distressed ressel, and inquires those of the responding boats. In a few seconds the aptain is able to deduce the distance separating him from his nearest help, and, knowing the average speed of the latter by consultation of his reference-book, can estimate how much time must elapse before his rescuer 


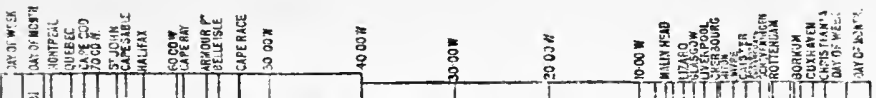

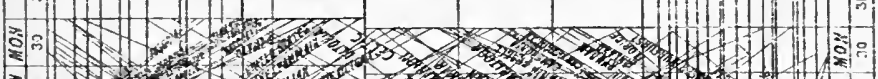

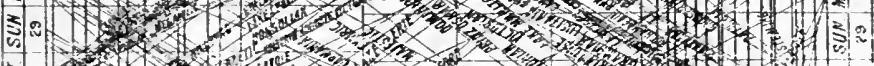
政

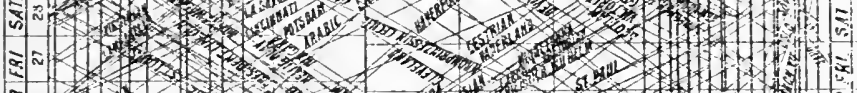
S: a. - 14 .

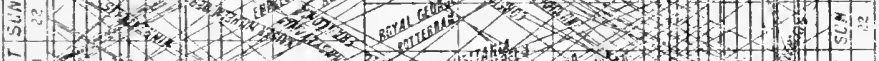

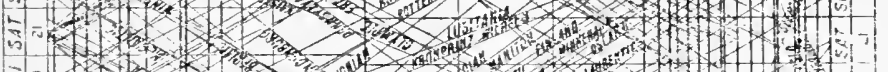

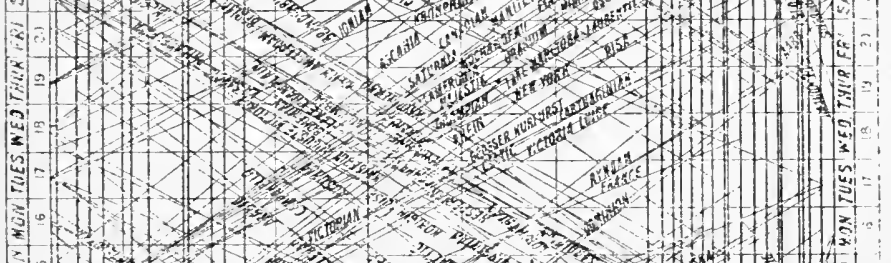

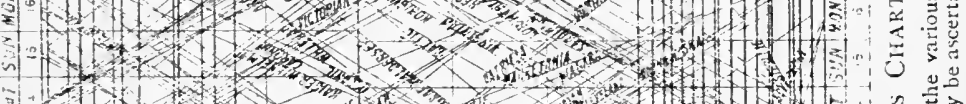

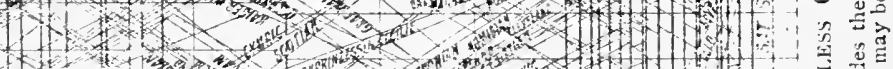

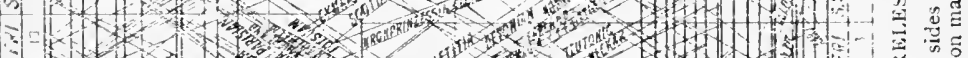
5.

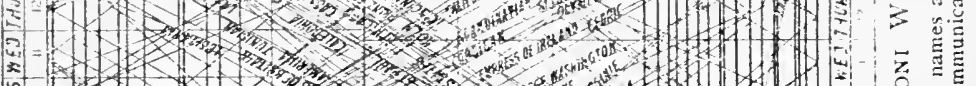

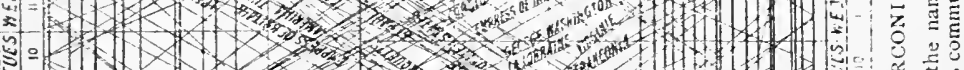

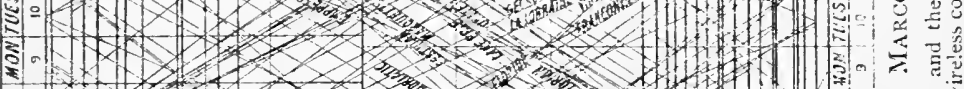

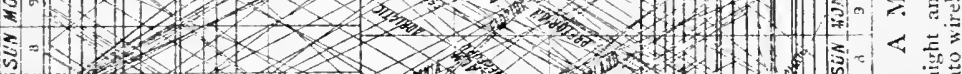

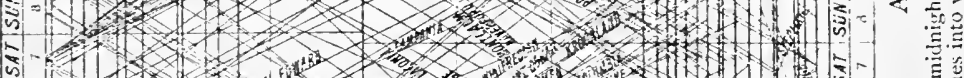
a. (1) 
can come alongside. If the interval is longer than the sinking ship can last, he can direct the laden life-boats so that the vessel hastening to assistance may be intercepted, and be able to pick up the survivors.

Wireless messages are divided into six broad classes. First and foremost, as already mentioned, comes the distress signal. In the second group are the messages of the British Admiralty and other Government departments, which, although they may not concern the vessel immediately receiving them, must be passed on towards their destinations. Third on the list come the communications of foreign Governments, which are treated in a like manner, followed by messages relating to navigation. The fifth class comprises messages on the radio-telegraphic service, while last of all is ordinary correspondence embracing the messages of passengers, etc.

The perfection of this invention has removed fifty per cent. of the perils besetting navigation, while the travelling public realise that they have an incalculably greater measure of security. For the purposes of navigation elaborate charts have been prepared (p. 281). At first sight the chart relating to the Atlantic resembles a network of lines which have gone awry, but each line represents the passage of a vessel across the Atlantic, as well as the approximate points and times when its wireless installation will come within range of those of other vessels proceeding either in the same or in the opposite direction.

Vessels are continually talking to one another during the royage, transmitting information as to weather conditions, natural phenomena, obstructions, and so on. A liner may loold converse with half-a-dozen or more ships simultaneously if her instruments are sufficiently powerful. For instance, the wireless of the Olympic is able to talk over 350 miles at least, and in practice its range is considerably greater. To facilitate conversation between respective captains relative to navigation, a universal code has been drawn up, thereby abbreviating the message as well as expediting its transmission.

Captains experience no more difficulty in conversing 


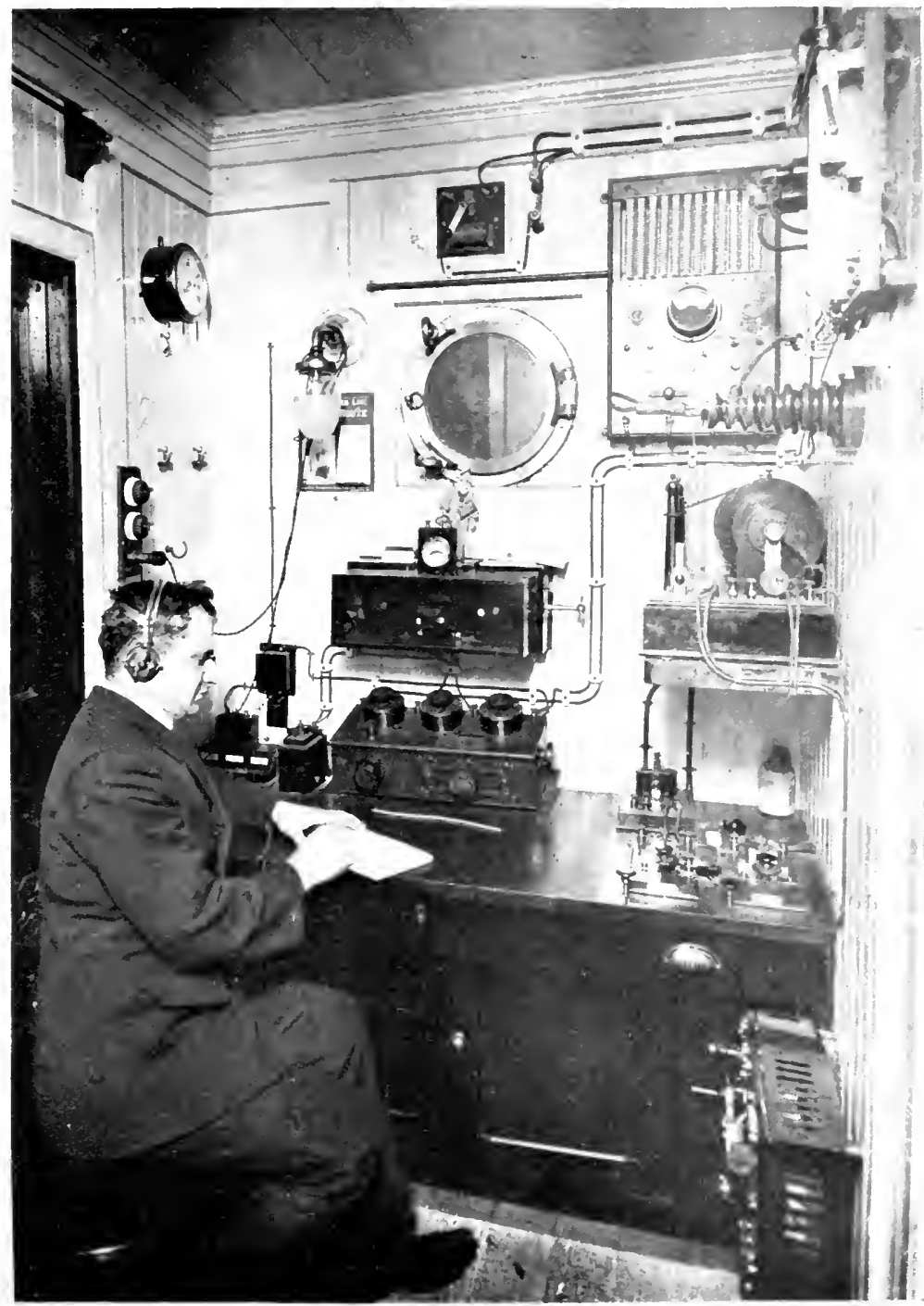

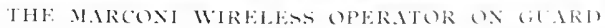

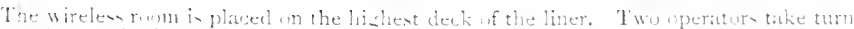

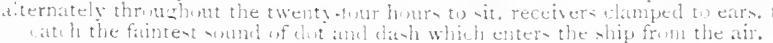




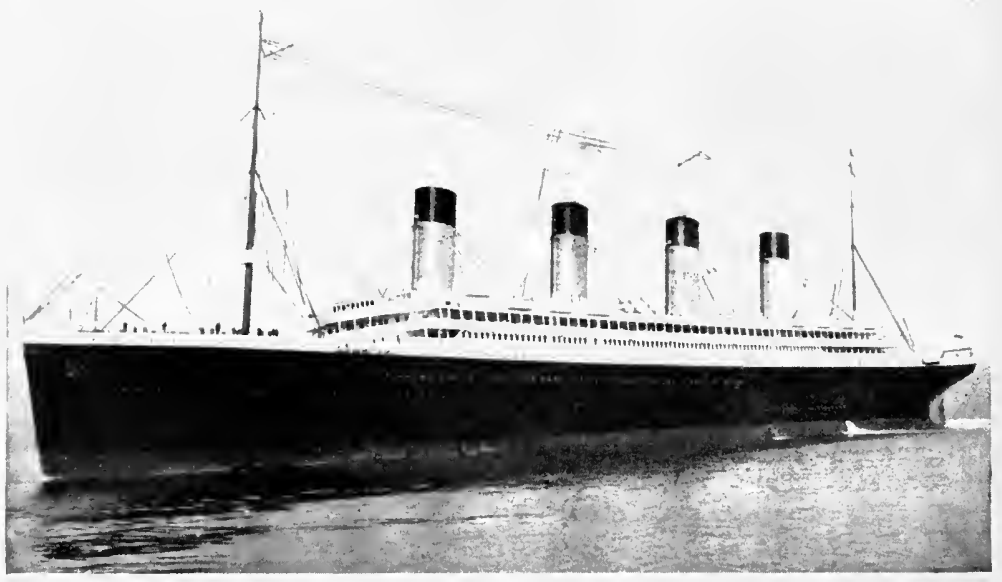

TIE NARCONI AERIAL QF THE O/.YM!'/

I heavs network of wires is shurg between the two masts, with connection junt forward of the second funnel to the oferator's cabin on the boat deck.

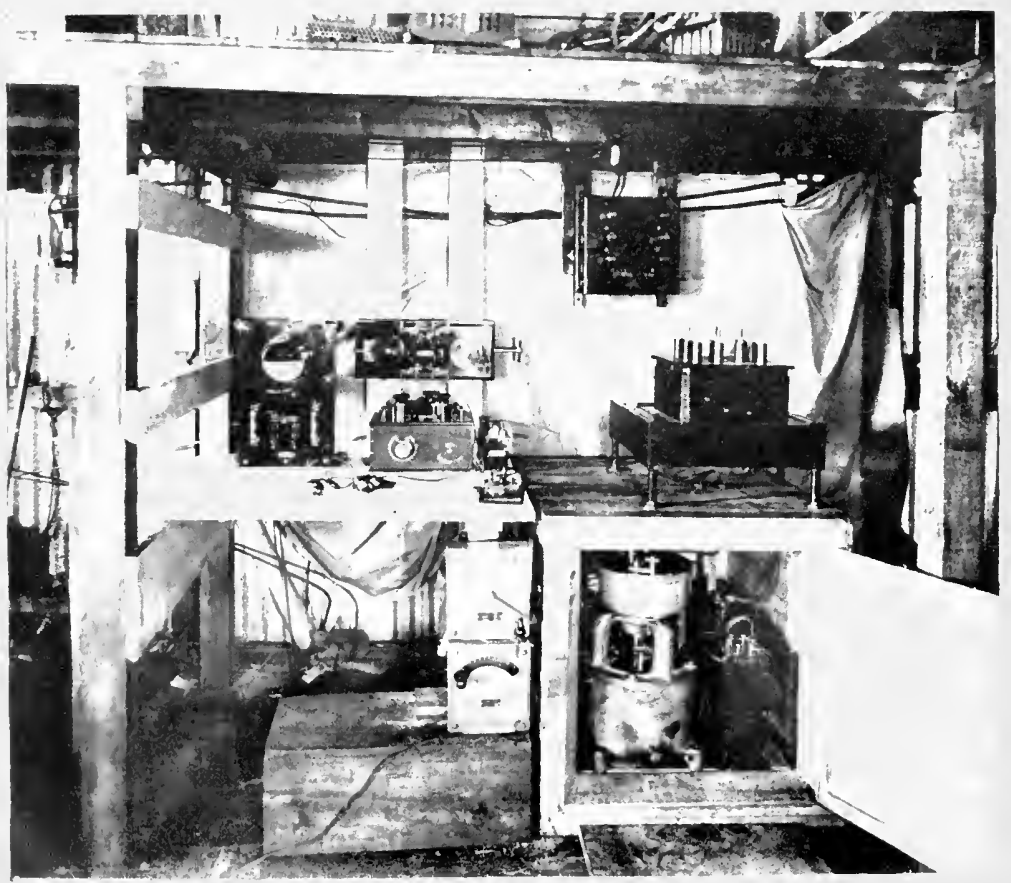

WIREILSS SET FUR ('AR(A) BU.JTS

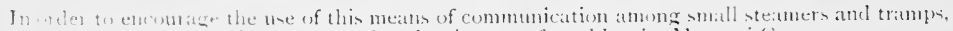

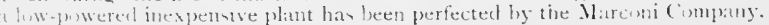


through space for 300 miles than when walking side by side along a street. The liner is driving her way fullspeed, possibly through dirty weather, and every now and again, as she rolls to meet a wave, she ships a comber. It is hard-going, for a north-west gale pounds heavily. In the wireless room is the operator with ears and eyes alert to catch the faintest tick of a dot or a dash. Presently he catches an inquiring call, and a glance at his wireless chart conveys the intimation that it is one of three or four ships, as they should be coming within range of his instrument. He throws out an inquiring call-

"Hello! Is that Baltic? This is Campania, latitude $3 \delta^{\circ} 45^{\prime}$, longitude $45^{\circ}$. What's your position?"

"Hello, Campania! This is Baltic, latitude $37^{\circ} 20^{\prime} \mathrm{I} 5^{\prime}$, longitude $47^{\circ}$. Passed derelict, sailing-ship, deck awash, name unknown, latitude $42^{\circ} 16^{\prime}$, longitude $61^{\circ} \mathrm{o}^{\prime}$, drifting east by north-east. Look out!"

"Thanks! What's the weather? We are driving against heavy head seas in a fifty-knot gale. Raining."

"Right; will prepare for it. Dense fog here, but smooth sea. Reduced to fifteen knots. Italian steamer reports ice passed last night, latitude $37^{\circ} 18^{\prime} 45^{\prime \prime}$, longitude $49^{\circ} 26^{\prime} 5 \mathrm{o}^{\prime \prime}$. Yesterday morning spoke British steamer Persia, bound Glasgow to Boston, with starboard engine broken down. Asks to be reported to other steamers as proceeding at reduced speed. Good-bye."

At times a ship proceeding westwards will have information which she desires to be sent on to New York, whither she is proceeding, and in this instance the message will be sent in a hop, skip and a jump from mid-ocean through all the vessels lying between the sender's position and the American port, whether proceeding east or west. The operator of the Minnehaha, say, will send out the C $Q$ call in the hope of picking up the Dentschland, which is eastward bound.

"Is that Deutschland? This is Minnehaha, latitude $35^{\circ} 16^{\prime} 47^{\prime \prime}$, longitude $37^{\circ} 2 \mathrm{O}^{\prime} 5 \mathrm{I}^{\prime \prime} . "$

"Hello, Minnehaha! This Deutschland, latitude $36^{\circ} \quad 12^{\prime} 27^{\prime \prime}$, longitude $39^{\circ} 50^{\prime} 42^{\prime \prime} . "$ 


\section{STEAMSHIP CONQUEST OF THE WORLD}

"Please report New York quarantine, case infectious disease, developed in John Smith, Main Street, Winnipeg, Canada. Diagnosed small-pox. Please advise relatives. Patient isolated in hospital. No danger. Will report again later."

The communication of such a message notifies the Imerican quarantine authorities of the approaching arrival of a passenger who has contracted infection, and who may have to be detained, pending removal by his friends. Accordingly, arrangements can be made in anticipation, probably for his transference to a sanatorium upon reaching New York.

Sometimes while a vessel is on the high seas, making for a certain scheduled port, her owners desire her diversion to another port. In this instance the instructions will be dispatched through the air from both sides of the ocean, being passed on from vessel to ressel until they reach the ship concerned. The Mauretauia may be driving homewards at full speed for Fishguard, and be about I, 200 miles off the Irish coast. A change of port is decided by the management at Liverpool. Consultation of the chart will show the approximate position of the liner, say at midnight, and those ressels which are within talking distance of her at that time. The message will be bandied across the ocean until it falls within the hands of the operator within range of the greyhound. Out goes the $\mathrm{C} \mathrm{Q}$ call.

"Lusitania wanted. St. Paul calling."

"Hello, St. Paul! What's the matter? Lusitania talling."

"Cunard Company, Liverpool, instruct Lusitania to call at Queenstown, land mails, onit Fishguard, and proceed straight to Liverpool."

"Right! Will report acceptance of instructions. Goodnight."

This possibility of diverting a ressel while on the high seas has demonstrated the value of wireless in a very marked manner. During the I ondon dock-strike several vessels, carrying perishable cargoes and making for the 
Thames, were caught well out to sea, and instructed to proceed to Southampton, Bristol, Liverpool, or some other port where labour was at peace, so as to clear her cargo expeditiously, thereby not only releasing the vessel for further use, but also relieving the underwriters of a liability in regard to the perishable products aboard, which were likely to become unfit for consumption if unloading were delayed.

Hitherto the wireless installation has been confined rather to the larger vessels, particularly to the liners, but at the moment several freighters are being equipped with the facilities. The Marconi Company has devised a special inexpensive installation for such vessels, which, although of low power and range in comparison with those fitted to the flyers, is adequate for the purpose.

The wisdom of the application was demonstrated very conclusively in the South Atlantic during the early part of 1912. A tramp had been engaged in a mighty tussle with the elements. She had been knocked and tossed about by the winds and the waves for several days, and although she put up a stern fight, and emerged from the storm little the worse for her hard experience, the captain had lost his bearings. The sky, with aggravating persistence, retained its overcast sullenness, so that the navigator was denied a glimpse of the sun. He kept his wireless operator steadily at work sending out the " $\mathrm{C} Q$ " call, in the hope that the dots and dashes might strike the ear of an operator on a passing liner within about 50 miles. For about a couple of days he called in vain, as the southern seas are not so thickly dotted with wireless-equipped ressels as the North Atlantic. At last came an interrogating reply. The captain of the tramp related his experiences, that he had lost his bearings, and desired to know approximately where he was from the position of the ship who had responded. The liner replied, and thereby the master was able to decide his position within a matter of 50 miles or so. The next day the liner happened to pass him within Io miles, and then the tramp was able to determine his 
bearings accurately. In this instance, but for his wireless, he might have blundered into a formidable unseen danger; and no stick of the ship have been seen again.

But the usefulness of wireless communication has been demonstrated from the passengers' point of view in its most compelling manner in connection with disaster. The first powerful illustration came when the Florida rammed the République. The captain of the latter, realising that his ship had received a mortal blow, ordered the " $\mathrm{CQ} D$ " call to be circulated. In the course of a few moments halfa-dozen or more vessels had responded and were asking for the République's position. It was given, and in less than five minutes every vessel within range had turned her nose to the indicated point, had piled on steam, and was rushing forward at full speed. The Baltic was the first to arrive, and although the unfortunate passengers had meanwhile been taken on board the Florida, the situation of the latter appeared to be so desperate that they were transferred to the White Star liner which had replied to the distress signal so promptly. Similar results attended the foundering of the Titanic, when the Carpathia, although a considerable distance away, raced at tip-top speed towards the scene of the disaster, which she gained within a few hours. Mlso, when the Cap Frio got entangled among some pitiless rocks, the frantic calls from her Telefunken apparatus enabled assistance to be brought alongside to take off her imperilled passengers. How many ships and passengers owe their safety to Marconi it is impossible to say, but wireless to-day is considered to be second in importance on board ship only to the compass.

The operating-room upon an Atlantic liner is one of the busiest corners of the vessel. Messages in two ceaseless streams pass to and from the hammock of wires slung between the two masts, whence the electric waves, corresponding to dots and dashes, are clispersed into, and collected from, the atmosphere. Many of the incoming messages have to be re-dispatched upon their invisible way. They lave entered in a weakened condition from their long radiation through the atmosphere, and the operator re- 
invigurates the communication by sending it on to the next ship ahead or astern with which he is in touch. Others have to be sorted out for delivery to the commander and other officials on board, while the remainder are translated for the passengers. The telegraph messenger has not appeared on board the modern greyhound yet. Probably he is one of those few conveniences which still remain to be introduced when the pressure of work demands such an innovation. Among the official messages, one important group is that referring to meteorological conditions. As the captain of a vessel receives intimation of the character of the weather ahead of him, and is able to make his preparations to meet it, so on shore the weather bureaux depend upon information gathered from mid-Atlantic and dispatched by wireless, to help them to forecast conditions more reliably than was possible a decade ago. In this manner we receive notification of approaching depressions, cyclones, spells of fine weather, and other variations, two or three days before they touch the shore line.

The travelling business man when he steps aboard a liner no longer settles himself down to a well-earned rest and welcome break from the harassing duties of commerce. By the aid of the wireless he is kept as closely in touch with his ofice as if he were at the end of a telephone wire. In the early days of the innovation he somewhat resented the intrusion of this handmaid of science, so far as his own particular welfare was concerned. He had been apt to relate that the only way in which he could escape from the turmoil and tribulations of the office was to take a voyage. Now this sanctuary is denied him. The volume of commercial messages from and to passengers which pass through the little cabin harbouring the Mlorse sender and sounder would astonish the average individual, but when it is remembered that over 2,500 souls, perhaps, are being housed on the ten floors of the greyhound, and that there is more activity within this shell of steel than in a slyy-scraper half as high as the liner is long, the pressure on the operator may be appreciated. On the large ressels two telegraplists are retained, working in regular shifts, as 
the stress of business is heavier during the night than throughout the day.

Another historical development was recorded on November 15, 1899. The liner St. Paul was nearing the south of England coast at 20 knots per hour. Among the 375 passengers aboard were Mr. Marconi and two of his engincers. They were returning home after having reported the American Cup Race for the Associated Press of the United States. The apparatus employed for this purpose was on board the liner, and the inventor had cabled from New York, just before sailing, that he would endeavour to get into touch with the Needles Marconi station as the liner swung up the Cliannel.

As the coast was approached Mr. Marconi established communication with the land, and in a short time terse items of news trickled aboard. Then a brilliant idea was conceived. Down in the depths of the ship was a small office in which the menu cards and other requirements on board ship were printed. Why not collect the items of news as they came to Mr. Marconi's hands, set them up, and issue a diminutive news-sheet? It was a novelty which appealed to all, and when the inventor and Captain Jamison were approached, they gave their consent readily, especially as the paper was to be produced in the interests of charity.

A full-fledged editorial staff was improvised hurriedly, the little sheet was born, and received the title of The Transallanlic Times. It was made up of a few editorial remarks and local information, enhanced with three stoppress foreign messages which came to hand 50 miles off the Needles. The type was set up with feverish haste, and before many minutes had elapsed 85 copies of the first newspaper published at sea were reeled off. A larger circulation was impossible hecause the printing department ran out of paper!

The demand for the novel news-sheet was instantaneous. Within an hour the whole edition was sold out at a dollar a copy, and the Seamen's Fund was swelled by $£ 17$, or 


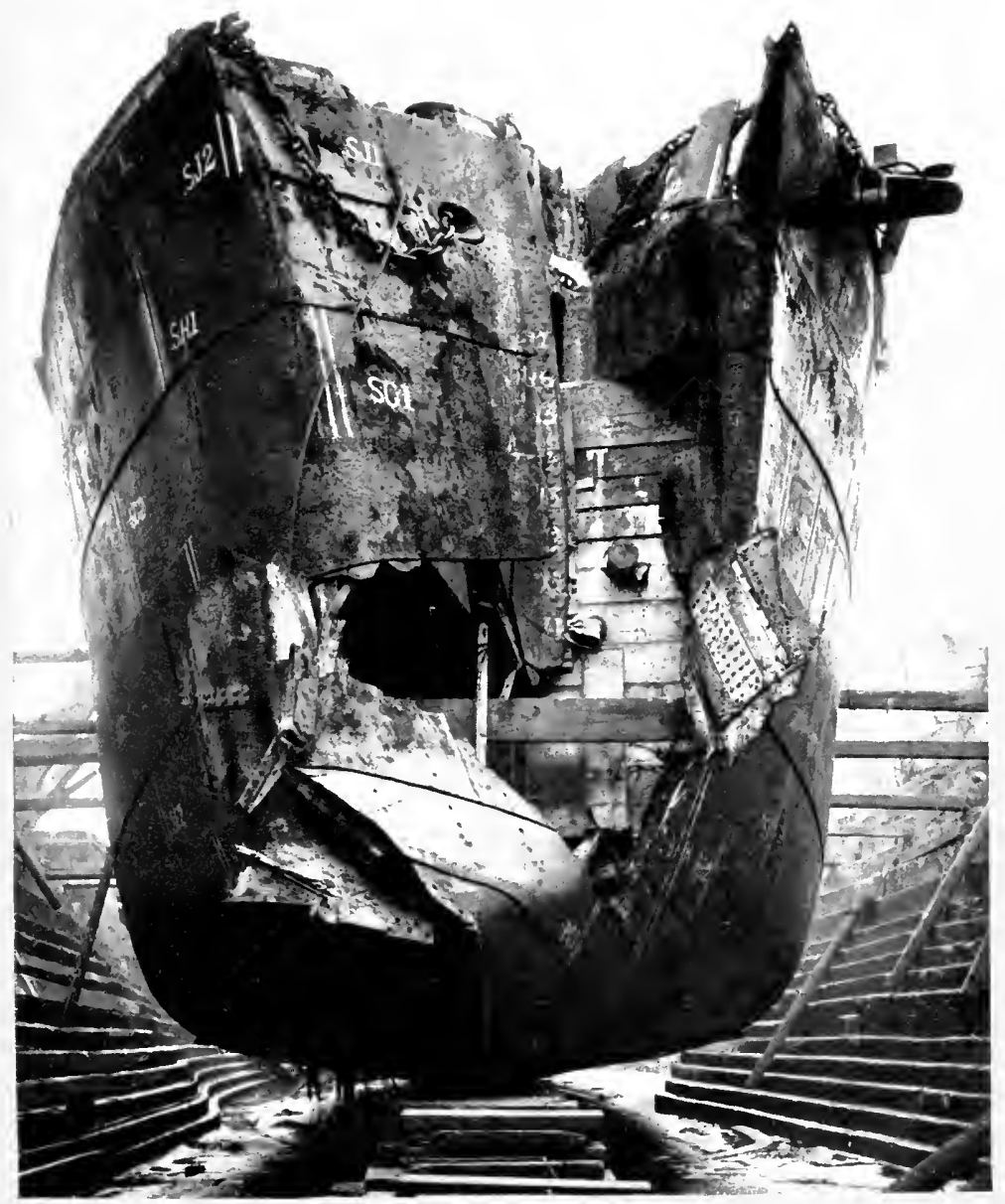

I BAHLY "BROKEX NOSE"

The shattered luw and stem of the It im thall. The damage was cut atwity, and at new part built hy Suith's lock (ompany at Michllestoronush. 


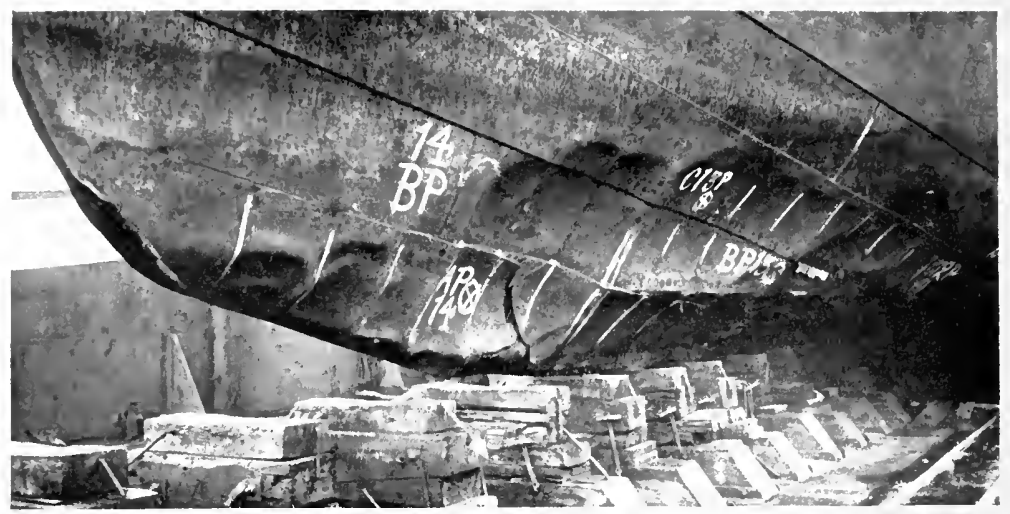

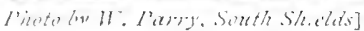

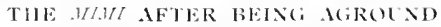

The bow waffered as severely as the stern. A litge number of plates had to be renuned atsme the whele boteon of the ship, together with many of the fromes.

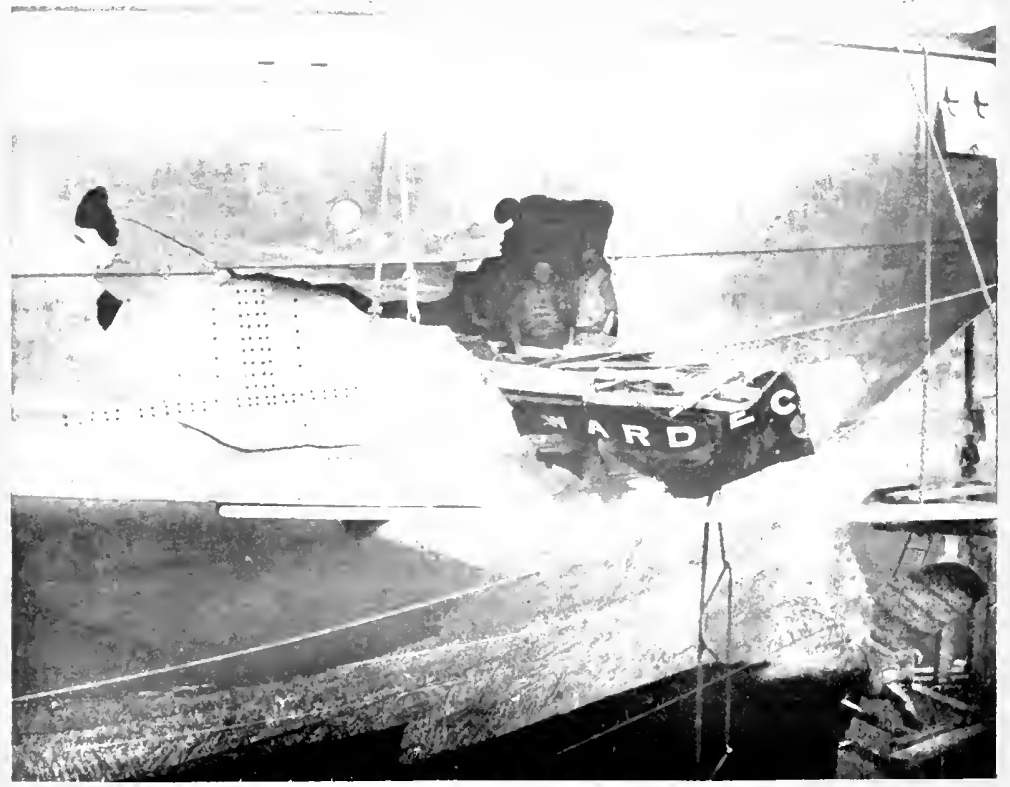

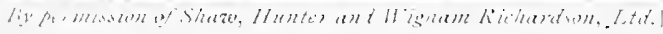

AXV IXIIECOME VISITUR

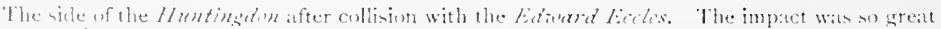

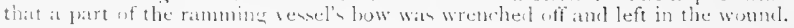


some $\$ 85$. From this humble beginning has grown "oceanic newspaperdom," which to-day has attained large proportions. No important greyhound of to-day omits to produce its newspaper, and its publication upon board ship precipitates a wave of intense excitement.

In many instances the bulk of the paper is prepared on shore in the form of an illustrated magazine-newspaper. The sheet printed on board ship, and containing all the news up to the moment of going to press, is inserted within this covering. In some cases the magazine section is omitted, the liner being content to publish merely the tiny newspaper. As may be imagined, the items of information are severely condensed, but they are varied, being garnered from all parts of the world. Probably no branch of industry has been created-certainly not a newspaperunder such peculiar and romantic circumstances as the wireless organ.

The passengers on those vessels which cannot boast a "local" newspaper are not denied tidings of the world's progress during their sojourn upon the water. Twice a week the Marconi organisation dispatches broadcast over the seas an elaborate summary of the world's happenings between the two poles, the items being pinned to the ship's "bulletin board" for the benefit of all and sundry. Consequently to-day, the time-worn phrase, "Oh, I was on the Atlantic at the time," no longer prevails as a feasible excuse for being ignorant of any particularly striking event in the world's happenings. If it is of paramount importance it is certainly Marconigraphed.

Wireless telegraphy is one of the many startling wonders which have entered into the field of marine navigation, and have succeeded in revolutionising the whole problem of sea-travel. While the day has not yet dawned when every ship, irrespective of its character, size and traffic, whether passenger or freighter, will be compelled by legislative action to be equipped with wireless telegraphy, developments are hastening rapidly towards this end. 


\section{CHAPTER XXI}

\section{GRAVEYARDS OF THE OCEAN}

EVERY highway of locomotion is beset with what might be termed its "danger-spots." The pedestrian making his way along the city street incurs risks when crossing the roadway at points where several arteries converge; the motorist or cyclist has to maintain a vigilant look-out for perilous corners; the driver of the railway express eases the pace of his train as he glides round a sharp curve; and so on. The steamship has still greater perils to encounter since the difficulties and danger-spots incidental to various forms of movement on dry land are combined. The navigator has to thread crowded waters; he has to round dangerous corners and curves; and must give a wide berth to hull-smashing obstacles in the form of sand-bars and rocks, both visible and invisible. The average person is frone to think that steering a vessel is the easiest and simplest task, owing to the amount of sea-room in which the craft may be manouvred; but space is not everything.

Congestion and convergence of streams of traffic are emphasised most forcibly at the entrances to busy rivers, such as the Thames, the Scheldt, Maas, Elbe and Hudson, though probably it is most pronounced in connection with the first-named estuary, especially during the seasons of the year when fogs are prevalent. London is the busiest port in the world, and when the waterway is gripped by this enemy and is rendered impassable there is complete disorganisation. Laden ressels from all parts of the world arrive continuously, to find that they cannot enter the river. They are forced to anchor in long queues at the Nore, anxiously anticipating the moment when the fog will lift to enable them to resume their journey. When the 
blanket of smoke and mist rises there is remarkable activity. The vessels, one and all, weigh anchor and endeavour to enter the narrow channel simultaneously. As a result collisions are frequent, and it is probable that more wrecks occur in the narrow, funnel-shaped mouth of the Thames than in any other estuary in the world. It may also be remarked in passing, that wrecks are cleared out of the way in less time in this waterway than in any other river.

The greatest dangers lie around the coast, and many stretches of shore-line have achieved such evil notoriety, as being the scene of many fearful marine disasters, that they are avoided very severely by the cautious mariner. The south-western extremity of England is dreaded particularly, since the granite cliffs drop abruptly into the water, to reappear here and there far out from the beach, or to lurk just beneath the water, ready to rip out the plates of the vessel which ventures to hug the coast too tightly. Probably more vessels have gone to their last account off the shores of Cornwall than upon any other stretch of shore around the British Islands. The dangerzone may be said to lie between the Eddystone Lighthouse and the Lizard and thence to the Longships, in the case of coasting vessels, while those setting out for the broad Atlantic to depart westwards or southwards have to make a broad sweep to clear the scattered granitic fangs lying around the Scillies.

The worst length in this section is the tumbled clump lying five and a half miles south of Falmouth Harbour, known far and wide as the Manacles. At this point the coast-line is very bold and forbidding, the ridge jutting about a mile and a half out to sea, and spreading over a wide area like a big fan, the whole being covered at high tide, and exposed only partially at low water. Many a vessel has lost her way through fog while passing this spot, or because she has strayed from her proper course, to come to grief against these fearful teeth, as the churchyard of St. Keverne, overlooking this channel graveyard, testifies, since it is crowded with rictims claimed by the 


\section{STEAMSHIP CONQUEST OF THE WORLD}

relentless sea. In fact, the catastrophes have been so numerous and terrible that the Cornish fishermen have come to regard the Manacles with superstitious fear, and in calm weather the boldest spirits will row the curious traveller out, and, pointing into the limpid water, will indicate what was formerly a stately vessel lying battered, broken and rusting on the rugged sea-bed.

Some captains declare that the rocks are magnetic and so upset their compasses, and that they are lured unavoidably to their doom. No exact evidence of this fact, however, has been forthcoming scientifically, and the greater number of the accidents placed to the account of the Manacles have been attributed to errors of judgment. While small boats innumerable have completed their sea careers abruptly on these cruel rocks, the latter have achieved most of their ill-fame from the victims they have claimed from among the larger vessels. On May Day I 855 the emigrant ship John crashed into them, and 200 souls were drowned. On October 14, 1898, the Atlantic liner Mohegan, while proceeding down Channel, en route for New York, fouled the tail of the ridge, swung round, slipped off the ledge with her bottom torn out, and sank in deep water alongside, dragging 103 of her total complement of $15^{\circ}$ people on board to a watery grave in twenty minutes. Less than six months later another stately Atlantic liner, the unlucky Paris, similarly bound for New York with 430 passengers and crew, struck a submerged hump, and was badly holed. In this case Fate was kinder, since the vessel was wedged firmly upon the sharp pinnacles, and although the escape was very narrow, there was no loss of life.

The reason why the Mohegan fouled the reef was inexplicable, as the weather was perfectly clear at the time. The look-out had been set, although, as the subsequent Court of Inquiry remarked, there was no means of telling whether the watch was properly kept. At all events the liner strayed seven miles out of her course, and the error of navigation claimed a heavy penalty. As regards the 
Paris, a fog prevailed at the time, the engines had been reduced to half-speed, and apparently the officer on the bridge was in doubt as to his precise whereabouts. $\mathrm{He}$ was searching for the Lizard Light, which, had it been discovered, would have enabled the liner to return to her right path, and thereby have evaded this terrible dangerspot. From the passengers' point of view this latter disaster was decidedly uncanny, since they could see the decrepit masts of the Mohegan projecting mournfully from the water a few hundred feet away-mute testimony to the fearful consequences attached to fouling this reef. For the second time in her career this liner emerged from a serious accident without any loss of life. By dint of great effort the Paris was removed from her perilous position, as described in another chapter, the huge gashes in her hull were repaired, she was overhauled, dressed in a new garb, given another name, and still passes the spot regularly where she narrowly escaped total destruction.

The outlying barriers of the Scilly Islands are even more cruel than the Manacles, as the submerged ridges are exposed to the full fury of the Atlantic rollers. These concealed teeth have claimed many a ship, and have extracted a heavy toll from those who pass this way.

Farther up the English Channel is the shingly spit thrusting itself seawards from the dismal stretch of Kentish marsh. This is Dungeness, which the mariner holds in fearful dread. In every gale or thick fog some vessel finds herself in trouble off this point, as by her course she must round a corner between Dover and Beachy Head. The powerful tug steamers in the former port, whenever a summons for assistance is received from the west, guess that Dungeness has claimed another victim. They are seldom wrong. Collision is the most prevalent form of accident off this nose of land, and the tugs have had some very exciting races to port with their crippled charges, reaching Dover in the nick of time. Nany a boat which has fallen foul of another ship within pistol-shot of the warning lighthouse has limped slowly up channel in the hope that she 
will reach harbour under her own effort, only to founder or to be thrown upon the inhospitable beach in the shadow of the cliffs forming St. Margaret's Bay.

North of Dover is that barrier of sand forming the rampart to the anchorage known as the Downs. The Goodwins have achieved a world-wide notoriety. Few steamers, if ever they bury their noses in its soft, viscous clutches, escape to make another voyage. They settle down quickly into the soft couch, which clings to them like glue, to be battered to pieces by storm and waves. When one lands on this fearful barrier at low tide, vivid impressions of the terrible toll of the sea are revealed in the rotting, jagged and blackened timbers of many a wind-jammer, and the rusting plates of a steam tramp, which have had the misfortune to foul this trap.

The heavy volume of traffic plying not only up and down, but also across the Channel, renders it one of the most dangerous waterways in the world, as the two streams of traffic pass one another at right angles. When one recalls the hundreds of vessels of all descriptions which beat up and down these waters in the course of a day, it is surprising that disasters are not more frequent. Now and again the community is stunned by the news of a frightful catastrophe-a liner has been rammed and has gone to the bottom with a long list of passengers. In April 1854 the Favourite was coming home from Baltimore with several hundred people, bound for Bremen, and had entered upon the last lap of her long journey, when the Hotspur crashed into her. Those were the days before bulkheads, water-tight compartments and self-closing doors were known, and the water rushed through the huge rent with terrific fury. The Favourite sank like a stone with some 300 passengers. The most appalling wreck in these crowded waters, however, was that of the North German Lloyd liner Elbe. She had left Bremen for New York but a few hours before, when the Crathie ran into her. The liner buckled up like paper under the impact, and disappeared beneath the water with 334 out of her human 


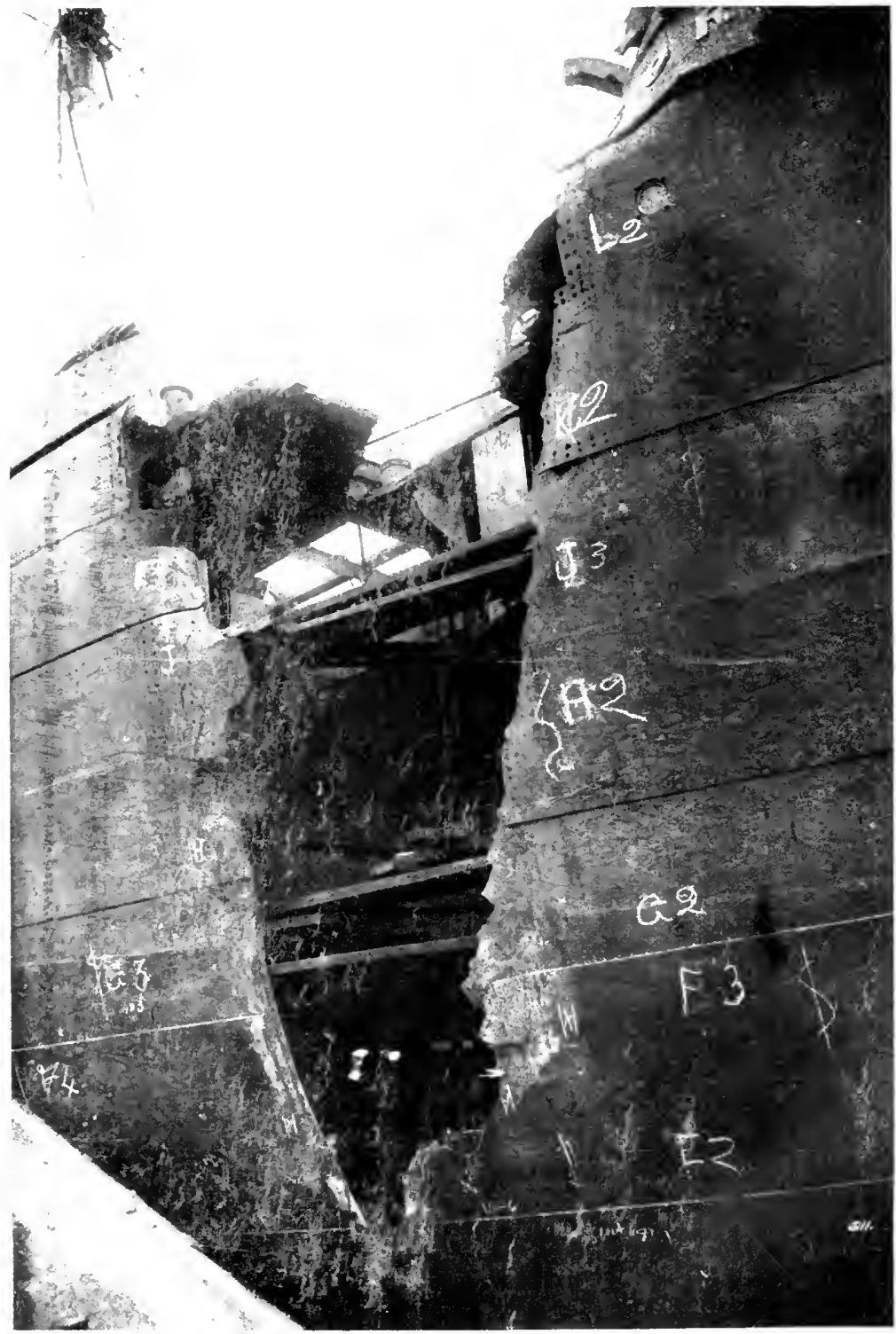

I 1316 HOLP:

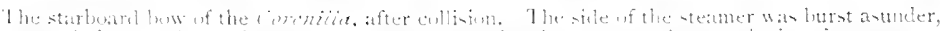

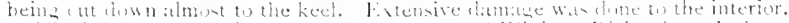

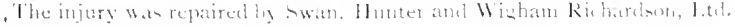




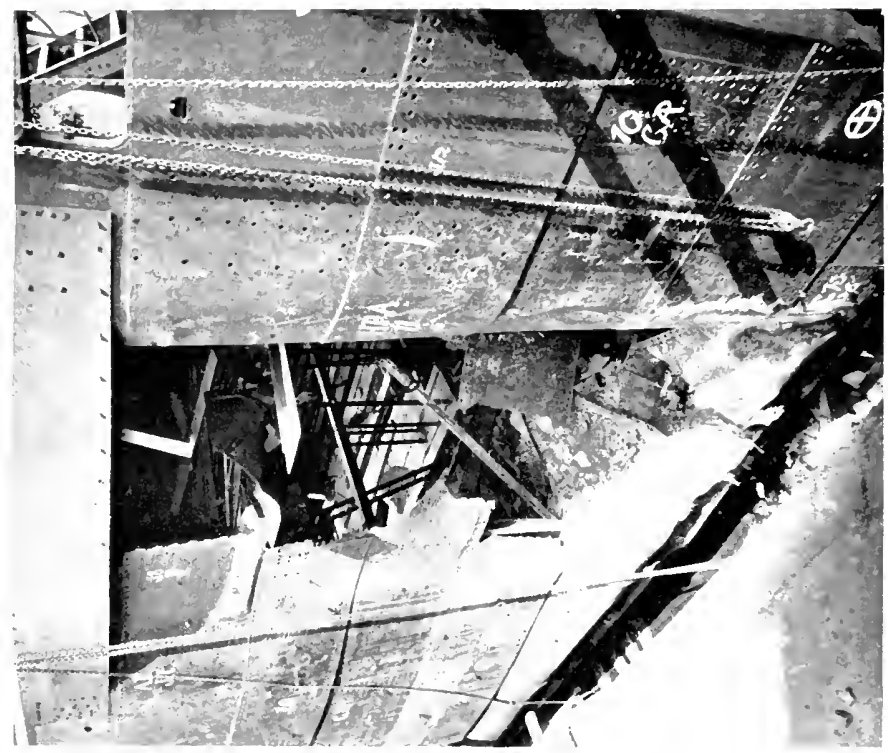

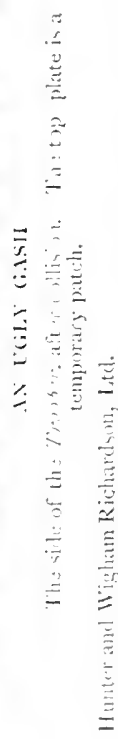

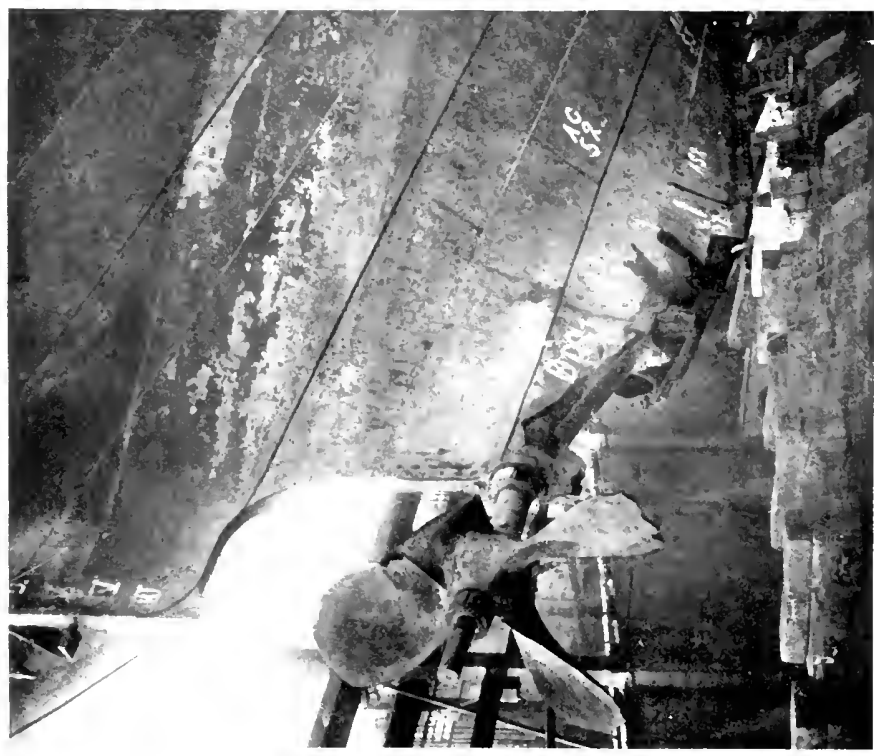

$\overline{\vec{s}}$

.

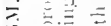

ร. $=$

$-5$

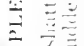

拝

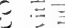

$-\cdots$

三

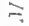

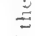

岁

5

$\underline{-}$ 
freight of 350 . The worst feature of this disaster was the callousness of the Crathie, which, after backing out of the liner, proceeded on her way without extending the slightest assistance or even inquiring how the liner had fared. When she reached Rotterdam she was arrested promptly, pronounced solely responsible for the catastrophe, and mulcted in damages to the tune of 565,500 florins, which sum was awarded to the owners of the lost liner.

Taking the southern side of the English Channel, there is a danger-spot as awe-inspiring as the Manacles-the Channel Islands. The waters around these islands are infested thickly with granite rocks, in the form of isolated humps rising abruptly from deep water, or wicked, rambling, barely submerged reefs and ridges. Possibly the worst clump is that known as the Casquets, off the coast of Alderney, skirting the edge of the highway between Plymouth and Cherbourg, and also the path for vessels taking a southerly route from the North Sea to pick up the Ushant Light. The loss of life around these death-traps has been exceedingly heavy, and the smashed hulks of innumerable vessels litter the sea-bed. The heaviest sufferers have been the cross-channel boats plying not only between English ports and the islands, but also with the French coast between Cherbourg and St. Malo. The strait between Jersey and the French mainland is dotted with reefs and ridges, and the navigation of these waters in a gale and dirty weather demands the skill of a pilot. The last occasion on which the Casquet cluster of rocks loomed prominently in the public eye was at Easter 1899, when the Stella blundered into one of the humps protruding from the angry seas, and was sent to the bottom with sixty-five passengers. Before the friendly lighthouse shed its warning light, wrecks in this wild district were so frequent that a rough stone domicile was erected upon one of the larger islets to provide shelter to those who were so unfortunate as to suffer shipwreck, where they could remain until help came from the island; while on storm-swept Alderney is a grass-grown God's 


\section{STEAMSHIP CONQUEST OF THE WORLD}

Acre filled with those who have paid their last account with the hungry waves.

At the entrance to the English Channel where the French coast protrudes far into the Atlantic, forming the northern arm of the indentation in the coast-line known as the Bay of Biscay, and where the mainland terminates in a dishevelled mass of rocks and islets, to form the deadly Ushant, the sea has waged its war with awful severity. Liners going to and coming from the south describe a sweeping curve in leaving or entering the English Channel, and in rough weather the navigator stands well out to sea, as he has no desire to be caught by the numerous and wickedly rushing currents among these rocky ridges. It is the most terrible part of the French mainland, and every effort has been made to mitigate the risks to the navigator by the provision of several lighthouses, so that the perilous coast is well patrolled. Nevertheless, many a tramp which has been pounded to disablement by the heavy cross seas of the Atlantic has escaped swamping in the Bay of Biscay, only to be battered to fragments upon the Ushant rocks. This graveyard attracted the attention of the non-travelling public in June I896, when the Drummond Castle fouled the pitiless rocks, and came to an untimely end with 193 of her crew and I 47 of her passengers. Those who escaped a watery grave suffered untold hardships from exposure, mitigated by the humane and sympathetic action of the Bretons and the curé of St. Molene, whose kindness was rewarded by a subscription raised in England, and wherewith the little village was presented with a clock and steeple for its church, as well as numerous personal gifts.

There are few gaunt rocks rearing their heads above the waste of water which are unprovided with means of warning the mariner of his whereabouts, either by sound or vision, but this is the case with Rockall. This death-trap rises from the bed of the northernmost Atlantic. Probably very few people ever had heard of the name of this islet, which stands 182 miles out to sea from St. Kilda, 
until July 3, 1904, when the Scandinavian emigrant ship Norge missed her way, crashed into it, and was wounded so mortally as to sink to the bottom in a very short time with 750 of her hapless passengers. The average atlas may be searched in vain for this rock, but it stands just eastward of the steamship lanes favoured by the Scandinavian vessels running to New York viâ the Pentland Firth. True, the volume of traffic in these latitudes is very small, but as it is in one of the most deserted stretches of the North Atlantic, far from the beaten track, the plight of those who happen to foul its pitiless fangs is desperate indeed. It is a kind of no-man's rock, unthought of and uncared for, but capable of sending a shiver through the whole world, as this particular catastrophe demonstrated. Fortunately, in this latitude the fog evil does not assume impressive proportions, as the rock lies just clear of the fog zone, which hangs around the north-west coasts of Scotland.

The whirling waters which rush through the narrow, bottle-neck strait forming the connection between the Mediterranean Sea and the Atlantic is an evil stretch of water feared by mariners. The currents swirl with fiendish velocity, and the conditions in dirty weather have been productive of many calamities. It was in these troublesome seas on an inclement night that the captain of the P. \& O. liner Delhi missed his course, to scrape over the reef standing out from the wild, inhospitable North African shore, and to become a total wreck. Equally fearsome are the coasts of the Red Sea until the mouth of the Gulf of Aden is entered or left, while the narrow run of water, the Straits of Bab-el-Mandeb, has an appropriate name, "The Gate of Tears." The island of Perim is the centre of a surging vortex of rapid currents, with a forbidding shore on either hand, offering very slender chances to the wrecked crew and passengers of a vessel. The lane for the liners making for or coming from Colombo is between the island of Socotra and Cape Guardafui on the Somali coast, while the lane between Bombay and Aden runs north of this island. In this 


\section{STEAMSHIP CONQUEST OF THE WORLD}

region the perils of shipwreck are supplemented by the marauding expeditions of the nomads dwelling on either shore, for they regard a wreck as lawful prey, and the hapless human beings who succeed in cheating the sea run the risk of encountering death either from starvation on the arid shores, or from the diabolical inhumanity of the barbarous tribes eking out an existence on the sunblistered sand. The P. \& O. liner Aden was caught in the toils of this forbidding danger-spot in June 1897 , and lost 87 passengers.

Ask any mariner who is familiar with the seven seas his opinion of Cape Hatteras, and he will express it in true sailor terms, with an accompanying shudder. This projecting spit of coast off North Carolina is to the United States what the Goodwins are to England. How many magnificent vessels and lives this graveyard has claimed no one can say. The ocean hereabouts is littered with shallow shoals and wicked sand-bars, which, if they once grasp a vessel, never let it escape. Fine weather in this latitude and region is rarely known to the navigator, and if he is overwhelmed by bad weather and survives the tempest, his craft generally will bear grim evidences of the conflict. The wind-jammer suffers especially, as masts and sails are invariably stripped, while the steamer has a sorry-looking deck after it has emerged through the battering mill of a Cape Hatteras storm. More ships are wrecked at this point during the course of a year than upon any other part of the North American continent, and the greatest sufferers are among the large fleet of vessels wandering up and down the coast-line with local traffic.

Until a few years ago the St. Lawrence River had an unenviable reputation; even to-day it has not fully survived it, and underwriters regard it askance. I have seen as many as four riddled, rusting hulls, presenting forlorn sights, cast on the banks near Quebec. Either they have run aground to save themselves, or have been hauled out of the fairway to leave the channel open, only to become so damaged as to be written off as total losses. Now, how- 
ever, this noble river is better lighted, and navigation is fairly safe, though the navigable channel is somewhat narrow, with certain disaster if the slightest deviation is made from it. Calamity in this case appears to be centred upon the tramp, although now and again the monotony of this class of wreck is varied by the incapacitation of a small liner.

Lying due east of and about eighty-five miles off Nova Scotia is the most ill-famed spot in the Atlantic Ocean. This is a crescent-shaped stretch of sand, vainly endeavouring to keep its dreary knoll above the surging ocean. Sable Island is its name, and its mere mention sends an involuntary shiver through the master of the tramp and windjammer frequenting those seas. He knows it by its reputation. He has no desire to make a close acquaintance, as he knows only too well that he might lose his staunch little craft, and probably have a desperate struggle for his life.

The danger lies not so much in the sandy isle itself, but in the shoals and sand-bars which stretch far out to sea on either shore. At some places a small vessel dare not approach within sixteen miles of the undulating, shimmering line breaking up the horizon, as the breakers roll, tumble and foam over bank after bank, set behind one another like lines of soldiers. If a ship were so fortunate as to miss one bar, it would be caught by another. It is sufficiently awe-inspiring to look upon the waste of foam when the Atlantic is at rest, but when this ocean is writhing in the throes of a gale the outlook is a thousand times more terrifying. There is only one possible point where a landing can be effected to render succour and provisions to the two lighthouses erected on this isolated spot, and even then the little steamer dare not approach within a mile.

Sable Island has earned the lugubrious name, "The Graveyard of the Atlantic." And it deserves it. According to Mr. S. D. Macdonald, F.G.S., of Halifax, who has made a special study of this danger-spot, it has been the scene of no fewer than 150 disasters since 1802 , and he has prepared an interesting chart indicating the points where 
the various types of craft have come to grief. A perusal of this grim record proves that the whole barrier has no specially fatal spots, but that every mile is haunted with the ghosts of vessels and their unlucky crews. On the island is a dismal though revered small enclosure-the last resting-place of those victims of the sea who have been retrieved by one or other of the twenty-two men imprisoned on its sterile banks in the interests of humanity.

Although this graveyard is slipping gradually from sight, centuries must pass before it disappears entirely from mortal ken, unless a seismic disturbance hurries the process of demolition. Even when all vision of sand has passed from sight it will still be a treacherous spot, with the hungry quicksand lurking beneath the water to trap and hold the innocent vessel. But what is far worse, in regard to navigation, is the fact that the whole mass of sand is moving slowly but surely farther out into the Atlantic, as if maddened that its present whereabouts are so well known that the mariner avoids its precincts, and so seeks to destroy in new fields. In the course of roo years the island has moved bodily eastwards a distance of 25 miles. Its disappearance would not be mourned, provided that it was covered by a sufficient depth of water to permit the floating of vessels in safety over its sucking mass; but so long as it is visible in any form it will be known by its sinister name.

Yet, if one asks an old salt who has roved every sea between the Poles which is the most wicked stretch of water on the globe, his reply probably will provoke amazement. His verdict would not be in favour of the North Sea, the English Channel, Cape Hatteras, or even Sable Island. He would reply bluntly-the waters round Cape Colony. In passing from the eastern to the western ports of Soutl Africa the vessel threads the most cruel sea in the world, where wind, tide, currents and waves all combine against the ship, and harass the master sorely. One has only to recall the innumerable wrecks that have occurred on these coasts to prove the statement. The 
wreck of the Birkenhead alone would serve to emphasise the point, but the survivor of many a tramp who has parted unwillingly with his ship on this shore is able to relate just as heroic and grim stories of the fight for life.

In our school-boy days lurid stories were painted of the Sargasso Sea and of the maelstrom off Norway. We were told that ships never ventured into those stretches of water, or if they did, never were heard of again. The Sargasso in particular was a fabled graveyard, where derelicts, after their aimless wanderings about the Atlantic, were drawn in, to be seen no more. Unfortunately for the imaginative young mind, steam has dispelled these illusions-they are no more true than the stories associated with the Flying Dutchman and other phantom ships of the sea. The Sargasso Sea is no more difficult to traverse than the lakes of North America, Windermere or Loch Lomond. Many a captain has travelled across its breadth and reputedly most wicked part, where, we were told, there was a huge whirlpool which acted unwittingly as a destructor. He may have noticed a greater accumulation of algae, or gulfweed, but nothing else to distinguish this area of water from the more crowded parts of the Atlantic. More vessels would steam across the Sargasso Sea to-day were it not for the fact that it lies somewhat off the beaten tracks. The illusion in regard to the Norwegian maelstrom has been shattered just as relentlessly. There is a violent eddying, caused by rapidly running currents, at this spot, but the sea is easily negotiable in calm weather. In stormy periods the average master steers clear of it, not because of the mythical whirlpool, but from dictates of prudence to avoid an unkind, rock-bound coast washed by rapidly moving currents. From the danger point of view neither of the last-named is to be compared in wickedness with many of the Graveyards of the Ocean which I have described. 


\section{H A P TER XXII}

\section{STEAMSHIP SURGERY}

THE inexorable hand of Father Time is felt upon the steamship, just as forcibly as upon other methods of transportation. The lordly and superlatively luxurious liner, which occasions so much wonder to-day, becomes the commonplace of to-morrow, so rapid are the advances in steamship constructional skill and those of the decorative architect. A liner is a costly luxury : now-a-days a million of money brings a very small return in matters belonging to steamship travel. The public is extremely fickle. It loves to live in luxury when afloat, and the shipowner is hard-pressed to fulfil these desires in order to retain the patronage of his client.

Underwriters also will not part with the vessel which they have insured heavily without a herculean effort towards reclamation and rejuvenation. A ship may have rested upon the bed of the sea and have become encrusted with barnacles, while its curtains and hangings may have been rotted and discoloured by prolonged immersion. But that does not mean that the vessel is unfitted for further service. A hole can be repaired; paint and new upholstery are capable of restoring a departed glory and fine finish; while, when its name is changed, the public fail to associate the new with the old. They have no idea that the stately vessels whose decks they tread may have made a determined effort to penetrate Davy Jones's locker. There is one popular liner riding the Atlantic to-day which about a decade ago made a very spirited attempt to enter an ocean graveyard. It was recovered, considerably wounded and battered, but the shipbuilder attacked the pounded hull, replaced the plates which had been torn away and strained, while the architect, entering its interior, replanned and 
redecorated its cabins and state-rooms, so that when it re-emerged from the shipyard it was, to all intents and purposes, a new vessel. It was rechristened, and to-day it spans the broad Atlantic within a week.

The shipyard is not only a cradle on which new maritime titans are reared; it is also the ward in which injured vessels are submitted to surgical operations, to restore them for further use or to give them a new lease of life. Many of the injuries inflicted are the result of too affectionate embraces with other vessels, a rock-bound coast, or a glutinous sand shoal. The injuries which come for treatment are various : one ship has sustained a broken nose, another has fractured ribs, a third has severe abrasions of the hull, a fourth has been ravaged by the fire fiend, while still a fifth may require to be severed and lengthened.

The ship in hospital is a dismal sight. Maybe it arrives swathed in bandages, where the salvage engineer has extended first aid with formidable patches of wood. The surgical staff, comprising the ship-designer-he of the mathematical calculations--the riveters, the frame-bender and the marine engineer, apparently play sad havoc. The cripple or aged is first warped into a dry dock, supported on crutches or props, and keel-blocks, leaving the ineit mass high and dry, when the water is pumped out. The nurses appear upon the scene, and with hammers, chisels, cranes and many other weird devices and appliances set to work. The body around the wound is laid bare, and the damaged parts are amputated. Then fresh pieces of metal are fashioned and put into place, a new skin is applied over the gaping hole, made fast and tight with rivets, the painter comes aboard and with brush and oleaginous compounds or other expedients imparts a fresh protective coating to the affected part, cleans and restores the remainder, the props are removed, the water is admitted and the vessel is hauled off her operating-table, otherwise out of the dry dock. A new life-stream of steam is circulated through her engines. Her steel muscles are set in motion once more, and she moves away as sedately 
as on the day she left her creators' hands. There may be a little stiffness in the joints, but this soon passes off as she settles down to her work.

The march of progress is responsible to a marked degree for the aid of the steamship surgeon. When the screw propeller came into vogue, several steamship companies, catering for the over-seas passenger trade, found themselves at a heavy disadvantage. They possessed paddlewheel vessels, many of them almost new. Accordingly, in order to come into the ranks of modernity, they arranged for their vessels to be converted to the new order of things. Among these owners was the Compagnie Générale Transatlantique. Its fleet was comparatively new when the screw propeller emphasised its superiority. So it decided upon a bold course of action in $\mathrm{r} 87 \mathrm{r}$. A contract was made with Hawthorn, Leslie \& Company of Hebburnon-Tyne for complete modernisation. Five vessels were handed over to these steamship surgeons, and their task was of a most comprehensive and intricate character. The paddle machinery and wheels were not only to be removed to make way for the screw propeller and its machinery, but the vessels were to be lengthened fifty feet into the bargain. Such extensive treatment virtually involved the reconstruction of the vessels. The hull had to be disembowelled, then cut in half, the sections drawn apart, new frames inserted, together with modern cabins and state-room accommodation. It was a delicate task, but the British engineers displayed their ability most effectively, and when they turned the old ships loose once more, they were unrecognisable, owing to their complete transformation. They were slimmer, more graceful, and gave more emphatic appearances of speed and comfort. They proved great favourites with passengers in their new guise, and for years upheld the mail service between France and the United States.

Lengthening a liner is one of the most interesting of steamship surgical operations. One of the earliest and most noticeable undertakings of this character was in 


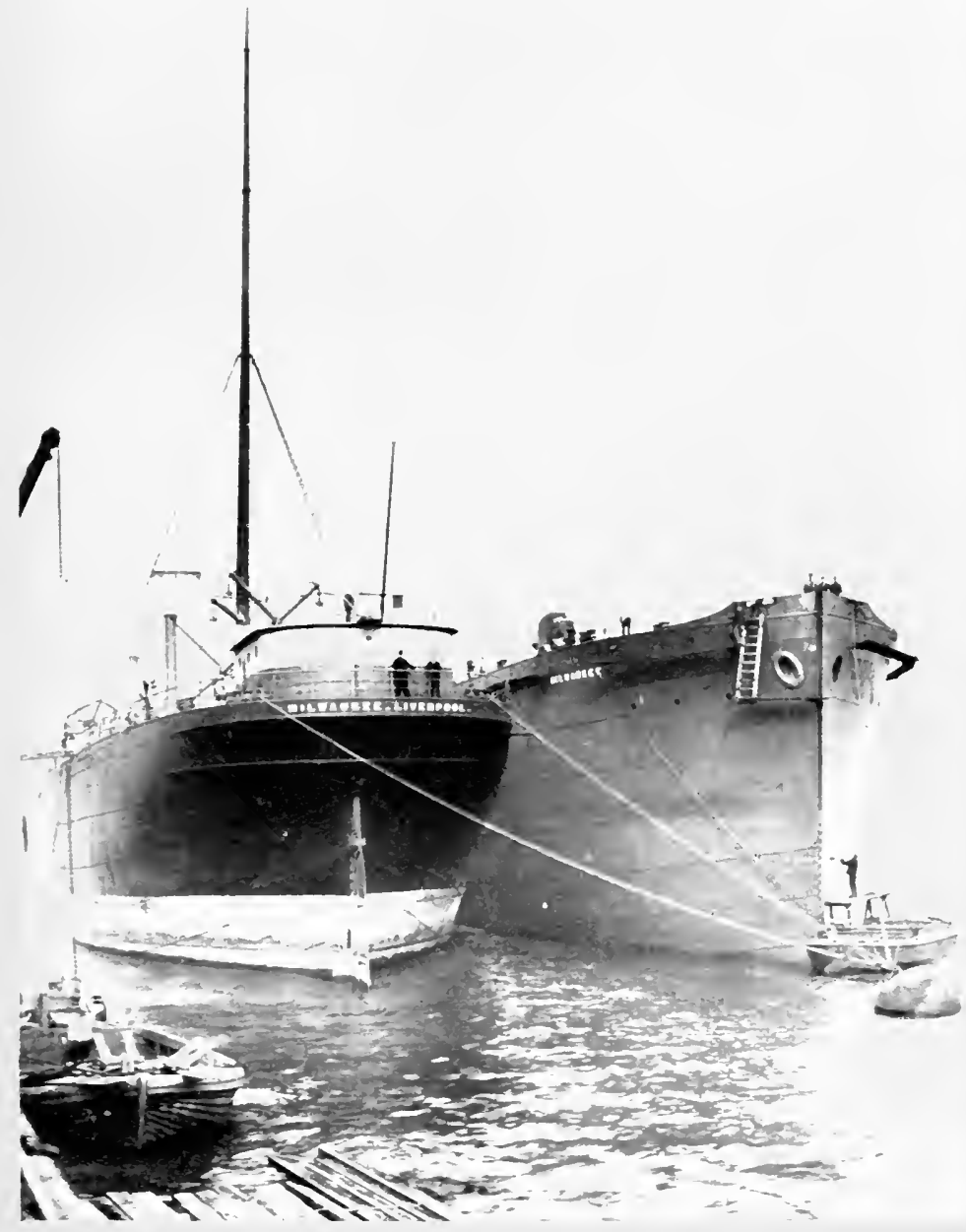

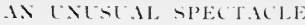

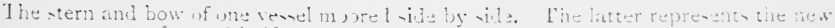

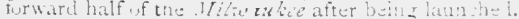




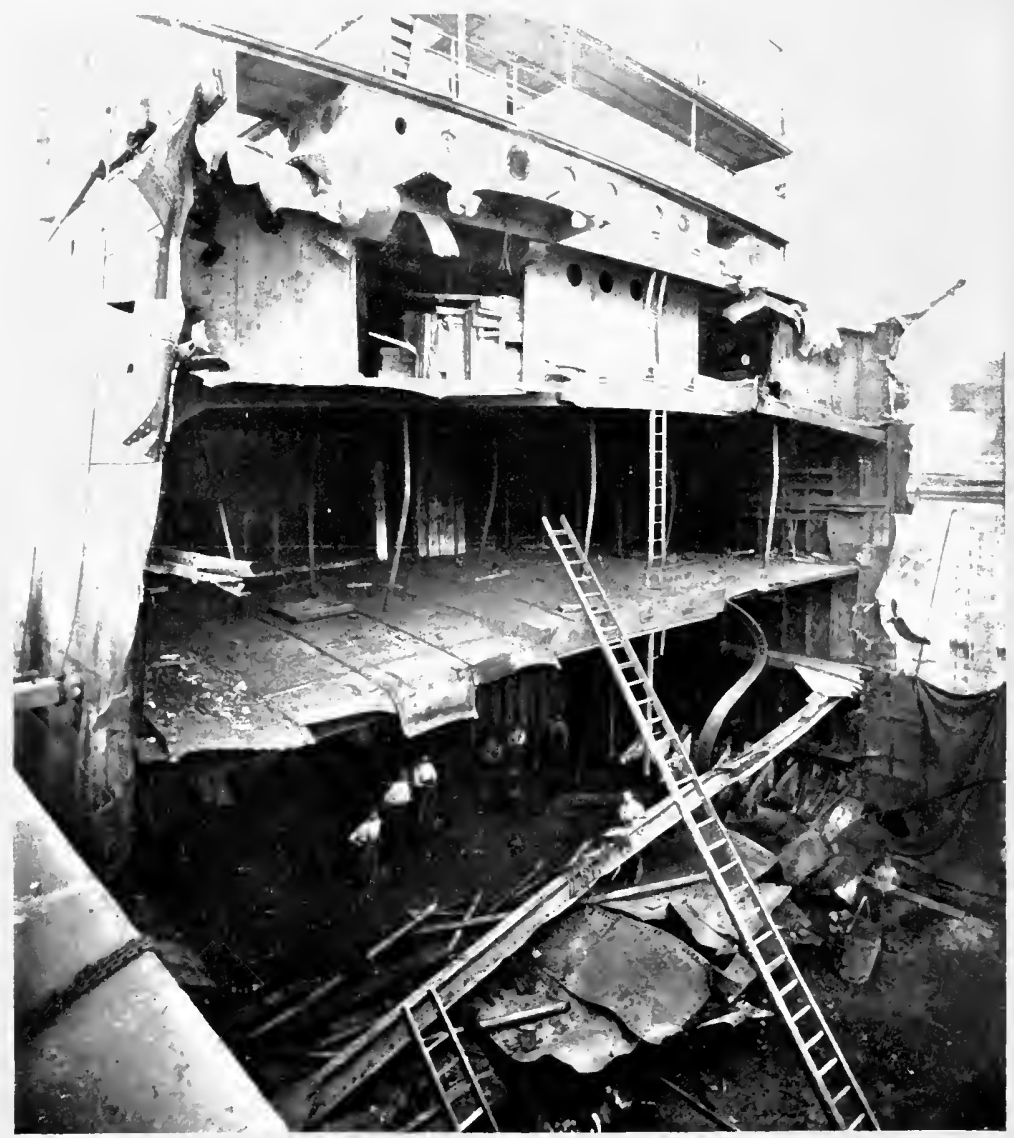

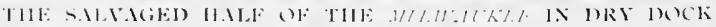

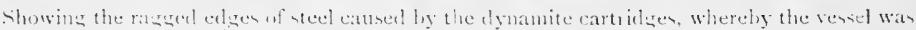
cut in twatu while helet on the rock. The sern half was towed inte the line. asisting with her own engines. 
connection with the P. \& O. liner Poona, which, although a good boat, was considered by the owners as possible of distinct improvement. So they sent her to the Clyde, where she was cut in twain, and about sixty feet inserted between the two ends. Before the lengthening process this steamship was described as a boat with two ends but no middle. When she returned from the shipyard after her operation, she looked as trim and as attractive as any vessel in her trade. Moreover, she benefited from the extension, since she notched another knot per hour.

The Norddeutscher Lloyd Company also had a steamer which required to be brought up-to-date to meet the exigencies of the times. This was the Wittekind. She was sent to the hospital at Wallsend-on-Tyne and drydocked. There Messrs. Swan, Hunter, \& Wigham Richardson, Limited, cut her in halves amidships. It was an exciting time drawing the two halves apart. Hawsers were attached to the bow, and when the command was given powerful winches commenced to grunt and creak as they hauled steadily at the cables. There was a terrible groaning, followed by a terrifying $\mathrm{Zip!} \mathrm{The} \mathrm{cables}$ snapped in two like pack-threads. Thicker and stronger hawsers were brought up, passed round the drums of the winches and made fast to the bow. Once more the steam pressure was applied. The drums revolved slowly, and amid terrible creaking and groaning the bow was hauled back.

The foreman sang out a command, and the winches stopped. The two pieces were sufficiently far apart. Expert workmen then advanced with their instruments and "sighted" the two moieties to see that they were absolutely in line. A little packing here, and little loosening there, and the two parts were dead true. Then the riveters attacked the keelson, inserting a new length of back-bone, frames were swung up and lowered into position, beams and girders of steel were lowered and made fast, the shell plating was attached, the decks connected up, new staterooms and other accommodation installed, and in a few 
months the Wittekind steamed out of Bremen laden with passengers and cargo, quite a new vessel. Among British shipbuilders, the lengthening of a liner has become quite a commonplace occurrence: the masters of craft think no more of introducing fifty, sixty, or more feet of hull into a liner, than of replacing a broken propeller, and the ship invariably benefits from the operation.

The Canadian Pacific Railway owns a smart line of ships plying on the Great Lakes of North America, bearing passengers anxious to enjoy a unique passage between Port Arthur and Owen Sound. The greater number of these fresh-water liners have been built on the Clyde, and dispatched to their home port across the Atlantic under their own steam. Upon reaching Canada the tumble of water forming Niagara has had to be compassed, viâ the Canal. Unfortunately the locks of this artificial waterway are not adapted to the passage of lengthy vessels. But the shipbuilders have not been dismayed. The vessels leaving the $\mathrm{Clyde}$ have carried one or two expert workmen armed with plans and drawings. These latter have indicated very plainly where the ships might be divided in twain, and on the east side of the locks the rivets holding the plates amidships as well as the keelson have been extracted. Each part, with a bulkhead strong and solid enough to hold back the water, has been floated through the lock separately. Upon reaching the western end of the lock, the two parts have been taken into a dry dock, where the sections have been brought dead in line, the water pumped up, the keelson reconnected, the rivets, as well as the plates, replaced, and the vessels then have steamed to their home port, just as if they had floated through the locks intact and never had been dismembered.

I have described the remarkable salvage of the stern section of the Milwaukee, which was wrecked off the east coast of Scotland, and how the stern-half, after severance, worked its way over 180 miles back to the Tyne, partly under its own steam. When it reached the yards of Messrs. Swan, Hunter, \& Wigham Richardson it was 
dry-docked. The dynamite cartridges amputating the bow when firmly jammed on the Errol Rocks had played sad havoc with the plates. They were jagged and twisted in the most fantastic manner, as well as being bent outwards. The rivets were drawn and the torn and damaged plates removed. The decks forward of the bulkhead were littered with masses of rock, shingle and sand. This débris was cleared out and preparations were hastened forward to permit a new bow to be attached; the latter was built on a slip in the usual manner and launched. People on Tyneside were treated to a unique spectacle, the bow and stern of a ship pointing in the same direction, because the two sections were moored side by side.

The stern was now floated into the dry dock once more and secured. Then the bow was brought in and gradually warped up until the expert "sighters" signalled that both were dead in line in every particular. Both were then made fast, so that neither could move an inch. The water was pumped out and the two parts were drawn tightly together to bring the holes in the strakes of plates of the new bow exactly over the relative holes of the respective plates of the stern section. The rivets were driven home, and when the water was re-admitted the splicing was effected so perfectly that no one could distinguish the joint.

This ranks as one of the best pieces of work of its character on record. When the Milwaukee once more floated upon the bosom of the Tyne, her gross tonnage differed from her original weight by only six tons! Since this classic repair considerable praise has been bestowed upon the construction and fitting of a new bow to the severed Suevic, but this operation lacked novelty. The only striking feature in connection with it was the towing of the new bow from Belfast to Southampton, but so far as the actual idea and connecting-up were concerned, the shipbuilders in this instance were able to follow the precedent set by the repairers of the Milwaukee, which ranked certainly as a decided triumph for Tyneside shiprepairing skill. 
Another wonderful illustration of the shipbuilder's surgical ability was exhibited in connection with the Russian ice-breaker Ermack. As originally designed by Admiral Makaroff, and built by Sir William Armstrong, Whitworth \& Company, this unique vessel was fitted with a screw propeller in the bow. It was anticipated that the provision of this additional screw would facilitate the clearing away of the ice as it was broken up by the weight of the bow, thus giving a more open channel as the ship moved forward. When the Ermack was set to work in the Baltic, however, expectations were not fulfilled, and it was decided to dispense with this front propeller.

Accordingly the Ermack returned to the Tyne to be fitted with a new bow. She was dry-docked by Swan, Hunter, \& Wigham Richardson, and the forepart of the vessel was cut away completely, together with the propeller and its tube. While this work was in progress a new bow was designed, constructed and launched, to be attached to the ship. This operation was somewhat delicate, and demanded special arrangements. It was necessary to build a special pontoon on which to float the new bow, to bring it more easily into position. This pontoon acted as a kind of cradle and supported the new structure, as shown in the illustration facing p. $3 \mathbf{2}$.

Launching-ways were laid down in the dock in which the main part of the vessel was secured, and the new bow, on its pontoon, was floated into the dock and brought to rest fairly and squarely upon these launching-ways. Powerful hauling tackle was then attached to the new structure, and it was dragged forwards bodily until it came up to, and dead in line with, the after part. The two sections were then connected up. When this task was completed the pontoon was demolished, and the Ermack refloated out of dock, to steam back to the scene of her operations in the Russian seas.

Although a vessel when she meets with an accident may seem to ride easily in her unusual situation, considerable damage often is done which is not apparent to the eye, 


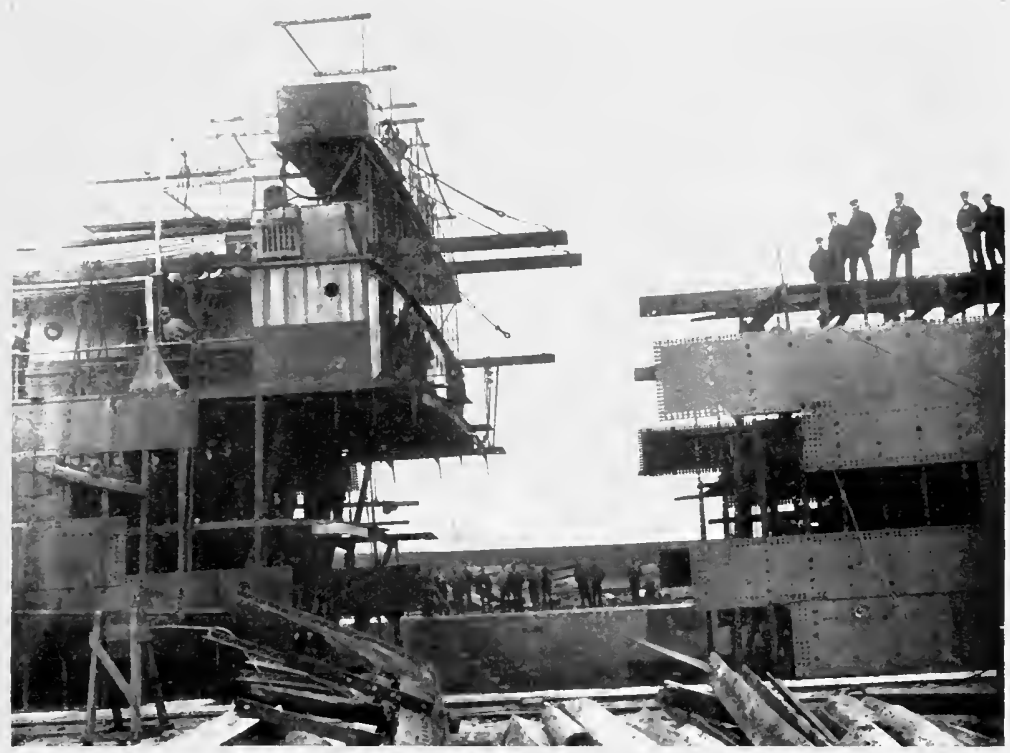

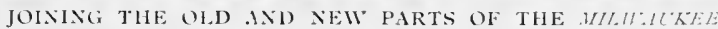

The two sections were foated into dry dock, lought dead in line, and then connected.

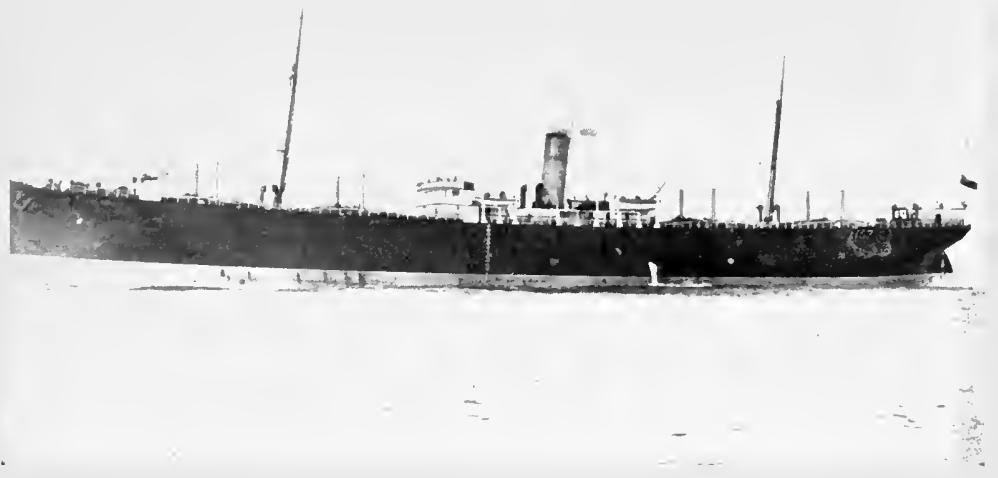

THE RESTURED WIL W ITKY:

The part firward of the dotted line represent the vection which was built and added to the salvaged stern. 


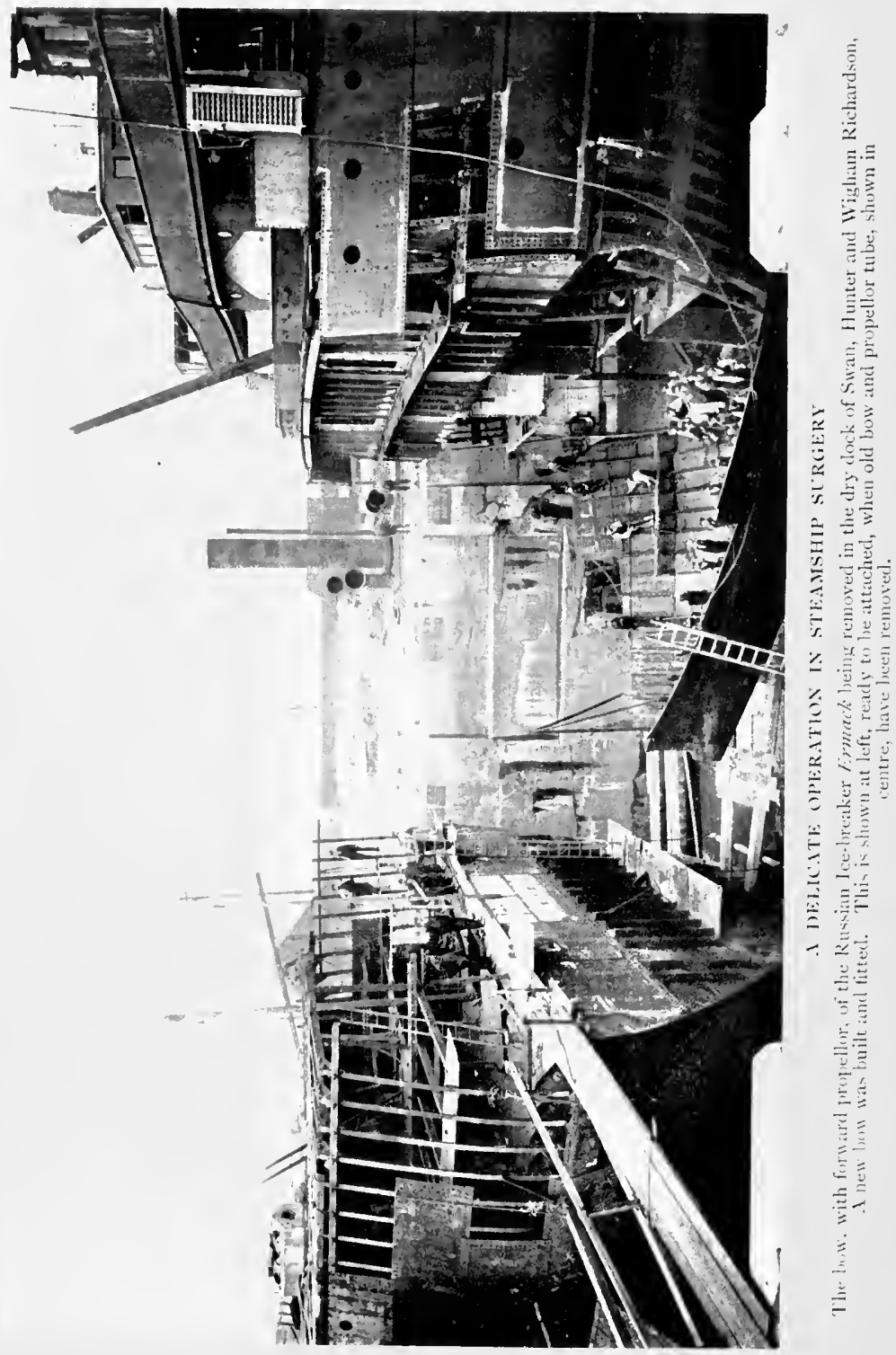


in addition to holes, broken ribs and splintered plates. When the wreck is received into the hospital she has to be submitted to an operation akin to "lining-up" in the reerection of a motor-car. She has to be sighted to see that all her lines are as true as they were on the day she slipped down the ways. She may have been buckled, bent or twisted by the action of the waves. The repair is by no means restricted to the visible area. Often when a ship has been wrecked and salvaged, the owners talse the opportunity of having the craft remodelled and modernised, and she is converted practically into a new craft. Boilers and machinery are taken out, the interior is demolished and redesigned to provide improved or increased passenger accommodation. When the Denton Grange, after being exposed to the elements for some eight months on the shore at Las Palmas, reached Hebburn-on-Tyne, she was rebuilt practically. The propelling installation was removed and overhauled, and the double bottom was renewed entirely. When the Booth liner Ambrose, after being refloated from an exposed position at Para, in South America, reached the same yards, the opportunity was seized, as she was being rebottomed, to revise the whole of her internal arrangements and upper works. When rescued she had a short poop, a well and a bridge-house. The poop deck was raised bodily to the level of the midship bridge-house, the two were connected by plating, and the well was eliminated. In this way, together with other structural alterations, accommodation was found on the vessel for some 160 persons, the state-rooms in the first-class accommodation were made more commodious, and baths and other comforts for about 300 emigrants were introduced. As a result the owners became possessed of a vessel rivalling the latest creations of the ship-designer for a comparatively low sum.

A large percentage of the cases demanding the attention of the shipbuilding surgeon assumes the form of a broken nose or twisted stem. The sharp knife-edge, cutting the water, has to bear the brunt of the force arising from a 
collision, whether it be with another vessel, rock, a breakwater or derelict. The Deutschland missed a voyage or two by becoming too familiar with the pier-works at Dover, and had to enter the repairing wards at Southampton. The Finland emulated this affectionate embrace with the protective works at the same port, and was obliged to go to the Tyne, with the lower part of her stem battered in, for treatment. A Canadian Pacific liner crashed into a collier, sank the latter, but received a severe injury to this part of her hull, and when she returned to port there was not only the gaping wound telling the story of the accident, but also a massive chunk of metal, weighing some fifty tons, which had been torn from the unfortunate antagonist, and had become embedded firmly in the body of the aggressive liner.

Curiously enough, collisions at sea, ninery-nine times out of a hundred, are productive of the same class of wounds inflicted in identical places. The ramming vessel withdraws from the combat with a badly damaged bow, while the stricken ship generally is caught just forward of the bridge. Indeed, this appears to be the most vulnerable part of a boat. If the casualties from collision between two vessels are examined, this point will receive striking confirmation. The Bywell Castle caught the Princess Alice forward of the engine-room, sending her to the bottom of the Thames with 760 souls; the Vesta struck the Arctic near the same place; the Cromartyshire got her blow well home into La Bourgogne near the bridge; and the Florida drove into the République amidships. Another remarkable point is that a vessel so wounded invariably goes to the bottom within a short time, while the striking vessel, although she may be crippled at the bow, is able almost always to licep afloat and to make port safely.

The most amazing effects of such a collision were revealed in connection with the Florida. So tremendous was the impact that thirty feet of the bow of this liner were doubled up into a space of five feet. The bow collapsed like a pair of bellows, and the deck drooped over the 
buckled section. In this case the collision bulkhead stood up to its work in the most convincing manner. To realise the tremendous force that caused this damage, one must remember that the Florida weighed some 7000 tons and was travelling at fourteen miles an hour. The République weighed about 25,000 tons, and at the time was travelling at a somewhat less speed.

The repair of the Florida was a remarkable achievement. She steamed into New York, and was laid up for several weeks. Her owners feared that, under the force of the impact, the whole of the ship had been strained, and that many months would be occupied in her complete overhaul and repair. Investigation, however, revealed the remarkable fact that the force of the collision was localised entirely in the crumpled bow. Accordingly, tenders were called for the replacement of the damaged forepart, and the Morse Dry Dock and Repair Company of Brooklyn received the contract. This firm undertook

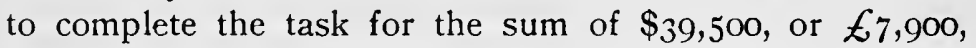
and to have the vessel ready for sea within 24 days. Time played an important part in the decision in favour of this hospital, since the nearest competitor required fifty per cent. more time, while another contractor demanded 56 days for the work.

The vessel was handed over to the Brooklyn surgeons, and immediately workmen, armed with pneumatic tools, swarmed aboard to cut away the damaged section. They commenced with the deck, and selected a point two feet beyond the farthest point of the damage for the severance. They then worked down the sides of the hull to the waterline, the vessel being still afloat. While this work was in progress the steel mills were busy rolling and fashioning new frames, beams and plates, while a new stem was being cast. The repairers set aside six days for the formation of this last-named piece, but it was delivered to them ready for setting in position within three and a half days of the giving of the order. Five days after the workmen first stepped aboard the Florida the liner was dry-docked, stern 


\section{I2 STEAMSHIP CONQUEST OF THE WORLD}

first, and at one o'clock mid-day, after the removal of the water, the workmen resumed operations, completing the severance from water-line level to the bottom of the keel.

While this task was proceeding, heavy lengths of chain were secured to the crumpled bow, and a floating derrick, capable of lifting 300 tons, was brought up to lean over the gate of the dock. Within the short space of $5 \frac{1}{4}$ hours the workmen had completed their cutting operations, the derrick grabbed the chains secured to the severed portion, and lifted it out of the way in one piece. This part weighed about Ioo tons, and as old iron it fetched the sum of $\$ 75$ or $£ 15$ !

The Florida was now floated out of the dry dock, turned round and re-dry-docked, in order to bring the bow to the opposite or inner end of the berth near the workshops, to facilitate the handling of the new material. When once the new stem was set up the frames were placed in position quickly, while plating proceeded so rapidly that thirteen days after the crumpled bow was removed the vessel was afloat once more, and moored alongside the wharf to enable the finishing touches to be applied to the interior. This latter task was finished within a fortnight, and the Florida was returned to her owners, safe and sound, ready for instant service, within the twenty-four days contracted for the repair, the surgeons winning with a few hours to spare. Of course, in this instance, repair operations were facilitated very appreciably by the owners being able to secure the drawings and particulars of the integral parts of the bow within the damaged section. These plans set out in specific detail every requirement. It was merely a question of organisation, in which feature this particular repair yard stands pre-eminent among American shipbuilders. Everything considered, this operation compares favourably with similar work accomplished in British yards.

The Tyne and North-East Coast shipbuilders and repairers have achieved a unique reputation for dispatch and thoroughness in this peculiar phase of their work, and 


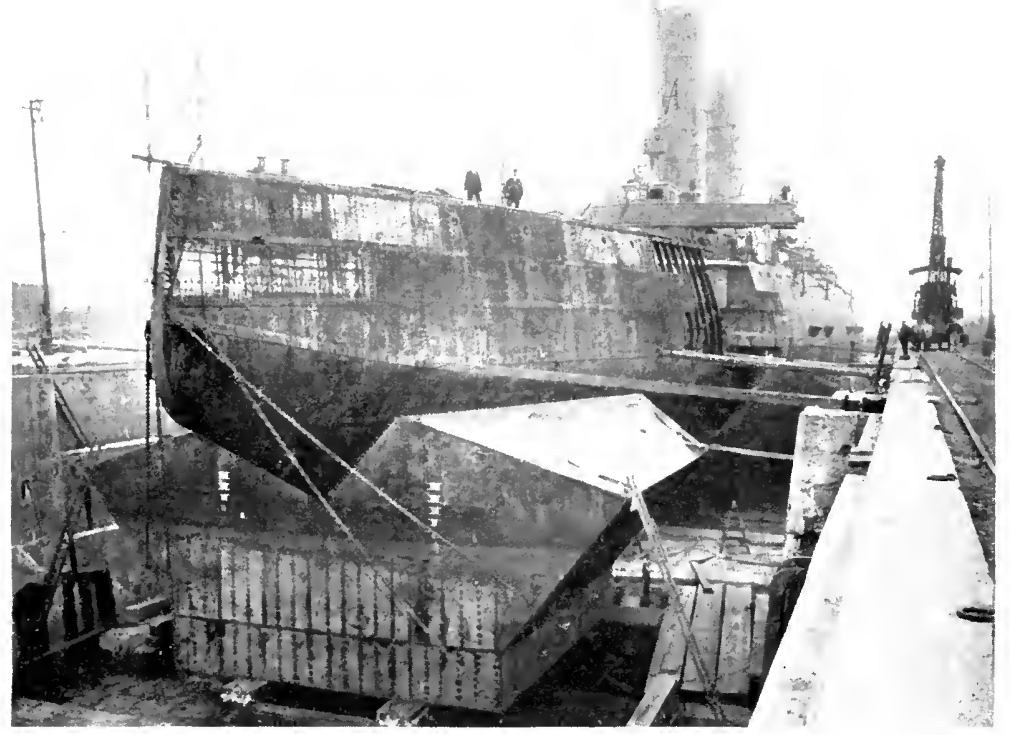

FITING THE NEW DOW TO THE KR,KC

The specinl pontom on which it wh flonted, and the ways to slite it into position.

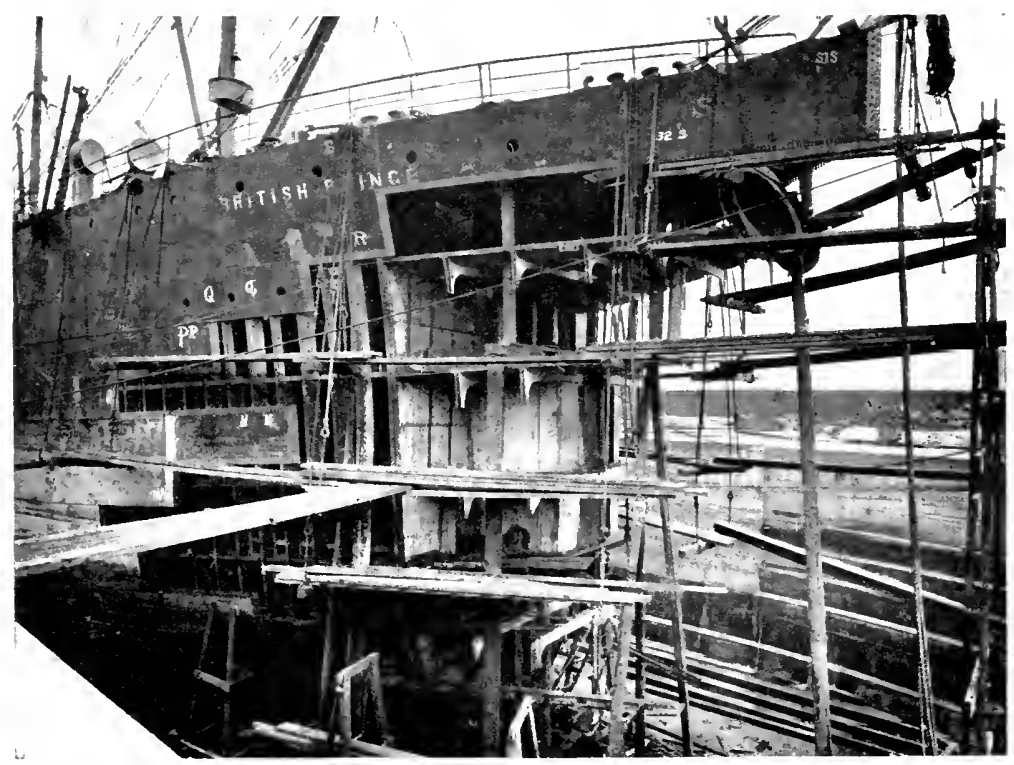

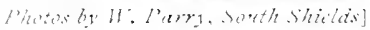

A DISISYROLS (MILISION

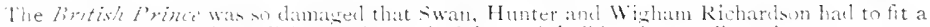
new stem-har, all frames forwart of the peak luthlieal, an well as phates. 


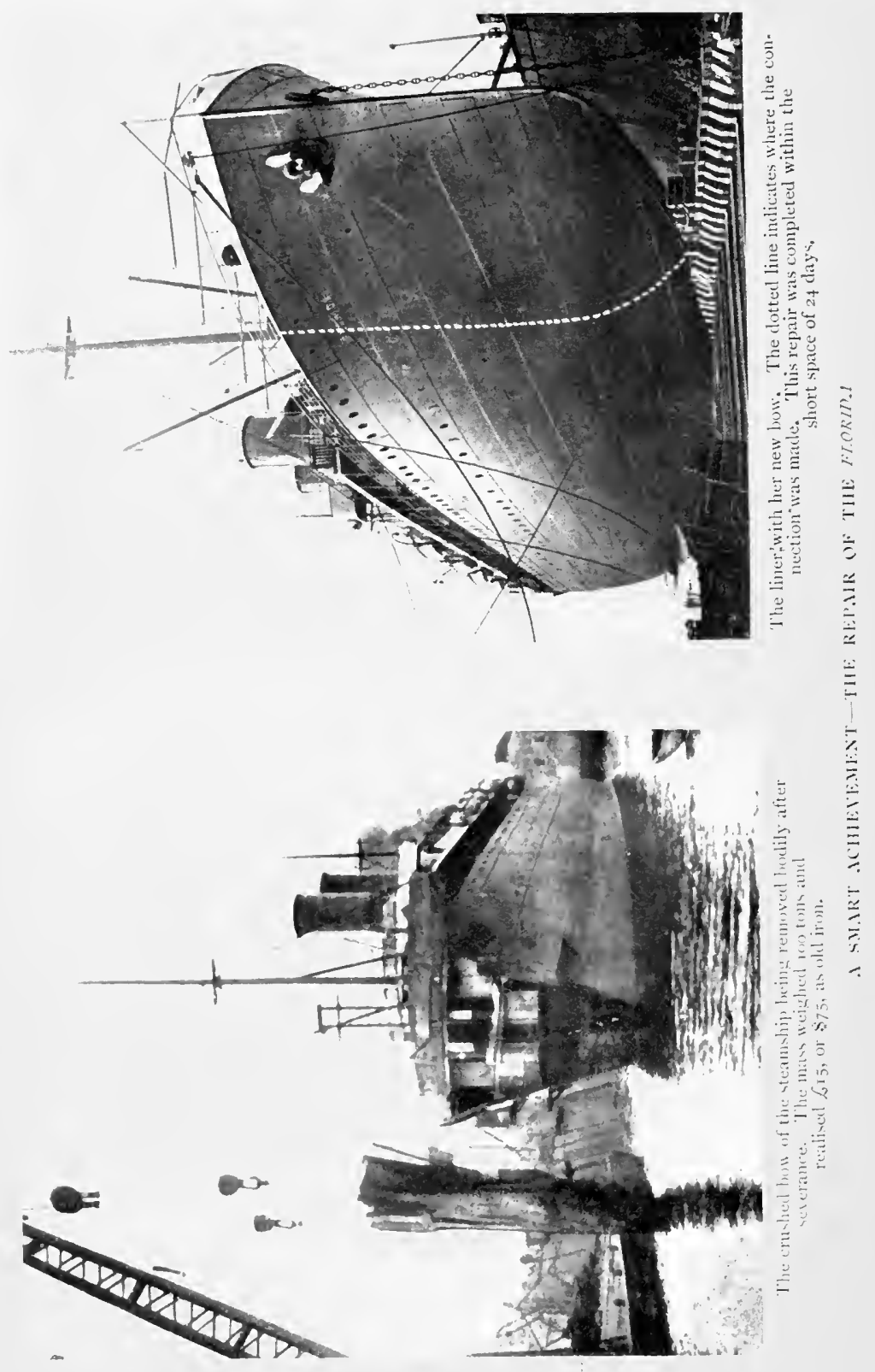


some of the cases sent for treatment have been of a most remarkable character. The British Prince, when she arrived at the yards of the Wallsend Slipway and Engineering Company, presented a sorry sight. Her bows were bent and bruised almost out of recognition. The vessel was taken into dry dock, and the whole of her bow below the uppermost strake, or line of plates, was removed to allow new ribs, beams and plates to be introduced. This was a more striking piece of work than the repair of the Florida, since the damage was felt at some distance from the stem, and in an irregular manner. Practically it involved the reconstruction of a quarter of the ship. When a damaged section can be cut completely away the task of repair is simplified, but when the repairer is compelled to renovate the damaged parts, involving the removal of big sections which extend into the sound portions of the hull, and that with the minimum of further damage, the task becomes much more exacting. The situation is analogous to that of a surgeon who is called upon to remove a bone from a person's arm or leg. He would rather amputate the whole limb than extract the damaged part.

The collier Vauxhall came to grief in the Tyne. She was run down, and foundered just inside the piers at the estuary, in a position where she was exposed to the action of the sea. The salvors, Messrs. Smith's Dock Company, Limited, got hold of her by passing stout steel wire hawsers beneath her. The ends of these were secured to lighters on either side, so that when the tide rose the wreck was lifted in her sling, and borne into shallow water. Here she was patched up to enable her to be taken into dry dock, where, after the water was pumped out, she presented a dismal spectacle. The lower part of her bow was torn open and rent in the most fantastic manner, while her stem was unrecognisable. It had been bent round and inwards, in the most extraordinary manner by the blow. The whole of the bow had to se cut clean away and reconstructed. It was a ticklish job, but when the marine surgeons had 
completed their work the Vauxhall steamed away sounder than ever.

There is one remarkable feature which cannot fail to impress one in connection with these head-on smashes. This is the localisation of the effects of the blow. When a vessel blunders into an obstruction at full speed, naturally one would imagine that the force of the impact would be experienced from stem to stern. But it is not so. The forepart acts as a kind of cushion, or spring buffer. It crumples up readily enough, but it absorbs the whole of the impact, so that the engine-room and other parts do not show the slightest ill-effects. This is readily explained. The vessel is built up of a million parts, so that when one end is struck with tremendous force, the blow in its transmission becomes diminished, and a smash at the bow is never felt at the stern. On the other hand, if the vessel were a solid mass, $i . e$. were formed of one piece from end to end, the blow would be felt throughout. The vast number of small pieces secures a pronounced elasticity which ensures the whole effect of the most staggering shock being absorbed within a short distance of the point of impact.

In some instances the ship repairer will buy up what is regarded as a useless hulk, overhaul and repair it, in the hope that upon completion a purchaser will be found at a price which will recompense the surgeon for his work. The Trevilley was a good illustration of this form of speculation. She came into collision in the Scheldt and a huge rent was torn in her side. She foundered, and when she was examined, the underwriters, owing to the extent of the damage inflicted, concluded that it would be cheaper to write her off as a total loss than to incur the expense of repair. However, a firm bought up the dishevelled mass of steel, got it afloat and into dry dock. Here the ship was reconstructed practically from end to end, and within the incredibly short time of twenty-eight days she was out once more receiving her final touches, and awaiting the survey for the highest classification to enter the service of 
a firm who had bought her. In another case this same firm secured another ship, which had run ashore in an almost inextricable position, and had been written off as a total loss by the underwriters as they considered her more fit for the ship-breakers than the ship-repairers. This particular firm entertained a different opinion. They pulled her off the shore and took her into hospital. A huge sum was expended upon her renovation from end to end, as she had suffered badly from the breaking seas. She came out of dock, gained the highest classification certificate, and instantly found a new owner, the repairers netting a comfortable profit over the transaction.

The ship repairer has come to be regarded as indispensable in marine circles. There are many enterprising firms who have become specialists in this branch of marine engineering, and the practice is lucrative. Now-a-days a ship has to be in a very bad way indeed before she is allowed to be pounded to pieces by the waves on a pitiless coast, or left to dissolve in rust. The salvage engineer will get the cripple afloat, and the marine surgeon will restore her form and shape, even when, as already described, the outlook is most dismal, and the vessel seems more suited for destruction than rejuvenation 


\section{CHAPTER XXIII}

\section{STEAMLESS SHIPS}

THE latest development in marine engineering circles, which has aroused the greatest interest, and has not failed to make its impression upon the public, is the steamless ship. This means no more than a bold bid to supersede steam as a means of generating power for the propulsion of a vessel. This development is inevitable. The remarkable achievements of the internal combustion motor in various other fields of human activity led to the suggestion that, in some form or other, it might be rendered suitable for the propulsion of large ships, and experiments to this end accordingly were made.

The idea of superseding steam is not new by any means - the perfection of the petrol engine merely revived the idea, and enabled theoretical discussion to be resolved into practice. The high-speed petrol engine, so familiar to one and all, is not being employed, as it is unsuited to the purpose; its bigger and more cumbersome slow-speed brother is the type which has been selected. One engineer, Dr. Diesel, has devoted practically the whole of his life to the solution of this problem, and his efforts appear to be within reach of success, if not for the largest classes of boats, at least for certain descriptions of the type generically designated as tramps and freighters.

The engine, in its most approved form, works upon the four or two cycle, although the latter is becoming the more popular. The motor differs from the automobile engine in a variety of ways, although following its basic principles and characteristics. There is no need to vaporise the oil fuel, while electrical and other forms of ignition are dispensed with. It works upon what is 
known as a constant pressure method. On the suction stroke, air is admitted into the cylinder, and on the upstroke of the piston this air is compressed to an extreme degreeabout 500 pounds per square inch. This compression of the air raises its temperature to about $1000^{\circ}$ Fahrenheit. When the piston has ascended to its limit, and the degree of maximum compression is obtained, a certain quantity of oil is blown into the cylinder, in the form of a spray, by compressed air, the force of this jet being in excess of the pressure prevailing within the cylinder. The temperature which the compressed air has reached within the cylinder is sufficient to ignite the incoming oil, causing it to expand, and thereby to drive down the piston. There is no explosion as with the petrol motor, so there is no violent shock as the fuel ignites. Rather, the expansion takes place quietly and evenly, the action being somewhat similar to that produced in a hot-air engine. After the charge has been ignited and the piston has descended, the products of combustion are swept through an exhaust port which is uncovered by the descending piston, so that when the latter re-ascends the air admitted into the cylinder is quite pure and free from impregnation with gases from the previous charge.

The Diesel engine has been in operation for many years in connection with land stations, and for this class of work has been brought to a high standard of efficiency and reliability by British engineers who have exploited the invention. Consequently, when it was decided to adapt the system to marine operations, the projectors of the idea had valuable experience to guide them. The advantage of the Diesel engine is that it will operate with practically any description of liquid fuel of the crudest character.

When the oil motor of this type was first taken in hand for marine purposes, it was installed rather as an auxiliary engine upon sailing vessels. Dr. Nansen's old exploration ship Fram, when acquired by Amundsen for his dash to the South Pole, was fitted with a motor developing 180 horse-power, and several other vessels have been equipped 
in a similar manner. The experience with these boats confirmed the investigators of the suitability of the Diesel engine for propulsion, and accordingly the motor was adopted on certain vessels instead of steam engines.

At the moment a variety of boats have made their appearance on the seven seas driven upon this system. British marine engineers were not attracted by the innovation, and regarded the development with characteristic misgivings. The British shipbuilding industry has not been alone in its lack of enthusiasm. The Americans, who are generally regarded as the most enterprising nation in the world, have been equally backward, and for the same reason-they are not convinced. The steam-engine has been brought to a high standard of perfection, and the dictates of prudence favour a policy of "make haste slowly."

The development was fostered for the most part by those countries whose resources of coal are very slender, but who, on the other hand, have an abundance of oil. Moreover, the idea was taken up most vigorously by the firms engaged in the exploitation of the oil deposits, as they were presented with a means of being entirely independent of outside sources. The oil-motor coincided with their requirements; they could obtain fuel in unlimited quantities for this purpose for next to nothing, instead of having to pay prohibitive prices for imported coal.

Great activity is being displayed among continental shipbuilders and marine engineers in the construction of engines of this class for marine work. Motors up to 5000 horse-power and more have been designed and are under erection for large ships. The oil magnates of Europe have extensive fleets of oil-driven ships in operation, varying from 300 horse-power upwards, and trading for the most part upon the inland waterways and rivers of Europe and Asia.

Modified forms of the Diesel oil-engine are being placed upon the world's markets by different manufacturers. Fundamentally they are all the same, but there are wide divergences in detail, which have been conceived and 


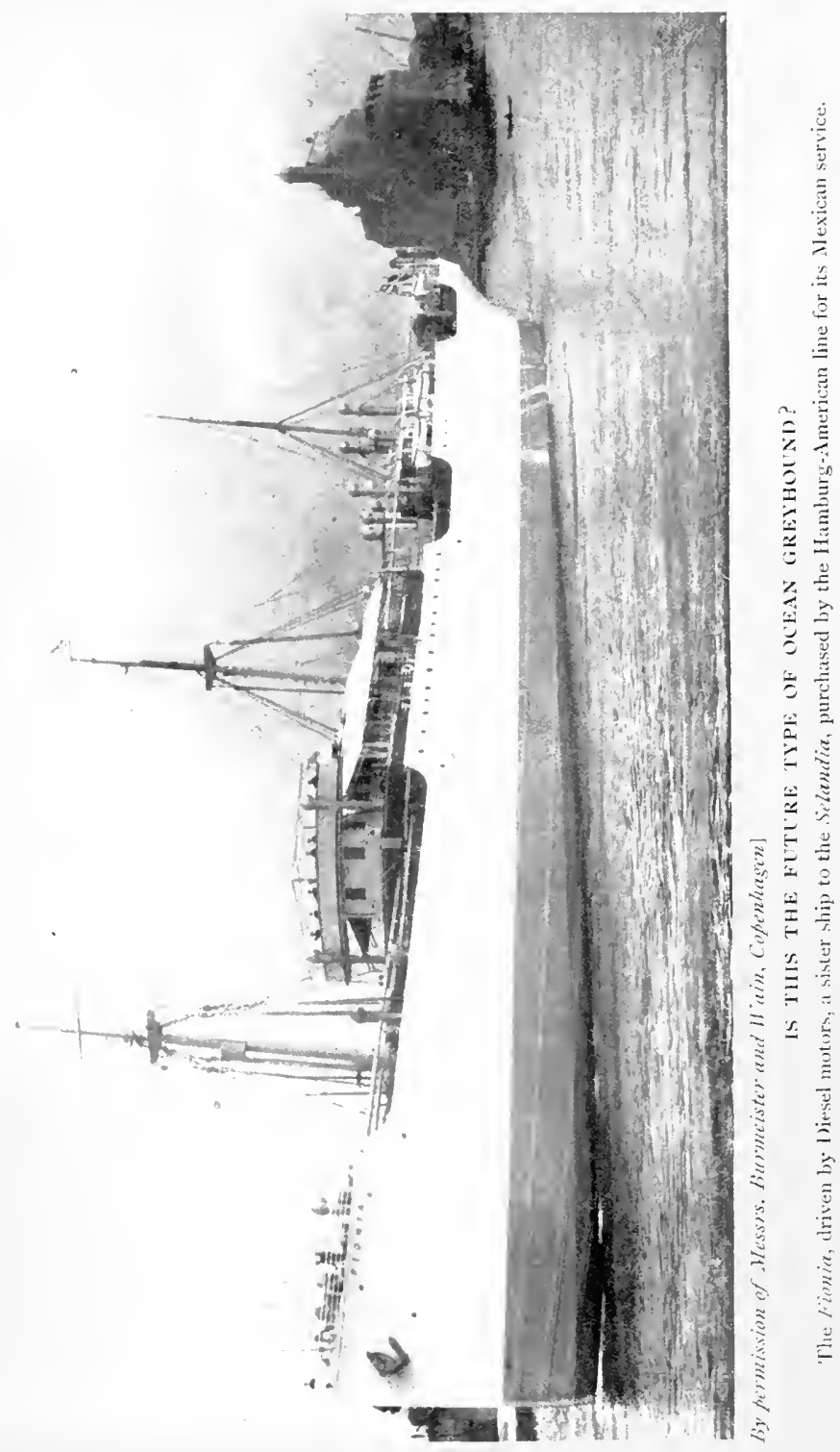




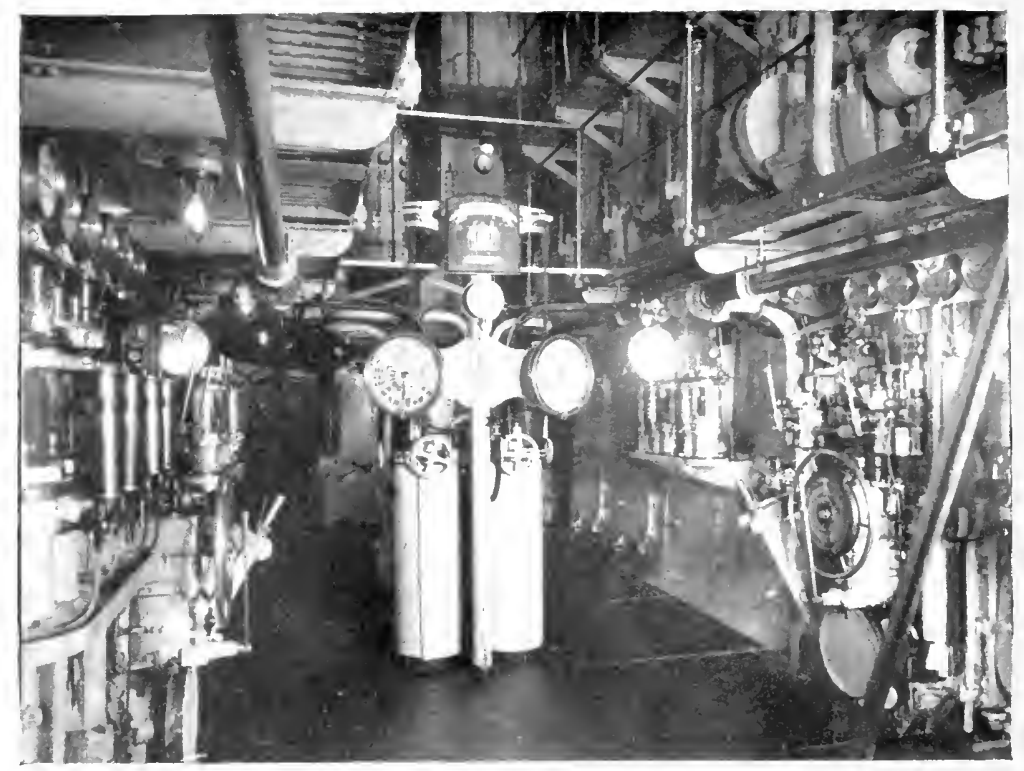

THE STARTING PLATFURM IX THE RXGINE-ROWU thowing telegraph and matmenving wheet.

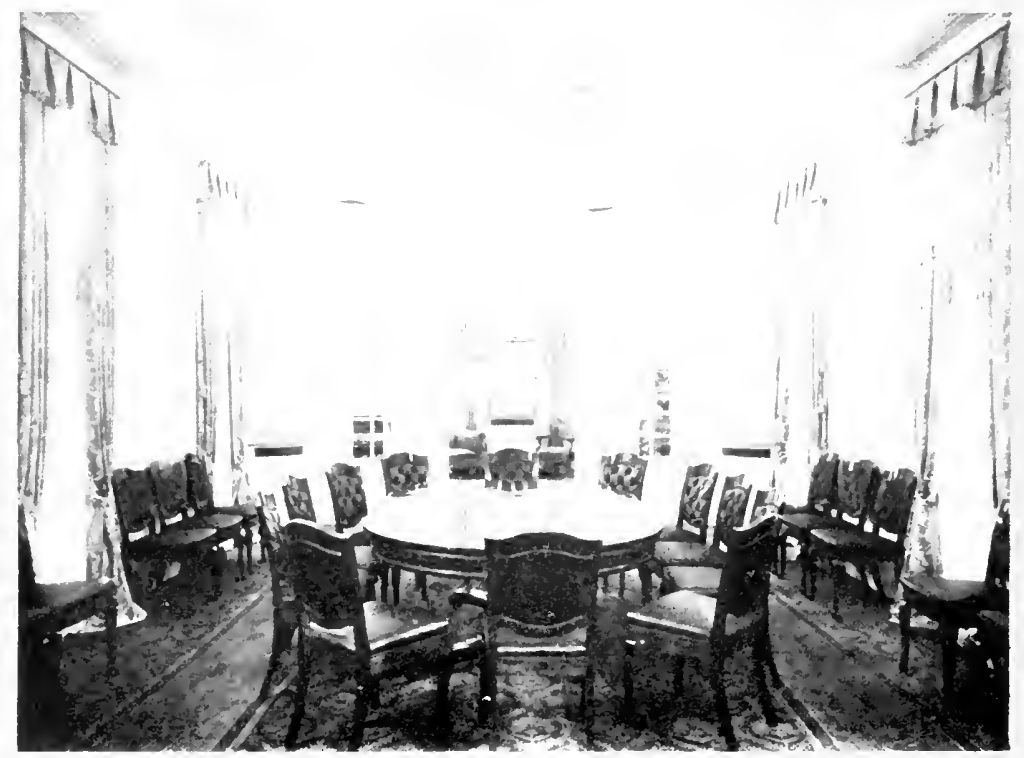

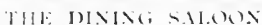

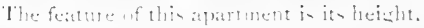

'THE YOTOR-SHH' SE/.ATOKA 
elaborated by the individual firms who have taken up the idea and are engaged in its development. Thus we have the Vickers-Diesel, the Carels-Diesel, the Polar-Diesel, and so on without end.

Shipping and pubiic attention became attracted to this new order of things by the construction of the twin ships Selandia and Jutlandia. The first-named was built at Copenhagen by the eminent firm of Burmeister and Wain, while the second came from the Clyde yards of Messrs. Barclay Curle \& Company, who have adopted the type of Diesel motor perfected by the foregoing Danish engineers. These two vessels, in their main features, are exactly alike, so that a description of one applies to the other. The length is 384 feet, beam 53 feet, moulded depth 30 feet, and the displacement 10,550 tons. There are two motors, each developing about I,250 horse-power at 140 revolutions per minute, giving a total output of 2,500 horse-power, which is sufficient to yield a speed of 12 knots-neariy 14 miles-per hour. In this type the four-cycle system is adopted, the working being exactly the same as in the petrol motor, the four strokes comprising a cycle being suction, compression, firing and exhaust respectively. It may be pointed out that the main difference between the two- and four-cycles is that in the former instance a powerstroke is obtained for every revolution of the crankshaft, while in the second the power-stroke of the piston is developed once in two revolutions.

The maiden voyage of the Selandia to Bangkok and back was a complete triumph for the motor-ship. She covered altogether 21,840 miles, experiencing all kinds of weather, and thus a good opportunity was secured for testing the practical qualities and reliability of the machinery under all and varying conditions. What might be termed the vulnerable parts of a motor-the piston rings and valves-were found to be in perfect condition when examined from time to time on the journey, while the cylinders were discovered to be quite clean. The journey proved conclusively that a ship of this type can carry 9,300 
tons of cargo over a distance of 21,840 miles on a consumption of 9 tons of fuel per 24 hours.

There is one outstanding advantage incidental to the motor-ship. This is the reduction in the staff requisite to keep the machinery going. On this particular trip the engine-room crew consisted of 10 men and 3 boys. The whole of the stokehold crew is eliminated, which in the case of a modern liner is a formidable factor, representing as it does, in the case of an Atlantic greyhound, about $35^{\circ}$ men. In the case of the above motor-vessels, the respective advantages, as compared with a steam-ship similar in every particular, are set out as follows-

\section{VESSEL ENGINED WITH DIESEL MOTORS}

Fuel capacity, oil (sufficient for 28,800 nautical miles)

Caro. I,000 tons.

Cargo deadweight (for 6,850 nautical miles) . 7,105 tons.

Cargo capacity $\quad . \quad$. $\quad . \quad$. $\quad . \quad$. $35 \mathrm{I}, 000$ cubic feet.

Oil consumption $. \quad . \quad . \quad . \quad . \quad$ IO tons per day.

Engine-room staff ( 4 engineers and 4 assistants)

Cost of

Cost of fuel [oil at 40 . $(\$ 10)$ per ton]. $\quad £ 600(\$ 3,000)$ per month.

Wages for engineers' staff

Catering for engineers' staff $: \quad \cdot \quad \cdot \quad \underbrace{}_{24}(\$ 120)$ per month.

\section{SAME VESSEL ENGINED WITH STEAM ENGINES}

Fuel capacity, coal (sufficient for 6,850 nautical miles) . . . 1,000 tons.

Cargo deadweight (for 6,850 miles) . . 6,210 tons.

Cargo capacity . . . . . . 304,000 cubic feet.

Coal consumption . . . . 42 tons per day.

Engine-room staff ( 4 engineers and 12 firemen) 16 men.

Cost of fuel [coal at $14 s .(\$ 3.50)$ per ton] . $\$ 882(\$ 4,410)$ per month.

Wages for engineers' staff . . . EI I4 (\$570) " "

Catering for engineers' staff . . . . \&39(\$195) " "

Comparison of the above shows a pronounced economy in favour of the Diesel engines, and one may marvel at the hesitation of the shipowning community with regard to the adoption of the internal combustion engine for propulsion purposes.

Unfortunately for the enthusiastic advocates of the motor-liner, the shipowner is somewhat longsighted. At the moment crude oil is comparatively cheap, although it 
is rising steadily in price. As the movement develops the cost of this commodity is certain to rise in accordance with the laws of supply and demand. This statement at the present moment is ridiculed, but it is supported only too strongly by experience in other fields-the motor industry, for instance. Twenty years ago the oil-refineries concentrated their energies upon the production of paraffin. The petrol which was obtained, being marketless, was burned or thrown away. Paraffin was produced in prodigious quantities mainly to meet the demands of illumination, but the introduction of the incandescent gas-mantle developed a system of petrol-gas lighting, while motor-cars demanded spirit for their engines. Accordingly the refiners, seeing the vanishing market for paraffin, devoted their energies to the production of petrol. Paraffin became the waste product, and for a time was practically valueless, while even to-day it may be obtained at a very low price. The shipowner does not appreciate the situation of being at the tender mercies of trusts, such as virtually control the world's supplies of oil, and which, although apparently at variance, yet have a protective community of interests with well-defined spheres of individual activity.

On the other hand, coal cannot be cornered, and its price, under normal conditions, is not subject to wild fluctuations; but the market value of oil is as sensitive as the mercury in a thermometer, and in the above table of comparisons is quoted at almost its lowest figure. A twenty-five per cent. increase in the above price, which is quite feasible, would bring the cost of oil perilously near that of coal consumption per month.

There is another factor which is responsible, in a pronounced degree, for the British attitude towards the oilengine. This is the perfection of the system for firing steam-boilers with liquid fuel instead of coal. The possibilities of this method were driven home very forcibly by the noteworthy voyage of the steamer Goldmouth, which, with oil fuel, steamed from Singapore, by the long route via the Cape of Good Hope, to Rotterdam, a distance of 
I I,791 miles in 52 days. The engines were not stopped once during this journey, which ranks as one of the longest "non-stop" runs ever made by marine machinery. The consumption of oil was so low that, upon reaching the Dutch port, sufficient fuel still remained in the bunkers to carry the vessel nearly half-way back to the East.

By this method of raising steam practically all the virtues incidental to the motor-ship, pure and simple, are obtained. It is maintained in some quarters, by those who are familiar with both oil- and coal-fired systems, that the motor-ship cannot excel the oil-fired steamship either from the view of economy, reliability, efficiency or cargocarrying capacity. The oil in this instance may be stowed on board in precisely the same manner as obtains with the motor-ship, thereby leaving increased space for cargo, while the engineering staff is reduced, so that sister ships propelled by the two systems are placed on all-fours in regard to the most important features. The shipowner who favours oil-fuel for raising steam has also another advantage. If he puts into a port for fuel he can take coal or oil, as the furnaces are adapted for burning either.

At the same time, the possibilities of the steamless ship must not be overlooked. So far as the general mercantile marine is concerned the Fionia, a sister ship of the Selandia and also built at Copenhagen, was purchased upon completion by the Hamburg-American line and rechristened Christian $\mathrm{X}$ in honour of the King of Denmark, for its Mexican trade. This line is adopting the system upon a liberal scale for its minor traffic, while another German company, the Woerman Line, is also embracing the idea. No sensational, ambitious efforts so far are contemplated, and the day when the Atlantic greyhounds will travel to and fro under motor propulsion still seems somewhat remote. It is certainly a big jump from $1,75^{\circ}$ to 45 ,ooo horse-power, which will be necessary to consummate this end. Undoubtedly the day of $\mathbf{2 5}$-knot motor flyers will dawn, but there are so many difficult problems to be solved, coupled with the shipowner's deep-rooted 
prejudice to noveity to overcome, that it will require a heavy subsidy on the part of an energetic Government to enable the experiment to be fulfilled.

The motor, pure and simple, however, is not without a rival for priority. A group of marine engineers are disposed towards the marine gas-engine, in which virtually a complete gas generating plant is installed upon the vessel. The Germans have displayed distinct initiative in this direction with small craft devised for river and canal work, and some years ago the British Government carried out a series of determined investigations. Many of the foremost marine engineers of the world have expressed the opinion that this is the true rival to steam, but there was a lack of enterprise to prove or disprove the feasibility of the idea, so far as sea-going work was concerned. However, a small syndicate was formed by Mr. Holzapfel of Newcastle-on-Tyne to build and operate a small vessel driven by this type of power-generator. These experiments were prompted by the remarkable success of the plant at the Newcastle works of Holzapfels Limited, where gas-power is generated at the cost of $\frac{3}{4} \mathrm{lb}$. of bituminous coal per indicated horse-power per hour.

The greatest difficulty experienced in this experiment was in connection with reversing, mancuvring and other operations, for which the gas-engine is not adapted. A German inventor, Professor Föttinger, meantime had devised what is known as a hydraulic transformer, and this was adopted. This device acts as an intermediary between the gas-engine and the propeller-shaft, so that the number of revolutions per minute of the latter may be reduced (within certain limits), or it may be stopped and reversed, while the gas-engine is running at full speed ahead. The action is almost instantaneous, and the loss of power arising from its introduction is very smali.

Having overcome the most perplexing problem, a gasship was built at South Shields. It measures I 20 feet in length, by 22 feet beam, and $11 \frac{1}{2}$ feet moulded depth, and is designed to carry a cargo of 300 tons on a draught of ten 
feet. The adaptation of the vessel to the new conditions was no easy matter, but the co-operation of the builders, J. T. Eltringham \& Company, enabled these to be surmounted satisfactorily. The gas plant is placed aft, in the space normally occupied by engines and boilers, and it comprises two gas generators, each of 100 horse-power, with two vaporisers and scrubbers for cleaning the gas. Special arrangements are provided to secure gas-tightness of the space housing the plant. The two producers each measure $3 \frac{1}{2}$ feet square, while the scrubbers are 13 feet high, by $2 \frac{1}{2}$ feet diameter. The most careful precautions have been adopted to eliminate entirely the danger of explosion. The gas-engines have six cylinders with a bore of $10 \frac{3}{4}$ inches and a stroke of 10 inches, and develop I 80 horse-power. They are designed to run at $45^{\circ}$ revolutions per minute, which is reduced to 120 revolutions on the propeller-shaft through the intermediary of the transformer.

The vessel, from her practical operations, certainly fulfills the hopes of her creators. She plies in the coasting trade, and handles loads ranging from 240 to 34.0 tons. The fuel consumption has averaged between 2,800 and 3,696 pounds of coal per twenty-four hours-about half that required for steam-engines in a vessel of similar size.

Electric propulsion, also, is making a powerful bid for popularity. Several electrical systems have been elaborated, but none have been subjected to the stern test of commercial application. The most promising results have been obtained with the system developed by Messrs. Mavor and Coulson of Glasgow. They acquired a small vessel 50 feet in length between perpendiculars, by I 2 feet beam, 7 feet 4 inches moulded depth, and a maximum draft of $4 \frac{1}{2}$ teet, certified by the Board of Trade to carry 50 passengers. The propelling equipment of the Electric Arc, as she is called, comprises a 45 brake-horse-power Wolseley petrol-motor which drives an alternating current dynamo with its exciter, and the propeller is coupled to an alternating current motor. The switch-gear controlling 


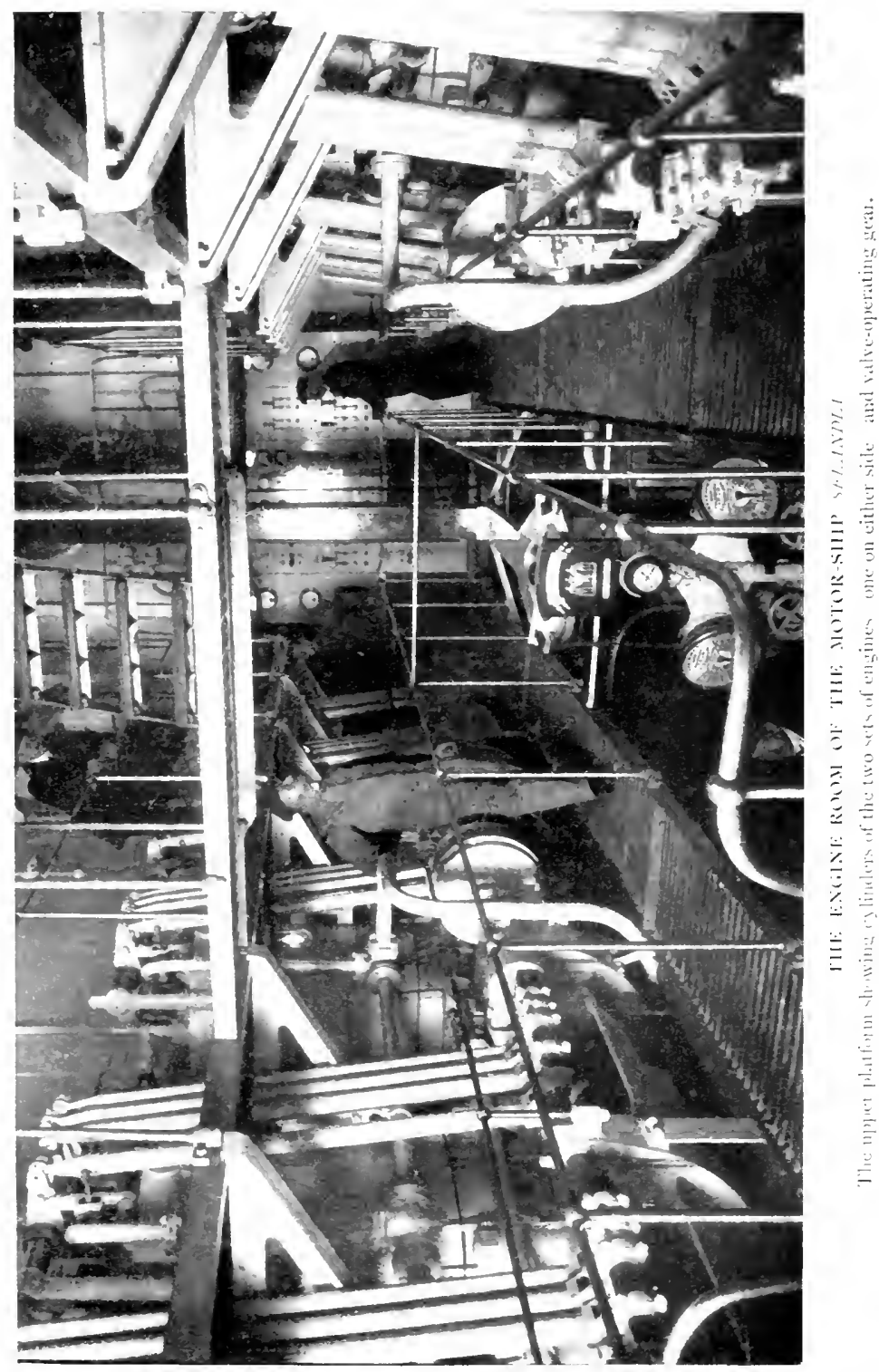



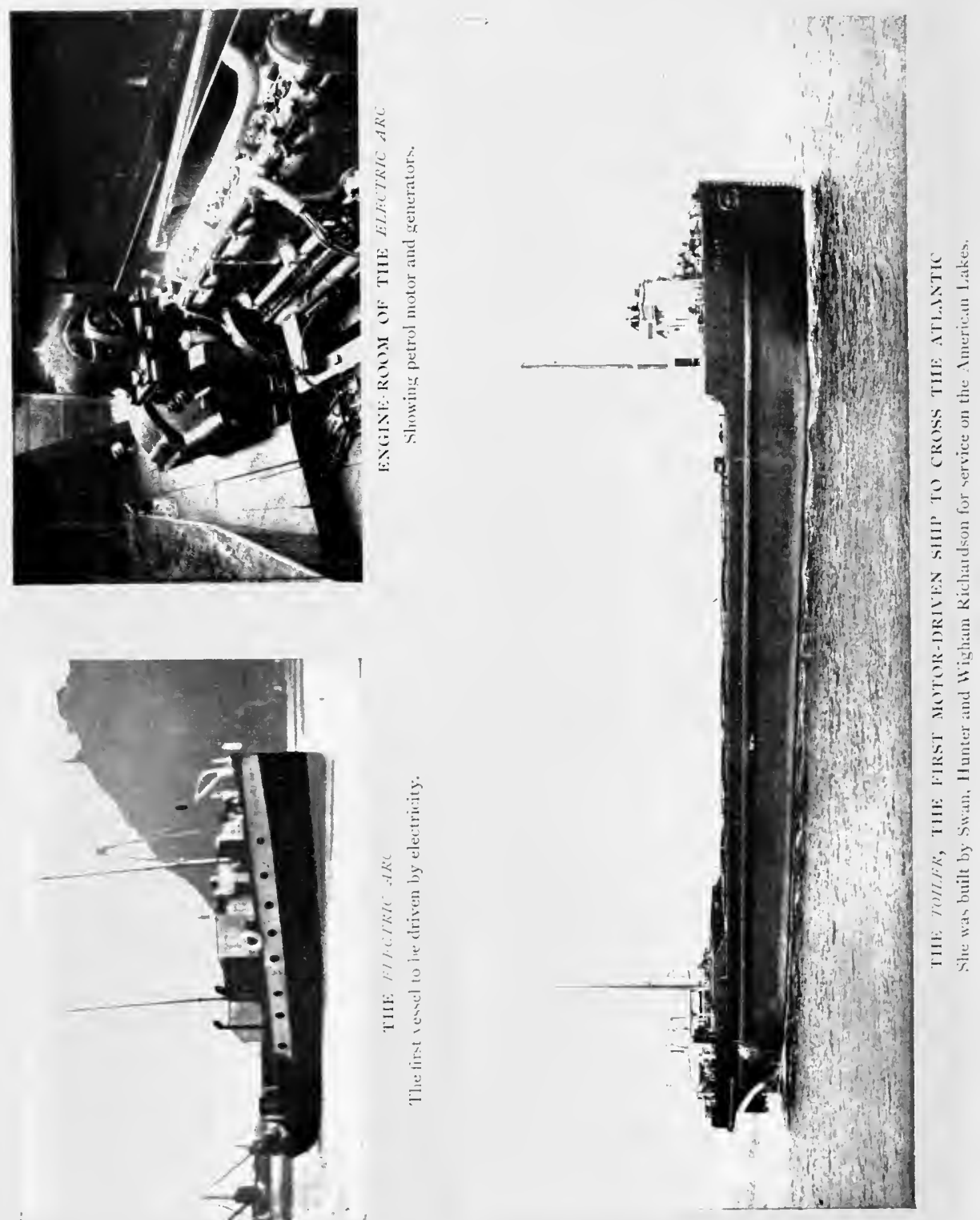
the machinery is in duplicate, and may be operated either from the bridge or the engine-room. The electrical equipment is of special design, of the simplest character and control. The little vessel has been able to attain a speed of $7 \frac{1}{4}$ knots per hour with about 25 brake-horse-power delivered to the propeller-shaft. The manœuvring properties of the system have been proved to be highly satisfactory, and the most extreme movements of the switchcontrol, corresponding to the various movements of the rudder, can be effected instantaneously without adversely affecting the electric installation, the changes being made while the circuit is quite dead. This vessel is still being used for the purposes of experiments, and developments will be followed with keen interest by those concerned with marine engineering.

In Germany the propulsion of barges and river craft by electricity has been in vogue for many years past. One of the most novel vessels is the Summer Night's Dream, practically a house-boat, or craft for touring the lakes and rivers, with well-appointed passenger accommodation. The vessel measures I 3 I feet in length, by i 5 feet beam, and draws 30 inches of water. The propeller runs at about roo revolutions per minute, being driven by an electric motor, which derives its current from a battery of accumulators. The latter, in turn, are charged off a dynamo coupled to a petrol motor, this operation being carried out, for the most part, during those periods when the boat is stationary.

It will be recognised that determined efforts are being made to depose steam from the position which it has held for a century, as a means of propelling ships. Whether this tried and reliable friend will be superseded by any of its rivals, time alone can prove, but the fact that marked activity and ingenuity are being displayed to arcomplish this end affords ample evidence that shipbuilders and marine engineers are maintaining a vigilant eye on the future. Seeing that electricity is effecting such complete revolutions in all the varied fields of human en- 
deavour, it would not be surprising if this agency at last proved the conqueror, more particularly in view of the fact that the resolution of all forms of energy, latent and active, into this one class of power is being pursued so actively, and for the most part successfully and economically. 


\section{CHAPTER XXIV}

WHY GERMANY BUILDS HER OWN LINERS

ONE of the most fascinating and at the same time one of the most interesting chapters in the history of the mercantile marine is the story of how Germany came to build her own vessels for trans-oceanic service. The American Civil War dealt a heavy blow to the United States shipbuilding industry, from which the country has never recovered. Great Britain benefited from that crisis, and secured supremacy on the seven seas. By keeping pace with progress the cost of construction in these islands was reduced more and more, until at last it became impossible for other countries to produce their own vessels at anything approaching a competitive price. Moreover, the art of shipbuilding was far more advanced in this country than abroad, owing to the enterprise of our marine engineers and the initiative of those who were responsible for the direction of our yards. The result was, that up to the year 1884 all the vessels engaged in the passenger and mail service upon the seven seas hailed either from the Tyne, Clyde or from Belfast: the magnificent boats of those days which flew the flags of the Hamburg-American, Norddeutscher Lloyd and the French Compagnie Générale Transatlantique were all British products.

Although the British shipbuilding position was unassailable, naturally the German nation chafed under the yoke. As the Teuton merchant marine commenced to grow, a stern resolve was made to become independent of the British marine engineer. The first move came about in 1874, when the German Government sought to stimulate native activity by giving out the contracts for naval vessels to private yards in the country, thereby compelling them 


\section{STEAMSHIP CONQUEST OF THE WORLD}

to enlarge their premises, to scrap existing and effete plant, to encourage the training of their younger employees, and to become established as a spirited rival to Great Britain in this ramification of industry.

Naval orders, however, owing to their restricted extent, could not keep the yards going. The heavy expenditure involved in modernisation demanded more business than the Government could hope to guarantee. Moreover, the native resources were in an undeveloped state, and it was far cheaper to purchase the raw material from Great Britain in order to set the German shipbuilding industry on its feet. Even then the cost of a ship was greatly in excess of the sum for which it could be obtained in Great Britain. But turning the German shipyards merely into erecting shops was not what the country required. It demanded that German ships should be built in German yards of German materials. By this means a wide range of industries would be affected, and receive the requisite impetus to carry them to prosperity.

The Hamburg-American Line led the way in what was in reality a risky experiment. In 1882 the orders for two new liners were handed, not to British yards, but to two German shipbuilding organisations. This development was followed with intense interest. Would the enterprise meet with success? At this juncture German construction received still greater support. The Norddeutscher Lloyd Company received the Imperial Mail Contract for an East Asian line, which the Government subsidised very heavily in a determined effort to establish the German shipping flag in the East. Accordingly, the successful company reciprocated by placing the contracts for five vessels with native yards. In this manner the foundations of the German shipbuilding industry were laid, and from that day the latter company at least has never departed from the practice of building its ships at home.

Even then it is doubtful whether this bold start would have achieved the desired end, had it not been for the astute moves of Dr. Wiegand when he assumed control of 

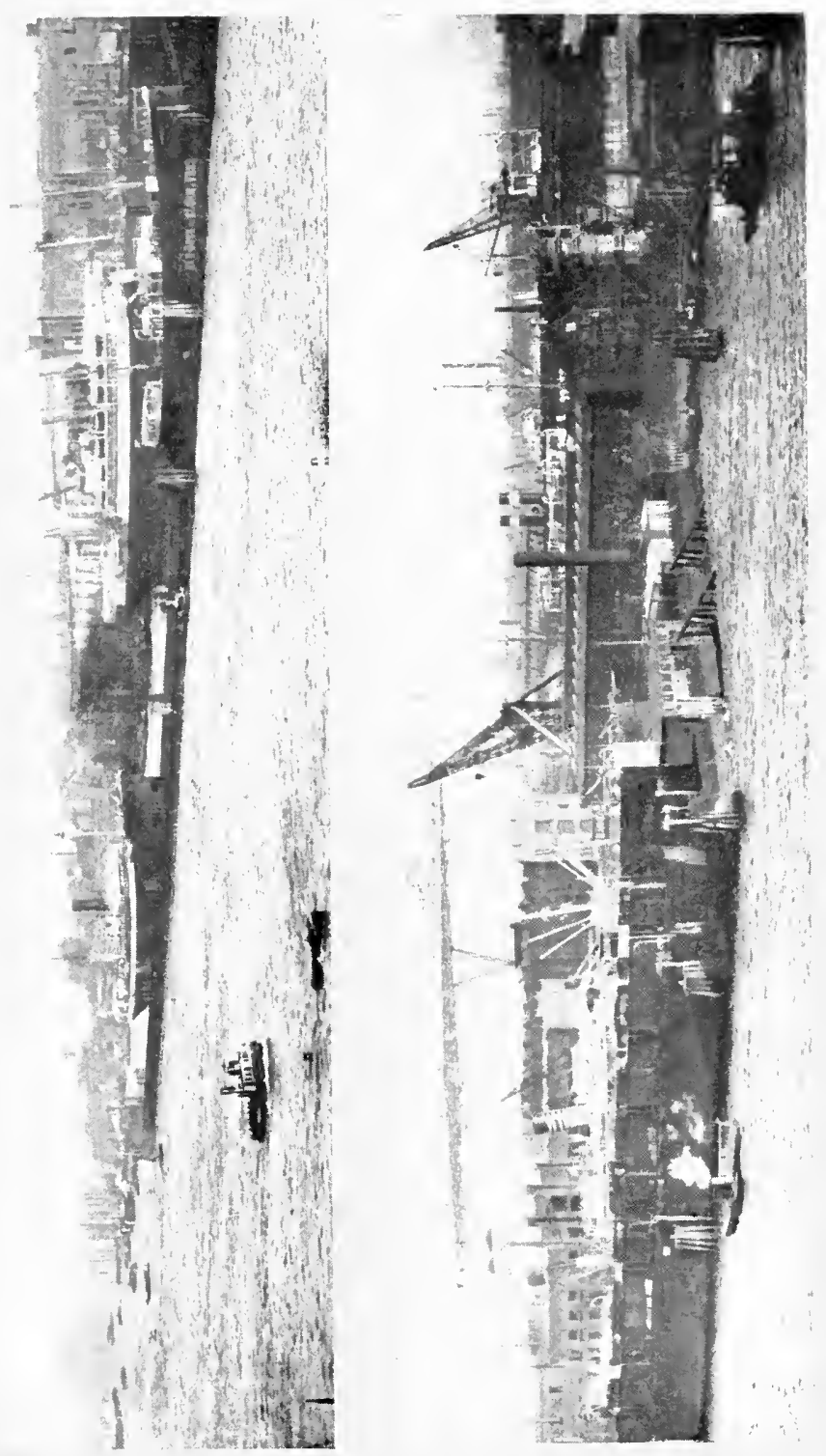

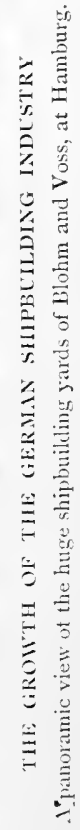




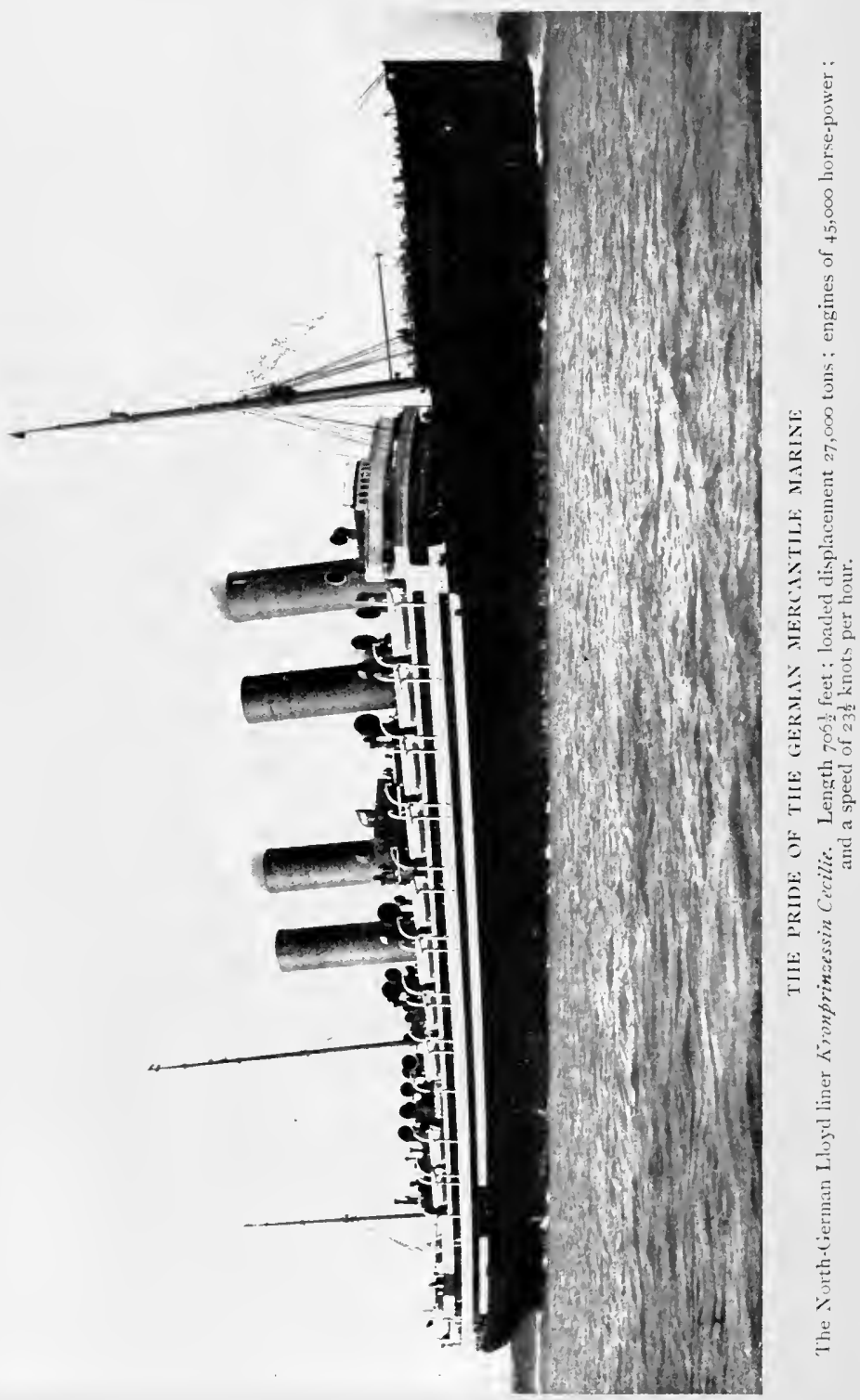


the Norddeutscher Lloyd Company's destinies. The subsidised mail line was effective so far as it went, but it recalled to mind the efforts of the United States to gain control of the Atlantic with the Collins Line, by "smashing the Cunard windows with sovereigns." The German subsidised line was a failure, and had British companies trading in the East displayed a little initiative they might have kept the German flag out, or at any rate minimised its influences very materially. Dr. Wiegand visited Chinese waters and realised the hopelessness of his position, since the whole of the trade was in British hands, carried on by local coasting lines with a very powerful connection and influence. The director saw that competition was worse than useless, so he adopted the other alternative. He bought out the companies in possession, and by one stroke consummated German ambitions for the time being, as the purchase of the British fleet improved the German position from one insignificant boat to a fleet of 26 steamers aggregating 35,145 registered tons. Having secured a firm foothold, he followed up this success by placing orders with German yards for 9 steamers of about 14,000 tons, purchased a number of vessels from other quarters, and for a time the German flag was practically paramount in the East. One cannot refrain from wondering what British lines trading to those seas were doing at this period to permit a rival to secure such a foothold. Certainly they failed to display any enterprise, being content to repose in a false haven of security and to despise their rising rivals.

The Hamburg-American Line was equally aggressive. The success of the Bremen company's tactics spurred this organisation to enter the same field. A bitter commercial war was the result, and the British companies succeeded in retrieving partially the position they had lost through the quarrel. Meantime the Japanese were quietly forging ahead, and this new influence soon exercised its effect upon Teuton ambitions.

This manifestation of energy was also affecting the 
German industries at home. The existing yards found themselves somewhat taxed, and accordingly new companies and establishments came into existence. Simultaneously the mining and steel industries, which had languished for so many years, were in danger of being overwhelmed by orders for raw material. 'They also put their houses in order. Capital was invested heavily to finance expansions and the installation of up-to-date timeand labour-saving machinery. Manufactories sprang up in all directions devoted to the design and production of cranes and handling plants, both for the yards, the mines and the ironworks.

The mercantile awakening of Germany in less than two decades was amazing. Whereas in 1880 the two or three shipbuilding establishments then in existence were in a semi-bankrupt condition, and were compelled to be satisfied with the crumbs that fell from the British tables, in 1907 they had attained a position of complete independence. In that year vessels aggregating 310,000 registered tons were built by some fo firms, employing altogether about zo,ooo men. Whereas in the 'seventies and 'eighties those of the rising German generation who had a leaning towards marine engineering found employment in British yards, since they were denied the opportunity to practise their bent at home, to-day very few Germans are found outside the native organisations. These men, drilled and schooled in British practice, so soon as they realised the significance of the German awakening, returned to the Fatherland, taking with them the knowledge acquired in these islands; and how successfully they have been able to apply this knowledge is reflected amply by the many magnificent boats which have been turned out of the German yards.

The British workman profited hugely from the boom. The finest skill was enticed from the yards of the Tyme and Clycie to Germany by high wages to teach the rising Teuton generation. In the course of a few years the Germans were able to walk alone, and the British teachers 
were dismissed, to return to their former scenes of activity. It was English knowledge in German hands which produced the Kaiser Wilhelm der Grosse, followed by the Deutschland, which for some years ranked as the fastest vessel afloat, and thus wrested the blue ribbon of the Atlantic from these islands. Speed was only one phase of their enterprise. The German companies followed British practice, recognised the value of the heavy combined passenger boat and freighter, and entered this field with similar craft, of which the George II ashington is the finest example in the German service, and this skill has culminated in the Imperator, of 65,000 tons.

It will be remarked that the Germans have followed slavislly in British footsteps, but this is only in accordance with Teuton traditions. The German is a magnificent copyist, but a poor pioneer. This is the sole reason why German mercantile shipbuilding has not produced a pattern to be copied universally. The Britisher, taken on the whole, is said to be hidebound by conservatism and prejudice, but however true this may be of some industries, it certainly does not apply to marine engineering. Here the Parsons steam turbine has made great advances in shipbuilding circles-in Germany it is still in its infancy. For some occult reason or other the Germans do not appear to be disposed to its adoption-at first they ridiculed its possibilities. This is the one failing which the Teuton possesses in regard to shipbuilding - he is content to follow about seven years behind British practice. It is admitted that the British shipbuilders have made the pace very hot, and shipbuilding is an expensive game.

This manifestation of "follow the leader" is bringing the German mercantile marine face to face with another rival. For many years the Compagnie Générale Transatlantique was content to jog along in a quiet manner. When it desired new boats it purchased them from British yards, but, the traffic being limited, no attempt was made to keep in the van of progress. As, however, the focus of transAtlantic travel became shifted from Liverpool to the Einglish 
Channel, and the trade between American and European ports developed, as a result of the success of the German vessels, this old French company shook off its lethargy, and incidentally its patronage of British yards for its crack vessels. It placed its orders with French firms, and the significance of this move was revealed by the production of the magnificent twin liners Savoie and Provence. They created a sensation upon their appearance, and the skill of the French shipbuilders was revealed in no uncertain manner. The Germans felt the arrival of these competitors severely, as both these vessels pressed the famous Deutschland hard for speed. On her second trip across the Atlantic from New York the Provence, which had started from the American port twenty minutes behind the crack liner of the Hamburg-American Company, passed the Lizard only fifty miles behind, having driven the German greyhound hard all the way across the Atlantic.

These French liners proving successful, the Compagnie Générale Transatlantique resolved to attempt bigger things, and their latest boat, the France, is probably the speediest boat on the Atlantic, with the exception of the Cunard flyers. Like her consorts, she hailed from a French yard, and her owners and builders, recognising the qualities of the Parsons turbines, fitted this 23,000-tonner, measuring 715 feet from end to end, with engines of this type developing 45 , 000 horse-power, which is sufficient to give the vessel a speed of $2.3 \frac{1}{2}-24$ knots per hour. On her official trials she reached a speed of $25^{\circ} 9$ knots per hour, so that she is a formidable rival, when roused, to the German grevhounds.

The growth of the German mercantile marine is reflected very convincingly in every direction. The activities of the Norddeutscher Lloyd have completely clanged the old town of Bremen and its harbour. Huge graving docks, capable of carrying the largest vessels of the above steamship line, have been laid down, with miles of quays and acres of workshops and factories. The civic authorities, 


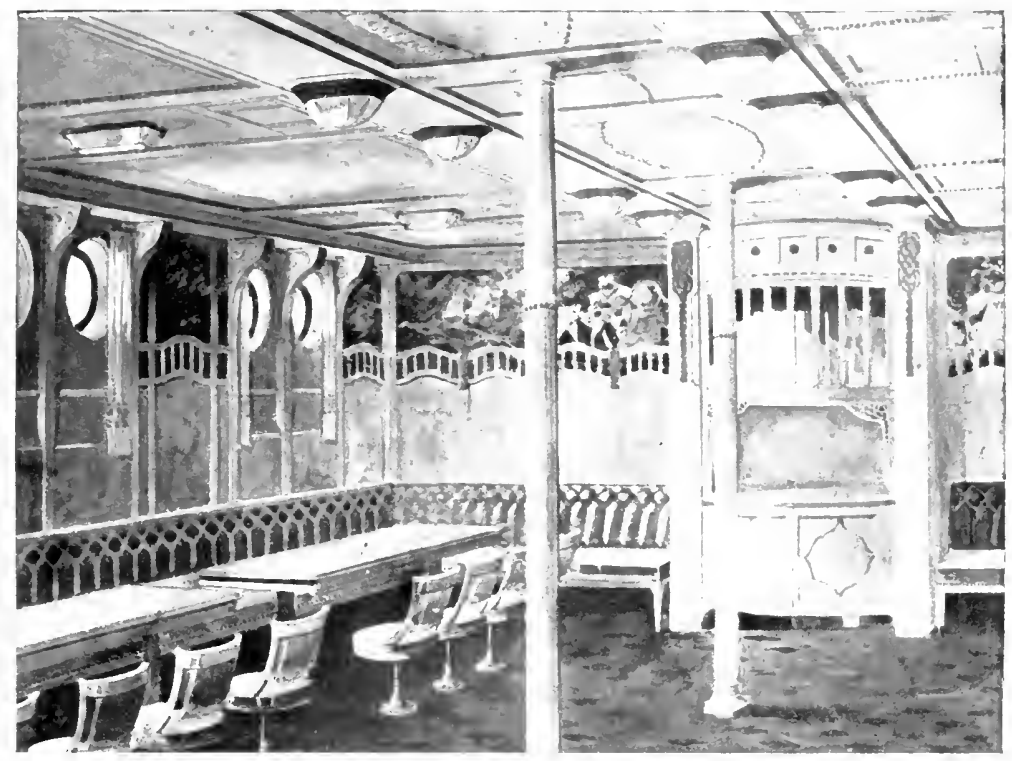

A GHMPSE OF THF CHILDREN S ROOM

Designed by Heinrich Pallenverg.

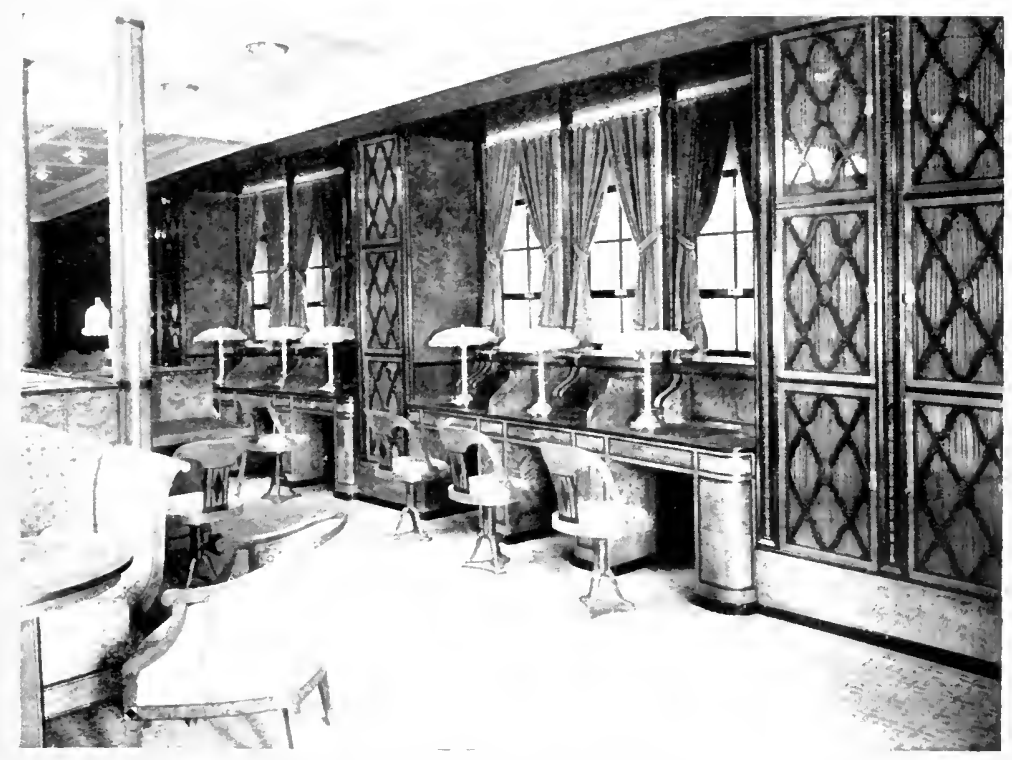

I CORNLR QF THE LHBRIRI

beringed lig l'rufesor lirmm, l'anl.

MOHERN DOMESTC ARCHITETLRE LPON TIE NORTH GERMAX I.LOYD LINER GEORGE WLAHITGTON 


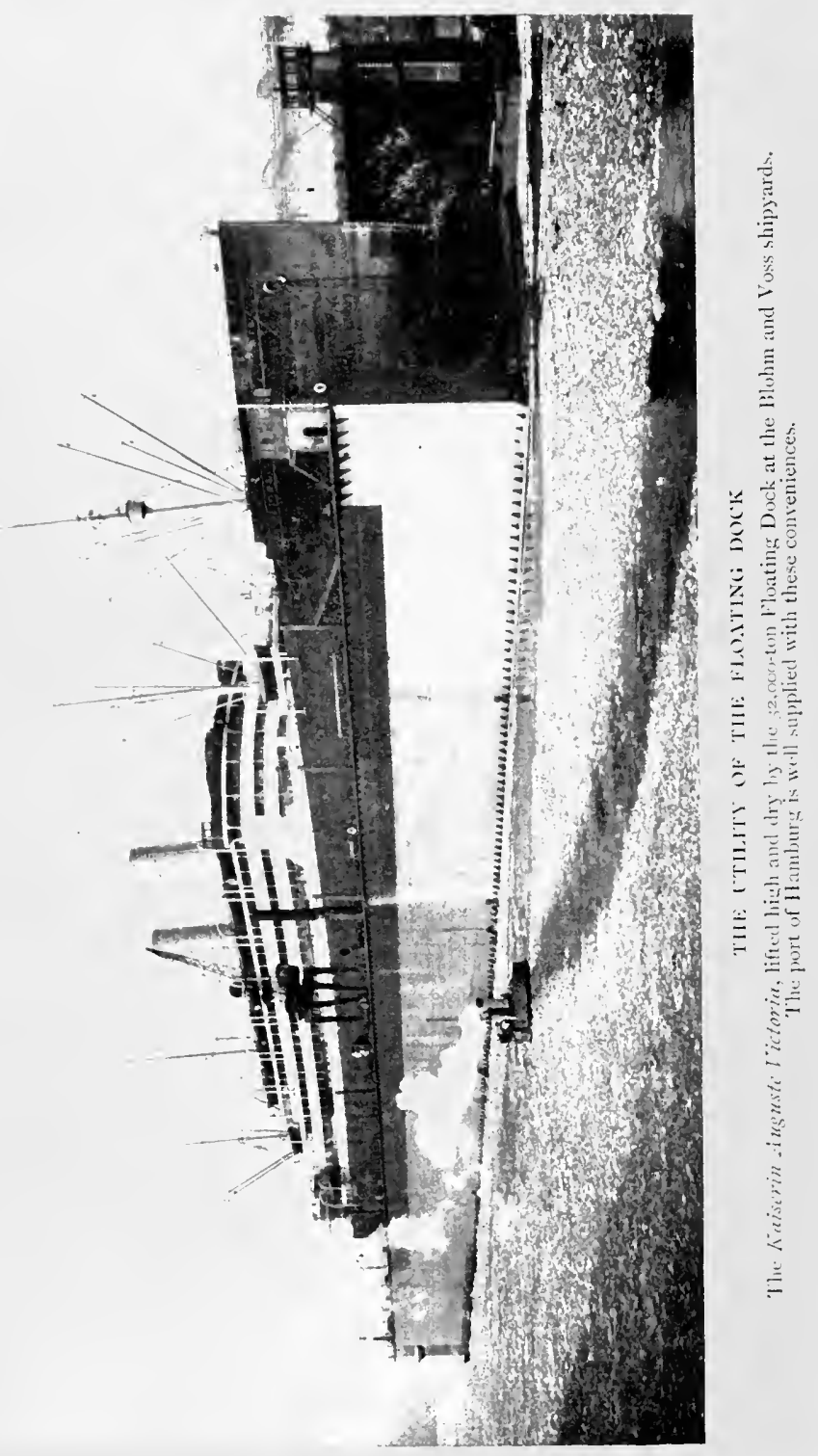


recognising the fact that their existence depends upon the steamship company so closely identified with the port, have displayed striking enterprise and co-operation. When the company sought a new dock for their largest vessel, the State of Bremen offered to make it 1000 feet in length; but the Norddeutscher Lloyd declaring that the increase in the length of their vessels using Bremerhaven was limited by the fairway conditions of the Weser, a length of about 760 feet was decided as sufficient. In Hamburg the same activity is displayed. Here the floating dock has emphasised its possibilities in no uncertain manner, one immense structure of this character, able to lift some 46,000 tons, being in operation. The yards not only undertake the construction of vessels, but are exceedingly busy in connection with repairs. Whereas vessels were wont to come to British yards for overhaul, this work is now carried out almost exclusively in German yards, and constitutes a successful feature in their business operations.

The growth of these two prominent steamship companies has been phenomenal. By acquisition of existing lines in different parts of the world, the inauguration of new routes and development of existing lines of communication, they now rank among the biggest shipping organisations in operation. The Hamburg-American flag to-day flies over vessels aggregating 961,804 gross tons, while that of the Norddeutscher Lloyd aggregates 700,000 gross tons. It has been calculated that in the course of twenty years native shipbuilding operations benefited other German industries to the extent of nearly $£ 75,000,000$, or $\$ 375,000,000$.

Unlike the British yards and manufacturing businesses, the respective plants have not been improved in consonance with the march of progress. The various industries of Germany bearing upon the shipbuilding industry were called into existence suddenly to meet a new situation. The outlay was heavy, undoubtedly, but the works had the smallest scrap-heap, for the simple reason that they were founded when those of other countries 
had completed their organisation to meet the conditions prevailing very many years before. Accordingly, German works simply were called upon to copy the best facilities of the day, with an eye upon the future. Nothing had to be demolished to make way for the new plant, since there was nothing to supersede.

As already mentioned, this sudden development brought several firms into being, who devoted their energies towards the production of special plants. Among these the crane-builder stands pre-eminent. The shipbuilding yards of Germany are extensively equipped with powerful and strange-looking devices for lifting and handling the thousands of parts which form the fabric of a modern liner. Some of them are of striking design and power. In fact, if Germany is compared with any other nation practising shipbuilding, it is evident, so far as the yards are concerned, that she is far and away in advance of all her competitors. In the shipyards of Great Britain and on the American Great Lakes manual effort is in urgent and continuous demand for the removal of material : in Germany it is reduced to the minimum. The result has been somewhat remarkable. When any country requires a powerful crane for special purposes, ninety-nine times out of one hundred it will go to Germany for its needs. On the Tyne they have a floating crane which will lift a matter of 150 tons, which was requisitioned in connection with the fitting out of the Mauretania; it is of German origin. At Belfast, Messrs. Harland \& IVolff required a like appliance for similar work; that also came from Germany. And the same condition applies to other parts of the world. Among the German yards, an ounce of muscle is saved by mechanical effort when possible.

The essential reason for this tendency is not to save time or labour, as might be supposed. It is to remedy a severe handicap under which the German industry suffers, and which cannot be avoided. Placed beside an English or American workman, the Teuton artificer is sadly deficient. He does not possess the stamina or physique of his rivals, 
so accordingly Nature must be supplemented by mechanical effort. In this particular instance mechanical labour does not necessarily cheapen the cost of production. In Germany labour is cheaper than in Great Britain, material approximates the same figure, and yet it is impossible to build a ship as cheaply in Germany as in Britain. This has been proved time after time. When an order has been thrown in the open market, the German has been hopelessly eclipsed.

The reason, bearing in mind the foregoing advantages, seems somewhat obscure, and yet it is easily explained. The native workman in the German shipbuilding yard is the product of one generation : his colleague in the British yard is the product of centuries. In marine engineering hereditary qualifications go a very long way. Son has followed father in the yards of the Clyde and Tyne for so many generations that shipbuilding has developed almost into a sixth sense, and this is the sole reason why Germany cannot secure a footing as a builder of ships outside her own borders. She cannot even meet all the demands of her own shipping. About thirty per cent. of the year's annual contribution to German shipping is built abroad, the greater part in Great Britain, and this state of affairs tends to increase rather than decrease. Instead of the mining and steel industries disposing of about onethird of their total output to the shipyards, as is the case in Britain, barely one-fifteenth is consumed by German shipbuilders. If it were not for the patriotism of the Hamburg-American and Norddeutscher Iloyd lines in placing orders for their ships with native builders, Germany, as a shipbuilding nation, would rank very low in the scale. The last-named line in particular has been the bulwark of this industry. The Hamburg-American Line, on the other hand, is not so loyal as its native rival. It still patronises British yards, where it is able to obtain what it requires more quickly, cheaper and better than at home. This tendency applies particularly to vessels departing in design from the orthodox, or required for 


\section{STEAMSHIP CONQUEST OF THE WORLD}

special services. The pride of German shipbuilding at the moment is concentrated in the Imperator-the first of a trio of this type-the order for which was placed in the first instance with the Belfast firm of Harland \& Wolff, to be abandoned for the time being owing to financial depression. When the situation became readjusted, pressure was brought to bear upon the shipowners from powerful quarters, the contract was reconsidered and handed to a German firm. The Imperator is virtually a larger edition of the Olympic, and in this instance again Germany is resting content with a design several years old. Meantime the British yards have forged ahead, and although the German mercantile marine will possess the first $65,000-$ tonner afloat, its glory will be short-lived, as it is being surpassed by two British representatives.

The German mercantile marine secured its strong position by practising the policy of absorption and amalgamation, by eliminating inter-competition and securing a foothold in new trading centres of the globe, with the attendant reduction in expenses that must follow any community of interests. On more than one occasion rate wars and quarrels between the two leading lines have reduced the shipping trade to chaos, while it must be remembered that occasionally rate wars break out between rival nations. The Cunard Line has been a somewhat aggressive offender in this respect, especially after the appearance of its two crack liners, which, on account of their speed and luxury, secured the greatest proportion of the Atlantic passenger trade. A rate war immediately followed their commission, precipitated by the Germans, and, like a malignant epidemic, it spread with astonishing virulence, until at last one could cross the Atlantic for a matter of thirty shillings $(\$ ; .50)$. The differences were adjusted finally, with the Cunard Line triumphant, and it was agreed that there should be a sliding scale of fares, according to the classification of the boats. The Cunard flyers were placed in the highest scale, with the result that the line benefited appreciably, since it 
retained and increased its popularity. The revenue rose owing to the higher rating of the boats than was the case upon their first appearance.

In Great Britain the shipping interests are supported by subsidies, in the form of payments for carrying the mails, and the reservation of approved vessels as auxiliary cruisers for the navy in time of war. The German lines receive like recompenses from their Government for similar duties, and in addition obtain substantial subsidies in a direct form for the maintenance of the German flag in waters where the trade otherwise would be impossible, owing to insufficiency of traffic or stress of competition. It was in this manner, as already explained, that Germany secured her footing in the East. In addition, the German lines were guaranteed a limited dividend, on the basis of six per cent., by the Morgan Shipping Trust, which sought to bring the German lines within its meshes, but for political reasons the suggestion was repulsed, and a reciprocal sharing of profits and guarantees arranged.

Although Germany has achieved a strong position in the world's mercantile marine, history is repeating itself. As Germany threatened Great Britain, she herself is being subjected to the force of competition. The French nation is making a bold bid for the increasing and remunerative traffic between the North American continent and Europe, and it would not be surprising if the greyhounds of the Compagnie Générale Transatlantique, instead of sailing direct between Havre and New York, were to make a call at Plymouth, to participate in the British traffic. The divergence would not affect the length of the passage. In the East the Japanese shipbuilding interests are in the ascendant, where, indeed, an evolution similar to that characteristic of Germany is in rapid progress. Moreover, there is a spirit of amalgamating interests springing up among the shipping communities of Great Britain, obvious competitive lines consolidating to effect economies and to give enhanced efficiency. A general speeding up in ocean travel throughout the world is being also displayed. The 


\section{STEAMSHIP CONQUEST OF THE WORLD}

growing new countries desire to be brought closer to the markets of the Old World. Whereas formerly the North Atlantic was the sea on which the demand for speed was waged most keenly, to-day it is only one in many. This means that the country which possesses the fullest resources, the best-equipped yards, the finest class of workmen, and the ability to bring the very latest developments into practical application, is the one which will forge ahead. For more than a decade shipbuilders and shipowners in Great Britain followed a somewhat laissez faire policy, but under the spirited competition arising from the awakening German nation it received a fresh impetus, which at the present moment is developing rather than retarding. If the signs of the times can be read aright, the next decade will witness a more powerful bid than ever for mercantile supremacy and the more complete "Steamship Conquest of the World." 


\section{INDEX}

Adelaide, the, 139

Aden, the, 298

Adriatic, the, II

Airy, Sir George, $27 \mathrm{I}$

Alaska, the, 140

Allan Line, $47^{-45}, 138$

"Alligator" type of boat, 246

Alma Cummings, the, 193-194

Ambrose, the, 309

American, the, I40

Anecdotes: City of Rome, 68; launching in Italy, 66; the Kaiser Friedrich, 68; the Mauretania, 7o; the Kaiser Wilhelm der Grosse, 90; sea surveying, 268; utility versus decoration, 74-75

Angle-bar, 32

Anson, H.AI.S., 21 ,

Aquitania, the, 15

Arctic, the, 136-137, I52-153

Arizona, the, 88, 140

Armit, Thomas Napier, 217-220, 230

Armstrong, Whitworth \& Co., Sir IV., 247

Asloun, the, 2 I 3

“Balsa," Peruvian boat, 237

Baltic, the, I I, 136

Barnes, Dr. H. T., 169

Batchelor, Captain, salvage engineer, 225

Bell, Henry, 2

Bell, submarine; see Submarine bell

Belle Halliday, the, 200

Bender, mechanical, 32, 33

Bermuda, the, 230-23I

Berth, or building slip, 29-30

"Between perpendiculars" (measurement), 37

Bevelling machine, 31

Bilge keel, 34,48

Blengfell, the, is6
"Blink" of the iceberg, I68

"Blue Ribbon of the Atlantic," 133; historic contest, 134-135; first race, I36; American competition, $137-138$; speed development, I38-I44; the course, 139-140; German competition, $146-147$

"Boat control," I02

"Bossed," term in shipbuilding, 34

Boulton \& Watt, Messrs., 2

Bourgogne, the, $89,175^{-1} 7^{6}$

Bow, McLachlan \& Co., Messrs., 233

Bower, Lieut. James St. John, $27^{2}$

"Bridge," the (ice block), 168

Briggs, Arthur (diver), 227-229

Britannia, the, 7,56 ; Charles Dickens as passenger, $7^{2}$; first trans-Atlantic race, 136,138

Britannic, the, 139

British Hydrographical Dept., 262

British Prince, the, 178,313

British Queen, the, I33

British Queen Navigation Co., the, I33

Brum, Dr. (engineer), 20

Brunel, Isambard K., I, 3 ; the Great Eastern, 4-6, 88 ; transAtlantic service, I33

Buenos Ayrean, the, 48

Building slip, or berth, 29-30

Bulkhead, collision, 88

Bulwarra, the, 178-179

Burns, George, 3

Callao, the (floating dock), 259

Campania, the, $41-42,49$; coal consumption, 48 ; Blue Ribbon contest, $143^{-1}+4$

Canadian Pacific Iake liners, I 29 
Canton, the, 224-225

Carels-Diesel engine, 319

Cargoes: dangerous, $165^{-187}$; on the tramp, 204-209; salvage of, 226-229

Casquets, the (rocks), 295

Catterthurn, the, 227-229

Cedric, the, II

Celtic, the, II

"Centre keelson" of a ship, 33

China, the, 40

Christian $X$, the, 322

City of Berlin, the, I38, 139

City of Boston, the, 162

City of Brussels, the, ${ }^{1} 3^{8}$

City of Glasgore, the, 40, 162

City of New York, the, 9, I42I43; coal consumption, 148

City of Paris, the, 9, 142-143; breakdown, 188 ; coal consumption, I48; on the Manacles, 292 ; salvage of, 2 I $^{-2}-27$

City of Rome, the (I873), 68, 139

City of Rome, the (188I), I 40

Clan (irant, the, 225-226

Clark and Standfield, Messrs., $25^{2}$

Classification societies, 24,74

Clipperton Island, 206

Coal consumption, 53,148

Coffer dam, 97 ; process in salvaging, $218-219$

Collins Line, 87, 136 ; Blue Ribbon contest, I3 8

Collision bullkhead, 88

Comet, the, I

Commissariat of liners, II4-II7

Compagnie Générale Transatlantique, La, 138, 33I-332 ; modernisation of vessels, 304

Compound engine, $4 \mathrm{I}$

Condenser, the, 54

Congo, the, 264

Cook, Captain, of the Russia, ${ }_{13} 8$

Coya, the, $238-243$

"C Q" signal, 279

"C Q D" signal, 279, 280

Cradles, in shipbuilding, 60

Crathie, the, 204

Cromarlyshire, the, $175^{-17} 6$

Crow'n, the, I90-19I

Cubana, the, 196

Cunard line, 34 ; propelling machinery, 50 $54 ;$ Blue Ribbon contest, I36-I43, I47-148; mail contracts, $144^{-1} 45$; rate wars, 336-337

Cunard, Samuel, 3

Cyril, the, 229

Daily paper on Atlantic liner, 85

Dakota, the, I 3,177

Danger-spots (of the ocean), 290 ; in English Channel, 291-296; in Red Sea, 297-298; in tlie Atlantic, 296-300; off Cape Colony, 300

Daphne, the, 65

Darlington Forge Company, 35

"Dead reckoning" in navigation, 177

Décotte, Robert, $8_{3}$

Delhi, the, 297

Denny Brothers, 4o, 45, 49; speciality of, 233,238

Denton Grange, the, $3(10)$

Derelicts, I 89 ; famous derelicts, I90-I95; salvage of, $195^{-196}$, 200-20I ; destruction of, $197^{-}$ $200,230-23 \mathrm{I}$

Dentschland, the, 42 , I 46 ; coal consumption, 148; commissariat dept., II5; damaged nose, 3 Io

Dickens, Charles, $7^{2}$

Diesel engine, $316-320$

"Displacement" of vessel, 37

"Dogs" in shipbuilding, 31

"Drawing the lines" of a vessel, 25

I)rummond Castle, the, 296

Dungeness, Cape, 293-294

Dunmore, the, I9t-I95

Earle's Shipbuilding and Engineering Co., 243

Elbe, the, 294-295

Electric Arc, the, 324

Electric propulsion, 324-325

Eltringham \& Co., J. T., 324

Emigrants, accommodation for, I 37

Engineer, marine, I2; some difficult problems for, 232-248

Engines: steam, 41-49, 321-322; internal combustion motor, $316-326$

Ermach, the, 308

Etruria, the, 49.69 ; l3lue libbon contest, If $1,1+2$ 
Fairfield Engineering Co., 42, 49

Fannie E. Wolston, the, 192-193

Favourite, the, 294

Fire, at sea, 185 ; fire alarm, 112I1 3 ; some accidents, 186-187

Fitch, Henry, I

Floating dock, 249-25I ; story of origin, 151-152; advantages of, $253^{-255}, 257^{-2} 5^{8}$; types of, 253-257; at Hamburg, 332

Floor-plates, in shipbuilding, 34

Florida, the, 88, 310-312

log, 175-178; at Thames mouth, 290

Föttinger, Prof. (inventor), 323

Fram, the, 317

France, the, $82-8+$; commissariat, IJ6-II7; life-saving appliances, 104

Freighter, lake, 122-127

Froude, W. and R. E., 20

Fulton, Robert, 2-3

Gas-engine, marine, 323-325

George Washington, the, 8o

Georgian Bay Canal, 13

Germanic, the, I39

Goodwins, the, 294

Grand Banks fisheries, 1 ;0

Grant, Richard, $23+$

"Graveyard of the Atlantic," the, 299

Graveyards, ocean; see I)angerspots, ocean

Gray, Prof. Elisha, 104

Great Britain, the, 39

Great Eastern, the, 4-6, 61, 88

Great Lakes of America, 119I22, I30-I3I; freight traffic, 122-127; passenger traffic, $128-130$

Great Western, the, I33-135

"Great White IVaterway," the, 124

Grecian, the, 176

"Greyhound of the Atlantic," the, 140

Gringoes, the, of S. America, $2+1$

"Growlers" (iccbergs), I68

Guion Line, 139. Ifo

"Half-model" of a vessel, 25

Hamburg. Inmrican L.ine, o, I38, 257; Blue Ribbon contest,
I47; British-built vessels, 145; German vessels, 15, 328, 335 ; growth of, 333; steamless vessels, 322

Harland \& IVolff, Messrs., 8, I5

Harmonic, the, 128-129

Haslar, experimental tank at, 20-2 I

Hatteras, Cape, 298

Hawthorn, Leslie \& Co., 304

Hill, James J., I3

Holzapfels Limited, 323

Humphrys, Robert, 43

Hunter, George B., 20

Ianthe, the ; see Daphne, the

Ice : disasters, $162-164$; icebergs, $164-165$; field ice, 167 ; indications of, 168-169; utility of bergs, 169-170; on inland seas, 170-173; adventure on an ice floe, $27^{1-272}$

Ice-breaking ferry, 247

Imperator, the, $15,60,336$

Inca, the, 243

Inman or International Line, 1o, 40, $137^{-13} 8$; Blue Ribbon contest, 139

Inverclyde, Lord, $I_{5}$

Ismay, Imrie \& Co., 7

lvitgut (port), 204

Japan, shipping on the Pacific, I3

Jean, the, $4^{8}$

Johns, IV. (engineer), 20

Jutlandia, the, 3 I9

Kaiser Friearich, the, 68

Kaiser Wilhelm der Grosse, the, Io, 146 ; Stone-Lloyd watertight doors, 89-90; unlucky experience, I83; wireless telegraphy, 278

Kaiser Wilhelm $I I$, the, I2

Keel, of a vessel, 33-3t

King Edward, the, 45

Kinkora, the, 211-212

Kromprinzessin Cecilie, the, 12 , 43, 95 ; decoration, 81

Kronprinz Wilhelm, the, Io, It7

Krüger, Prof. F. A. O., so

"Kyrolith," $20+$

I.aing, indrew, t9 
Lambert (diver), 227

Laroix (artist), $\mathrm{s}_{3}$

La Touche (artist), $\mathrm{s}_{3}$

Launching : of a liner, 57-63; ceremony described, 63-04; a mishap, 64-66; of a lifeboat, os foll.

"Lay down the lines" in shipbuilding, 24

Lifeboats, $98-103$

"Lifting" in launching, $5^{8}$

Linkleter life-raft, $\mathrm{IO}_{3}-\mathrm{IO}+$

Liquid fuel, 32 I-322

Liverpool Salvage Association, $221-222,224-226$

Loch Maree, the, I95-196

"Loftsman," the, in shipbuilding, 27

Loveridge \& Co., Messrs. WV. H1., 223-224

Lucania, the, I43-144; engines described, 41-42; luxurious appointments, 73 ; breakdown, $187-188$

Lusitania, the, I9-20, 95-96, I 47 ; trial trips, 69-70 ; decorations, $7^{8}$; record, 148

Macdonald, S. D., 249

MacIver, David, 3

Mail contract: British, 144 I45; German, 328

Majestic, the, $9,73,1+2$

Malsaroff, Admiral, y;0-1 $7 \mathrm{I}$

Manacles, the, 29I-29.3

Manganese bronze, for propellers, $5^{2}$

Marconi, Guglielmo, 276, 288

Marconi Wireless Chart of the North Atlantic, 2s' (illus.)

Marine Survey of India, 262

Mauretania, the, 19-23, 49; details of construction, $33-36$; propelling machinery, $5^{0-5 t}$; launching of, 60-64; trial trips, 69-71; decorations, 77-78; water-tight compartments, 9596; electric station on, rogI Io; Blue Ribbon contest, r 47 ; records, Its

Maury, Matthew Fontaine, I54$16 \mathrm{r}$

Mavor and Coulson, Messrs., 324

May, William, 227-229
"Midship section" drawings, 24

Milton, the, I84

Milwaukee, the, 221-222；306307

Minnesota, the, 13

Mohegan, the, 292-293

Morgan Shipping Trust, 337

Morse Dry Dock and Repair Co., 3I I-3I 2

Mould-loft, in shipbuilding, 27

Mundy, A. J., I04

"Naked form" of a vessel, 2 I

Naronic, the, 162

National Line, 7, I40

Nelson, Lord, and Bell's invention, 2

Nelson (sculptor), 83

Nessmore, the, I67

Netta Champion, the (derelict), I9I

Norddeutscher Lloyd Co.; see North German Lloyd Co.

Norge, the, 297

North German Lloyd Co., 9, 138 ; decoration of vessels, 76,80 ; Stone-Lloyd water-tight doors, S9; commissariat, Ir6; Blue Ribbon contest, $\mathrm{r}_{4} 6-r+7$; modernisation of vessels, 305 ; growth of, 328; German-built vessels, 335

Northern Navigation and Grand Trunk Railway Co., 128

Nyanza, the, 236

Oceana, the, 226-227

(Oceanic, the (first), 7-8

Oceanic, the (second), 6, In-II

Olbrich, Josef, $8 \mathbf{I}$

Olympic, the, 14, 60; compared with the Comet, 2 ; details of construction, 35 ; propelling machinery, $55^{-} 5^{6}$; decorative styles on, $77-78$

Oregon, the, 69. I40

Otaki, the, 49

Owen, Vice-Admiral IV. F., 264 266

Pacific, the, $13^{6}, 153$

Paddle-wheel, 5, 39

Parisian, the, $4^{8}$

Parker, llenry, 215-217 
Parsons, Hon. Sir Charles A., $40,44^{-4} 6$

Paul, Prof. Bruno, $80-\delta_{2}$

Pavonia, the, $180-183$

Pellenberg, Heinrich, So

Penguin, the, 270

Pentland, the, 172

Philadelphia, the, 143

Pirrie, Lord, 15

Planing machine, in shipbuilding, $3^{\circ}$

Poisson (artist), $8_{3}$

Polar-Diesel engine, 319

Polaris, the, 271

Poona, the, 305

Poppe, Johann, 76, 8o

Port Darwin, the, 209-2 I I

"Pride of the Atlantic," the, I39

Prince Friedrich Wilhelm, the, 80

Prince George, the, 48

Prince Rupert, the, 48

"Profile" of a vessel, 24

Propeller brackets, 34

Propelling machinery : propellers, $39-40$; engines, $41-5^{\circ}$, 317-325; miscellaneous, $5^{1-56}$

Provence, the, 332

Punching machine, in slipbuilding, 30

Quadrant davit; see IVelin davit Quadruple expansion engine, 4 I

Radio-telegraphic Conference, 1906, 277, 280

Ram, hydraulic, in launching, 6I

Ranger, the, 227, 229

Rankine, McQuorn, 20

Rate-wars, $336-337$

Reciprocating engine, 44,47

Reed. Sir E. J., 20

Refrigerating machinery, on a liner, II I

Repairs and alterations, 302304 ; in mid-ocean, $179,183_{-}^{-}$ 185 ; modernisation of vessels, 304-306 ; examination of vessel, 309 ; collision wounds, 3 Io; some interesting cases, 306 $309,311-315$

République, the, 286

Research, the, 273-274

Ribs, shaping of, $3 \mathrm{I}-32$

Riemerschmidt, Richard, $8 \mathrm{I}$
Rigaud, Hyacinthe. 83

Riveting, in shipbuilding, $35^{-36}$

Rockall (rock), 296-297

Root's Blower, 2 I6

Rose, the; see Daphne, the

"Rotor" of the turbine, 46, 51

Royal William, the, 133

Russia, the, 138

Sable Island, 299-300

Safety devices, 86-107; wireless telegraphy, $279^{-282}$

St. Louis, the, 143

St. Paul, the, 143

Salvage: of vessels, 215-226; of cargo, 226-229; a failure, 230

Sandfly, the, 272

Sarah Brough, the, 226

Sargasso Sea, the, 301

Sault Ste.-Marie, docks at, 120, 126

Savannah, the, 3

Savoie, the, 332

Schlick, Dr. Otto, 43

Scilly Islands, 293

Screw (propeller), 5, 40

"Scrieve-board," 27

Selandia, the, 319-320

Seneca, the, 197-201

Servia, the, 140

Shipbuilding: development of steamship, I-16; Admiralty requirements, 9 ; preliminary calculations and tests, $17-28$; construction of vessel. 29-38; 232-248; equipment of modern liner, $72-85,108-118$

Shipyard, 29,36

Sidonia, the, 139

Simon, Lieut., 244-245

Sirius, the, 39, 134-135

Slipway, $249^{-250}$

Smith, Capt.. of the Titanic, 86

Smith's Dock Co., 313

Snorre, the, 186

Snowden, Capt., of the Wolviston, $\mathrm{I} 82$

"Soo locks." 126, 126)-130

"Soo Rapids," I 26

"S O S" sienal, 280

Spithead Review (r889), a

"Stator" of a turbine, $\$ 6$

Steanıless ships, 316-326

Steamship routes, 154,160 ; necessity for, $15^{0-1} 53$ 
Stella, the, 295

Stern-post, in shipbuilding, 34

Stone \& Company, 89

Stone-Lloyd water-tight doors, 89

"Strakes," in shipbuilding, 36

Submarine bell and detector, 104I06

Summer Night's Dream, the, 325

Surveying, marine, 268-271; some adventures, 271-274

Swan, Hunter, \& Wigliam Richardson, Ltd., Messrs., 18, 48 ; and the Turbinia, 50; foating docks, $25^{8}$; modernisation of vessels, 305

Sybil, the, 235

Tank oil steamer, 97

Tank-top plating, 34

Telefunken system, 277

Template, in shipbuilding, 28 , 30-3I

Teutonic, the, 9, 73; Blue Ribbon contest, $\mathrm{I}_{42} 2$

Thermo-tank, I 13

"Tipping," in launching. 58

Titanic disaster, lessons from, 96-98, 102, 159

Tonnage of a vessel, 37

Tramp fieet, the, $203^{-20}$; some adventures, 209-213

Transatlantic Times, the, 288

Trevilley, the, 314-3 I5

Trial trip of a vessel, $66-71$

Triple expansion engine, 41

Tuckey, Commander, $264-265$

Turbine, the, $44-47$; on Atlantic liners, $47-56$

Turbinia, the, $44-45,5^{\circ}$

Tweedy, John, 43

Twin-screw svstem, Io. 40

Tyson, Capt., of U.S. IIvdrographical Dept., 271

Umbria, the, 49,69 ; Blue Ribbon contest, I4 I-142
United States Hydrographic Dept., I 57, I89

United Workshops for Arts and Crafts, $\mathrm{S}_{2}$

Ushant, Cape, 296

Utopia, the, 217

Vauxhall, the, $3 \mathrm{I} 3$

Ventilation, 113-114

$V$ esta, the, $15^{2}$

Vibration, 43-44, 77

Vickers-Diesel engine, 319

Victorian, the, 48

Virginian, the, 48

Waikato, the, 212-2I3

Wallsend Slipway and Engineering Co., 49

Washington, the, ${ }_{3} 6$

"Ways," launching, 59, 60

Welin, Axel, 98

Welin davit, 99-101

WVelin Lower Deck Davit, 102

White, Sir IVilliam, 10, 20

White Star Line, 7-1 I, 139

Wick Bay, the, $23^{\circ}$

Wiegand, Dr., $8 \mathrm{I}-82,328-320$

William Mackinnon, the, 234

Wilson, John, 237-243

Wind and wave, dangers from, I78-181

Ving propeller, 23

Winifred, the, 235

Wireless telegraphy, $276-289$; in fog, 177 ; in survey work, 271

Wittekind, the, $3^{\circ} 5$

Worrman Line, 322

Wolviston, the, is $\mathrm{I}-\mathrm{I}_{3}$

Woodiriff, Capt., 264

Wyer G. Sargent, the, 191-192

Yanrow, 1. Fi., ti

Yarrow-Schlick-Tweedy system, 44 

THIS BOOK IS DUE ON THE LAST DATE STAMPED BELOW.

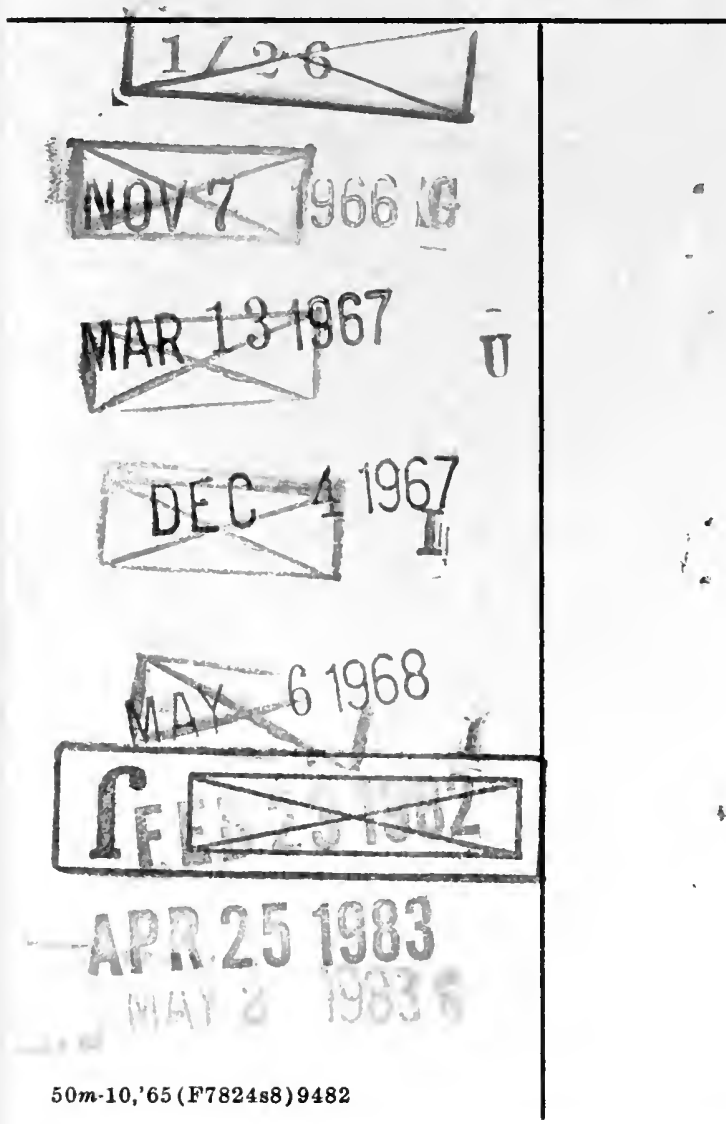




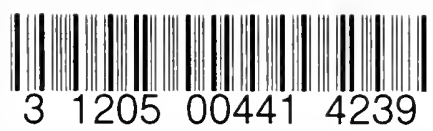

UC SOUTHERN

HIIIIIIIIIIIIIIIIIIIIIIIIIIIIIIIIIIIIIIIIIITY $\overrightarrow{A A} 000071583_{9}$ 
